\title{
Estudio de la comunidad planctónica en relación con las modificaciones antrópicas de la red de drenaje en la cuenca del Río Salado (Buenos Aires)
}

Trabajo para optar por el grado de Doctor en Ciencias Naturales

Autor

Lic. María Elisa Bazzuri

Directores

Dr. Néstor A. Gabellone y Dra. Lía C. Solari

Año 2016 
Quiero agradecer a mis directores Lía Solari y Néstor Gabellone, y a Cristina Claps, por darme la oportunidad de realizar este trabajo de tesis, por incorporarme a sus proyectos y equipo de trabajo, por la formación profesional y la capacitación que recibí durante este proceso. También agradezco a los jurados por contribuir a mejorar y enriquecer el contenido de esta tesis.

Agradezco a la Facultad de Ciencias Naturales y Museo (UNLP) por aceptarme como estudiante de posgrado; al CONICET, por el otorgamiento de las becas que financiaron esta tesis doctoral; a las autoridades del ILPLA y a todas las personas que integran el Instituto, quienes en el trato diario me han hecho sentir como parte integrante de una gran familia.

Agradezco a mis compañeros de trabajo, Hernán, Gonzalo, Martín, Karina, y a los que conocí después, Gabriela, Noelia, Javier, Sabina y Fernanda por los días compartidos y por su buena predisposición en todo momento. En especial, quiero agradecer a Hernán por su valiosa ayuda en la organización de los muestreos y en el laboratorio; a Gabriela por la identificación de los ciliados, a Analía Díaz por la determinación de los ostrácodos, y a la gente amable del Museo. Agradezco a Juan Paggi la determinación de los cladóceros, a Susana José de Paggi por su ayuda con los rotíferos y el material para reconocerlos, a Andrés Cesanelli por el aporte bibliográfico, a Paula Zaidman, a Julia Rouaux y a Luis Bree; a todos ellos, gracias por su generosa colaboración.

Quiero agradecer muy especialmente a todos mis afectos, a mis padres Susana y Mario por todo lo que me han dado en esta vida; a mi hermana Laura y a mis amigas del alma por estar en todo momento; a los amigos queridos, de acá, de allá y de siempre; a mi familia extendida, a mi suegra y a mis cuñadas, por saber que cuento con ellas en todo sentido, y a mis queridos sobrinos.

Agradezco de corazón a todos los que estuvieron con nosotros cuando nos inundamos y Tolosa era una catástrofe, cuando el agua lo abarcó todo y perdimos mucho más de lo material que podemos recordar. Gracias infinitas a todos los que nos tendieron una mano solidaria y nos ayudaron a reconstruir nuestro hogar, en esos meses interminables que nunca vamos a olvidar.

Agradezco a Dios por sobre todas las cosas, y a todas aquellas personas que hicieron posible la realización de esta tesis, a los que me dieron trabajo en los últimos años, a los que me brindaron su apoyo y me incentivaron a seguir adelante: gracias por la confianza y los buenos deseos.

Dedico esta tesis a mi marido Gastón, por inspirar la concreción de este sueño: gracias por acompañarme en cada una de las etapas, desde muestreos hasta el último detalle de este gran esfuerzo, gracias por la comprensión y las palabras de aliento. También dedico esta tesis a mi hija Priscila, quién nos ha colmado la vida de alegría y de momentos de pura felicidad; para ella todo mi amor y este mensaje: Todo es posible. Nunca dejes de intentar. 
Resumen $\quad$ vi

$\begin{array}{lll}\text { Abstract } & \mathbf{x}\end{array}$

1. Introducción 1

1.1. Justificación del tema de tesis $\quad 10$

1.2. Hipótesis

1.3. Objetivos $\quad 12$

2. Área de estudio

2.1. Cuenca del río Salado $\quad 14$

2.2. Clima de la región noroeste $\quad 15$

2.3. Geología y geomorfología $\quad 15$

2.4. Suelos 16

2.5. Hidrología 17

2.6. Vegetación 19

2.7. Desarrollo económico 19

2.8. Sitios de muestreo 20

2.9. Ejecución de obras de mejora hídrica $\quad 25$

2.10. Usos del suelo en el área de estudio 28

3. Materiales y Métodos 31

3.1. Mediciones in situ 32

3.2. Toma de muestras $\quad 32$

3.3. Análisis físico-químicos en laboratorio 33

3.4. Análisis del fitoplancton $\quad 35$

3.5. Análisis del zooplancton 36

3.6. Tratamiento de los datos 37

3.7. Análisis multivariados 39

\section{Resultados}

\subsection{Parámetros físico-químicos}

4.1.1. Parámetros medidos in situ 41

4.1.2. Conductividad y composición iónica del agua $\quad 41$

4.1.3. Turbidez, transparencia, sólidos suspendidos y materia orgánica particulada $\quad 48$

$\begin{array}{ll}\text { 4.1.4. Nutrientes } & 48\end{array}$

4.1.5. Polifenoles totales disueltos y materia orgánica disuelta 53

\subsection{Fitoplancton}

4.2.1. Abundancia y biomasa total de fitoplancton 58

4.2.2. Abundancia de los grupos de fitoplancton 59

$\begin{array}{ll}\text { 4.2.3. Biomasa de los grupos de fitoplancton } & 60\end{array}$

4.2.4. Abundancia y biomasa de las principales especies 66

4.2.5. Riqueza de especies y diversidad de fitoplancton $\quad 70$

$\begin{array}{ll}\text { 4.2.6. Otras especies representativas del fitoplancton } & 72\end{array}$

4.2.7. Correlaciones exploratorias 74 


\subsection{Zooplancton}

4.3.1. Abundancia y biomasa total de zooplancton 75

4.3.2. Abundancia de los grupos de zooplancton 76

4.3.3. Biomasa de los grupos de zooplancton $\quad 77$

4.3.4. Abundancia y biomasa de las principales especies $\quad 83$

4.3.5. Riqueza de especies y diversidad de zooplancton $\quad 87$

4.3.6. Otras especies representativas del zooplancton 88

4.3.7. Correlaciones exploratorias 91

4.4. Reproducción del plancton

4.4.1. Reproducción del fitoplancton $\quad 92$

4.4.2. Reproducción del zooplancton (rotíferos, copépodos, cladóceros y ostrácodos) 94

4.4.2.1. Riqueza de especies de zooplancton en reproducción por huevos 94

4.4.2.2. Abundancia total de huevos por grupo del zooplancton 95

4.4.2.3. Abundancia de adultos y hembras ovígeras de rotíferos 95

4.4.2.4. Abundancia de copépodos adultos, hembras ovígeras, copepoditos y nauplii 99

4.4.2.5. Distribución de adultos, hembras ovígeras, copepoditos y nauplii por grupo 99

4.4.2.6. Abundancia de cladóceros adultos, hembras ovígeras y juveniles 106

4.4.2.7. Reproducción de las especies más representativas del zooplancton 106

4.5. Fracciones del fitoplancton y relación con el zooplancton

4.5.1. Fracciones del fitoplancton y relación con el zooplancton 128

4.5.2. Especies componentes del zooplancton herbívoro 131

4.6. Relación entre los nutrientes, la materia orgánica particulada y el plancton 133

4.7. Índice del valor indicador $\quad 136$

4.8. Tasa de cambio de la comunidad del fitoplancton 138

4.9. Análisis multivariados

4.9.1. Ordenamiento MDS de la composición iónica del agua 140

4.9.2. Análisis de agrupamientos cluster de la composición iónica del agua 143

4.9.3. Análisis de componentes principales de las variables ambientales por muestreo 143

4.9.4. Análisis de agrupamientos k-means de las variables ambientales 147

4.9.5. Análisis de agrupamientos cluster de la composición del plancton 147

4.9.6. Análisis de redundancia (RDA) 151

\section{Discusión}

\subsection{Parámetros físico-químicos}

5.1.1. Conductividad y composición iónica del agua 160

5.1.2. Oxígeno disuelto 162

5.1.3. Sólidos suspendidos, materia orgánica particulada y polifenoles totales disueltos 162

5.1.4. Nutrientes 163

5.1.5. Análisis de componentes principales de las variables ambientales por muestreo 167

5.2. Relación entre los nutrientes, la materia orgánica particulada y el plancton 168

5.3. Fitoplancton

5.3.1. Clorofila $a \quad 170$

5.3.2. Riqueza de especies del fitoplancton $\quad 170$

5.3.3. Distribución de la abundancia y biomasa total de fitoplancton $\quad 171$

5.3.4. Morfologías del fitoplancton $\quad 172$

5.3.5. Composición de especies y principales grupos del fitoplancton 173

5.3.6. Diversidad del fitoplancton 181

\subsection{Zooplancton}

5.4.1. Riqueza de especies del zooplancton 183

5.4.2. Distribución de la abundancia y biomasa total de zooplancton $\quad 184$ 
5.4.3. Composición de especies y principales grupos del zooplancton 186

5.4.4. Diversidad del zooplancton 195

5.5. Reproducción del plancton

5.5.1. Reproducción del fitoplancton 196

5.5.2. Reproducción del zooplancton 196

5.6. Relaciones tróficas entre el fito y zooplancton 200

5.7. Índice del valor indicador 206

5.8. Tasa de cambio de la comunidad del fitoplancton 209

5.9. Plancton y variables forzantes
5.9.1. Características del plancton en la cuenca superior del río Salado

5.9.2. Variables forzantes del plancton $\quad 214$

5.9.3. Plancton y condiciones estacionales e hidrológicas 215

5.9.4. Plancton y nutrientes 216

5.10. Influencia de los aportes del sistema Bragado en el río Salado

5.10.2. Aportes del sistema Bragado al plancton del río Salado 219

5.10.3. Variación de los aportes de los tributarios según la condición hidrológica $\quad 220$

5.10.4. Rol de los ambientes lénticos vinculados en la atenuación de los aportes Pampa Arenosa 221

\subsection{Funcionamiento del sistema}

5.11.1. Plancton y rasgos geomorfológicos 224

5.11.2. Aportes de las zonas de almacenamiento $\quad 225$

5.11.3. Plancton, resiliencia y disturbios $\quad 227$

5.11.4. Plancton y conectividad hidrológica 230

5.11.5. Funcionamiento del sistema en diferentes condiciones hidrológicas 231

5.12. Implicancias de las actividades humanas

5.12.1. Efecto de la ejecución de obras de mejor hídrica

235

5.12.2. Efecto de las canalizaciones de la Pampa Arenosa en la cuenca superior del río Salado 237

$\begin{array}{ll}\text { 5.12.3. Perspectivas } & 238\end{array}$

6. Conclusiones 240

$\begin{array}{ll}\text { Referencias } & 246\end{array}$

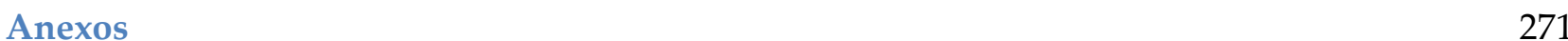


Abreviaturas y denominaciones utilizadas en el texto

OD: oxígeno disuelto

MOP: materia orgánica particulada

Polif.: polifenoles totales disueltos

$\mathrm{N}+\mathrm{N}$ : nitratos + nitritos

NTD: nitrógeno total disuelto

P: fósforo

PRP: fósforo reactivo particulado

PT: fósforo total

PTP: fósforo total particulado

POD: fósforo orgánico disuelto

: hembra(s)

ก: macho(s)
SS: sólidos suspendidos

MOD: materia orgánica disuelta

$\mathrm{N}$ : nitrógeno

NT: nitrógeno total

NTP: nitrógeno total particulado

PRS: fósforo reactivo soluble

PRT: fósforo reactivo total

PTD: fósforo total disuelto

POT: fósforo orgánico total

POP: fósforo orgánico particulado

no: número

egg ratio: $\mathrm{n}^{\mathrm{o}}$ promedio de huevos por + ovígera de una determinada especie

PCA: análisis de componentes principales

RDA: análisis de redundancia

MDS: ordenamiento "multidimensional scaling"

Veloc.: velocidad de corriente

cianobacterias: Phylum Cyanobacteria

clorofitas: Phylum Chlorophyta

diatomeas: Clase Bacillariophyceae, Phylum Bacillariophyta

dinoflagelados: Clase Dinophyceae, Infraphylum Dinoflagellata

criptofitas: Phylum Cryptophyta

euglenofitas: Phylum Euglenozoa

ciliados: Phylum Ciliophora

rotíferos: Phylum Rotifera

rizópodos: Superclase Rhizopoda, Phylum Protozoa

ostrácodos: Clase Ostracoda, Subphylum Crustacea, Phylum Arthropoda

copépodos: Subclase Copepoda, Subphylum Crustacea

cladóceros: Suborden Cladocera, Clase Branchiopoda, Subphylum Crustacea 
El río Salado constituye el río autóctono más importante de la provincia de Buenos Aires, y su cuenca drena una de las regiones agrícola-ganadera más productiva del país. El paisaje de la cuenca pertenece a la llanura Pampeana y se caracteriza por una baja pendiente, que limita el escurrimiento superficial. De esta forma, la hidrología está dominada por los movimientos verticales de agua (evapotranspiración), con una gran influencia de las aguas subterráneas. El clima es templado, y se caracteriza por ciclos alternados de sequía e inundación, los cuales afectan en gran medida el desarrollo económico de la región.

A fin de dar respuesta a la problemática de las inundaciones prolongadas y periódicas, en las últimas décadas se han llevado a cabo un gran número de obras de regulación. Entre ellas se encuentran las canalizaciones de la Pampa Arenosa en la región noroeste de la cuenca. Estos canales, vinculados de forma reciente, drenan una zona arreica con grandes cantidades de sales almacenadas en las aguas subterráneas, y sus aguas salinas son vertidas al río Salado luego de pasar por una serie de lagunas y humedales interconectados (sistema Bragado).

En este contexto, este trabajo de tesis representa el primer antecedente de un estudio limnológico en estos sistemas lóticos, cuya finalidad es conocer la dinámica del plancton en momentos hidrológicos contrastantes dentro del período estudiado (aguas altas, caudales medios, aguas bajas y muy bajas) y el efecto de los aportes de las canalizaciones sobre el río Salado. Los sitios analizados fueron: Canal Mercante (canal 1-C1), Canal de Vinculación (canal 2-C2), Canal del Este (canal 3-C3) y el A o Saladillo (arroyo), denominados en su conjunto como "sistema Bragado", y el río Salado, aguas arriba (R1) y abajo (R2) del trasvase de dicha subcuenca.

Las aguas fueron principalmente cloruro-sódicas y alcalinas, con algunas variaciones en su composición iónica según las condiciones hidrológicas: $\mathrm{Na}-\mathrm{ClHCO}_{3}$ en aguas altas, $\mathrm{Na}-\mathrm{ClSO}_{4}$ en caudales medios y en aguas bajas, y $\mathrm{Mg}-\mathrm{ClHCO}_{3}$ particularmente en el canal 3 en aguas muy bajas, lo que evidencia una estrecha relación con las aguas subterráneas. Las variables físicoquímicas estuvieron asociadas al régimen hidrológico en la mayoría de los sitios de muestreo, registrando los valores máximos de turbidez, sólidos suspendidos (SS), materia orgánica particulada (MOP), conductividad, alcalinidad, dureza y clorofila a en aguas bajas y los valores mínimos en aguas altas. Los polifenoles totales disueltos (Polif.) tuvieron una tendencia opuesta.

En todas las condiciones hidrológicas se observó un aumento de la conductividad en el río aguas abajo del trasvase del sistema Bragado dado por los aportes de las canalizaciones, presentando la máxima diferencia entre los sitios del río en aguas bajas, y mínima en aguas altas, 
por el efecto de dilución de la crecida. En aguas altas se observó la homogenización de las variables físico-químicas, mientras que en el último muestreo se observaron escasos cambios en el río aguas abajo del trasvase (caudales medios en el río), por la poca descarga del sistema Bragado (aguas muy bajas), prevaleciendo los aspectos locales: aguas muy salinas en el canal 1, de mediana conductividad en el canal 2 y de baja conductividad en el arroyo y el canal 3.

Los nutrientes no presentan un patrón claro de distribución estacional ni espacial a lo largo de los muestreos, excepto en el canal 1 en aguas altas y en el arroyo en todas las condiciones hidrológicas. Allí se observaron bajos valores de oxígeno disuelto (OD) y elevada concentración de amonio $\left(\mathrm{N}-\mathrm{NH}_{4}+\right)$, nitrógeno total, fósforo reactivos soluble (PRS) y fósforo total (PT), posiblemente asociado a descargas desde las ciudades aledañas (9 de Julio y Bragado, respectivamente).

En el río, predominaron las formas particuladas de $\mathrm{P}$ y $\mathrm{N}$ en las diferentes condiciones hidrológicas, y en el arroyo las disueltas, relacionado con una probable descarga de efluentes con alta carga de materia orgánica en este sitio. En los canales predominaron las formas disueltas en aguas altas y las particuladas en aguas muy bajas. En todos los sitios analizados, la mayor parte del carbono presente fue de origen alóctono, y la contribución de la biomasa del plancton a la MOP fue máxima en el canal 1 en caudales medios, seguido por el canal 2 en aguas bajas.

El plancton estuvo caracterizado por organismos de pequeño tamaño tolerantes a las condiciones lóticas, tales como las clorofitas clorococcales y los rotíferos, como representantes del fito y zooplancton, respectivamente. Su distribución estuvo asociada a la temperatura y a la descarga de caudal, presentando los valores máximos de abundancia y biomasa total en caudales medios (verano tardío) y lo opuesto en aguas altas (otoño-inverno). Entre los componentes del plancton, se hallaron especies típicas de ambientes eutróficos y meso-eutróficos, también indicadoras de aguas enriquecidas con nutrientes y materia orgánica, y de saprobios, en especial en el arroyo. Asimismo, se observaron especies propias de aguas alcalinas, salobres, mesosalinas o con tolerancia a la salinidad, algunas de ellas estuvieron ampliamente distribuidas en el área de estudio, y otras resultaron características de un sitio en particular.

El fitoplancton del río estuvo dominado por las clorofitas clorococcales (Monoraphidium spp., Actinastrum hantzschii) en aguas altas (otoño tardío) y en caudales medios (sept. 2009), con presencia de cianobacterias, diatomeas y criptofitas como grupos subdominantes. Las cianobacterias dominaron principalmente en los canales, prevaleciendo las formas coloniales (Aphanocapsa incerta) en aguas altas, y las filamentosas (Planktolyngbya spp., Sphaerospermopsis aphanizomenoides, Raphidiopsis mediterranea) en caudales medios y aguas bajas. Estas últimas 
coincidieron con los picos de abundancia del zooplancton y su preferencia por las algas nanoplanctónicas palatables. Entre las diatomeas se destacaron las centrales (Cyclotella glomerata, C. meneghiniana, Stephanodiscus sp.) siendo dominantes en el canal 1 en aguas bajas y en el río en caudales medios (primavera). Las pennales (Nitzschia, Navicula, Achnanthes, Diadesmis) predominaron en el arroyo, asociado a la escasa profundidad del cauce y a la presencia de aguas enriquecidas con nutrientes. En el río se observaron diatomeas pennales de gran tamaño (Surirella, Campylodiscus, Melosira) principalmente en aguas altas, posiblemente asociado a la estación climática y las mayores descargas de caudal. Las criptofitas (Cryptomonas spp., Plagioselmis nannoplanctonica, Komma caudata) fueron subdominantes en el canal 2 en aguas bajas y muy bajas, teniendo escasa relevancia en los restantes momentos hidrológicos y sitios de muestreo. Las euglenofitas se destacaron en el arroyo y los dinoflagelados en los canales 1 y 2.

El zooplancton estuvo dominado por especies de pequeño tamaño y con cortos ciclos de vida como los rotíferos, siendo abundantes en todos los sitios de muestreo y condiciones hidrológicas. Entre ellos se observó un reemplazo de especies con preferencias de la estación invernal (Keratella tropica) por otras con mejor tolerancia al verano (Brachionus plicatilis, B. angularis), y su abundancia estuvo relacionada al grado trófico. La máxima abundancia del grupo, dada por B. plicatilis (34.800 ind/L), y de zooplancton total se observó en el canal 2 en aguas bajas y cálidas temperaturas. Los ciliados se destacaron en el canal 1 y el arroyo, donde prevalecieron las formas bentónicas en deriva (peritricos, suctorios), con representantes típicos de aguas con alta carga de materia orgánica, partículas suspendidas y nutrientes.

Los copépodos predominaron en el río en caudales medios (verano tardío), en especial los cyclopoideos ubicuos (Acanthocyclops robustus, Metacyclops mendocinus). Los calanoideos (Notodiaptomus incompositus, Boeckella poopensis) se destacaron en los canales 1 y 2, y en el río aguas abajo, al igual que los harpacticoideos (Cletocamptus deitersi). Los cladóceros predominaron por su biomasa en los canales 1 y 2 en aguas altas, en especial Daphnia spinulata, en concordancia con a una mayor conectividad con los ambientes lénticos vinculados que actuaron como fuentes de inóculos. En el río, los cladóceros registraron valores máximos de densidad y riqueza en caudales medios (verano tardío), con la presencia de organismos litorales y de hábitos bentónicos (Simocephalus sp., Alona spp.). Los ostrácodos y los rizópodos estuvieron ampliamente distribuidos pero escasamente representados, y sólo se destacaron en el río.

La reproducción del zooplancton se observó principalmente en el canal 2, con elevada presencia de hembras ovígeras de rotíferos y de larvas nauplii en los diferentes muestreos. Este sitio también presentó la máxima riqueza de especies de zooplancton, en particular de rotíferos, y de riqueza 
acumulada de especies en reproducción. La reproducción fue máxima en aguas bajas, asociado a la estacionalidad climática (primavera), las elevadas temperaturas registradas y los bajos caudales.

En aguas altas, la conectividad entre ambientes promovió la homogenización del hábitat y la reducción de la variabilidad espacial entre los sitios, observándose comunidades del plancton más similares entre el sistema Bragado y el río Salado. Lo opuesto se observó en condiciones de aguas bajas y muy bajas, donde los controles locales favorecieron la diferenciación de las comunidades del plancton entre los sitios de muestreo.

Las variables forzantes que actuaron sobre el plancton fueron la conductividad, la temperatura y el nivel de agua (distancia hidrométrica pelo de agua - guardarruedas), y en menor medida el PRS y el OD. Otras variables ambientales que también regularon la distribución espacio-temporal del fitoplancton fueron los nitratos y nitritos, $\mathrm{N}-\mathrm{NH}_{4}{ }^{+}$, la $\mathrm{MOP}$, la velocidad de corriente y la alcalinidad, y en el zooplancton la clorofila $a$, el $\mathrm{pH}$ y la transparencia.

Durante los muestreos se observaron obras de mejor hídrica en el canal 2 que incluyeron la modificación del cauce y sus márgenes y la construcción de terraplenes. También se construyó un nuevo vertedero en las nacientes del arroyo en la laguna del Bragado, anulando el flujo de agua en el arroyo en los últimos muestreos. Estas obras, sumando a los vertidos de efluentes con alta carga de nutrientes y materia orgánica en descomposición, afectaron severamente la calidad de agua y la estructura del plancton del arroyo, con presencia de especies tolerantes a estas condiciones.

A través de este trabajo de tesis pudo demostrarse que las canalizaciones de la Pampa Arenosasistema Bragado afectan las propiedades físico-químicas de las aguas del río Salado (aumento de la conductividad y de los iones mayoritarios), así como la estructura y composición del plancton, incorporando además inóculos y organismos en reproducción aguas abajo de su trasvase.

Los humedales, los bañados y los cuerpos de agua lénticos presentes en el sistema Bragado cumplen importantes funciones como ecosistemas de servicio, reteniendo nutrientes, SS y MOP, a la vez que modulan el tenor salino de las aguas de los canales de drenaje. Tales beneficios se observaron particularmente en aguas altas, con un claro gradiente de concentración de sales, conductividad, turbidez, SS, MOP, PT, Polif., clorofila $a$, abundancia y biomasa total de fito y zooplancton, así como de los principales grupos del plancton y de las especies dominantes.

Los resultados obtenidos revisten importancia por sus futuras implicancias en la ejecución de otras obras proyectadas, como la ampliación prevista del Canal Mones-Cazón y su conexión directa al río Salado en el área de estudio, sin el pasaje previo por los ambientes lénticos presentes en el sistema Bragado que atemperen las condiciones alóctonas de las aguas salinas de la región, previendo un mayor impacto en el río aguas abajo de su trasvase. 
The Salado River is the most important river in the Buenos Aires Province, and its watershed drains a quite productive agricultural and livestock region. The landscape of the basin belongs to the Pampas plains and is characterized by a low slope and a limited runoff. Thus, hydrology is dominated by vertical water movements (evapotranspiration), with a strong influence of groundwater. The climate is temperate with alternating cycles of drought and flooding, which greatly affect the economic development of the region.

In order to cope with the problem of long and recurrent floods, in recent decades there have been carried out a number of regulation works like the channels from the Northwest region of the basin (Pampa Arenosa). These recently linked channels drain an areic area with large amounts of salts stored in groundwaters, and its saline waters are discharged into the Salado River after passing through a series of interconnected ponds and wetlands (sistema Bragado).

This thesis represents the first limnological study of these systems, whose purpose is to understand the dynamics of plankton in different hydrological moments within the period studied (high and low waters, mean flows), and the effect of channels' inputs on the Salado River. In this sense, the sites analyzed were, named as "Bragado system": Mercante Channel (C1), Vinculación Channel (C2), Este Channel (C3) and Saladillo stream; and the Salado River, upstream (R1) and downstream (R2) of the channels' discharge.

The waters were largely chloride-sodium and alkaline, although there were some variations in the ionic composition among the different hydrological moments: $\mathrm{Na}-\mathrm{ClHCO}_{3}$ in high waters, $\mathrm{Na}-$ $\mathrm{ClSO}_{4}$ in low waters and medium flows, and $\mathrm{Mg}-\mathrm{ClHCO}_{3}$ particularly in very low waters, with a close relationship with groundwater. The physico-chemical variables were associated with the hydrological regime in most sampling sites, with the maximum values of turbidity, suspended solids (SS), particulate organic matter (POM), conductivity, alkalinity, hardness and chlorophyll $a$ in low waters, and its minimum values at high waters. An inverse tendency was observed for total soluble polyphenols (Polyph.).

The conductivity increased in all hydrological conditions in the Salado River downstream site because of channel's inputs. This tendency was higher in low waters than in high waters, because of the dilution effect of the flood. Also, homogenization of the physical and chemical variables was observed at high waters. The opposite was observed in the last sampling (mean flows in the river and very low waters in channels) where the local aspects prevailed: highly saline waters in $\mathrm{C1}$, 
medium conductivity in C2 and low values in C3 and the stream. Also, very few changes were observed in the river downstream of the Bragado system discharge, because of base flows.

The nutrients did not show a clear seasonal or spatial pattern along samplings, except in the case of Saladillo stream and C1. These sites exhibited high concentrations of ammonium, total nitrogen, total reactive phosphorus, total phosphorus (PT) and total soluble reactive phosphorus and low values of dissolved oxygen. This could have been related to the inputs from the cities of 9 de Julio and Bragado, respectively. The particulate forms of phosphorus and nitrogen predominated in the Salado River along the different hydrological conditions. Whilst, the dissolved forms of nitrogen and phosphorus prevailed in the stream, thus indicating inputs with highly organic load (wastewaters). On channels, dissolved nutrients were important during high waters, and particulate ones in very low waters, in coincidence with phytoplankton development. Most of the carbon present had an allochthonous origin, and the maximum contribution of plankton biomass to POM was observed in $\mathrm{C} 1$ in medium flows and in $\mathrm{C} 2$ during low waters.

Plankton was characterized by small organisms known as tolerant to the lotic conditions (turbidity, turbulent flow, low light availability, flow velocity, discharge), with a rapid growth and reproductive rates, such as chlorococcals chlorophytes and rotifers. The plankton distribution was related to temperature and flow discharge. It had peaks of total abundance and biomass on average flows (late summer) and the opposite in high waters (autumn-winter). Plankton species were typical and of eutrophic-mesoeutrophic environments, with some representatives of saprobic community, particularly in the stream. Also, some of them were typical of alkaline, brackish and salt waters, or with a wide range of salinity tolerance. Some of them were widely distributed on the study area, and others characteristic of a particular site.

The river phytoplankton was dominated by chlorococcals chlorophytes in high waters and in mean flows (Monoraphidium spp., Actinastrum hantzschii), with the presence of cyanobacteria, diatoms and cryptophytes as subdominant groups. Cyanobacteria dominated mostly on channels, with colonial forms (Aphanocapsa incerta) in high waters and filamentous ones (Planktolyngbya spp., Sphaerospermopsis aphanizomenoides, Raphidiopsis mediterranea) in mean flows and low waters. The dominance of filamentous cyanobacteria was coincident with the highest zooplankton abundance, which prefers palatable nannoplanktonic algae. Among diatoms, the most important were Cyclotella glomerata, C. meneghiniana and Stephanodiscus sp., particularly at low waters in C1 and in mean flows (spring) in the river. Pennate diatoms like Nitzschia, Navicula, Achnanthes, Diadesmis, predominated in the stream, possibly related to its shallowness and the presence of nutrientenriched waters. On the river, larger pennate diatoms (Surirella, Campylodiscus, Melosira) were 
observed mainly in high waters, possibly related to higher flow rates. The cryptophytes (Cryptomonas spp., Plagioselmis nannoplanctonica, Komma caudata) were subdominant in C2 in low waters, but had a little relevance in the remaining hydrological moments and sampling sites. Euglenophytes stood out in the stream and dinoflagellates in C1 and C2 of the Bragado system.

Zooplankton was dominated by small species with short life cycles such as rotifers, which were relevant in all sampling sites and hydrological moments. Species replacement was observed, from species with winter preferences (Keratella tropica) to summer tolerant ones (Brachionus plicatilis, $B$. angularis), and its abundance was related to trophic level. The highest zooplankton and rotifers abundance, given by B. plicatilis (34,800 ind/L), was observed in C2 in low waters and under high summer temperatures.

Ciliates were important for their abundance and biomass in $\mathrm{C} 1$ and in the stream, where benthic drift forms prevailed (peritrichous, suctoria). Most of them were typical of environments with high load of organic matter, suspended particles and nutrients. Copepods were important in the river during mean flows (late summer), and were composed of ubiquitous cyclopoideos (Acanthocyclops robustus, Metacyclops mendocinus). Among the calanoids, Notodiaptomus incompositus and Boeckella poopensis were more relevant in C1, C2 and R2, and the same as for the harpacticoids (Cletocamptus deitersi).

Cladocerans presented the highest biomass values in $\mathrm{C} 1$ and $\mathrm{C} 2$ in high waters, possibly related to a greater connectivity with the associated lentic environments, which may act as sources of inoculum. Among them, Daphnia spinulata was dominant, which is typical specie of saline environments in the region. In the river, cladocerans had remarkably abundances and species richness during mean flows (late summer), with the presence of benthic organisms or from littoral habitats (Simocephalus sp., Alona spp.). Ostracods and rhizopods were of lesser importance and represented by widespread species, with peaks abundance in the river. The zooplankton reproduction was mainly observed in $\mathrm{C} 2$, with a great presence of ovigerous rotifers and nauplii, at different sampling moments. This site also had the highest species richness of zooplankton, particularly of rotifers, and maximum cumulative richness of species with reproduction by eggs. Reproduction was highest in low waters associated with the season (spring), high temperatures and low flows.

Under high waters conditions, connectivity encouraged the habitat homogenization and the reduction of spatial variability between sites, showing similar plankton communities at the Bragado system and the Salado River. The opposite was observed in low and very low waters, 
where local controls dominated and favored the differentiation of the plankton community among sampling sites.

In this context, the forcing variables that control the plankton community were conductivity, temperature and water level, and also PRS and OD. Other environmental variables that regulate the distribution of phytoplankton were nitrate + nitrite, ammonium, MOP, flow velocity and alkalinity, and those that forced the zooplankton were chlorophyll $a, \mathrm{pH}$ and transparency.

During this study some regulation works were carried out in C2 (dredging, embankments and flood defenses) and in the Bragado lagoon (a new floodgate), so the water flow was interrupted in the Saladillo stream in the last samplings. These hydraulic works, plus the effluent discharges with high load of nutrients and organic matter, severely affected water quality and plankton structure, with the presence of some tolerant species.

Through out this thesis, it could be shown that the Pampa Arenosa canalizations - Bragado system affect the physico-chemical properties of the Salado River waters (increased conductivity and major ions) as well as the structure and composition of the plankton community, also incorporating inocula and reproductive organisms downstream.

Wetlands, marshes and lentic waters bodies present in the Bragado system play an important role in the retention of nutrients, SS and POM, and also in the modulation of the saline characteristics of the channels' waters. Such benefits were particularly seen in high waters, where a clear gradient of salt concentration, conductivity, turbidity, SS, MOP, TP, Polyph. and chlorophyll a was observed. It was also true for the total abundance and biomass of phytoplankton and zooplankton and for the main groups and dominant species of plankton.

These results are important because of its future implications on other hydraulic projects planned, such as the expansion of Mones Cazón Channel with a direct connection to the Salado River. In that scenario, the salt waters of the region would not pass through the lentic environments present in the Bragado system, which actually reduce their allochthonous conditions, thus foreseeing a greater impact on the river downstream. 
Introducción 


\section{Introducción}

Los sistemas lóticos, definidos como las aguas que fluyen (Hynes, 1970), constituyen ambientes advectivos, caracterizados por un flujo unidireccional, con cortos tiempos de residencia y grandes entradas de nutrientes y materiales particulados suspendidos, relacionados en gran medida a las condiciones hidrológicas y a la geomorfología de su cuenca (Bukaveckas \& Crain, 2002; Vis et al., 2007). Se los reconoce como sistemas interactivos en tres dimensiones espaciales: lateral, entre el cauce principal y la planicie de inundación; vertical, con las aguas subterráneas; y longitudinal, del cauce principal consigo mismo, desde las cabeceras hasta su desembocadura (Ward, 1989). Estas características, sumadas a los cambios en el tiempo, le otorgan una heterogeneidad espaciotemporal propia de los sistemas fluviales (Townsend, 1996), donde sus variaciones tienen un efecto directo sobre la dinámica de sus procesos internos (Hildrew, 1996). De esta forma, la complejidad biológica de los sistemas fluviales surge de las interacciones entre los procesos que operan en diferentes escalas espaciales y temporales (Amoros \& Bornette, 2002). Los ríos presentan una gran superficie de interacción con los ecosistemas terrestres, y se ven influenciados por sus características y su grado de conservación (Margalef, 1983).

Los ríos constituyen sistemas bajo tensión que mantienen un ciclo relativamente acelerado de los nutrientes, exportan materiales y parte de su producción (Margalef, 1983), y cuentan con gran número de variables capaces de influenciar la estructura y el funcionamiento del plancton (Townsend, 1996). Entre éstos reguladores se encuentran los factores físicos (luz, turbulencia, turbidez, pérdidas por advección, deriva, sedimentación), químicos (concentraciones de sales y nutrientes) y las interacciones bióticas (depredación, competencia) (Reynolds, 1988a; Moss et al., 1989; Thorp et al., 1994; Basu \& Pick, 1996).

Asimismo, la estacionalidad (temperatura, fotoperíodo) y las condiciones hidrológicas e hidrodinámicas de la cuenca (descarga de caudal, tiempos de residencia, mezcla continua, flujo turbulento, drenaje de la cuenca aguas arriba y aportes) también afectan la dinámica del plancton (Soballe \& Kimmel, 1987; Admiraal et al., 1994; Basu \& Pick, 1994; Akopián et al., 1999; Ietswaart et al., 1999). La limitación por la luz, más que la limitación por los nutrientes, es una característica común de los sistemas acuáticos, turbios y turbulentos (Reynolds et al., 1994), debido a que la mezcla continua altera la calidad e intensidad de la luz, influyendo sobre la fotosíntesis y los procesos de biosíntesis celular (Köhler, 1993). 


\section{Características del plancton de ríos}

El plancton de ríos de llanura o potamoplancton, es un componente importante en la estructura y funcionamiento del ecosistema río, así como también de los flujos de energía (Hawkes, 1975; Margalef, 1983). Está integrado por algas euplanctónicas o de verdadero desarrollo planctónico; meroplanctónicas, con un estadio de vida bentónica; y ticoplanctónicas, pertenecientes a otras comunidades y cuya presencia es más bien esporádica o accidental (Wetzel, 2001). De esta forma, el fitoplancton de ríos está compuesto por un conglomerado de especies derivadas de diferentes fuentes contributivas, tanto de origen béntico como limnético (Talling \& Rzoska, 1967; Whitton, 1975). Se trata de especies capaces de vivir y reproducirse en condiciones de turbulencia o con limitaciones de luz, pudiendo generar nueva biomasa rápidamente dadas sus altas tasas de crecimiento intrínseco (Reynolds \& Descy, 1996).

Existen dos grandes hipótesis (no excluyentes) que tratan de explicar el origen y desarrollo del plancton en los ríos, conocido como el Paradigma del Plancton (Reynolds, 1988a). Una de ellas establece que las comunidades planctónicas se desarrollan en el propio cauce, en particular en los grandes ríos, donde los organismos disponen de tiempo suficiente para crecer y reproducirse a medida que son transportados aguas abajo (Pace et al., 1992; de Ruyter van Stevenick et al., 1992). Según esta hipótesis las cabeceras presentan menores abundancias y el plancton se incrementa aguas abajo por la conexión entre los parches (Walks \& Cyr, 2004). El reclutamiento de especies planctónicas depende entonces de la transferencia y del estado hidrológico del río (Reynolds \& Glaister, 1993). Asimismo, diferentes tramos o sectores del río pueden actuar como zonas de almacenamiento, promoviendo la generación de inóculos que luego son incorporados al cauce principal (Kohlër, 1994), y se cree que las especies más exitosas son aquellas con rápido crecimiento o las que presentan un gran cúmulo inicial de propágulos (Leland, 2003).

La otra hipótesis establece que las salidas de los cuerpos de aguas lénticos son las principales fuentes del plancton en los ríos (Shiel et al., 1982; Saunders \& Lewis, 1989; Kobayashi, 1997), pero existen evidencias contradictorias sobre este origen (Welker \& Walz, 1999; Basu et al., 2000). Según Pourriot et al. (1997) pocos ejemplos avalan el ingreso de plancton desde hábitats lénticos, conectados de forma permanente o temporaria con el río. Los detractores de esta hipótesis postulan que cuando el plancton lacustre ingresa a un río, raramente sobrevive aguas abajo, y sólo persisten unos pocos géneros típicos del potamoplancton (Köhler, 1993), debido al efecto del flujo y a la retención en las macrófitas y la vegetación ribereña (Margalef, 1983). Examinar los factores que intervienen en el transporte y la persistencia del plancton aguas abajo permite elucidar los mecanismos que afectan la fortaleza de estas conexiones dentro de la cuenca (Walks \& Cyr, 2004). 
Teorías y modelos conceptuales en ríos

Existen numerosas teorías y modelos conceptuales que intentar explicar los principales procesos que ocurren dentro de los sistemas lóticos y la distribución espacio-temporal de los organismos en estos ecosistemas. Entre estas primeras teorías se encuentran el River Continuum Concept (RCC) (Vannote et al., 1980), que destaca el rol preponderante de las variables físicas en generar un gradiente longitudinal continuo desde las cabeceras hasta la desembocadura. Sin embargo, ha sido criticada por su visión simplificada del desarrollo longitudinal del potamoplancton, al excluir a la diversidad hidromorfológica del cauce principal y sus discontinuidades (Ward \& Stanford, 1995a, b; Reckendorfer et al., 1999).

Otros autores proponen una inversión en el gradiente longitudinal concebido por el RCC, argumentando la existencia de cabeceras autótrofas en los arroyos de pradera (Wiley et al., 1990). Estos aspectos también se aplican a los arroyos pampeanos (Giorgi et al., 2005), aunque los autores también enfatizan ciertas diferencias con los anteriores, como el origen de los nutrientes presentes y las características geomorfológicas particulares de la región. Entre las teorías aplicadas a los sistemas lóticos de bajo orden se encuentra la Espiral de los nutrientes en su versión revisada (Newbold, 1992; Enring \& Doyle, 2006) y el Telescoping Ecosystem Model (TEM) (Fisher et al., 1998), que complementan a la anterior en su interpretación del ecosistema arroyo conformado por subsistemas concéntricos, hidrológicamente conectados (área central, hiporreico, parafluvial y ribereño). Estas teorías resultan válidas para los arroyos pampeanos (Giorgi et al., 2005; Feijoó et al., 2011) y de otras latitudes (Artigas et al., 2013), teniendo importantes implicancias en el marco de las predicciones sobre cambio climático global (Rodrigues Capítulo et al., 2010).

Entre los modelos conceptuales aplicados a los grandes ríos de llanura, se encuentran el Pulso de inundación (Junk et al., 1989) entendido como la fuerza directriz de los procesos del ecosistema ríoplanicie de inundación, el Serial Discontinuity Concept y la conectividad hidrológica (Ward \& Stanford, 1995b). Estos conceptos han sido amalgamados con la Hipótesis del Disturbio Intermedio (Connell, 1978) ya que los sistemas río-planicie de inundación se encuentran gobernados por los disturbios (Ward et al., 1999; Tockner et al., 2000). Los disturbios son eventos estocásticos que generan cambios graduales o discretos en un factor controlador cuando se excede un umbral crítico, afectando la estructura o el funcionamiento del ecosistema, la comunidad o población (Sparks et al., 1990).

La teoría de parches (Pringle et al., 1988; Hill et al., 1991) y los conceptos de las áreas de retención (Schiemer et al., 2001) resaltaron la importancia de la heterogeneidad hábitat en la distribución espacio-temporal de los organismos. El modelo de la Productividad Fluvial (Thorp \& Delong, 1994) indaga en los ciclos biogeoquímicos que se producen dentro del sistema río-planicie de inundación 
y en el rol de las conexiones laterales (Thoms, 2003), y los aportes de la Ecología de paisajes, a través del concepto de Paisaje Fluvial (Wiens, 2002) contribuyen al entendimiento de la complejidad presente en los ambientes fluviales y sus interacciones.

\section{Características de los sistemas río-planicie de inundación}

Las planicies de inundación de los grandes ríos presentan una diversa cantidad de ambientes acuáticos asociados y son considerados como un tipo particular de humedal (Bayley, 1995). Se trata de ecosistemas únicos que sostienen gran diversidad de hábitats y conforman un mosaico aluvial dinámico, de condiciones lóticas y lénticas integradas (Ward \& Stanford, 1995b; Ward, 1998; Delong \& Thorp, 2006; Wahl et al., 2008). Los cuerpos de agua que lo componen presentan distinto grado de comunicación según las crecidas, actuando como centros de especialización por aislamiento (Margalef, 1983). Esta conectividad hidráulica determina el grado de influencia del río sobre los ecosistemas de la planicie de inundación (Izaguirre et al., 2001), y su intercambio produce modificaciones en las características físicas, químicas y biológicas de ambos ambientes (Lewis \& Saunders, 1989), con transferencia parcial de contenidos (de Cabo et al., 2003), en particular en eventos de inundación (Saunders \& Lewis, 1989).

Los ecotonos son zonas transicionales entre sistemas ecológicos adyacentes, con características singulares definidas por las escalas espacio-temporales y por la fortaleza de las interacciones entre ambientes (Pinay et al., 1990; Wissmar \& Swanson, 1990; Ward et al., 1999). Los humedales son áreas caracterizadas por la inundación periódica, que exhiben un alto grado de diversidad genética y ambiental (Izaguirre et al., 2004). Las planicies de inundación de los grandes ríos constituyen humedales particulares dominados por los pulsos, representados por fases de inundación y sequía, también denominado como pulso hidrosedimentológico (Neiff, 1990; Neiff et al., 1994).

En estos ambientes se diferencia una fase de aislación o limnofase, cuando se interrumpe el intercambio de agua superficial entre la planicie de inundación y el cauce principal del río (eventos de sequía), y una fase conectada o potamofase donde se disuelve el ecotono entre ambos durante un período de inundación, funcionando como una unidad hidrológica de condiciones homogéneas (Neiff et al., 1994; Weilhoefer et al., 2008). Desde el punto de vista del transporte y el almacenamiento del agua, ambos ambientes constituyen una unidad hidrológica (Junk, 1999) que responde como un todo integrado (sistema río - planicie de inundación), y su interacción depende en gran medida de la geomorfología, geología e hidrología de la cuenca (Reckendorfer et al., 1999).

Los eventos de sequía e inundación producen cambios en los ambientes acuáticos, modifican las variables físico-químicas y los patrones biológicos (Vadadi-Fülöp et al., 2012), como el transporte 
aguas abajo, la composición de especies y la estructura de la comunidad del potamoplancton (García de Emiliani \& Devercelli, 2003; Devercelli, 2010). La dinámica fluvial está representada por la expansión (inundación) y la contracción (sequía) de las aguas superficiales, y constituye la variable forzante que sostiene la conectividad entre el río y su valle aluvial (Ward et al., 2002).

La conectividad hidrológica describe los procesos de intercambio entre el río y su planicie de inundación, y se refiere a la transferencia de energía, materiales u organismos entre los elementos de un corredor fluvial (Ward \& Stanford, 1995a). Representa un proceso clave en la disponibilidad y la retención de los nutrientes, y materiales suspendidos y en el ciclo del carbono de estos ambientes (Hein et al., 2003). De esta forma, influye sobre la producción primaria (Hein et al., 2005), la biomasa del plancton (Baranyi et al., 2002) y el transporte activo y pasivo de los organismos, constituyendo una eficiente ruta de dispersión (Bini et al., 2003). Además, a lo largo de este gradiente de conectividad se producen diferencias en la velocidad de corriente conformando un variado rango de hábitats para los organismos del plancton (Burdis \& Hoxmeier, 2011).

Estos procesos resultan esenciales para el funcionamiento y la integridad ecológica de los sistemas fluviales (Amoros \& Bornette, 2002), los cuales se ven afectados por el régimen hidrológico (Tockner et al., 2000) y la escala y la estructura física de esa conexión (Walks \& Cyr, 2004), generando una gran complejidad de hábitats y altas biodiversidades (Nabout et al., 2007; de Morais Costa et al., 2011). En una escala de paisaje integrado, se incorporan a la cuenca otros cuerpos de agua superficiales como son los humedales, los bañados y los sistemas lénticos vinculados. Estos ambientes cumplen una importante función en la retención de los materiales particulados, en la absorción de los nutrientes por parte de los organismos y en el proceso de denitrificación (Pinay et al., 1990; Reddy \& DeLaune, 2008).

\section{Actividades humanas en los sistemas fluviales}

Los grandes ríos son integradores naturales de los procesos superficiales de la cuenca aguas arriba y de su planicie de inundación (Richey et al., 1990), pero esta organización comenzó a desaparecer rápidamente por la influencia de la civilización (Margalef, 1983). La mayoría de los grandes ríos del mundo se encuentran impactados por las actividades humanas (Sparks, 1995), como son los embalses, las obras de regulación, las canalizaciones, la diversificación o rectificación del cauce y el dragado (Baigún et al., 2007). Estas obras hidráulicas constituyen un factor de disturbio, ya que modifican el caudal y la velocidad de corriente de los cursos de agua, afectando el transporte de materiales y de organismos aguas abajo. Asimismo, la relación entre el río y la planicie de inundación muchas veces se ve aminorada debido a la construcción de terraplenes y 
contenciones (Ward \& Stanford, 1995a; Weilhoefer et al., 2008). Actualmente el hombre tiene una gran influencia en las características de los ecosistemas fluviales, frecuentemente debido a la disrupción de esta interface ecotonal (Lair, 2006).

El ingreso de nutrientes inorgánicos y de materia orgánica alóctona a través de los tributarios representa otro disturbio observable en los ambientes acuáticos, el cual conlleva a la eutrofización, por un excesivo crecimiento autóctono de los productores primarios, siendo una fuente adicional de carbono orgánico en el río aguas abajo (Garnier \& Billen, 2007). Se entiende por eutrofización al proceso acelerado de producción de carbono orgánico en los ecosistemas acuáticos, donde los excesos de $\mathrm{P}$ y $\mathrm{N}$ promueven el aumento de las tasas fotosintéticas y la productividad heterotrófica y generan cambios importantes en las redes tróficas, afectando negativamente estos ambientes (Ensign \& Doyle, 2006). De esta forma, el uso de la tierra, la modificación de las cabeceras, la remoción o aislamientos de los humedales adyacentes y la eutrofización cultural, alteran severamente los procesos del río, como son la dinámica de los sedimentos y los ciclos biogeoquímicos, a través de los aportes de nutrientes y materia orgánica (Johnson et al., 1995; Neschuk, 2001).

\section{Plancton de ríos y variables ambientales}

En los sistemas fluviales templados, la variación estacional de las variables físico-químicas y la biota acuática dependen mayormente del régimen hidrológico (de Cabo et al., 2003; Petts, 2009; Poff \& Zimmerman, 2010), siendo un factor determinante en la dinámica del plancton (Basu \& Pick, 1997; Baranyi et al., 2002; Salmaso \& Zignin, 2010; Devercelli \& O’Farrell, 2013). Asimismo, la temperatura y el flujo regulan las condiciones del hábitat, afectando la composición biológica y la diversidad (Tockner et al., 2000; Bunn \& Arthington, 2002).

Tradicionalmente se reconoce que los sistemas lóticos son sistemas saturados de nutrientes, dado que las limitaciones de luz por la turbidez, el flujo turbulento y los cortos tiempos de residencia restringen el desarrollo algal y permiten una mayor disponibilidad de los nutrientes (Smith et al., 1999; Bukaveckas \& Crain, 2002). De esta forma, la producción primaria está controlada por los factores físicos (Descy \& Gosselain, 1994), y el flujo adquiere el rol de factor clave o dominante, siendo el principal determinante de la estructura del plancton (Margalef, 1983).

En los ríos, el aumento del flujo constituye una de las principales restricciones para el zooplancton, ya que las pérdidas por advección, limitan su retención y crecimiento en las aguas fluyentes (Hynes, 1970; Pace et al., 1992). De esta forma, la comunidad del zooplancton de la mayoría de los ríos de llanura presenta una estructura semejante (Kobayashi et al., 1998; Rossetti et 
al., 2009), debido a que los factores dominantes seleccionan a los organismos de pequeño tamaño, con altas tasas de crecimiento y cortos tiempos generacionales, de modo de compensar los cortos tiempos de residencia del flujo fluvial (Viroux, 1997). De esta forma, los ciliados y los rotíferos constituyen los grupos mejor adaptados a estas condiciones, aunque presentan escasa capacidad para regular la biomasa algal (Wehr \& Descy, 1998). En menor medida se observan algunos cladóceros y las larvas nauplii de copépodos (Lair \& Reyes-Marchant, 1997; Kim \& Joo, 2000; José de Paggi \& Paggi, 2007).

\section{Estrategias de vida y grupos morfofuncionales}

Dada la predominancia de las limitaciones físicas, el fitoplancton de los ríos de llanura se encuentra representado por un pequeño grupo de especies, pertenecientes en su mayoría a las diatomeas y a las clorofitas clorococcales (Reynolds \& Descy, 1996), y sus diferentes formas de vida pueden ser interpretadas como adaptaciones funcionales para sobrevivir en un ambiente turbulento e inestable (Margalef, 1978). De esta forma, las condiciones ambientales favorecen los grupos de especies que comparten similares aspectos adaptativos (Webb et al., 2002), modificando la composición de la comunidad en el tiempo.

Según Reynolds (1984), las estrategias primarias observadas en las comunidades terrestres (Grime, 1979), también pueden aplicarse al fitoplancton, diferenciando entre especies $C$ (competidoras), $\boldsymbol{S}$ (tolerantes al estrés) y $\boldsymbol{R}$ (ruderales). Asimismo, los organismos del fitoplancton pueden diferenciarse en estrategas $K$ y $r$, según su tamaño corporal y la relación área superficial/volumen $(A S / V)$, que determina su capacidad para enfrentar la sedimentación, optimizar la captación de la luz y la toma de nutrientes, incidiendo en tasas de duplicación celular (Reynolds, 1997). A este esquema de clasificación, Reynolds et al. (2002) proponen un enfoque funcional de las especies, creando 31 grupos (codones), polifiléticos, delimitados según su sensibilidad o tolerancia a determinadas condiciones ambientales, basado en sus atributos fisiológicos, morfológicos, ecológicos o de comportamiento (Devercelli, 2006).

Los estrategas $r$ se encuentran representados por algas unicelulares de pequeño tamaño, que típicamente dominan en los estados iniciales de la sucesión, siendo especies colonizadoras y oportunistas. Además, presentan ventajas competitivas como la captación de luz aún en bajas intensidades, la tolerancia a la turbulencia, y un menor daño celular por el arrastre, dada su forma esférica, ovoide o fusiforme (Reynolds, 1989; Reynolds \& Descy, 1996). Los estrategas K presentan mayor tamaño y menores cocientes $A S / V$, y típicamente dominan en ecosistemas más estables, con un ciclado de nutrientes más eficiente y alta diversidad de especies (García de Emiliani, 1993; 
Reynolds, 1997). Pertenecen a la primer categoría los grupos morfofuncionales X1, X2 y X3 e Y, y a la segunda los codones Lo, F, J, M, S1 y H1, con integrantes habituales del fitoplancton de ríos y arroyos de la región (Bauer, 2009; Devercelli, 2010; Devercelli \& O’Farrell, 2013).

\section{Relaciones tróficas entre el fito y el zooplancton}

En los ambientes fluviales puede observarse una regulación a través de las interacciones bióticas, como el control top-down por parte del pastoreo del zooplancton herbívoro, y las limitaciones bottom-up, como es la disponibilidad de nutrientes (Gosselain et al., 1994; Kobayashi et al., 1996; Köhler, 1993; Lair, 2006). De este modo, las fluctuaciones en la biomasa fitoplanctónica y sus cambios en la composición específica afectan su interacción con el zooplancton (Everbecq et al., 2001). Dado que el fito y el zooplancton son componentes clave en las redes tróficas fluviales, las variaciones en su estructura y dinámica pueden afectar en gran medida el metabolismo del sistema río-planicie de inundación (de Cabo et al., 2003).

En los ríos de llanura los nutrientes generalmente se encuentran en exceso, de modo que el fitoplancton no se ve afectado por la competencia por los recursos (Reynolds et al., 1994a), sino que son las variables ambientales (condición hidrológica, velocidad de corriente, turbulencia, turbidez, luz) las que ejercen un control, regulando la productividad primaria (Reynolds \& Descy, 1996). De esta forma, se considera que las interacciones tróficas entre el fito y zooplancton resultan débiles en la mayoría de los ríos de llanura, debido a esta fuerte influencia de los factores físicos (Köhler, 1995; Basu \& Pick, 1996, 1997; Wehr \& Descy, 1998).

\section{Plancton y rasgos geomorfológicos}

La morfología del cauce, su profundidad, la velocidad de corriente y la descarga de caudal determinan las características de los hábitats presentes en los sistemas fluviales, actuando sobre la producción primaria (Delong \& Thorp, 2006), la composición de especies y la distribución espaciotemporal del plancton (Reynolds, 1988b; Lair, 2005). La dinámica de los procesos geomorfológicos crea zonas con diferentes condiciones físicas, químicas y biológicas en los ríos (Casper \& Thorp, 2007), siendo muy importantes para el zooplancton, ya que cualquier irregularidad en estos rasgos, como son las modificaciones locales del flujo, pueden potenciar su desarrollo y reproducción (Viroux, 2002; Picard \& Lair, 2005). También se considera a la conectividad con los ambientes adyacentes y la presencia de las zonas de almacenamiento como condicionantes del plancton de ríos de llanura (Heiler et al., 1995, Reynolds, 1995). 


\section{Zonas de almacenamiento temporario y reproducción del plancton}

Los ríos de llanura presentan como característica particular la interrelación del cauce principal con la planicie de inundación, y sus intercambios promueven el enriquecimiento del plancton lótico. Los ambientes lénticos vinculados favorecen la reproducción y el crecimiento de los organismos al presentar menores tasas de renovación del agua (Reynolds, 1988a; Stoyneva, 1994; Pourriot et al., 1997). Asimismo, la heterogeneidad del flujo y los hábitats de retención presentes en los ríos incrementan el tiempo de residencia, otorgando mayores oportunidades para su desarrollo y supervivencia (Reynolds et al., 1994).

El plancton incrementa su abundancia en estas zonas de almacenamiento (backwaters, dead zones, flushing lakes, canales secundarios, brazos ciegos, remansos, lagunas de deflación encadenadas) que actúan como refugio y promueven el reclutamiento de organismos al cauce principal del río (Reynolds \& Glaister, 1993; Gosselain et al., 1994; Reynolds, 1995). La conformación de estas fuentes naturales de inóculos varía de un sistema fluvial a otro (Wehr \& Descy, 1998), y su presencia facilita el incremento de las poblaciones planctónicas, remarcando la importancia de la descarga de caudal y la variación de la velocidad de corriente en este intercambio (Walz \& Welker, 1998; Reckendorfer et al., 1999). De esta forma, el plancton de cada tramo del río está influenciado por las comunidades aguas arriba, donde la dinámica poblacional y sus interacciones, como la competencia ante la continua presión de colonización, determinan los ensambles de especies en el río aguas abajo (Margalef, 1983).

Entre los representantes del zooplancton, los rotíferos y los cladóceros han adoptado la partenogénesis como un modo de reproducción eficiente, presentado cortos tiempos generacionales (1 a varios días), con la posibilidad de producir huevos de resistencia y una rápida dispersión en el ambiente (Lair, 2006). Por el contrario, los copépodos presentan una reproducción sexual obligada y tiempos generacionales de semanas a meses (Lehman, 1988), por lo que requieren de ambientes más estables que propicien el apareamiento y la reproducción (Lair, 2006).

\section{Plancton como indicador}

El plancton es un componente fundamental de las cadenas tróficas acuáticas, y presenta una gran complejidad interna, pocas veces valorada a nivel de especie (Scheffer et al., 2003). Sin embargo, las especies son sensores muy precisos del ambiente, y su coexistencia en un determinado lugar permite su caracterización, por la superposición de los respectivos nichos ecológicos teóricos (Margalef, 1983). Variaciones en los factores ambientales pueden alterar las proporciones relativas de algunos pocos taxa, pero estos cambios por lo general tienen poco efecto 
en el ensamble completo de especies del plancton (Wehr \& Descy, 1998; O'Farrell et al., 2002). Además, el enriquecimiento cultural genera alteraciones en la calidad del agua, y su efecto se ve reflejado en las distintas comunidades acuáticas (José de Paggi \& Paggi, 1998).

De esta forma, se ha utilizado a las comunidades biológicas como el plancton para caracterizar a los sistemas lóticos (Gómez \& Licursi, 2001; Licursi, 2005; Bauer, 2009; Licursi et al., 2010), siendo un indicador biológico muy útil ya que refleja el tipo de hábitat, el grado trófico (José de Paggi \& Devercelli, 2011) y la relación de conectividad entre el río y su planicie de inundación. Además, dados sus cortos tiempos generacionales, responde de manera rápida a los cambios en las condiciones ambientales, permitiendo la valoración de la calidad del agua (Ibelings et al., 1998; O'Farrell et al., 2002).

\subsection{Justificación del tema de tesis}

La cuenca del río Salado (Buenos Aires) recibe aportes de nutrientes por las actividades agrícolas principalmente en el tramo superior, y en todo su curso por el desarrollo urbano, que afectan su estado trófico (Neschuk et al., 2000). Asimismo, se ha registrado un aumento de las distintas fracciones de fósforo en cuerpos de agua de la cuenca, como modificaciones en la estructura y dinámica del plancton (O'Farrell, 1993; Neschuk et al., 2002b; Claps et al., 2009; Gabellone et al., 2013). El enriquecimiento de los cursos de agua superficiales por la acción humana ha provocado cambios significativos en la biomasa y composición del plancton alterando su abundancia y variedad (Gosselain et al., 1994).

En las últimas décadas, la construcción de canales en la cuenca superior del río Salado ha provocado cambios en su red de drenaje, vinculando zonas arreicas o con escaso desarrollo del avenamiento al cauce principal del río. Como resultado de estas obras hidráulicas (canalizaciones), se ha producido la movilización de una gran cantidad de sales almacenadas hasta ese momento en las aguas subterráneas de la Pampa Arenosa. Este proceso promueve la salinización secundaria de los ambientes dulceacuícolas (Williams 1996, 1999; Herczeg et al., 2001) en regiones donde, debido a la intervención del hombre, se aumenta la concentración de sales, principalmente de las aguas superficiales (Gabellone et al., 2008). De esta forma, se producen aportes de aguas con características químicas diferentes, las cuales son transportadas a través de cuerpos lénticos y lóticos modificados, configurando sistemas complejos y desconocidos desde el punto de vista limnológico.

La ejecución de obras hidráulicas genera cambios en el caudal y en la velocidad de corriente, modificando la conformación natural de los cauces. Estos disturbios tienen consecuencias sobre el 
transporte y la deriva de los organismos del plancton, sobre la colonización aguas abajo, la selección de especies adaptadas a estos cambios y en las características poblacionales de las especies dominantes. Las obras de canalización y dragado son prácticas comunes en los sistemas lóticos pampeanos (Bauer et al., 2002a; Licursi, 2005; Rodrigues Capítulo et al., 2010), donde la escasa pendiente contribuye a la falta de flujo superficial y prolonga la duración de las inundaciones.

Los canales también afectan la recurrencia natural de las inundaciones, y por lo tanto, alteran la interacción entre el río con su planicie de inundación y los cuerpos lénticos asociados (Gabellone et al., 2003). Además, se reconoce que las modificaciones antrópicas en los cauces afectan el crecimiento y el desarrollo del plancton, y provocan la simplificación de las comunidades por la falta de incorporación de inóculos (Salmaso \& Zignin, 2010). En este contexto, es necesario conocer los orígenes y la dinámica de factores clave como son la salinidad, la incorporación de nutrientes y la influencia de los usos de la tierra, particularmente en relación con las condiciones de inundación y sequía (Herczeg et al., 2001).

Estudios previos en la cuenca han enfatizado la importancia de la geomorfología y el régimen hidrológico del río para el desarrollo del plancton, debido a que su dinámica y origen están relacionados a las contribuciones de los cuerpos de agua lénticos adyacentes (Solari et al., 2002; Neschuk et al., 2002b). Asimismo, han permitido identificar las principales especies o grupos dominantes del fito y zooplancton en diferentes situaciones y zonas del río (O'Farrell, 1993; Claps et al., 1997, 2009; Neschuk, 2001; Neschuk et al., 2002a,b; Bazzuri et al., 2008, 2010a,b; Gabellone et al., 2001, 2003, 2005, 2013; Solari \& Mac Donagh, 2014; Solari et al., 2014). Sin embargo, estos estudios no estuvieron dirigidos específicamente a reconocer los efectos de las canalizaciones afluentes (sistema Bragado) sobre la estructura, dinámica y composición del plancton del río Salado en su cuenca superior. Por este motivo, en el presente trabajo se analizan las características de estos aportes alóctonos provenientes de la Pampa Arenosa, de los cuales no se tiene ningún conocimiento limnológico.

\subsection{Hipótesis}

Como hipótesis de trabajo se plantea que:

I- Dado que el plancton de los sistemas lóticos responde a las variables ambientales, la comunidad planctónica de la cuenca superior del río Salado presentará cambios en su estructura y composición en relación con la condición hidrológica (conductividad, velocidad de corriente, distancia hidrométrica) y la estacionalidad (temperatura). 
II- Dado que las canalizaciones de la Pampa Arenosa drenan una zona arreica con aguas subterráneas salinas, presentan aguas con características físico-químicas particulares y el desarrollo de un plancton adaptado a estas condiciones. Sus aportes de origen alóctono, luego de pasar por las lagunas y humedales interconectados del sistema Bragado, descargan en el río Salado, afectando las aguas del río aguas abajo de su trasvase (conductividad, composición iónica, estructura del plancton), según la condición hidrológica.

A partir de estas hipótesis se predice que:

a- La abundancia y biomasa total del plancton será mayor en los momentos de temperaturas cálidas y bajas velocidades de corriente, y lo opuesto se observará con bajas temperaturas del agua y mayores velocidades de corriente.

b-Se observará un aumento en la abundancia y biomasa total del plancton en el río aguas abajo del trasvase por la incorporación de organismos por parte de los tributarios (sistema Bragado).

c- La abundancia, biomasa y composición de especies de fito y zooplancton presentará variaciones entre los sitios de muestreo, particularmente entre los canales y el río.

d- Se observarán planctontes típicos de ambientes salinos, principalmente en las canalizaciones.

e- Se observará un cambio en las características físico- químicas y biológicas de las aguas de los canales, al pasar por los sucesivos ambientes lénticos vinculados (humedales, bañados, lagunas) presentes en el sistema Bragado.

\subsection{Objetivos}

Objetivo general: Ampliar los conocimientos sobre la dinámica y estructura del plancton del río Salado, caracterizar desde el punto de vista limnológico al principal sistema afluente modificado por el hombre que recibe en su cuenca superior (canalizaciones de la Pampa Arenosa sistema Bragado), y analizar el efecto del trasvase de estos aportes alóctonos sobre el río.

\section{Objetivos específicos:}

1- Identificar y cuantificar los integrantes del fito y zooplancton del río Salado en su cuenca superior y de las canalizaciones provenientes de la Pampa Arenosa (sistema Bragado), siendo este último un sistema afluente desconocido desde el punto de vista limnológico.

2- Conocer los aportes de las canalizaciones, en términos de parámetros físico-químicos, composición iónica del agua, concentración de nutrientes y la estructura del plancton y los cambios que se producen en el río aguas abajo de su trasvase, en diferentes condiciones hidrológicas. 
3- Relacionar los cambios en la estructura y composición del plancton con las características físico-químicas del agua y la condición hidrológica. Identificar los principales factores que actúan sobre el plancton y su efecto en la distribución de los organismos, determinando la presencia de especies características en los diferentes sitios.

4- Analizar la variación en la abundancia y biomasa de los principales grupos y especies del plancton, durante su transporte a través de los canales, su pasaje por las lagunas y humedales asociados, y los cambios que se producen en el río Salado aguas abajo de la descarga de las canalizaciones.

5- Analizar el rol de las áreas adyacentes y de los ambientes lénticos vinculados como fuentes de inóculos para el río, mediante la cuantificación de los diferentes componentes del fito y zooplancton, incluyendo los organismos en reproducción y sus estadios de desarrollo. 
Área de estudio 


\section{2. Área de Estudio}

\subsection{Cuenca del río Salado}

El río Salado es el río autóctono más largo de la provincia de Buenos Aires, con $571 \mathrm{~km}$ de recorrido, desde el sur de Santa Fe hasta su desembocadura en la Bahía Samborombón. Su cuenca cubre $186.000 \mathrm{~km}^{2}$ y abarca más de la mitad de la superficie de la provincia, cubriendo 56 partidos y 134 municipios (Herzer, 2003; Gonzalez \& Fernandez, 2007). Es un río típico de llanura, con aportes de aguas superficiales y subterráneas, y un régimen hidrológico muy variable, con flujos de corriente que exceden los $1.500 \mathrm{~m}^{3} / \mathrm{s}$ durante los períodos de inundación, y no supera los 100 m³/s en condiciones de sequía (Gabellone et al., 2008; Cesanelli \& Guarracino, 2011).

El valle aluvial del río Salado no es muy extenso (Gabellone et al., 2005), pero en su planicie de inundación se incluye gran cantidad de lagunas someras y humedales, con diferentes grados de conectividad al río, los cuales se forman en las depresiones del terreno por la acumulación del agua de lluvia o la descarga de las napas subterráneas (Ludueña, 2006). Estas lagunas someras, no estratificadas, eutróficas o hiper-eutróficas, presentan variada concentración de sales y registran niveles de agua altamente fluctuantes (Quirós et al., 2002). En condiciones normales cubren alrededor de $1.000 \mathrm{~km}^{2}$, pero durante las inundaciones se interconectan, aumentando considerablemente su tamaño, número y extensión. Su escurrimiento superficial es muy pobre, y durante los períodos húmedos actúan como áreas de almacenamiento temporario atenuando el pico de crecida (Palmer et al., 2002; Carol et al., 2010). En las épocas de escasez de agua se evaporan completamente, dejando el terreno con escoriaciones y depósitos de sal alrededor de los márgenes (Imbellone \& Giménez, 1998). Los arroyos pampeanos se caracterizan por presentar bajas velocidades de corriente, escasa profundidad y altas irradiancias en toda su trayectoria. También reciben gran cantidad de efluentes domésticos e industriales, en su mayoría sin ningún tipo de tratamiento; y los aportes difusos de la agricultura intensiva, los cuales impactan severamente en los cuerpos de agua de la región (Feijoó \& Lombardo, 2007).

La cuenca del río Salado se halla en la llanura Pampeana, la que representa una de las regiones más importantes del país en términos económicos por el gran desarrollo de la agricultura y la ganadería. Una característica importante de la cuenca es que las cabeceras se encuentran densamente pobladas y con un uso agrícola intensivo, mientras que en la cuenca baja se desarrollan actividades ganaderas extensivas, estando prácticamente deshabitada su desembocadura (Gonzalez \& Fernandez, 2007). Si bien el paisaje es bastante homogéneo, en la 
cuenca pueden diferenciarse en 3 zonas principales: Noroeste, Salado-Vallimanca y las Lagunas Encadenadas del Oeste. El área de estudio se encuentra dentro de la zona Noroeste en el extremo de la provincia, y abarca $66.000 \mathrm{~km}^{2}$ de superficie (Ludueña, 2006).

\subsection{Clima de la región noroeste}

El clima es sub-húmedo templado de acuerdo a la clasificación de Thornthwaite (1948), con una estación seca en invierno y algunas características continentales. La temperatura media anual es de $16{ }^{\circ} \mathrm{C}$, con valores extremos en Enero $\left(23^{\circ} \mathrm{C}\right)$ y Julio $\left(9^{\circ} \mathrm{C}\right)$. En la actualidad, la precipitación media anual es de $850 \mathrm{~mm}$ y las lluvias se concentran entre los meses de Octubre a Marzo (68-74\%) (Forte Lay et al., 2007). Intensas precipitaciones durante el otoño-invierno (Mayo) causan importantes anegamientos, que se mantienen en la época invernal por la escasa evaporación, de modo que las lluvias de la primavera pueden provocar extensas inundaciones en el área (Gonzalez \& Fernandez, 2007). La evapotranspiración potencial es de $1092 \mathrm{~mm}$ promedio al año, con un balance hídrico negativo, en especial entre los meses de Noviembre y Febrero (Díaz-Zorita et al., 2002). Los vientos son más intensos en verano, y dadas las elevadas temperaturas y tasas de evapotranspiración, es frecuente la erosión eólica de los suelos en la zona, favorecida por su textura arenosa (Viglizzo \& Frank, 2006). La recarga de los suelos se concentra entre los meses de Marzo-Abril, y coincide con el inicio de las tareas de labranza y plantación de forrajes y pasturas (Ludueña, 2006).

Una característica fundamental del clima en la región pampeana es que está formado por ciclos hidrológicos interanuales, es decir, varios años secos son seguidos por otros tantos húmedos, con un patrón irregular (Iriondo \& Kröhling, 2007). La alternancia de períodos de exceso de agua y déficit en las precipitaciones promueven la ocurrencia de eventos de inundaciones y sequías recurrentes, que afectan tanto al ambiente como a las actividades humanas en la zona (Halcrow \& Partners, 1999; Scarpati et al., 2002; Herzer, 2003; Cesanelli \& Guarracino, 2011). En los años 197273 se observaron precipitaciones promedio de 700-750 mm en la región Noroeste, con la iniciación de un período húmedo a partir de esa década, hasta alcanzar valores de $950 \mathrm{~mm}$ en los últimos años (Forte Lay et al., 2007).

\subsection{Geología y geomorfología}

La cuenca del río Salado constituye una amplia cuenca sedimentaria, con una secuencia de sedimentos consolidados continentales y marinos del Mesozoico-Cenozoico de hasta 6.000m de profundidad. Estos sedimentos residen sobre dos unidades geológicas diferentes: una consiste en rocas ígneo-metamórficas del Precámbrico con intrusiones de granitos, gneiss y esquistos, y la otra 
es un basamento meta-sedimentario de las eras Proterozoica y Eopaleozoica. Sobre este basamento se depositaron sucesivas formaciones sedimentarias: Serra Geral, Río Salado, General Belgrano, Las Chilcas, Los Cardos, Olivos, Paraná, Araucano y Arenas Puelches, y Pampeano (Santa Cruz \& Silva Busso, 1999; Carol et al., 2010). La formación Pampeano representa la parte superior del acuífero regional, y todas las unidades están en continuidad hidráulica. El sistema puede ser considerado regionalmente como no confinado, pero también se registran áreas de acuífero confinado y semiconfinado, de distribución variable (Kruse \& Zimmermann, 2002)

En la región Noroeste se destaca en superficie la formación Junín, Post-Pampeana o del Médano Invasor, que se extiende hasta los $20 \mathrm{~m}$ de profundidad y constituye una sucesión de acumulaciones eólicas de arenas finas formadas en las condiciones semi-áridas del Holoceno tardío. Actualmente, conforman un paisaje típico de dunas, denominada como Pampa Arenosa (Santa Cruz \& Silva Busso, 1999; Iriondo \& Kröhling, 2007). Dentro de esta área se reconocen 2 zonas, una al Norte con la presencia de dunas longitudinales de $100 \mathrm{~km}$ de largo, y otra zona Sur con dunas parabólicas en dirección SO-N. La forma y altura de las dunas se han suavizado con el tiempo por la acción de las lluvias y el viento, y el paisaje no presenta formas topográficas conspicuas. La altitud es muy baja, y no supera los $100 \mathrm{~m}$ sobre el nivel del mar.

\subsection{Suelos}

En general predominan los suelos profundos del orden de los molisoles, bien drenados, de textura arenosa o areno-limosa con presencia de carbonato de calcio, de bajo a medio contenido de materia orgánica, y baja capacidad de retención de agua (Imbellone \& Giménez, 1998; Solbrig, 1997). Los suelos se desarrollaron a partir de materiales parentales arenosos, de espesor variable, asentados sobre sedimentos finos, poco permeables, denominados como thapto. Este horizonte enterrado se desarrolló en un paleoclima distinto al actual, y sobre el mismo se apoyan las napas freáticas ya que impide el movimiento del agua a través del suelo (Zárate, 2003). Este horizonte aflora en las zonas bajas, y promueve frecuentes inundaciones y anegamientos en aquellos lugares donde la napa freática es cercana a la superficie. La zona es bien conocida por la alta mineralización de las aguas subterráneas, y las secuelas que deja el ascenso capilar y posterior precipitación de las sales en superficie (Taboada et al., 2009). La región Noroeste presenta un entramado complejo de perfiles de suelos, que reflejan la sucesión sedimentaria y los eventos pedogenéticos en la historia geológica reciente (Pleistoceno-Holoceno). Esta variedad fue causada originariamente por las diferencias en la composición del material parental, pero los fuertes procesos erosivos de los inicios del período agrícola las han acentuado (Quiroga et al., 1999). 


\subsection{Hidrología}

Las cuencas de llanura se caracterizan por presentar límites difusos en las divisorias, con transfluencia temporaria en períodos húmedos (Iriondo \& Kröhling, 2007). Debido a los bajos gradientes topográficos se almacenan grandes volúmenes de agua en superficie, cubriendo vastas extensiones por largos períodos de tiempo. La falta de capacidad del sistema para evacuar los excedentes hídricos se traduce en inundaciones generalizadas y prolongadas (Herzer, 2003). Asociado a este fenómeno se encuentra el aumento generalizado de los niveles freáticos, los cuales generan anegamientos temporarios y bañados, afectando el desarrollo de las actividades agrícolaganaderas en la zona (Scarpati et al., 2002). En los períodos secos, con el déficit de lluvias y al balance negativo del suelo, las napas freáticas se retraen y las depresiones del terreno se secan, haciendo que la producción agrícola también decaiga (Forte Lay et al., 2007). Además, tiende a producirse la salinización de los suelos en las cubetas, siendo ambos efectos muy perjudiciales para la explotación económica de los terrenos (Badano, 2010).

Dada la historia geomorfológica reciente de la cuenca del río Salado, la región presenta escasos procesos fluviales, debido a la falta de un mínimo gradiente de energía que pueda producir la erosión del paisaje, combinado a la muy baja pendiente y la presencia de sedimentos finos no consolidados (Halcrow \& Partners, 1999; Palmer et al., 2002). El sistema de drenaje del río aún no se ha ajustado al régimen actual de clima y escorrentía, y la mayoría de los afluentes no han desarrollado las propiedades geométricas de un sistema estable, ni en términos de sección transversal ni de perfiles longitudinales, con una muy baja densidad de cursos $\left(\mathrm{km} / \mathrm{km}^{2}\right)$. Esto es especialmente relevante en la región Noroeste, dadas sus características geomorfológicas particulares y de los sedimentos en superficie (Badano, 2010).

Entre los aspectos más destacables de la Pampa Arenosa se observa su condición arreica, donde la red de drenaje natural está pobremente desarrollada y carece de jerarquía e integración (Ludueña, 2006; Carol et al., 2010). La baja pendiente del terreno $(0,107 \mathrm{~m} / \mathrm{km}$ hacia el Este), la baja energía morfológica del sistema y los suelos pobremente drenados en los bajos, por la presencia de sedimentos permeables cercanos a la superficie, hacen que las pequeñas formas topográficas sean importantes desde el punto de vista hidrológico (Tanco \& Kruse, 2001; Forte Lay et al., 2007). Las dunas presentes en la zona, son un obstáculo adicional para el escurrimiento superficial, conformando áreas de almacenamiento temporario en los espacios interdunas y depresiones del terreno, siendo una fuente importante de agua para el sistema (Badano, 2010). La disposición de estos médanos también entorpece el drenaje, y los cuerpos de agua formados durante los períodos húmedos sólo pueden ser eliminados a través de la infiltración profunda o la evapotranspiración 
(Matossian et al., 2007; Taboada et al., 2009). El escaso escurrimiento superficial (<10\%) es más bien errático y laminar, y está determinado por las diferencias micro-topográficas del terreno, la cubierta vegetal y la dirección del viento (Herzer, 2003). En este contexto, las geoformas locales tienen efectos hidrológicos importantes en la cuenca, y representan verdaderas barreras para el escurrimiento superficial, incluidas las construcciones antrópicas, como obras civiles viales, ferroviarias, terraplenes y puentes (Ludueña, 2006; Badano, 2010).

Como consecuencia de estas condiciones, en la región predominan los movimientos verticales del agua (evapotranspiración e infiltración) por sobre los movimientos horizontales (escurrimiento superficial y sub-superficial), con el almacenamiento temporario de los excesos en las depresiones del terreno y las aguas subterráneas (Varni \& Usunoff, 1999; Tanco \& Kruse, 2001; Palmer et al., 2002; Forte Lay et al., 2007; Gonzalez \& Fernandez, 2007; Iriondo \& Kröhling, 2007; SADS, 2007). En este sentido, se considera que el río Salado representa un río evaporado en sus cabeceras (Gabellone et al., 2008), mientras que en el resto de la cuenca la salinidad se debe a la meteorización de evaporitas continentales (Iriondo, 1999), con presencia de suelos hidromórficos con alto contenido de sales y la predominancia de las características locales (O’Farrell, 1993).

El incremento de las precipitaciones en la región en las últimas décadas ha producido anegamientos e inundaciones periódicas, de gran magnitud y permanencia, y el proceso sedimentológico más relevante es la movilización de grandes volúmenes de sales disueltas, particularmente cloruros y sulfatos (Iriondo \& Kröhling, 2007). Al prevalecer la evapotranspiración por sobre los demás procesos, se contribuye al anegamiento constante de las depresiones del terreno, que sumado a la presencia de altas concentraciones de sales en las aguas subterráneas se promueve la salinización y sodificación del suelo (Ludueña, 2006). La frecuencia de estas inundaciones ha aumentado durante los últimos 20 años en la cuenca del río Salado, y el problema requiere una solución rápida y definitiva debido a la gran importancia económica y la densidad poblacional que presenta el área afectada (Gonzalez \& Fernandez, 2007). Este comportamiento hidrológico tan dinámico genera severos impactos y restricciones, no sólo en la escala regional, sino que también afecta el desarrollo de las actividades socio-económicas nacionales (Halcrow \& Partners, 1999). A raíz de estas pérdidas, se han construido gran cantidad de canales de drenaje y aliviadores para incrementar la producción agrícola de la región (Palmer et al., 2002). Según algunos antecedentes, la cuenca del río Salado originariamente ocupaba alrededor de $94.000 \mathrm{~km}^{2}$, pero en los últimos 100 años debido a la ejecución de sucesivas obras hidráulicas se duplicó la superficie de injerencia hasta alcanzar los valores actuales (Ludueña, 2006). 
Es importante destacar que la región Noroeste era una zona hidrológicamente independiente, y es a partir de las grandes inundaciones de los años 1987-88 que el gobierno provincial decide iniciar diversas intervenciones hidráulicas. En 1991, a fin de dar respuesta a estas demandas sociales, se construyó una red de canales primarios (urbanos) y secundarios (rurales) que drenaron el exceso de agua directamente al río Salado. Es así como los canales Jauretche, República de Italia, Mercante y San Emilio, entre otros, conectaron las lagunas El Hinojo y Las Tunas y otros cuerpos de agua superficiales con el río Salado.

A través de estas canalizaciones, esta zona arreica del noroeste de la provincia de Buenos Aires (Pampa Arenosa) quedó "oficialmente" integrada a la cuenca del río Salado, en su sector superior. Esta obra luego se continuó con la ejecución del Plan Maestro Integral de la Cuenca del Salado encargado a Halcrow \& Partners en 1999. Este plan integrado fue financiado por el Banco Mundial, y su objetivo era mitigar los impactos negativos de las inundaciones y sequías, mejorar la actividad económica de la zona, y proteger y desarrollar el valor ambiental de la cuenca. En este estudio se plantearon distintas medidas estructurales que consistieron básicamente en la excavación de nuevos canales de drenaje y aliviadores, la ampliación de los existentes, la generación de reservorios temporarios en lagunas actuales, y la construcción de diversas obras de control (Ludueña, 2006; Badano, 2010).

\subsection{Vegetación}

El área de estudio se encuentra en el Dominio de la Pradera Pampeana, siendo uno de los pastizales templados más extendidos del mundo, aunque con bajo estado de conservación (Solbrig, 1997). En la actualidad, ninguno de los hábitats naturales se mantiene intacto, y la composición y estructura de la vegetación nativa ha sido modificada en gran medida en los últimos 120 años, debido al uso de la tierra por la agricultura, la introducción de forrajes y cultivos, el incremento del pastoreo por la ganadería extensiva, la invasión de plantas exóticas, la contaminación de lagos y ríos, y las obras hidráulicas asociadas a la cuenca (Palmer et al., 2002; Ludueña, 2006). Estos cambios han causado disrupciones en el ecosistema pampeano afectando la provisión de servicios ecológicos como el control de la erosión y la regulación del agua, esenciales para la prevención de catástrofes (Viglizzo \& Frank, 2006). Sin embargo, se considera que las inundaciones son importantes para el mantenimiento de los hábitats naturales de la cuenca, ya que re-establecen el proceso sucesional de lagos y humedales, reducen los efectos negativos de la salinización y la eutrofización, y el dominio de las plantas invasoras y exóticas en los pastizales (Palmer et al., 2002). 


\subsection{Desarrollo económico}

La agricultura del centro de la región pampeana, que representa el área más productiva de la Argentina, está usualmente amenazada por el riesgo de las inundaciones y las sequías (Matossian et al., 2007). La región Noroeste tiene una historia agrícola reciente, ya que las pampas se mantuvieron como pastizales nativos hasta fines del siglo XIX. La principal actividad económica es la producción mixta, que incluye el desarrollo de la ganadería extensiva con la alternancia y rotación de cultivos y pasturas. Con el aumento de las lluvias en los últimos 30 años y el corrimiento de las isohietas hacia el Oeste, la productividad de la zona se ha incrementado, alcanzando hoy en día su mayor desarrollo (Ghersa et al., 2002; Viglizzo et al., 1997). Gran parte de las tierras son usadas para el cultivo de granos (girasol, maíz, soja y trigo), forrajes anuales (avena, centeno) y pasturas perennes (pastos y alfalfa), y sólo una pequeña proporción $(<25 \%)$ de las tierras persisten como zonas no cultivadas (Viglizzo et al., 2001; Viglizzo \& Frank, 2006). Sin embargo, las actividades sociales y económicas de la región están fuertemente influenciadas por la disponibilidad de agua en el sistema (Forte Lay et al., 2007), de modo que las inundaciones y los anegamientos recurrentes constituyen una limitación importante a la inversión en el sector, afectando el valor de las tierras. Debido a estas actividades el impacto humano sobre la cuenca se ha incrementado, alterando la dinámica, biodiversidad y usos del río Salado (Moscuzza et al., 2007). Entre estas modificaciones se encuentran el crecimiento poblacional, el vertido de efluentes industriales y domiciliarios, la construcción de infraestructura (caminos, terraplenes) y manejo hídrico (dragado, canalizaciones, cambios en el drenaje) (Conzonno et al., 2002).

\subsection{Sitios de muestreo}

El sector superior de la cuenca del río Salado recibe los aportes de las canalizaciones que drenan la Pampa Arenosa y el Complejo Hinojo-Las Tunas, conteniendo aguas de elevado tenor salino y alta carga de nutrientes, que luego se descargan en cuerpos de agua receptores, como lo son las lagunas Municipal y del Bragado. Esta serie de lagunas, arroyos y humedales interconectados confluyen al río Salado a través del $\mathrm{A}^{\mathrm{o}}$ Saladillo y el Canal del Este. El otro sector seleccionado corresponde al cauce principal del río Salado, previo y posterior a la confluencia de este sistema interconectado, denominado como "sistema Bragado". Los sitios seleccionados se diferencian por los caudales aportados, la entrada de nutrientes y el aporte salino de los canales involucrados. Con el fin de analizar la dinámica del sistema y los efectos de estos aportes sobre el plancton se fijaron 6 sitios de muestreo: Canal Mercante (canal 1 - C1), Canal de Vinculación (canal 2 - C2), A o Saladillo (arroyo), Canal del Este (canal 3 - C3), y en el cauce principal del río cercano a la Ruta Provincial 
№ 42 (Río Arriba - R1) y cerca de la localidad de Alberti (Río Abajo - R2), siendo sitios aguas arriba y abajo del trasvase, respectivamente (Fig. 2.1). Los muestreos corresponden a cuatro momentos hidrológicos: aguas altas (mayo 2007), caudales medios (marzo 2008), aguas bajas (nov. 2008), y aguas muy bajas en los afluentes (sistema Bragado), pero con caudales medios en el río (sept. 2009).

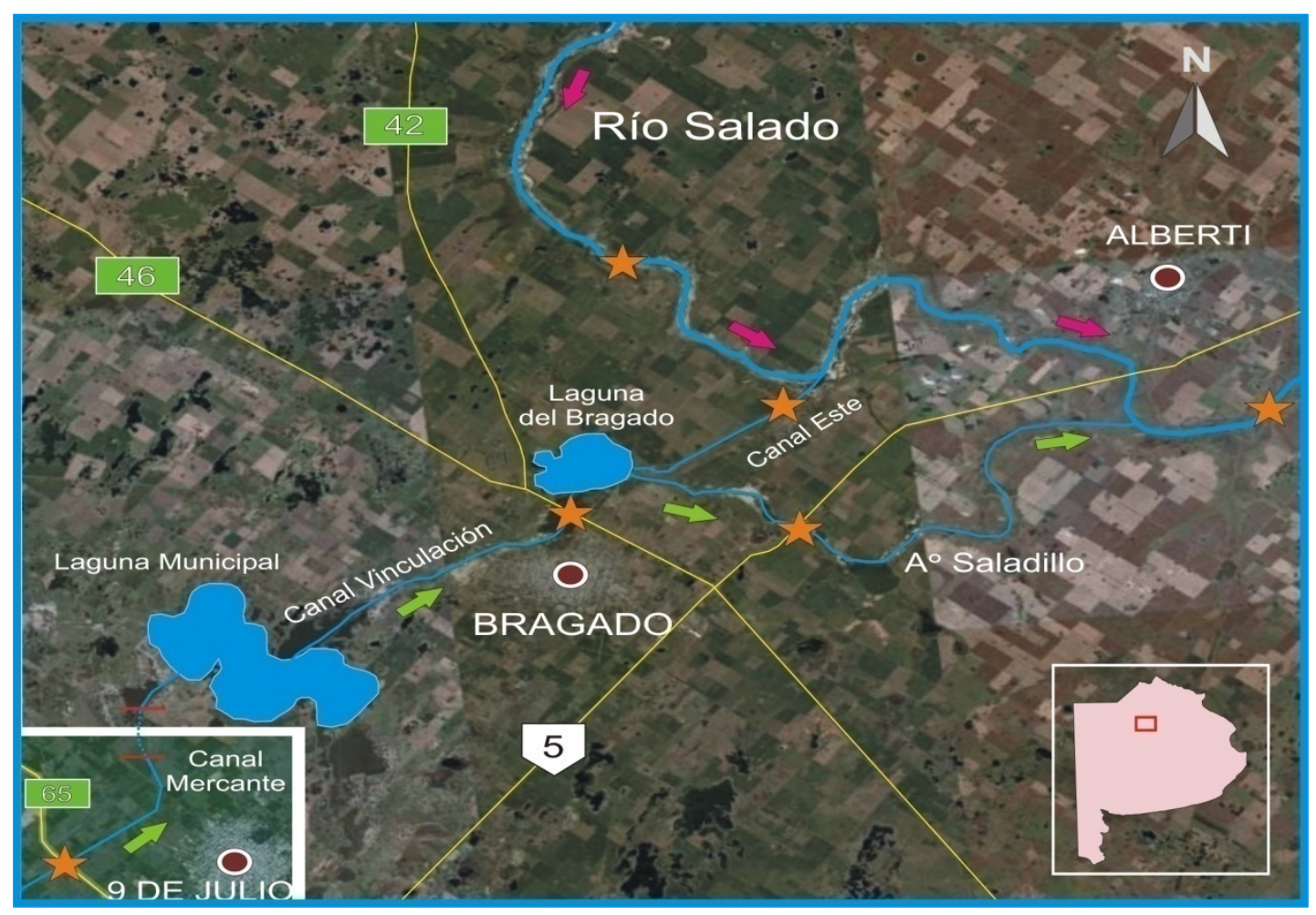

Figura 2.1: Mapa del área de estudio y localización de los sitios de muestreo: Canal Mercante, Canal de Vinculación, Canal del Este, A o Saladillo y el río Salado, aguas arriba y abajo del trasvase.

\section{Canal Mercante}

Este canal proviene del Complejo Hinojo-Las Tunas y drena las lagunas homónimas en el Partido de Trenque-lauquen; luego atraviesa la Pampa Arenosa y recibe aportes de innumerables afluentes a lo largo de su trayecto. Representa un canal de drenaje típico, con tramos totalmente rectos, cauce en forma trapezoidal y márgenes escarpadas, con escasa vegetación ribereña. El sitio de muestreo

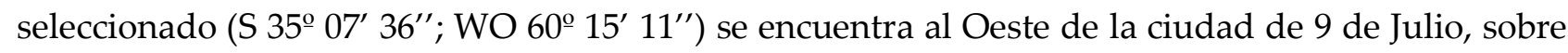
la Ruta Provincial № 65 (Fig. 2.2). En condiciones de aguas bajas se evidenciaron eflorescencias salinas debajo del puente, en los pilotes y en las márgenes del canal. También se hallaron plantas suculentas y halófitas en sus márgenes, dando cuenta de la elevada cantidad de sales presentes. En los márgenes se observó el cultivo de girasol y la ganadería extensiva. Este canal luego recorre unos 75km aproximadamente en forma paralela a la Ruta Nacional № 5, hasta llegar a la laguna Municipal de Bragado. 


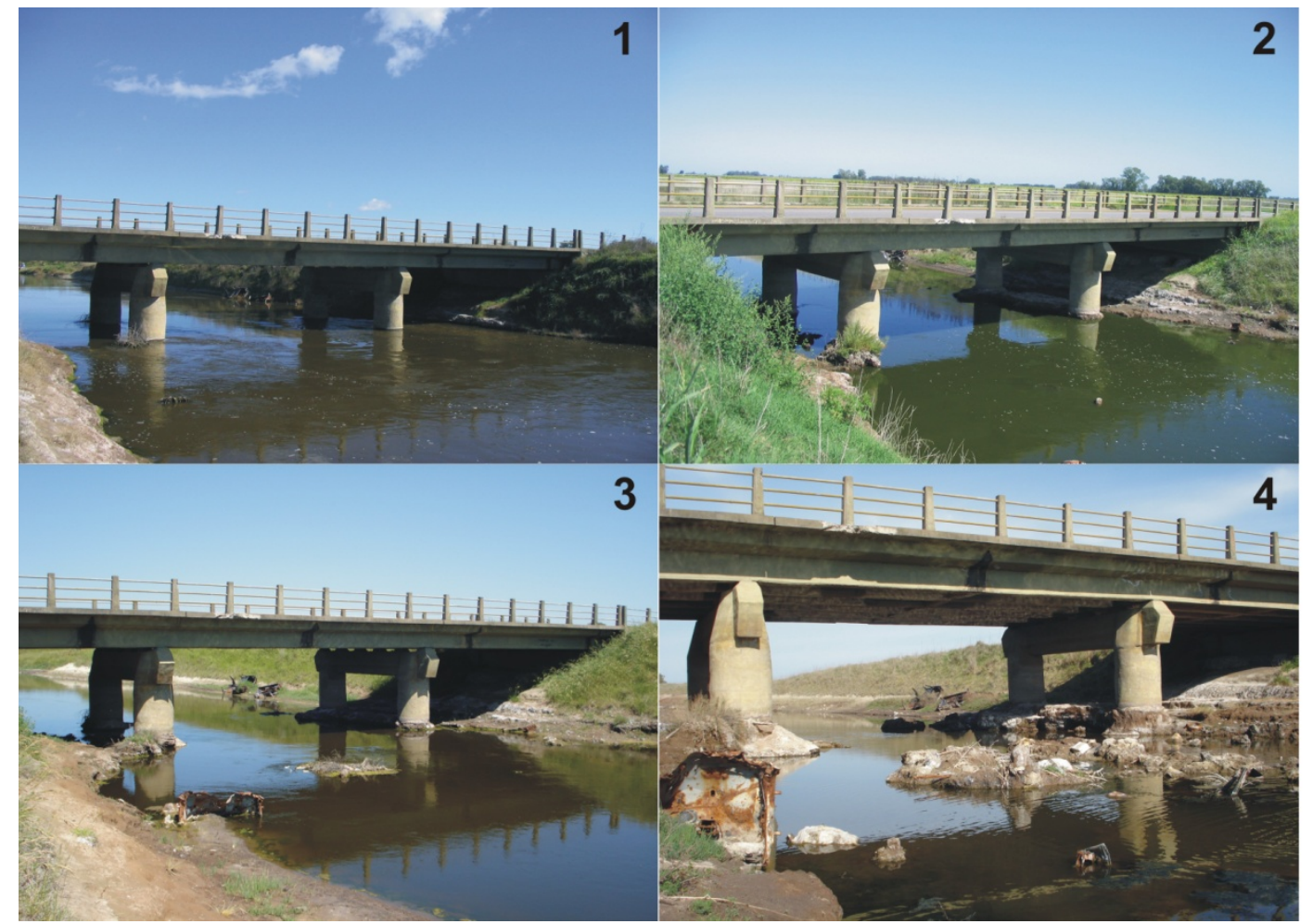

Figura 2.2: Fotografías del Canal Mercante en las diferentes campañas de muestreo: 1- aguas altas (mayo 2007), 2- caudales medios (marzo 2008), 3- aguas bajas (nov. 2008) y 4- aguas muy bajas (sept. 2009).

\section{Canal de Vinculación:}

Este canal nace en la laguna Municipal de Bragado, rodea a la ciudad en dirección al Este, y luego desemboca en la laguna del Bragado. Es profundo, y atraviesa un humedal natural muy extenso que comunica ambas lagunas, siendo interrumpido por el terraplén de la Ruta Provincial

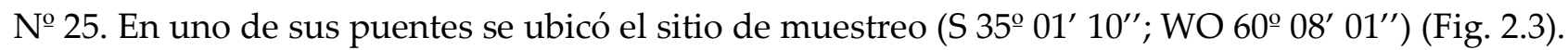
El lugar fue modificado a lo largo de los muestreos, debido a la ejecución de un plan de mejoras hídricas del estado nacional. Durante ese tiempo se observó la ampliación y modificación de las márgenes del canal (marzo 2008), la construcción de terraplenes como defensas contra las inundaciones (nov. 2008), y de un muro de contención (transitorio) aguas abajo del sitio de muestreo, que obstruía parcialmente el flujo de agua hacia la laguna del Bragado, donde se estaba construyendo un nuevo vertedero en las nacientes del $\mathrm{A}^{\circ}$ Saladillo (Fig. 2.11). De esta laguna del Bragado surgen dos afluentes, el Ao Saladillo y el Canal del Este.

\section{Canal del Este:}

Se inicia en la laguna del Bragado y su caudal está regulado por una exclusa que mantiene el nivel de agua de la laguna. Luego de un pequeño recodo, continúa su recorrido en línea recta en dirección Este hacia el río Salado. Representa un canal típico de forma trapezoidal y de márgenes escarpadas, con la presencia de montículos del material extraído a la vera del cauce, vegetado y consolidado a lo largo de su trayecto. El sitio de muestreo se ubicó en un puente de un camino 


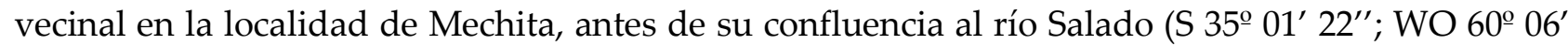
$\left.15^{\prime \prime}\right)$. Allí se observaron dunas de arena en sus márgenes, vegetadas por gramíneas y cortaderas, y una pequeña plantación de eucaliptos, cercana a los predios del ferrocarril del pueblo (Fig. 2.4).

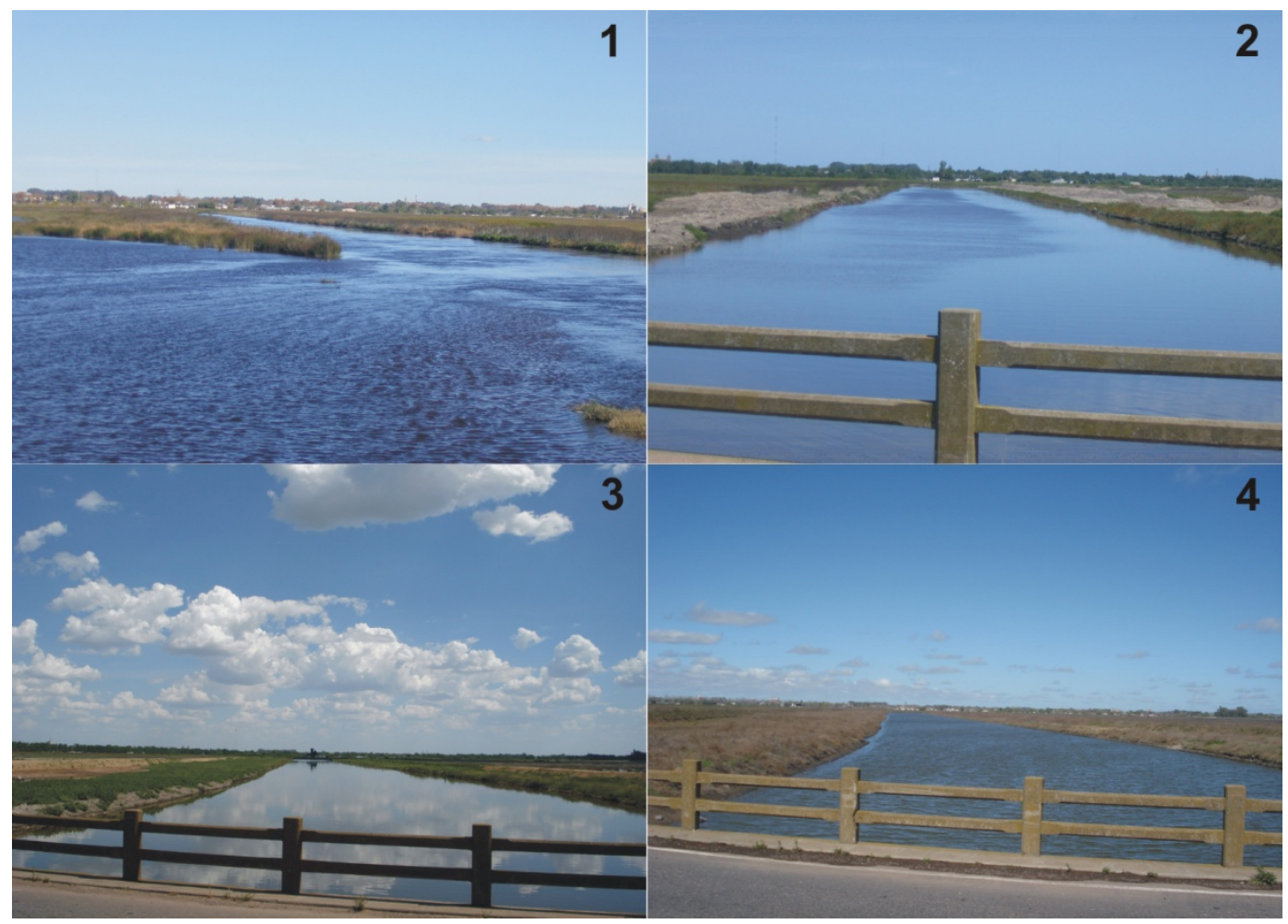

Figura 2.3: Fotografías del Canal de Vinculación en las diferentes campañas de muestreo: 1- aguas altas (mayo 2007), 2- caudales medios (marzo 2008), 3- aguas bajas (nov. 2008) y 4- aguas muy bajas (sept. 2009).

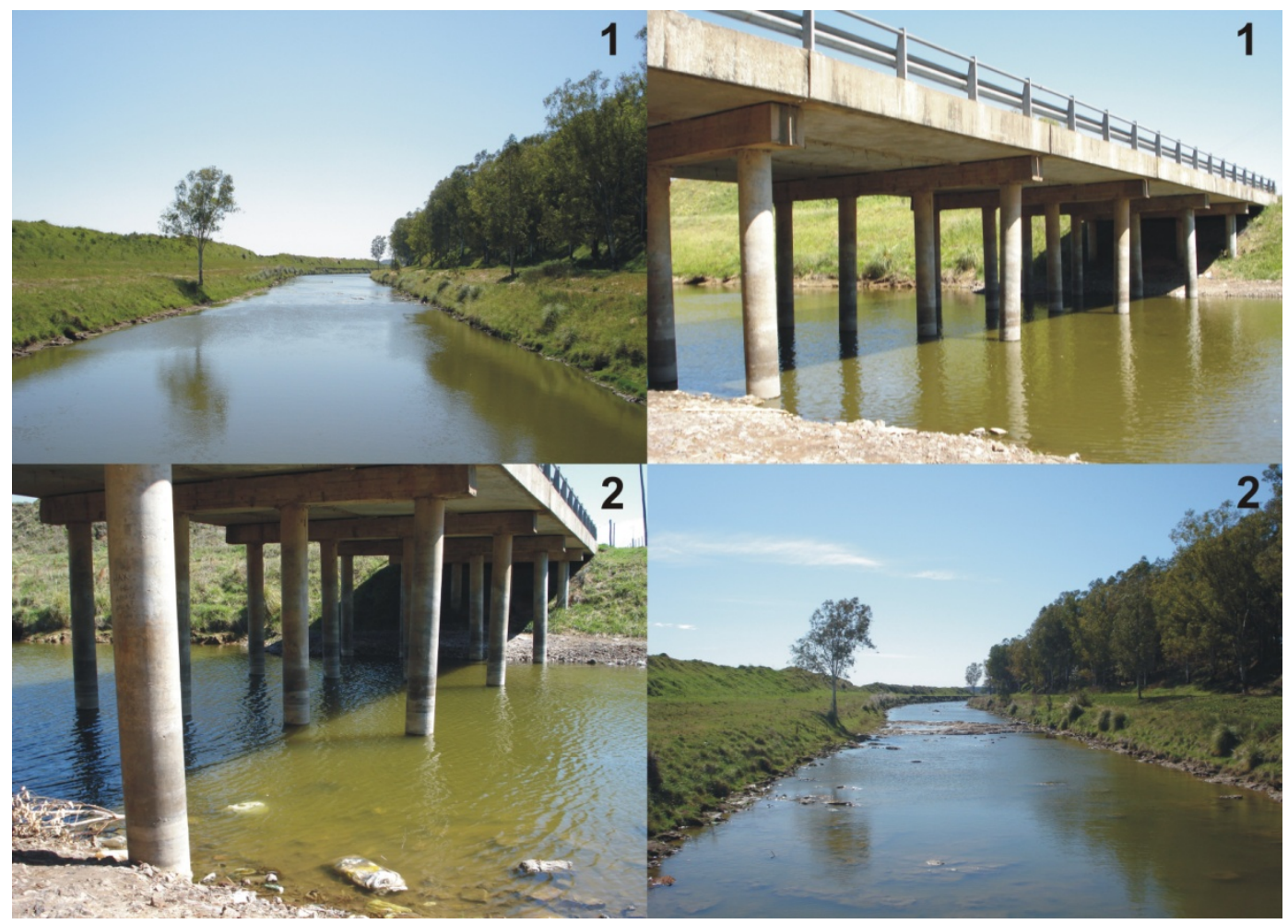

Figura 2.4: Fotografías del Canal del Este en las campañas de muestreo: 1- aguas bajas (nov. 2008) y 2- aguas muy bajas (sept. 2009). 


\section{Arroyo Saladillo:}

Este arroyo drena la laguna del Bragado, y desagua en el río Salado luego de atravesar algunos bañados. Sus nacientes se encuentran canalizadas y rectificadas, y durante este estudio se observó la construcción de un nuevo vertedero sobre sus nacientes en la laguna, con la interrupción del flujo de agua hacia el arroyo (nov. 2008 y sept. 2009). A lo largo de los muestreos, su cauce principal presentó escasa profundidad $(20-50 \mathrm{~cm})$. En sus márgenes se observó variada vegetación litoral, con algunas plantas halófitas y gramíneas, y el desarrollo de ganadería extensiva. El sitio de muestreo se ubicó sobre la Ruta Nacional № 5, en el puente carretero de dicha ruta (S 35우 01' 12'”;

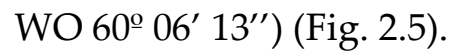

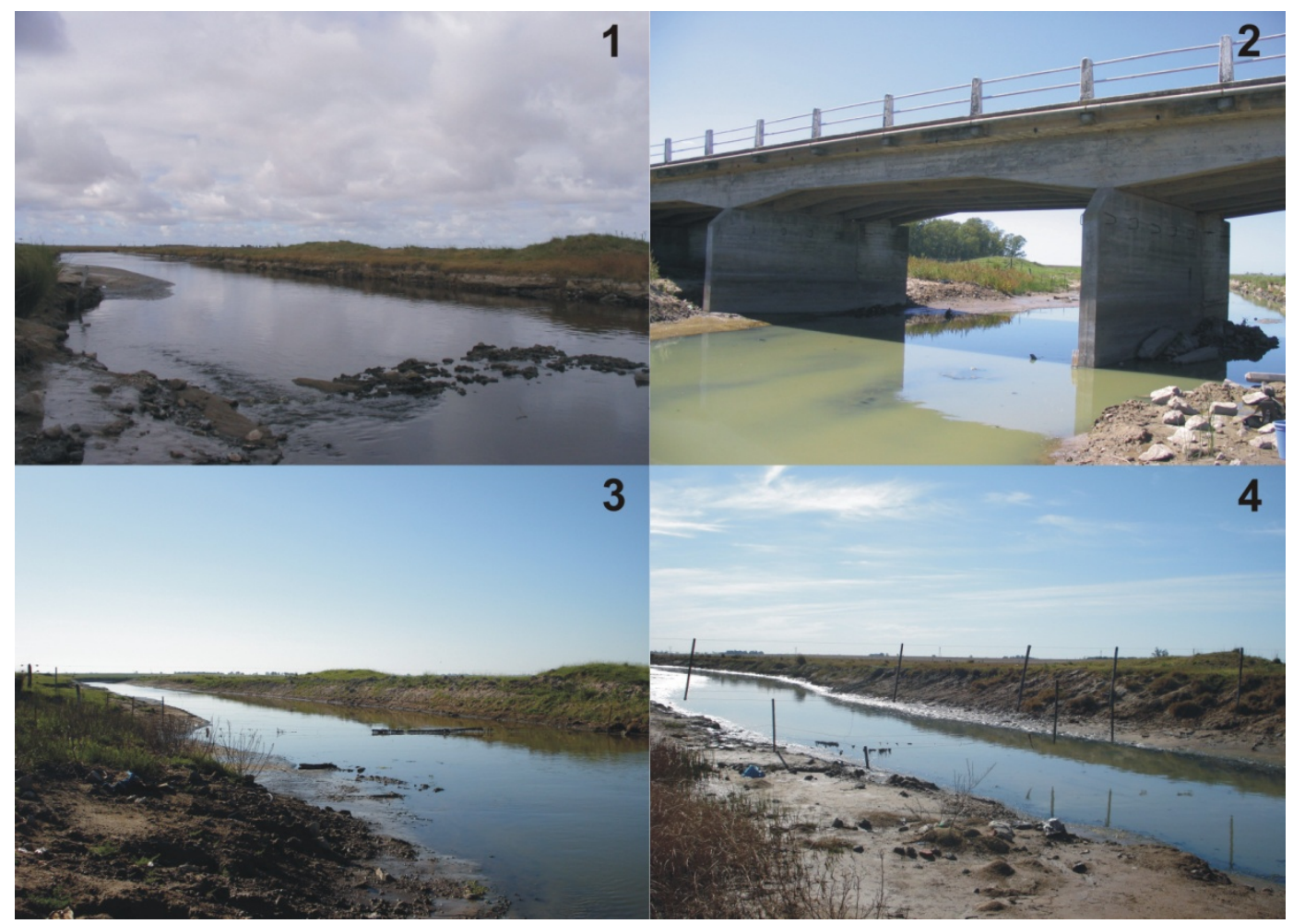

Figura 2.5: Fotografías del $\mathrm{A}^{\circ}$ Saladillo en las diferentes campañas de muestreo: 1- aguas altas (mayo 2007), 2- caudales medios (marzo 2008), 3- aguas bajas (nov. 2008) y 4-aguas muy bajas (sept. 2009).

\section{Río Salado aguas arriba:}

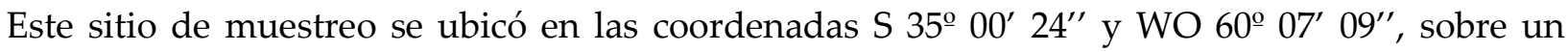
puente viejo en un camino vecinal que une la Ruta Provincial № 42 con la ciudad de Alberti. En este lugar el río se encuentra en condiciones naturales, presentado abundante vegetación ribereña, y márgenes típicas de un río de llanura, sin intervención de obras hidráulicas recientes. Durante los muestreos se observó el desarrollo de ganadería extensiva y la presencia de cultivos de girasol y soja en sus márgenes. En la época de bajante pudo constatarse el elevado tenor salino de sus aguas y la presencia de costras blanquecinas en la costa (Fig. 2.6). 


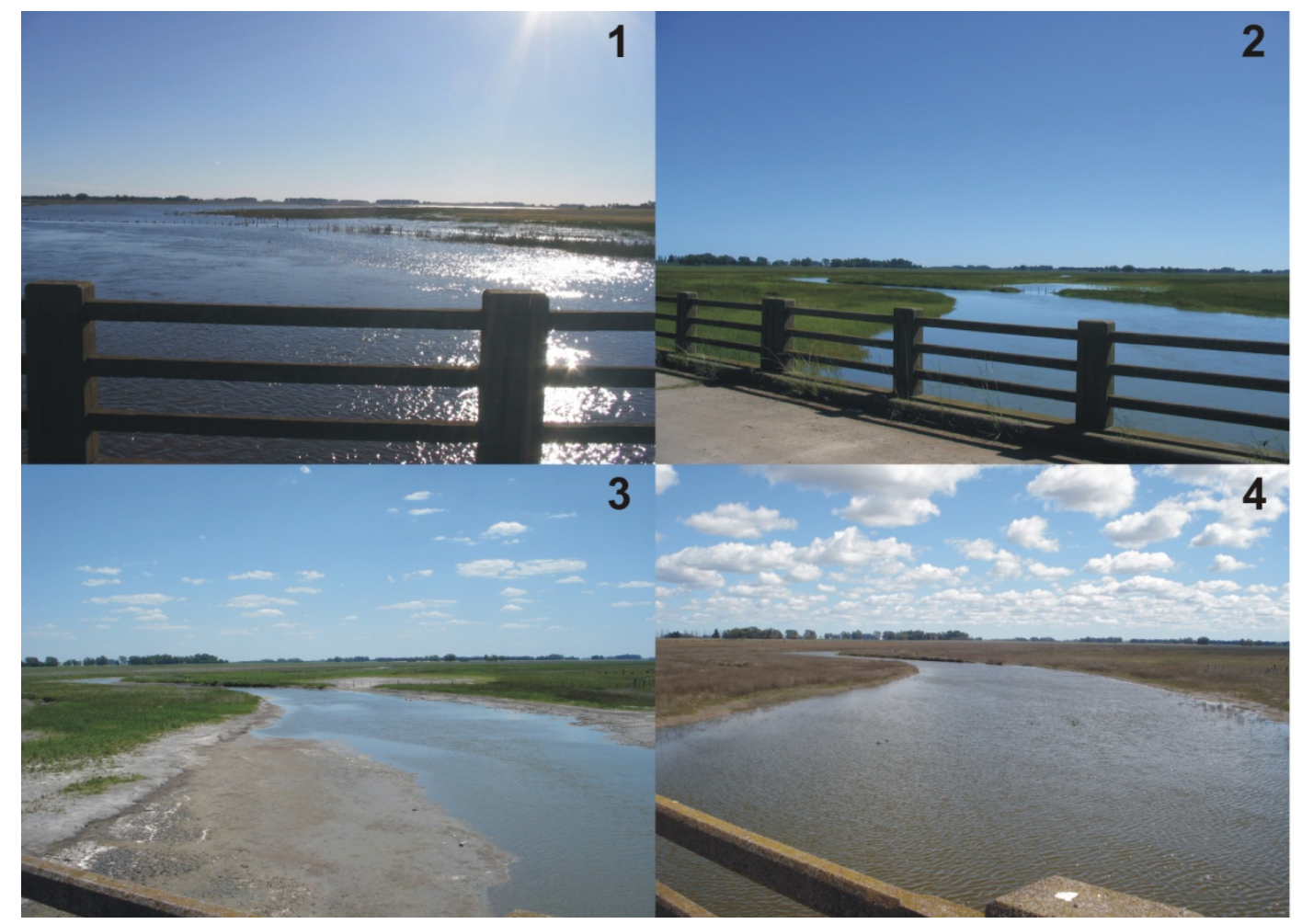

Figura 2.6: Fotografías del río Salado aguas arriba en las diferentes campañas de muestreo: 1- aguas altas (mayo 2007), 2-caudales medios (marzo 2008), 3- aguas bajas (nov. 2008) y 4-aguas muy bajas (sept. 2009).

\section{Río Salado aguas abajo:}

Este sitio de muestreo se ubicó aguas abajo de la desembocadura del Canal del Este y del arroyo Saladillo, sobre un puente en un camino vecinal que une la localidad de Alberti con Plá (S 35º 01' $24^{\prime \prime}$; WO 60 $40^{\prime} 12^{\prime \prime}$ ). A diferencia del otro sitio sobre el río, este puente representa una vía de comunicación más reciente, con un largo terraplén y una amplia luz central. En este lugar, la planicie de inundación es más extensa, por lo que sólo se observó escasa ganadería extensiva, sin advertirse el desarrollo de cultivos durante los muestreos (Fig. 2.7).

\subsection{Ejecución de obras de mejora hídrica}

A partir del segundo muestreo (marzo 2008 - caudales medios) se observó la ejecución de obras en el Canal de Vinculación y luego en el arroyo Saladillo, relacionadas a un plan de mejoras hídricas, que incluyó: la ampliación de los márgenes del cauce del canal (marzo 2008); la construcción de terraplenes como defensas contra las inundaciones (nov. 2008), y un muro de contención aguas abajo del sitio de muestreo, que interrumpía parcialmente el flujo de agua hacia la laguna del Bragado (sept. 2009).

Estas obras también afectaron al arroyo Saladillo, ya que se construyó un nuevo vertedero en sus nacientes en la laguna del Bragado, momentos durante el cual se anuló el flujo de agua hacia el arroyo (nov. 2008 y sept. 2009) (Fig. 2.8-10). 


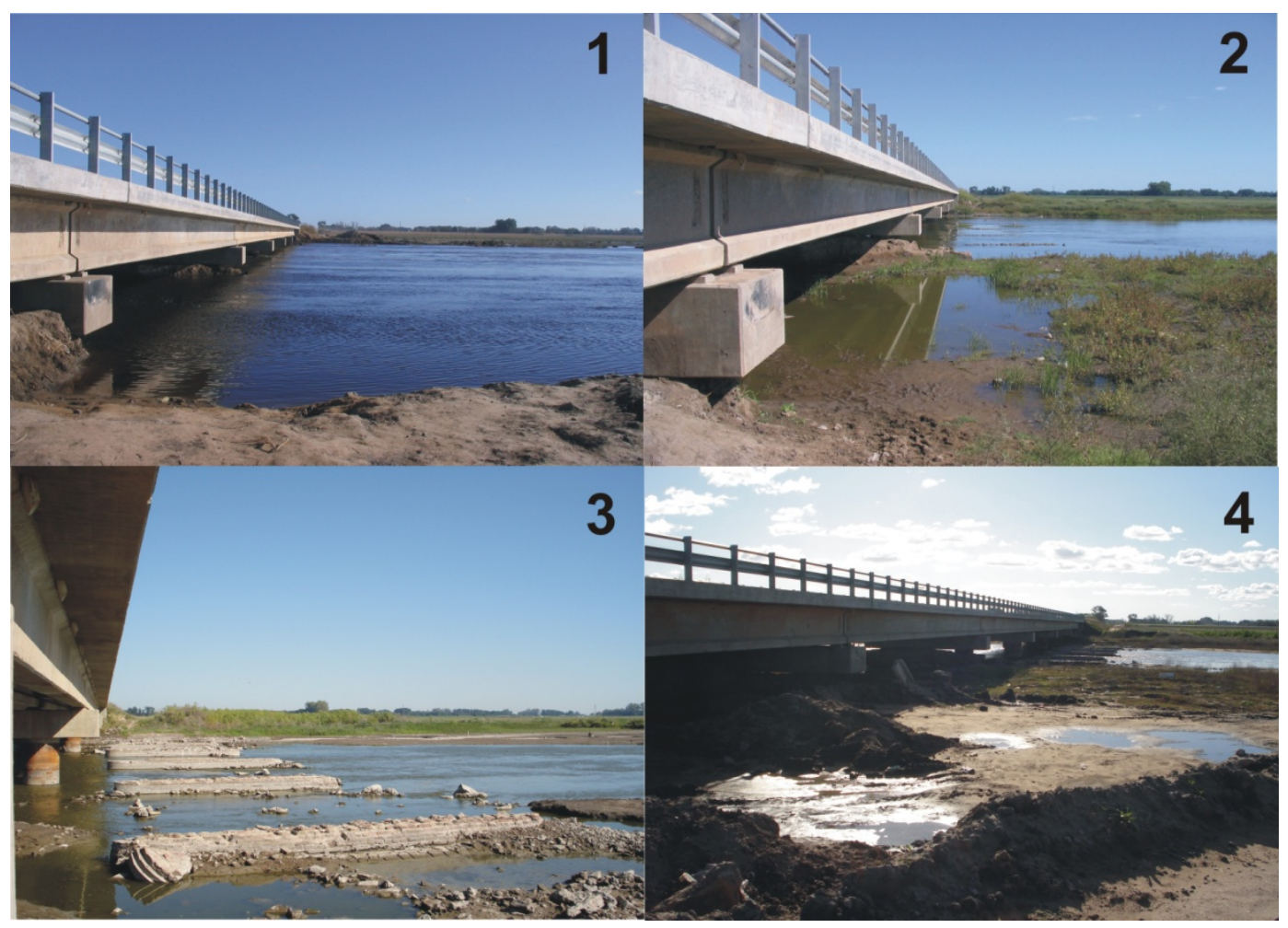

Figura 2.7: Fotografías del río Salado aguas abajo en las diferentes campañas de muestreo: 1- aguas altas (mayo 2007), 2- caudales medios (marzo 2008), 3- aguas bajas (nov. 2008) y 4- aguas muy bajas (sept. 2009).
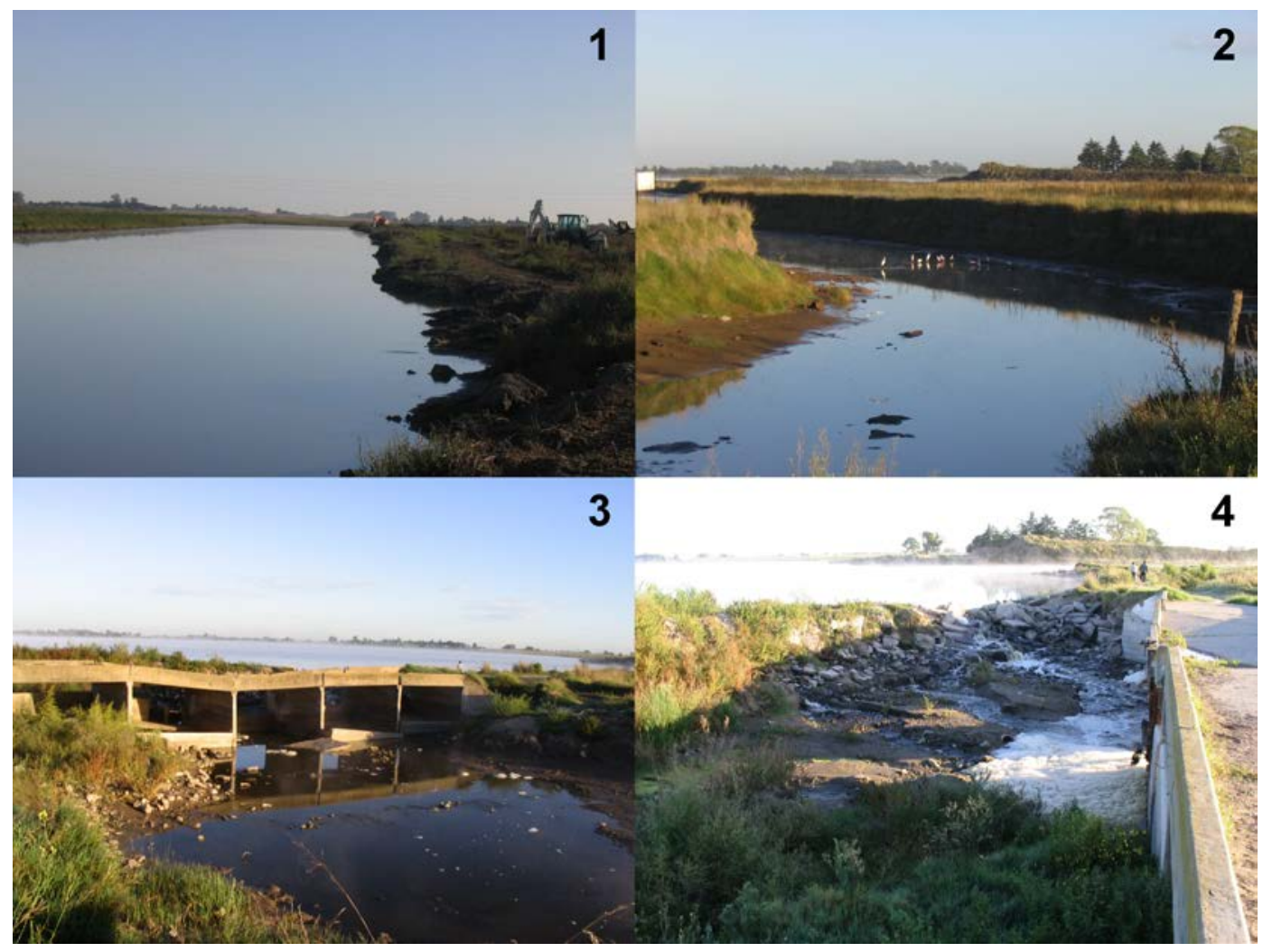

Figura 2.8: Fotografías del Canal de Vinculación y las nacientes del $\mathrm{A}^{\mathrm{o}}$ Saladillo en el muestreo de marzo 2008 (caudales medios). Referencias: 1- Máquinas retroexcavadoras realizando trabajos de ampliación del cauce del Canal de Vinculación, aguas abajo del sitio de muestreo. 2- Márgenes rectificados en las cabeceras del arroyo Saladillo. 3 y 4 - Nacientes del arroyo Saladillo en la laguna del Bragado (fondo). Nótese la espuma presente debajo de la alcantarilla en 4. 


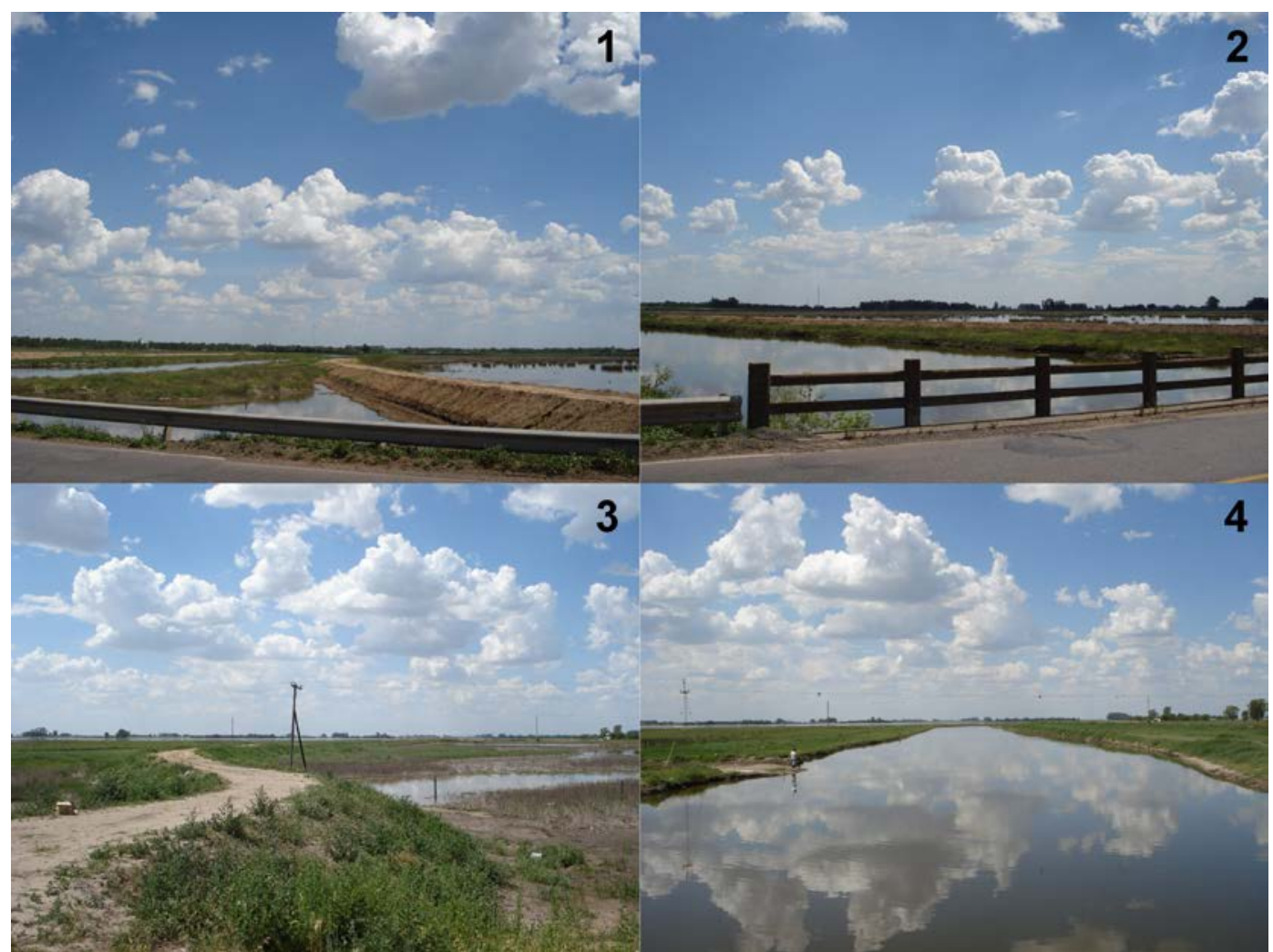

Figura 2.9: Fotografías del Canal de Vinculación en noviembre 2008 (aguas bajas). 1 y 2- Vista del terraplén construido aguas arriba del sitio de muestreo, nótese la interrupción del humedal (fondo). 3 y 4- Vistas hacia la laguna del Bragado (aguas abajo del sitio de muestreo), 3- terraplén construido en los márgenes y 4ampliación del cauce del canal, luego de las obras.

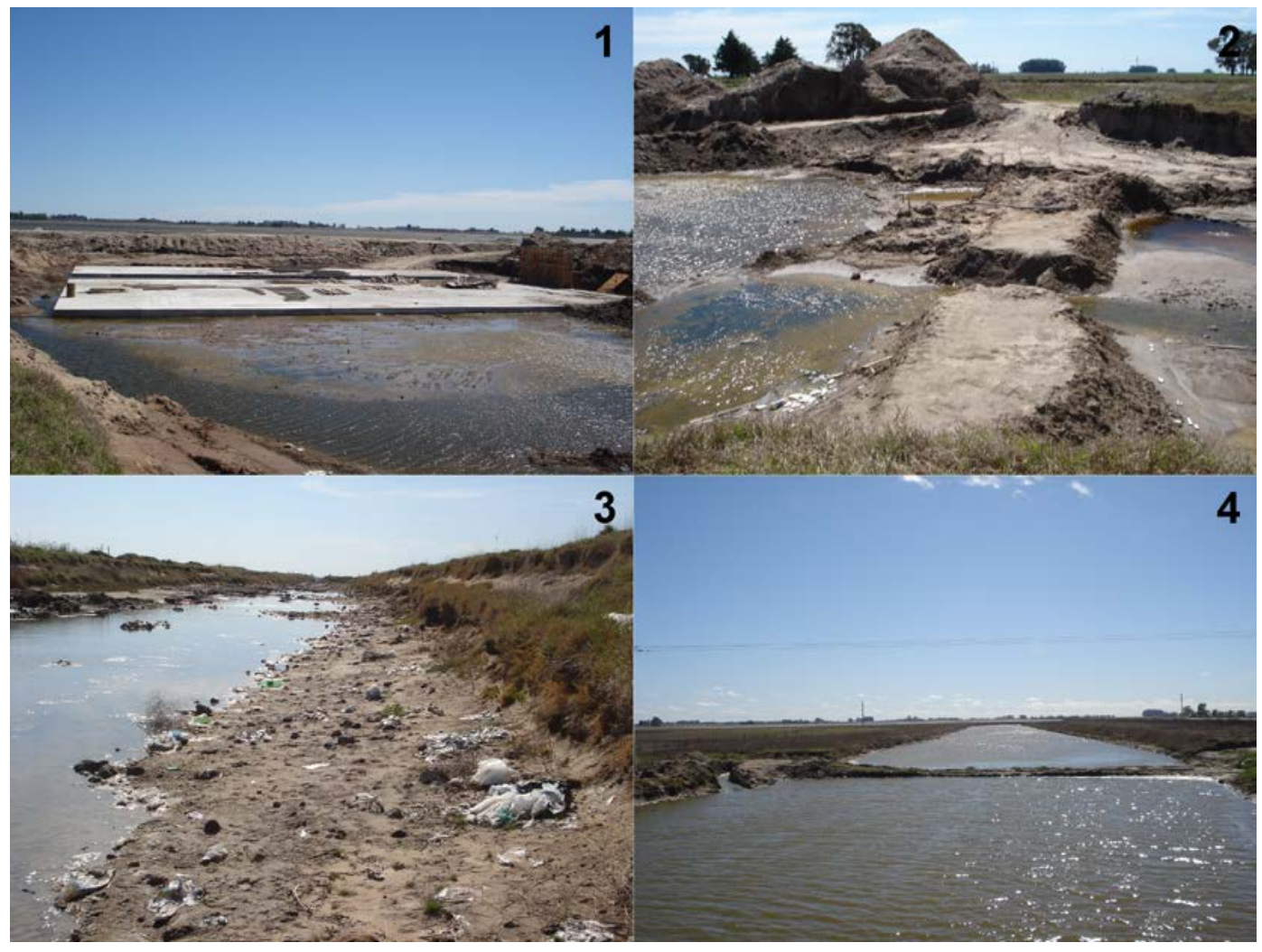

Figura 2.10: Referencias: 1 y 2 - Obras en las cabeceras del A o Saladillo (sept. 2009), durante la construcción de un nuevo vertedero en la laguna del Bragado (comparar con las fotos 3 y 4, Fig. 2.8). 3- Canal Mercante (sept. 2009 - aguas muy bajas); nótese la presencia gran cantidad de residuos. 4- Vista del muro de contención construido en el Canal de Vinculación en sept. 2009 (aguas muy bajas), aguas abajo del sitio de muestreo, hacia la laguna del Bragado (fondo). El flujo de agua corría por una derivación en el margen izquierdo. 


\subsection{Usos del suelo en el área de estudio}

Los sitios de muestreo se encuentran en los Partidos de 9 de Julio (canal 1), Bragado (canales 2 y 3, arroyo, río Salado margen derecha) y Alberti (río Salado margen izquierda) de la Provincia de Buenos Aires. De acuerdo a las zonas establecidas por el Plan Maestro Integral de la Cuenca del Río Salado y los datos suministrados por la Secretaría de Agricultura, Ganadería y Pesca de la Provincia, los sitios de muestreo (canales 1, 2 y 3, arroyo y río Salado margen derecha) se encuentran en la zona (d), con una población media de $7 \mathrm{hab} / \mathrm{km}^{2}$ y el uso del suelo se reparte en 7,9\% de agricultura y 92,1\% área ganadera (Gabellone et al., 2013b).

El margen izquierdo de los sitios del río Salado se encuentra en otra zona (c), cuya densidad poblacional promedio es de 10,2 hab./ $\mathrm{km}^{2}$ y registra un mayor uso agrícola del suelo $(34,5 \%)$ que la zona anterior, y $65,5 \%$ de desarrollo ganadero. Entre los cultivos presentes en la zona se encuentran principalmente la soja, pero también el trigo, el girasol y el maíz. En la Figura 2.11 se muestran los usos del suelo de la cuenca del río Salado, según el Plan Maestro Integral de la Cuenca del río Salado. En la Tabla 2.1. se muestran las notas de campo con el uso del suelo observado en cada sitio y condición de muestreo.

Tabla 2.1: Notas de campo sobre el uso del suelo en cada sitio y condición de muestreo.

\begin{tabular}{|c|c|}
\hline Sitios de muestreo & Usos del suelo y obras de mejora hídrica observadas \\
\hline Canal Mercante & ganadería extensiva (mayo 2007, nov. 2008 y sept. 2009) \\
\hline (canal 1) & cultivos de girasol y pasturas, y ganadería extensiva (marzo 2008) \\
\hline \multirow{6}{*}{$\begin{array}{l}\text { Canal de Vinculación } \\
\text { (canal 2) }\end{array}$} & humedal canalizado con vegetación ribereña, sin desarrollo de ganadería ni agricultura \\
\hline & ejecución de un plan de mejoras hídricas a partir del $2^{\text {do }}$ muestreo: \\
\hline & * modificación de las márgenes y ampliación del cauce (marzo 2008) \\
\hline & * construcción de terraplenes como defensas, aislando al cauce del humedal (nov. 2008) \\
\hline & * muro de contención aguas abajo del sitio de muestreo, para reducir el ingreso de agua \\
\hline & a la laguna del Bragado (construcción del nuevo vertedero del arroyo) \\
\hline Canal Este & márgenes con dunas colonizadas por gramíneas y cortaderas, plantación de eucalipto \\
\hline (canal 3) & sin desarrollo de ganadería ni agricultura \\
\hline$A^{o}$ Saladillo & pastizales naturales y ganadería extensiva (mayo 2007, marzo 2008 y sept. 2009) \\
\hline \multirow[t]{3}{*}{ (arroyo) } & cultivo de girasol y ganadería extensiva (nov. 2008) \\
\hline & ${ }^{*}$ posible vertido de los efluentes cloacales de Bragado en las cabeceras \\
\hline & $\begin{array}{l}\text { * anulación del flujo por construcción de vertedero en la laguna del Bragado } \\
\text { (nacientes) (nov. } 2008 \text { y sept. 2009) }\end{array}$ \\
\hline río Salado & pastizales naturales y ganadería extensiva (mayo 2007) \\
\hline \multirow[t]{3}{*}{ aguas arriba } & cultivo maíz y pasturas aguas arriba (marzo 2008) \\
\hline & cultivo de trigo, soja y girasol aguas arriba (nov. 2008) \\
\hline & cultivo de trigo y ganadería extensiva (sept. 2009) \\
\hline río Salado & pastizales naturales y ganadería extensiva en todos los muestreos \\
\hline aguas abajo & \\
\hline
\end{tabular}



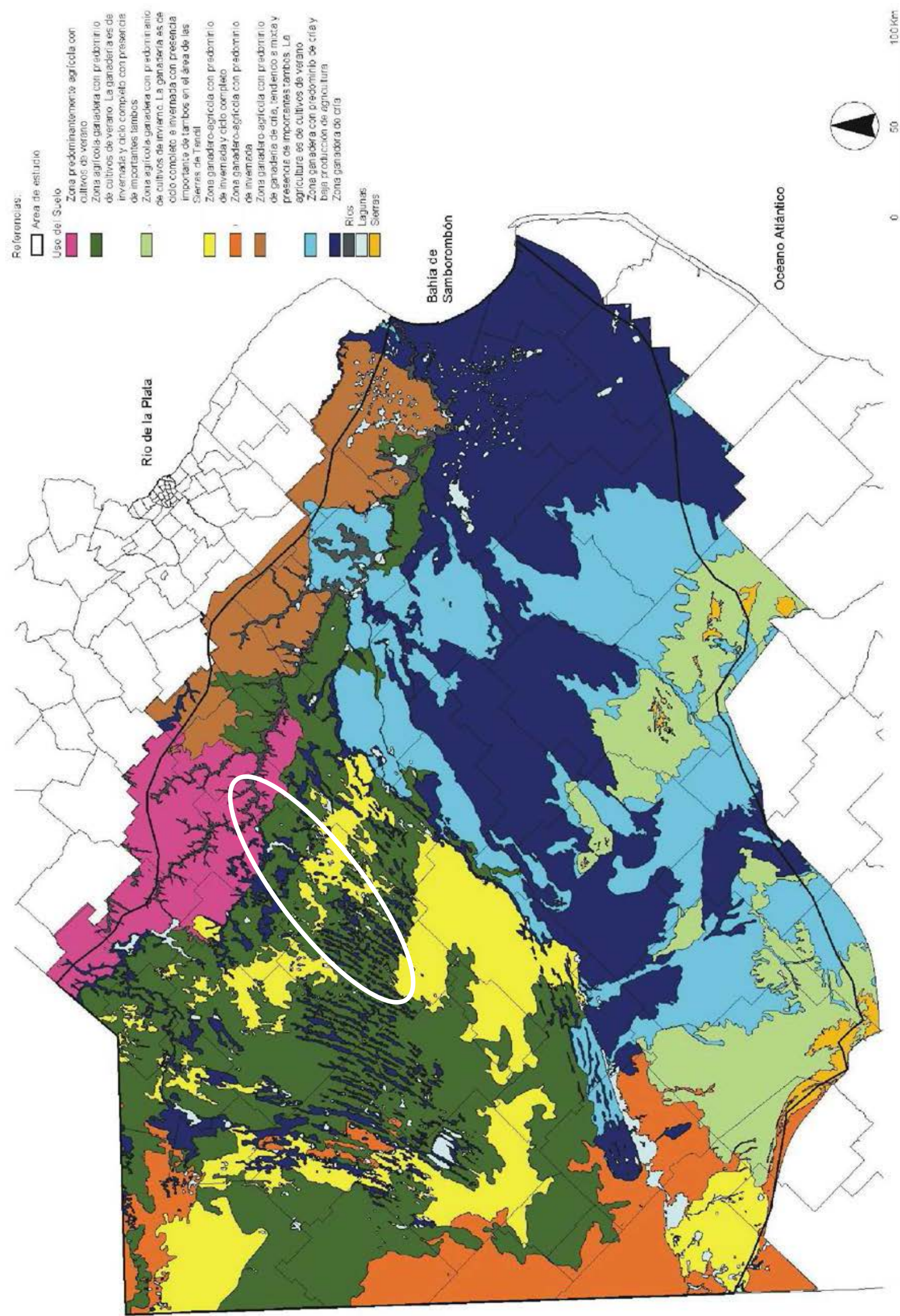

Figura 2.11: Mapa del uso del suelo en la cuenca del río Salado, según el Plan Maestro Integral de la cuenca del río Salado (modificado de Dos Santos, 2015). Referencias: la elipse en blanco señala el área de estudio, correspondiendo a una zona con predominio agrícola con cultivos de verano (rosado), a una zona agrícolaganadera con cultivos de verano (verde oscuro), zona ganadera-agrícola (amarillo) y zona ganadera de cría (azul). 
Materiales y métodos 


\section{Materiales y Métodos}

Se realizaron 4 campañas de muestreo en 5 sitios, descriptos en el Área de estudio, a saber: el Canal Mercante (canal 1 - C1), el Canal de Vinculación (canal 2 - C2), el arroyo Saladillo (arroyo), y el río Salado aguas arriba (Río Arriba - R1) y aguas abajo del trasvase (Río Abajo - R2), durante 2 días consecutivos. Las campañas correspondieron a condiciones hidrológicas contrastantes dentro del período de estudio, denominadas como: aguas altas (22 y 23 de mayo de 2007), caudales medios (11 y 12 de marzo de 2008), aguas bajas (12 y 13 de noviembre de 2008) y aguas muy bajas en el sistema Bragado pero con caudales medios en el río Salado (19 y 20 de septiembre de 2009).

En los últimos 2 muestreos se incorporó el Canal del Este (canal 3 - C3) que también drena la laguna del Bragado y desemboca en el río Salado aguas arriba del arroyo. Este cambio se debió a la construcción de un nuevo vertedero en esta laguna, el cual afectó severamente el caudal del arroyo Saladillo por la anulación de sus nacientes, modificando la relación de continuidad dentro del sistema. Durante este evento el agua de la laguna del Bragado sólo fue derivada por el Canal del Este. Las denominaciones de aguas altas o aguas bajas son a los fines comparativos entre los muestreos realizados durante el período de estudio, y no corresponden a niveles hidrométricos históricos de la cuenca del río Salado.

De acuerdo a estudios geofísicos-climatológicos (modelos de evapotranspiración a partir de datos gravimétricos satelitales) llevados a cabo en la cuenca del río Salado (Cesanelli, 2012), el período de muestreo de esta tesis abarcó momentos de temperaturas extremadamente frías (mayo 2007), y posteriormente un período de déficit hídrico provocado por el evento La Niña (ENOS). Durante la mayor parte del año 2008 se registraron temperaturas medias por encima de lo normal (marzo 2008), y escasas precipitaciones, provocando severas sequías en la región (nov. 2008), que se extendieron hasta el año siguiente (sept. 2009).

Los sitios de muestreo fueron seleccionados en función de los objetivos planteados, teniendo en cuenta además la accesibilidad y la ubicación del puente carretero requerido para la toma de muestras y las referencias de la condición hidrológica (distancia hidrométrica pelo de aguaguardarruedas del puente). Asimismo, los lugares de muestreo fueron considerados en función de futuras canalizaciones proyectadas en el área de estudio, como la ampliación del Canal MonesCazón y su vinculación al río Salado aguas abajo del arroyo Saladillo, conociendo de esta manera el estado previo del sistema. 
Durante los muestreos se observó la ejecución de un plan de mejoras hídricas en la laguna del Bragado, relacionadas a la construcción de un nuevo vertedero en las nacientes del A o Saladillo. Estas obras anularon la salida de agua desde la laguna al arroyo, mermando considerablemente el flujo de agua del arroyo en el sitio de muestreo (aguas abajo) en las 2 últimas campañas (nov. 2008 y sept. 2009). También se observaron modificaciones en el Canal de Vinculación (canal 2) como parte de estas mejoras, relacionadas con la modificación de los márgenes del cauce (marzo 2008), la construcción de terraplenes como defensas contra las inundaciones (nov. 2008), y un muro de contención aguas abajo del sitio de muestreo, que interrumpía parcialmente la entrada de agua en la laguna (sept. 2009).

\subsection{Mediciones in situ}

Se midió la temperatura, la turbidez, el pH y la conductividad utilizando un sensor múltiple Horiba U-10, el oxígeno disuelto (OD) mediante un oxímetro YSI y la intensidad lumínica con un radiómetro Licor. Se obtuvo la transparencia del agua con un disco de Secchi; la velocidad de corriente mediante un molinete SIAP y la distancia desde el pelo de agua hasta el guardarruedas de cada puente (estimación del nivel de agua). Esta distancia es una denominación común que utiliza la Dirección Provincial de Hidráulica (Bs. As.) y a partir de la cual se pueden reconstruir los caudales, de contarse con los aforos. Dado que es una medida propia de la altura de cada puente, se la transformó a valores porcentuales relativos para poder utilizarla en los posteriores análisis estadísticos y estudios comparativos. De esta forma se asignaron \% relativos entre los valores máximos registrados en aguas altas (100\%) y los mínimos en aguas muy bajas (0\%), y se los denominó como "nivel de agua". Se tomaron datos de campo relevantes durante cada muestreo (hora del día, coloración del agua, condiciones meteorológicas en días previos, nubosidad, vegetación ribereña, presencia de cultivos en las márgenes, obras en construcción, etc.).

\subsection{Toma de muestras}

Se utilizó una bomba centrífuga sumergible para la extracción de muestras de agua subsuperficial en el punto medio del cauce. Las muestras para análisis químicos y de pigmentos se transportaron refrigeradas y en oscuridad hasta su posterior análisis en laboratorio en botellas de $1 \mathrm{~L}$ de capacidad. Para el estudio del fitoplancton se colectaron muestras sin filtrar y filtradas con red de plancton, para una mejor identificación y abordaje de los diferentes componentes que lo integran. Las muestras de fitoplancton sin filtrar $(250 \mathrm{~mL})$ se preservaron con Lugol acético al 1\%. Para el fitoplancton de red se filtró in situ un volumen de 5-10L utilizando una red de $35 \mu \mathrm{m}$ de 
abertura de malla, y las muestras obtenidas se fijaron con formol al $4 \%$. Las muestras de zooplancton se separaron en dos fracciones, una conservada en formol al 4\% para su cuantificación e identificación, y otra en solución de sacarosa al 45\% P/V (Haney \& Hall, 1972) para la observación de estructuras frágiles como huevos y embriones. Esta última técnica permite una mejor conservación de la morfología de los organismos, y evita la deformación y apertura de las valvas de cladóceros, manteniendo la descendencia en su interior. Para ambas fracciones se filtraron in situ un volumen de alrededor de 50L en cada muestreo, y sólo en algunas pocas ocasiones se filtró un volumen menor debido a la colmatación de la red por la abundancia de plancton o al taponamiento del colector por la elevada cantidad de sólidos suspendidos en condiciones de aguas muy turbias.

Para la técnica con solución de sacarosa, se procedió de la siguiente forma: luego de filtrar in situ se pasó la muestra a través de un tamiz confeccionado con malla de red de plancton $(35 \mu)$ y una rosca de caño de pvc (policloruro de vinilo). De esta forma los organismos quedaron retenidos en la malla, y luego se los trasvasó a una botella plástica de $250 \mathrm{~mL}$ utilizando un embudo y una piseta con la solución de sacarosa. Con este procedimiento los organismos quedan totalmente embebidos en la solución azucarada, manteniendo su forma natural.

También se colectaron muestras vivas con el fin de mejorar la identificación de organismos frágiles tales como ciliados, rotíferos bdelloideos y protozoos en general. Para las muestras vivas se filtraron entre 5-10L de agua en cada sitio de muestreo y se colocaron en un recipiente de acrílico transparente con tapa. El material fue observado lo más rápido posible en microscopio invertido Labomed, y fotografiado con cámara Moticam 2000, analizando las imágenes mediante el correspondiente software.

\subsection{Análisis físico-químicos en laboratorio}

En el laboratorio se determinó la composición iónica del agua $\left(\mathrm{Na}^{+}, \mathrm{Cl}^{-}, \mathrm{K}^{+}, \mathrm{SO}_{4}=\mathrm{Ca}^{++} \mathrm{y} \mathrm{Mg}^{++}\right)$, dureza total, alcalinidad total, polifenoles solubles (Polif.), materia orgánica disuelta (MOD) medida por la absorbancia a 440nm, materia orgánica particulada (MOP), sólidos suspendidos (SS)

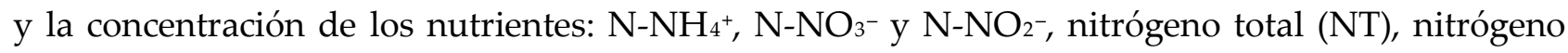
total particulado (NTP), nitrógeno total disuelto (NTD), fósforo reactivo total (PRT), fósforo reactivo soluble (PRS), fósforo reactivo particulado (PRP), fósforo total (PT), fósforo total disuelto (PTD) y fósforo total particulado (PTP), siguiendo las metodología propuestas en APHA (1995).

Para la determinación de los iones sodio y potasio se utilizó un fotómetro de llama (Mét. 3500 D; APHA, 1995) y los sulfatos mediante el método turbidimétrico con espectrofotómetro Unico. La 
dureza total (calcio y magnesio) y la alcalinidad total se determinaron mediante titulación con EDTA y ácido sulfúrico $(0,02 \mathrm{~N})$, respectivamente. Para el contenido de cloruros se utilizó el método argentométrico con la titulación con nitrato de plata. La concentración de los carbonatos y bicarbonatos se estimó mediante el programa Cicles utilizando los valores de $\mathrm{pH}$, conductividad y temperatura obtenidos in situ (Armengol, 1992). El balance de iones para los diagramas de Piper se generó con los principales aniones y cationes (Aquachem, 2006).

Los nitratos se determinaron mediante la reducción con hidracina (Mét. 4500-H; APHA 1995), nitritos mediante sulfanilamida (Mét. 4500-( $\left.\mathrm{NO}_{2}{ }^{-}\right)-\mathrm{B}$; APHA, 1995) y para el amonio se utilizó el método del indofenol (Mét. 4500-F; APHA, 1995). El fósforo reactivo soluble (PRS) se obtuvo mediante la reducción con ácido ascórbico (Mét. 4500-(P)-E; APHA, 1995), y el PT y PTP mediante la oxidación con persulfato y posterior determinación con ácido ascórbico. Las fracciones del fósforo orgánico se calcularon de la siguiente manera: fósforo orgánico disuelto (POD = PTD PRS), fósforo orgánico particulado (POP = PTP - PRP) y fósforo orgánico total (POT = POD + POP) (APHA, 1995).

El NT se obtuvo por oxidación con persulfato y ácido sulfúrico y posterior autoclavado a 1 atm de presión en frascos especiales con cierre hermético. Para la lectura en espectrofotómetro a 220nm se utilizaron celdas de cuarzo de 1cm y lámpara de deuterio; metodología descripta en Tartari \& Mosello (1997). La materia orgánica disuelta se estimó de manera indirecta en espectrofotómetro a una densidad óptica de 440nm (DO 440) (Kirk, 1983). Los polifenoles totales se obtuvieron por el método colorimétrico de Folín Ciocalteus-carbonato tartrato (Mét. 5550 b; APHA, 1995).

En todos los análisis químicos realizados mediante espectrofotómetro y fotómetro de llama se utilizaron blancos y patrones de distintas concentraciones para la construcción de una recta patrón, cuya ecuación se utilizó para la determinación de las muestras problema. Las muestras fueron diluidas hasta obtener una concentración tal que se encontrara entre 0,1-0,5 de absorbancia, de forma de asegurar la eficiencia en el cálculo del método.

Para los sólidos suspendidos (SS) se filtró en el laboratorio un volumen de muestra determinado, utilizando un kitasato y filtros Whatman GF/C previamente secados en estufa y tarados (Mét. 2540 D; APHA, 1995). La MOP se obtuvo mediante la pérdida por ignición (LOI), donde se muflaron los filtros en crisoles a $550{ }^{\circ} \mathrm{C}$, y posteriormente se pesaron. Las estimaciones de clorofila $a$ se realizaron mediante la extracción con acetona al 90\% y lectura en espectrofotómetro Unico con corrección para feopigmentos (Mét. 10200-H, APHA 1995; Wetzel \& Likens, 1991). 


\subsection{Análisis del fitoplancton}

Para el análisis cuali-cuantitativo del fitoplancton sin filtrar se utilizaron cámaras de $5 \mathrm{~mL}$ de capacidad, dejando sedimentar el material durante 24 hs de acuerdo a la metodología de Utermöhl. Se analizaron mediante un microscopio invertido con aumento de 400x, y solo se utilizó aumento de 1000x con inmersión en casos específicos de determinación de algunas especies. Los recuentos celulares se realizaron mediante el análisis de campos al azar hasta alcanzar un mínimo de 400 unidades de sedimentación (células, filamentos, colonias), obteniendo un error $<10 \%$ (Padisák, 1991). Las muestras se contaron por réplicas hasta alcanzar un coeficiente de variación $<20 \%$ de la abundancia de la especie dominante, y se utilizaron los valores promedios en los análisis posteriores de los resultados. Sólo se practicaron diluciones en aquellos casos donde la elevada abundancia del fitoplancton dificultó los conteos por solapamiento del material.

Adicionalmente, las muestras de fitoplancton sin filtrar fueron observadas en cámaras de Sedgewick-Rafter de 0,4mL de capacidad (APHA 1995) en microscopio convencional binocular con contraste de fases, con aumentos de 200x. Las muestras filtradas de fitoplancton de red también fueron observadas por esta última técnica. En ambos casos se observó la cámara completa, y los recuentos se hicieron por réplicas hasta obtener un coeficiente de variación <20\%, utilizándose los valores promedios en los análisis posteriores de los resultados. En cada ocasión, sólo se consideraron aquellos organismos que no fueron observados en los recuentos anteriores (fitoplancton sin filtrar). Finalmente, los datos obtenidos en los diferentes recuentos de fitoplancton, expresados ind/mL (células, filamentos, colonias), se integraron en una única planilla de datos. Este análisis en diferentes escalas permitió evaluar la importancia de estas especies poco frecuentes, pero de grandes dimensiones, en términos de biomasa, dada su contribución al total.

Durante los recuentos se contabilizó la abundancia de organismos en división y la presencia de estados o estructuras de resistencia, aunque sólo fueron observadas autosporas de clorococcales, reproducción asexual de Cosmarium spp., auxosporas de diatomeas y acinetos de cianobacterias.

Para los cálculos de biovolumen se obtuvieron 10-15 medidas de la longitud linear máxima (LLM), ancho máximo y alto de cada especie según su ajuste a figuras geométricas, y para especies con formas particulares (Gomphonena, Surirella, Gyrosigma, Campylodiscus, etc.) se utilizaron formas geométricas complejas de acuerdo a Hillebrand et al. (1999), Padisák \& Adrian (1999) y Sun \& Liu (2003). En aquellas especies dominantes y sub-dominantes del fitoplancton, que incluyendo formas filamentosas, cenobiales, coloniales o unicelulares de gran tamaño, se tomaron 30-50 mediciones para cada una. A partir de cada set de medidas obtenidas se calcularon los biovolumenes individuales y su promedio constituyó el biovolumen asignado a cada especie. Las especies de 
fitoplancton en reproducción se midieron por separado, obteniendo un valor de biovolumen promedio diferente al de la especie. Durante los recuentos celulares, las colonias fueron diferenciadas por clases de tamaño midiendo su diámetro y luego el número de células presentes en cada categoría, y los cenobios por el número de células presentes en cada uno (e.g. 1, 2, 3, 4, ncélulas) dentro de una misma especie. Esta información fue utilizada en la obtención del biovolumen promedio de cada uno y sus valores de biomasa, calculada en términos de carbono mediante las fórmulas de Menden-Deuer \& Lessard (2000). De esta forma se obtuvieron biovolumenes promedio y sus correspondientes valores de biomasa asignados a: especies, a organismos en reproducción dentro de la especie, a cada una de las clases de tamaño halladas en una especie colonial, y a cada una de las categorías de número de células presentes en cenobios de una misma especie. Estos valores se multiplicaron por la densidad obtenida en cada categoría, y su sumatoria constituyó la biomasa total promedio para cada taxón por sitio y momento de muestreo.

Se utilizó bibliografía específica para la determinación de cada uno de los grupos taxonómicos presentes: Bourrelly (1968, 1970, 1972), Guarrera et al. (1968, 1972), Weber (1971), Germain (1981), Komárek \& Fott (1983), Tell \& Conforti (1986), Klaveness (1988), Paerl (1988), Komárek \& Anagnostidis (1998, 2005), Metzeltin \& García-Rodriguez (2003), Patrick \& Reimer (1966, 1975), Conforti et al. (2009). Para la delimitación de las categorías del fitoplancton consumible por el zooplancton se dividió en microplancton $(\mathrm{LLM}>20 \mu \mathrm{m})$ y nanoplancton $(<20 \mu \mathrm{m})$ al igual que otros autores (Gosselain et al., 1998a), y a su vez diferenciando entre ellas las clorofitas clorococcales como especies palatables preferidas por el zooplancton (Gabellone et al., 2014).

\subsection{Análisis del zooplancton}

Se observaron las muestras de zooplancton en cámaras de Sedgwick-Rafter de 1mL de capacidad bajo microscopio convencional binocular, con conteos por duplicado o hasta alcanzar un error menor al 20\% de la especie dominante. También se utilizaron cámaras de Bogorov de 10mL de capacidad observadas bajo lupa estereoscópica. Para las estimaciones de biomasa de zooplancton se tomaron medidas de largo corporal para copépodos y cladóceros, y ancho máximo y espesor para los rotíferos. Se aplicaron las fórmulas de Dumont et al. (1975) y Bottrell et al. (1976), y para los cálculos de biomasa en términos de carbono y peso seco: Peters (1987), Lawrence et al. (1987), Putt \& Stoeckner (1989), Andersen \& Hessen (1991) y Rahkola et al. (1998). Se utilizó bibliografía específica de cada grupo del zooplancton presente para la determinación de los organismos hasta el mínimo nivel taxonómico posible: Ruttner-Kolisko (1974), Koste (1978), Shiel 
\& Koste (1992), Paggi (1995a, b, 1998), Segers (1995), De Smet (1996), Foissner et al. (1999), José de Paggi (2002), Dussart \& Defaye $(2002,2006)$.

En cada muestra de zooplancton se contabilizó la abundancia de los organismos en reproducción por huevos (rotíferos, copépodos, cladóceros y ostrácodos), diferenciando la presencia de machos $\left({ }^{\Uparrow}\right)$, hembras $(+)$ ), + ovígeras y sus estadios intermedios (larvas nauplii, copepoditos, cladoceritos, juveniles de cladóceros y de ostrácodos). También se consideraron como q ovígeras a aquellas $q$ con huevos de resistencia en formación, todavía adosados a los individuos. Se contabilizó el $\mathrm{n}^{\mathrm{o}}$ total de huevos portados por las $q$ ovígeras, el $\mathrm{n}^{\mathrm{o}}$ de los huevos libres en la muestra (no adosados a + ) y la presencia de estados de resistencia (huevos de resistencia de rotíferos y efipios de cladóceros).

Se utilizó el índice egg ratio que es el $n^{\circ}$ promedio de huevos por $q$ ovígera, el cual se calcula a partir del cociente entre el $\mathrm{n}^{\mathrm{o}}$ total de huevos portados por $\odot$ de la especie considerada sobre la abundancia total de las $q$ ovígeras de la especie. El nº de huevos por individuo (de la población) se calculó a partir del cociente entre el $\mathrm{n}^{\mathrm{0}}$ total de huevos portados por las $q$ de la especie sobre la abundancia total de los adultos de la especie considerada. Entre los rotíferos, se diferenció a los morfotipos S (Small) y L (Large) de Brachionus plicatilis, contabilizando por separado la abundancia total de $O$ ovígeras y el no de huevos portados por cada una de ellas.

\subsection{Tratamiento de los datos}

Con la finalidad de detectar posibles variaciones en los datos obtenidos en los días 1 y 2 de cada muestreo se practicó el test no paramétrico Prueba de los rangos con signo de Wilcoxon, el cual no arrojó diferencias significativas $(p<0,05)$ en ninguna de las variables analizadas: todos los parámetros físico-químicos medidos in situ y en el laboratorio, y los componentes del fito y zooplancton). De esta forma, por razones prácticas se utilizaron los valores promedios de los días 1 y 2 de cada muestreo en la exposición de los Resultados; a excepción del canal 3 y el arroyo que sólo fueron muestreados en el día 1 de las campañas de nov. 2008 y sept. 2009, respectivamente.

Como descriptores de la comunidad del plancton se utilizó a la abundancia y biomasa total y de cada grupo componente, la composición específica, la riqueza de especies, el índice de diversidad de Simpson (1/D), que se aplicaron al fito y zooplancton por separado. El índice de diversidad de Simpson es considerado como uno de los índices de diversidad más robustos y denota básicamente la variación de la abundancia de las especies, resaltando las dominantes y siendo menos sensible a la riqueza (Magurran, 2004). 
A fin de observar las posibles relaciones entre las variables ambientales y el plancton se realizaron correlaciones de Spearman a los valores promedio (días 1 y 2) de los datos obtenidos en cada campaña. Sólo se exponen en los resultados aquellas correlaciones significativas $(p<0.05)$ con valores $>0,6$.

El índice del valor indicador (INDVAL) (Dufrêne \& Legendre, 1997) discrimina la importancia de cada una de las especies de fito y zooplancton observadas en las diferentes campañas, pudiendo diferenciar entre especies características y especies comunes (all habitat, según los autores) según los valores obtenidos mediante la siguiente fórmula:

$$
\text { INDVAL }_{\mathrm{ij}}=\mathrm{A}_{\mathrm{ij}} \times \mathrm{B}_{\mathrm{ij}} \times 100
$$

Donde $\mathbf{i}$ representa la abundancia de las especies halladas por grupo de sitios de muestreo $\mathbf{j}, A_{i j}$ es la abundancia promedio de la especie $\mathbf{i}$ en los sitios del grupo $\mathbf{j}$ comparado con la abundancia en todos los grupos en estudio, y $\mathrm{B}_{\mathrm{ij}}$ es la frecuencia relativa de la especie $\mathbf{i}$ en los sitios del grupo $\mathbf{j}$, calculados de esta manera:

$\mathrm{A}_{\mathrm{ij}}=\mathrm{N}^{\mathrm{o}}$ individuos $\mathrm{ij} / \mathrm{N}$ o total de individuos i

$B_{i j}=$ № sitios ij / № sitios j

Se consideraron como especies características de un determinado sitio a aquellas con más de 40 puntos. Las especies comunes del fitoplancton fueron aquellas presentes en al menos 5 de los sitios muestreados (incluido uno del río) y con más de 10 puntos en al menos 4 de estos lugares. En el caso del zooplancton, se consideró como especies comunes a las presentes en al menos 4 sitios, incluido uno del río, y con más de 4 puntos del índice INDVAL.

Se aplicó la tasa de cambio de la comunidad $\sigma_{s}\left(0 ; \infty^{+}\right)$(Lewis, 1978), a fin de analizar las variaciones en las abundancias relativas de las especies de fitoplancton de un día y el siguiente en los diferentes sitios de muestreo y momentos hidrológicos, mediante la fórmula:

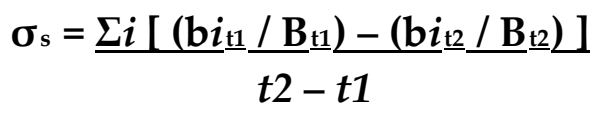

Donde: $\mathrm{b} i=$ abundancia de la especie $i$ en el tiempo $t$

$\mathrm{B}=$ abundancia total de fitoplancton en el tiempo $t$

t1 y t2 = tiempo inicial y final, respectivamente

El cálculo de este índice se basa en la sumatoria de las diferencias de las abundancias relativas de las especies en los momentos $\mathrm{t}_{1}$ y $\mathrm{t}_{2}$, midiendo la distancia entre comunidades en el tiempo. El 
mismo puede visualizarse como un hipervolumen de superficies planas, formando un polígono de n-dimensiones donde cada una de ellas representa a una especie de la comunidad. El mínimo valor que expresa es 0 y corresponde a una comunidad hipotética donde todas las especies cambian a una velocidad idéntica (Lewis, 1978). Se estimó el valor de $\sigma_{s}$ en cada muestreo, utilizando la abundancia relativa de las especies presentes (438 taxa en total), variando entre 290 taxa (sept. 2009) y 305 taxa (nov. 2008) según los muestreos.

\subsection{Análisis multivariados}

Con el fin de identificar patrones en la composición iónica del agua en los diferentes sitios y condiciones de muestreo, se testeó la concentración de los iones mayoritarios a través de un ordenamiento MDS (multidimensional scaling), basados en una matriz de similitud (distancia Euclidiana, ligamiento completo). El mismo se complementó con un Análisis de Agrupamientos (cluster) con una prueba de significancia SIMPROF con 999 simulaciones (programa PRIMER). Los datos de las variables consideradas $\left(\mathrm{Na}^{+}+\mathrm{K}^{+}, \mathrm{Ca}^{++}, \mathrm{Mg}^{++}, \mathrm{Cl}, \mathrm{SO}_{4}=\right.$ y $\left.\mathrm{HCO}_{3}=\right)$ fueron previamente normalizados.

Se practicaron Análisis de Componentes Principales (PCA) a fin de explorar el ordenamiento de los sitios según el momento de muestreo, considerando los parámetros físico-químicos medidos in situ y algunas variables ambientales asociadas a la contaminación orgánica y la eutrofización: conductividad, dureza, $\mathrm{pH}$, alcalinidad, oxígeno disuelto (OD), turbidez, transparencia medida por disco de Secchi, velocidad de corriente (Veloc.), sólidos suspendidos (SS), materia orgánica particulada (MOP), materia orgánica disuelta (MOD), polifenoles totales disueltos (Polif.), nitrato+nitrito $(\mathrm{N}+\mathrm{N})$, amonio $\left(\mathrm{N}-\mathrm{NH}_{4}{ }^{+}\right)$, PRS (fósforo reactivo soluble), PTD (fósforo total disuelto) y PT (fósforo total). Para el desarrollo de este análisis se utilizó el programa STATISTICA 6.0.

Asimismo, se realizó un Análisis de Agrupamiento mediante la técnica de $k$-means (Dufrêne \& Legendre, 1997) a los datos de las variables ambientales con la finalidad de establecer posibles asociaciones entre los sitios de muestreo, considerando todas las condiciones hidrológicas. Se aplicó distancia Euclidiana con ligamiento completo a una matriz básica de datos estandarizados de los parámetros físico-químicos medidos in situ y en el laboratorio: temperatura, conductividad, turbidez, $\mathrm{pH}$, Veloc., OD, transparencia, alcalinidad, dureza, SS, MOP, MOD, Polif., N+N, N-NH4 $4^{+}$, PRS, PTD, PT y la distancia hidrométrica. Para el desarrollo de este análisis se utilizó el programa STATISTICA 6.0 .

A fin de identificar patrones en la estructura del fito y zooplancton a lo largo de los muestreos se analizó la composición específica a través de un Análisis de Agrupamientos (cluster), previa 
transformación de los datos por log $(x+1)$. Se eliminaron aquellas especies que sólo aparecieron en una ocasión, quedando 361 taxa de fitoplancton y 132 taxa de zooplancton para su análisis por separado. Se aplicó el índice de similitud Bray-Curtis (ligamiento completo), y se practicó una prueba de significancia (SIMPROF) con 999 simulaciones $(p<0,05)$ utilizando el programa PRIMER.

Con la finalidad de estudiar la composición específica del plancton en relación con las variables ambientales se consideraron por separado los datos cuantitativos del fito y zooplancton obtenidos en los diferentes muestreos. En cada caso se seleccionaron a aquellos taxa que presentaron una abundancia relativa $>1 \%$ del total en alguna de las muestras (89 taxa de fitoplancton y 62 taxa de zooplancton). Los datos de las variables ambientales fueron estandarizados y la abundancia de las especies seleccionadas se transformaron aplicando logaritmo $(\mathrm{x}+1)$. Se practicaron Análisis de Correspondencia sin tendencia (Detrended Correspondence Analysis) preliminares para determinar si los modelos de respuesta de las especies eran lineales o unimodales, utilizando el programa CANOCO (ter Braak \& Smilauer, 1998). Dado que la longitud máxima de los gradientes fue <2 unidades de desviación estándar, se aplicaron Análisis de Redundancia (RDA). Para éstos análisis sólo se tuvieron en cuenta las variables ambientales con un factor de inflación $<10$, a modo de prevenir la multicolinearidad entre variables (ter Braak \& Verdonschot, 1995). Se analizó la significancia del primer eje de la ordenación y del modelo completo mediante el test de Monte Carlo, utilizando 499 permutaciones no restringidas (ter Braak \& Smilauer, 1998). 
Resultados 


\subsection{Parámetros físico-químicos}

\subsubsection{Parámetros medidos in situ}

En aguas altas (mayo 2007), se registraron bajas temperaturas del agua, con escasas variaciones entre sitios $\left(11-13^{\circ} \mathrm{C}\right)$, al igual que en el pH $(8,16-8,6)$ y la alcalinidad $(400-457 \mathrm{mg} / \mathrm{L})$. La velocidad de corriente fue máxima en el río $(1,67 \mathrm{~m} / \mathrm{s})$ y mínima en el arroyo $(0,17 \mathrm{~m} / \mathrm{s})$, con valores intermedios en los canales 1 y 2 (0,7 y 1 m/s, respectivamente). En este muestreo la radiación solar bajo el agua varió entre 43 y 250 moles/s.m², con valores máximos al mediodía (río aguas abajo).

En caudales medios (marzo 2008), la temperatura del agua varió entre 21 y $29^{\circ} \mathrm{C}$, el pH se mantuvo dentro del rango alcalino $(8,5-9,2)$ y la alcalinidad total se halló entre 320 y 565 mg/L, con valores mínimos en los canales y máximos en el río. El canal 1 y el río aguas abajo registraron velocidades de corriente de $0,5 \mathrm{~m} / \mathrm{s}$, el canal 2 y el río aguas arriba de 0,34 y 0,27 m/s, respectivamente, pero sin flujo detectable en el arroyo. La radiación solar bajo el agua varió entre 42 y $1.160 \mu$ moles/s.m² con valores máximos al mediodía (canal 1).

En aguas bajas (nov. 2008) la temperatura del agua estuvo entre 24 y $33^{\circ} \mathrm{C}$, y los valores de $\mathrm{pH}$ dentro del rango alcalino (8,4-9,3). La alcalinidad varió entre 387 y 785 mg/L, con valores extremos en el canal 1 y en el río aguas arriba, respectivamente. En el canal 1 la velocidad de corriente fue de $0,36 \mathrm{~m} / \mathrm{s}$, en el arroyo de $0,25 \mathrm{~m} / \mathrm{s}$, en el río $<0,3 \mathrm{~m} / \mathrm{s}$, y en los canales 2 y $3<0,05 \mathrm{~m} / \mathrm{s}$. La radiación solar bajo el agua varió entre 348 y 1.225 moles/s.m², con valores máximos al mediodía (canal 3).

En sept. 2009, la temperatura del agua estuvo entre 14 y $19^{\circ} \mathrm{C}$, y los valores de $\mathrm{pH}$ dentro del rango alcalino (8,6-9,5). La velocidad de corriente fue de 0,3 m/s en el arroyo, de 0,2 m/s en el río, y en los canales el flujo no fue detectable (aguas muy bajas). La radiación solar bajo el agua varió entre 286 y 1.389 mmoles/s.m², con máximos al mediodía en el canal 3. La alcalinidad total registró valores extremos en el sistema Bragado, con $1.000 \mathrm{mg} / \mathrm{L}$ en el canal 1 y $235 \mathrm{mg} / \mathrm{L}$ en el canal 3, e intermedios en el río (caudales medios), aumentando un 13\% aguas abajo del trasvase (574 mg/L).

\subsubsection{Conductividad y composición iónica del agua}

La conductividad eléctrica registró los valores máximos en el canal 1 en todas las condiciones hidrológicas, siendo elevada o muy elevada según el momento de muestreo (Tabla 4.1). En los canales 2 y 3 y en el arroyo se observó un descenso en los valores de conductividad, variando entre elevadas, muy elevadas o bajas, de acuerdo a la condición hidrológica. En el río, la conductividad fue por lo general moderada, con aumentos en el sitio aguas abajo del trasvase. Las aguas fueron 
principalmente clorurado-sódicas, y la concentración de los iones mayoritarios siguió la misma tendencia que la conductividad, variando su proporción según los sitios de muestreo y el momento hidrológico (Fig. 4.1). En este sentido, se hallaron correlaciones positivas significativas ( $p$ $<0,05 ; \mathrm{r}>0,6)$ entre la conductividad, la dureza y la concentración de iones mayoritarios $\left(\mathrm{Na}^{+}, \mathrm{Cl}\right.$, $\left.\mathrm{K}^{+}, \mathrm{SO}_{4}=\mathrm{Mg}^{++} \mathrm{y} \mathrm{Ca}^{++}\right)$(Tablas - Anexo II).

En aguas altas, la conductividad fue de 10,2 mS/cm en el canal 1, descendiendo luego en el canal 2 (4,18 mS/cm) y el arroyo, y en el río se observaron los valores mínimos $(3,7 \mathrm{mS} / \mathrm{cm})$, con un leve aumento aguas abajo del trasvase. Los cationes más relevantes fueron $\mathrm{Na}^{+}, \mathrm{Mg}^{++}, \mathrm{Ca}^{++} \mathrm{y} \mathrm{K}, \mathrm{y}$ entre los aniones $\mathrm{Cl}^{-}, \mathrm{HCO}_{3}^{-}$y $\mathrm{SO}_{4}{ }^{-}$, en este orden de importancia (Fig. 4.2-3).

Tabla 4.1: Principales características iónicas del agua por sitio de muestreo y campaña realizada: A- mayo 2007 (aguas altas), B- marzo 2008 (caudales medios), C- noviembre 2008 (aguas bajas) y D- septiembre 2009 (aguas muy bajas en el sistema Bragado con caudales medios en el río Salado).

\begin{tabular}{|c|c|c|c|c|}
\hline Sitios & Cationes (meq/L) & Aniones (meq/L) & Conductividad (mS/cm) & Descripción \\
\hline Canal 1 & $\mathrm{Na}^{+}>\mathrm{Mg}^{++}>\mathrm{Ca}^{++}>\mathrm{K}^{+}$ & $\mathrm{Cl}^{-}>\mathrm{HCO}_{3}^{-}>\mathrm{SO}_{4}{ }^{=}$ & $10,25( \pm 0,07)$ - elevada & aguas cloruro-sódicas \\
\hline Canal 2 & $\mathrm{Na}^{+}>\mathrm{Mg}^{++}>\mathrm{Ca}^{++}>\mathrm{K}^{+}$ & $\mathrm{Cl}^{-}>\mathrm{HCO}_{3}^{-}>\mathrm{SO}_{4}{ }^{=}$ & $4,15( \pm 0,05)-$ moderada & aguas cloruro-sódicas \\
\hline Arroyo & $\mathrm{Na}^{+}>\mathrm{Mg}^{++}>\mathrm{Ca}^{++}>\mathrm{K}^{+}$ & $\mathrm{Cl}^{-}>\mathrm{HCO}_{3}^{-}>\mathrm{SO}_{4}=$ & $4,65( \pm 0,06)$ - moderada & aguas cloruro-sódicas \\
\hline Río Abajo & $\mathrm{Na}^{+}>\mathrm{Mg}^{++}>\mathrm{Ca}^{++}>\mathrm{K}^{+}$ & $\mathrm{Cl}^{-}>\mathrm{HCO}_{3}^{-}>\mathrm{SO}_{4}{ }^{=}$ & $3,77( \pm 0,03)-$ moderada & aguas cloruro-sódicas \\
\hline Río Arriba & $\mathrm{Na}^{+}>\mathrm{Mg}^{++}>\mathrm{Ca}^{++}>\mathrm{K}^{+}$ & $\mathrm{Cl}^{-}>\mathrm{HCO}_{3}^{-}>\mathrm{SO}_{4}=$ & $3,71( \pm 0,03)-$ moderada & aguas cloruro-sódicas \\
\hline
\end{tabular}

B-Caudales Medios

\begin{tabular}{lllll}
\hline \multicolumn{1}{c}{ Sitios } & Cationes $(\mathrm{meq} / \mathrm{L})$ & Aniones $(\mathrm{meq} / \mathrm{L})$ & Conductividad $(\mathrm{mS} / \mathrm{cm})$ & Descripción \\
\hline Canal 1 & $\mathrm{Na}^{+}>\mathrm{Mg}^{++}>\mathrm{Ca}^{++}>\mathrm{K}^{+}$ & $\mathrm{Cl}^{-}>\mathrm{SO}_{4}{ }^{-}>\mathrm{HCO}_{3}{ }^{-}$ & $17,75( \pm 0,07)$ - elevada & aguas cloruro-sódicas \\
Canal 2 & $\mathrm{Na}^{+}>\mathrm{Mg}^{++}>\mathrm{Ca}^{++}>\mathrm{K}^{+}$ & $\mathrm{Cl}^{-}>\mathrm{SO}_{4}{ }^{\circ}>\mathrm{HCO}_{3}{ }^{-}$ & $9,75( \pm 0,78)$ - elevada & aguas cloruro-sódicas \\
Arroyo & $\mathrm{Na}^{+}>\mathrm{Mg}^{++}>\mathrm{Ca}^{++}>\mathrm{K}^{+}$ & $\mathrm{Cl}^{-}>\mathrm{SO}_{4}{ }^{\circ}>\mathrm{HCO}_{3}{ }^{-}$ & $7,25( \pm 0,72)$ - elevada & aguas cloruro-sódicas \\
Río Abajo & $\mathrm{Na}^{+}>\mathrm{Mg}^{++}>\mathrm{Ca}^{++}>\mathrm{K}^{+}$ & $\mathrm{Cl}^{-}>\mathrm{SO}_{4}{ }^{\circ}>\mathrm{HCO}_{3}{ }^{-}$ & $8,83( \pm 0,53)$ - elevada & aguas cloruro-sódicas \\
Río Arriba & $\mathrm{Na}^{+}>\mathrm{Mg}^{++}>\mathrm{Ca}^{++}>\mathrm{K}^{+}$ & $\mathrm{Cl}^{-}>\mathrm{SO}_{4}{ }^{\circ}>\mathrm{HCO}_{3}{ }^{-}$ & $5,9( \pm 0,03)$ - moderada & aguas cloruro-sódicas \\
\hline
\end{tabular}

C-Aguas Bajas

\begin{tabular}{|c|c|c|c|c|}
\hline Sitios & Cationes (meq/L) & Aniones (meq/L) & Conductividad $(\mathrm{mS} / \mathrm{cm})$ & Descripción \\
\hline Canal 1 & $\mathrm{Na}^{+}>\mathrm{Mg}^{++}>\mathrm{Ca}^{++}>\mathrm{K}^{+}$ & $\mathrm{Cl}^{-}>\mathrm{SO}_{4}{ }^{=}>\mathrm{HCO}_{3}^{-}$ & $25( \pm 0,21)-$ muy elevada & aguas cloruro-sódicas \\
\hline Canal 2 & $\mathrm{Na}^{+}>\mathrm{Mg}^{++}>\mathrm{Ca}^{++}>\mathrm{K}^{+}$ & $\mathrm{Cl}^{-}>\mathrm{SO}_{4}{ }^{=}>\mathrm{HCO}_{3}^{-}$ & $19,15( \pm 0,21)$ - elevada & aguas cloruro-sódicas \\
\hline Canal 3 & $\mathrm{Na}^{+}>\mathrm{Mg}^{++}>\mathrm{Ca}^{++}>\mathrm{K}^{+}$ & $\mathrm{Cl}^{-}>\mathrm{SO}_{4}{ }^{=}>\mathrm{HCO}_{3}^{-}$ & $16,9( \pm 0,0)$ - elevada & aguas cloruro-sódicas \\
\hline Arroyo & $\mathrm{Na}^{+}>\mathrm{Mg}^{++}>\mathrm{Ca}^{++}>\mathrm{K}^{+}$ & $\mathrm{Cl}^{-}>\mathrm{SO}_{4}{ }^{=}>\mathrm{HCO}_{3}^{-}$ & $16,6( \pm 0,28)$ - elevada & aguas cloruro-sódicas \\
\hline Río Abajo & $\mathrm{Na}^{+}>\mathrm{Mg}^{++}>\mathrm{Ca}^{++}>\mathrm{K}^{+}$ & $\mathrm{Cl}^{-}>\mathrm{SO}_{4}{ }^{=}>\mathrm{HCO}_{3}^{-}$ & $13,9( \pm 0,71)$ - elevada & aguas cloruro-sódicas \\
\hline Río Arriba & $\mathrm{Na}^{+}>\mathrm{Mg}^{++}>\mathrm{Ca}^{++}>\mathrm{K}^{+}$ & $\mathrm{Cl}^{-}>\mathrm{SO}_{4}{ }^{=}>\mathrm{HCO}_{3}^{-}$ & $5,6( \pm 0,13)-$ moderada & aguas cloruro-sódicas \\
\hline
\end{tabular}

D- Aguas muy bajas en el sistema Bragado pero con caudales medios en el río Salado

\begin{tabular}{lllcc}
\hline \multicolumn{1}{c}{ Sitios } & Cationes $(\mathrm{meq} / \mathrm{L})$ & Aniones $(\mathrm{meq} / \mathrm{L})$ & Conductividad $(\mathrm{mS} / \mathrm{cm})$ & Descripción \\
\hline Canal 1 & $\mathrm{Na}^{+}>\mathrm{Ca}^{++}>\mathrm{Mg}^{++}>\mathrm{K}^{+}$ & $\mathrm{Cl}^{-}>\mathrm{HCO}_{3}{ }^{-}>\mathrm{SO}_{4}{ }^{-}$ & $13,7( \pm 0,14)$ - elevada & aguas cloruro-sódicas \\
Canal 2 & $\mathrm{Na}^{+}>\mathrm{Ca}^{++}>\mathrm{Mg}^{++}>\mathrm{K}^{+}$ & $\mathrm{Cl}^{-}>\mathrm{SO}_{4}{ }^{-}>\mathrm{HCO}_{3}{ }^{-}$ & $10,7( \pm 0,28)$ - elevada & aguas cloruro-sódicas \\
Canal 3 & $\mathrm{Mg}^{++}>\mathrm{Na}^{+}>\mathrm{Ca}^{++}>\mathrm{K}^{+}$ & $\mathrm{Cl}^{-}>\mathrm{HCO}_{3}{ }^{-}>\mathrm{SO}_{4}{ }^{-}$ & $1,03( \pm 0,0)$ - baja & aguas cloruro-magnésicas \\
Arroyo & $\mathrm{Na}^{+}>\mathrm{Ca}^{++}>\mathrm{Mg}^{++}>\mathrm{K}^{+}$ & $\mathrm{Cl}^{-}>\mathrm{HCO}_{3}{ }^{-}>\mathrm{SO}_{4}{ }^{-}$ & $2,73( \pm 0,0)$ - baja & aguas cloruro-sódicas \\
Río Abajo & $\mathrm{Na}^{+}>\mathrm{Ca}^{++}>\mathrm{Mg}^{++}>\mathrm{K}^{+}$ & $\mathrm{Cl}^{-}>\mathrm{SO}_{4}{ }^{-}>\mathrm{HCO}_{3}^{-}$ & $6,7( \pm 0,28)$ - moderada & aguas cloruro-sódicas \\
Río Arriba & $\mathrm{Na}^{+}>\mathrm{Ca}^{++}>\mathrm{Mg}^{++}>\mathrm{K}^{+}$ & $\mathrm{Cl}^{-}>\mathrm{SO}_{4}{ }^{-}>\mathrm{HCO}_{3}{ }^{-}$ & $5,6( \pm 0,6)$ - moderada & aguas cloruro-sódicas \\
\hline
\end{tabular}




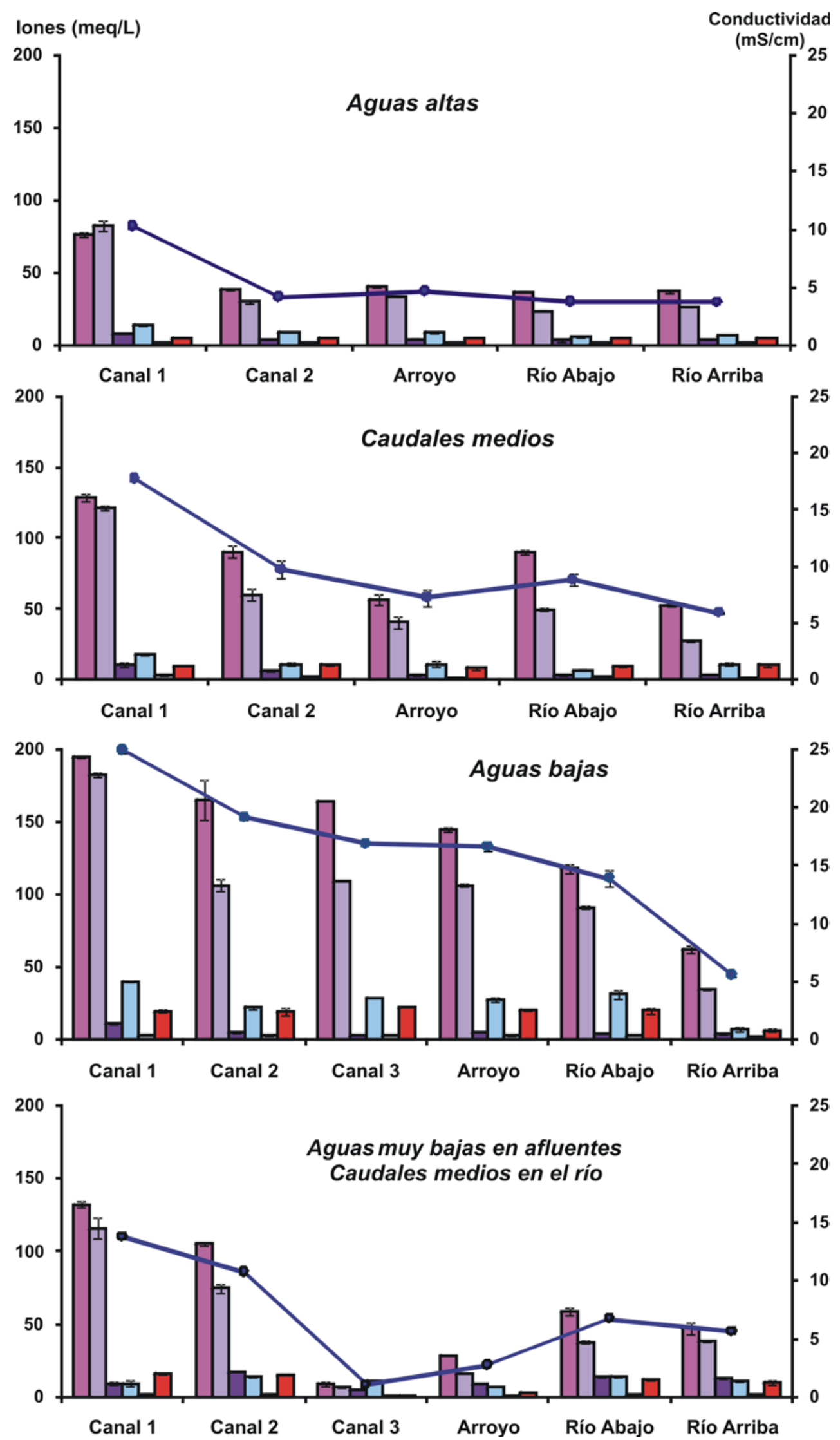

Figura 4.1: Conductividad (línea azul) y concentración de los iones mayoritarios (en columnas): $\mathrm{Na}^{+}$ (rosado), $\mathrm{Cl}^{-}$(lila), $\mathrm{Ca}^{++}$(violeta), $\mathrm{Mg}^{++}$(celeste), $\mathrm{K}^{+}$(gris) y SO $4^{=}$(rojo). Se muestran los valores promedios (días 1 y 2) y sus respectivos desvíos, por sitio de muestreo y condición hidrológica: aguas altas (mayo 2007), caudales medios (marzo 2008), aguas bajas (noviembre 2008) y aguas muy bajas en afluentes (sistema Bragado) con caudales medios en el río (septiembre 2009). 


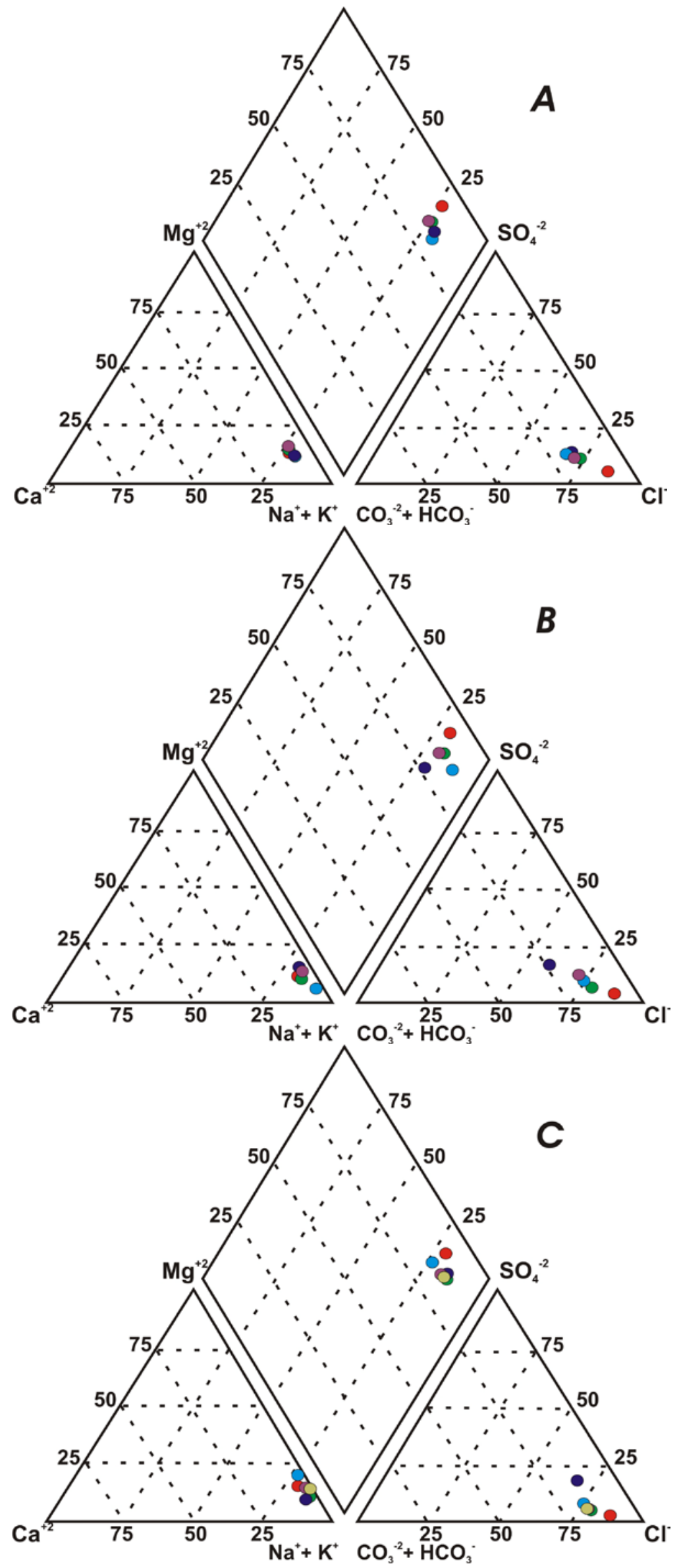

Figura 4.2: Diagramas de Piper de la composición iónica promedio (días 1 y 2) por sitio de muestreo (círculos) y condición hidrológica: A- aguas altas (mayo 2007), B- caudales medios (marzo 2008) y C-aguas bajas (nov. 2008). Referencias: canal 1 (rojo), canal 2 (verde), canal 3 (amarillo), arroyo (violeta), río aguas arriba (azul) y aguas abajo (celeste). 


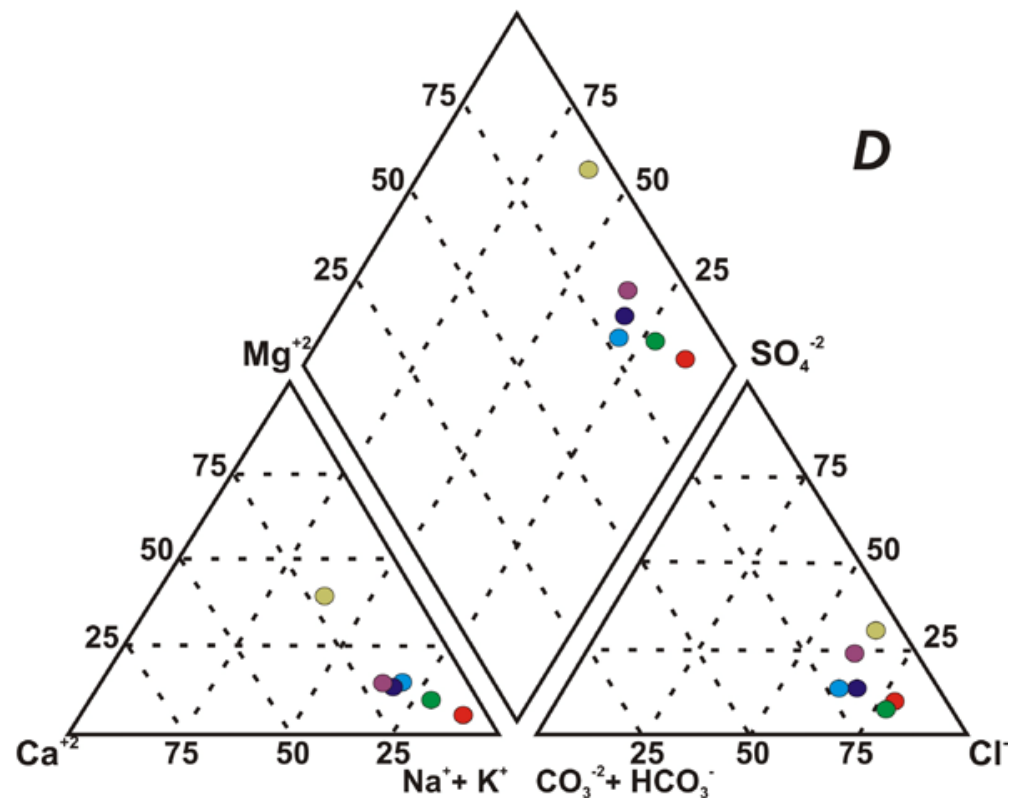

Figura 4.3: Diagramas de Piper de la composición iónica promedio (días 1 y 2) por sitio (círculos) en el muestreo D- aguas muy bajas en el sistema Bragado pero con caudales medios en el río (sept. 2009). Referencias: canal 1 (rojo), canal 2 (verde), canal 3 (amarillo), arroyo (violeta), río aguas arriba (azul) y aguas abajo (celeste).

En caudales medios, en el canal 1 se observaron elevadas conductividades $(17,8 \mathrm{mS} / \mathrm{cm})$, que disminuyeron en el canal 2 y el arroyo, y en el río se observó un aumento de 5,9 mS/cm (moderada) a $8,8 \mathrm{mS} / \mathrm{cm}$ (elevada) en el sitio aguas abajo del trasvase. Los cationes más relevantes fueron $\mathrm{Na}^{+}, \mathrm{Mg}^{++}, \mathrm{Ca}^{++}$y $\mathrm{K}^{+}$, y los aniones $\mathrm{Cl}^{-}, \mathrm{HCO}_{3}^{-}$y $\mathrm{SO}_{4}{ }^{-}$, en este orden de importancia, en caudales medios y aguas bajas (Fig. 4.4).

En aguas bajas, la conductividad del canal 1 fue muy elevada $(25 \mathrm{mS} / \mathrm{cm})$, descendiendo luego a $19 \mathrm{mS} / \mathrm{cm}$ en el canal 2, y a alrededor de 16,4 mS/cm en el canal 3 y el arroyo. En el río se observó un aumento de la conductividad de 5,6 mS/cm (moderada) aguas arriba a $14 \mathrm{mS} / \mathrm{cm}$ (elevada) aguas abajo (Tabla 4.1-C). Asimismo, la concentración de los iones mayoritarios se duplicó en el río aguas abajo del trasvase.

En condiciones de aguas muy bajas en el sistema Bragado, la conductividad fue muy variable entre los sitios de muestreo, con valores extremos en el canal $1(13,8 \mathrm{mS} / \mathrm{cm})$ y el canal $3(1 \mathrm{mS} / \mathrm{cm})$. En el río se registró un aumento de la conductividad de 5,6 mS/cm aguas arriba a 6,7 $\mathrm{mS} / \mathrm{cm}$ aguas abajo, en presencia de caudales medios (sept. 2009). Se observaron aguas clorurado-sódicas de elevada (canales 1 y 2), moderada (río) y de baja conductividad (arroyo), mientras que en el canal 3 se hallaron aguas cloruro-magnésicas de baja conductividad (Tabla 4.1-D). Los cationes más relevantes fueron $\mathrm{Na}^{+}, \mathrm{Ca}^{++}, \mathrm{Mg}^{++}$y K en este orden de importancia, a excepción del canal 3 donde prevaleció el $\mathrm{Mg}^{++}$(Fig. 4.5). Entre los aniones, predominaron los $\mathrm{Cl}^{-}$en todos los sitios de muestreo, seguido por los $\mathrm{HCO}_{3}^{-}$en los canales 1 y 3 y en el arroyo, y los $\mathrm{SO}_{4}{ }^{=}$en el río y en el canal 2 (Fig. 4.3). 


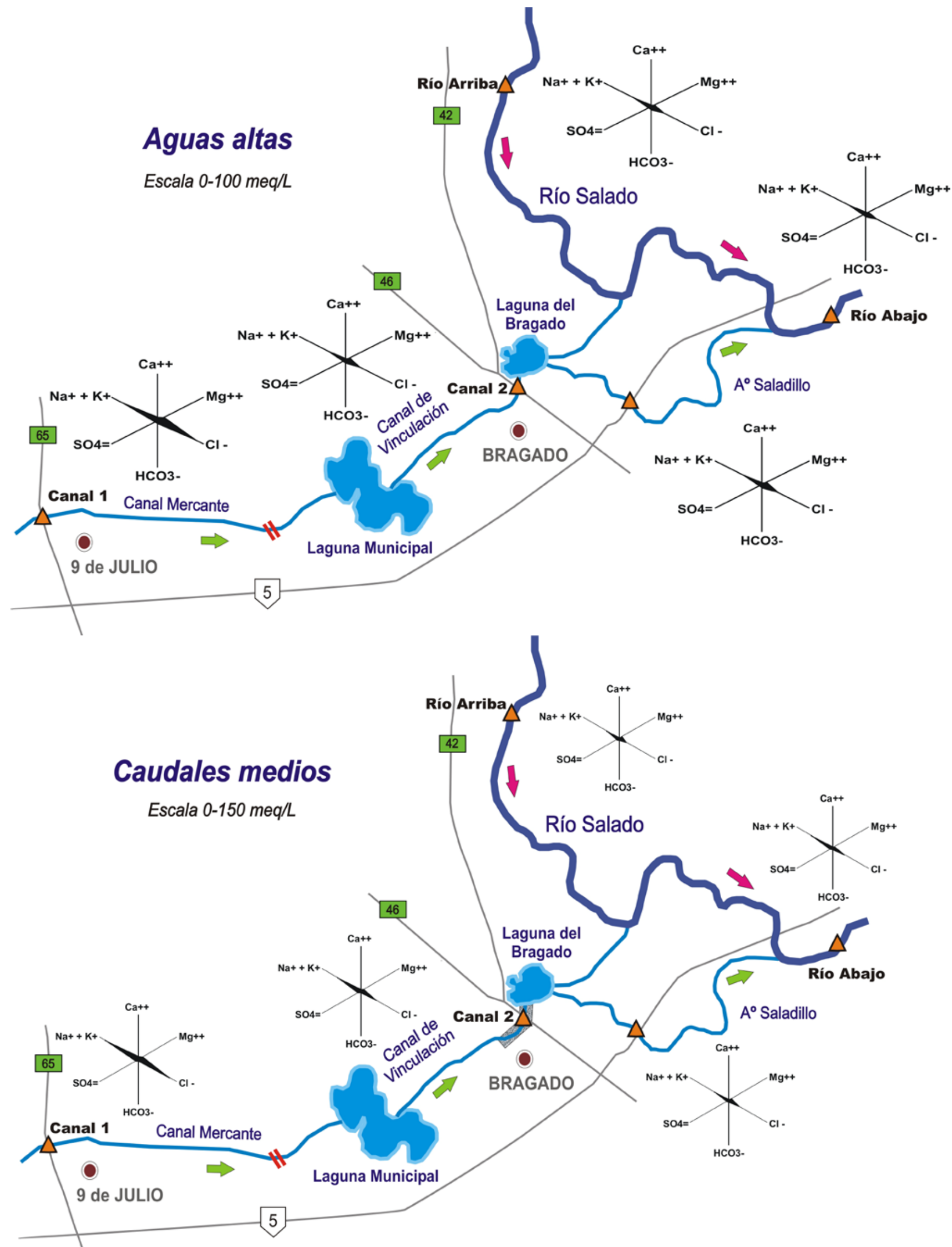

Figura 4.4: Esquemas radiales de composición iónica. Se grafican los valores promedio (días 1 y 2) de la concentración de los principales cationes $\left(\mathrm{Na}^{+}+\mathrm{K}^{+}, \mathrm{Mg}^{++} \mathrm{y} \mathrm{Ca}{ }^{++}\right)$y aniones $\left(\mathrm{Cl}^{-}, \mathrm{HCO}_{3}^{-}\right.$y $\mathrm{SO}_{4}=$ por sitio de muestreo en condiciones de aguas altas (mayo 2007) y en caudales medios (marzo 2008). Referencias: La zona sombreada en el canal 2 representa los movimientos de tierra observados en ese momento (modificación de los márgenes y el cauce con máquinas retroexcavadoras). 


\section{Aguas bajas}

Escala 0-200 meq/L

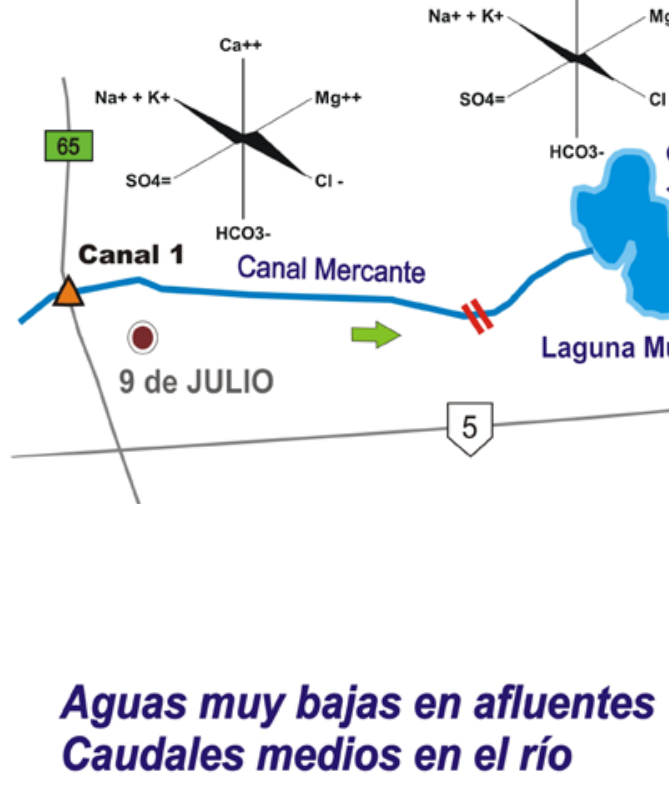

Escala 0-150 meq/L

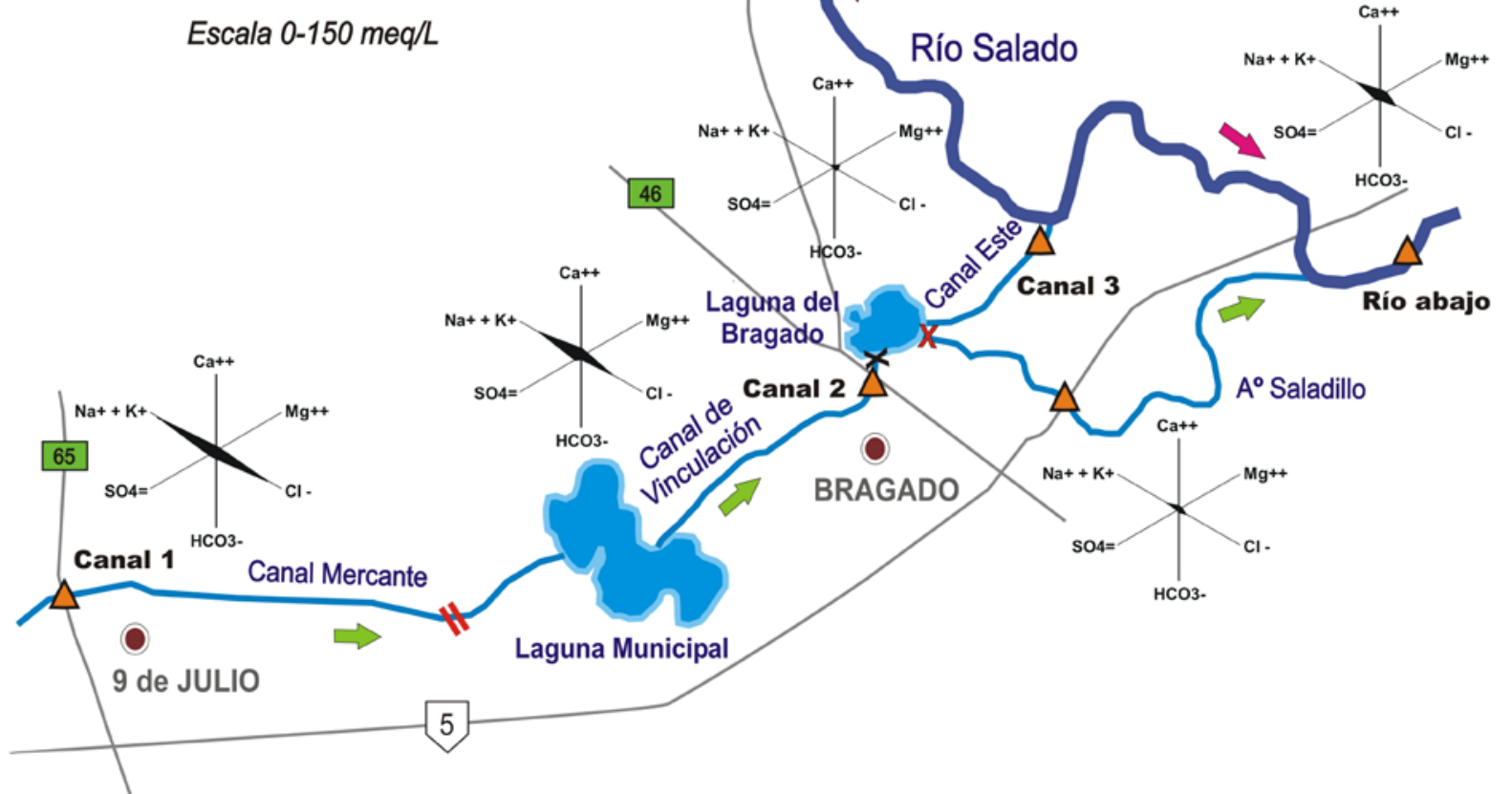

Figura 4.5: Esquemas radiales de composición iónica. Se grafican los valores promedio (días 1 y 2) de la concentración de los principales cationes $\left(\mathrm{Na}^{+}+\mathrm{K}^{+}, \mathrm{Mg}^{++}\right.$y $\left.\mathrm{Ca}^{++}\right)$y aniones $\left(\mathrm{Cl}^{-}, \mathrm{HCO}^{-}\right.$y $\mathrm{SO}_{4}=$ por sitio en condiciones de aguas bajas (nov. 2008) y aguas muy bajas en los afluentes (sistema Bragado) pero con caudales medios en el río Salado (sept. 2009). Referencias: La zona sombreada en el canal 2 representa la creación de defensas contra las inundaciones. La cruz $(X)$ roja simboliza la anulación del flujo de agua en el arroyo por la construcción de un nuevo vertedero en sus nacientes en la laguna del Bragado. La cruz negra representa la interrupción parcial del flujo de agua hacia la laguna (canal 2) por esta misma mejora hídrica. 


\subsubsection{Turbidez, transparencia, sólidos suspendidos y materia orgánica particulada}

Se hallaron correlaciones positivas significativas $(p<0,05 ; \mathrm{r}>0,6)$ entre la turbidez, los SS (sólidos suspendidos) y la MOP (materia orgánica particulada), y negativas con la transparencia, medida a través del disco de Secchi (Anexo II). En aguas altas, los SS, la MOP y la turbidez presentaron los valores máximos en el canal 1, con una tendencia decreciente a lo largo del sistema Bragado, hasta el río aguas abajo del trasvase. La transparencia registró los valores máximos en el río (Fig. 4.6). En caudales medios, los canales y el río aguas abajo presentaron similares valores de SS, MOP, turbidez y transparencia. En el río aguas arriba se observaron los valores máximos de estos parámetros, con una tendencia decreciente aguas abajo del trasvase ( $50 \%$ del total). La transparencia registró los valores máximos en el arroyo y mínimos en el río aguas arriba.

En aguas bajas, se observó escasa variación en los SS, la MOP y la turbidez en el sistema Bragado, mientras que en el río aguas arriba se observaron los valores máximos de estos parámetros y los mínimos de transparencia, con un importante descenso aguas abajo del trasvase (52-54\%). En aguas muy bajas, también se registraron bajos valores de SS, MOP y turbidez en el sistema Bragado, asociados a una mayor transparencia, particularmente en el canal 3. Lo opuesto se observó en el río, con valores máximos de SS, MOP y turbidez, y mínimos de trasparencia, con escasas variaciones entre sitios.

\subsubsection{Nutrientes}

En todas las condiciones hidrológicas se observaron picos de concentración de $\mathrm{N}_{-} \mathrm{NH}_{4}{ }^{+}$en el arroyo, registrando los valores mínimos en aguas altas $(1.500 \mu \mathrm{g} / \mathrm{L})$ y los máximos en caudales

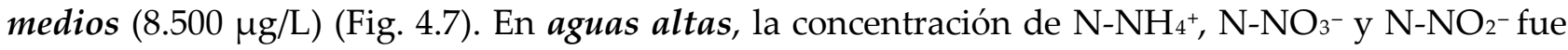
máxima en el sistema Bragado, particularmente en el canal 1 y el arroyo. El amonio registró picos de concentración en estos sitios, en situaciones de bajo contenido de oxígeno disuelto (OD) (5,6 7,8 mg/L promedio). Los $\mathrm{NO}_{3}{ }^{-}$también fueron elevados en el río aguas arriba, disminuyendo 3,7 veces su concentración aguas abajo. El contenido de OD fue mínimo en el canal 1 y en el arroyo, y en los restantes sitios de muestreo se halló en alrededor de 9,5 mg/L.

En caudales medios, los canales 1 y 2 y el río aguas abajo presentaron similares concentraciones de $\mathrm{N}-\mathrm{NH}_{4}{ }^{+}, \mathrm{N}^{-\mathrm{NO}_{3}-}$ y $\mathrm{N}-\mathrm{NO}_{2}{ }^{-}$. En el río, estos compuestos decrecieron aguas abajo del trasvase (37-52\% del total). La concentración de OD estuvo entre 6 y 15,4 mg/L, con valores extremos en el arroyo y el canal 2 respectivamente, y en el río varió entre 9,3-10,7 mg/L. El NT también registró los valores máximos en el arroyo $(12.000 \mu \mathrm{g} / \mathrm{L})$ con prevalencia del NTD (75\%). En los canales también predominó el NTD, mientras que en el río fue superior el NTP (Fig. 4.8). 

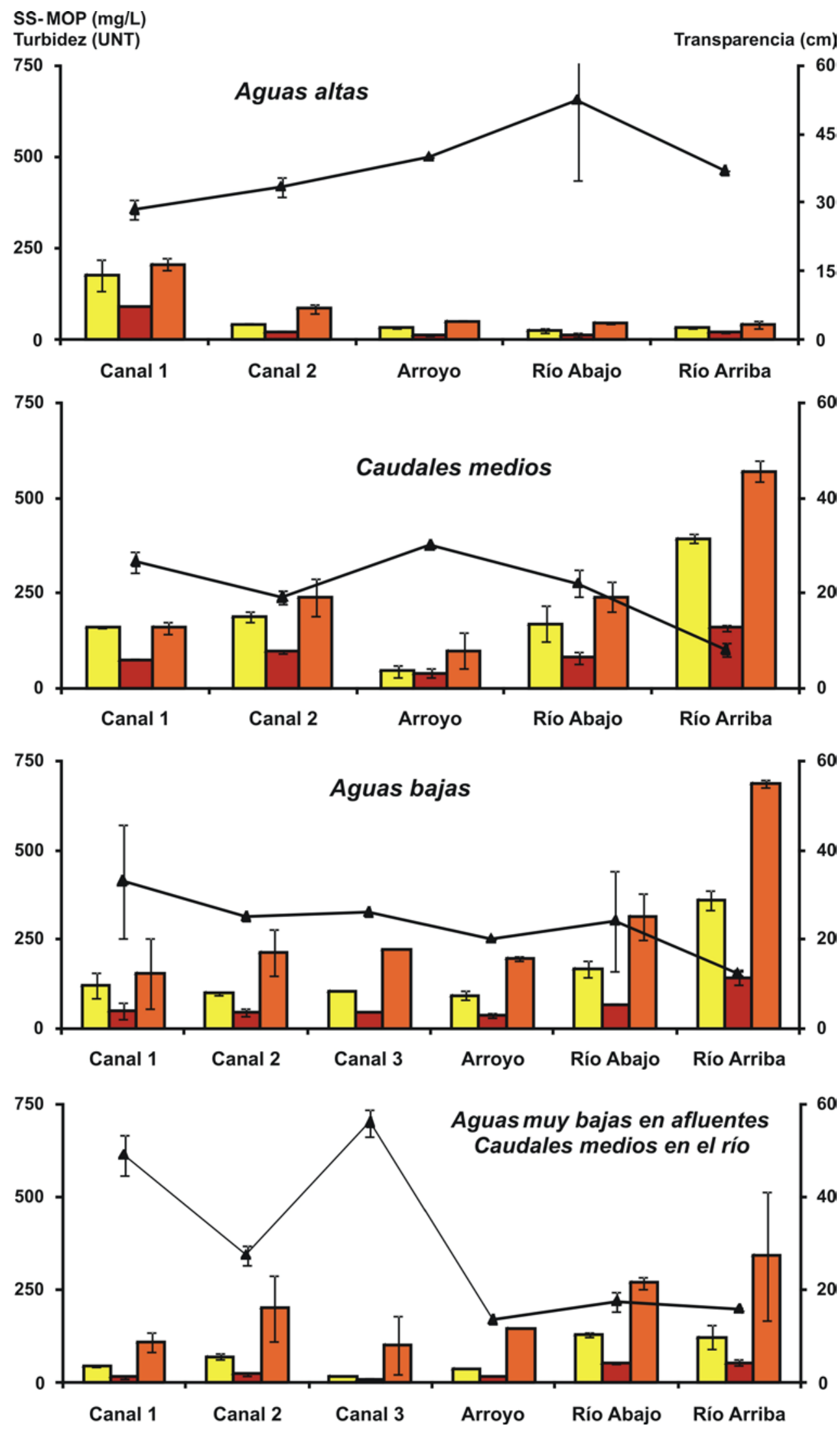

Figura 4.6: Valores de transparencia medida por disco de Secchi (línea marrón), sólidos suspendidos (SS) (columna en amarillo), materia orgánica particulada (MOP) (columna roja) y turbidez (columna anaranjada). Se muestran los valores promedios (días 1 y 2) y sus respectivos desvíos hallados por sitio de muestreo y condición hidrológica: aguas altas (mayo 2007), caudales medios (marzo 2008), aguas bajas (nov. 2008) y aguas muy bajas en afluentes con caudales medios en el río (sept. 2009). 


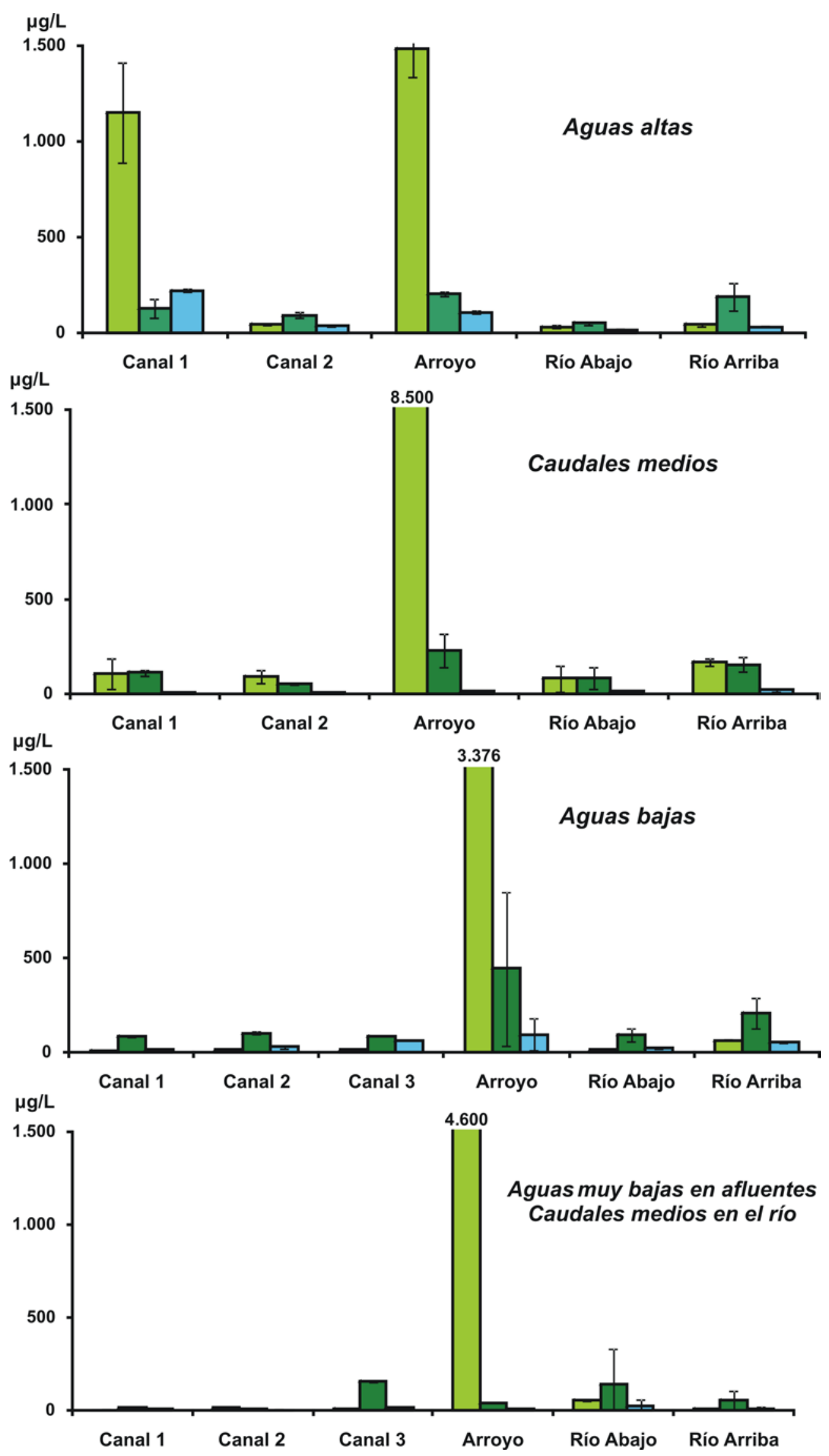

Figura 4.7: Concentración de amonio (columnas verde claro), nitrato (verde oscuro) y nitrito (celeste). Se muestran los valores promedios (días 1 y 2) y sus respectivos desvíos hallados por sitio de muestreo y condición hidrológica: aguas altas (mayo 2007), caudales medios (marzo 2008), aguas bajas (nov. 2008) y aguas muy bajas en afluentes (sistema Bragado) con caudales medios en el río (sept. 2009). 


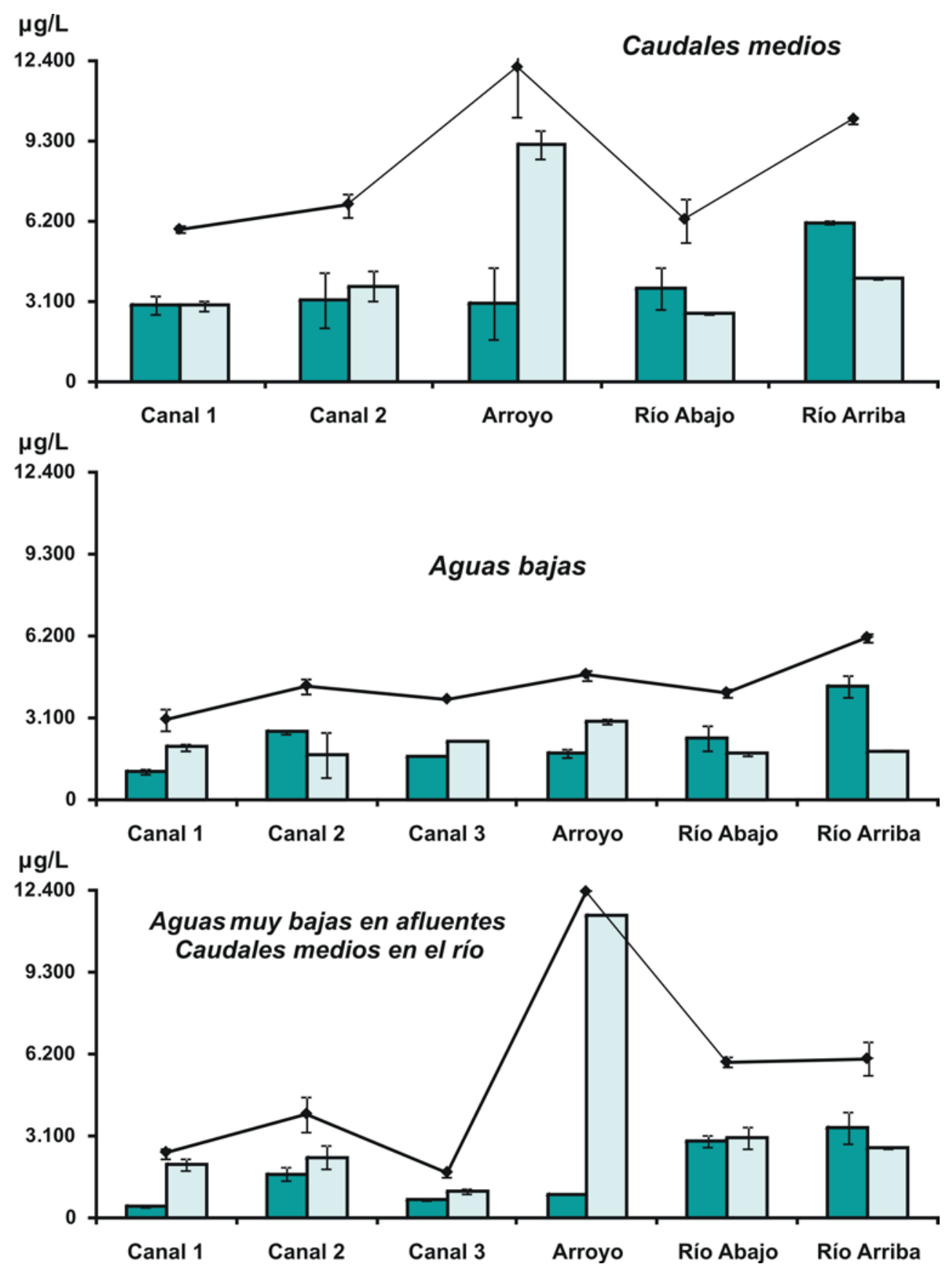

Figura 4.8: Nitrógeno total (NT) (línea negra), y sus fracciones (en columnas): particulado (NTP) (verde) y disuelto (NTD) (celeste). Se muestran los valores promedios (días 1 y 2) y sus respectivos desvíos hallados por sitio de muestreo y condición hidrológica: caudales medios (marzo 2008), aguas bajas (nov. 2008) y aguas muy bajas en afluentes (sistema Bragado) con caudales medios en el río (sept. 2009) (Missing data: aguas altas - mayo 2007).

En aguas bajas, el arroyo se registró un pico de $3.400 \mu \mathrm{g} / \mathrm{L}$ de $\mathrm{N}-\mathrm{NH}_{4}{ }^{+}$y los valores máximos de $\mathrm{N}^{-\mathrm{NO}_{3}}{ }^{-}$y N-NO${ }^{-}$, mientras que en los canales su concentración fue baja. En el río se observó una reducción de estos compuestos aguas abajo del trasvase $\left(83,56\right.$ y $53 \%$ respectivamente). El N-NH $4^{+}$ se incrementó en situaciones de baja concentración de OD, como los hallados en el arroyo (5,6 mg/L), seguido por el canal 3 (6,3 mg/L). En el canal 1 y en el río aguas arriba se observaron los valores máximos de OD (15 mg/L). El NT aumentó escalonadamente a lo largo del sistema Bragado, desde el canal 1 al arroyo, donde prevaleció la fracción disuelta. En el río aguas arriba se 
halló el valor máximo de NT $(6.100 \mu \mathrm{g} / \mathrm{L})$, mayormente constituido por NTP (70\%), reduciéndose aguas abajo del trasvase (34\%).

En aguas muy bajas (sept. 2009), se halló máxima concentración $\mathrm{N}-\mathrm{NH}_{4}{ }^{+}$y $\mathrm{NT}$ en el arroyo (4.600 y $12.300 \mu \mathrm{g} / \mathrm{L}$, respectivamente), siendo hasta 2.300 veces superior a lo hallado en el otro efluente de la laguna del Bragado (canal 3). La concentración de este compuesto se incrementó en presencia de bajas valores de OD, siendo mínima en el arroyo y en el canal $1(<8,8 \mathrm{mg} / \mathrm{L})$. En el río en caudales medios (sept. 2009) se observaron aguas más oxigenadas (>16 mg/L), pero se

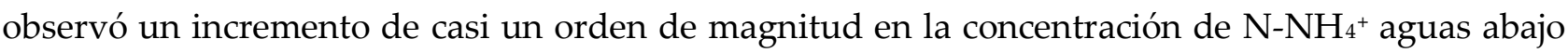
del trasvase. La concentración de $\mathrm{N}^{-\mathrm{NO}_{3}}$ y $\mathrm{N}-\mathrm{NO}_{2}$ - fue baja en la mayoría de los sitios de muestreo, salvo para el canal 3 y el río aguas abajo. En las aguas muy bajas del sistema Bragado prevaleció la fracción disuelta del NT, particularmente en el arroyo (93\%). En el río (caudales medios), se observó escasa variación en el contenido de NT entre sitios $(<2 \%)$, con un leve aumento del NTD en el sitio aguas abajo del trasvase.

En aguas altas, el fósforo registró un comportamiento variable según los sitios de muestreo. En el río disminuyó el PRT, el PT, el POT y sus respectivas fracciones aguas abajo del trasvase (18-48\% del total). El PRT registró los valores máximos en el arroyo, con prevalencia del PRS (>85\%) en este sitio y en el canal 2, mientras que en el canal 1 se destacó el PRP (Fig. 4.9). El PT fue máximo en el arroyo y en el canal 1, y en todos los sitios de muestreo prevaleció el PTD (Fig. 4.10). El PRS constituyó la mayor parte del PTD, variando entre 69-87\% en el canal 2, el arroyo y el río, y con mínimos valores en el canal 1 (14\%). El fósforo orgánico total (POT) registró los valores máximos en el canal 1, siendo el único sitio donde predominó el POD (57\%). El POT disminuyó a lo largo del sistema Bragado y hasta el río, donde dominó del POP (55-72\%) (Fig. 4.11).

En caudales medios, también se observaron los valores máximos de PRT, PRS, PT y POT en el arroyo, con la predominancia de las fracciones disueltas (<76\% del total). El PRS constituyó el 55$61 \%$ del PTD en el río, pero su predominancia fue menor en el sistema Bragado ( $46 \%$ arroyo). En el río aguas abajo se registró un menor contenido de PRT, PT, POT y sus fracciones que en el sitio aguas arriba (57\% menos). En los restantes sitios de muestreo se destacaron el PTP y el POP, con valores máximos en el río aguas arriba.

En aguas bajas, los valores de PT, PRT y POT fueron mínimos en los canales y máximos en el río aguas arriba, disminuyendo aguas abajo (64\%, 85\% y 51\%, respectivamente). El PRS superó al PRP en todos los sitios de muestreo, y lo opuesto se observó en el PO, donde predominó el POP (65-81\%). Sólo en el arroyo y en el río aguas arriba el PRS constituyó la mayor parte del PTD (6065\%). En el río aguas arriba se observaron los valores máximos de PRS y PTD, que se redujeron 
hasta un orden de magnitud aguas abajo. En el sistema Bragado se observaron los valores máximos de PRS, PRP, PT y POT en el arroyo. El PTP fue relevante en el sistema Bragado y en el río aguas abajo (52-74\% del PT).

En aguas muy bajas, se registraron los valores máximos de PRT, PT y POT en el arroyo (1.500, 3.760 y $2.270 \mu \mathrm{g} / \mathrm{L}$, respectivamente) y los mínimos en los canales, en particular en el canal 3. En el río aguas abajo se observó la disminución del PRT y PT (9-22\%) y el aumento del POT (5\%), respecto al sitio aguas arriba (caudales medios). El PRS y el PTD predominaron en el arroyo, en el río y en el canal 1 (82-98\% del PRT), en este orden de importancia. En los canales 2 y 3 se destacaron el PRP y el PTP. El PRS representó la mayor parte del PTD en el arroyo y en el río (6180\%). En el canal 1 prevaleció el POD, y en los restantes sitios de muestreo, el POP representó la mayor parte del POT (51-76\%). Se observaron correlaciones positivas $(p<0,05$ y $r>0,6)$ entre las fracciones de fósforo total particulado (PTP), fósforo reactivo soluble (PRS) y fósforo reactivo particulado (PRP), y negativa entre la transparencia y el PTP (Anexo II).

\subsubsection{Polifenoles totales disueltos y materia orgánica disuelta}

En aguas altas, se observó la máxima concentración de polifenoles totales disueltos (Polif.) entre muestreos, variando entre 1,9 mg/L (río) y 3,5 mg/L (canal 1). En el río aguas abajo se observó un aumento del 17\% de su concentración, respecto al sitio aguas arriba. La materia orgánica disuelta (MOD) registró los valores máximos en el canal 2, y en el río se observó una disminución de 18,6\% del total aguas abajo del trasvase (Fig. 4.12). En caudales medios, los Polif. variaron entre 1,2 y 2,1 mg/L, con valores extremos en los canales, y el río aguas abajo se observó un aumento de 13,4\%, respecto al sitio aguas arriba. La MOD tuvo un comportamiento similar, con altos valores en el arroyo y en el canal 2, y mínimos en el canal 1, pero escasas variaciones entre los sitios del río. En aguas bajas, la concentración de los Polif. fue mínima en el canal 1 (0,59 mg/L), mientras que en los restantes sitios de muestreo se mantuvo entre 0,92-1,07 mg/L. La MOD fue máxima en el río aguas arriba $(0,72)$ y descendió a la mitad en el río aguas abajo, mientras que varió entre 0,14 y 0,18 en el sistema Bragado. En aguas muy bajas, la concentración de los Polif. y la MOD fue mínima, considerando todos los muestreos, particularmente en el canal 3. En el río (caudales medios), se observó escasa variación entre sitios, y en el arroyo los valores máximos de ambas variables. Los Polif. estuvieron correlacionados positivamente $(p<0,05)$ con la velocidad de corriente (Anexo II). 


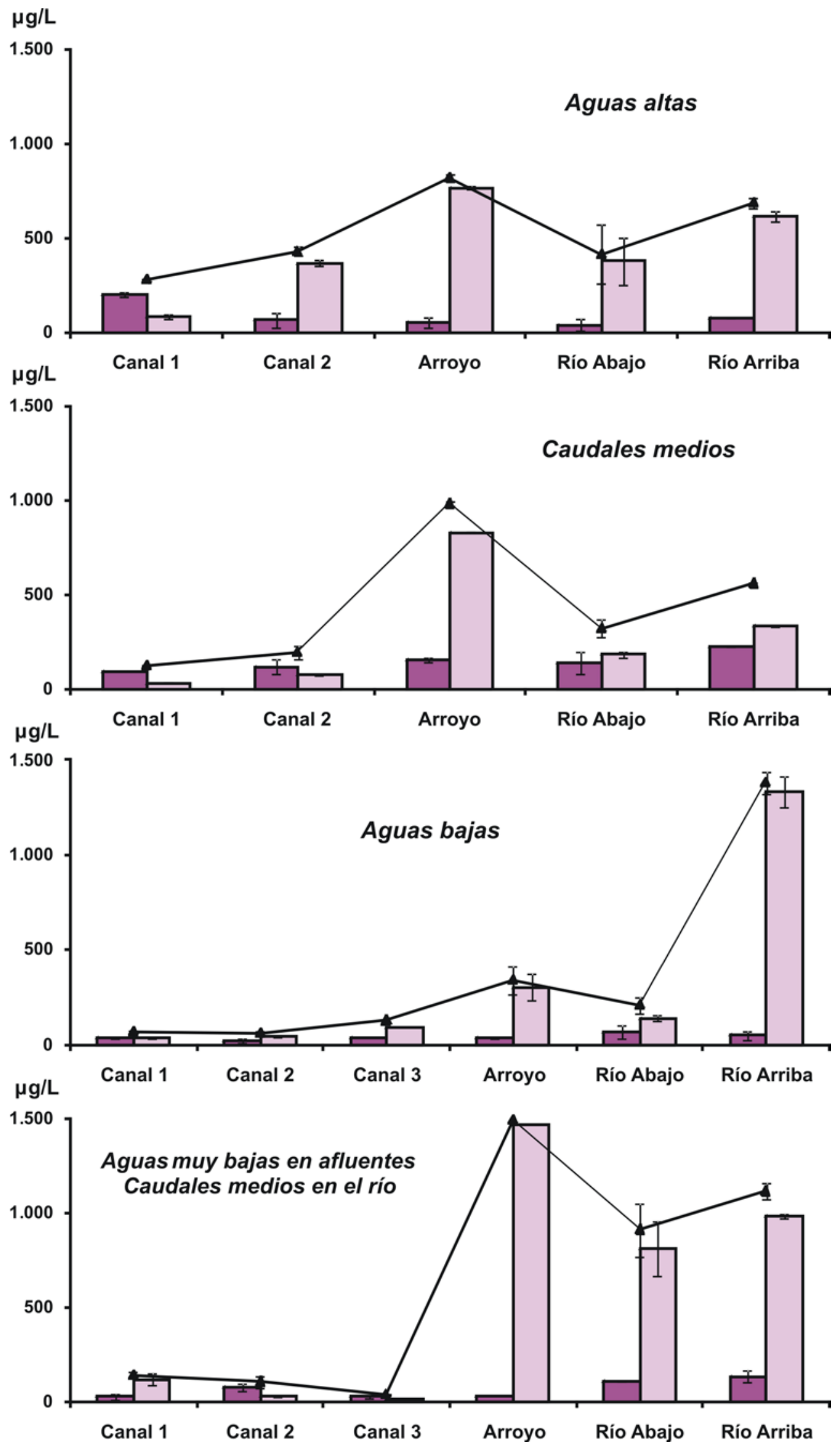

Figura 4.9: Fósforo reactivo total (PRT) (línea negra), y sus fracciones (en columnas): fósforo reactivo soluble (PRS) (rosado) y particulado (PRP) (magenta). Se muestran los valores promedios (días 1 y 2) y sus respectivos desvíos, hallados por sitio de muestreo y condición hidrológica: aguas altas (mayo 2007), caudales medios (marzo 2008), aguas bajas (nov. 2008) y aguas muy bajas en afluentes (sistema Bragado) con caudales medios en el río (sept. 2009). 


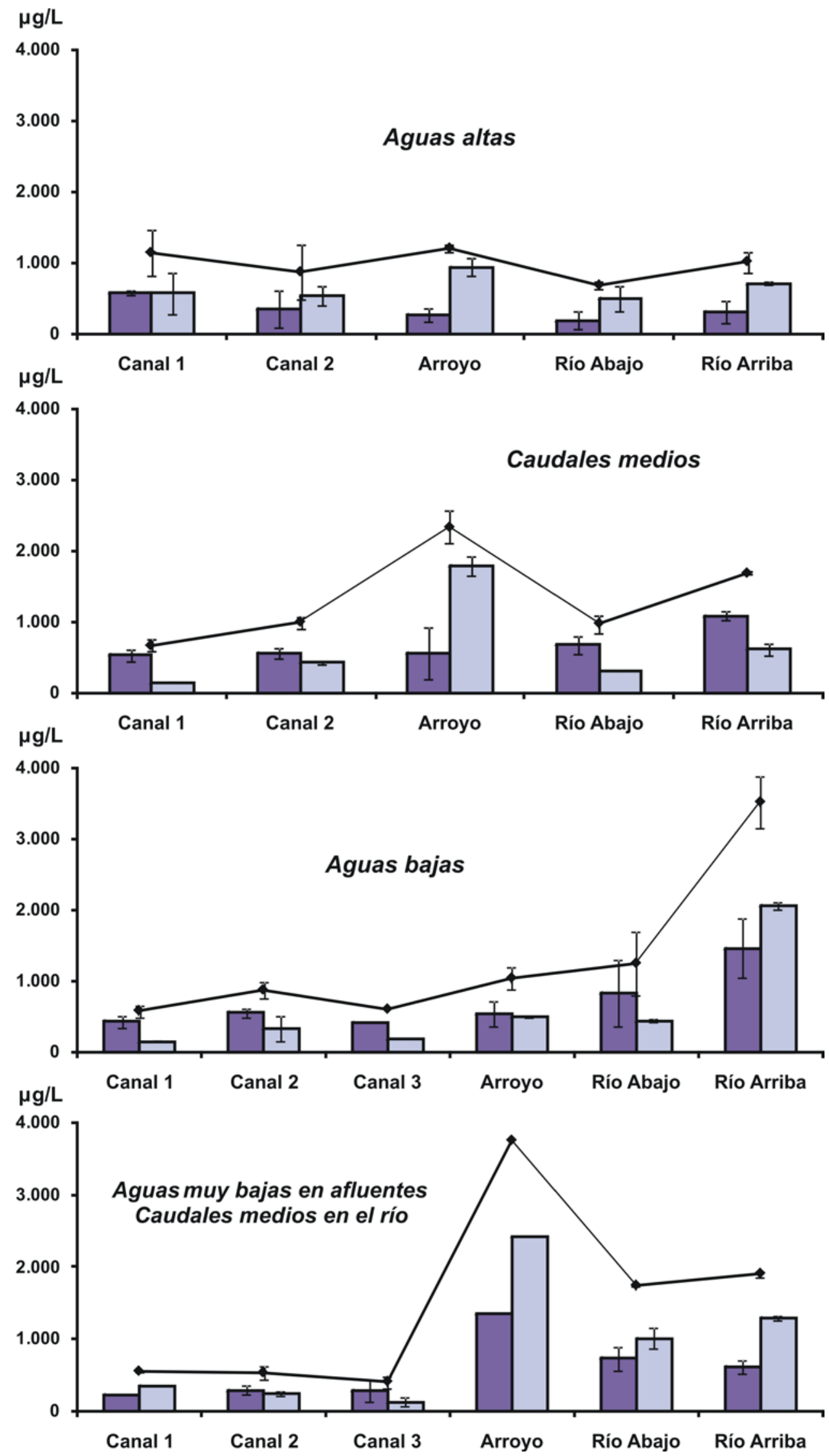

Figura 4.10: Fósforo total (PT) (línea negra) y sus fracciones (en columnas): particulado (PTP) (violeta) y disuelto (PTD) (lila). Se muestran los valores promedios (días 1 y 2 ) y sus respectivos desvíos hallados por sitio de muestreo y condición hidrológica: aguas altas (mayo 2007), caudales medios (marzo 2008), aguas bajas (nov. 2008) y aguas muy bajas en afluentes (sistema Bragado) con caudales medios en el río (sept. 2009). 
$\mu \mathrm{g} / \mathrm{L}$

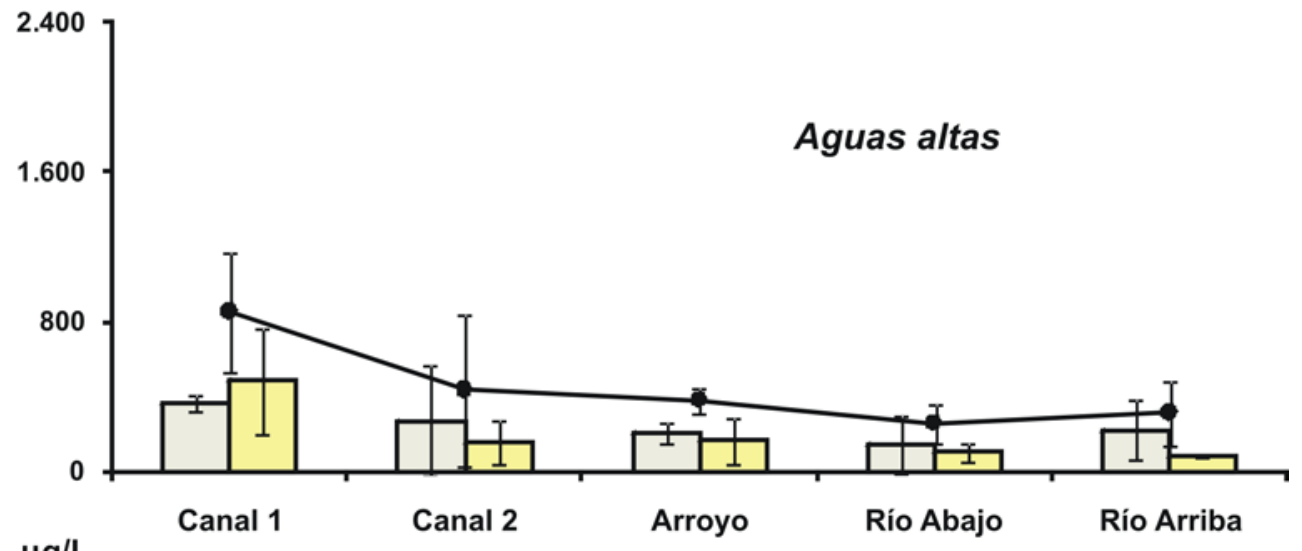

$\mu \mathrm{g} / \mathrm{L}$

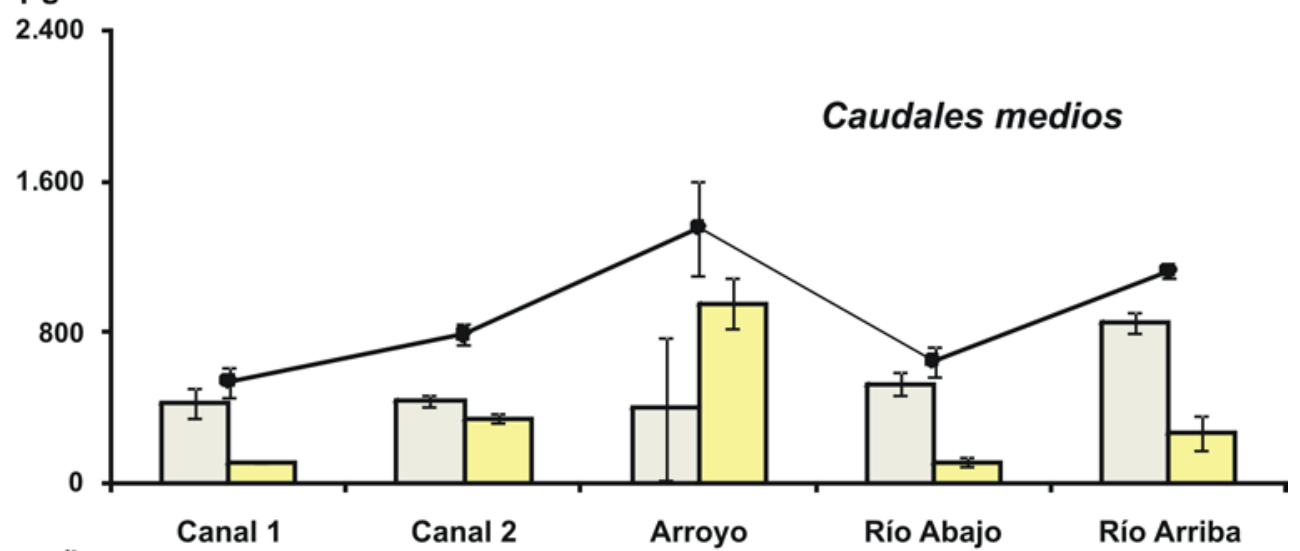

$\mu \mathrm{g} / \mathrm{L}$

Canal 1

Canal 2

Arroyo

Río Abajo

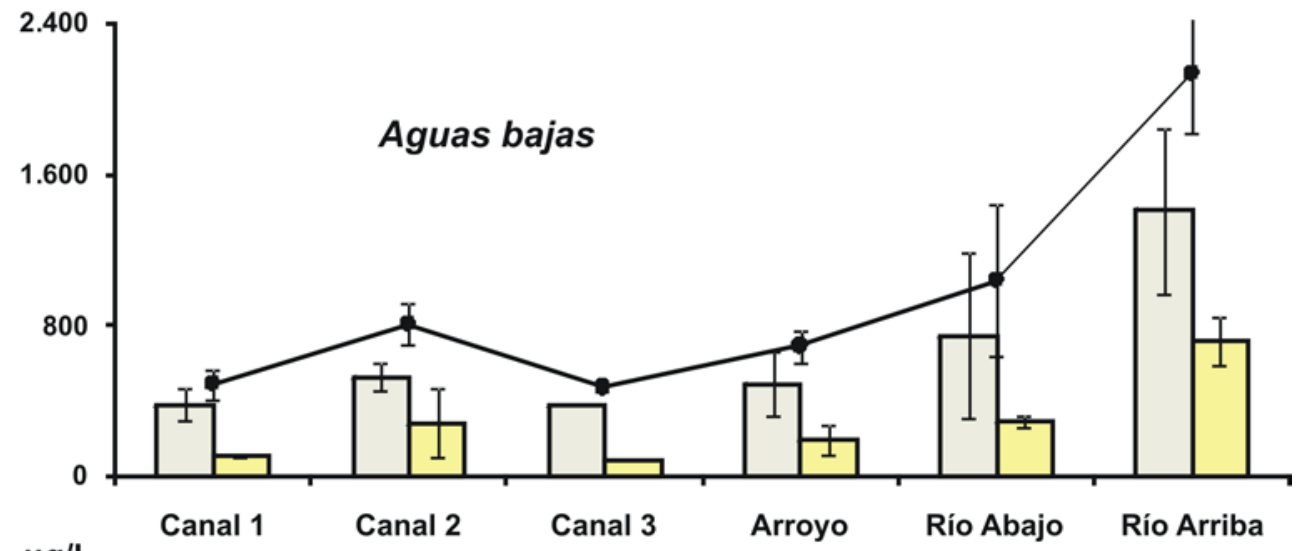

$\mu \mathrm{g} / \mathrm{L}$

2.400

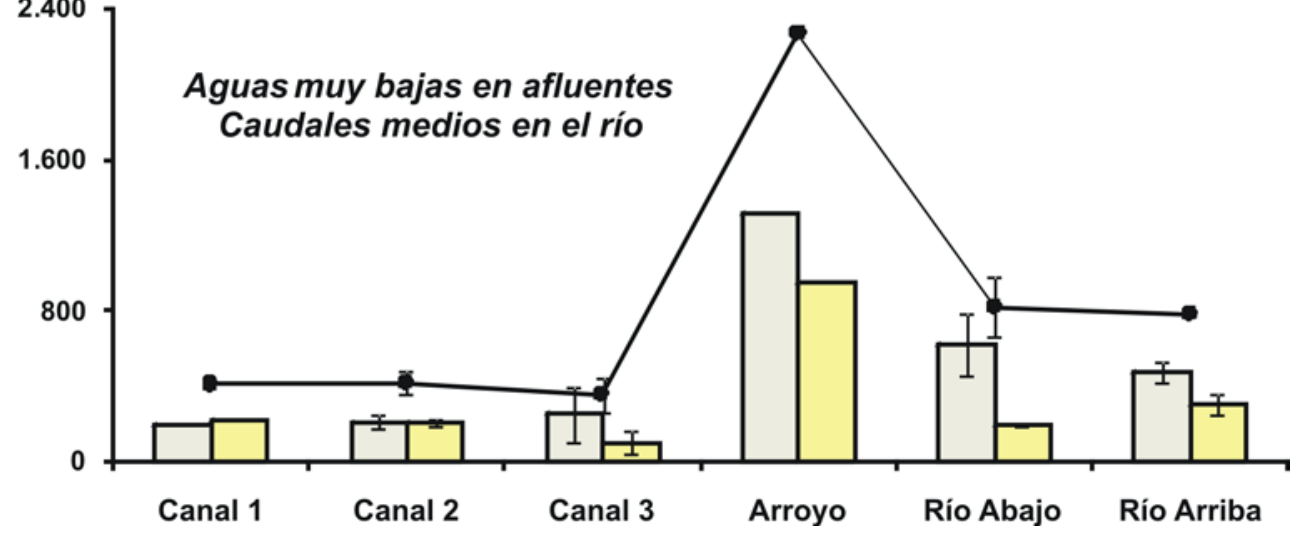

Figura 4.11: Fósforo orgánico total (POT) (línea negra) y sus fracciones: particulado $(\mathrm{POP}=\mathrm{PTP}-\mathrm{PRP})$ (columna gris) y disuelto (POD = PTD - PRS) (columna en amarillo). Se muestran los valores promedios (días 1 y 2) y sus respectivos desvíos hallados por sitio de muestreo y condición hidrológica: aguas altas (mayo 2007), caudales medios (marzo 2008), aguas bajas (nov. 2008) y aguas muy bajas en afluentes (sistema Bragado) con caudales medios en el río (sept. 2009). 


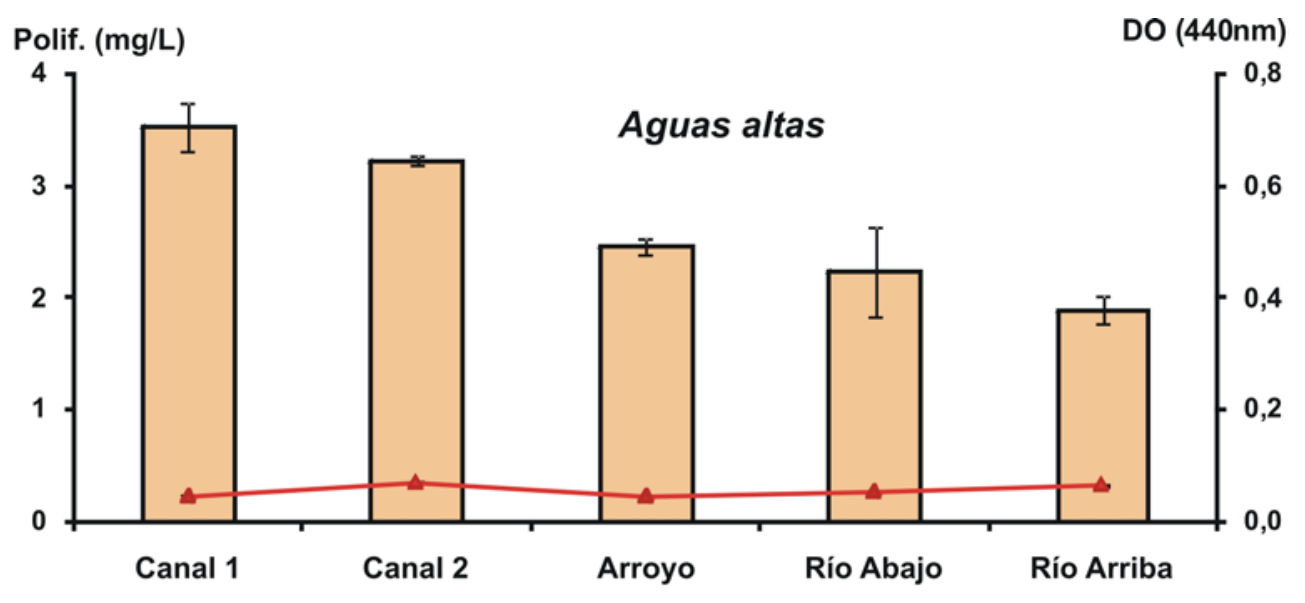

Polif. (mg/L)
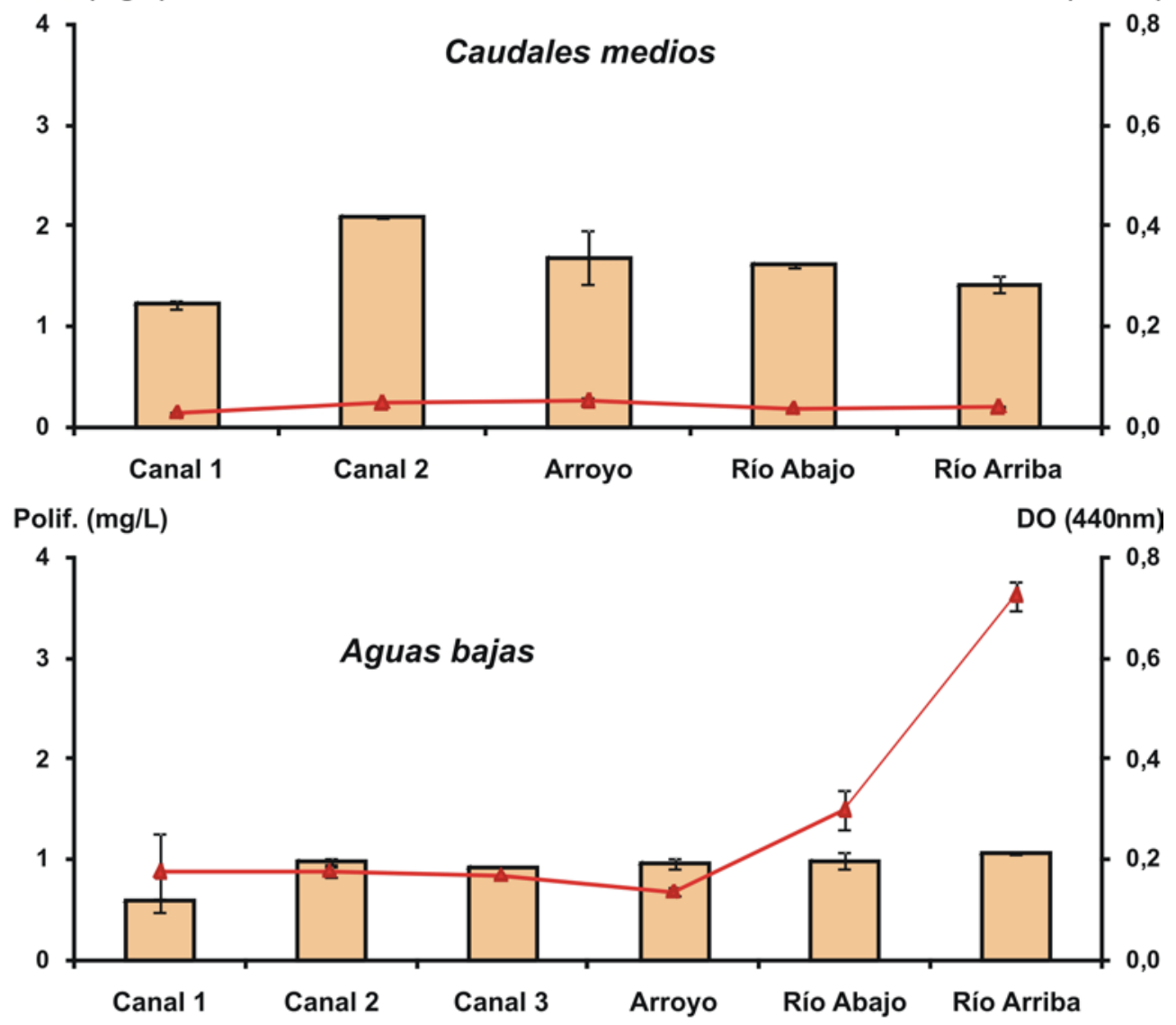

Polif. (mg/L)

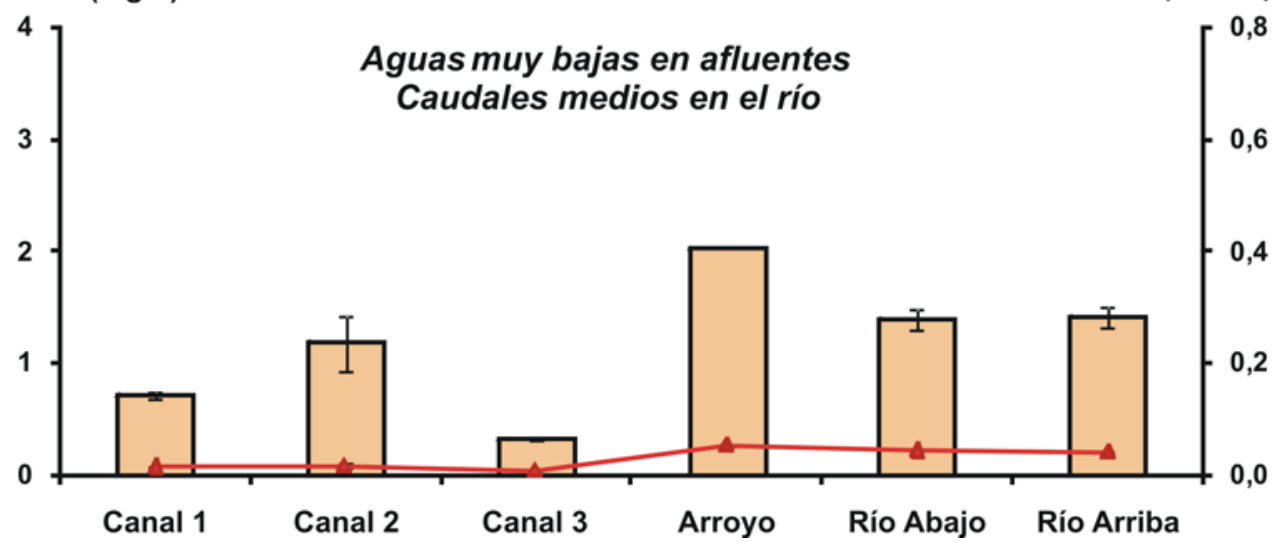

Figura 4.12: Polifenoles solubles totales (Polif.) (columnas) y materia orgánica disuelta (línea roja) medida por la absorbancia a 440nm (DO 440nm). Se muestran los valores promedios (días 1 y 2) y desvíos, hallados por sitio de muestreo y condición hidrológica: aguas altas (mayo 2007), caudales medios (marzo 2008), aguas bajas (nov. 2008) y aguas muy bajas en afluentes con caudales medios en el río Salado (sept. 2009). 


\subsection{Fitoplancton}

\subsubsection{Abundancia y biomasa total de fitoplancton}

La abundancia y biomasa total de fitoplancton (incluyendo células, colonias y filamentos) y la clorofila $a$ registraron los valores máximos en el canal 1 en caudales medios (marzo 2008), seguido por el canal 2, considerando todos los muestreos (Fig. 4.13). En aguas bajas (nov. 2008), también se observaron elevados valores de abundancia total en los canales 2 y 3, pero menor relevancia en los valores de biomasa y la clorofila $a$. En el arroyo se registraron los valores mínimos de abundancia y biomasa total y clorofila a en caudales medios y aguas bajas, y en el canal 1 en aguas muy bajas. En el río, la abundancia y biomasa total de fitoplancton y la clorofila a fue máxima en caudales medios (marzo 2008 y sept. 2009).

En aguas altas, se observaron los valores máximos de abundancia y biomasa total de fitoplancton (incluyendo células, colonias y filamentos) y clorofila $a$ en el canal 1, estos valoers luego decrecieron en el canal 2 y en el arroyo. En el río, se observaron los valores mínimos de estos estos descriptores, y con escasa variación entre sitios. El contenido de clorofila a se redujo levemente en el sitio aguas abajo a pesar de que los valores de la biomasa total presentaron una tendencia inversa (Tabla A, Anexo VI). En caudales medios, también se observaron los valores máximos de abundancia y biomasa total de fitoplancton en el canal 1, disminuyendo a lo largo del sistema Bragado, pero el río aguas arriba se destacó por los valores de clorofila $a$. En el río, se observó un aumento en la abundancia y biomasa total de fitoplancton en el sitio aguas abajo, pero lo inverso para la clorofila $a$ (Tabla B, Anexo VI).

En aguas bajas, los valores máximos de abundancia total de fitoplancton se hallaron en el canal 3, los de biomasa en el canal 2, y los de clorofila $a$ en el río aguas arriba. La abundancia total de fitoplancton aumentó desde el canal 1 al canal 3, mientras que en el canal 2 se observaron picos de biomasa y clorofila $a$. En el río, la abundancia y biomasa total de fitoplancton aumentaron aguas abajo del trasvase, pero lo inverso para la clorofila a (Tabla C, Anexo VI). En los caudales medios de sept. 2009, se observaron los valores máximos de abundancia y biomasa total de fitoplancton y la clorofila $a$ en el río, con escasas variaciones entre sitios (Tabla D, Anexo VI). Entre los sitios del sistema Bragado (aguas muy bajas), se destacó el canal 2 por los valores de estos descriptores. 

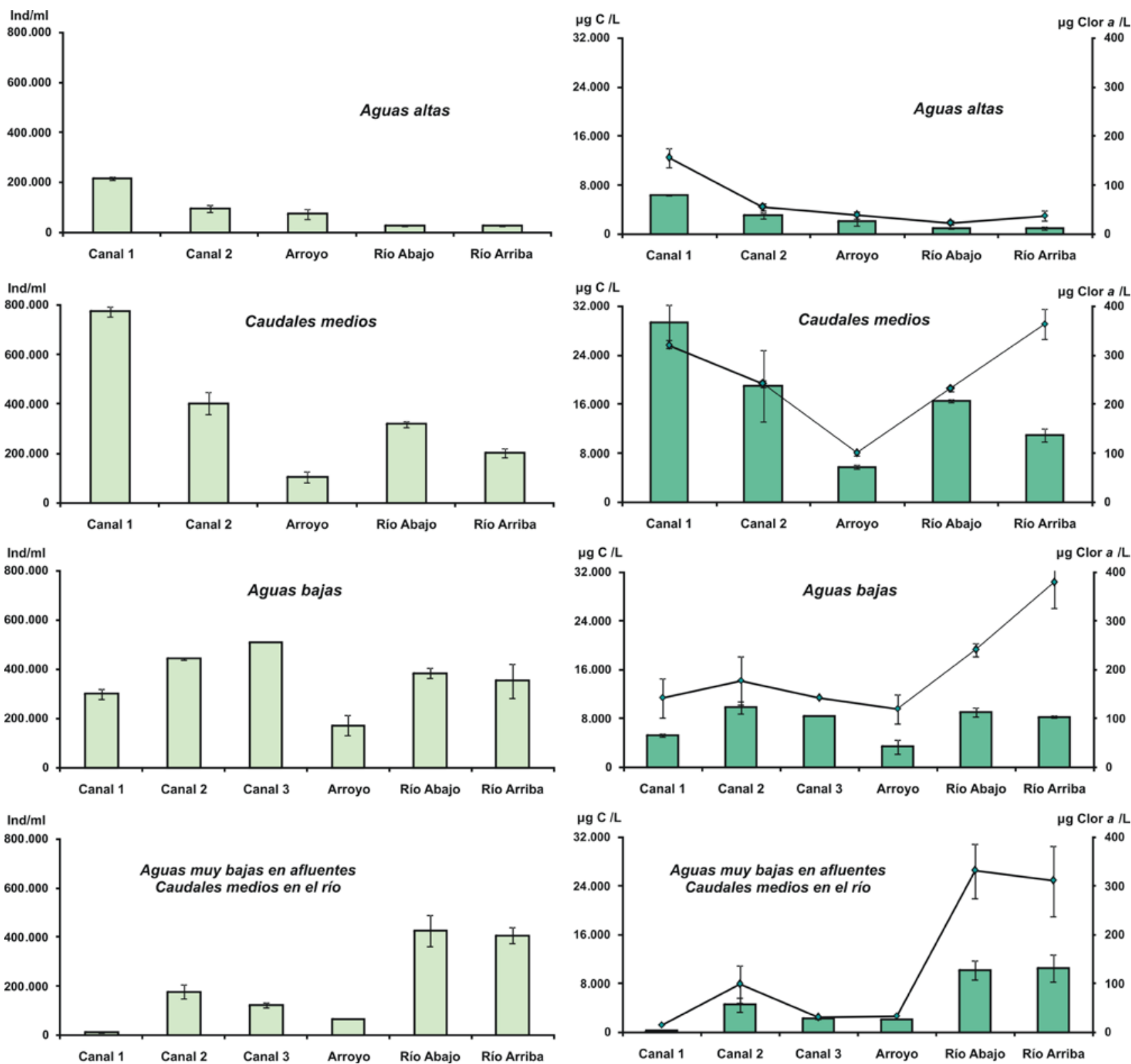

Figura 4.13: Abundancia y biomasa total de fitoplancton. Se muestran los valores promedio (días 1 y 2 ) y los rangos de valores (máximos y mínimos) hallados por sitio de muestreo y condición hidrológica: aguas altas (mayo 2007), caudales medios (marzo 2008), aguas bajas (noviembre 2008) y aguas muy bajas en afluentes (sistema Bragado) con caudales medios en el río (septiembre 2009).

\subsubsection{Abundancia de los grupos de fitoplancton}

En aguas altas, las cianobacterias, las clorofitas, las diatomeas, las euglenofitas y los dinoflagelados, registraron picos de abundancia total en el canal 1, y las criptofitas se destacaron en el canal 2 (Fig. 4.14). En el río, todos los grupos presentaron los valores mínimos, y aunque la densidad total de fitoplancton varió poco entre los sitios, se registraron cambios en la composición, con el aumento en las cianobacterias, las criptofitas y las diatomeas aguas abajo del trasvase, en detrimento de las clorofitas. Las cianobacterias dominaron la abundancia relativa en los canales, las clorofitas y las diatomeas en el arroyo y el río, particularmente en el sitio aguas arriba, y las criptofitas aguas abajo. Las euglenofitas y los dinoflagelados estuvieron escasamente representados (Fig. 4.15). 
En caudales medios, las cianobacterias, clorofitas, criptofitas y diatomeas estuvieron mejor representadas en los canales, particularmente en el canal 1, donde se observaron los valores máximos de abundancia, considerando todos los muestreos. Las euglenofitas se destacaron en el arroyo y en el río aguas abajo, y los dinoflagelados en el canal 2. En el río se observó un aumento de la densidad total de las cianobacterias, clorofitas, criptofitas y euglenofitas aguas abajo del trasvase, en detrimento de las diatomeas. Las cianobacterias dominaron la abundancia relativa, las clorofitas fueron subdominantes, las criptofitas presentaron similares \% entre los sitios de muestreo, y las diatomeas y las euglenofitas se destacaron en el arroyo.

En aguas bajas, las cianobacterias registraron picos de abundancia en los canales 2 y 3 , las criptofitas en el canal 2, las clorofitas en el canal 3, y las diatomeas y los dinoflagelados en el canal 1. Los dinoflagelados redujeron su importancia en los restantes sitios del sistema Bragado, pero se incorporaron al río, aguas abajo del trasvase. En el río, se observó una disminución en la densidad total de las cianobacterias y las diatomeas aguas abajo del trasvase, y lo opuesto para las clorofitas y las euglenofitas. La abundancia relativa de fitoplancton estuvo dominada por las diatomeas en el canal 1, por las cianobacterias en los canales 2 y 3 y en el río aguas arriba, y por las clorofitas en el río aguas abajo y el arroyo.

En el río en caudales medios (sept. 2009), se registraron picos de densidad de las clorofitas, diatomeas, cianobacterias y euglenofitas, y las criptofitas y los dinoflagelados se destacaron en el canal 2. Las clorofitas y las cianobacterias aumentaron levemente en el río aguas abajo del trasvase, y lo opuesto se observó para las criptofitas y euglenofitas. Los dinoflagelados se incorporaron en el río Salado, estando ausentes en el sitio aguas arriba. Las cianobacterias dominaron la abundancia relativa en el canal 1 y en el arroyo, y las clorofitas en el canal 3 y en el río. En el canal 2 compartieron la dominancia las clorofitas y las criptofitas. En el río, las diatomeas fueron subdominantes junto con las cianobacterias. Los dinoflagelados registraron \% máximos de abundancia relativa en los canales 1 y $2(0,5 \%)$, y las euglenofitas en el canal 1 y el arroyo $(<0,4 \%)$.

\subsubsection{Biomasa de los grupos de fitoplancton}

En aguas altas, la biomasa total de los grupos de fitoplancton siguió la misma tendencia que su abundancia, donde todos ellos se destacaron en canal 1 y en el río registraron los valores mínimos, con una distribución más equitativa de los grupos subdominantes (Fig. 4.16). Las cianobacterias dominaron la biomasa, seguidas por las clorofitas. Las diatomeas fueron relevantes en el arroyo y en el canal 1, y las criptofitas en el canal 2. Las euglenofitas se destacaron por su biomasa total y relativa en el sistema Bragado, y los dinoflagelados en los canales 1 y 2, y el río aguas abajo. 

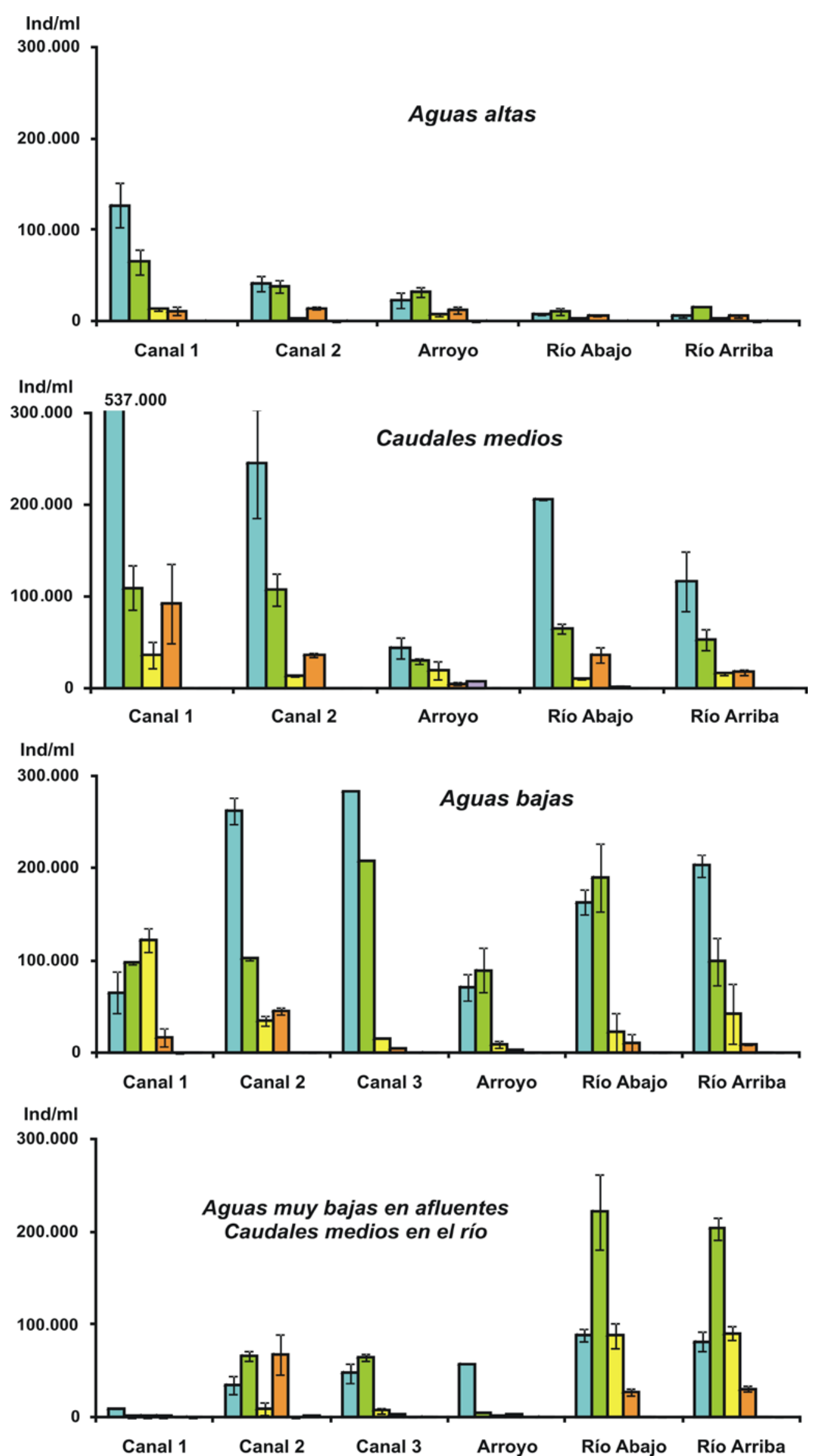

Figura 4.14: Abundancia total de los grupos de fitoplancton $(\mathrm{Ind} / \mathrm{mL})$. Referencias: cianobacterias (columna celeste), clorofitas (verde), diatomeas (amarillo), criptofitas (anaranjado), euglenofitas (lila) y dinoflagelados (rosado). Se muestran los valores promedio (días 1 y 2 ) y los rangos de valores hallados por sitio de muestreo y condición hidrológica: aguas altas (mayo 2007), caudales medios (marzo 2008), aguas bajas (nov. 2008) y aguas muy bajas en afluentes (sistema Bragado) con caudales medios en el río (sept. 2009). 

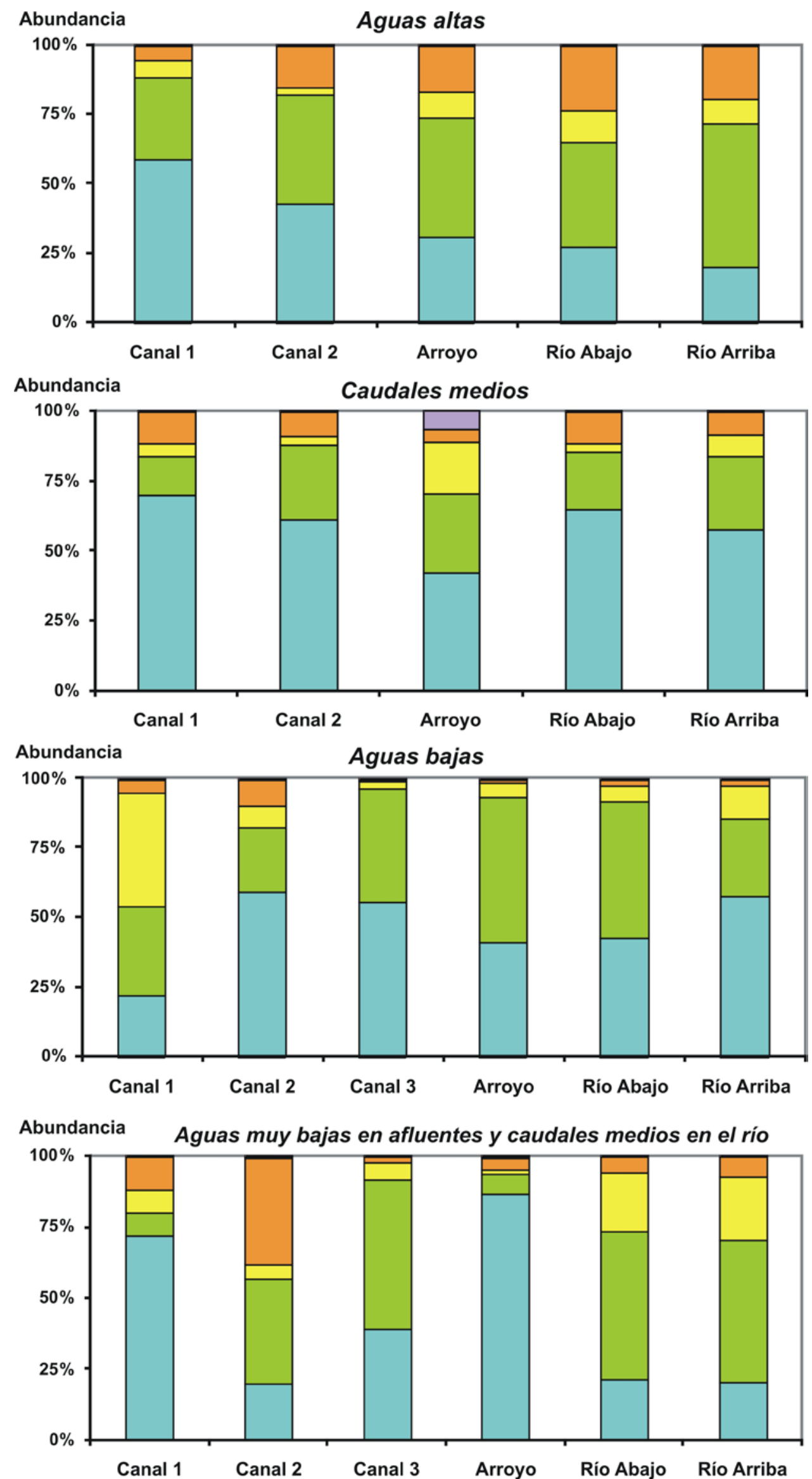

Figura 4.15: Abundancia relativa de los grupos de fitoplancton ( $\mathrm{Ind} / \mathrm{mL}$ ). Referencias: cianobacterias (columna celeste), clorofitas (verde), diatomeas (amarillo), criptofitas (anaranjado), euglenofitas (lila) y dinoflagelados (rosado). Se muestran los valores promedio (días 1 y 2) por sitio de muestreo y condición hidrológica: aguas altas (mayo 2007), caudales medios (marzo 2008), aguas bajas (nov. 2008) у aguas muy bajas en afluentes (sistema Bragado) con caudales medios en el río (sept. 2009). 
En el río se observó el aumento de la biomasa de las cianobacterias, diatomeas y dinoflagelados aguas abajo, en detrimento de las clorofitas y criptofitas. Las cianobacterias dominaron la biomasa relativa en todos los sitios de muestreo, particularmente en los canales, y las clorofitas fueron subdominantes, siendo más relevantes en el arroyo y el canal 2 (Fig. 4.17). En el río se observaron los \% máximos de contribución de las criptofitas (aguas arriba) y de las diatomeas (aguas abajo).

En caudales medios, la biomasa de los grupos del fitoplancton siguió un patrón diferente a la abundancia, registrando los valores máximos según los sitios de muestreo: las cianobacterias y las criptofitas en el canal 1, los dinoflagelados en el canal 2, las euglenofitas en el arroyo, las diatomeas en el río aguas arriba y las clorofitas aguas abajo. En el río Salado, las cianobacterias, las euglenofitas, las clorofitas, los dinoflagelados y las criptofitas aumentaron su biomasa total aguas abajo del trasvase del sistema Bragado, y lo opuesto se observó en las diatomeas. Las cianobacterias dominaron la biomasa relativa en todos los sitios de muestreo, a excepción del arroyo, donde prevalecieron las euglenofitas. Estas últimas tuvieron escasa relevancia en los restantes sitios, al igual que los dinoflagelados. Las clorofitas se destacaron por su biomasa relativa en el río, las diatomeas en el arroyo y las criptofitas en los canales.

Algo similar se observó en aguas bajas, donde los grupos de fitoplancton registraron picos de biomasa total según los sitios de muestreo: cianobacterias, criptofitas y euglenofitas en el canal 2; clorofitas en el canal 3 y en el río aguas abajo; diatomeas en el río aguas arriba y dinoflagelados en los canales 1 y 3 . En el río, se observó el aumento de la biomasa total de las cianobacterias, las clorofitas y las euglenofitas, y lo opuesto para las diatomeas. La biomasa relativa estuvo dominada por las cianobacterias en los canales 1 y 2, siendo subdominantes en los restantes sitios de muestreo. Las clorofitas dominaron en el canal 3, en el arroyo y en el río aguas abajo del trasvase, y las diatomeas en el sitio aguas arriba.

En aguas muy bajas en el sistema Bragado pero con caudales medios en el río, las cianobacterias dominaron la biomasa en todos los sitios de muestreo, particularmente en el río aguas arriba. Las clorofitas y diatomeas se destacaron en el río y en el canal 3, y las criptofitas y los dinoflagelados en el canal 2. Las euglenofitas se observaron en el arroyo y en el río aguas abajo, aumentando su biomasa respecto al río aguas arriba. Las cianobacterias y las criptofitas disminuyeron su biomasa en el río aguas abajo del trasvase. Las cianobacterias dominaron la biomasa relativa en los canales 1 y 3 , en el arroyo y en el río aguas arriba, y las clorofitas en el canal 2 y en el río aguas abajo. La biomasa relativa de las cianobacterias fue muy elevada en el canal 1 y en el arroyo (80-95\%). Las criptofitas se destacaron en el sistema Bragado (canal 2), las diatomeas en el río, las euglenofitas en el arroyo, y los dinoflagelados en los canales 1 y 2, en este orden de importancia. 

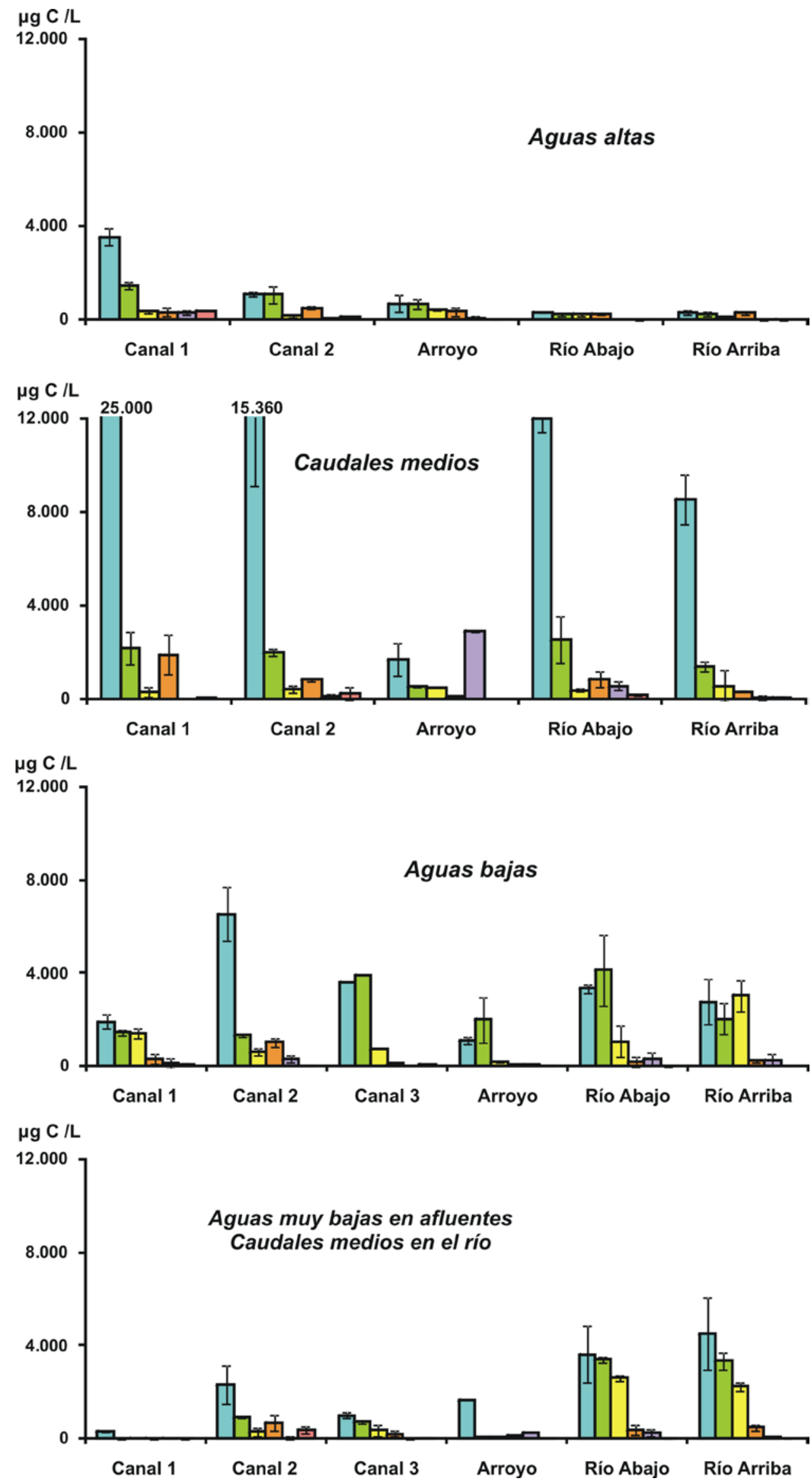

Figura 4.16: Biomasa total de los grupos de fitoplancton $(\mu \mathrm{g} \mathrm{C} / \mathrm{L})$. Referencias: cianobacterias (columna celeste), clorofitas (verde), diatomeas (amarillo), criptofitas (anaranjado), euglenofitas (lila) y dinoflagelados (rosado). Se muestran los valores promedio (días 1 y 2) y rangos de valores (máximos y mínimos) por sitio de muestreo y condición hidrológica: aguas altas (mayo 2007), caudales medios (marzo 2008), aguas bajas (nov. 2008) y aguas muy bajas en afluentes (sistema Bragado) con caudales medios en el río (sept. 2009). 

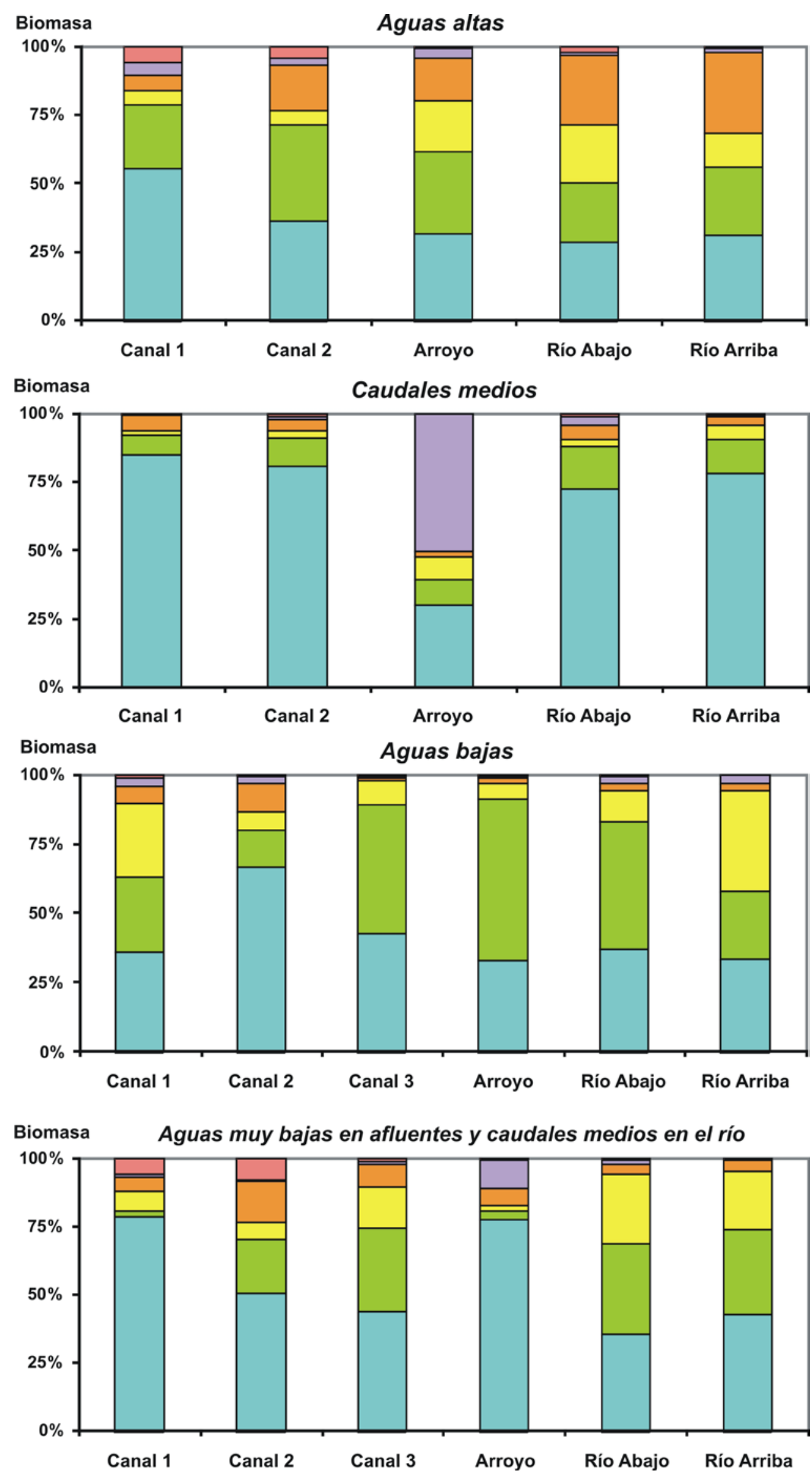

Figura 4.17: Biomasa relativa de los grupos de fitoplancton $(\mu \mathrm{g} \mathrm{C/L})$. Referencias: cianobacterias (columna celeste), clorofitas (verde), diatomeas (amarillo), criptofitas (anaranjado), euglenofitas (lila) y dinoflagelados (rosado). Se muestran los valores promedio (días 1 y 2) por sitio de muestreo y condición hidrológica: aguas altas (mayo 2007), caudales medios (marzo 2008), aguas bajas (nov. 2008) y aguas muy bajas en afluentes (sistema Bragado) con caudales medios en el río (sept. 2009). 


\subsubsection{Abundancia y biomasa de las principales especies}

En aguas altas (mayo 2007), la cianobacteria colonial Aphanocapsa incerta constituyó la especie más abundante, registrando los valores máximos en el canal 1, decreciendo a lo largo del sistema Bragado, pero aumentando su densidad en el río aguas abajo del trasvase (Fig. 4.18). Esta misma tendencia se observó para las clorofitas clorococcales Monoraphidium spp., las cianobacterias filamentosas Planktolyngbya minor y Raphidiopsis mediterranea, y la diatomea central Cyclotella meneghiniana. La criptofita Cryptomonas obovoidea se destacó por su abundancia en el arroyo y en el canal 2, y en menor medida en el río aguas abajo. En el río Salado, se observó el aumento de la abundancia total de Aphanocapsa incerta, Cyclotella meneghiniana y Cryptomonas obovoidea aguas abajo del trasvase, a la vez que una reducción en la densidad de Monoraphidium spp., siendo la especie dominante del sitio aguas arriba. Asimismo, Aphanocapsa incerta constituyó la especie dominante de la biomasa total de fitoplancton en el sistema Bragado, principalmente en el canal 1, y en el río registró la misma tendencia que para la abundancia (Fig. 4.19). Lo mismo se observó para Raphidiopsis mediterranea, Monoraphidium spp. y Cylcotella meneghiniana, pero en el canal 1 también se destacó por su biomasa Euglena oblonga, estando poco representada en los restantes sitios de muestreo. Cryptomonas erosa se observó en todos los sitios de muestreo, pero fue la especie dominante del río, disminuyendo en gran medida su biomasa aguas abajo del trasvase.

En caudales medios (marzo 2008), la especie más abundante fue Raphidiopsis mediterranea, siendo dominante en el canal 1 y en el río aguas abajo, aumentando considerablemente su densidad respecto al río aguas arriba. Aphanocapsa incerta y Cryptomonas obovoidea también siguieron este mismo patrón, presentando picos de densidad en el canal 1, disminuyendo luego su importancia en el canal 2, para incorporarse en el río aguas abajo del trasvase. Lo opuesto se observó en la cianobacteria filamentosa Sphaerospermopsis aphanizomenoides, que dominó por su abundancia en el río aguas arriba, y redujo su densidad aguas abajo del trasvase. El canal 2 y el río aguas abajo presentaron similares valores de densidad de S. aphanizomenoides, A. incerta, C. obovoidea y de $R$. mediterranea, y una composición de especies afín. Las clorofitas Monoraphidium spp. (M. arcuatum, M. circinale, M. contortum, M. fontinale, M. griffithii, M. komarkovae, M. minutum, M. nanum, M. pusillum, M. pseudobraunii, M. tortile) estuvieron mejor representadas en el sistema Bragado, particularmente en el canal 2, aumentando su abundancia en el río aguas abajo del trasvase. Entre las diatomeas, Cyclotella glomerata se destacó en el canal 1, y aunque fue menos relevante en el canal 2 y el arroyo, su abundancia también aumentó en el río aguas abajo, respecto al sitio aguas arriba (Fig. 4.20). Raphidiopsis mediterranea también se destacó por su biomasa, siendo la especie dominante de los canales 1 y 2 y el río aguas abajo del trasvase, aumentando 
considerablemente sus valores en el río Salado (Fig. 4.21). Sphaerospermopsis aphanizomenoides fue subdominante en estos mismos sitios de muestreo, pero se destacó particularmente en el río aguas arriba. En el canal 2 también se halló a Anabaenopsis nadsonii como especie subdominante, seguida por Cryptomonas obovoidea. Las clorofitas Monoraphidium spp. y Oocystis spp. (O. borgei, O. lacustris, O. marsonii, O. parva y O. solitaria) registraron biomasas relativas $<4 \%$ del total en todos los sitios analizados, y se destacaron por sus valores absolutos en el canal 2 y en el río aguas abajo, respectivamente. Euglena retronata fue la especie dominante del arroyo y también se halló en el río aguas abajo, estando ausente o escasamente representada en los restantes sitios de muestreo.

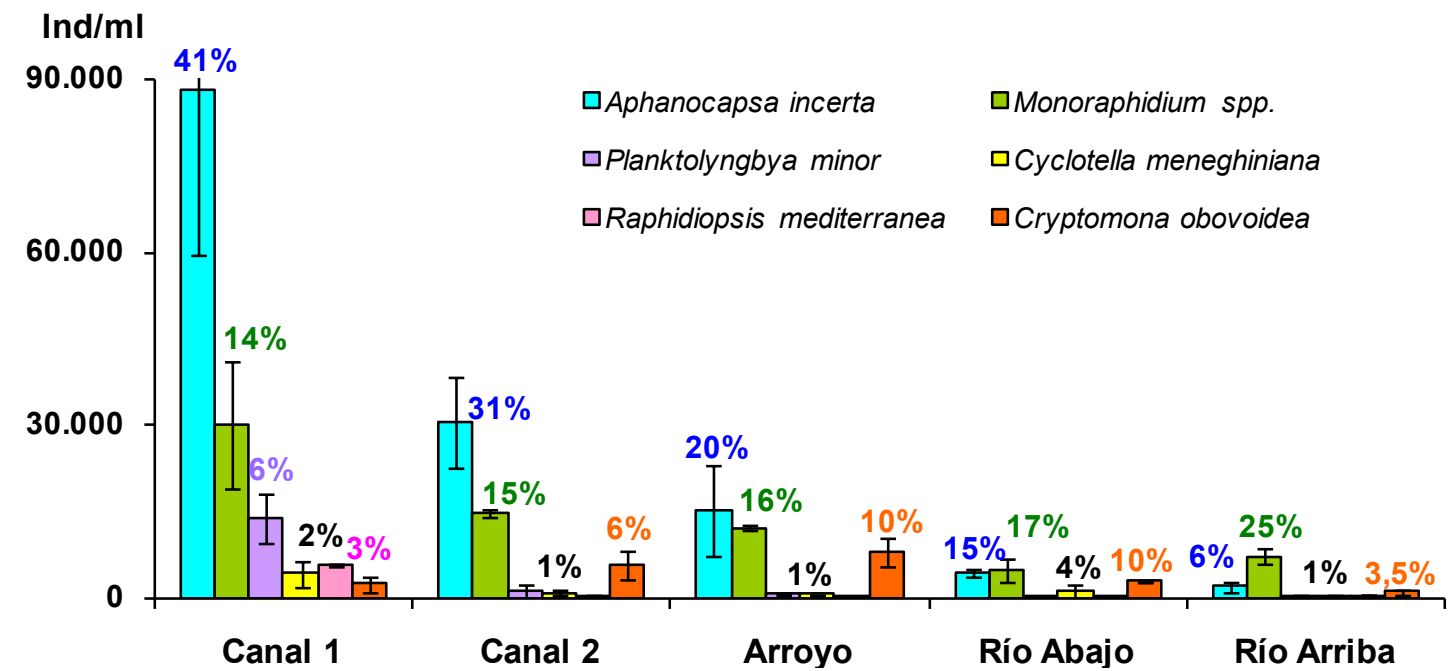

Figura 4.18: Abundancia total de las especies dominantes de fitoplancton en aguas altas (mayo 2007). Se muestran los valores promedio (días 1 y 2), sus rangos de valores (máximos y mínimos), y los porcentajes de contribución de cada especie a la abundancia total de fitoplancton hallados por sitio de muestreo.

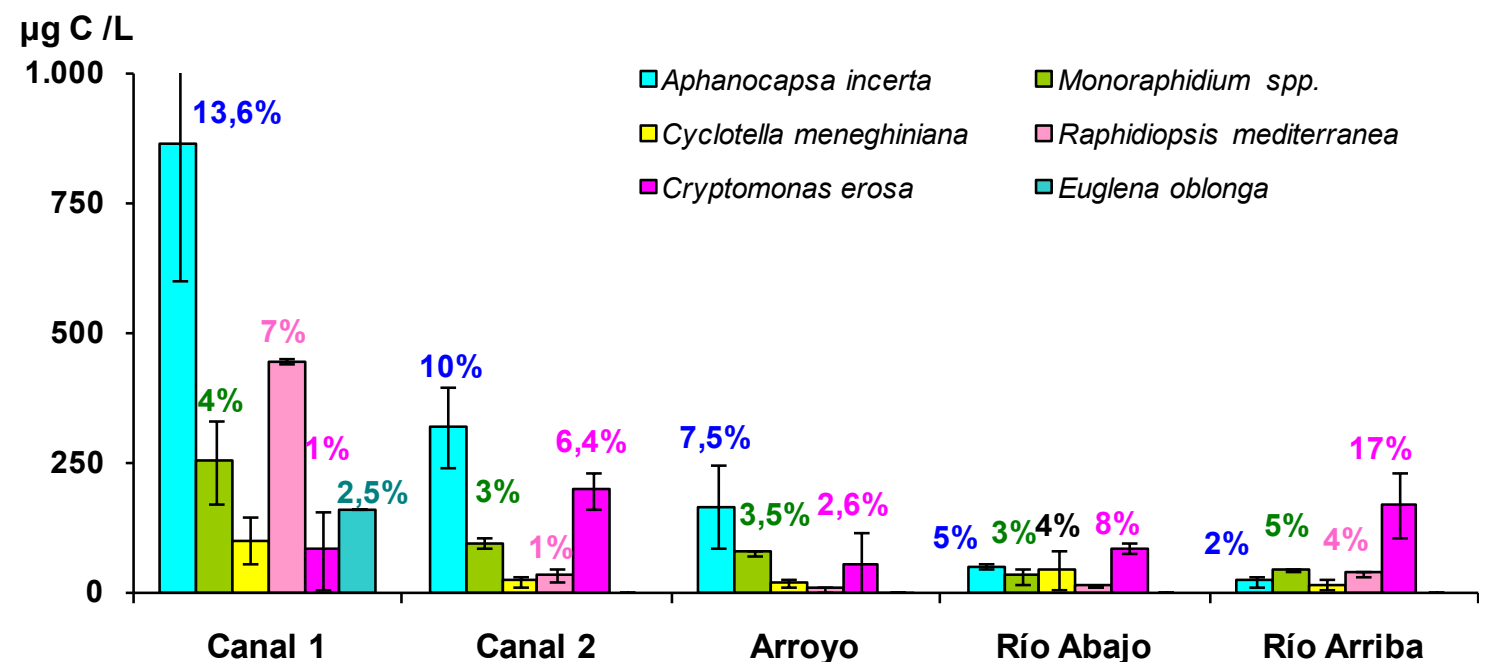

Figura 4.19: Biomasa total de las especies dominantes de fitoplancton en aguas altas (mayo 2007). Se muestran los valores promedio (días 1 y 2), sus rangos de valores, y los porcentajes de contribución de cada especie a la abundancia total de fitoplancton hallados por sitio de muestreo.

En aguas bajas (nov. 2008), se destacaron por su abundancia Aphanocapsa incerta, Planktolyngbya limnetica, Cyclotella glomerata, Stephanodiscus sp. y Monoraphidium spp., y en su conjunto 
representaron más del $60 \%$ de la abundancia total de fitoplancton en los sitios de muestreo (Fig. 4.22). En el canal 1 dominó C. glomerata, seguida por Pseudoschroederia robusta y en menor medida se hallaron Stephanodiscus sp., Planktolyngbya limnetica y Monoraphidium spp. En el canal 2, P. limnetica registró picos de abundancia siendo dominante, al igual que en el canal 3, el arroyo y el río aguas abajo. Cryptomonas obovoidea también se destacó en el canal 2 y Aphanocapsa incerta en el canal 3, siendo especies subdominantes en ambos casos. Monoraphidium spp. se destacaron por su abundancia en el canal 3, en el río aguas abajo y en el arroyo en este orden de importancia. En el río aguas arriba dominaron la abundancia total de fitoplancton A. incerta y Planktolyngbya limnetica.

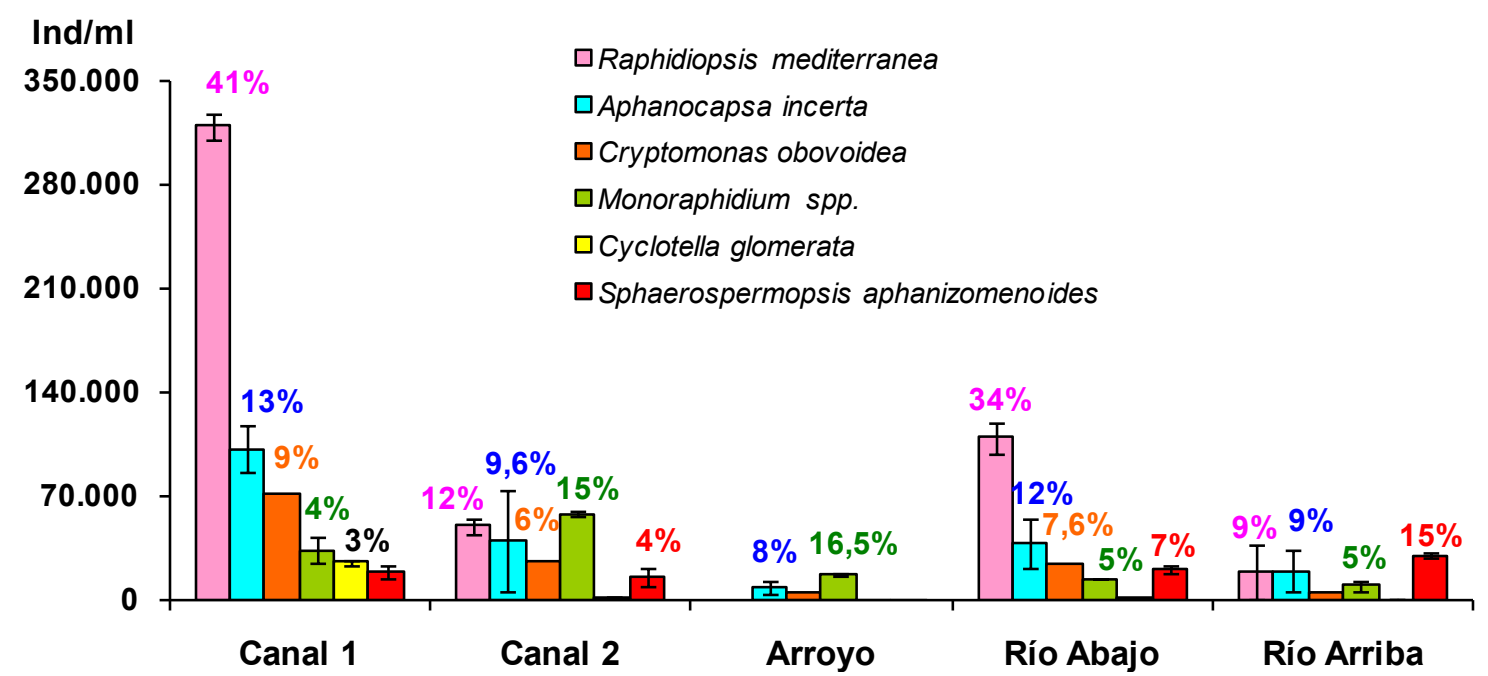

Figura 4.20: Abundancia total de las especies dominantes de fitoplancton en caudales medios (marzo 2008). Se muestran los valores promedio (días 1 y 2), sus rangos de valores (máximos y mínimos), y los porcentajes de contribución de cada especie a la abundancia total de fitoplancton hallados por sitio de muestreo.

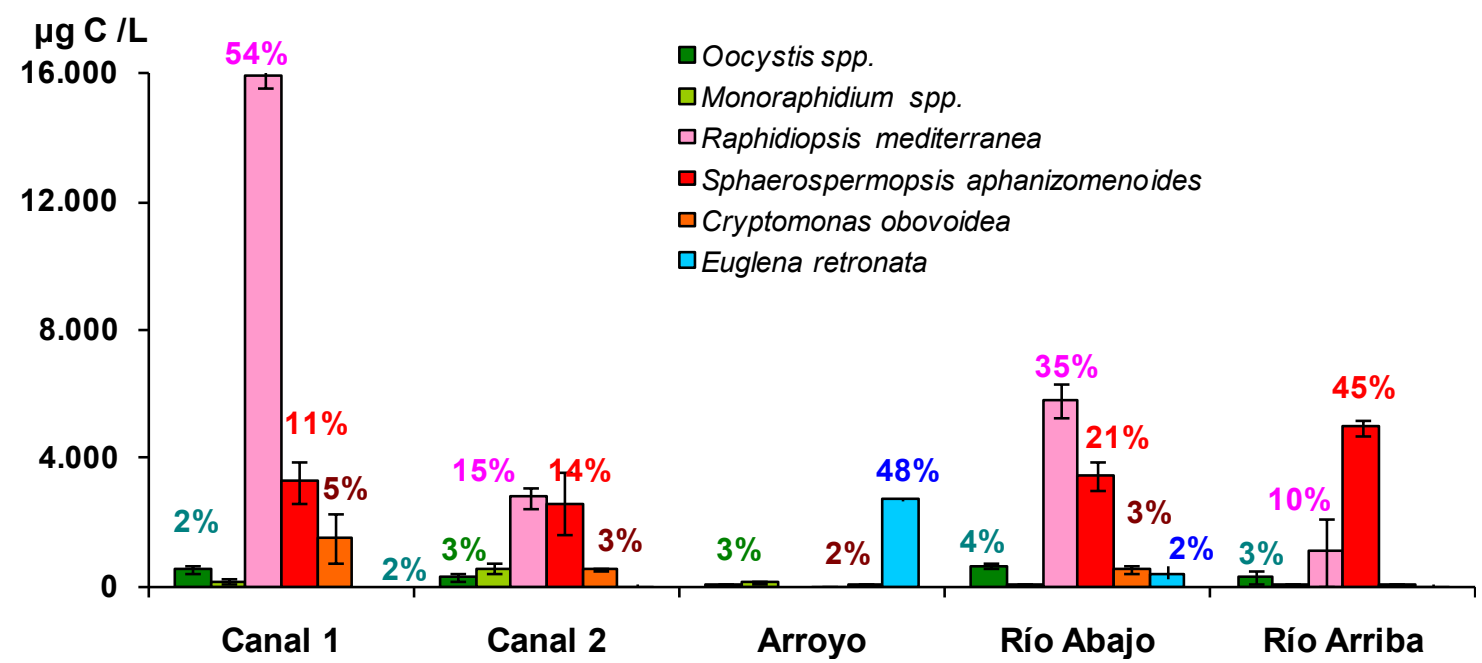

Figura 4.21: Biomasa total de las especies dominantes de fitoplancton en caudales medios (marzo 2008). Se muestran los valores promedio (días 1 y 2), sus rangos de valores, y los porcentajes de contribución de cada especie a la abundancia total de fitoplancton hallados por sitio de muestreo.

En el río se observó el aumento de la densidad de Monoraphidium spp., Cryptomonas obovoidea y P. limnetica aguas abajo del trasvase del sistema Bragado, en detrimento de Aphanocapsa incerta, 
Cyclotella glomerata y Stephanodiscus sp. También se destacaron por su biomasa en aguas bajas, Planktolyngbya limnetica, Aphanocapsa incerta, Stephanodiscus sp., Pseudoschroederia robusta, Cryptomonas obovoidea y otras tales como: Geitlerinema amphibium, Melosira nummuloides, Surirella striatula, y Oocystis spp. (Fig. 4.23).

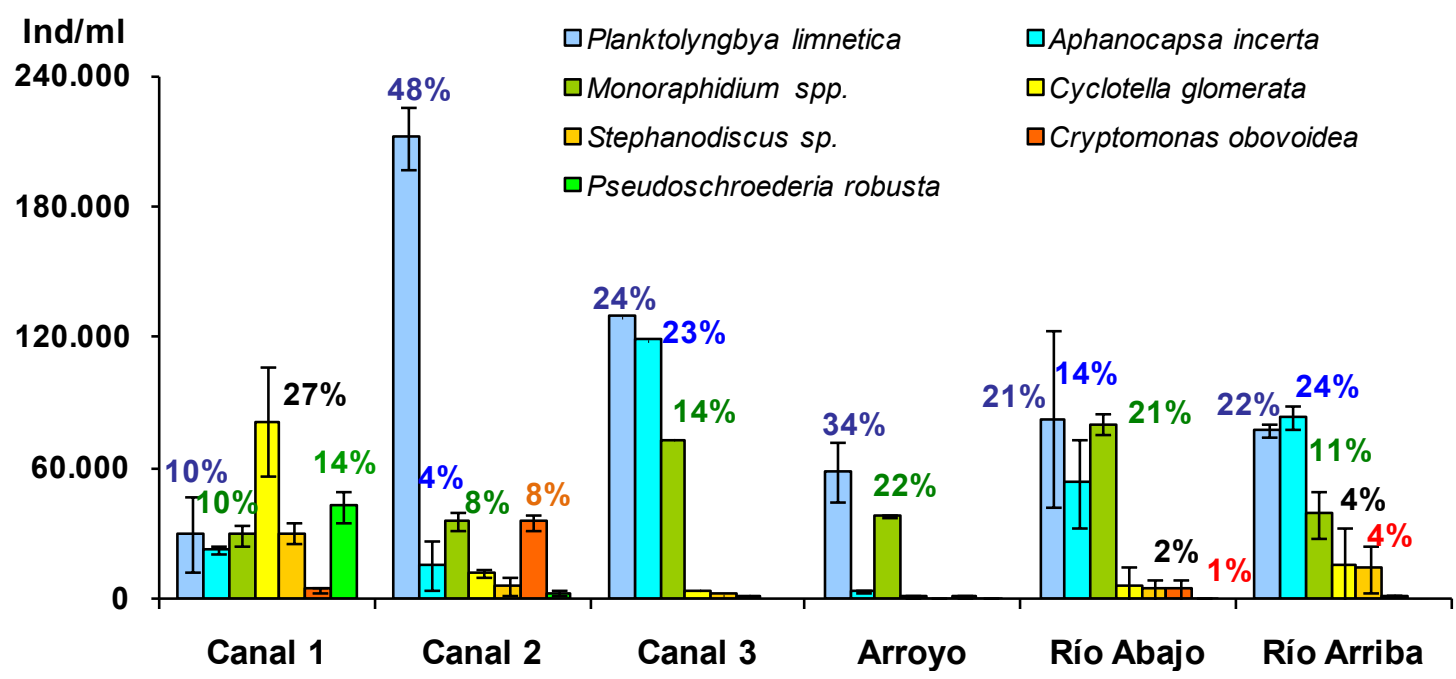

Figura 4.22: Abundancia total de las especies dominantes de fitoplancton en aguas bajas (noviembre 2008). Se muestran los valores promedio (días 1 y 2), sus rangos de valores (máximos y mínimos), y los porcentajes de contribución de cada especie a la abundancia total de fitoplancton hallados por sitio de muestreo.

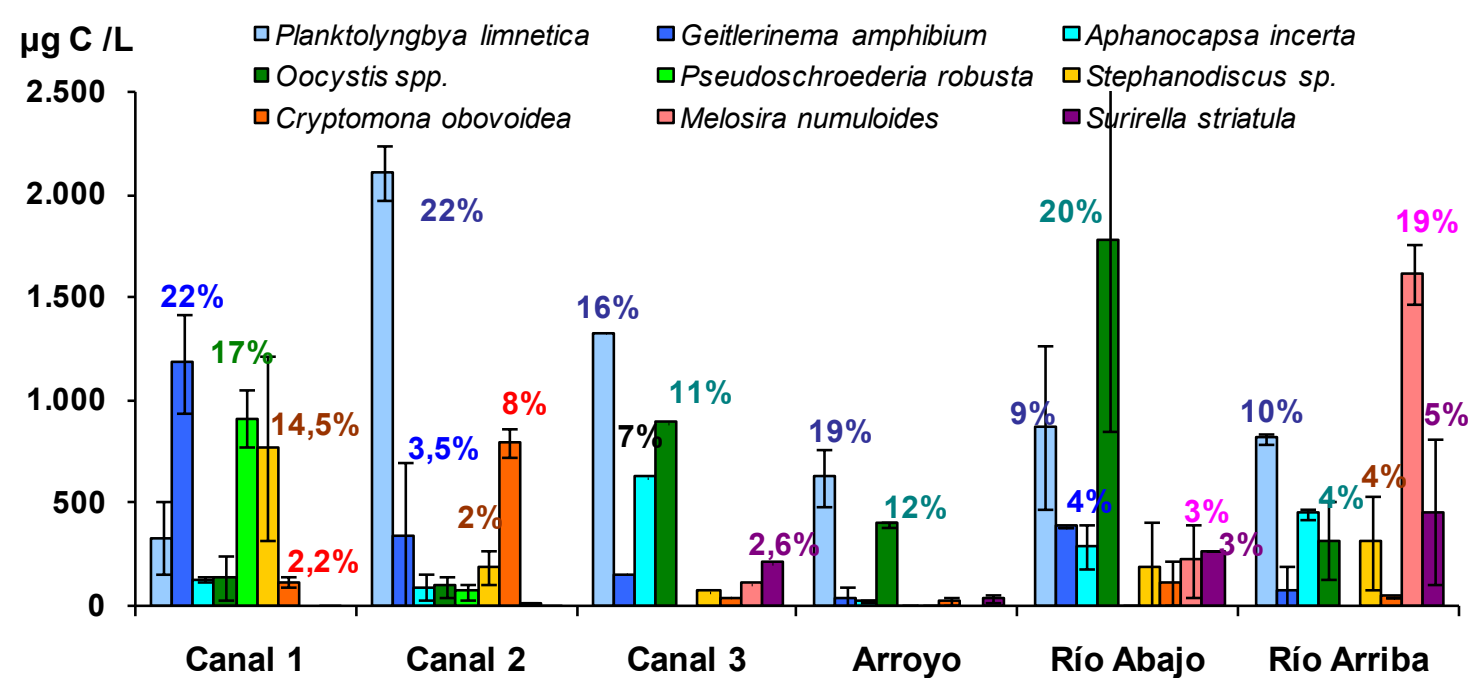

Figura 4.23: Biomasa total de las especies dominantes de fitoplancton en aguas bajas (noviembre 2008). Se muestran los valores promedio (días 1 y 2), sus rangos de valores, y los porcentajes de contribución de cada especie a la abundancia total de fitoplancton hallados por sitio de muestreo.

La suma de estas especies constituyó entre el 35 y 67\% de la biomasa total de fitoplancton, con valores extremos en el arroyo y el canal 1. P. limnetica dominó en los canales 2 y 3 y en el arroyo, y en el río fue subdominante. En el canal 2, también se destacó como subdominante la cianobacteria filamentosa Phormidium diguetii, siendo poco relevante en los restantes sitios de muestreo. G. amphibium dominó en el canal 1, seguida por la clorofita Pseudokirchneriella robusta y Stephanodiscus sp. Asimismo, G. amphibium también se halló en el sistema Bragado y en el río aguas abajo. 
Cryptomonas obovoidea se destacó como subdominante en el canal 2, y en menor medida en el canal 1 y en el río aguas abajo. Las clorofitas clorococcales del género Oocystis (O. parva, O. borgei, O. lacustris, O. solitaria, O. submarina y O. pusilla) también fueron subdominantes en los canales 2 y 3 , pero dominaron la biomasa en el río aguas abajo del trasvase. En el río se observó el aumento de la biomasa de G. amphibium, P. limnetica, C. obovoidea y Oocystis spp. aguas abajo del trasvase, y una tendencia opuesta en Melosira nummuloides, Stephanodiscus sp., Surirella striatula y A. incerta.

En aguas muy bajas (sept. 2009), Monoraphidium spp. dominaron la abundancia en los canales, siendo subdominante Planktolyngbya minor en el canal 1, el canal 3 y el arroyo, y las criptofitas Plagioselmis nannoplanctica y Komma caudata en el canal 2 (Fig. 4.24). En el río (caudales medios), se destacó por su densidad Actinastrum hatzschii, seguida por Monoraphidium spp., Cyclotella glomerata, Stephanodiscus sp. y Aphanocapsa incerta y Raphidiopsis mediterranea, en este orden de importancia. Otras especies de cianobacterias fueron relevantes en el arroyo y en el canal 1, como Synechococcus spp., Chroococcus spp., Planktolyngbya spp., Leptolyngbya spp., Romeria okensis y Spirulina abbreviata. En el río se registró un aumento en la densidad de Actinastrum hantzschii, A. incerta, P. minor, Plagioselmis nannoplanctica y Komma caudata aguas abajo del trasvase, a la vez que una disminución en la abundancia de Cyclotella glomerata y Stephanodiscus sp. y Raphidiopsis mediterranea.

En el sistema Bragado (aguas muy bajas), fueron relevantes por su biomasa Geitlerinema amphibium, Chroococcus spp. y Monoraphidium spp. (Fig. 4.25). Como especies subdominantes se hallaron Euglenaria caudata en el arroyo y las diatomeas Fragilaria spp. en el canal 3. En el canal 2, también se destacaron por su biomasa Nodularia spumigena y el género Chroococcus, integrado por las especies C. minutus, C. turgidus, C. dispersus, C. minimus, C. obliteratus y C. limneticus, y en menor medida Plagioselmis nannoplanctica y Komma caudata. En el río (caudales medios), dominaron la biomasa A. hantzschii, R. mediterranea y G. amphibium, seguida por Melosira nummuloides. En el sitio aguas abajo del trasvase se observó el aumento de la biomasa de Euglenaria caudata, A. hantzschii, Fragilaria spp. y M. numuloides, y lo opuesto para R. mediterranea y G. amphibium.

\subsubsection{Riqueza de especies y diversidad de fitoplancton}

En todas las condiciones hidrológicas, las clorofitas y las diatomeas fueron los grupos mejor representados, seguidos por las cianobacterias, las euglenofitas, las criptofitas y los dinoflagelados, en este orden de importancia. La diversidad de Simpson del fitoplancton fue máxima en aguas altas y mínima en aguas bajas, registrando variaciones según los sitios de muestreo en las restantes condiciones hidrológicas. En aguas altas, se identificaron 298 taxa de fitoplancton, y la riqueza de especies fue similar entre los sitios de muestreo (189-207 taxa), aunque hubo diferencias 
en la distribución de los grupos algales. Las clorofitas estuvieron mejor representadas en los canales, las diatomeas en el arroyo (66 taxa) y las cianobacterias en el canal 2 (48 taxa). Las euglenofitas registraron máximo nº de especies el canal 1 y el arroyo (14 taxa), seguido por el canal 2, donde se destacaron las especies de criptofitas (9 taxa). La diversidad de Simpson del fitoplancton fue mínima en los canales, y aumentó escalonadamente en el sistema Bragado, siendo máxima en el río aguas arriba (1/D=31), reduciendo su valor aguas abajo del trasvase (Fig. 4.26).

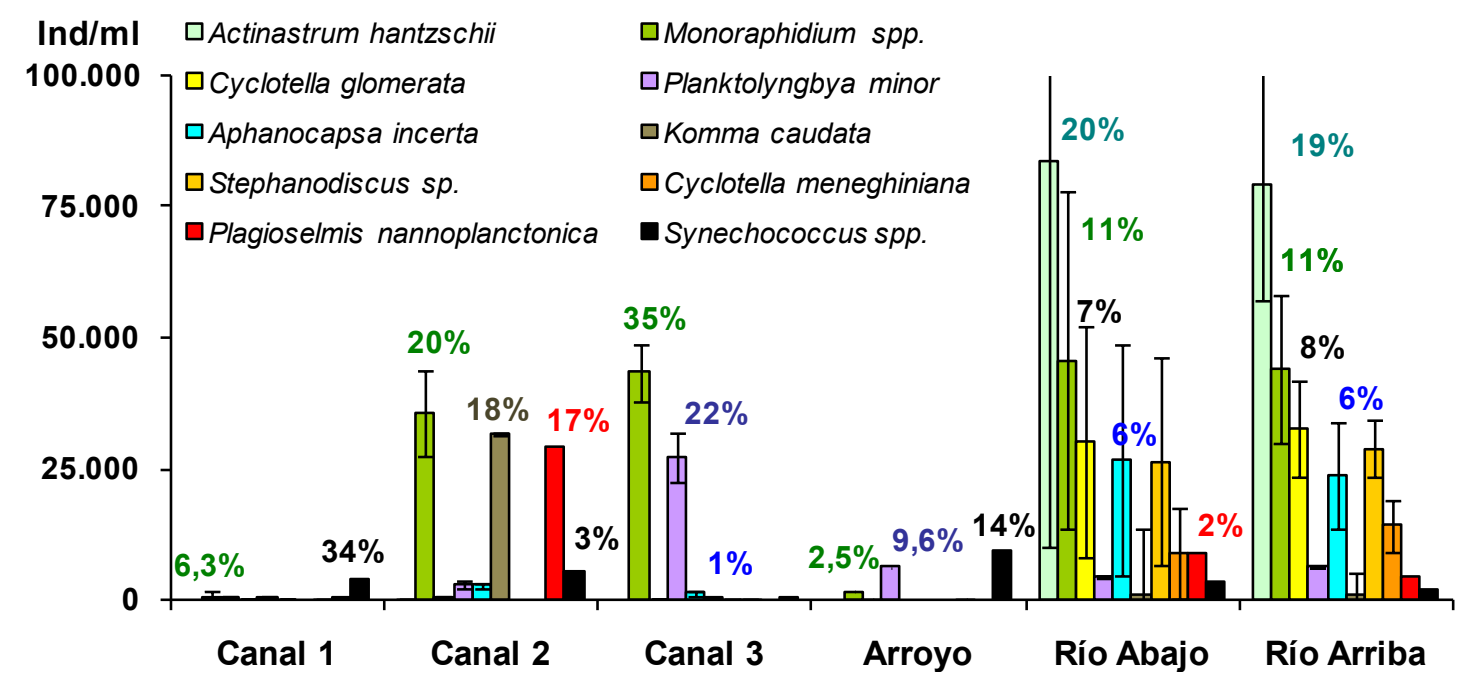

Figura 4.24: Abundancia total de las especies dominantes de fitoplancton en aguas muy bajas en el sistema Bragado pero con caudales medios en el río (sept. 2009). Se muestran los valores promedio (días 1 y 2), sus rangos de valores (máximos y mínimos), y los porcentajes de contribución de cada especie a la abundancia total de fitoplancton por sitio de muestreo.

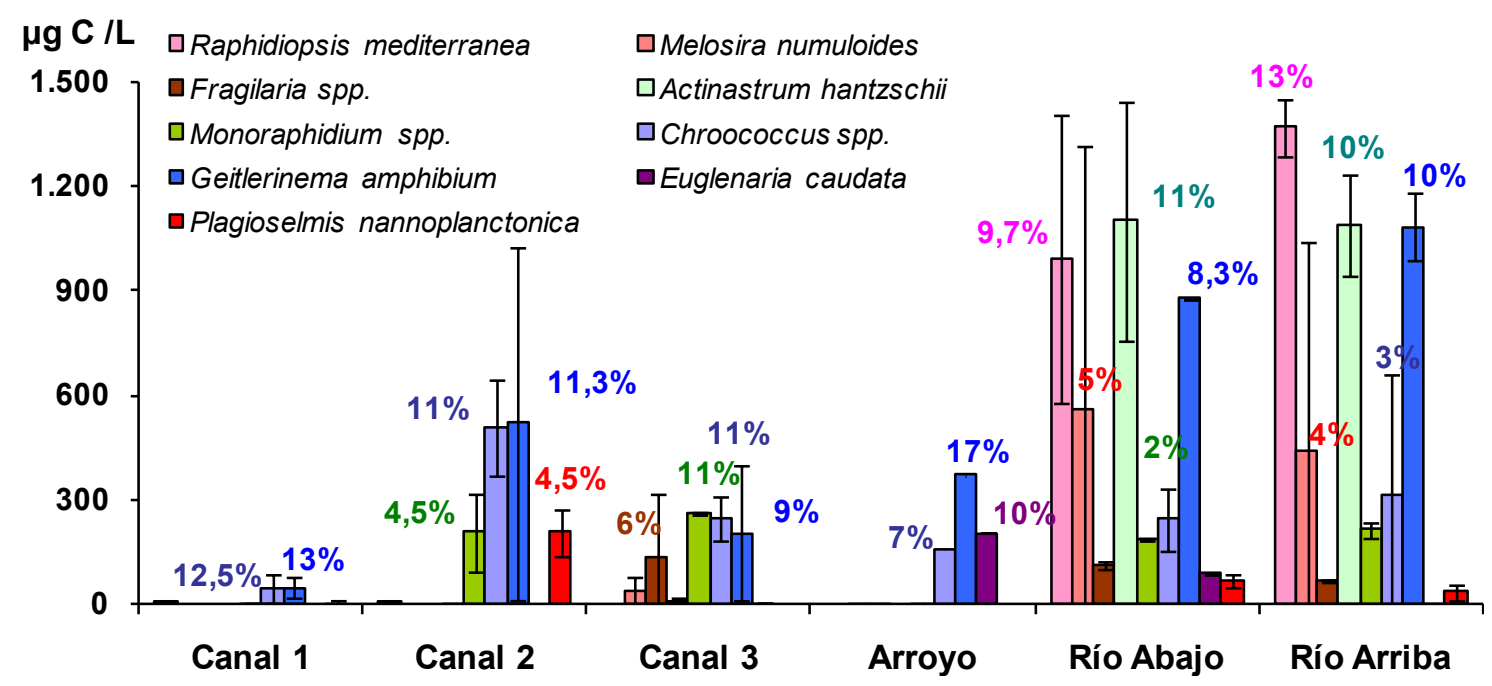

Figura 4.25: Biomasa total de las especies dominantes de fitoplancton en aguas muy bajas en el sistema Bragado pero con caudales medios en el río (septiembre 2009). Se muestran los valores promedio (días 1 y 2 ), sus rangos de valores y los porcentajes de contribución de cada especie a la abundancia total de fitoplancton por sitio de muestreo.

En caudales medios, también se identificaron 298 taxa de fitoplancton, con predominancia de las especies de clorofitas en la mayoría de los sitios de muestreo. En el canal 2 de destacaron por su riqueza las clorofitas (71 taxa), las cianobacterias (41 taxa), las criptofitas y los dinoflagelados. Las 
diatomeas fueron más diversas en el río aguas abajo (69 taxa), al igual que las euglenofitas (16 taxa), que triplicaron su riqueza respecto al río aguas arriba. En el canal 1 se registraron los valores mínimos de riqueza de especies y de diversidad de Simpson. En el río, la diversidad se redujo a la mitad aguas abajo del trasvase, a pesar del incremento en la riqueza específica. En aguas bajas, se identificaron 309 taxa de fitoplancton, entre las cuales se destacaron las clorofitas, las diatomeas y las cianobacterias por su riqueza específica en el río aguas abajo, y en los canales las euglenofitas, las criptofitas y los dinoflagelados, en este orden de importancia. En el río, la diversidad y de la riqueza de especies aumentó aguas abajo del trasvase, observándose la incorporación de 33 taxa (ausentes aguas arriba). De esta forma, la riqueza de especies fue máxima en el río aguas abajo (194 taxa), al igual que la diversidad. En el sistema Bragado se observaron los valores mínimos de riqueza específica (canal 1) y de diversidad (canal 2). En aguas muy bajas en el sistema Bragado pero con caudales medios en el río, se identificó un total de 286 taxa de fitoplancton. En el río se hallaron los valores máximos de riqueza (183 taxa) y de diversidad, destacándose por el no total de especies de clorofitas, diatomeas, cianobacterias y euglenofitas, particularmente en el sitio aguas abajo. En el arroyo y en el canal 1 se registraron los valores mínimos de riqueza específica y de diversidad, con predominancia de las especies de cianobacterias. En los restantes sitios de muestreo, las clorofitas fueron el grupo más diverso. Las criptofitas fueron relevantes por su riqueza específica en el canal 2 y en el río aguas arriba, y los dinoflagelados en los canales 2 y 3.

\subsubsection{Otras especies representativas del fitoplancton}

Además de las anteriormente mencionadas, otras especies del fitoplancton también fueron relevantes por su abundancia en los diferentes sitios y momentos de muestreo, tales como: las cianobacterias chroococcales coloniales Merismopedia warmingiana, M. tenuissima; las clorofitas clorococcales Kirchneriella spp. (K. aperta, K. irregularis, K. lunaris, K. microscopica, K. obesa, K. pseudoaperta), Scotiellopsis reticulata, Eutetramorus tetrasporus, Crucigenia quadrata, Crucigeniella rectangularis; las criptofitas Cryptomonas pusilla y Chroomonas coerulea; y las diatomeas Nitzschia palea, Planothidium delicatulum y Rossithidium linearis, estas últimas en especial en el arroyo. Se observaron algunos taxa peridineales y Gymnodinium spp, particularmente en los canales 1 y 2. En aguas altas, también fueron relevantes Aphanocapsa delicatissima, Chroococcus minutus, las clorofitas Hindakochloris nygaardii, Pseudodidymocystis fina, Chlamydomonas grovei y Planctonema lauterbornii. En el arroyo se observaron varios taxa de euglenofitas, entre ellas Monomorphina pyrum, Phacus pleuronectes y P. granum. 

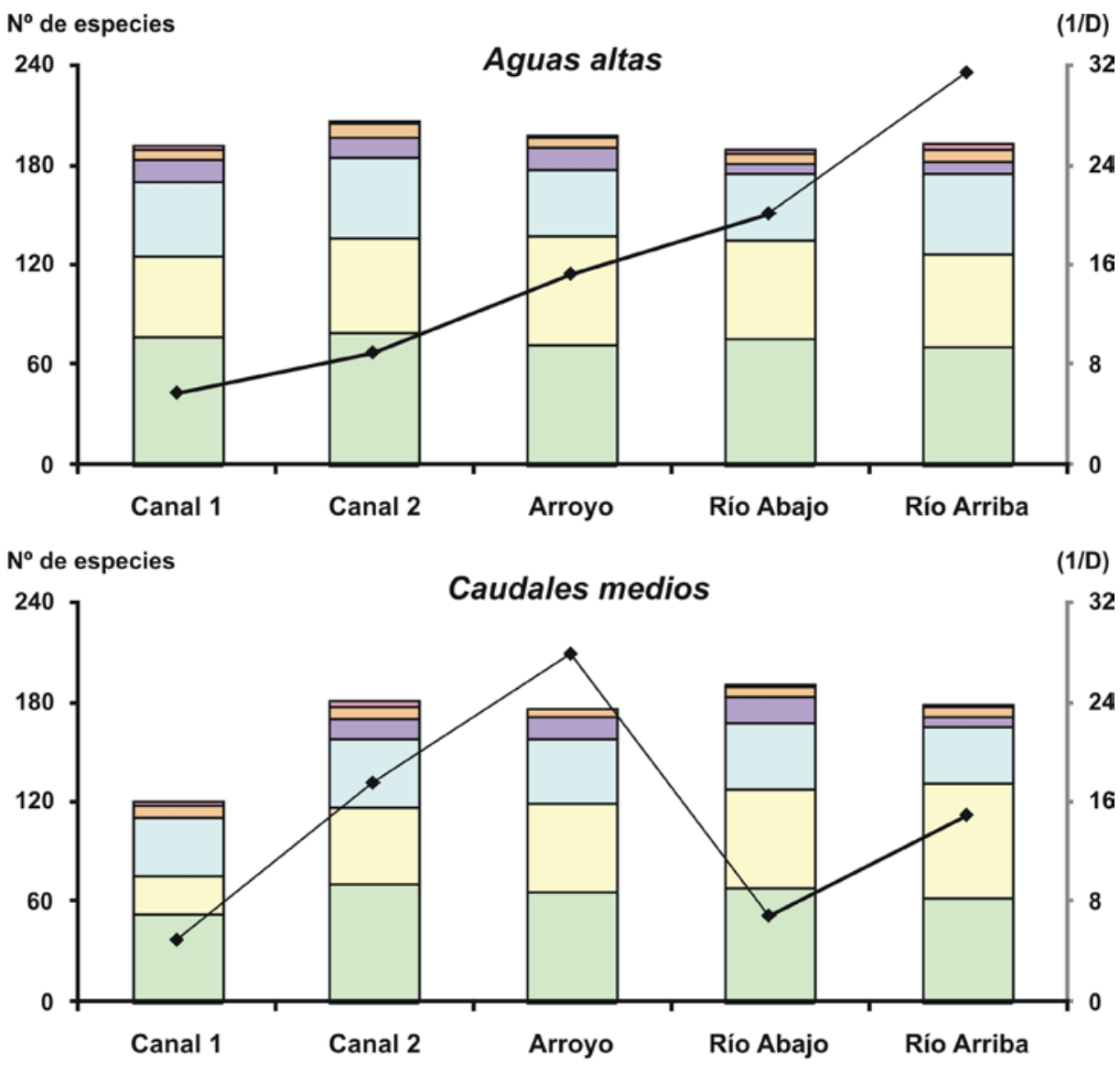

$N^{\circ}$ de especies
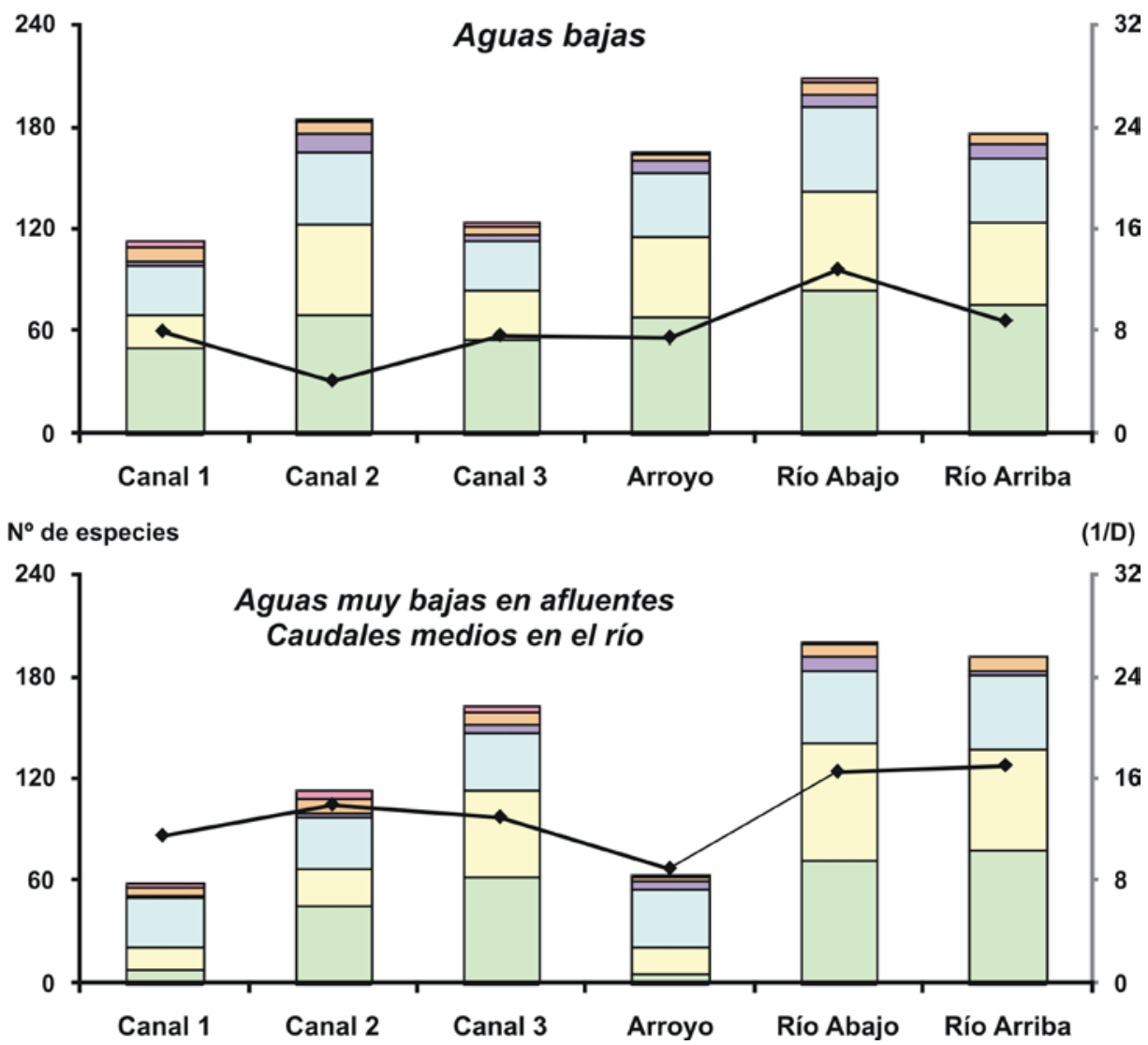

Figura 4.26: Riqueza de especies por grupo de fitoplancton (columnas) e índice de diversidad de Simpson (1/D) (línea negra). Referencias: cianobacterias (celeste), clorofitas (verde), diatomeas (amarillo), criptofitas (anaranjado), euglenofitas (lila) y dinoflagelados (rosado). Se muestran los valores promedio (días 1 y 2) por sitio de muestreo y condición hidrológica: aguas altas (mayo 2007), caudales medios (marzo 2008), aguas bajas (nov. 2008) y aguas muy bajas en afluentes pero con caudales medios en el río (sept. 2009). 
En caudales medios, también se destacaron las clorofitas Chlamydomonas epibiotica y C. grovei, Tetraedron minimun, Lagerheimia genevensis y L. subsalsa; las diatomeas Achnanthes microcephala (arroyo) y Chaetoceros sp. (canal 1). Entre las cianobacterias, también se observó a Planktolyngbya minor y P. limnetica, y a varias especies de Chroococcus (C. dispersus, C. limneticus, C. minimus, C. minutus, C. prescottii y C. turgidus). Otras criptofitas abundantes pertenecieron al género Rhodomonas, y entre las euglenofitas se observó Lepocinclis oxyuris y Euglena variabilis en el canal 2.

Otras especies relevantes por su abundancia en aguas bajas fueron las clorofitas Hindakochloris nygaardii, Schizochlamydella sphaerica y Chlamydomonas grovei; las diatomeas Planothidium lanceolata, Diploneis minuta y Synedra cyclopum; y las cianobacterias Merismopedia glauca, Chroococcus minutus, Microcystis aeruginosa y Phormidium granulatum. Entre las euglenofitas se observó a Monomorphina pyrum y Euglena oblonga en varios sitios de muestreo, a E. viridis en especial en el río, y a Lepocinclis acus y Phacus curvicauda en el arroyo.

En aguas muy bajas en el sistema Bragado pero con caudales medios en el río, también fueron relevantes Chlamydomonas grovei y C. epibiotica, Pseudoschroederia indica y Scenedesmus obliquus, y las diatomeas Melosira varians, Nitzschia fruticosa y Synedra cyclopum. Entre las cianobacterias también se observó a Raphidiopsis indica, Spirulina major y S. laxissima, y Komma caudata entre las criptofitas. Habitualmente se encontró a las euglenofitas Phacus granum y Strombomonas spp. en los diferentes sitios de muestreo, y Euglena proxima en el río Salado.

\subsubsection{Correlaciones exploratorias}

Se hallaron correlaciones positivas significativas $(p<0,05 ; \mathrm{r}>0,6)$ entre la clorofila $a$ y la turbidez, los SS, la MOP, la abundancia y biomasa total de fitoplancton y de los principales grupos (clorofitas, cianobacterias, diatomeas, criptofitas), e inversa con la transparencia. Se observaron correlaciones entre la temperatura y la abundancia total de fitoplancton, y de las cianobacterias y diatomeas. La densidad total de cada grupo estuvo relacionada con sus respectivos valores de biomasa, y la riqueza de especies con los polifenoles disueltos totales (Anexo II). También se hallaron correlaciones entre la abundancia total de las clorofitas con la dureza, y su biomasa con la MOP. La densidad total de las diatomeas estuvo correlacionada con la saturación de oxígeno. La abundancia y biomasa total de las criptofitas de manera inversa con la distancia hidrométrica, y lo mismo para la densidad de las cianobacterias y la diversidad de fitoplancton. Las principales especies de fitoplancton se correlacionaron positivamente con la clorofila a (Monoraphidium spp., Aphanocapsa incerta, Cyclotella glomerata y C. meneghiniana). Algunas de estas especies estuvieron correlacionadas con la MOP, la temperatura, turbidez, dureza, SS, conductividad, y la concentración de los iones $\mathrm{Na}^{+}, \mathrm{K}^{+}$y Cl- 


\subsection{Zooplancton}

\subsubsection{Abundancia y biomasa total de zooplancton}

La abundancia y biomasa total de zooplancton registró los valores máximos en el canal 2 en aguas bajas (nov. 2008), considerando todos lo sitios y momentos de muestreo. En el canal 1 se observaron los valores máximos en aguas altas (mayo 2007), y en el canal 3 y el arroyo en aguas bajas. En el río se observaron los valores máximos de biomasa en caudales medios (marzo 2008), pero el sitio aguas arriba se destacó por su abundancia en caudales medios (sept. 2009) mientras que el sitio agua abajo en aguas bajas.

En aguas altas (mayo 2007), los valores máximos de abundancia y biomasa total de zooplancton se observaron en el canal 1, siendo muy superiores a los valores hallados en los restantes sitios de muestreo. En el sistema Bragado se observó una tendencia decreciente en el canal 2 y el arroyo, registrando los valores mínimos en el río (Fig. 4.27). Por otro lado, los sitios del río registraron escasa variación en la abundancia total, pero la biomasa se duplicó aguas abajo del trasvase (Tabla A, Anexo VI).

En caudales medios (marzo 2008), los valores máximos de abundancia total de zooplancton se registraron en el canal 2, seguido por el río aguas abajo, aumentando respecto al sitio aguas arriba. Sin embargo, la biomasa registró una tendencia inversa, con valores máximos en el río aguas arriba, disminuyendo aguas abajo del trasvase. En el arroyo se observaron los valores mínimos, tanto en abundancia como biomasa (Tabla B, Anexo VI).

En aguas bajas (noviembre 2008), también se observaron los máximos de abundancia total de zooplancton en el canal 2 (47.000 ind/L), seguido por el arroyo y el río aguas abajo del trasvase, siendo los valores más altos registrados en estos sitios a lo largo de los muestreos. La biomasa total también fue máxima en el canal $2(4.840 \mu \mathrm{g} C / \mathrm{L})$, seguido por el canal 3 y el arroyo. En el canal 1 se observaron los valores mínimos de densidad y biomasa total. En el río aguas abajo se observó un marcado aumento de la densidad pero una reducción en la biomasa total (Tabla C, Anexo VI).

En aguas muy bajas en el sistema Bragado pero con caudales medios en el río (sept. 2009), la abundancia total de zooplancton fue máxima en el río aguas arriba y la biomasa en el canal 2. En el arroyo y en el canal 1 se observaron los valores mínimos. En el río aguas abajo disminuyó la abundancia y biomasa total de zooplancton, respecto al sitio aguas arriba (Tabla D, Anexo VI). 

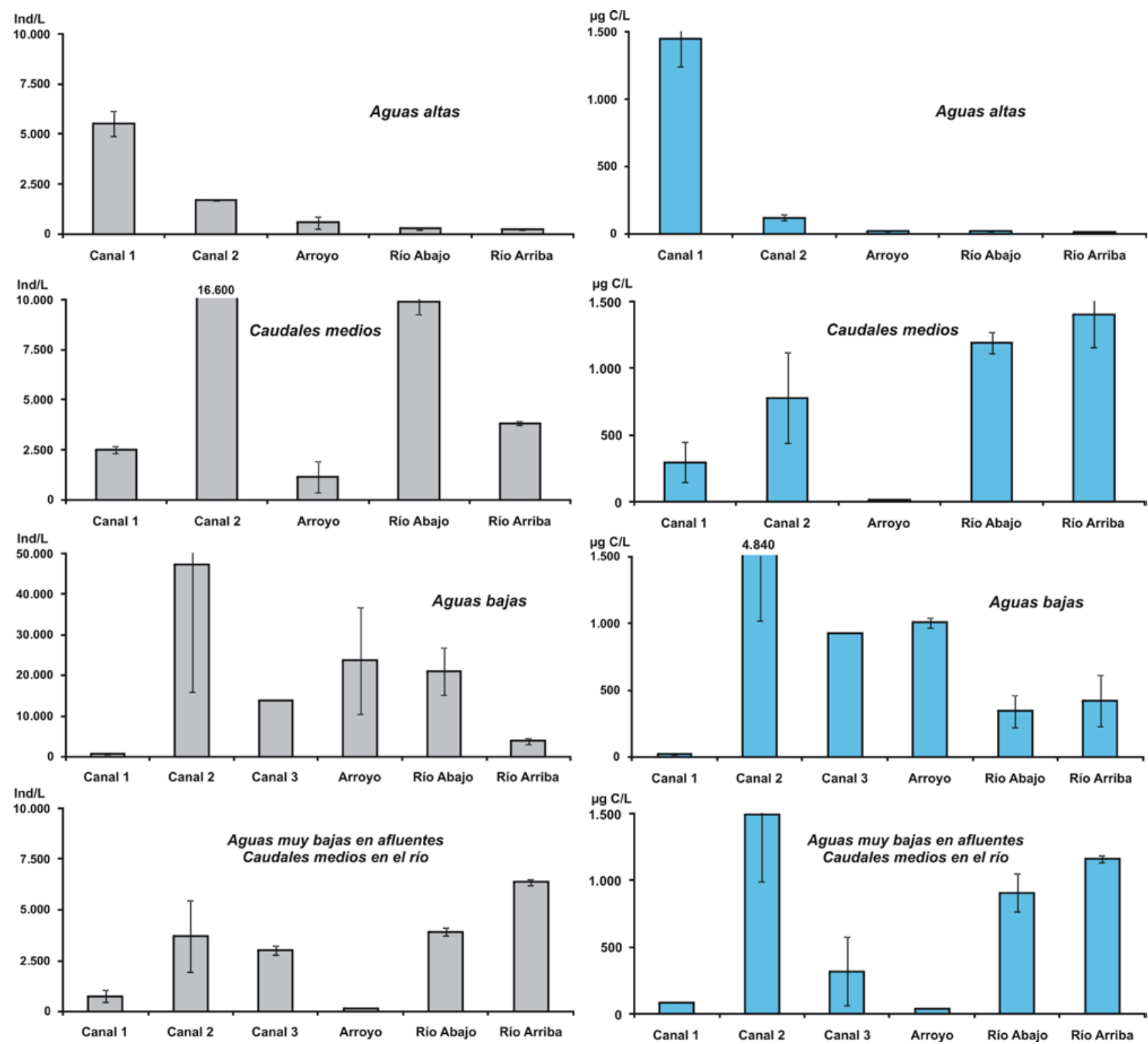

Figura 4.27: Abundancia y biomasa total de zooplancton. Se muestran los valores promedio (días 1 y 2) y sus rangos de valores (desvíos) por sitio de muestreo y condición hidrológica: aguas altas (mayo 2007), caudales medios (marzo 2008), aguas bajas (noviembre 2008) (con diferente escala), y aguas muy bajas en afluentes (sistema Bragado) con caudales medios en el río (septiembre 2009).

\subsubsection{Abundancia de los grupos de zooplancton}

En aguas altas, todos los grupos del zooplancton (rizópodos, ciliados, rotíferos, copépodos, cladóceros y ostrácodos) estuvieron mejor representados en el canal 1, disminuyendo su abundancia total en gran medida en el canal 2 y el arroyo, con los valores mínimos en el río (Fig. 4.28). Los rizópodos registraron picos de densidad en el canal 1 y en el río aguas arriba, pero la abundancia de los ostrácodos fue muy baja en todos los sitios de muestreo (4-10 ind/L). Los ciliados, cladóceros y copépodos aumentaron su abundancia en el río aguas abajo del trasvase, y lo opuesto se observó para los rizópodos y ostrácodos. Los rotíferos dominaron la abundancia relativa en todos los sitios de muestreo, principalmente en los canales (Fig. 4.29). Los ciliados constituyeron el segundo grupo en importancia en los canales y el arroyo, los rizópodos en el río 
aguas arriba, y los copépodos aguas abajo. Los cladóceros se destacaron en el canal 1 y en el río aguas abajo, al igual que los ostrácodos.

En caudales medios, los rotíferos y los ciliados presentaron picos de abundancia en el canal 2 y el río aguas abajo, los cladóceros y los ostrácodos en el río aguas arriba, y los rizópodos en ambos sitios del río, siendo mínima su presencia en el sistema Bragado. En el río se observó el aumento de los rotíferos y los ciliados en el sitio aguas abajo, en detrimento de los cladóceros, los copépodos y los ostrácodos. Los ciliados dominaron la abundancia relativa en el arroyo y en el canal 1, y los rotíferos en el canal 2 y en el río, particularmente aguas abajo del trasvase.

En aguas bajas, los rotíferos fueron relevantes por su abundancia en el canal 2 (42.300 ind/L), seguido por el río aguas abajo del trasvase (19.800 ind/L). Los ciliados se destacaron en el arroyo (9.300 ind/L), y en el canal 2. En el canal 1 se observaron los valores mínimos de abundancia, con similar proporción de rotíferos y ciliados. Los copépodos y los cladóceros predominaron en el río aguas arriba, los ostrácodos se destacaron en el río aguas abajo y los rizópodos en el canal 3 y el arroyo. En el río, se observó el aumento de los rotíferos, ciliados y ostrácodos aguas abajo del trasvase, a la vez que la disminución de la densidad de copépodos y cladóceros. Los rotíferos dominaron la abundancia relativa en todos los sitios de muestreo (49-94\%), seguidos por los ciliados, principalmente en los canales. Los copépodos, cladóceros, rizópodos y ostrácodos sólo se destacaron por su abundancia relativa en el río aguas arriba, en este orden de importancia.

En aguas muy bajas en el sistema Bragado pero con caudales medios en el río, los ciliados registraron picos de abundancia en el río aguas arriba, seguido por el sitio aguas abajo y el canal 3. Los rotíferos y los copépodos se destacaron por su abundancia total y relativa en el canal 2. Los rizópodos sólo fueron relevantes en el canal 3 y en el río aguas abajo, los cladóceros en este último sitio, y los ostrácodos en el río aguas arriba. En el arroyo se observaron los valores mínimos de abundancia de todos los grupos. En el canal 1 dominaron la abundancia relativa los rotíferos y los ciliados. Los ciliados dominaron en el arroyo, el canal 3 y el río, en este orden de importancia.

\subsubsection{Biomasa de los grupos de zooplancton}

La biomasa de los diferentes grupos del zooplancton siguió la misma tendencia que la densidad, registrando los valores mínimos en aguas altas (mayo 2007) y los máximos en aguas bajas (nov. 2008), a excepción del canal 1 (Fig. 4.30). En aguas altas, los cladóceros, copépodos, ciliados y rotíferos se destacaron por su biomasa en el canal 1, pero decrecieron en gran medida en el canal 2 y el arroyo, registrando los valores mínimos en el río. En el río, se destacaron por su biomasa los cladóceros y copépodos, aumentando aguas abajo, al igual que los rotíferos. 

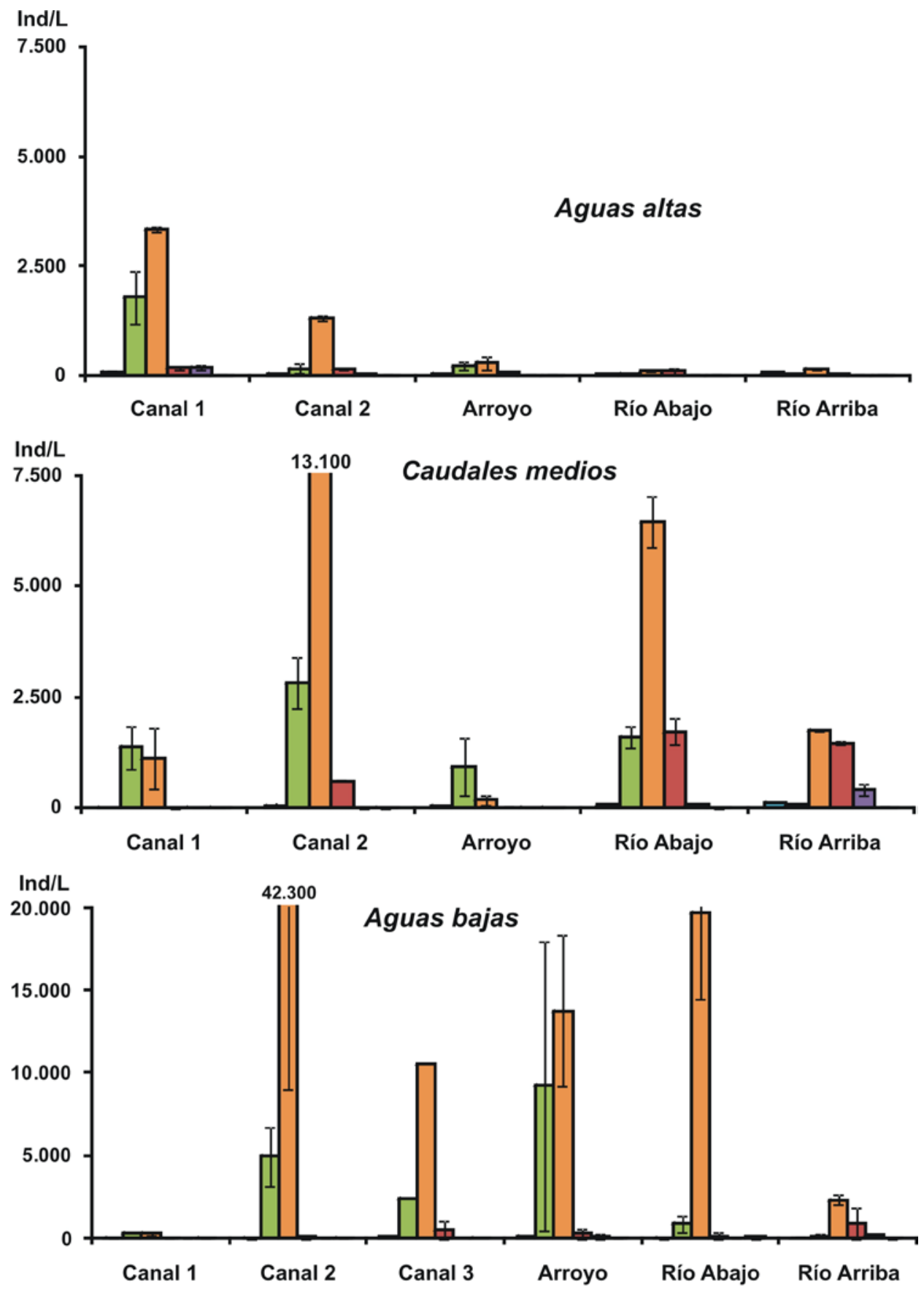

Ind/L

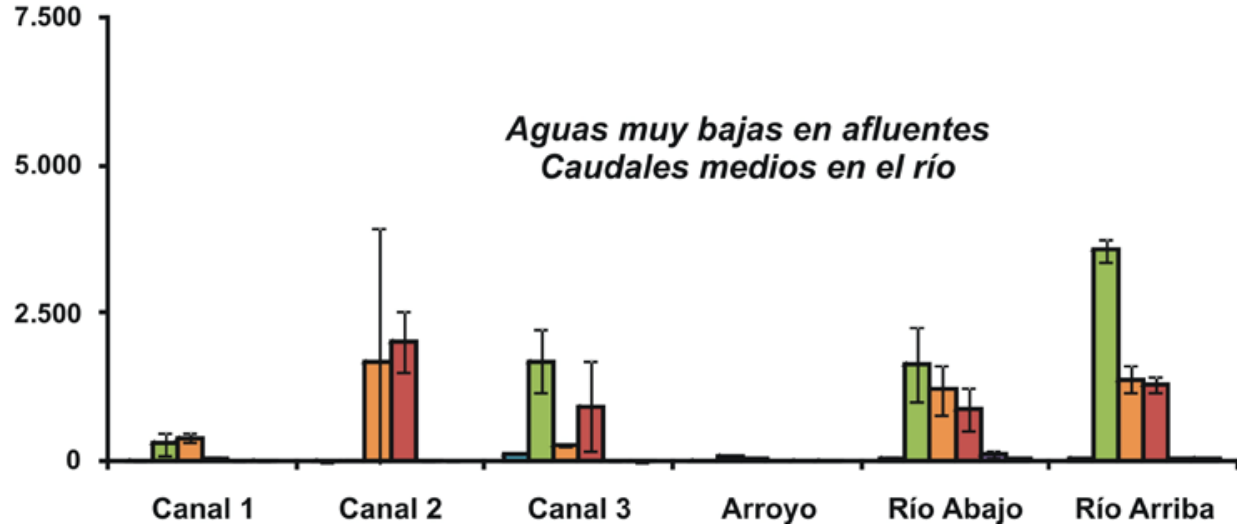

Figura 4.28: Abundancia total de los grupos de zooplancton (Ind/L). Referencias: ciliados (columna verde), rotíferos (anaranjado), copépodos (rojo), rizópodos (celeste), ostrácodos (rosado) y cladóceros (violeta). Se muestran los valores promedio (días 1 y 2) y sus rangos de valores, por sitio de muestreo y condición hidrológica: aguas altas (mayo 2007), caudales medios (marzo 2008), aguas bajas (nov. 2008) (con otra escala), y aguas muy bajas en afluentes (sistema Bragado) con caudales medios en el río (sept. 2009). 

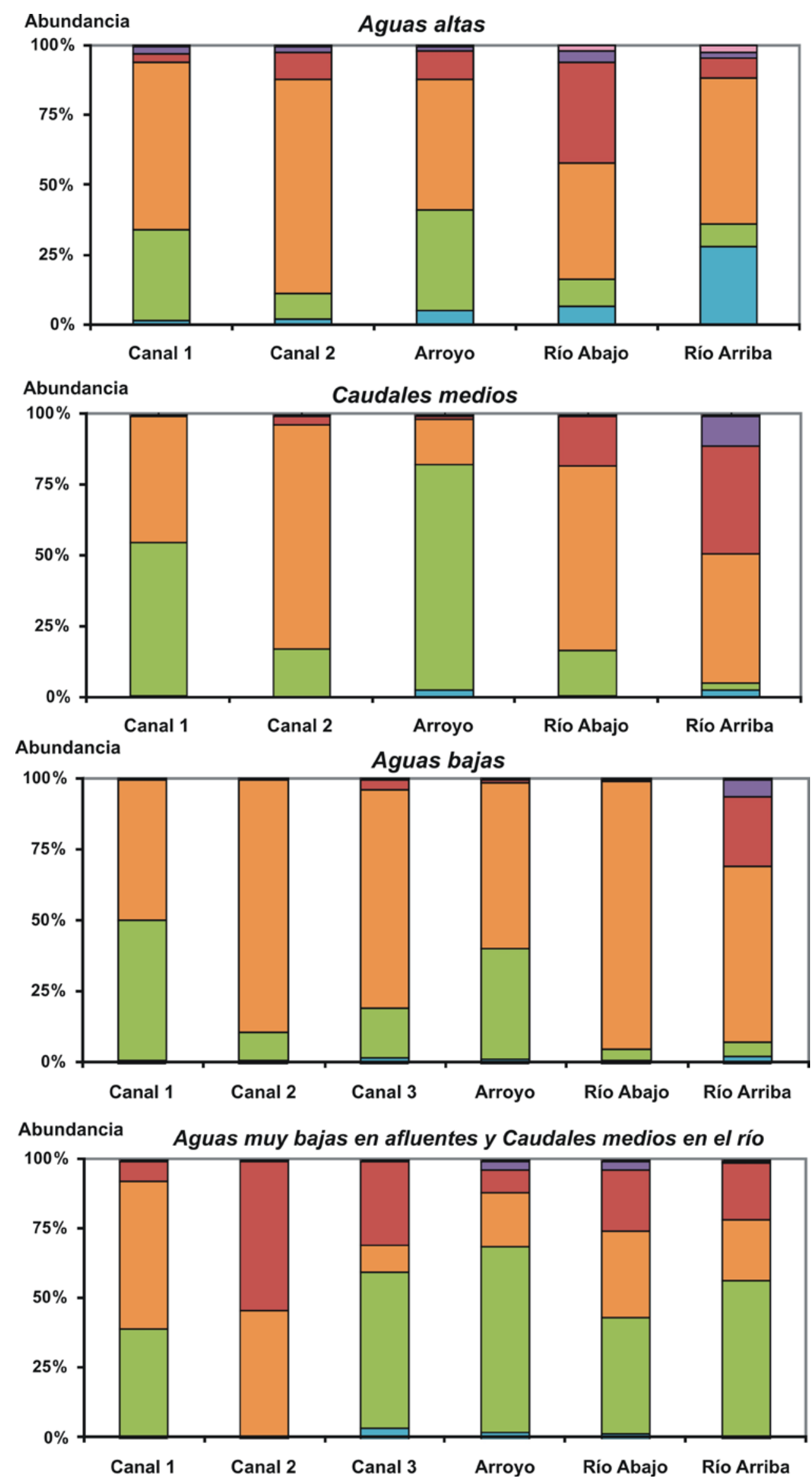

Figura 4.29: Abundancia relativa de los grupos de zooplancton $(\mu \mathrm{g} C / \mathrm{L})$. Referencias: ciliados (columna verde), rotíferos (anaranjado), copépodos (rojo), rizópodos (celeste), ostrácodos (rosado) y cladóceros (violeta). Se muestran los valores promedio (días 1 y 2) por sitio de muestreo y condición hidrológica: aguas altas (mayo 2007), caudales medios (marzo 2008), aguas bajas (nov. 2008) y aguas muy bajas en afluentes (sistema Bragado) con caudales medios en el río (sept. 2009). 
En aguas altas, la biomasa relativa dominada por los cladóceros en los canales 1 y 2 y el río aguas arriba, y por los copépodos en el arroyo y en el río aguas abajo del trasvase. Los ciliados constituyeron el tercer grupo en importancia en el canal 1 y el arroyo, y los rotíferos sólo se destacaron en el canal 2 (Fig. 4.31).

En caudales medios, los rotíferos y los ciliados se destacaron por su biomasa en el canal 2, y los cladóceros en el río aguar arriba. Los ciliados también fueron relevantes en el canal 1 y en el río aguas abajo del trasvase. Los copépodos dominaron la biomasa absoluta y relativa en el río, con escasa variación entre sitios. En el arroyo se observaron los valores mínimos de biomasa de todos estos grupos. En el río aguas abajo se observó el aumento de la biomasa de los ciliados y los rotíferos, en detrimento de los cladóceros. La biomasa relativa estuvo dominada por los rotíferos en los canales, seguido por los ciliados, que se destacaron en el arroyo. Los copépodos predominaron en el río, y como grupos subdominantes se hallaron los cladóceros (aguas arriba) y los rotíferos (aguas abajo).

En aguas bajas, los rotíferos se destacaron por su biomasa en el canal 2 (4.415 $\mu \mathrm{g} \mathrm{C/L})$, al igual que los ciliados. Los copépodos fueron relevantes en el canal 3, los cladóceros en el arroyo, y ambos grupos también se destacaron en el río aguas arriba. En el canal 3 se observaron similares valores de biomasa para copépodos, cladóceros y rotíferos. Todos los grupos registraron los valores mínimos de biomasa en el canal 1. En el río aguas abajo se observó el aumento de la biomasa de los rotíferos y ciliados, y una disminución en los copépodos (5,3 veces) y cladóceros (33 veces), respecto al sitio aguas arriba. Los rotíferos dominaron la biomasa relativa en el sistema Bragado y en el río aguas abajo del trasvase, particularmente en el canal 2 (90\%), y los ciliados fueron subdominantes, salvo en el canal 3. En el río aguas arriba dominaron los copépodos, seguidos por los rotíferos y los cladóceros.

En aguas muy bajas en el sistema Bragado pero con caudales medios en el río, los copépodos dominaron la biomasa absoluta y relativa de todos los sitios de muestreo, a excepción del arroyo, donde prevalecieron los ciliados. La biomasa de los copépodos y los rotíferos fue máxima en el canal 2, y mínima en el arroyo y el canal 1(aguas muy bajas). En el río (caudales medios), se destacaron los copépodos, cladóceros y ciliados, particularmente en el sitio aguas arriba, disminuyendo aguas abajo. A pesar de estos cambios, la biomasa relativa de los grupos de zooplancton fue similar en ambos sitios de río. 
$\mu \mathrm{g} \mathrm{C/L}$

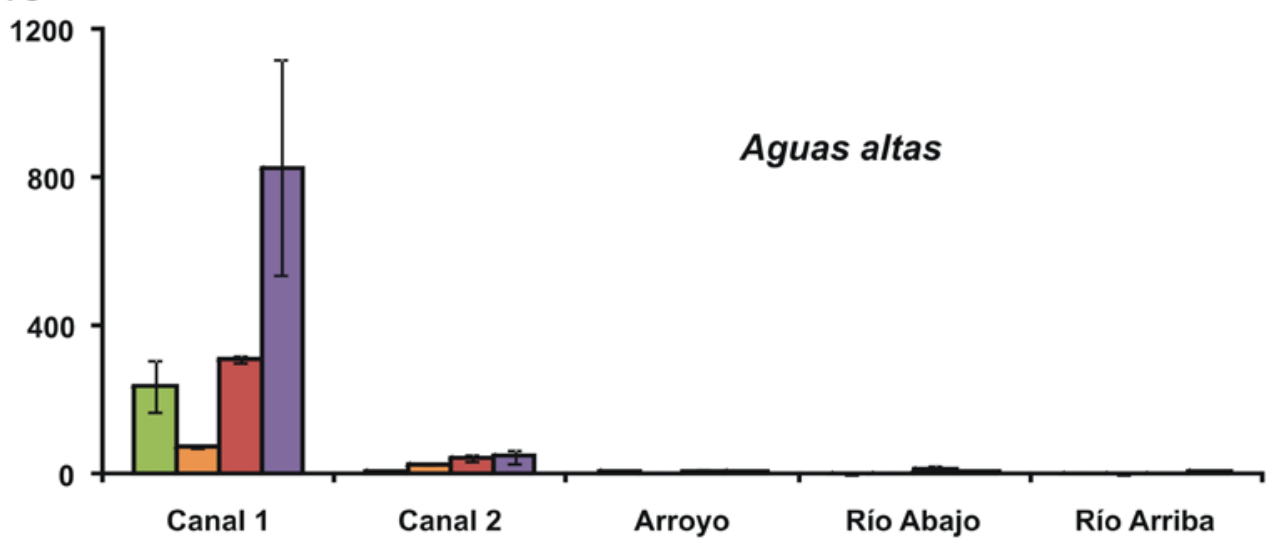

$\mu \mathrm{g} \mathrm{C/L}$
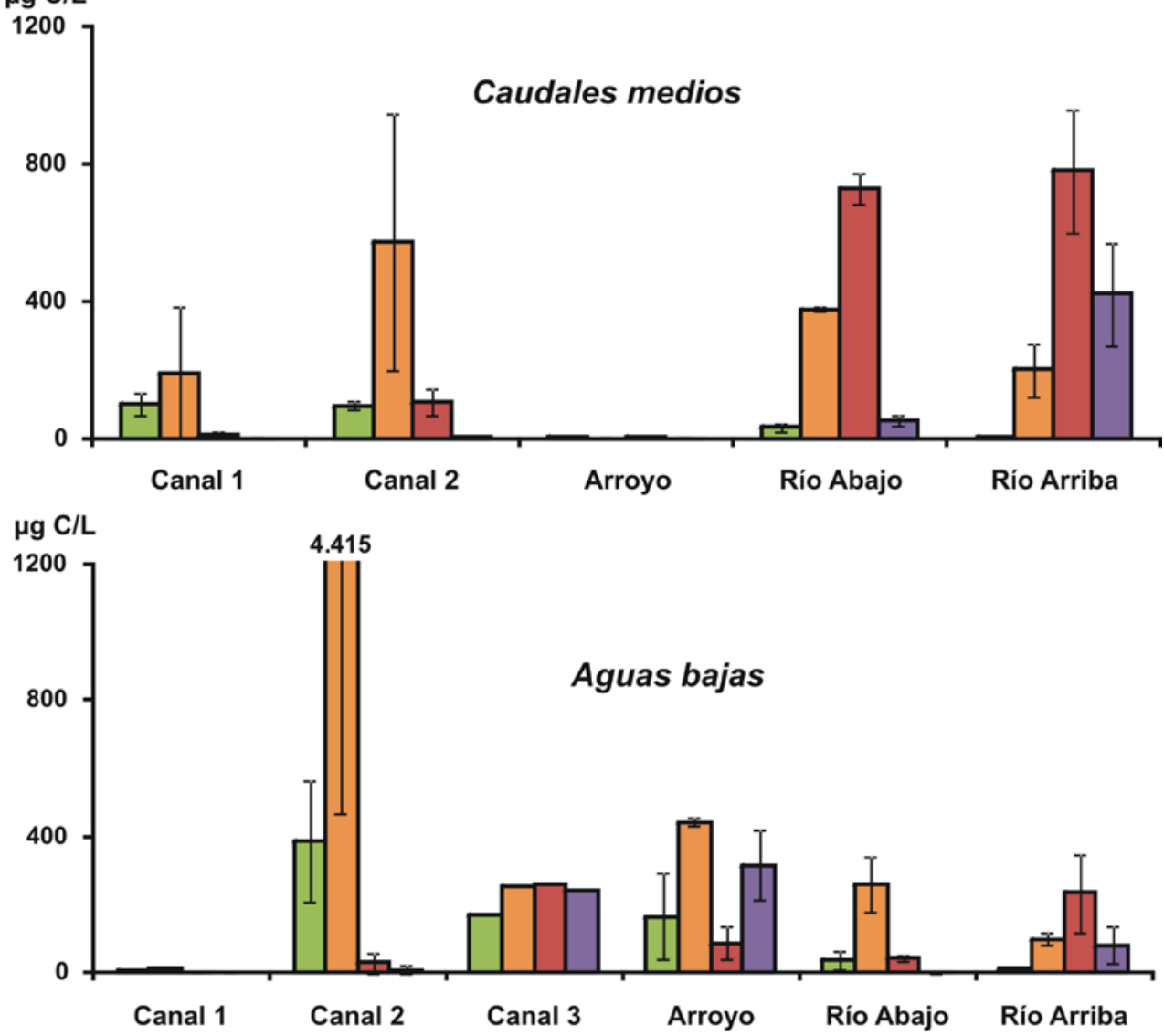

$\mu \mathrm{g} \mathrm{C/L}$

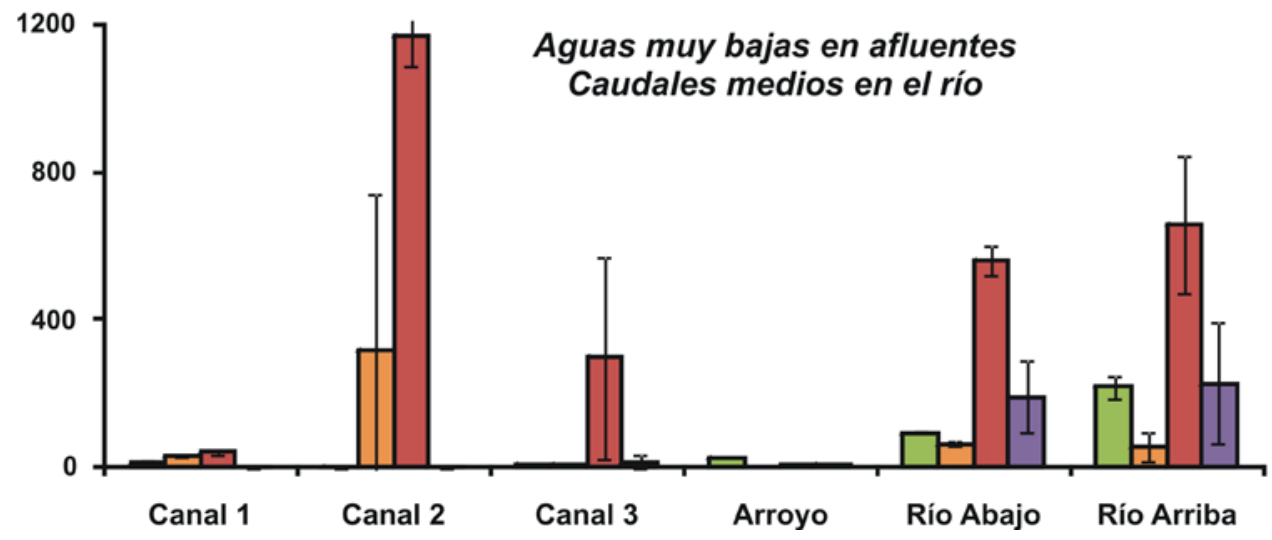

Figura 4.30: Biomasa total de los grupos de zooplancton $(\mu \mathrm{g} \mathrm{C} / \mathrm{L})$. Referencias: ciliados (columna verde), rotíferos (anaranjado), copépodos (rojo) y cladóceros (violeta). Se muestran los valores promedio (días 1 y 2 ) y sus rangos de valores, por sitio de muestreo y condición hidrológica: aguas altas (mayo 2007), caudales medios (marzo 2008), aguas bajas (nov. 2008) y aguas muy bajas en afluentes (sistema Bragado) con caudales medios en el río (sept. 2009). 

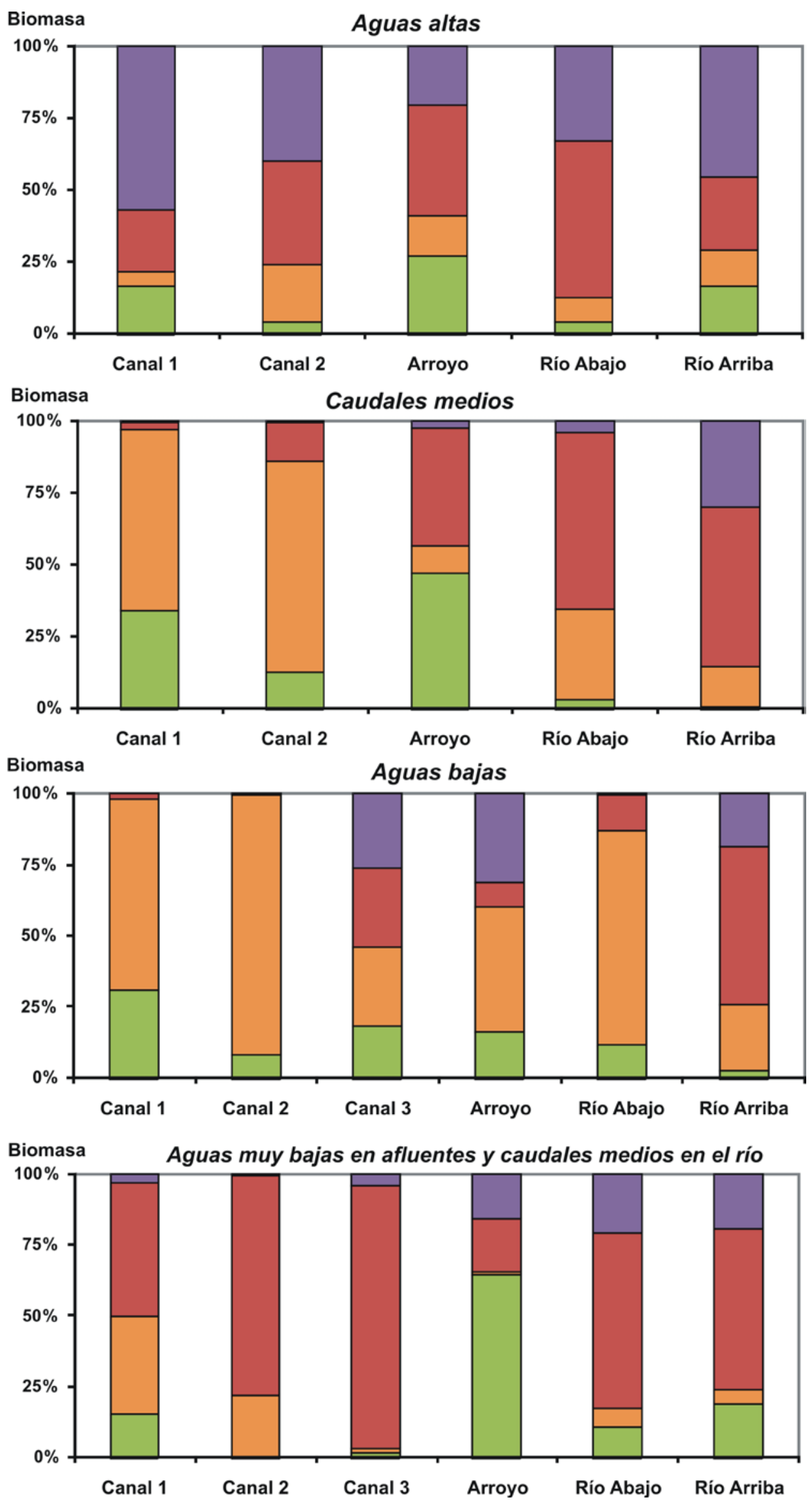

Figura 4.31: Biomasa relativa de los grupos de zooplancton ( $\mu \mathrm{g} C / \mathrm{L}$ ). Referencias: ciliados (columna verde), rotíferos (anaranjado), copépodos (rojo) y cladóceros (violeta). Se muestran los valores promedio (días 1 y 2 ) por sitio de muestreo y condición hidrológica: aguas altas (mayo 2007), caudales medios (marzo 2008), aguas bajas (nov. 2008) y aguas muy bajas en afluentes (sistema Bragado) con caudales medios en el río (sept. 2009). 


\subsubsection{Abundancia y biomasa de las principales especies}

En aguas altas, se destacó por su abundancia el rotífero Keratella tropica, particularmente en el canal 1 (3.000 ind/L), pero decreció a lo largo del sistema Bragado y registró los valores mínimos en el río, sin variaciones entre sitios (Fig. 4.32). En el canal 1 también fueron abundantes los ciliados Stentor sp1 y sp2, seguidos por el cladócero Daphnia spinulata y el copépodo Acanthocyclops robustus. En el canal 2 se destacaron los rotíferos Synchaeta pectinata y Brachionus plicatilis, los cuales aumentaron su abundancia en el río, aguas abajo del trasvase. El rizópodo Arcella hemisphaerica se destacó en el canal 1 y en el río aguas arriba, disminuyendo su densidad aguas abajo.

En aguas altas, Daphnia spinulata dominó la biomasa en el canal 1, seguido por Daphnia obtusa y A. robustus, pero todas estas especies disminuyeron abruptamente sus valores en el canal 2 y en los restantes sitios (Fig. 4.33). En orden decreciente, se destacaron por su biomasa Stentor sp1 y sp2 y Keratella tropica, que disminuyeron su importancia a lo largo del sistema Bragado, mientras que Acineta sp., sólo estuvo presente en el canal 1. El cladócero Ceriodaphnia cf. dubia fue la especie dominante del canal 2, el arroyo y el río aguas arriba. Los copépodos Metacyclops mendocinus y Notodiaptomus incompositus se destacaron por su biomasa en los canales, y N. incompositus dominó la biomasa en el río aguas abajo, registrando bajos valores en el sitio aguas arriba.

En caudales medios (marzo 2008), se destacaron por su abundancia los rotíferos Brachionus plicatilis, B. angularis, Trichocerca pusilla, Proalides sp1, Proalides sp2, y Synchaeta pectinata, en el canal 2 y en el río aguas abajo (Fig. 4.34). Entre estas especies, B. plicatilis fue dominante en el canal 2 y en el río, seguido por B. angularis; y ambas especies aumentaron su abundancia en el río aguas abajo del trasvase. Trichocerca pusilla y Proalides sp2 sólo se destacaron en el canal 2. En el canal 1 se destacó Synchaeta pectinata, y en menor medida en el canal 2, el arroyo y en el río aguas abajo. Entre los ciliados, Stentor sp1 se destacó en el canal 1 y en el río aguas abajo, estando ausente aguas arriba. Epistylis sp1 fue la especie dominante del arroyo, pero presentó picos de abundancia en el canal 2. Ambas especies de ciliados aumentaron en gran medida en el río aguas abajo del trasvase, al igual que el rotífero Proalides sp1. Las especies Acanthocyclops robustus, Alona glabra y Moina micrura se destacaron en el río aguas arriba, disminuyeron su densidad aguas abajo.

En caudales medios, Brachionus plicatilis se destacó por su biomasa en el canal 2, y en el río fue subdominante, aumentando en el sitio aguas abajo del trasvase (Fig. 4.35). El ciliado Prorodon sp2 fue relevante por su biomasa en el canal 2, pero constituyó la especie dominante del arroyo. Stentor spp. se destacaron en el canal 1, pero la especie dominante fue el rotífero depredador Asplanchna brigthwellii. En el río dominó Achantocyclops robustus, y como especies subdominantes se hallaron el cladócero Moina micrura (aguas arriba) y Brachionus plicatilis (aguas abajo), con un importante 
aumento y disminución de sus valores entre los sitios del río, respectivamente. Otras especies relevantes en el río aguas arriba fueron el copépodo Metacyclops mendocinus y el cladócero Alona graba, y en el sitio aguas abajo Microcyclops alius y Paracyclops fimbriatus.

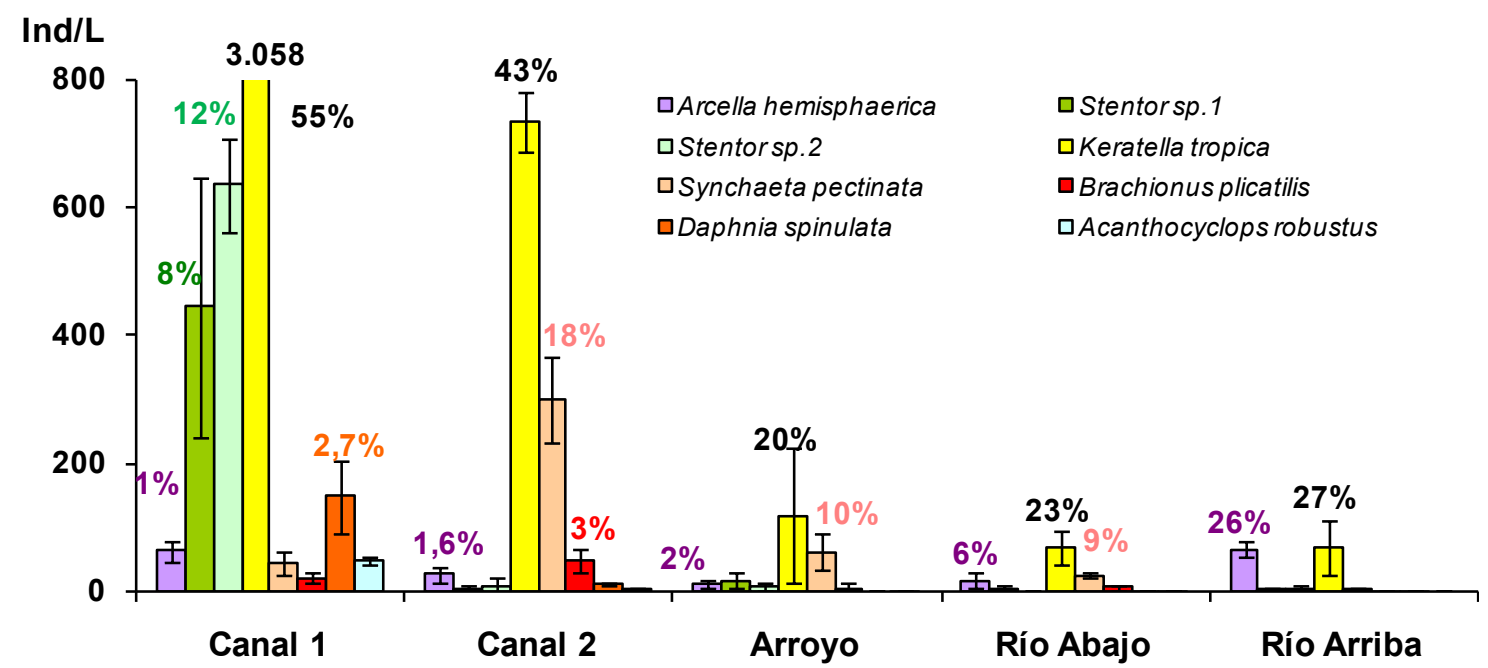

Figura 4.32: Abundancia total de las especies dominantes de zooplancton en aguas altas (mayo 2007). Se muestran los valores promedio (días 1 y 2), sus rangos de valores, y los porcentajes de contribución de cada especie a la abundancia total de zooplancton hallados por sitio de muestreo.

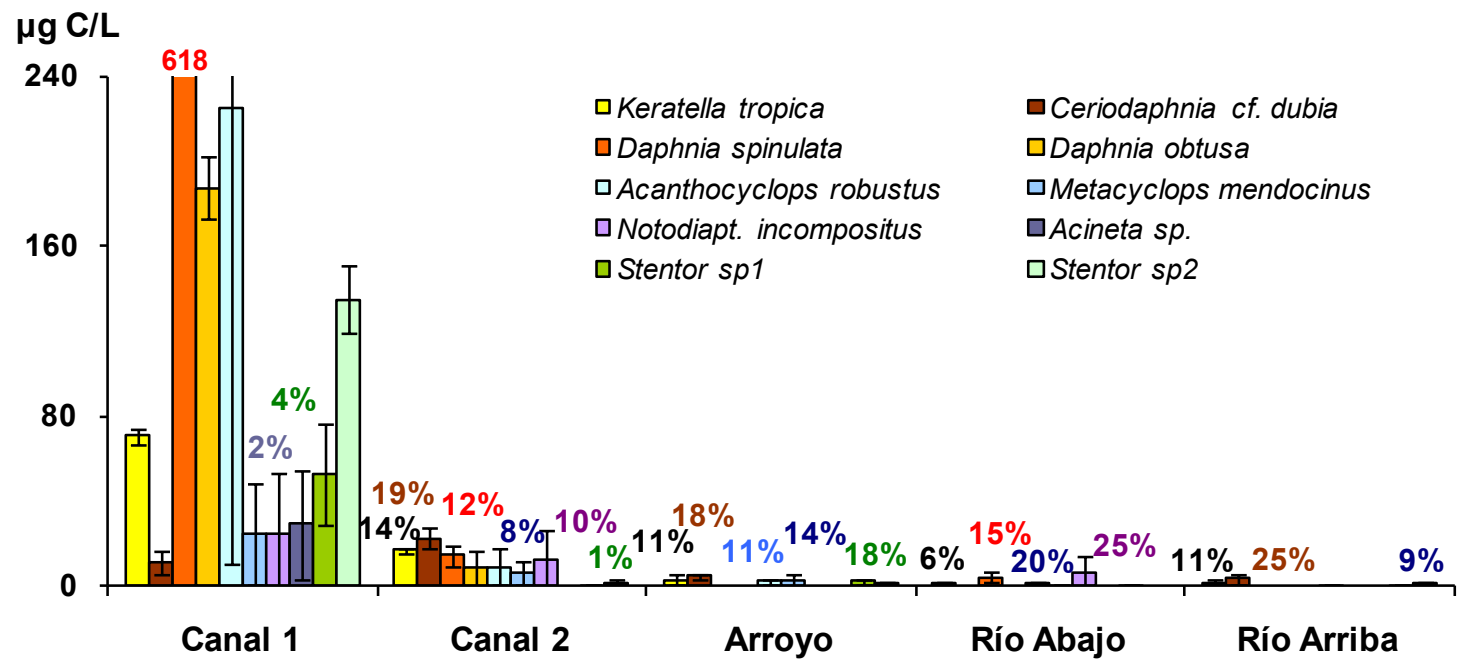

Figura 4.33: Biomasa total de las especies dominantes de zooplancton en aguas altas (mayo 2007). Se muestran los valores promedio (días 1 y 2), sus rangos de valores, y los porcentajes de contribución de cada especie a la abundancia total de zooplancton hallados por sitio de muestreo.

En aguas bajas, Brachionus plicatilis fue la especie más abundante y registró picos de 34.800 ind/L en el canal 2, y aunque estuvo presente en todos los sitios de muestreo, nunca superó los $1.300 \mathrm{ind} / \mathrm{L}$ (arroyo) (Fig. 4.36). B. plicatilis fue la especie dominante de los canales 1 y 2, y Brachionus angularis dominó en el canal 3, el arroyo y el río, y ambas especies aumentaron su abundancia y biomasa en el río aguas abajo del trasvase. Otros rotíferos abundantes del canal 2 fueron Conochilus sp. y Pompholyx sulcata, y los ciliados Strobilidium caudatum y Blepharisma sp., estando escasamente representados en los restantes sitios de muestreo. Epistylis sp1 se destacó en 
el arroyo y en el canal 3, y aumentó en gran medida en el río aguas abajo, respecto al sitio aguas arriba. Diferentes especies dominaron la biomasa, según los sitios de muestreo: Brachionus plicatilis en los canales 1 y 2; Daphnia obtusa en el canal 3; Moina micrura en el arroyo; Acanthocyclops robustus en el río aguas arriba y Brachionus angularis en el río aguas abajo. Entre éstos, B. plicatilis registró picos de $4.380 \mu \mathrm{g} \mathrm{C/L}$ en el canal 2, constituyendo el 91\% de la biomasa total de zooplancton para este sitio (Fig. 4.37). Los ciliados se destacaron en los canales y el arroyo (Strobilidium caudatum, Stentor spp, Prorodon sp2). El rotífero Asplanchna brigthwellii fue relevante en el canal 3 y el arroyo, pero el cladócero Moina micrura fue la especie dominante de este último sitio. Alona glabra se destacó como especie subdominante del río aguas arriba, luego de Acanthocyclops robustus, y ambas especies disminuyeron su biomasa en el sitio aguas abajo del trasvase.

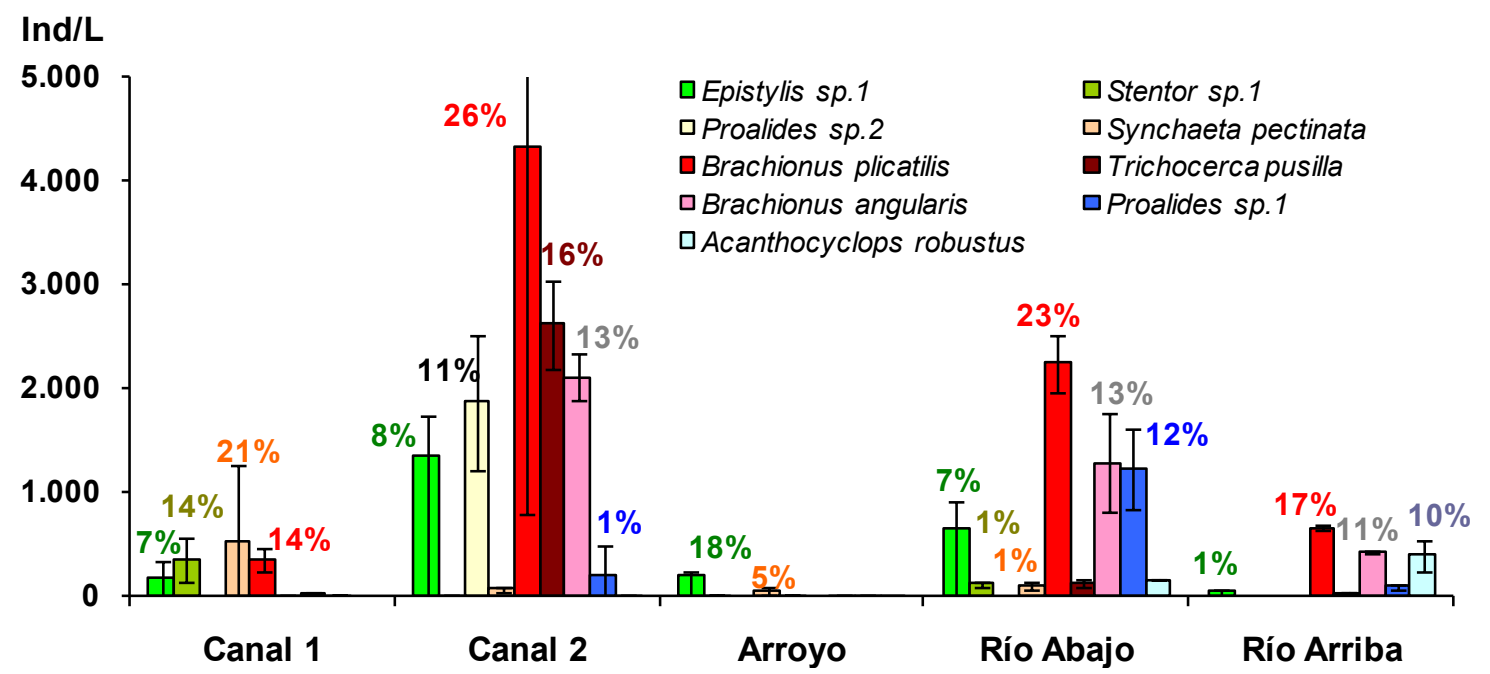

Figura 4.34: Abundancia total de las especies dominantes de zooplancton en caudales medios (marzo 2008). Se muestran los valores promedio (días 1 y 2), sus rangos de valores, y los porcentajes de contribución de cada especie a la abundancia total de zooplancton hallados por sitio de muestreo.

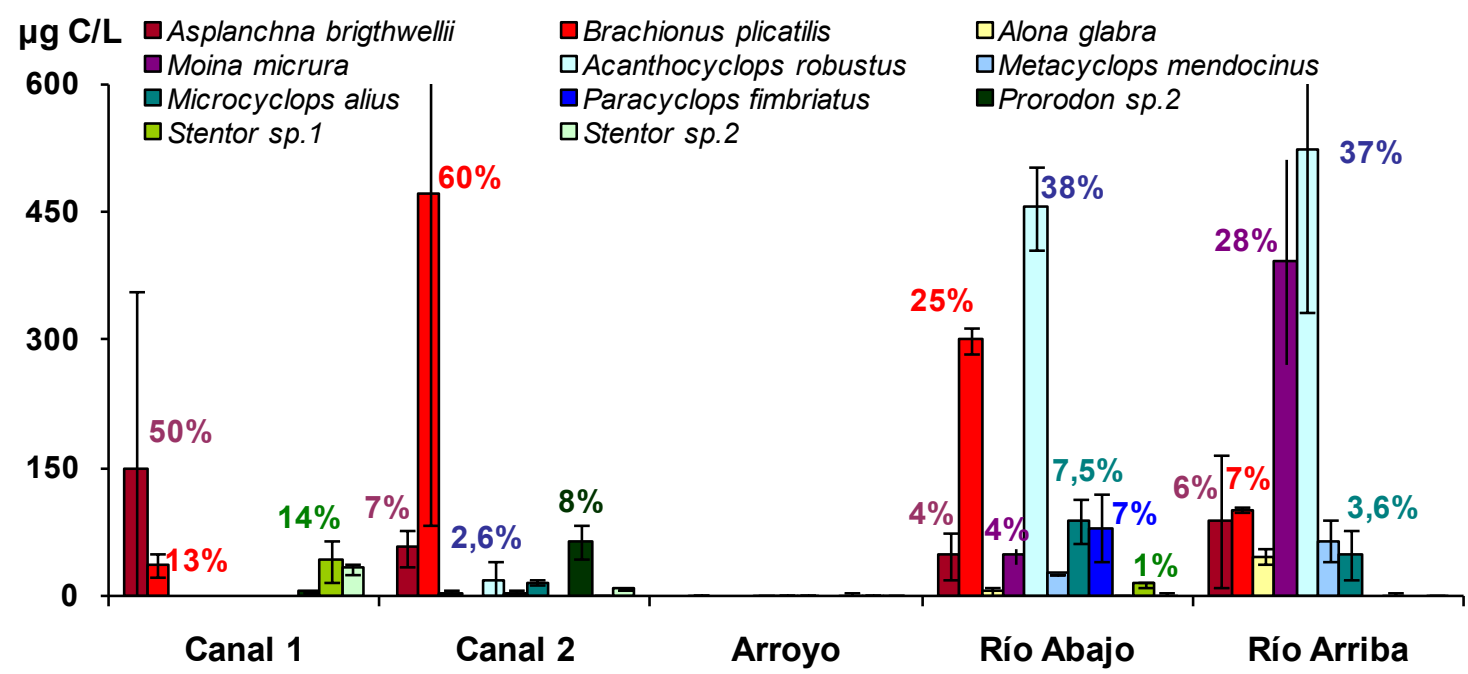

Figura 4.35: Biomasa total de las especies dominantes de zooplancton en caudales medios (marzo 2008). Se muestran los valores promedio (días 1 y 2), sus rangos de valores, y los porcentajes de contribución de cada especie a la abundancia total de zooplancton hallados por sitio de muestreo. 


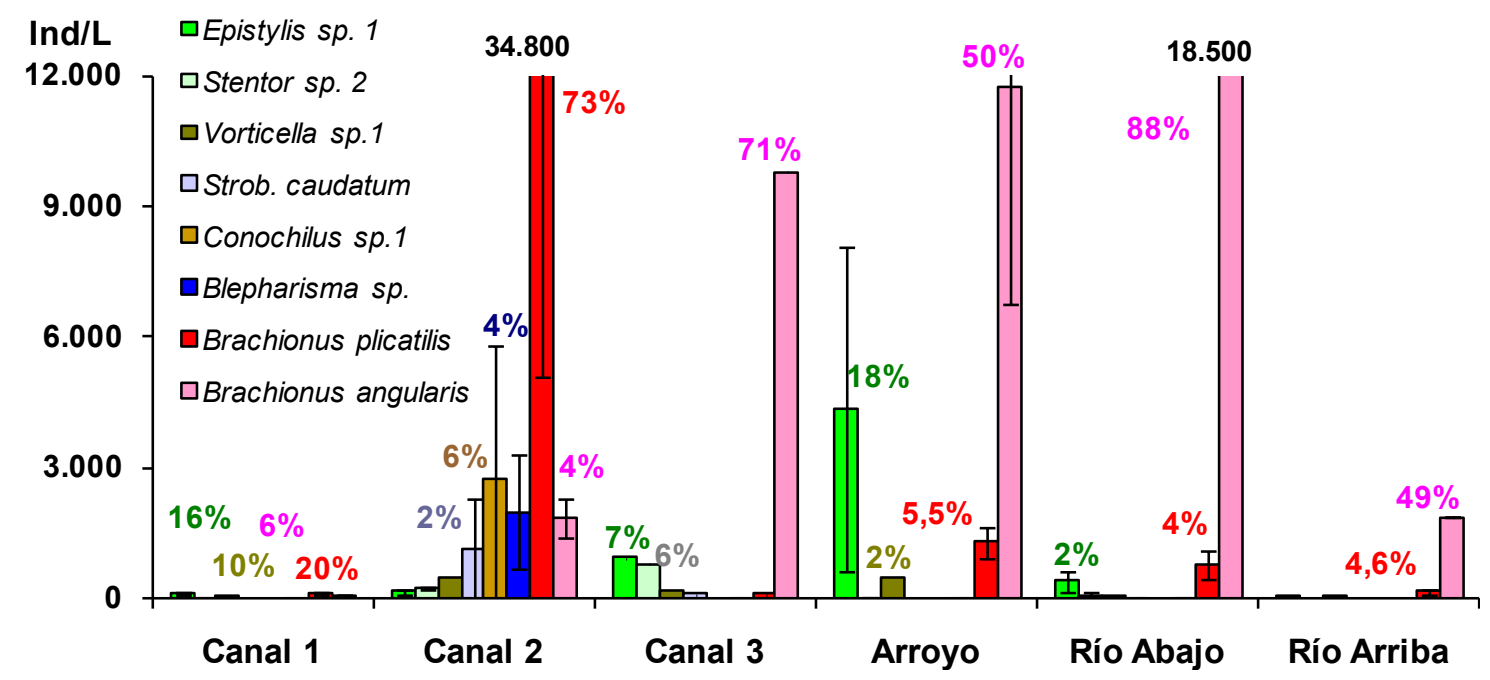

Figura 4.36: Abundancia total de las especies dominantes de zooplancton en aguas bajas (noviembre 2008). Se muestran los valores promedio (días 1 y 2), sus rangos de valores, y los porcentajes de contribución de cada especie a la abundancia total de zooplancton hallados por sitio de muestreo.

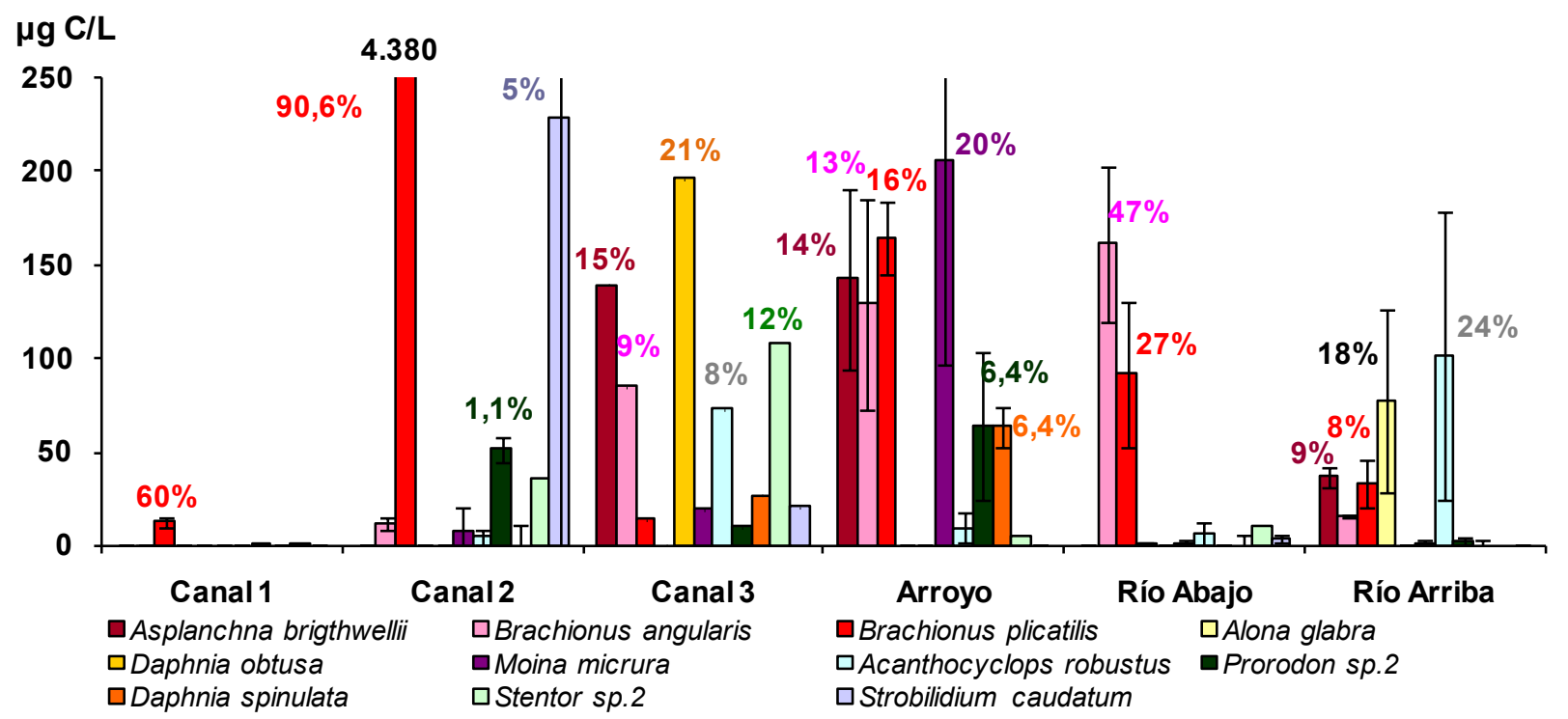

Figura 4.37: Biomasa total de las especies dominantes de zooplancton en aguas bajas (noviembre 2008). Se muestran los valores promedio (días 1 y 2), sus rangos de valores, y los porcentajes de contribución de cada especie a la abundancia total de zooplancton hallados por sitio de muestreo.

En aguas muy bajas en el sistema Bragado y caudales medios en el río, las especies más abundantes fueron los ciliados Euplotes sp. (canal 3), Epistylis sp1, Vorticella sp1 y Opercularia sp1, este último particularmente en el río aguas arriba, disminuyendo su importancia aguas abajo. Los rotíferos Brachionus plicatilis y Keratella tropica se destacaron por su abundancia en el canal 2, y Brachionus urceolaris y B. pterodinoides en el río aguas abajo (Fig. 4.38). Los copépodos dominaron la biomasa en los canales 2 y 3, y en el río, y entre las especies más relevantes se hallaron: Notodiaptomus incompositus, Acanthocyclops robustus, Paracyclops fimbriatus y Microcyclops alius, y en menor medida Cletocamptus deitersi (Fig. 4.39). Entre éstas, N. incompositus fue la especie dominante de la biomasa del canal 2, A. robustus del río aguas arriba y $M$. alius aguas abajo. El rotífero Brachionus plicatilis dominó por su biomasa en el canal 1, y fue subdominante en el canal 2, 
aumentando su importancia en el río aguas abajo del trasvase. En el arroyo, el ciliado Prorodon sp2 dominó la biomasa del sitio, aunque el valor máximo de la especie se halló en el río, donde también se destacaron Opercularia spp. Los cladóceros Moina micrura y Daphnia obtusa fueron subdominantes por su biomasa en el río aguas arriba, y Alona glabra en el sitio aguas abajo.

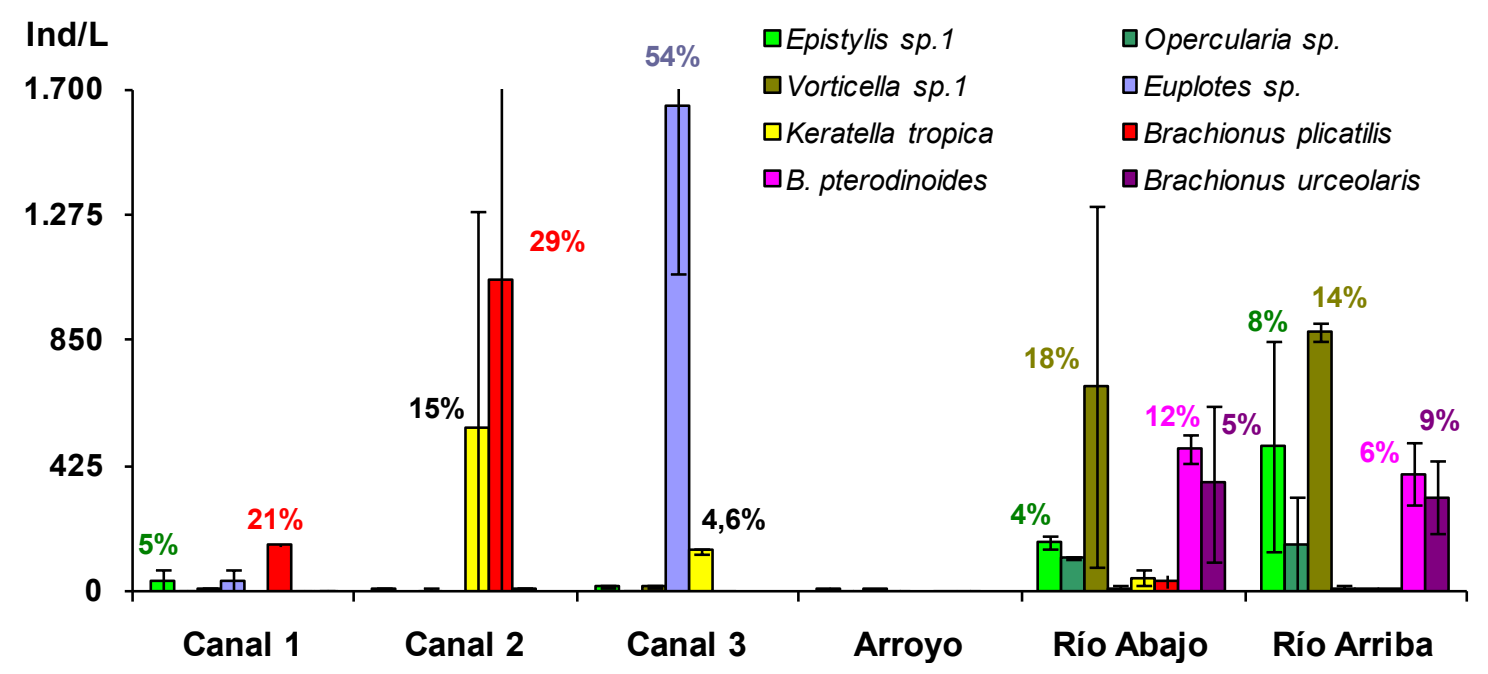

Figura 4.38: Abundancia total de las especies dominantes de zooplancton en aguas muy bajas en el sistema Bragado (afluentes) pero con caudales medios en el río (septiembre 2009). Se muestran los valores promedio (días 1 y 2), sus rangos de valores, y los porcentajes de contribución de cada especie a la abundancia total de zooplancton hallados por sitio de muestreo.

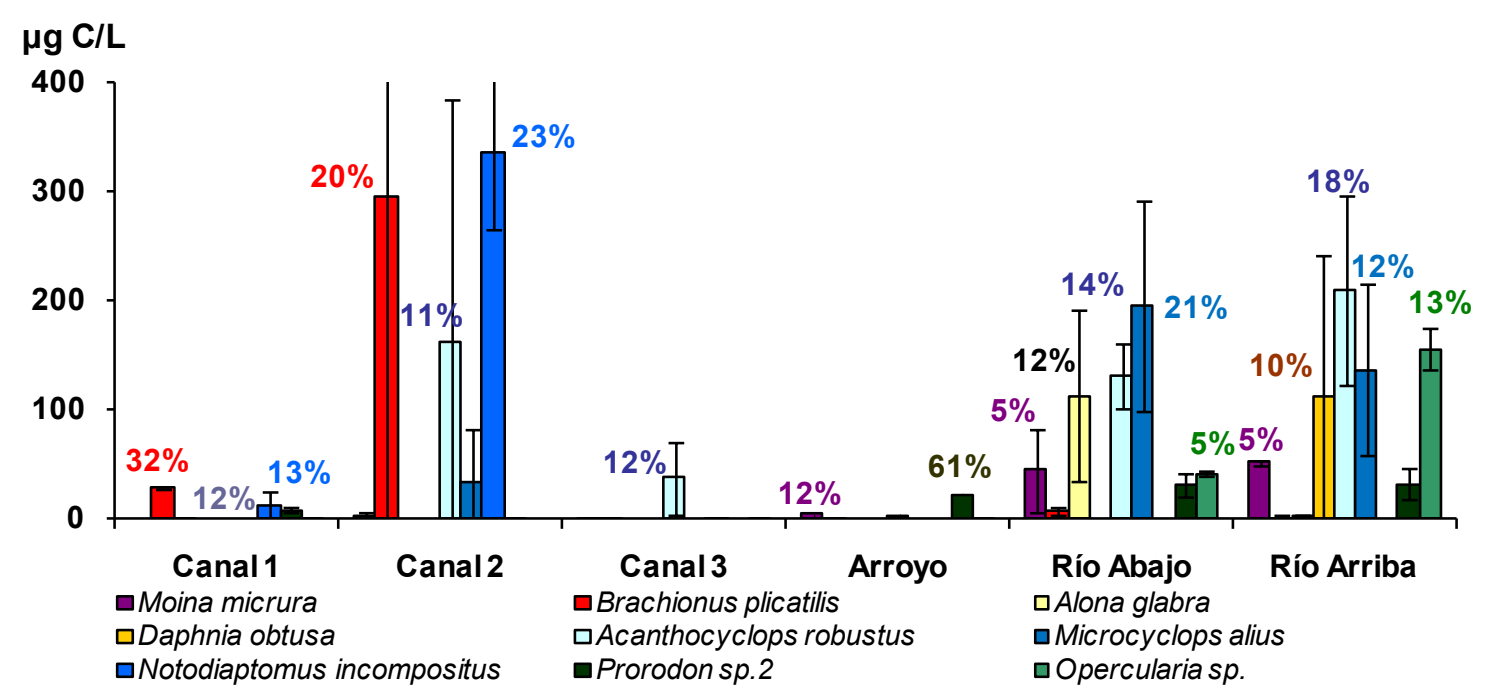

Figura 4.39: Biomasa total de las especies dominantes de zooplancton en aguas muy bajas en el sistema Bragado (afluentes) pero con caudales medios en el río (septiembre 2009). Se muestran los valores promedio (días 1 y 2), los rangos de valores hallados y los porcentajes de contribución de cada especie a la abundancia total de zooplancton por sitio de muestreo.

\subsubsection{Riqueza de especies y diversidad de zooplancton}

En todas las condiciones hidrológicas predominaron por su riqueza los rotíferos y los ciliados, y en menor medida se hallaron los copépodos y cladóceros, estando los rizópodos y ostrácodos escasamente representados. El nº total especies de zooplancton registradas en cada muestreo varió entre 99 y 110 taxa, con valores extremos en aguas muy bajas (sept. 2009) y caudales medios 
(marzo 2008), respectivamente. La diversidad fue máxima en el arroyo en aguas altas, a pesar de registrar el mínimo valor de riqueza, y en el canal 1 en los restantes muestreos (Fig. 4.40). Los sitios con mayor riqueza acumulada de especies de zooplancton fueron los canales 1 y 2 y el río aguas abajo (105-110 taxa), seguido por el río aguas arriba (87) y el canal 3 (77).

En aguas altas, los canales registraron los valores máximos de riqueza de especies (63-68 taxa), y entre éstas, los ciliados se destacaron en el canal 1, y los rotíferos y copépodos en el canal 2, mientras que los cladóceros presentaron 3-5 taxa por sitio de muestreo. El río aguas abajo del trasvase presentó mayor diversidad que el sitio aguas arriba, a pesar de que ambos tuvieron similar $n^{0}$ de especies. En caudales medios, el canal 2 se destacó por la riqueza específica de zooplancton (70 taxa), seguido por el río aguas abajo, y los valores mínimos se hallaron en el arroyo. En el río se observó un importante aumento de la riqueza de especies aguas abajo del trasvase, pero la diversidad fue similar en ambos sitios. La riqueza de especie de rotíferos, copépodos y ciliados fue máxima en el canal 2, seguido por el río aguas abajo, aumentando el n⿳o de especies de los rotíferos (22 taxa más) y triplicando la riqueza de los ciliados. Los cladóceros y rizópodos se destacaron por su riqueza específica en el río aguas arriba.

En aguas bajas (nov. 2008), los canales 2 y 3 registraron los valores máximos de riqueza específica (54-58 taxa), y mínimos en el río aguas arriba, aumentando el nº de especies aguas abajo. Los rotíferos y los ciliados fueron más diversos en el sistema Bragado, particularmente en el canal 2, y lo opuesto se observó con los cladóceros y los copépodos, que se destacaron por su riqueza en el río. Asimismo, en el río se observó la disminución de los valores de diversidad aguas abajo del trasvase. El río se destacó por su riqueza específica en los caudales medios de sept. 2009, mientras que en el canal 2 se halló el valor mínimo (aguas muy bajas). Los ciliados y los rotíferos fueron muy diversos en los canales 1 y 3 (23-25 taxa), mientras que en el río se halló mayor riqueza de especies de copépodos y de cladóceros. En el río la riqueza específica total y por grupos del zooplancton fue similar entre sitios, pero la diversidad aumentó aguas abajo del trasvase.

\subsubsection{Otras especies representativas del zooplancton}

Además de las anteriormente mencionadas, también se hallaron otras especies del zooplancton presentes a lo largo de los muestreos, tales como: los rizópodos Arcella hemisphaerica, Trinema sp.; los ciliados Epistylis spp., Vorticella spp., Prorodon spp., Tintinnidium fluviatilis, Vaginicola sp., Colpoda sp., Peridiscophrya sp., Acineta sp., Euplotes spp., Askenasia sp.; los rotíferos Brachionus spp., Asplanchna spp., Polyarthra dolichoptera, Synchaeta pectinata, Testudinella patina, Pompholyx sulcata; los copépodos Microcyclops alius, Microcyclops sp., Harpacticoideo sp., y los ostrácodos Cypridopsis vidua y Heterocypris incongruens. 


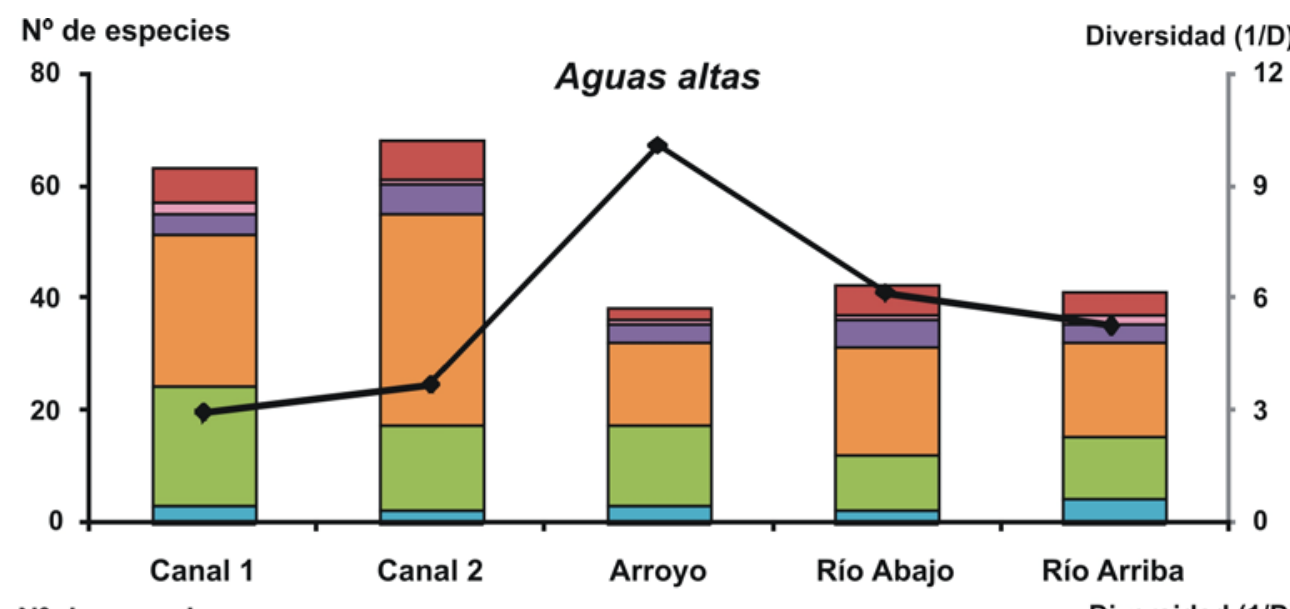

$\mathrm{N}^{\circ}$ de especies

Diversidad (1/D)
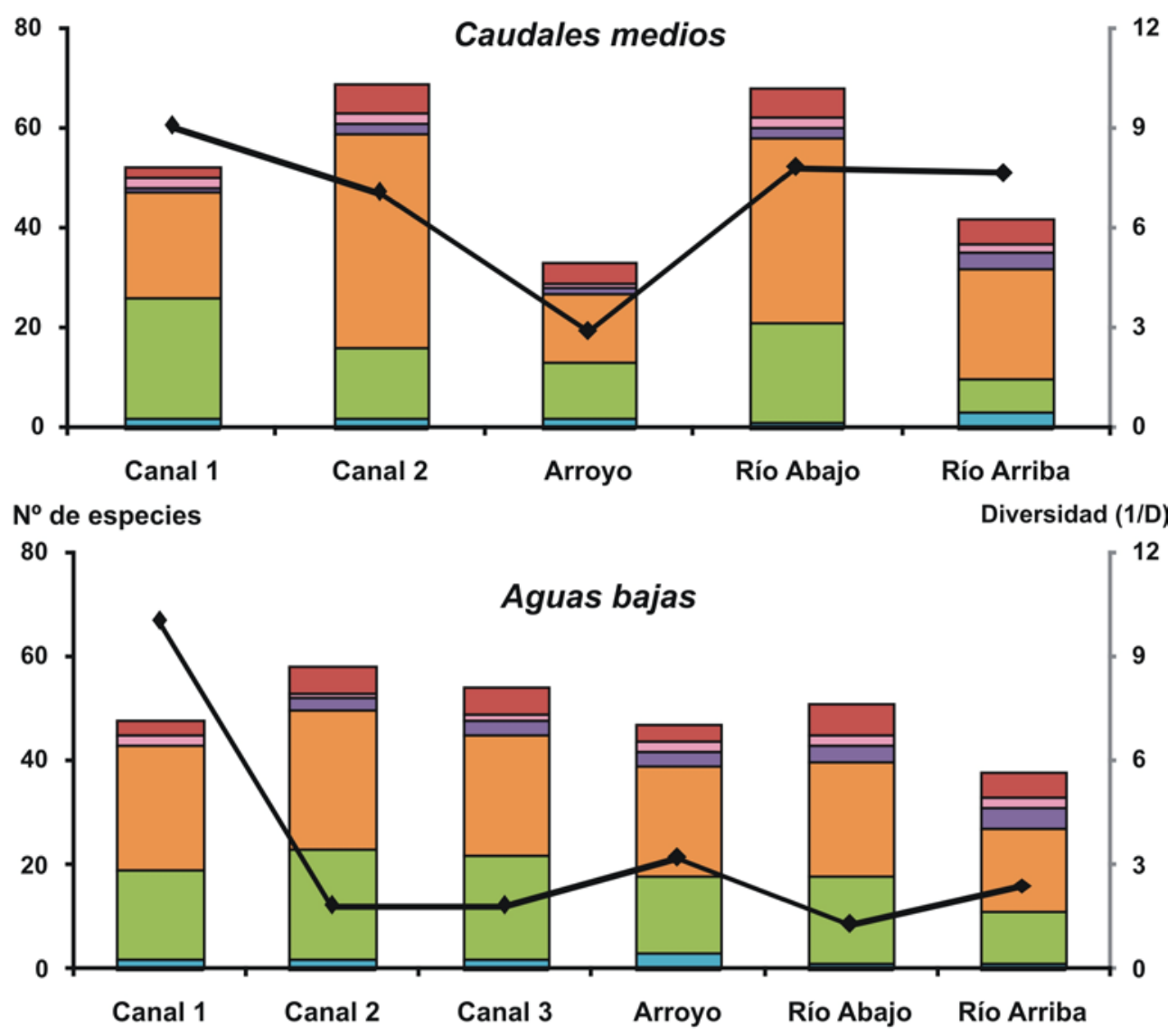

$N^{\circ}$ de especies

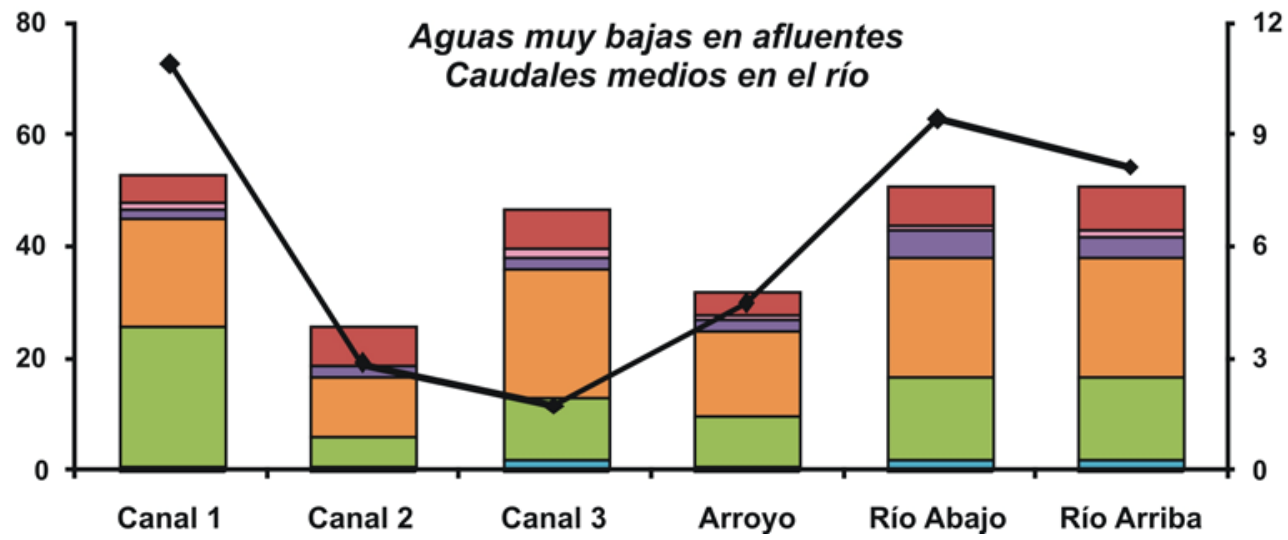

Figura 4.40: Riqueza de especies por grupo de zooplancton (columnas) e índice de diversidad de Simpson (1/D) (línea negra). Referencias: rizópodos (celeste), ciliados (verde), rotíferos (anaranjado), cladóceros (violeta), copépodos (rojo) y ostrácodos (rosado). Se muestran los valores promedio (días 1 y 2) por sitio de muestreo y condición hidrológica: aguas altas (mayo 2007), caudales medios (marzo 2008), aguas bajas (nov. 2008) y aguas muy bajas en afluentes pero con caudales medios en el río (sept. 2009). 
Los rizópodos Arcella discoides y Euglypha sp. sólo estuvieron presentes en el río, y Amoeba sp. en los canales 1 y 2, en aguas altas y caudales medios. Algunos ciliados sólo estuvieron presentes en los canales: Strobilidium spp., Strombidium spp., Halteria spp., Codonella sp. y Enchelys sp. El cladócero Simocephalus sp. sólo estuvo presente en el río, y Ceriodaphnia cf. dubia en el canal 2 y el arroyo. El copépodo calanoideo Boeckella poopensis sólo estuvo presente en el canal 1, y Paracyclops fimbriatus en el río aguas abajo, y el rotífero Hexarthra fennica en el canal 3.

Los rotíferos se destacaron por su riqueza de especies en el canal 2, registrándose a lo largo de los muestreos a: Anuraeopsis fissa, Proales spp., Proalides spp., varios representantes de Brachionus (B. bidentanta, B. quadridentatus, B.urceolaris), de Lecane (L. bulla, L. clara, L. closterocerca, L. curvicornis, L. grandis, L. hamata, L. hastasta, L. hemimonostila), Trichocerca (T. pusilla, T. capuchina, T. cilíndrica, T. stylata.), Notholca acuminata, Dicranophorus sp., Cephalodella spp., Colurella spp., Encentrum spp., Lepadella ovalis, Polyarthra sp., Asplanchna spp., y varios bdelloideos.

En aguas altas (mayo 2007), el ciliado Blepharisma sp. se halló en el canal 1 y Tokophrya sp. en el sistema Bragado y en el río aguas abajo. Los rotíferos Conochilus sp. y Colotheca sp. se observaron en el canal 1 y Ptygura sp. en el río aguas arriba. El cladócero Leydigia louisi sólo estuvo presente en el río. En caudales medios (marzo 2008), el ciliado Urothrichia sp. estuvo presente en los canales, y particularmente en el canal 1: Blepharisma sp., Monodinium sp., Strobilidium sulcatum y suctorios; así como también los rotíferos Colotheca sp2 y Lecane quadridentatus. Los ciliados Euplotes sp. y Strobilidium caudatum se hallaron en el sistema Bragado y en el río aguas abajo. Algunos rotíferos estuvieron presentes en el canal 2 y en el río aguas abajo: Brachionus dimidiatus inermis, B. caudatus, B. calyciflorus, B. bidentata, Filinia longiseta, Proales sp. y Trichotria tetractis. Otros ciliados como Holophrya sp., Opercularia sp. y Metacineta sp., los rotíferos B. havanaensis y Lecane piriformis y el cladócero Diaphanosoma birgei fueron observados en el río aguas arriba.

En aguas bajas (nov. 2008), Prorodon sp1 y Blepharisma sp. estuvieron presentes en el sistema Bragado y en el río aguas abajo. Lo mismo para los rotíferos: Brachionus rotundiformis, Pompholyx sulcata, Ascomorpha ovata, Colurella uncinata y Proalides sp1. Algunos rotíferos sólo estuvieron presentes en los canales (Brachionus dimidiatus inermis, Colotheca sp1, Colurella spp., Encentrum spp., Dicranophorus sp., Euchlanis dilatata, Conochilus sp.). Otros ciliados como Fabria salina, Monodinium sp., sólo se hallaron en el canal 2, y Dileptus sp. y Litonotus sp. en el canal 3.

En aguas muy bajas, el ciliado Fabria salina estuvo restringida a los canales, mientras que en el canal 1 se hallaron: Spirostomun sp., Strobidium sp1, Halteria grandinella, Euplotes patela, Metacineta sp. y Urothrichia sp. Algunos rotíferos estuvieron restringidos a determinados sitios, como: 
Collotheca spp. (canal 1); Polyarthra spp., Anuraeopsis fissa, Ascomorpha ovata, Filinia spp., Trichocerca pusilla y B. calyciflorus (canal 3), y Cephalodella macrodactyla y Proales spp. en el río.

\subsubsection{Correlaciones exploratorias}

Se hallaron correlaciones positivas significativas $(p<0,05 ; \mathrm{r}>0,6)$ entre la abundancia y biomasa total de zooplancton, de los rotíferos y los copépodos con la turbidez, la clorofila $a$ y la abundancia y biomasa total de fitoplancton. Asimismo, la densidad total de zooplancton y de los rotíferos estuvo positivamente correlacionada con los SS, la MOP, turbidez y la abundancia total de fitoplancton. Los copépodos se correlacionaron con el $\mathrm{pH}$ y la turbidez, tanto en la abundancia como biomasa. La abundancia de cada uno de los grupos del zooplancton estuvo positivamente correlacionada a sus valores de biomasa. También se hallaron relaciones positivas entre la abundancia de algunas especies del zooplancton y los parámetros físico-químicos, a saber: Brachionus angularis con la temperatura; B. plicatilis también con la conductividad, SS y el contenido de $\mathrm{Na}^{+}, \mathrm{K}^{+}, \mathrm{Cl}^{-}$y $\mathrm{SO}_{4}=$; los copepoditos con el $\mathrm{pH}$, y la abundancia de Acanthocyclops robustus con la turbidez (Anexo II). 


\subsection{Reproducción del plancton}

\subsubsection{Reproducción del fitoplancton}

Todas las especies de fitoplancton en reproducción halladas en los diferentes muestreos pertenecieron a las clorofitas, principalmente a las clorococcales, salvo algunos taxa de desmidiáceas (Cosmarium spp.) que sólo estuvieron presentes en aguas altas (mayo 2007) y caudales medios (marzo 2008). En general, la abundancia total de los organismos por especie en reproducción fue muy baja, y su abundancia relativa, respecto a la abundancia total de la especie, varió entre $0,14-100 \%$ del total a lo largo de los muestreos (Tabla 4.2, A-D). En aguas altas, los canales 1 y 2 presentaron el n⿳o máximo de especies de fitoplancton en reproducción (12-13 taxa en c/u), y en caudales medios también se destacó el canal 2 (6 taxa), seguido por el río aguas abajo (4 taxa). En aguas bajas (nov. 2008), el no máximo de especies de fitoplancton en reproducción se halló en el río aguas arriba y en el canal 3 (5 taxa en c/u). En caudales medios (sept. 2009), se destacaron los sitios del río por la riqueza de especies de fitoplancton en reproducción (7-4 taxa).

En aguas altas (mayo 2007) todos los sitios de muestreo registraron especies en reproducción, mientras que en las restantes condiciones hidrológicas la presencia de organismos en reproducción fue disminuyendo, particularmente en el sistema Bragado. En este sentido, no se observaron especies en reproducción en el canal 1 en caudales medios (marzo 2008), en el arroyo en aguas bajas y en los canales 1 y 2 y el arroyo en aguas muy bajas (sept. 2009). La mayoría de las especies de fitoplancton se hallaron en reproducción en un solo sitio de muestreo por condición hidrológica, aunque en aguas altas (mayo 2007) se observó la distribución de Didymocystis bicellularis y Oocystis lacustris a lo largo del sistema Bragado y en el río aguas abajo. Cosmarium sp. se observó en reproducción en los canales 1 y 2 en aguas altas, y en el río aguas abajo en caudales medios (marzo 2008) y aguas bajas (nov. 2008). Otras especies también se hallaron en reproducción en más de un sitio de muestreo, como Oocystis borgei en el canal 2 y el arroyo en caudales medios, Lagerheimia genevensis y Crucigenia quadrata en ambos sitios del río en aguas bajas, al igual que Oocystis lacustris, O. marsonii y O. parva en el río y el canal 3. En general, las estructuras de dispersión como los acinetos de cianobacterias se hallaron en el sistema Bragado, al igual que las auxosporas de diatomeas. Sin embargo, en aguas altas no se observaron auxosporas ni acinetos en ninguno de los sitios de muestreo. En caudales medios sólo se hallaron acinetos en el canal 1 y en aguas bajas en el arroyo. Se observaron auxosporas en el canal 1 y en el río aguas arriba en aguas bajas y en todos los canales en aguas muy bajas, y también acinetos en el canal 2. 
Tabla 4.2: Abundancia relativa (\%) de cada especie del fitoplancton en reproducción respecto a su abundancia total por sitio y campaña de muestreo. Referencias: El $\mathrm{N}$ máx representa los valores máximos de la abundancia de los organismos en reproducción de cada especie (Ind/mL) y el asterisco $\left({ }^{*}\right)$ señala el sitio donde se observó tal valor. Se grafican los valores promedio de los días 1 y 2 de los muestreos: A- mayo 2007, B- marzo 2008, C- nov. 2008 y D- sept. 2009. En azul se destacan los sitios afectados por la construcción de un nuevo vertedero en la laguna del Bragado: modificación de los márgenes y movimientos de tierra en el canal 2, e interrupción del flujo de agua en las nacientes del arroyo.

A-Aguas altas (mayo 2007)

\begin{tabular}{|c|c|c|c|c|c|c|}
\hline Especies & Canal 1 & Canal 2 & Arroyo & Río Abajo & Río Arriba & $\mathrm{N}_{\text {máx }}$ \\
\hline Cosmarium sp. & $2 \%$ & $17 \%$ * & & & & 3 \\
\hline Crucigenia tetrapedia & & $0,14 \% *$ & & & & 3 \\
\hline Crucigeniella rectangularis & $0,32 \%$ & & & & & 2 \\
\hline Desmodesmus opoliensis & & $53 \%$ & & & & 84 \\
\hline Desmodesmus quadricaudatus & $59 \% *$ & $17 \%$ & & & & 836 \\
\hline Didymocystis bicellularis & $57 \%$ & $77 \% *$ & $54 \%$ & $28 \%$ & & 418 \\
\hline Franceia amphitrichia & $80 \% *$ & $67 \%$ & & & & 209 \\
\hline Lagerheimia genevensis & $29 \%$ & $67 \% *$ & & & & 167 \\
\hline Lagerheimia subsalsa & $44 \% *$ & $80 \%$ & & & & 209 \\
\hline Oocystis borgei & $7 \% *$ & $11 \%$ & & & $9 \%$ & 8 \\
\hline Oocystis lacustris & $3 \%$ & $48 \%$ & $44 \% *$ & $6,7 \%$ & & 210 \\
\hline Oocystis parva & $90 \% *$ & $79 \%$ & $40 \%$ & & & 993 \\
\hline Oocystis solitaria & $11 \%$ & & & & & 1 \\
\hline Ooplanctella planoconvexa & & $20 \% *$ & & & $0,87 \%$ & 84 \\
\hline Quadricoccus ellipticus & $67 \%$ & & & & & 418 \\
\hline Tetrastrum triangulare & & $80 \%$ & & & & 167 \\
\hline
\end{tabular}

B-Caudales medios (marzo 2008)

\begin{tabular}{|c|c|c|c|c|c|c|}
\hline Especies & Canal 1 & Canal 2 & Arroyo & Río Abajo & Río Arriba & $\overline{\mathrm{N}_{\text {máx }}}$ \\
\hline Cosmarium sp. & & & & $2,3 \%$ & & 6 \\
\hline Franceia amphithrichia & & $1,3 \%$ & & & & 4 \\
\hline Lagerheimia genevensis & & $33 \%$ & & & & 84 \\
\hline Lagerheimia subsalsa & & $0,21 \%$ & & & & 3 \\
\hline Monoraphidium nanum & & & & $12,5 \%$ & & 84 \\
\hline Oocystis borgei & & $0,5 \%$ & $10 \% *$ & & & 3 \\
\hline Oocystis marsonii & & & & & $25 \%$ & 84 \\
\hline Oocystis solitaria & & $1,45 \%$ & & & & 1 \\
\hline Ooplanctella planoconvexa & & & & $14 \%$ & & 84 \\
\hline Quadrigula sabulosa & & $80 \%$ & & & & 5 \\
\hline Pseudoschroederia robusta & & & & $16,7 \%$ & & 84 \\
\hline
\end{tabular}

C-Aguas bajas (nov. 2008)

\begin{tabular}{|c|c|c|c|c|c|c|c|}
\hline Especies & Canal 1 & Canal 2 & Canal 3 & Arroyo & Río Abajo & Río Arriba & $\mathrm{N}_{\text {máx }}$ \\
\hline Closteriopsis acicularis & & & $4 \%$ & & & & 199 \\
\hline Cosmarium abbreviatum & & & & & & $100 \%$ & 1 \\
\hline Cosmarium sp. & & & & & $0,6 \%$ & & 1 \\
\hline Crucigenia quadrata & & & & & $5 \% *$ & $0,5 \%$ & 105 \\
\hline Lagerheimia genevensis & & & & & $4 \% *$ & $25 \%$ & 105 \\
\hline Oocystis borgei & & & $32 \%$ & & & & 398 \\
\hline Oocystis solitaria & $20 \%$ & & & & & $20 \%$ & 1 \\
\hline Ooplanctella planoconvexa & & & $10 \%$ & & & & 199 \\
\hline Quadricoccus ellipticus & & & $17 \%$ & & & & 199 \\
\hline Tetraedron minimum & & & $11 \%$ & & & $20 \%$ & 313 \\
\hline Tetrastrum triangulare & & $0,4 \%$ & & & & & 1 \\
\hline
\end{tabular}


D- Aguas muy bajas en el sistema Bragado pero con caudales medios en el río (sept. 2009)

\begin{tabular}{|c|c|c|c|c|c|c|}
\hline Especies & Canal 1 Canal 2 & Canal 3 & Arroyo & Río Abajo & Río Arriba & $\mathrm{N}_{\text {máx }}$ \\
\hline Actinastrum hantzschii & & & & & $8 \%$ & 6268 \\
\hline Closteriopsis acicularis & & $25 \%$ & & & & 42 \\
\hline Crucigenia tetrapedia & & & & & $33 \%$ & 209 \\
\hline Crucigeniella rectangularis & & & & $37,5 \%$ & & 313 \\
\hline Lagerheimia circumfilata & & & & & $39 \%$ & 183 \\
\hline Lagerheimia subsalsa & & & & & $16,7 \%$ & 105 \\
\hline Monoraphidium griffithii & & $0,6 \%$ & & & & 1 \\
\hline Oocystis lacustris & & & & $26,7 \% *$ & $4,8 \%$ & 836 \\
\hline Oocystis marsonii & & & & $50 \% *$ & $100 \%$ & 209 \\
\hline Oocystis parva & & $11 \%$ & & & $6 \% *$ & 105 \\
\hline Pseudoschroederia robusta & & & & $43 \%$ & & 313 \\
\hline
\end{tabular}

\subsubsection{Reproducción del zooplancton (rotíferos, copépodos, cladóceros y ostrácodos)}

En aguas altas se registraron en el canal 1 los valores máximos de abundancia total de $q$ ovígeras de organismos con reproducción por huevo (rotíferos, copépodos, cladóceros y ostrácodos), $\mathrm{n}^{\mathrm{o}}$ de huevos portados por $q$ y libres en las muestras, con una tendencia decreciente a lo largo del sistema Bragado (Fig. 4.41). En el río se observaron los valores mínimos de estas variables, aunque con un aumento aguas abajo de la densidad de + ovígeras y de huevos portados por ${ }_{+}$, a la vez que un descenso en el no de huevos libres (Anexo VI).

En caudales medios, se hallaron picos de abundancia total de $q$ ovígeras, de huevos en $\uparrow$ y de huevos libres en el canal 2 y en el río aguas abajo, aumentando su densidad respecto al sitio aguas arriba. Algo similar ocurrió en aguas bajas, donde la reproducción del zooplancton considerado fue máxima en el canal 2, seguido por el río aguas abajo, con picos de abundancia de $q$ ovígeras, de huevos en $q$ y libres en la muestra. En aguas muy bajas en el sistema Bragado pero con caudales medios en el río (sept. 2009), se hallaron picos de densidad de $q$ ovígeras en el canal 2 y de $\mathrm{n}^{\mathrm{o}}$ de huevos en $q$ y libres en la muestra en el río aguas arriba. En el arroyo y en el canal 1 se registraron los valores mínimos de abundancia total de + ovígeras y $\mathrm{n}^{\mathrm{o}}$ total de huevos en caudales medios, aguas bajas y muy bajas. La presencia de hembras ovígeras estuvo correlacionada positivamente $(p<0,05 ; \mathrm{r}>0,6)$ a la abundancia y biomasa total de los grupos del zooplancton considerado (rotíferos, copépodos y cladóceros) (Anexo II).

\subsubsection{Riqueza de especies de zooplancton en reproducción por huevos}

La riqueza de especies de zooplancton en reproducción por huevos fue máxima en el canal 2 en aguas altas y en caudales medios (13-18 taxa) (Fig. 4.42). En el canal 1 se halló máximo no de especies en reproducción en aguas altas (9 taxa), en el arroyo en aguas bajas (7 taxa) y en el río en caudales medios (13-16 taxa). La mayor parte de ellas fueron rotíferos, y junto con los copépodos, 
se destacaron por su riqueza en el canal 2 en caudales medios, y los cladóceros en aguas altas. Sólo se hallaron ostrácodos en reproducción en el canal 1 en condiciones de aguas bajas.

En aguas altas los copépodos, cladóceros y rotíferos se reprodujeron a lo largo del sistema Bragado, mientras que en el río sólo se observaron 2 especies de rotíferos. En caudales medios se observó la reproducción de rotíferos, copépodos y cladóceros principalmente en el canal 2, seguido por el río aguas abajo y arriba, en este orden de importancia. En aguas bajas, se observó escasa variación en la riqueza de especies de zooplancton en reproducción entre los sitios de muestreo (710 taxa), mayormente representada por los rotíferos.

\subsubsection{Abundancia total de huevos por grupo del zooplancton}

$\mathrm{El} \mathrm{n}^{\mathrm{o}}$ total de huevos portados por $q$ ovígeras (densidad de $q$ ovígeras $\mathrm{x} \mathrm{n}^{\mathrm{o}}$ de huevos presente en cada una de ellas) fue mínimo en aguas altas y máximo en aguas bajas, acompañando la abundancia de $q$ ovígeras (Fig. 4.43). En el canal 2 y en el río aguas abajo se hallaron los valores máximos de abundancia de huevos de rotíferos portados por + en aguas bajas. Sólo se observaron huevos de ostrácodos en este muestreo (canal 1) y los copépodos y cladóceros se destacaron por el $\mathrm{n}^{\mathrm{o}}$ de huevos portados en $q$ en el río aguas arriba.

En aguas altas el no de huevos/L fue máximo en el canal 1, perteneciendo a rotíferos, copépodos y cladóceros, en este orden de importancia. En caudales medios, el no de huevos en $q$ de rotíferos fue máximo en el canal 2, seguido por el río aguas abajo. Los copépodos y los cladóceros se destacaron por su producción de huevos en el río, y en menor medida en el canal 2. Un patrón similar se observó en aguas muy bajas en el sistema Bragado con caudales medios en el río (sept. 2009), observando los valores mínimos en el canal 1 y el arroyo.

\subsubsection{Abundancia de adultos y hembras ovígeras de rotíferos}

En todos los sitios de muestreo y condiciones hidrológicas se observaron $q$ ovígeras de rotíferos, y sus picos de abundancia siguieron al total del grupo: en el canal 1 en aguas altas, en el canal 2 y el río aguas abajo en caudales medios y aguas bajas, y en el río y el canal 2 en sept. 2009 (Fig. 4.44). Se observó un aumento en la abundancia de las $q$ ovígeras de rotíferos en el río aguas abajo del trasvase en condiciones de aguas altas, caudales medios y aguas bajas. La abundancia relativa de las $q$ ovígeras varió entre los sitios de muestreo según la condición hidrológica, registrando los \% mínimos en aguas altas y los máximos en aguas bajas en el canal 2 y en ambos sitios del río. En el canal 1 se observó una tendencia opuesta, y en el arroyo la abundancia relativa de las + ovígeras de rotíferos estuvo entre 2-6\% del total, salvo en aguas bajas (23\%). 
$\mathrm{N}^{\circ}$ huevos/L

Ind/L

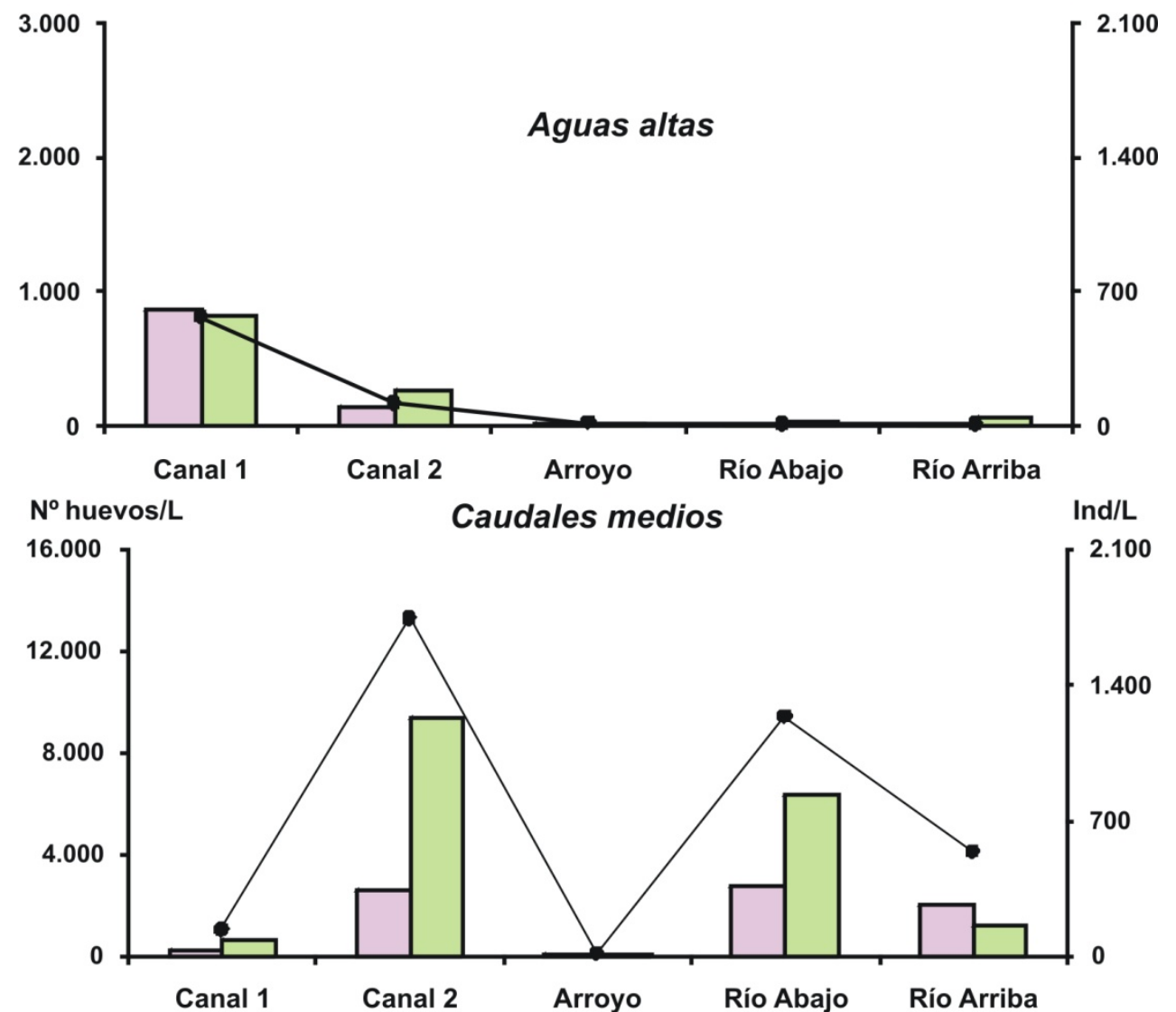

Nohuevos/L

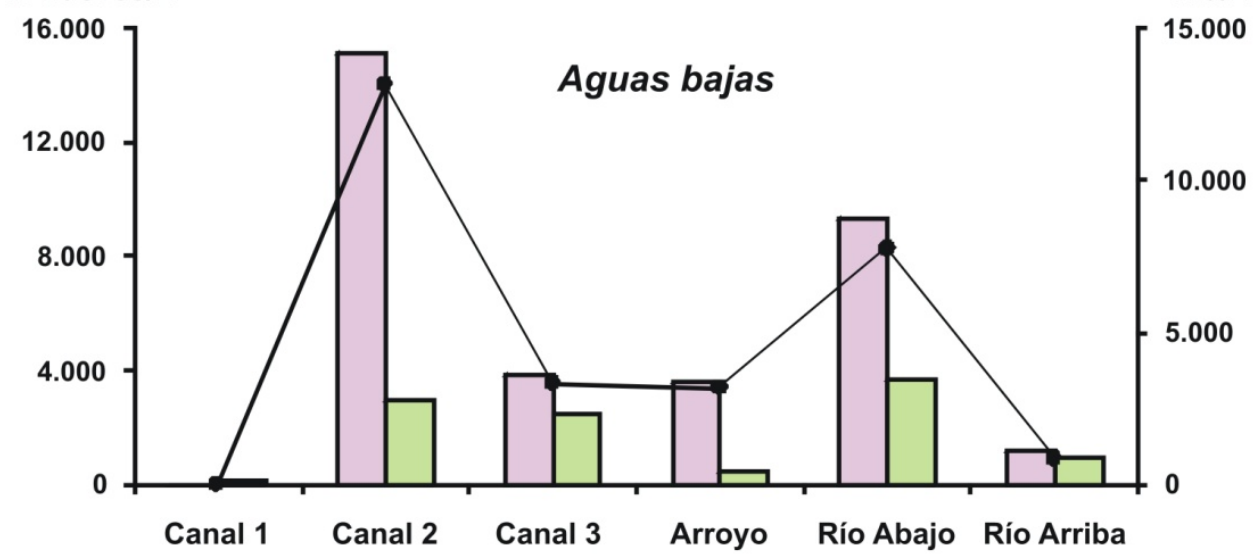

Nohuevos/L

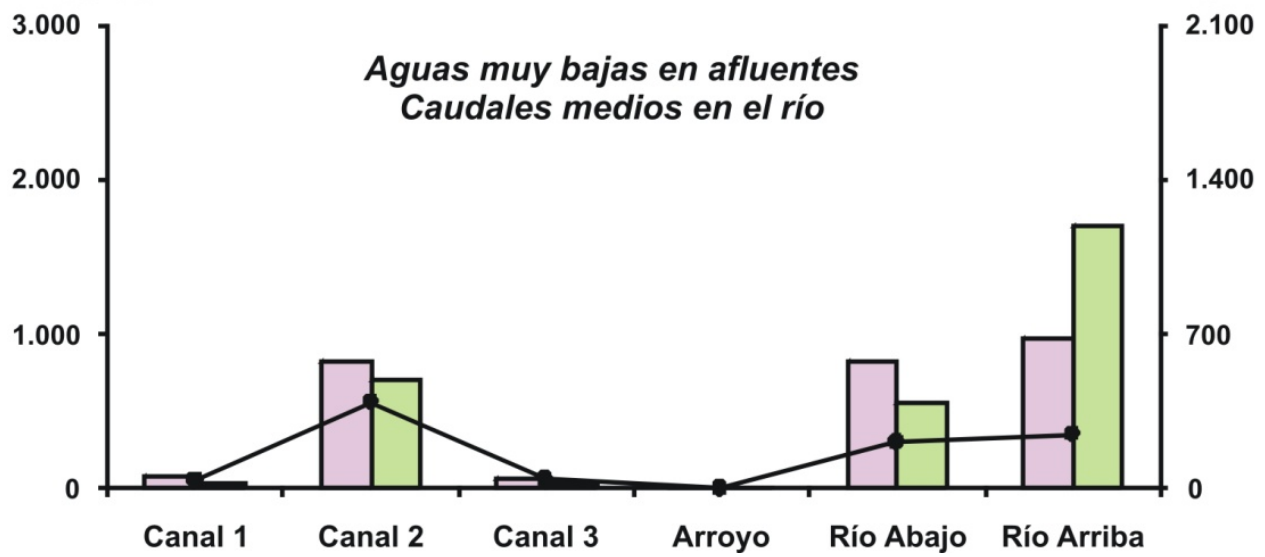

Figura 4.41: Abundancia total de hembras ovígeras con reproducción por huevos (rotíferos, cladóceros, copépodos y ostrácodos) (línea negra), no total de huevos en hembras (columna rosada) y no total de huevos libres en la muestra (columna verde). Se muestran los valores promedio (días 1 y 2) por sitio de muestreo y condición hidrológica: aguas altas (mayo 2007); caudales medios (marzo 2008) y aguas bajas (nov. 2008) con diferente escala; y aguas muy bajas en afluentes (sistema Bragado) con caudales medios en el río (sept. 2009). 

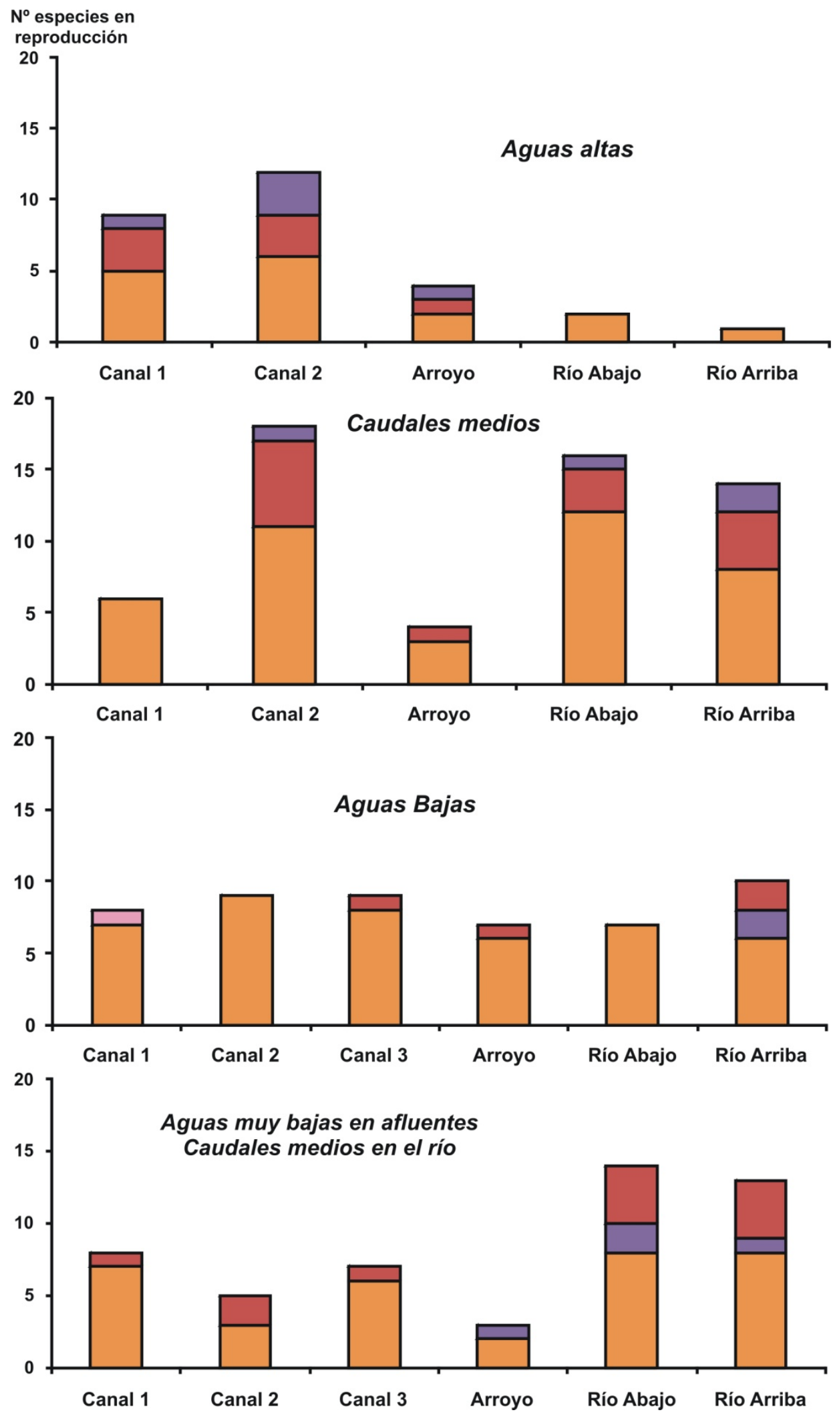

Figura 4.42: № de especies en reproducción por grupo del zooplancton considerado (días 1 y 2) por sitio de muestreo y condición hidrológica: aguas altas (mayo 2007), caudales medios (marzo 2008), aguas bajas (nov. 2008) y aguas muy bajas en afluentes (sistema Bragado) con caudales medios en el río (sept. 2009). Referencias: especies de rotíferos (anaranjado), de copépodos (rojo), de cladóceros (violeta) y ostrácodo (rosado), sólo presente en aguas bajas. 


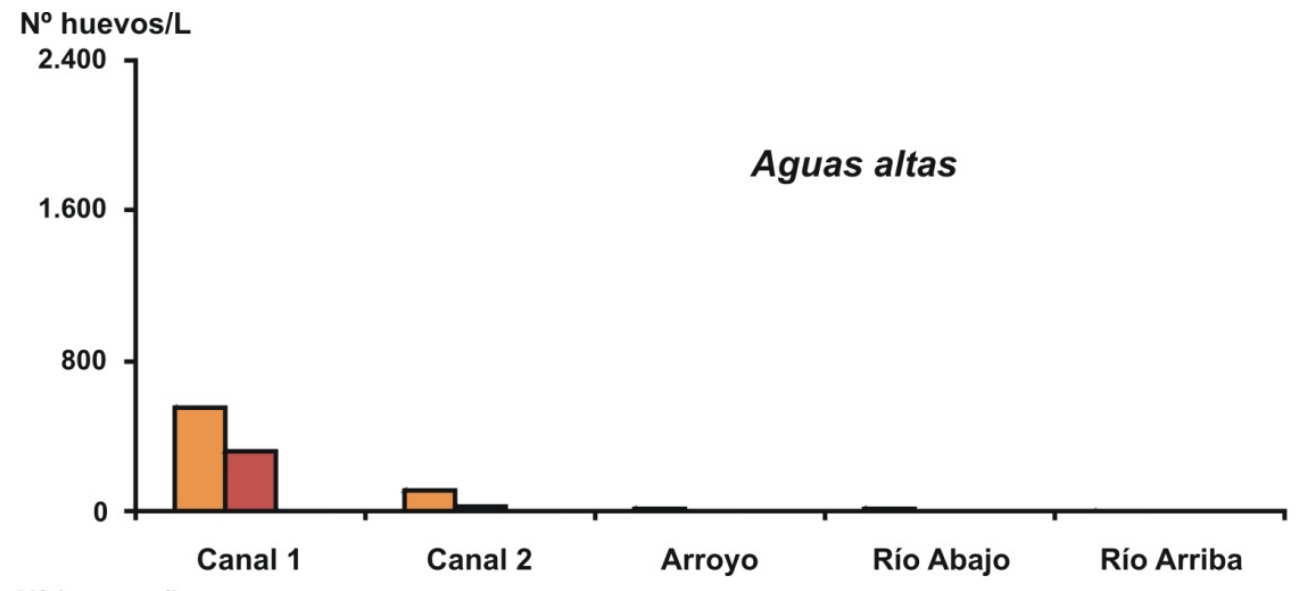

$N^{\circ}$ huevos/L

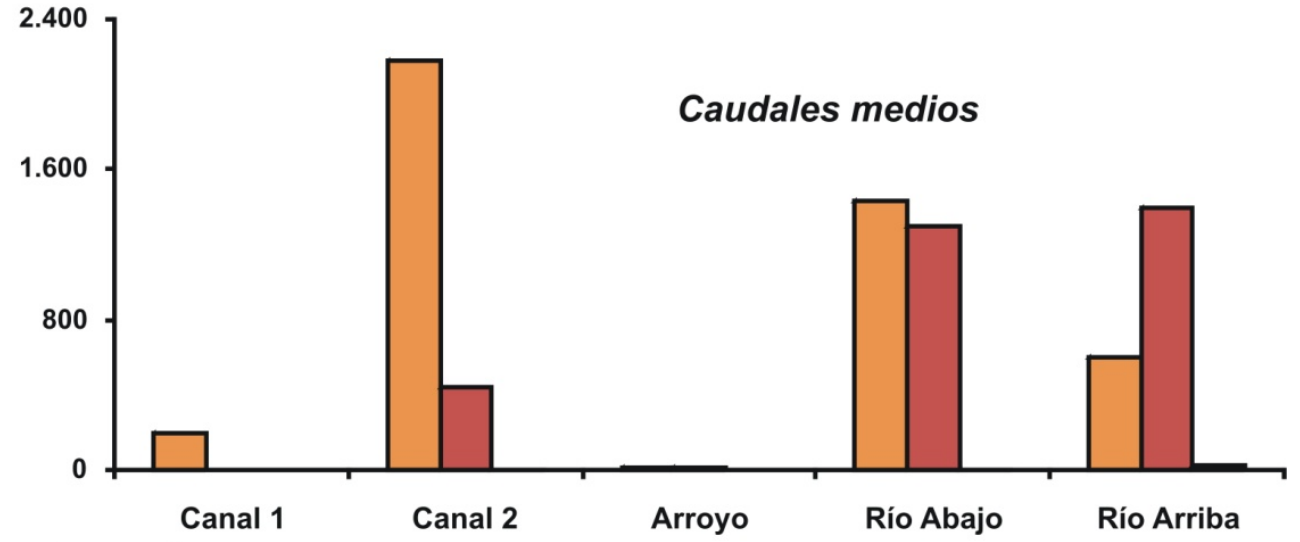

$N^{\circ}$ huevos/L

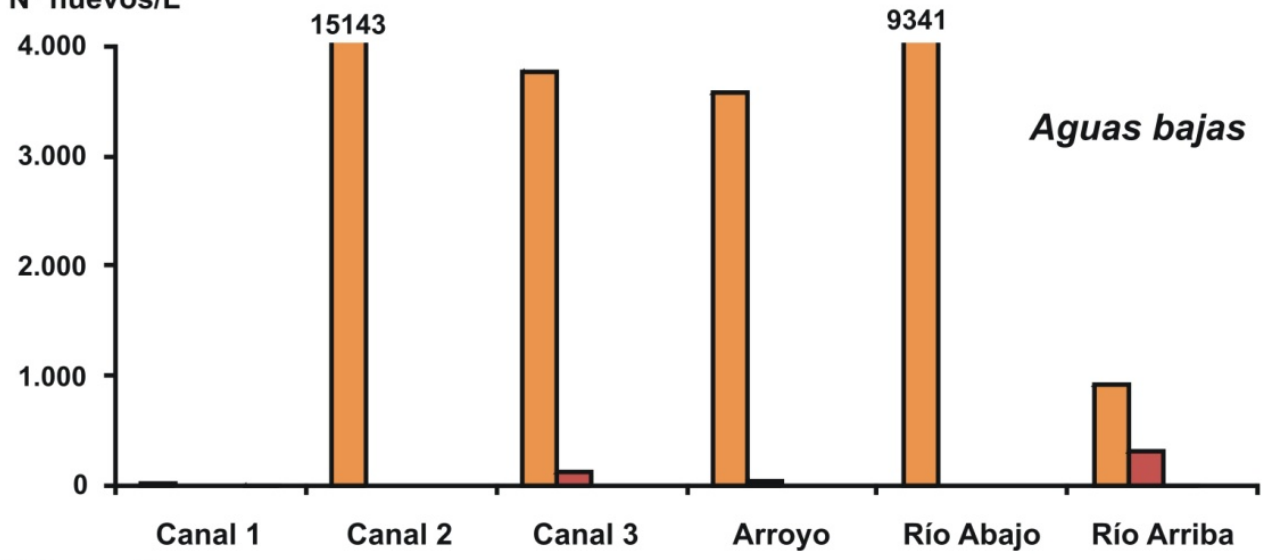

$N^{\circ}$ Huevos/L

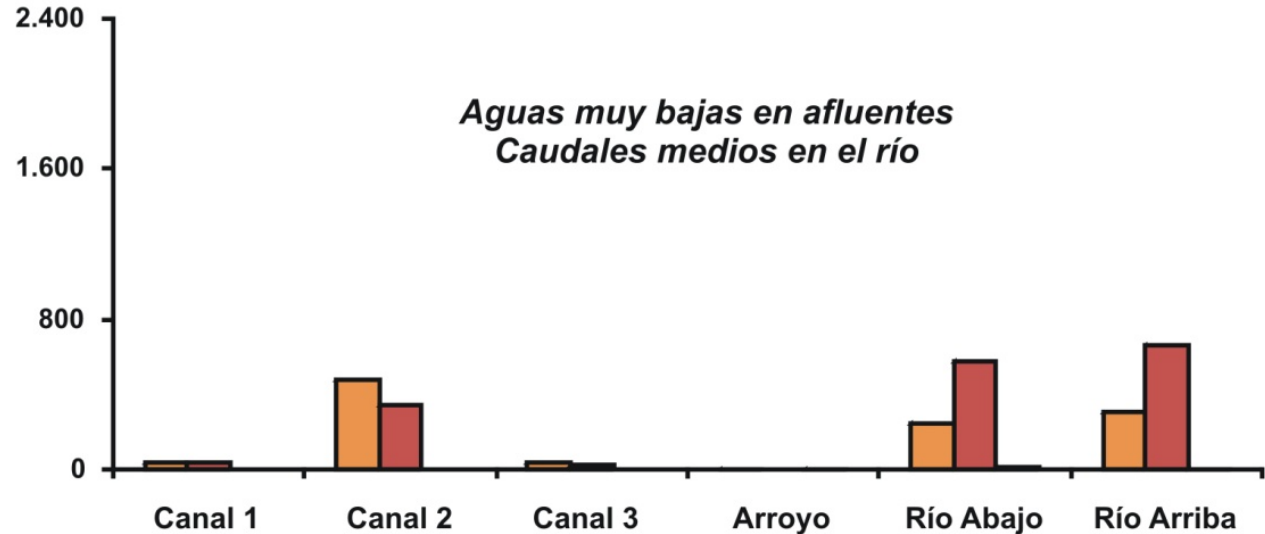

Figura.4.43: № total de huevos en hembras (densidad de hembras ovígeras $\mathrm{x} \mathrm{n}^{\mathrm{o}}$ de huevos presente en cada una de ellas). Se muestran los valores promedio (días 1 y 2) por sitio de muestreo y condición hidrológica: aguas altas (mayo 2007), caudales medios (marzo 2008), aguas bajas (nov. 2008) (con diferente escala), y aguas muy bajas en afluentes (sistema Bragado) con caudales medios en el río (sept. 2009). Referencias: huevos de rotíferos (anaranjado), de copépodos (rojo) y de cladóceros (violeta). 


\subsubsection{Abundancia de copépodos adultos, hembras ovígeras, copepoditos y nauplii}

En aguas altas (mayo 2007), se observó baja abundancia de copépodos, siendo relevante la presencia de $q$ ovígeras y de copepoditos en el canal 1, y de las larvas nauplii en el canal 2 y el río aguas abajo (Fig. 4.45). En caudales medios (marzo 2008), se observaron picos de abundancia total de copépodos adultos y de $q$ ovígeras en el río aguas arriba, y de copepoditos y las larvas nauplii aguas abajo. En aguas bajas (nov. 2008), la abundancia total de adultos, + ovígeras y larvas nauplii fue máxima en el río aguas arriba, y de copepoditos en el canal 3. En el canal 1 no se observaron $ᄋ$ ovígeras ni de copepoditos, y la densidad de adultos y nauplii fue muy baja. En aguas muy bajas en el sistema Bragado pero con caudales medios en el río (sept. 2009) se observó elevada densidad de nauplii en los canales 2 y 3 y en el río (600-1500 ind/L). Los copepoditos se destacaron en el canal 3 y las $q$ ovígeras de copépodos en el río.

En el río se observó un aumento de la abundancia total de las larvas nauplii en aguas altas y caudales medios, aguas abajo del trasvase. En aguas bajas, se observó una disminución en la densidad de nauplii y copepoditos, y la ausencia de $q$ ovígeras en el río aguas abajo. En caudales medios (sept. 2009), disminuyó la abundancia total de nauplii y de + ovígeras en el río aguas abajo, sin variaciones en los copepoditos.

\subsubsection{Distribución de adultos, hembras ovígeras, copepoditos y nauplii por grupos}

Entre los grupos de copépodos dominaron los cyclopoideos en la mayoría de los sitios de muestreo y condiciones hidrológicas, tanto de $q$ ovígeras como copepoditos y larvas nauplii (Fig. 4.46-49). En aguas altas, se hallaron representantes de copépodos cyclopoideos, harpacticoideos y calanoideos en todos los sitios de muestreo, en al menos un estadio de desarrollo (nauplii, copepodito o adulto). Sin embargo, los calanoideos adultos estuvieron restringidos a los canales 1 y 2 y el río aguas abajo, sin la presencia de $q$ ovígeras. En caudales medios, predominaron en el río los copepoditos y q ovígeras de cyclopoideos y en el canal 2 los de harpacticoideos. Los calanoideos fueron escasos, y sólo se observaron adultos de Boeckella poopensis en el canal 1 y de Notodiaptomus incompositus en el canal 2 y en el río aguas abajo. En aguas bajas, los harpacticoideos prevalecieron en el río (nauplii, copepoditos y $q$ ovígeras), mientras que los copepoditos de calanoideos sólo se hallaron en los canales 2 y 3, en bajas densidades. En aguas muy bajas en el sistema Bragado pero con caudales medios en el río (sept. 2009), todos los sitios registraron larvas nauplii de los tres grupos de copépodos. En el canal 2 se destacaron por su abundancia los calanoideos (nauplii, copepoditos y adultos) y en el río los harpacticoideos, aunque también se hallaron $q$ ovígeras en los canales 1 y 2. 

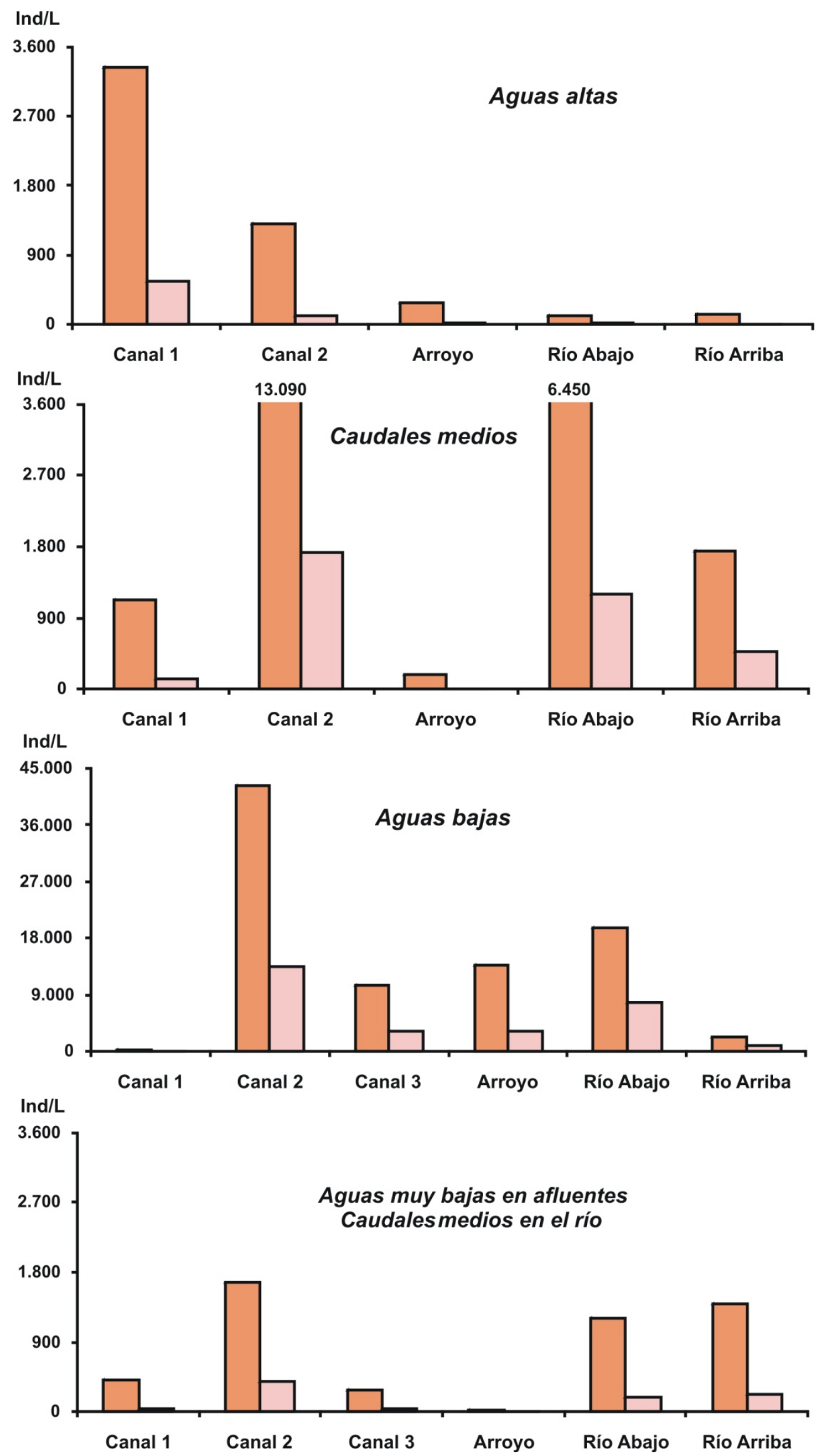

Figura 4.44: Abundancia total de rotíferos (anaranjado) y de sus hembras ovígeras (rosado). Se muestran los valores promedio (días 1 y 2) hallados por sitio de muestreo y condición hidrológica: aguas altas (mayo 2007), caudales medios (marzo 2008), aguas bajas (nov. 2008) (con diferente escala), y aguas muy bajas en afluentes (sistema Bragado) con caudales medios en el río (sept. 2009). 


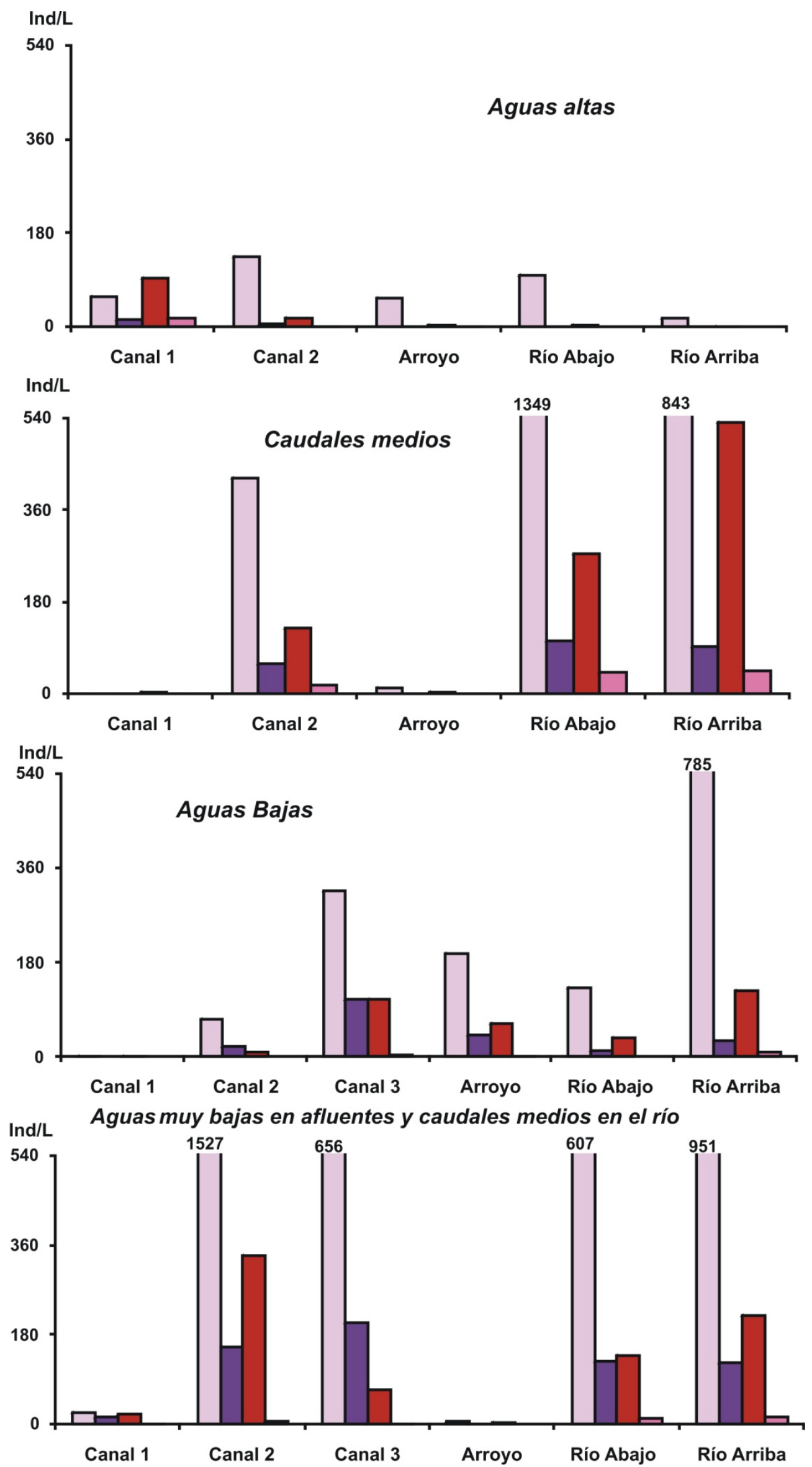

Figura 4.45: Abundancia total de copépodos adultos no reproductivos (rojo), de sus hembras ovígeras (magenta), copepoditos (violeta) y larvas nauplii (rosado). Se muestran los valores promedio (días 1 y 2) hallados por sitio de muestreo y condición hidrológica: aguas altas (mayo 2007), caudales medios (marzo 2008), aguas bajas (nov. 2008) y aguas muy bajas en afluentes con caudales medios en el río (sept. 2009). 

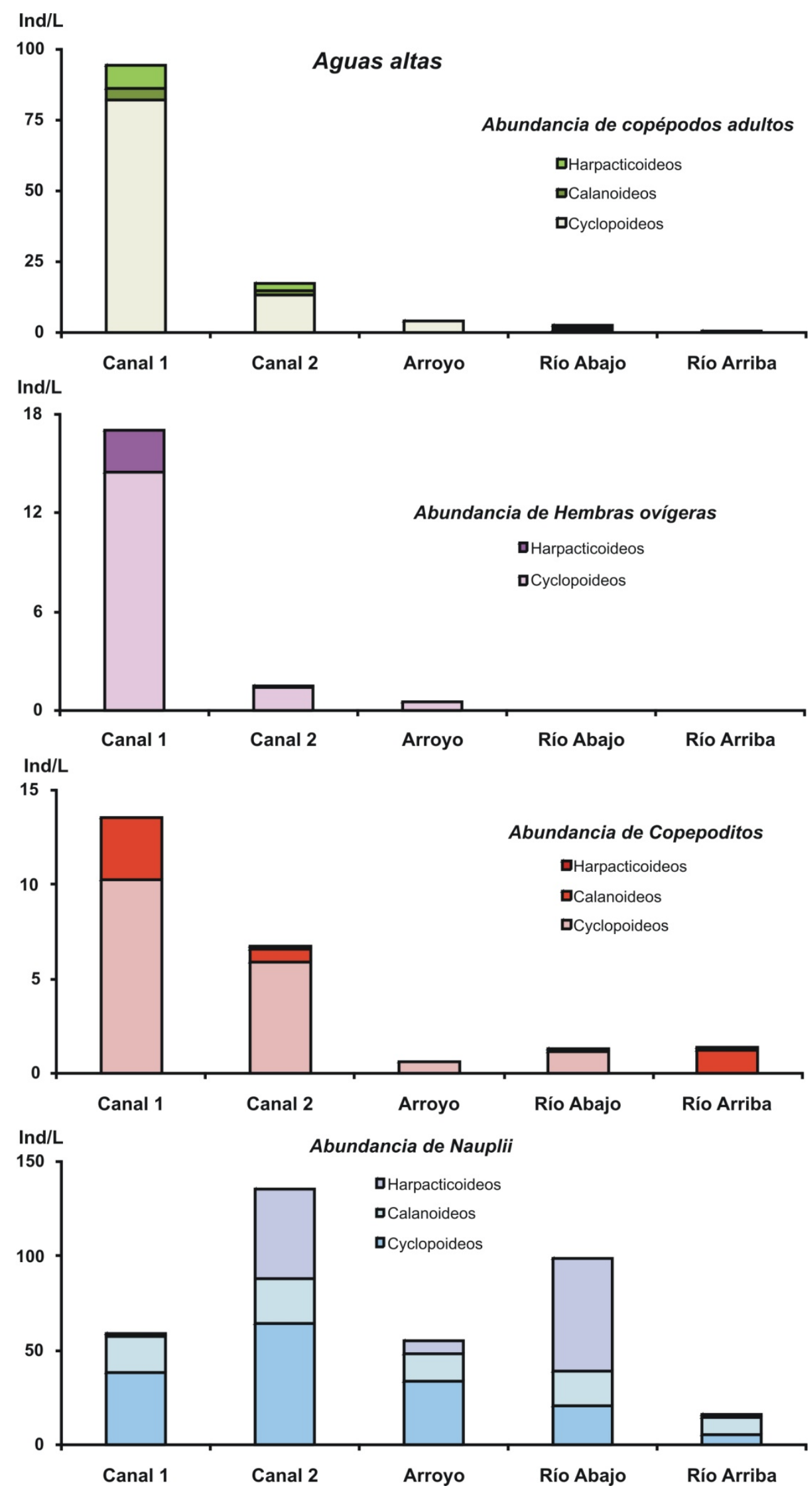

Figura 4.46: Abundancia total de adultos de copépodos, de hembras ovígeras, de copepoditos y larvas nauplii por grupo al que pertenecen (cyclopoideos, calanoideos y harpacticoideos). Se muestran los valores promedio (días 1 y 2) hallados por sitio de muestreo, en condiciones de aguas altas (mayo 2007). 

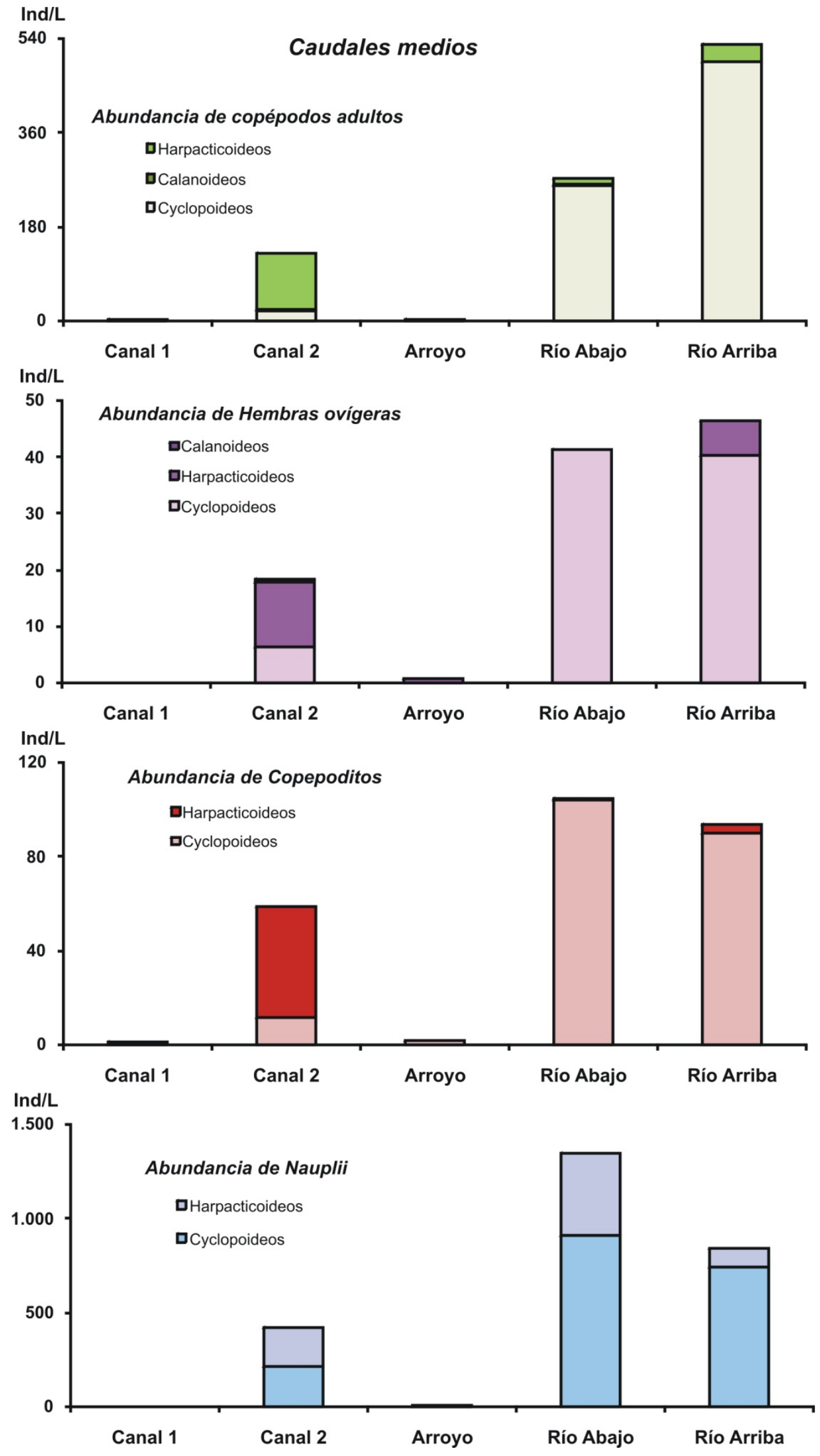

Figura 4.47: Abundancia total de adultos de copépodos, de hembras ovígeras, de copepoditos y larvas nauplii por grupo al que pertenecen (cyclopoideos, calanoideos y harpacticoideos). Se muestran los valores promedio (días 1 y 2) hallados para cada sitio de muestreo, en condiciones de caudales medios (marzo 2008). 

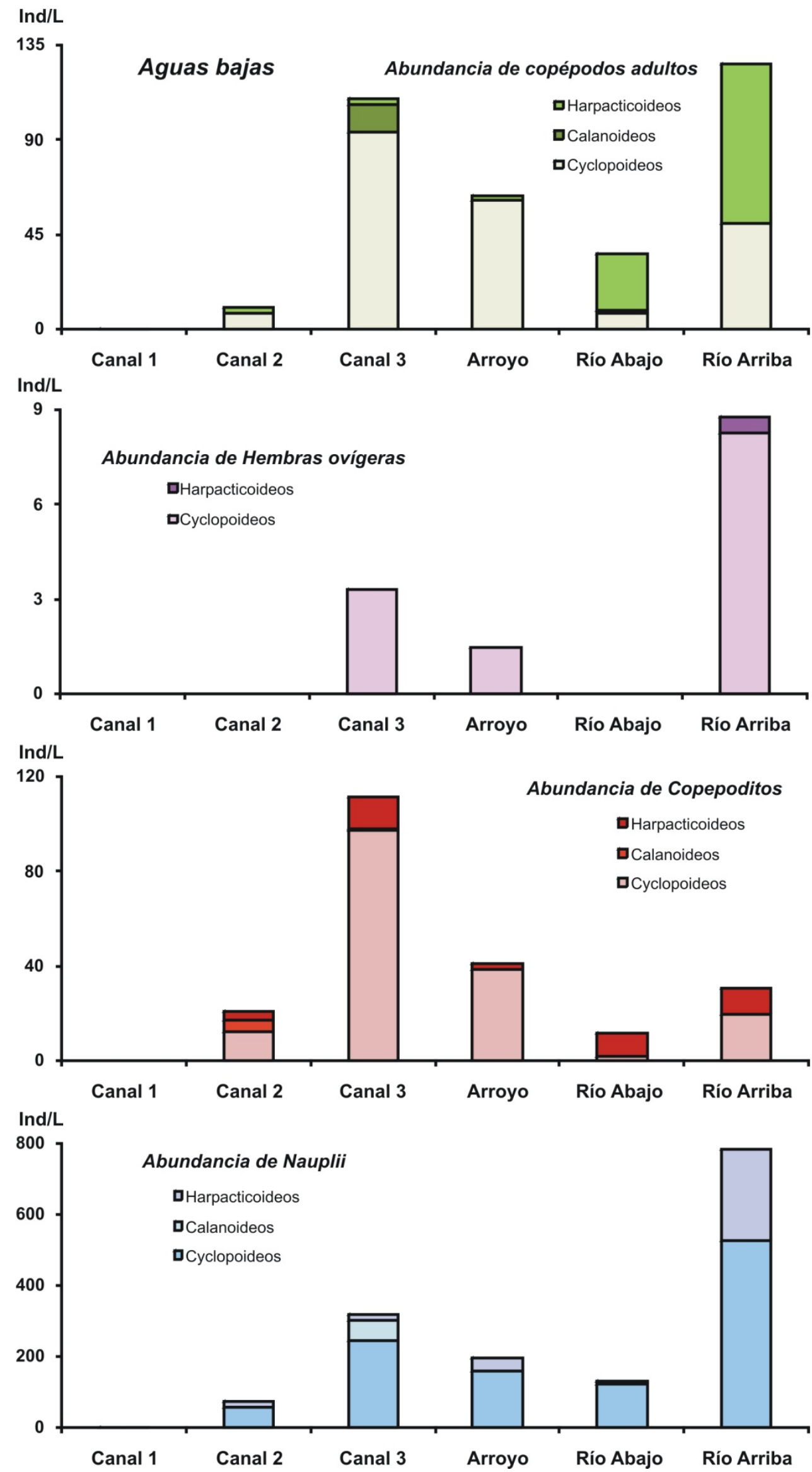

Figura 4.48: Abundancia total de adultos de copépodos, de hembras ovígeras, de copepoditos y larvas nauplii por grupo al que pertenecen (cyclopoideos, calanoideos y harpacticoideos). Se muestran los valores promedio (días 1 y 2) hallados para cada sitio de muestreo, en condiciones de aguas bajas (nov. 2008). 

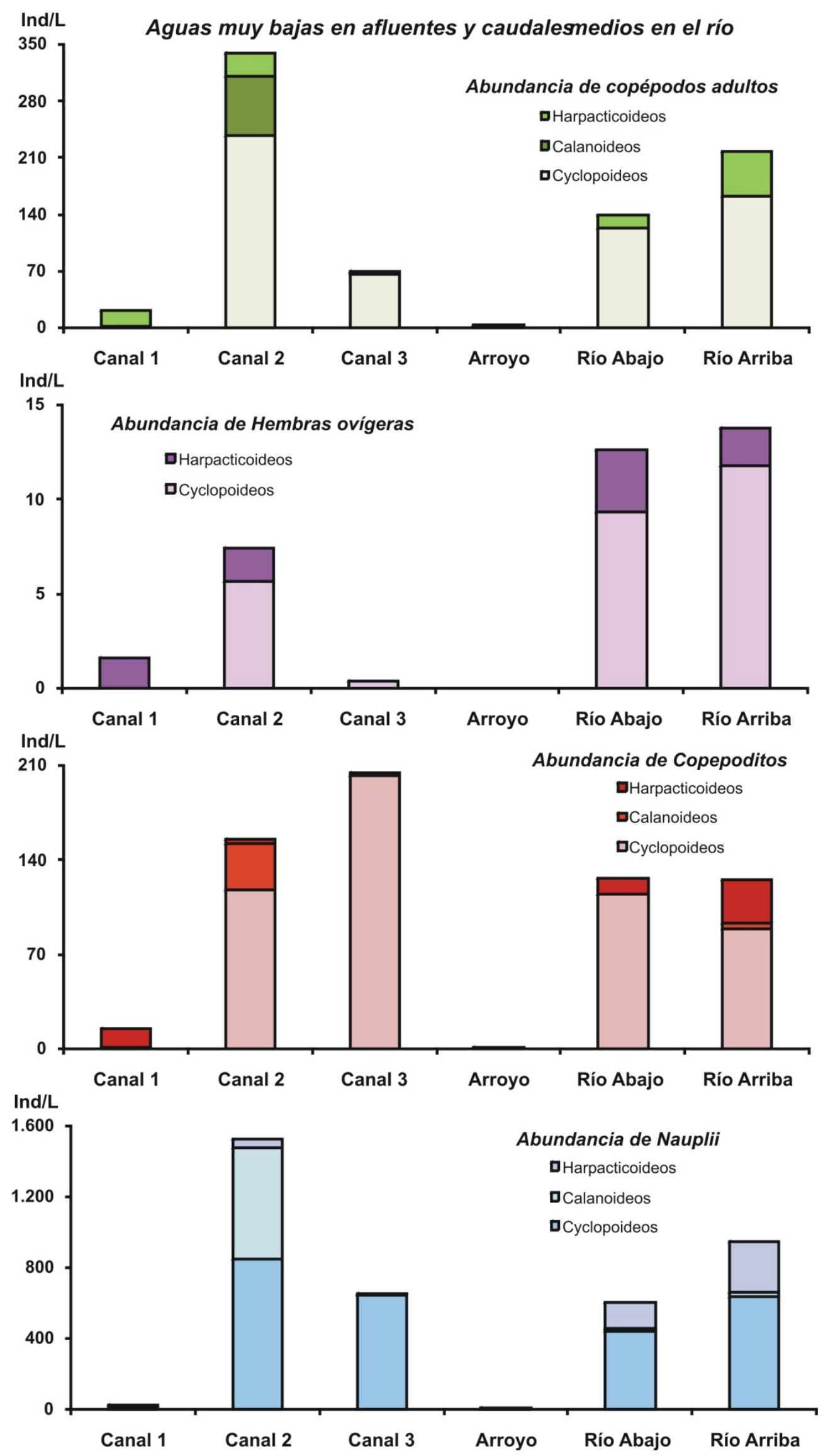

Figura 4.49: Abundancia total de adultos de copépodos, de hembras ovígeras, copepoditos y larvas nauplii por grupo al que pertenecen (cyclopoideos, calanoideos y harpacticoideos). Se muestran los valores promedio (días 1 y 2) hallados cada sitio de muestreo en condiciones de aguas muy bajas en el sistema Bragado pero con caudales medios en el río (sept. 2009). 


\subsubsection{Abundancia de cladóceros adultos, de hembras ovígeras y juveniles}

En aguas altas los cladóceros se destacaron por su abundancia total de $q$ ovígeras, juveniles y cladoceritos en el canal 1, reduciendo su importancia a lo largo del sistema Bragado, mientras que en el río se observaron juveniles, aumentando aguas abajo (Fig. 4.50). En caudales medios, la abundancia del grupo fue máxima en el río aguas arriba ( $q$ ovígeras, juveniles y cladoceritos), disminuyendo aguas abajo. En el sistema Bragado, las $q$ ovígeras fueron escasas, sin cladoceritos ni juveniles. Algo similar ocurrió en aguas bajas, donde sólo se registraron $q$ ovígeras en el río aguas arriba, pertenecientes a las especies Alona glabra y A. rectangula. El grupo estuvo ausente en el canal 1, y en el arroyo se observaron los valores máximos de densidad de cladoceritos (53 ind/L) y juveniles. En caudales medios (sept. 2009), se destacaron por su abundancia los juveniles, 우 ovígeras y cladoceritos, mientras que en el sistema Bragado fueron escasos (aguas muy bajas).

\subsubsection{Reproducción de las especies más representativas del zooplancton}

En las Tablas 4.3-6 se muestran las especies de zooplancton con reproducción por huevos (rotíferos, copépodos, cladóceros y ostrácodos) halladas en los diferentes muestreos. Se detalla el egg ratio ( $\mathrm{n}^{\mathrm{o}}$ de huevos promedio por + ovígera) y el rango de valores del $\mathrm{n}^{\mathrm{o}}$ de huevos hallado por especie. Asimismo, el \% de $q$ ovígeras respecto a la abundancia total de cada especie por sitio de muestreo, y la presencia de huevos de resistencia en formación, todavía adosados a las $\$$. La abundancia relativa de las $q$ ovígeras de cada especie en reproducción fue muy variable $(0,14-$ $100 \%$ ), perteneciendo los valores extremos a especies con muy bajas densidades como Ceriodaphnia cf dubia en aguas altas, Trichocerca pusilla y Cletocamptus deitersi en caudales medios, y Brachionus dimidiatus, B. calyciflorus y B. bidentata en aguas muy bajas. Las especies abundantes y ampliamente distribuidas registraron menor variación (B. plicatilis, B. angularis y B. pterodinoides).

\section{Brachionus plicatilis}

La especie estuvo presente en todos los sitios de muestreo y se destacó como especie dominante del zooplancton en varios sitios y condiciones hidrológicas (Fig. 4.51). La densidad de las 9 ovígeras siguió el mismo patrón de la abundancia total, variando su proporción relativa (\%) según los sitios y momentos de muestreos (Tablas 4.3-6). La densidad de $q$ ovígeras fue mínima en aguas altas y máxima en aguas bajas, particularmente en el canal 2. En aguas bajas también se observaron elevados valores de egg ratio y un gran $n^{0}$ de huevos por $q$ ovígera en el río aguas abajo (Fig. 4.52-53). En todas las condiciones hidrológicas se hallaron huevos de resistencia de la especie, ya sea en formación o libres en la muestra, siendo más relevantes aguas bajas. 

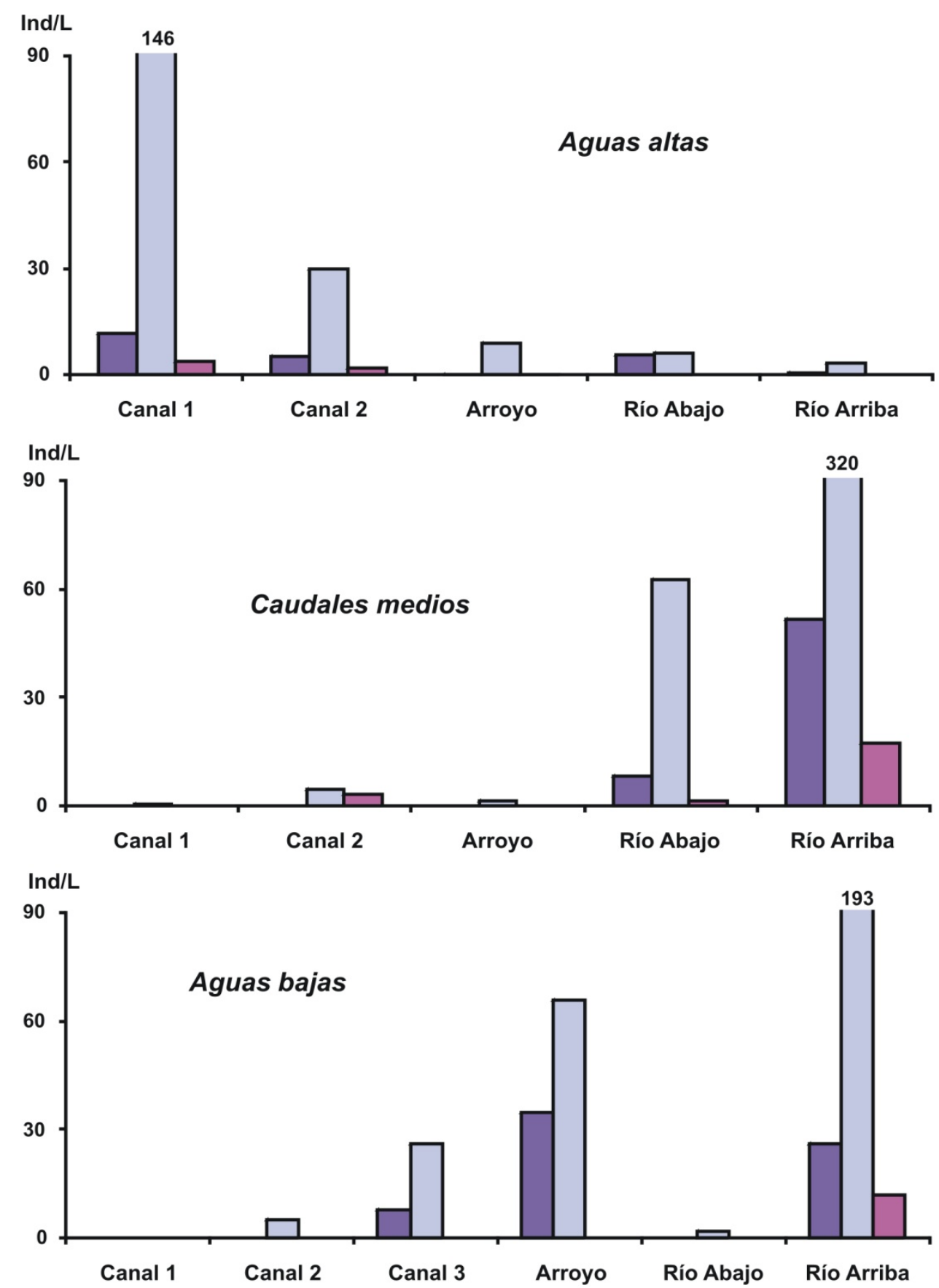

Ind/L

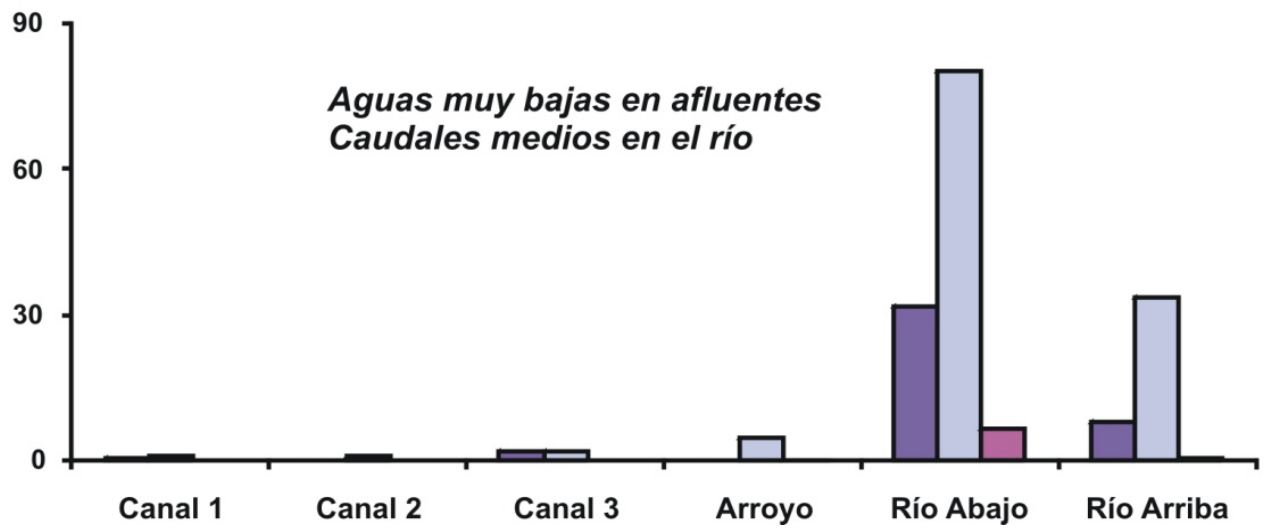

Figura 4.50: Abundancia total de adultos de cladóceros (lila), de hembras ovígeras de cladóceros (magenta) y juveniles (violeta). Se muestran los valores promedio (días 1 y 2) hallados por sitio de muestreo y condición hidrológica: aguas altas (mayo 2007), caudales medios (marzo 2008), aguas bajas (nov. 2008) y aguas muy bajas en afluentes (sistema Bragado) con caudales medios en el río (sept. 2009). 
Tabla 4.3: Valores promedio (días 1 y 2) del egg ratio (no de huevos promedio por hembra ovígera) de cada especie de zooplancton con reproducción por huevos hallada en el muestreo de mayo 2007 (aguas altas), y el rango de variación del $\mathbf{n}^{\mathbf{0}}$ de huevos hallados por especie entre corchetes. Entre paréntesis se muestra el \% de hembras ovígeras respecto a la abundancia total de cada especie, por sitio de muestreo. El $\mathrm{N}_{\text {máx }}$ corresponde a la abundancia máxima de hembras ovígeras registrada entre los sitios analizados (Ind/L). El asterisco indica la presencia de huevos de resistencia en formación, todavía adosados a la hembra.

\begin{tabular}{|c|c|c|c|c|c|c|}
\hline Aguas altas (Mayo 2007) & Canal 1 & Canal 2 & Arroyo & Río Abajo & Río Arriba & $\mathrm{N}_{\text {máx }}$ \\
\hline \multicolumn{7}{|l|}{ Rotíferos } \\
\hline Brachionus bidentata & & $1(16 \%)$ & & & & 0,43 \\
\hline Brachionus caudatus & $1(43 \%)$ & $1(12 \%)$ & & & & 3,85 \\
\hline Brachionus dimidiatus inermis & & $2(100 \%)$ & & & & 0,43 \\
\hline Brachionus plicatilis & $1(17 \%)$ & $1,3[1-2](11 \%)$ & $1(11 \%)$ & $1(34 \%)$ & & 3,75 \\
\hline Keratella tropica & $1(18 \%)$ & $1(14 \%)$ & $1(13 \%)$ & $1(16 \%)$ & $1(14 \%)$ & 345 \\
\hline Notholca acuminata & $1(17 \%)$ & & & & & 1,35 \\
\hline Polyarthra sp. & & $1(100 \%)$ & & & $1(100 \%)$ & 2,83 \\
\hline Synchaeta pectinata & $1(3 \%)$ & & & & & 1,25 \\
\hline \multicolumn{7}{|l|}{ Copépodos } \\
\hline Acanthocyclops robustus & $20[12-28](29 \%)$ & $20(5 \%)$ & & & & 10,2 \\
\hline Cletocamptus deitersi & & $17(100 \%)$ & & & & 0,13 \\
\hline Harpacticoideo sp. & $19(39 \%)$ & & & & & 2,5 \\
\hline Metacyclops mendocinus & $19[16-20](21 \%)$ & $18(20 \%)$ & $20(23 \%)$ & & & 4,3 \\
\hline \multicolumn{7}{|l|}{ Cladóceros } \\
\hline Alona rectangula & & $1,5[1-2](19 \%)$ & $1(29 \%)$ & & & 0,58 \\
\hline Ceriodaphnia cf. dubia & & $5(3 \%)$ & $3[2-4]$ & & & 0,43 \\
\hline Daphnia spinulata & $2,65[2-4]^{*}(3 \%)$ & $2^{*}(9 \%)$ & & & & 2,6 \\
\hline
\end{tabular}

En aguas altas (mayo 2007), la especie estuvo presente en todos los sitios de muestreo pero con bajas abundancias. Las $q$ ovígeras presentaron 1 y 2 huevos, y estuvieron ausentes en el río aguas arriba. Su abundancia relativa fue máxima en el río aguas abajo (34\%) y el egg ratio en el canal 2 $(1,3)$. Sólo se hallaron huevos de resistencia en el canal 1 y el río aguas arriba.

En caudales medios (marzo 2008), las $q$ ovígeras de B. plicatilis registraron picos de abundancia en el canal 2 y el río aguas abajo, y su abundancia relativa varió entre 22-31\%, con valores extremos en los canales. Se observaron morfotipos S y L de la especie en la mayoría de los sitios, a excepción del arroyo, donde sólo se encontraron formas S (Fig. 4.54). En el sistema Bragado predominaron los morfotipos S (66-100\%), y en el río los L, principalmente aguas arriba (72\%). La abundancia relativa de las $q$ ovígeras $S$ y $\mathrm{L}$ fue similar en todos sitios de muestreo, a excepción del río aguas arriba (92\% $q$ ovígeras L). Ambas formas presentaron elevado $\mathrm{n}^{\circ}$ de huevos, pero el morfotipos $\mathrm{S}$ registró hasta 9 huevos por $q$ ovígeras (río aguas abajo), siendo el valor más alto observado a lo largo de este estudio (Tabla 4.7). La mayor parte de las $q$ ovígeras presentaron 1 huevo (50\%) y 2 huevos (17\%). El egg ratio varió entre 1 y 1,54, y el no de huevos por individuo entre 0,47 y 0,3, con valores extremos para el arroyo y el río aguas arriba, respectivamente. 
Tabla 4.4: Valores promedio (días 1 y 2) del egg ratio ( $n^{\circ}$ de huevos promedio por hembra ovígera) de cada especie de zooplancton con reproducción por huevos hallada en el muestreo de marzo 2008 (caudales medios), y el rango de variación del no de huevos hallados por especie entre corchetes. Entre paréntesis se muestra el \% de hembras ovígeras respecto a la abundancia total de cada especie, por sitio de muestreo. El

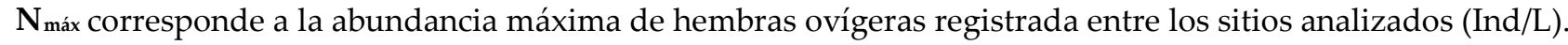
El asterisco simboliza la presencia de huevos de resistencia en formación, todavía adosados a la hembra.

\begin{tabular}{|c|c|c|c|c|c|c|}
\hline Caudales medios (Marzo 2008) & Canal 1 & Canal 2 & Arroyo & Río Abajo & Río Arriba & $\mathrm{N}_{\text {máx }}$ \\
\hline \multicolumn{7}{|l|}{ Rotíferos } \\
\hline Anuraeopsis fissa & & $1(29 \%)$ & & & & 6,4 \\
\hline Brachionus angularis & $1(33 \%)$ & $1,2[1$ a 4$](27 \%)$ & & $1,1[1-2-4]^{*}(37 \%)$ & $1,1[1$ a 3$](46 \%)$ & 473 \\
\hline Brachionus bidentata & & $1,3[1-2](6 \%)$ & & $1(13 \%)$ & & 6,4 \\
\hline Brachionus caudatus & & $1(63 \%)$ & & & & 8,9 \\
\hline Brachionus plicatilis & $1,5[1$ a 4$](31 \%)$ & $1,3[1 \text { a } 5]^{*}(22 \%)$ & $1(30 \%)$ & $1,3$ [1 a 9$]^{*}(26 \%)$ & $1,5[1 \text { a } 5]^{*}(29 \%)$ & 339 \\
\hline Brachionus quadridentatus & & & & $1(25 \%)$ & $1(16 \%)$ & 6,56 \\
\hline Brachionus rotundiformis & & $1,5[1$ a 3$](23 \%)$ & & $1(21 \%)$ & $1(62 \%)$ & 12 \\
\hline Brachionus urceolaris & $1(19 \%)$ & & & $1(2 \%)$ & & 2,05 \\
\hline Colurella uncinata & & & & $1(11 \%)$ & & 1,6 \\
\hline Filinia longiseta & & & & $1[1-2](27 \%)$ & & 62,4 \\
\hline Filinia terminalis & & $1,88[1-3-4](13 \%)$ & & $1(6 \%)$ & $1,24$ [1 a 3$](14 \%)$ & 37,4 \\
\hline Keratella tropica & & & & $1(31 \%)$ & $1(39 \%)$ & 16,6 \\
\hline Pompholyx sulcata & $1,13[1-2](44 \%)$ & $1(16 \%)$ & & $1(21 \%)$ & $1(28 \%)$ & 10,7 \\
\hline Proales sp.2 & & & $1(43 \%)$ & & & 1,87 \\
\hline Proalides sp.1 & & & & $1(3 \%)$ & $1(3 \%)$ & 33,9 \\
\hline Proalides cf. sordida & & $1(2 \%)$ & & & & 40,6 \\
\hline Synchaeta pectinata & $1(1 \%)$ & & $1(3 \%)$ & & & 5,6 \\
\hline Trichocerca capuchina & & $1(8 \%)$ & & & & 60,4 \\
\hline Trichocerca pusilla & $1(100 \%)$ & $1(0,14 \%)$ & & & & 3,8 \\
\hline \multicolumn{7}{|l|}{ Copépodos } \\
\hline Acanthocyclops robustus & & $25[18-36](58 \%)$ & & $32[16-44](38 \%)$ & 27 [16-36] (12\%) & 37,5 \\
\hline Cletocamptus deitersi & & $23,6[16-30](10 \%)$ & $23,6(100 \%)$ & & $15(46 \%)$ & 7,8 \\
\hline Metacyclops mendocinus & & & & $17,3[12-24](35 \%)$ & $20,8[16-28](3 \%)$ & 1,9 \\
\hline Harpacticoideo sp. & & $23,8(18 \%)$ & & & & 3,8 \\
\hline Microcyclops alius & & $24,7[20-28](46 \%)$ & & 26 [18-32] (5\%) & 21 [16-28] (20\%) & 3,19 \\
\hline Notodiaptomus incompositus & & $26[20-32](26 \%)$ & & & & 0,4 \\
\hline \multicolumn{7}{|l|}{ Cladóceros } \\
\hline Alona glabra & & $2(100 \%)$ & & $2(29 \%)$ & $1,4[1-2](19 \%)$ & 5,58 \\
\hline Moina micrura & & & & & $2,1[1-2-4](3 \%)$ & 4,35 \\
\hline
\end{tabular}

En aguas bajas (nov. 2008), Brachionus plicatilis constituyó la especie más importante del zooplancton, observándose en el canal 2 los valores máximos de abundancia total de $q$ ovígeras (18.000 ind/L), siendo también elevada su contribución relativa (36\%). Se observaron morfotipos $\mathrm{S}$ y L en la mayoría de los sitios de muestreo, a excepción del canal 3, donde sólo se encontraron formas L. En el canal 1 y en el arroyo predominaron los morfotipos S (80\%), en el río aguas arriba los morfotipos L (98\%) y en el canal 2 y en el río aguas abajo su relación fue cercana al $50 \%$. La mayor parte de las $q$ ovígeras acarrearon 1 huevo, pero ambos morfotipos presentaron amplio rango de variación en el $\mathrm{n}^{\circ}$ de huevos por + ovígera (Tabla 4.8). El egg ratio de la especie fue máximo en el río aguas abajo (2) al igual que el no de huevos por individuo (0,49) (Fig. 4.55).

En el muestreo de aguas muy bajas en el sistema Bragado pero con caudales medios en el río (sept. 2009), Brachionus plicatilis se destacó por la abundancia de + ovígeras en el canal 2, y en 
menor en el canal 1. Sólo se hallaron $q$ ovígeras en los canales 1 y 2 y en el río aguas abajo, la mayoría de ellas portaron 1 huevo, y sólo en el canal 2 acarrearon de 1 a 5 huevos. El egg ratio fue máximo en el canal 2 y también el no de huevos por individuo $(0,4)$.

Tabla 4.5: Valores promedio (días 1 y 2) del egg ratio (no de huevos promedio por hembra ovígera) de cada especie de zooplancton con reproducción por huevos hallada en el muestreo de nov. 2008 (aguas bajas), y el rango de variación del no de huevos hallados por especie entre corchetes. Entre paréntesis se muestra el \% de hembras ovígeras respecto a la abundancia total de cada especie, por sitio de muestreo. El $\mathbf{N}_{\text {máx }}$ corresponde a la abundancia máxima de hembras ovígeras registrada entre los sitios analizados (Ind/L). El asterisco indica la presencia de huevos de resistencia en formación, todavía adosados a la hembra.

\begin{tabular}{|c|c|c|c|c|c|c|c|}
\hline Aguas bajas (Noviembre 2008) & Canal 1 & Canal 2 & Canal 3 & Arroyo & Río Abajo & Río Arriba & $\mathbf{N}_{\text {máx }}$ \\
\hline \multicolumn{8}{|l|}{ Rotíferos } \\
\hline Anuraeopsis fissa & & $1(17 \%)$ & $1(50 \%)$ & & & & 37 \\
\hline Ascomorpha ovata & & & $1(50 \%)$ & $1(8 \%)$ & & & 3,3 \\
\hline Brachionus angularis & $1(7 \%)$ & $1[1-2](28 \%)$ & $1,1[1 \text { a } 3]^{*}(33 \%)$ & $1,1$ [1 a 3$](23 \%)$ & $1,2[1 \text { a } 5]^{*}(41 \%)$ & $1[1 \text { a } 3]^{*}(41 \%)$ & 6146 \\
\hline Brachionus bidentata & & & & & $1(26 \%)$ & $1(21 \%)$ & 10 \\
\hline Brachionus calyciflorus & & & & & & $1(40 \%)$ & 1,7 \\
\hline Brachionus caudatus & & $1(18 \%)$ & & & & & 8 \\
\hline Brachionus dimidiatus inermis & & $1,33[1-2](1 \%)$ & & & & & 5 \\
\hline Brachionus plicatilis & $1[1-2](15 \%)$ & $1,1[1$ a 5$](36 \%)$ & $1(14 \%)$ & $1,2[1 \text { a } 4]^{*}(30 \%)$ & $2[1 \text { a } 4,7]^{*}(24 \%)$ & $1,4[1-2](33 \%)$ & 6922 \\
\hline Brachionus pteridinoides & & & $1(100 \%)$ & & $1^{*}(27 \%)$ & & 3,3 \\
\hline Brachionus quadridentatus & & & & & & $1(27 \%)$ & 24 \\
\hline Brachionus rotundiformis & $1(25 \%)$ & & $1(28 \%)$ & & & & 37 \\
\hline Colurella uncinata & $1(3 \%)$ & & & & & & 0,5 \\
\hline Dicranophorus sp. & & & & 1,07 [1-2] (42\%) & & & 61 \\
\hline Filinia terminalis & & $1,8[1-2](56 \%)$ & & & & $1,7$ [1 a 3$](40 \%)$ & 10 \\
\hline Hexarthra fennica & & & $1(50 \%)$ & & & & 3,3 \\
\hline Keratella americana & $1(8 \%)$ & & & & & & 0,5 \\
\hline Keratella tropica & & $1(100 \%)$ & $1(2 \%)$ & & $1(28 \%)$ & & 23 \\
\hline Pompholyx sulcata & $1(16 \%)$ & $1,1[1-2](27 \%)$ & $1,38[1-2](68 \%)$ & $1(28 \%)$ & $1(41 \%)$ & & 165 \\
\hline Proales sp.4 & & $1(100 \%)$ & & & & & 10 \\
\hline Proalides sp.1 & $1(6 \%)$ & & & $1(9 \%)$ & $1^{*}(11 \%)$ & & 6 \\
\hline \multicolumn{8}{|l|}{ Copépodos } \\
\hline Acanthocyclops robustus & & & $(21 \%)$ & & & 36 [24-56] (40\%) & 8,3 \\
\hline Cletocamptus deitersi & & & & & & $18(2 \%)$ & 0,5 \\
\hline Metacyclops mendocinus & & & & $29,5(3 \%)$ & & & 1,5 \\
\hline \multicolumn{8}{|l|}{ Cladóceros } \\
\hline Alona glabra & & & & & & $1(6 \%)$ & 11 \\
\hline Alona rectangula & & & & & & $1(8 \%)$ & 1 \\
\hline Ostrácodos & & & & & & & \\
\hline Heterocypris incongruens & $7(6 \%)$ & & & & & & 0,1 \\
\hline
\end{tabular}

Brachionus pterodinoides y B. urceolaris

Ambas especies fueron relevantes por su abundancia en el río Salado en caudales medios (sept. 2009), aumentando su importancia aguas abajo (Fig. 4.56-57). En el sistema Bragado, B. pterodinoides se halló en muy bajas densidades ( $<6$ ind/L) y B. urceolaris estuvo prácticamente ausente. La presencia de + ovígeras de B. pterodinoides estuvo limitada al río y al canal 1, con un egg ratio de 1,6 y 1, respectivamente, siendo similar el $n^{\circ}$ de huevos por individuo entre sitios (0,20,24). Sólo se observaron + ovígeras de B. urceolaris en el río, particularmente aguas arriba. El egg ratio de $B$. urceolaris fue de 1,42 y 1,55 huevos por $q$ ovígera aguar arriba y abajo, respectivamente, siendo mayor el no de huevos por individuo aguas arriba $(0,34)$. 


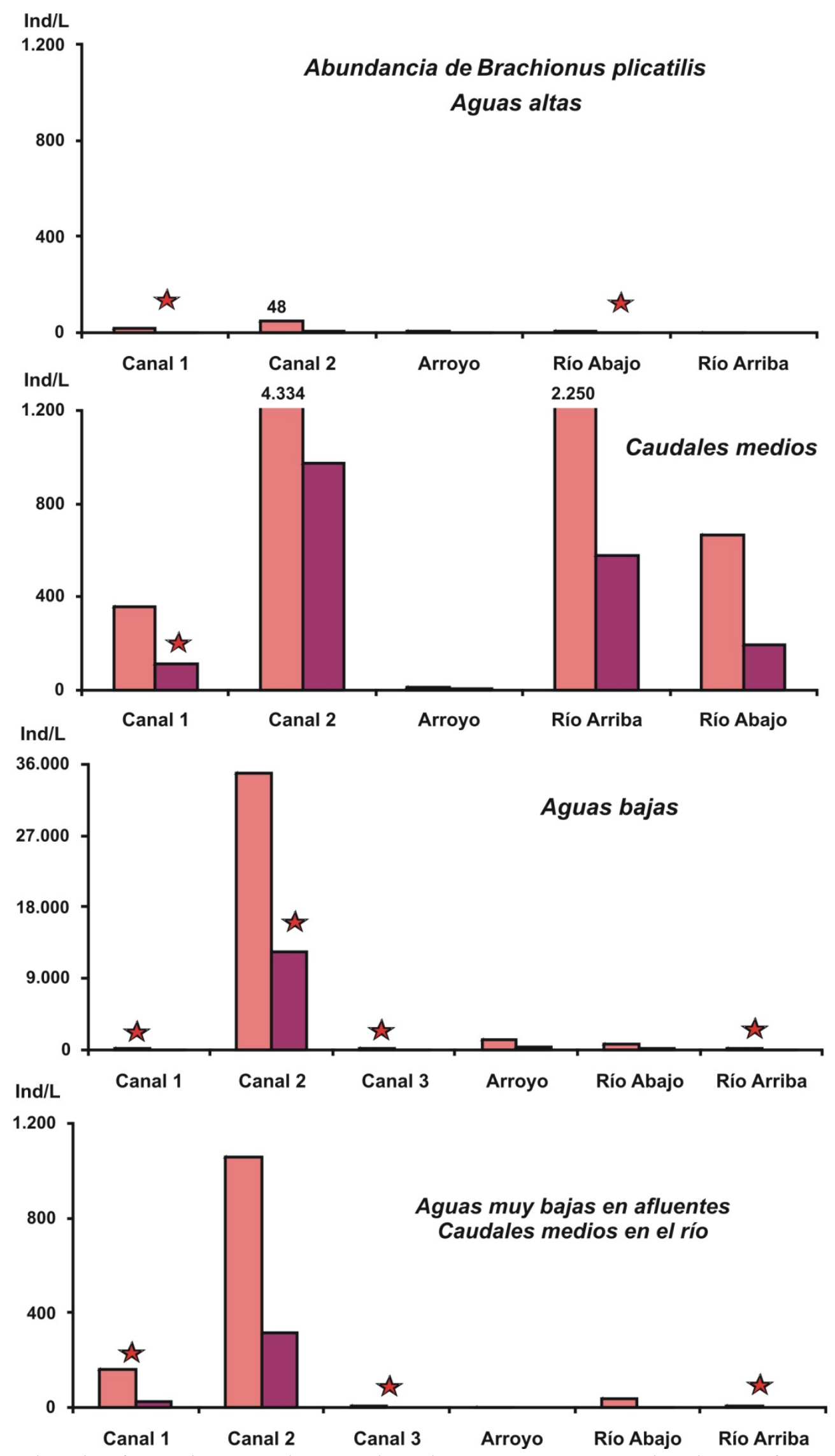

Figura 4.51: Abundancia total de Brachionus plicatilis (rosado) y de sus hembras ovígeras (bordó). Se muestran los valores promedio (días 1 y 2) hallados por sitio de muestreo y condición hidrológica: aguas altas (mayo 2007), caudales medios (marzo 2008), aguas bajas (nov. 2008) y aguas muy bajas en afluentes con caudales medios en el río (sept. 2009). Las estrellas rojas indican la presencia de huevos de resistencia libres en la muestra. 

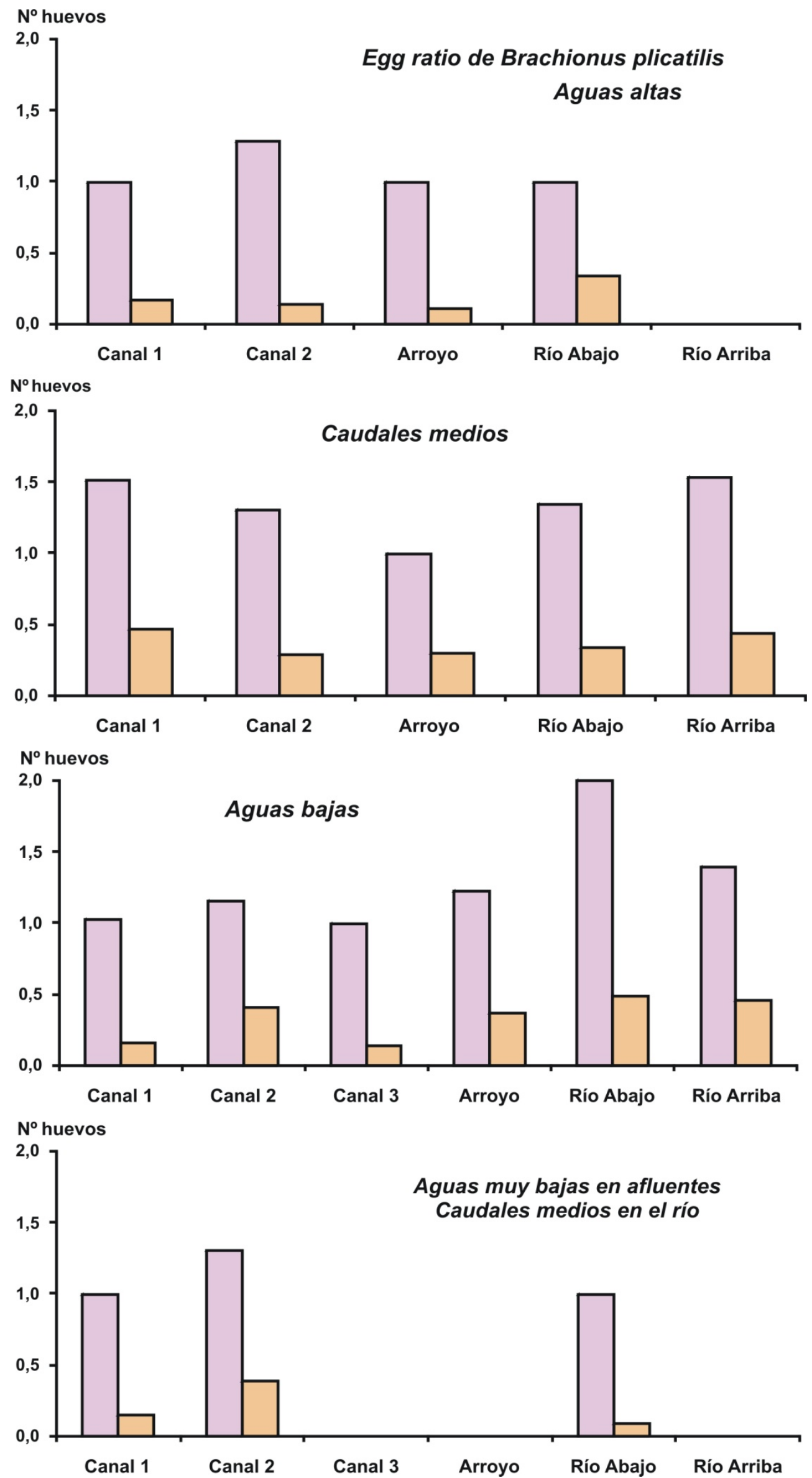

Figura 4.52: № de huevos promedio por hembra ovígera (egg ratio) (rosado) y n⿳o promedio de huevos por individuo (anaranjado) de Brachionus plicatilis. Se muestran los valores promedio (días 1 y 2) por sitio de muestreo y condición hidrológica: aguas altas (mayo 2007), caudales medios (marzo 2008), aguas bajas (nov. 2008) y aguas muy bajas en afluentes (sistema Bragado) con caudales medios en el río (sept. 2009). 

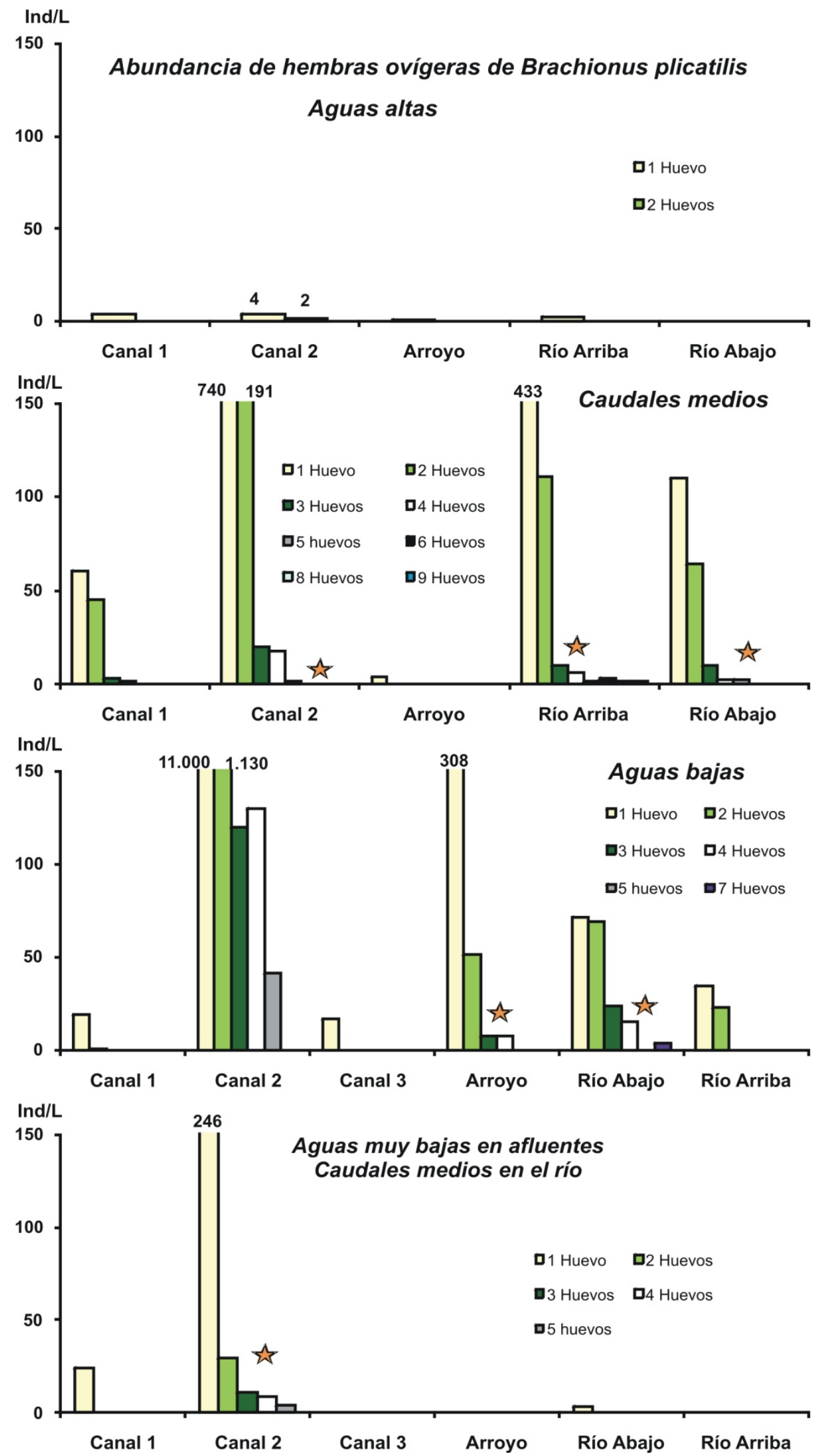

Figura 4.53: Abundancia total de las hembras ovígeras de Brachionus plicatilis según el $\mathbf{n}^{\mathbf{0}}$ de huevos presentes en cada una de ellas. Se muestran los valores promedio (días 1 y 2 ) hallados por sitio de muestreo y condición hidrológica: aguas altas (mayo 2007), caudales medios (marzo 2008), aguas bajas (nov. 2008) y aguas muy bajas en afluentes (sistema Bragado) con caudales medios en el río (sept. 2009). Las estrellas indican la presencia de huevos de resistencia en formación todavía adosados a las hembras. 


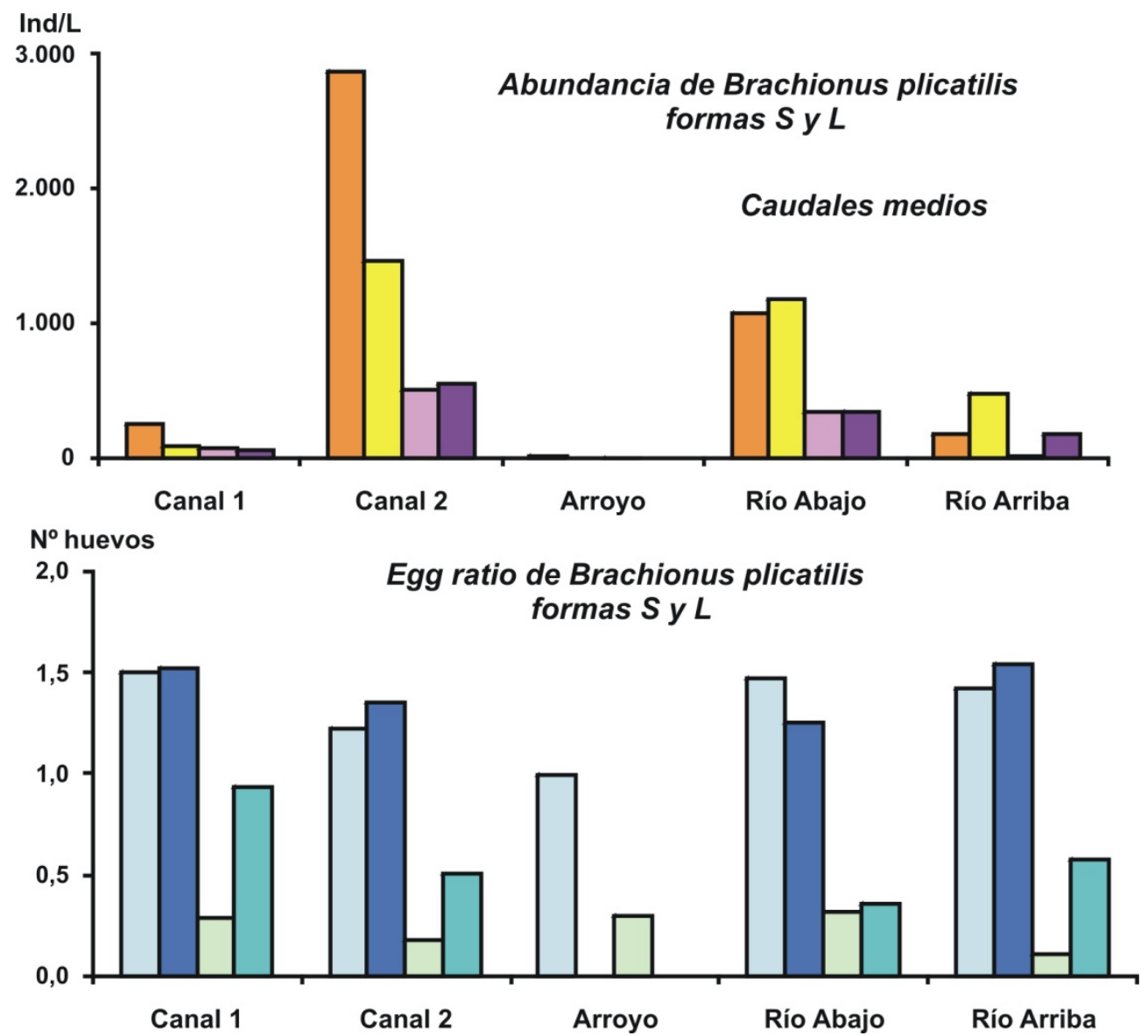

Figura 4.54: Arriba: Abundancia total de los morfotipos S (anaranjado) y L (amarillo) de Brachionus plicatilis y de las hembras ovígeras forma S (rosado) y L (violeta) de la especie. Abajo: № promedio de huevos por hembra ovígera (egg ratio) de las formas $\mathbf{S}$ (celeste) y $\mathbf{L}$ (azul), y no promedio de huevos por individuo de los morfotipos $\mathbf{S}$ (verde claro) y $\mathbf{L}$ (turquesa) de la especie. En ambos gráficos se muestran los valores promedios (días 1 y 2) hallados por sitio de muestreo en caudales medios (marzo 2008).

\section{Brachionus angularis}

Este rotífero se destacó como especie subdominante del zooplancton en caudales medios (marzo 2008) y en aguas bajas (nov. 2008), siendo muy poco abundante en los restantes muestreos $(<5$ ind/L). En caudales medios la especie registró picos de abundancia total y de $q$ ovígeras en el canal 2 y el río aguas abajo, aumentando respecto al sitio aguas arriba. La proporción de $q$ ovígeras varió entre $25-27 \%$ en los canales y en entre 37-46\% en el río, siendo máxima aguas arriba. El egg ratio estuvo entre 1 y 1,2 huevos por $q$ ovígera (canal 2). El no de huevos por individuo fue más relevante en el río $(0,51-0,4)$, y sólo se hallaron huevos de resistencia en el río aguas abajo (Fig. 4.58). En aguas bajas, se observaron $q$ ovígeras en todos los sitios de muestreo, registrando los valores máximos en el río aguas abajo (7.500 ind/L), aumentando un orden de magnitud respecto al sitio aguas arriba (Fig. 4.59). La abundancia relativa de las + ovígeras varió entre 7\% (canal 1) y $41 \%$ (río). El egg ratio estuvo entre 1 y 1,2 huevos por $q$ ovígera, con valores máximos en el río aguas abajo. El no de huevos por individuo también fue importante en el río $(0,42-0,48)$. 
Tabla 4.6: Valores promedio (días 1 y 2) del egg ratio (no de huevos promedio por hembra ovígera) de cada especie de zooplancton con reproducción por huevos hallada en el muestreo de sept. 2009 (aguas muy bajas en afluentes y caudales medios en el río), y el rango de variación del $\mathbf{n}^{\circ}$ de huevos hallados por especie entre corchetes. Entre paréntesis se muestra el \% de hembras ovígeras respecto a la abundancia total de cada especie, por sitio de muestreo. El $\mathbf{N}_{\text {máx }}$ corresponde a la abundancia máxima de hembras ovígeras registrada entre los sitios analizados (Ind/L). El asterisco indica la presencia de huevos de resistencia en formación, todavía adosados a la hembra.

\begin{tabular}{|c|c|c|c|c|c|c|c|}
\hline Aguas muy bajas (Septiembre 2009) & Canal 1 & Canal 2 & Canal 3 & Arroyo & Río Abajo & Río Arriba & $\mathbf{N}_{\text {máx }}$ \\
\hline \multicolumn{8}{|l|}{ Rotíferos } \\
\hline Brachionus angularis & & & $1,36[1-2](53 \%)$ & & & & 0,93 \\
\hline Brachionus bidentata & $1(100 \%)$ & & & & $1,33[1-2]^{*}(33 \%)$ & $1,18[1-2]^{*}(35 \%)$ & 8,33 \\
\hline Brachionus calyciflorus & & & $1(100 \%)$ & & & & 0,5 \\
\hline Brachionus dimidiatus & $1(100 \%)$ & & & & & & 0,5 \\
\hline Brachionus ibericus & $1(14 \%)$ & & & & & & 1 \\
\hline Brachionus plicatilis & $1(15 \%)$ & $1,3[1 \text { a } 5]^{*}(30 \%)$ & & & $1(10 \%)$ & & 245,7 \\
\hline Brachionus pterodinoides & $1(20 \%)$ & & & & $1,22[1$ a 4$](19 \%)$ & $1,6[1 \text { a } 3]^{*}(15 \%)$ & 75 \\
\hline Brachionus quadridentatus & & & & $1(50 \%)$ & $1(89 \%)$ & $1,95[1-3](77 \%)$ & 6,7 \\
\hline Brachionus rotundiformis & $1(26 \%)$ & $1,33[1-2](18 \%)$ & & & $1(10 \%)$ & $1(14 \%)$ & 6,54 \\
\hline Brachionus urceolaris & & & & & $1,55[1-2,4](14 \%)$ & $1,42[1-3]^{*}(24 \%)$ & 47,5 \\
\hline Encentrum sp.3 & & & & & & $1(6 \%)$ & 5 \\
\hline Encentrum marinium & $1(2 \%)$ & & & & & & 2,02 \\
\hline Euchlanis dilatata & & & & $1(33 \%)$ & & & 0,29 \\
\hline Filinia longiseta & & & $1,09[1-2](8 \%)$ & & & & 4,17 \\
\hline Filinia terminalis & & & $1,17[1-2](21 \%)$ & & & & 5,1 \\
\hline Keratella tropica & & $1^{*}(12 \%)$ & $1(20 \%)$ & & $1(28 \%)$ & $1(100 \%)$ & 34,3 \\
\hline Polyarthra sp. & & & $1(11 \%)$ & & & & 0,51 \\
\hline Proalides sp.1 & & & & & $1,2[1-2]^{*}(19 \%)$ & $1,08[1-2]^{*}(24 \%)$ & 48,5 \\
\hline \multicolumn{8}{|l|}{ Copépodos } \\
\hline Acanthocyclops robustus & & $50,5[20-54](20 \%)$ & $(3 \%)$ & & $(29 \%)$ & $(39 \%)$ & 11 \\
\hline Cletocamptus deitersi & $26[20-37](12 \%)$ & $(17 \%)$ & & & $(37 \%)$ & $(5 \%)$ & 3,33 \\
\hline Microcyclops alius & & & & & $45(1 \%)$ & $45(1 \%)$ & 0,4 \\
\hline Paracyclops fimbriatus & & & & & $49(7 \%)$ & $49(5 \%)$ & 0,67 \\
\hline \multicolumn{8}{|l|}{ Cladóceros } \\
\hline Alona glabra & & & & & $1,26(11 \%)$ & & 4,67 \\
\hline Alona rectangula & & & & $1(9 \%)$ & & & 0,29 \\
\hline Daphnia obtusa & & & & & & $1(5 \%)$ & 0,5 \\
\hline Simocephalus sp. & & & & & $15(9 \%)$ & & 0,33 \\
\hline
\end{tabular}

Tabla 4.7: Rango de valores del $n^{o}$ de huevos presentes en las hembras ovígeras de Brachionus plicatilis, diferenciando los morfotipos S y L por sitio de muestreo, en condiciones de caudales medios (marzo 2008).

\begin{tabular}{lcc}
\hline Sitios de muestreo & "S" & "L" \\
\hline Canal 1 & $1-2$ & $1-2-3-4$ \\
Canal 2 & $1-2-3-4$ & $1-2-3-4-5$ \\
Arroyo & 1 & \\
Río Abajo & $1-2-3-4-5-6-8-9$ & $1-2-3-4$ \\
Río Arriba & $1-2$ & $1-2-3-4-5$ \\
\hline
\end{tabular}

Tabla 4.8: Rango de valores del $n^{o}$ de huevos portados por las hembras ovígeras de Brachionus plicatilis, diferenciando los morfotipos S y L por sitio de muestreo y en condiciones de aguas bajas (nov. 2008).

\begin{tabular}{lcc} 
Sitios de muestreo & "S" & "L" \\
\hline Canal 1 & $1-2$ & 1 \\
Canal 2 & $1-2-3-4-5$ & $1-2-3-4-5$ \\
Canal 3 & & 1 \\
Arroyo & $1-2-3-4$ & $1-2-3-4$ \\
Río Abajo & $1-3-4$ & $1-2-3-4-7$ \\
Río Arriba & & $1-2$ \\
\hline
\end{tabular}



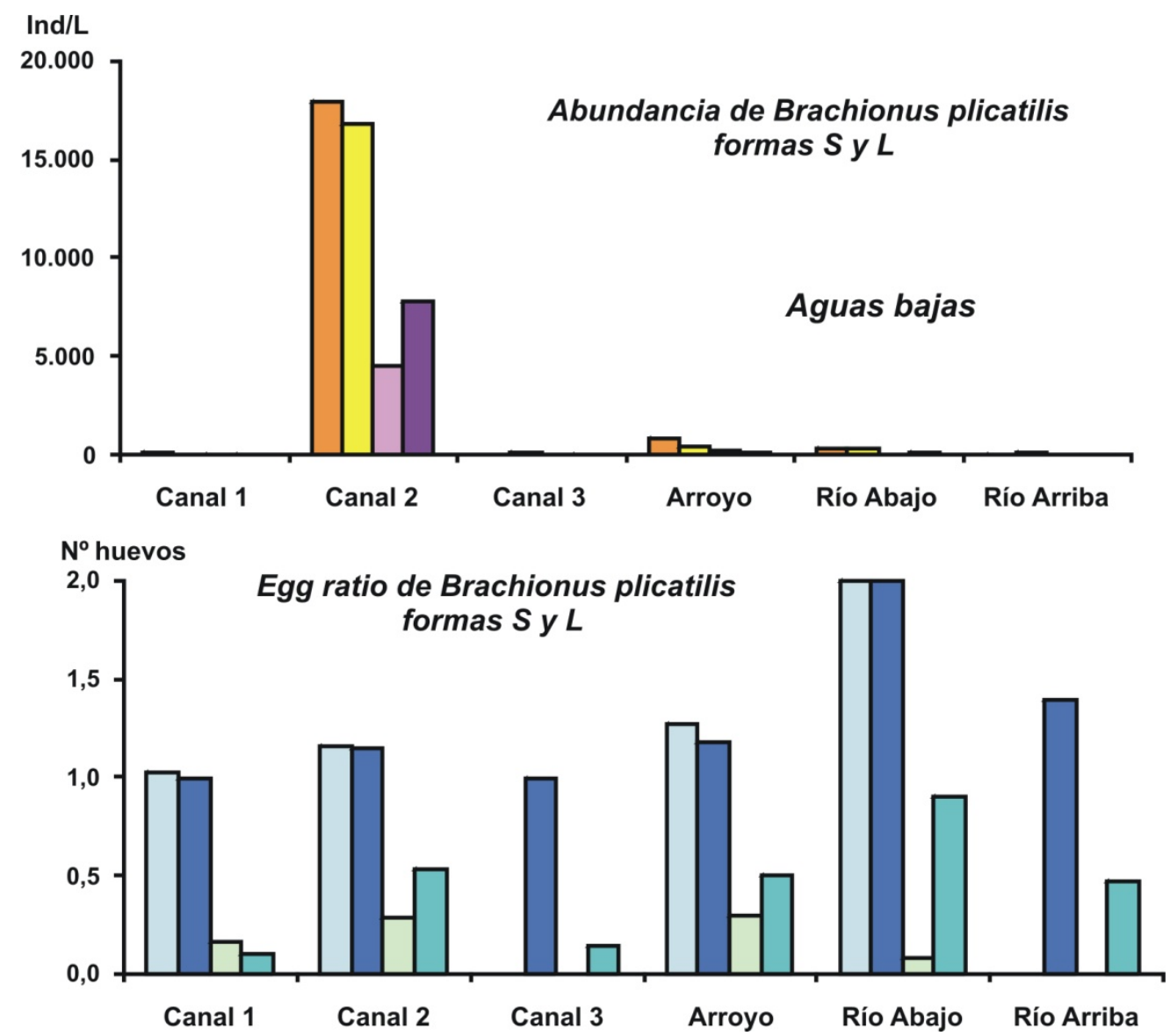

Figura 4.55: Arriba: Abundancia total de los morfotipos S (anaranjado) y L (amarillo) de Brachionus plicatilis y de las hembras ovígeras forma $\mathbf{S}$ (rosado) y $\mathbf{L}$ (violeta) de la especie. Abajo: № promedio de huevos por hembra ovígera (egg ratio) de los morfotipos S (celeste) y L (azul), y no promedio de huevos por individuo de los morfotipos $\mathbf{S}$ (verde claro) y $\mathbf{L}$ (turquesa) de la especie. En ambos gráficos se muestran los valores promedios (días 1 y 2) hallados por sitio de muestreo en condiciones de aguas bajas (nov. 2008).

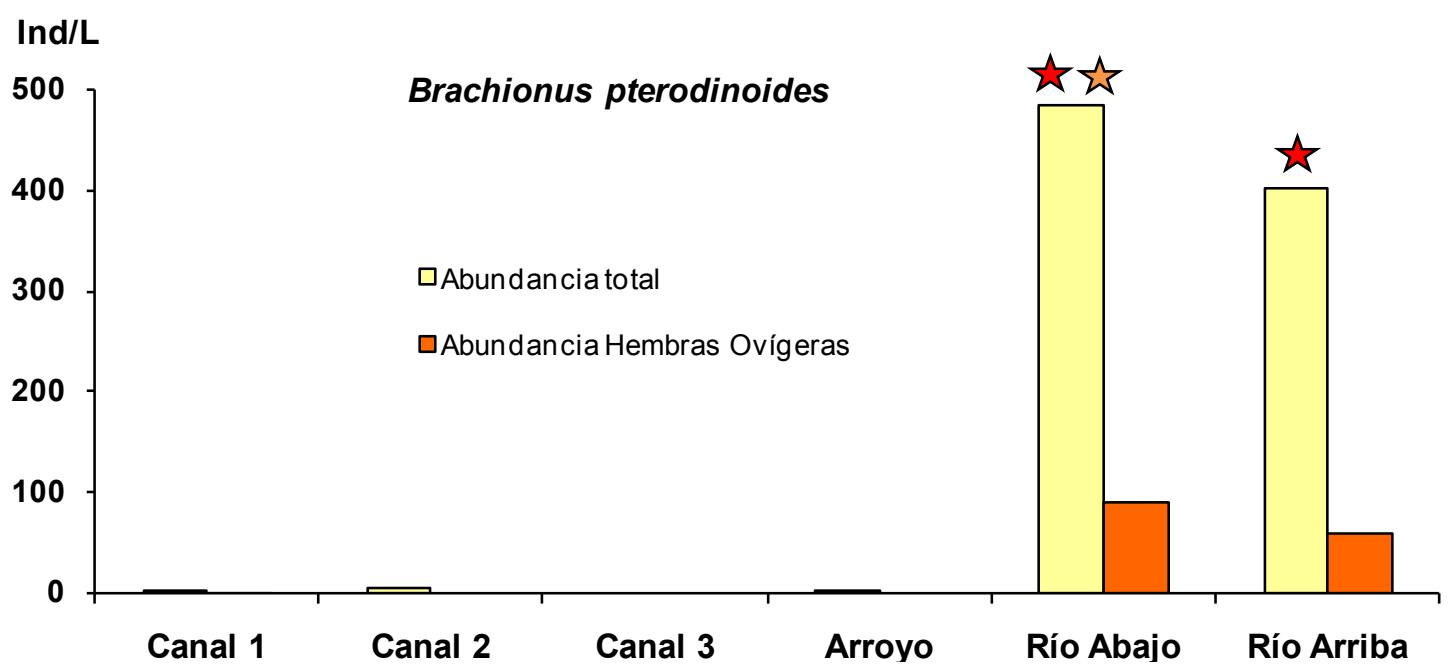

Figura 4.56: Valores promedio (días 1 y 2) de la abundancia total de Brachionus pterodinoides y de sus hembras ovígeras para cada sitio de muestreo en condiciones de aguas muy bajas en los afluentes (sistema Bragado) y caudales medios en el río Salado (sept. 2009). Las estrellas indican la presencia de huevos de resistencia libres en la muestra (rojo) y en formación (anaranjado), todavía adosados a las hembras. 


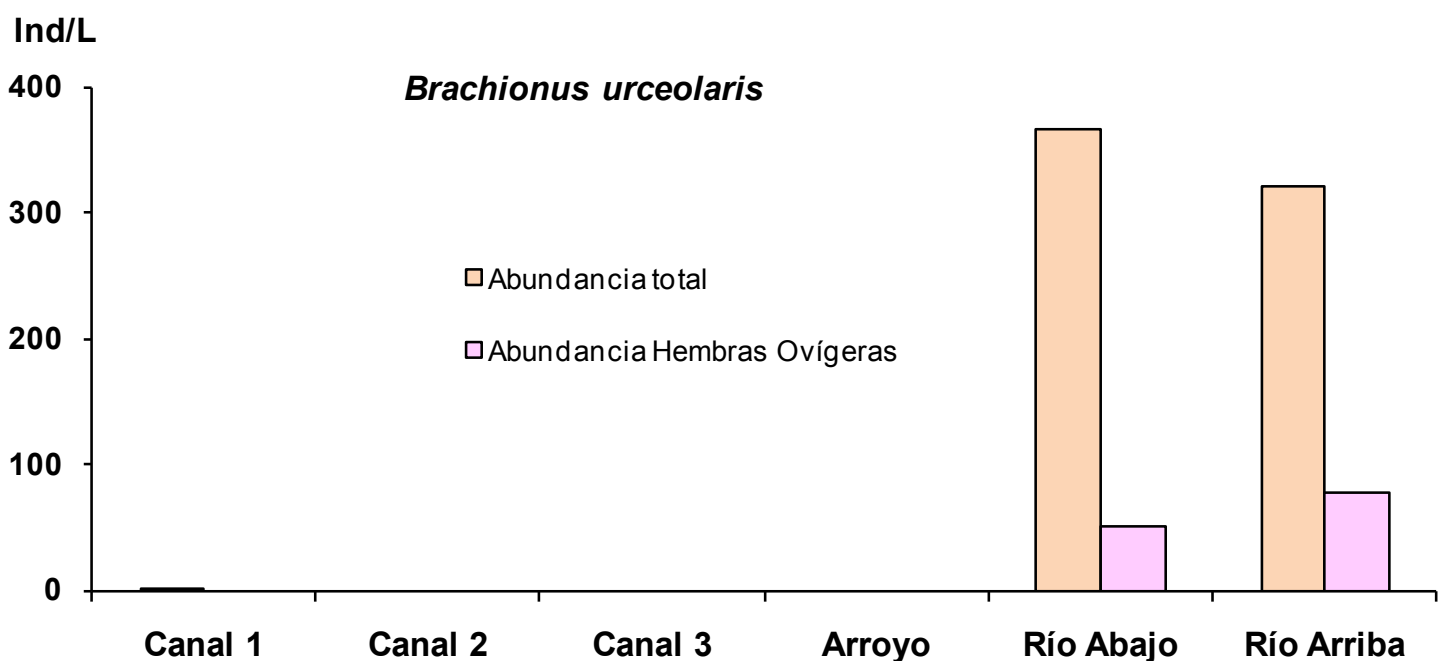

Figura 4.57: Valores promedio (días 1 y 2) de la abundancia total de Brachionus urceolaris y de sus hembras ovígeras para cada sitio de muestreo, en condiciones de aguas muy bajas en los afluentes (sistema Bragado) y caudales medios en el río Salado (sept. 2009).
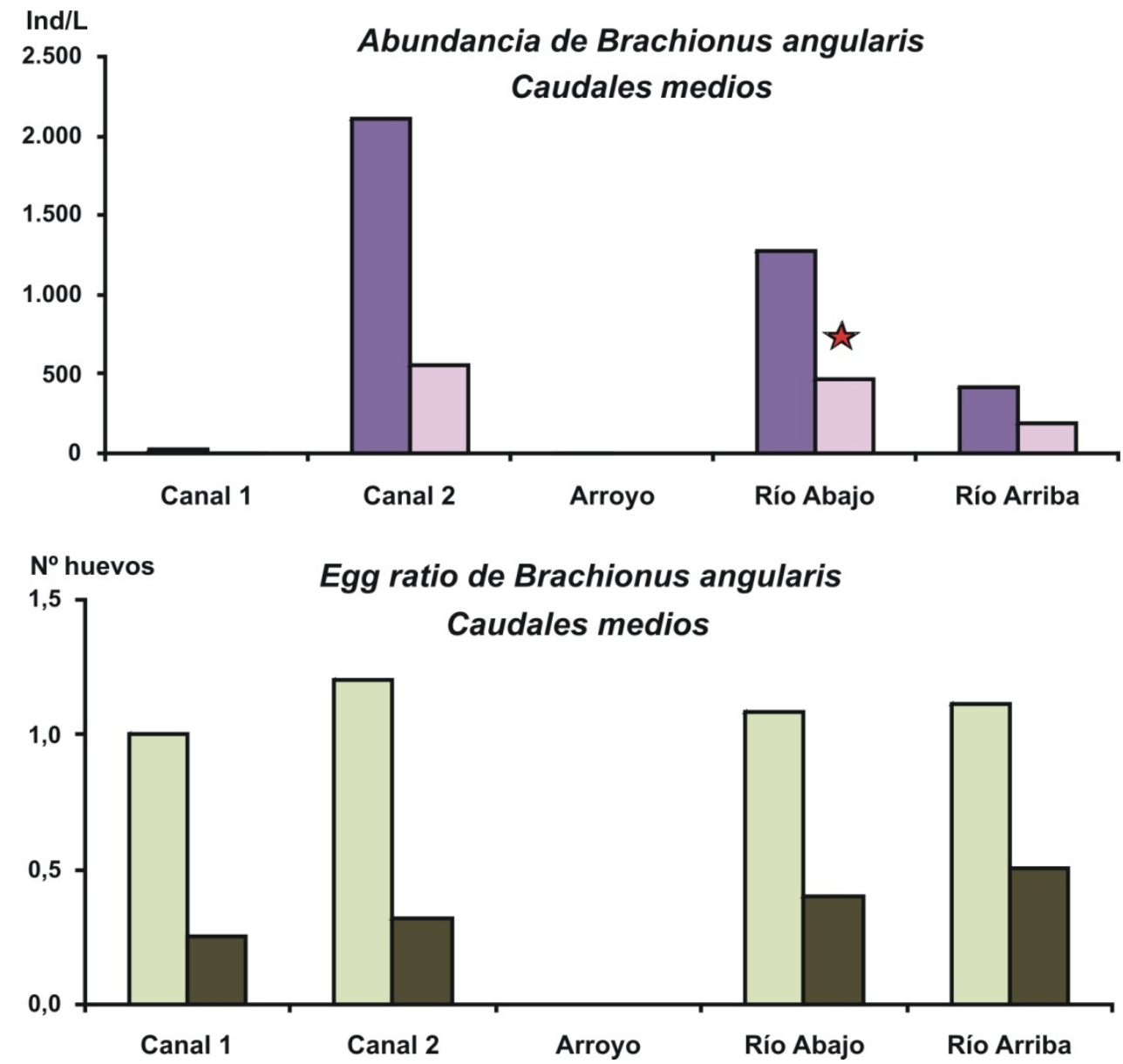

Figura 4.58: Arriba: Abundancia total (violeta) y de hembras ovígeras (rosado) de Brachionus angularis, y presencia de huevos de resistencia de la especie libres en la muestra (estrella roja). Abajo: № de huevos promedio por hembra ovígera (egg ratio) de la especie (verde claro) y $\mathrm{n}^{\mathrm{o}}$ promedio de huevos por individuo de la población (verde oscuro). En ambos gráficos se muestran los valores promedios (días 1 y 2) hallados por sitio de muestreo en condiciones de caudales medios (marzo 2008). 

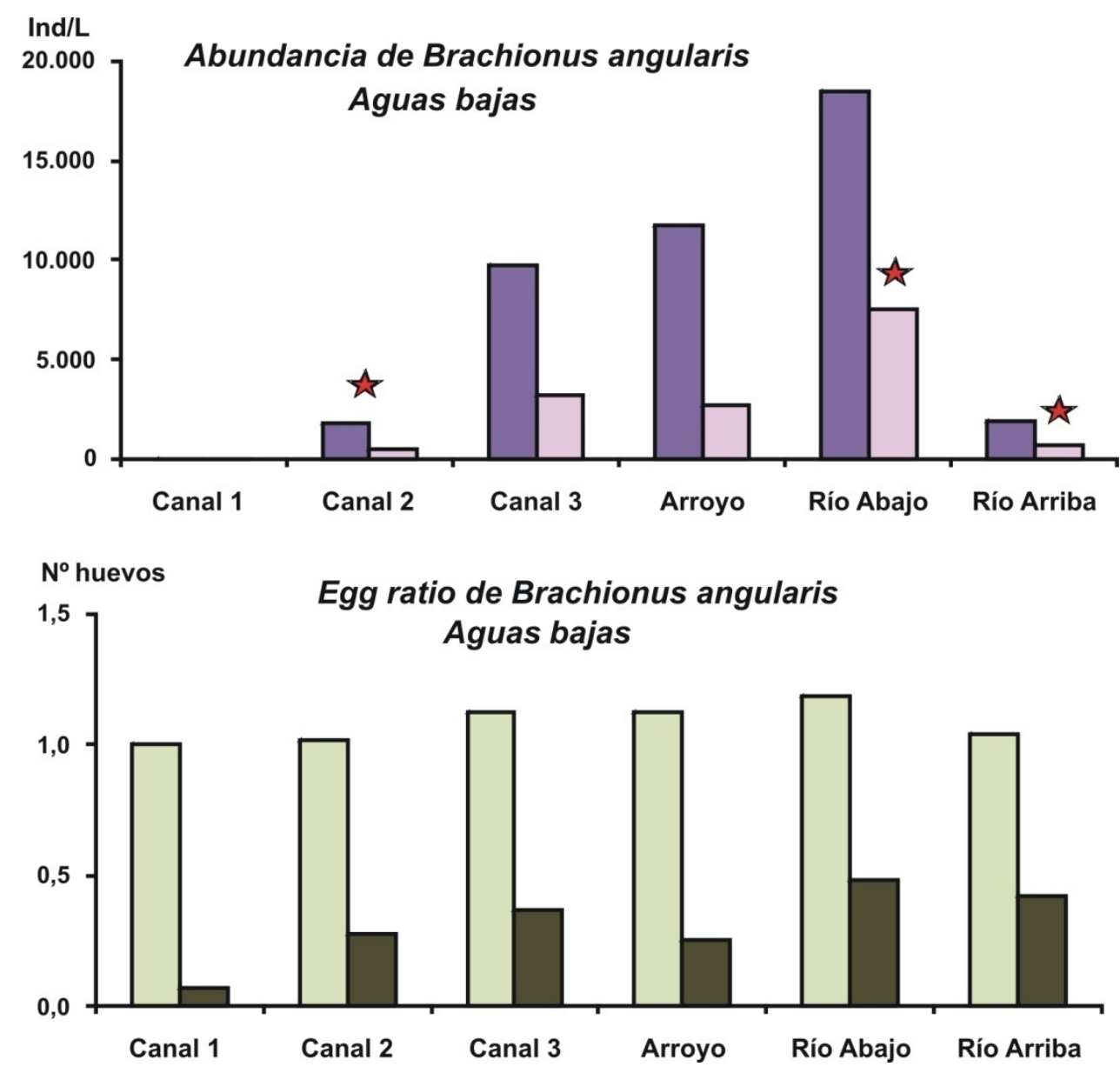

Figura 4.59: Arriba: Abundancia total (violeta) y de hembras ovígeras (rosado) de Brachionus angularis, y presencia de huevos de resistencia de la especie libres en la muestra (estrellas rojas). Abajo: № de huevos promedio por hembra ovígera (egg ratio) de la especie (verde claro) y $\mathrm{n}^{\mathrm{o}}$ promedio de huevos por individuo de la población (verde oscuro). En ambos gráficos se muestran los valores promedios (días 1 y 2) hallados por sitio de muestreo en condiciones de aguas bajas (nov. 2008).

\section{Keratella tropica}

La abundancia total de este rotífero y de sus $q$ ovígeras fue máxima en aguas altas (mayo 2007), estando presente en todos los sitios de muestreo y con $q$ ovígeras, siendo además la especie más abundante del zooplancton (Fig. 4.60). El egg ratio de la especie fue de 1 huevo promedio por q ovígera y el no de huevos por individuo varió entre 0,13 y 0,18, con valores extremos en el arroyo y el canal 1, respectivamente. Sólo se hallaron $q$ ovígeras de $K$. tropica en el canal 1 y en el arroyo en estas condiciones, estando ausentes en los muestreos subsiguientes. En caudales medios (marzo 2008), la especie fue muy poco abundante y sólo estuvo presente en el canal 2 y en el río, destacándose en el sitio aguas arriba. Sólo se observaron $q$ ovígeras en el río (31-39\%) y el nº de huevos por individuo fue de 0,39 y 0,31, aguas arriba y abajo, respectivamente. En aguas bajas (nov. 2008), se hallaron $q$ ovígeras en los canales 2 y 3 y en el río aguas abajo, siendo máxima su proporción y el $\mathrm{n}^{\mathrm{o}}$ de huevos por individuo $(0,28)$ en este último sitio. En aguas muy bajas, Keratella tropica se destacó por la abundancia de $q$ ovígeras en el canal 2, pero también se hallaron 
en el canal 3 y en el río. El $n^{\text {o }}$ de huevos por individuo fue máximo en el río aguas arriba (1) y mínimo en el canal $2(0,12)$ (Tabla 4.4).

\section{Acanthocyclops robustus}

Esta especie de copépodo estuvo presente en la mayoría de los sitios de muestreo, pero varió su abundancia total, de machos $(ð)$ y de $q$ ovígeras según la condición hidrológica (Fig. 4.61). En aguas altas (mayo 2007), se destacó por su abundancia total, de $\hat{o}$ y de $q$ ovígeras en el canal 1 , disminuyendo su importancia a lo largo del sistema Bragado. La especie estuvo ausente en el sitio aguas arriba, y aguas abajo se registraron los valores mínimos de abundancia total. Sólo se registraron $q$ ovígeras en los canales y el no promedio de huevos por $q$ ovígera fue de 20 huevos, considerando ambos sacos. Sólo en aguas altas se halló a la especie en el canal 1, estando ausente en este sitio en los muestreos subsiguientes.

En caudales medios se observaron picos de abundancia de $\widehat{\partial}$ de $A$. robustus en el río aguas arriba, y en menor medida aguas abajo, pero la densidad de $q$ ovígeras fue similar en ambos sitios. En el sistema Bragado la especie fue poco abundante, y sólo se observaron $\widehat{\partial}$ y $q$ ovígeras en el canal 2, con valores máximos de proporción relativa y 32 huevos promedio por $q$ ovígera. En aguas bajas, la especie sólo fue relevante en el canal 3 y en el río aguas arriba, con picos de densidad de $\hat{\sigma}$ y de $q$ ovígeras en este último sitio. La abundancia relativa de las $q$ ovígeras también fue mayor en el río aguas arriba (40\%) y se contabilizó un promedio 36 huevos por cada una. En aguas muy bajas en el sistema Bragado y caudales medios en el río, A. robustus se destacó por su abundancia total y de $\widehat{\partial}$ en el canal 2, seguido por el río, con escasa variación entre sitios. La abundancia total de las $q$ ovígeras fue relativamente baja comparada a otros muestreos, pero se observó el máximo n⿳o promedio de huevos por $q$ ovígera (52 huevos), considerando ambos sacos.

\section{Harpacticoideos}

La abundancia de las especies de copépodos harpacticoideos fue muy baja en aguas altas (Fig. 4.62). Entre ellas, Cletocamptus deitersi se destacó por densidad total en el canal 2 en caudales medios y en el río aguas arriba en los caudales medios de sept. 2009, mientras que la otra especie de harpacticoideo fue relevante por su abundancia en el río en aguas bajas.

En aguas altas (mayo 2007), se observaron $\widehat{\partial}$ de C. deitersi en los canales 1 y 2, y de $q$ ovígeras sólo en el canal 2, con 17 huevos promedio por saco ovígero. La otra especie de harpacticoideo fue relevante en el canal 1, con presencia de 9 ovígeras y 19 huevos promedio por saco. 


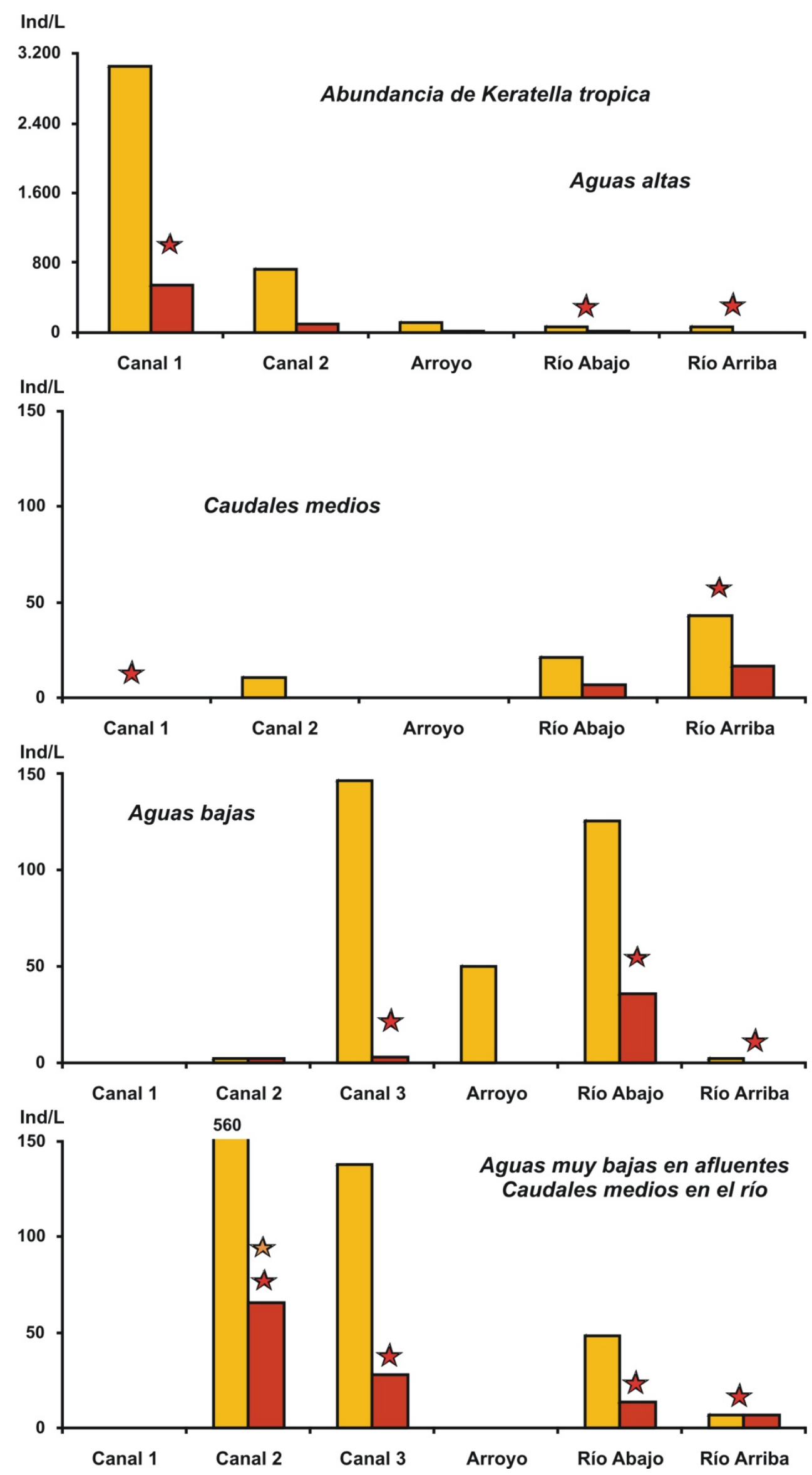

Figura 4.60: Abundancia total de Keratella tropica (amarillo) y de sus hembras ovígeras (anaranjado). Se muestran los valores promedio (días 1 y 2) por sitio de muestreo y condición hidrológica: aguas altas (mayo 2007), caudales medios (marzo 2008), aguas bajas (nov. 2008) y aguas muy bajas en afluentes con caudales medios en el río (sept. 2009). Las estrellas indican la presencia de huevos de resistencia de la especie: libres en la muestra (rojo) y en formación, todavía adosados a las hembras (amarillo). 


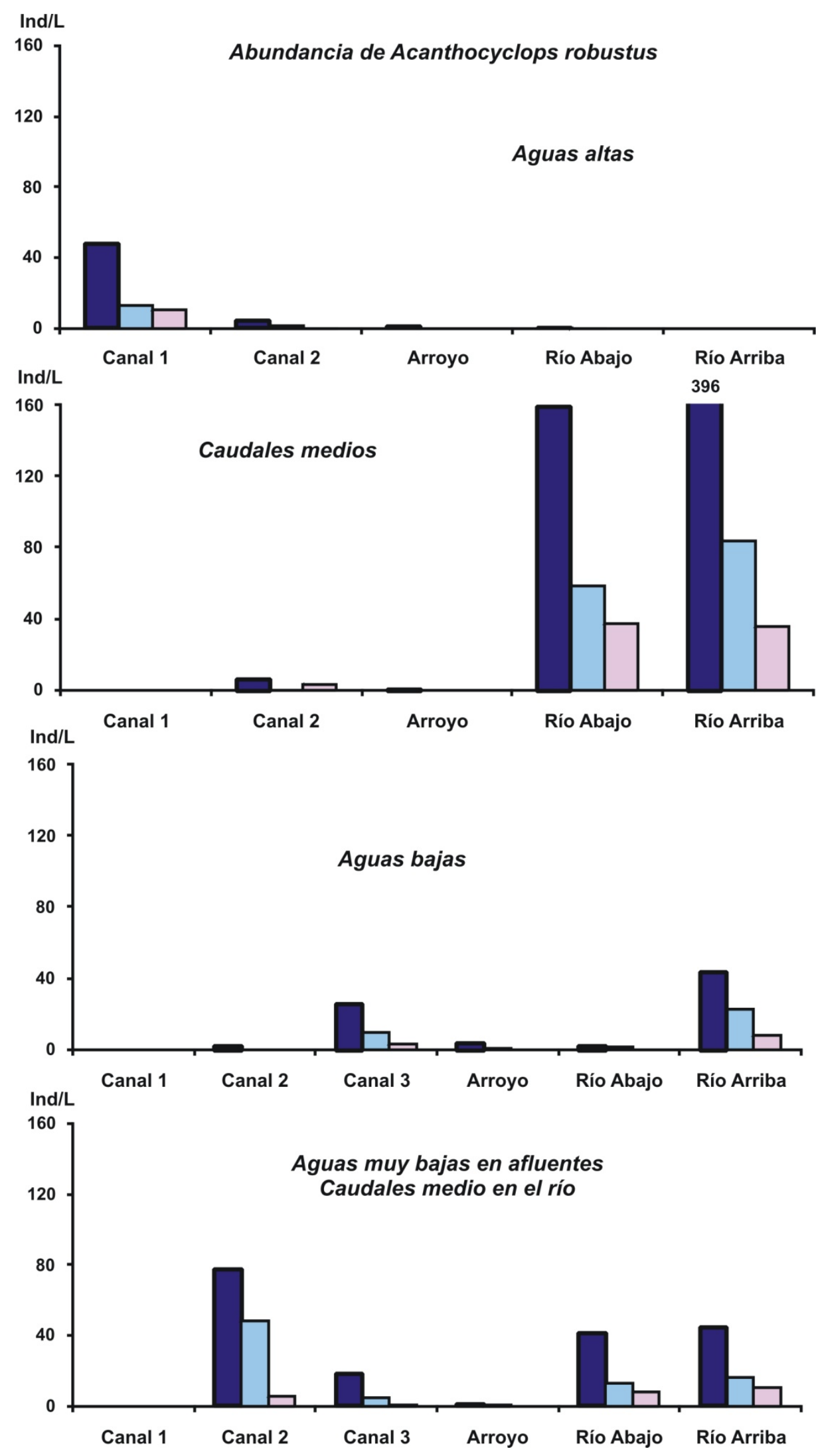

Figura 4.61: Abundancia total de adultos (columna azul), hembras ovígeras (columna rosa) y machos (columna celeste) de Acanthocyclops robustus. Se muestran los valores promedio (días 1 y 2) por sitio de muestreo y condición hidrológica: aguas altas (mayo 2007), caudales medios (marzo 2008), aguas bajas (nov. 2008) y aguas muy bajas en afluentes (sistema Bragado) con caudales medios en el río (sept. 2009). 

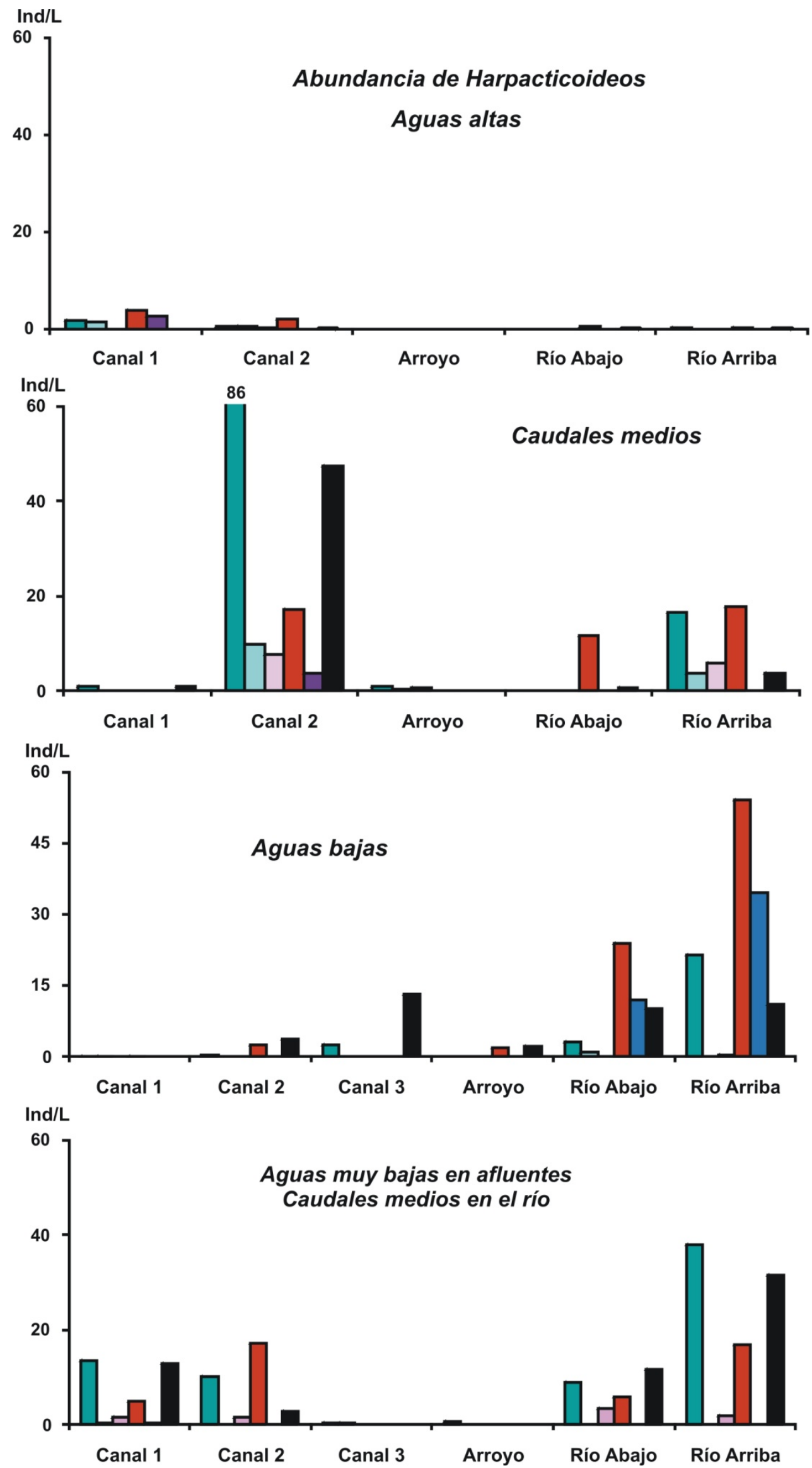

Figura 4.62: Valores promedio (días 1 y 2) de la abundancia total de harpacticoideos por sitio de muestreo y condición hidrológica: aguas altas (mayo 2007), caudales medios (marzo 2008), aguas bajas (nov. 2008) y aguas muy bajas en afluentes (sistema Bragado) con caudales medios en el río (sept. 2009). Referencias: copepoditos (columna negra), adultos de Cletocamptus deitersi (verde), + ovígeras (columna rosada) y $\gtrsim$ (columna celeste); adultos de Harpacticoideo sp. (rojo), ㅇ ovígeras (violeta) y $\widehat{\jmath}$ (azul). 
En caudales medios, Cletocamptus deitersi se destacó por la abundancia de $\widehat{\sigma}$ y $q$ ovígeras en el canal 2, y en menor medida en el río aguas arriba. Sólo se registraron $q$ ovígeras de Harpacticoideo sp. en el canal 2. Ambas especies registraron un promedio de 24 huevos por saco ovígero. En aguas bajas, C. deitersi sólo registró $q$ ovígeras en el río aguas arriba, con 18 huevos en promedio. Los $\hat{\sigma}$ de la especie se hallaron en el canal 1 y en el río aguas abajo, en muy baja densidad $(<1$ ind/L). Harpacticoideo sp. se destacó por la abundancia de $\widehat{o}$ en el río. La abundancia de los harpacticoideos fue muy baja en el sistema Bragado en aguas muy bajas, pero ambas especies registraron picos de abundancia en el río aguas arriba. Se observaron $q$ ovígeras de $C$. deitersi en la mayoría de los sitios de muestreo, con un promedio de 26 huevos por saco, pero sólo se hallaron $\widehat{o}$ de la especie en los canales 1 y $3(<1$ ind/L). Harpacticoideo sp. no registró $q$ ovígeras en ninguno de los sitios de muestreo.

En aguas altas se observó escasa presencia de copepoditos en todos los sitios de muestreo, y en caudales medios registraron los valores máximos de abundancia total en el canal 2. En aguas bajas, los copepoditos de harpacticoideos fueron más abundantes en el canal 3 y en el río. En aguas muy bajas en el sistema Bragado y caudales medios en el río, los copepoditos del grupo fueron abundantes en el río aguas arriba, y en menor medida en el canal 1 y en el río aguas abajo.

\section{Alona rectangula}

Esta especie de cladócero fue poco abundante en todas las condiciones hidrológicas ( $<15$ ind/L), pero registró los valores mínimos de densidad en caudales medios, sin la presencia de + ovígeras (Fig. 4.63). En aguas altas (mayo 2007), se destacó por su abundancia total y de $q$ ovígeras y máximo $\mathrm{n}^{\circ}$ promedio de huevos por $q$ ovígera $(1,5)$ en el canal 2 . También se hallaron $q$ ovígeras en el arroyo, con un egg ratio de 1. En aguas bajas (nov. 2008), sólo se observó a la especie en el río aguas arriba, con presencia de $q$ ovígeras y un egg ratio de 1. En aguas muy bajas, la especie estuvo presente en el canal 1, en el arroyo y en el río aguas abajo, con valores máximos de abundancia total y juveniles en este último sitio. Las $q$ ovígeras se observaron en el arroyo, en muy bajas densidades, y con un egg ratio de 1.

\section{Alona glabra}

La especie fue muy poco abundante en condiciones de aguas altas ( $<3$ ind/L), se observaron juveniles pero no así $q$ ovígeras (Fig. 4.64). En caudales medios (marzo 2008), las $q$ ovígeras estuvieron presentes en el canal 2 y en el río, con valores máximos de densidad en el río aguas arriba. Sólo se observaron estadios juveniles de la especie en el río. El n⿳ํ promedio de huevos por 
q ovígera fue máximo en el canal 2 y el río aguas abajo (2). En aguas bajas, se hallaron los valores máximos de abundancia de A. glabra, destacándose en el río aguas arriba (adultos, $q$ ovígeras y juveniles), pero se observó mínimo valor de egg ratio (1). En el último muestreo (sept. 2009), la especie se halló en el canal 1 (aguas muy bajas), y en el río (caudales medios), pero su abundancia total y de $q$ ovígeras registró los valores máximos en el río aguas abajo, con un egg ratio de 1,26.

Se registraron efipios del género Alona en el canal 1 en aguas altas, en el río en caudales medios y aguas bajas, y en el canal 3 y en el río aguas abajo en el muestreo de aguas muy bajas en el sistema Bragado pero con caudales medios en el río.

\section{Daphnia spinulata y D. obtusa}

Estas especies de dáfnidos se destacaron por su abundancia total en condiciones de aguas altas, registrando los valores máximos en el canal 1 (120 y 17 ind/L, respectivamente) (Fig. 4.65). D. obtusa sólo estuvo presente en los canales, donde también se hallaron $\widehat{\partial}$ de la especie en bajas densidades, y efipios del género. Por otro lado, D. spinulata se halló en los canales y en el río aguas abajo, aunque en muy bajas densidades en el río. Las $q$ ovígeras y los juveniles de D. spinulata estuvieron restringidos a los canales, particularmente en el canal 1.

En caudales medios no se encontraron representantes de ninguna de las dos especies, ya sean de adultos ( $\widehat{\partial} \mathrm{y}$ q no ovígeras), + ovígeras o juveniles. En aguas bajas estos dáfnidos presentaron muy bajas densidades y fueron poco frecuentes, sin la presencia de cladoceritos ni de $q$ ovígeras. Daphnia spinulata registró formas adultas y juveniles en el canal 3 y en el arroyo, y sólo se observaron adultos de Daphnia obtusa en el canal 3. Se encontraron efipios tanto en los canales como en el río aguas abajo.

En el muestreo de aguas muy bajas en el sistema Bragado pero con caudales medios en el río, D. spinulata estuvo presente en los canales 1 y 3 y en el río. D. obtusa sólo estuvo presente en el río aguas arriba y en muy bajas densidades, pero con presencia de $q$ ovígeras y juveniles. D. spinulata registró los valores máximos de abundancia total de adultos en el río aguas arriba, disminuyendo aguas abajo. También se hallaron juveniles de D. spinulata en los canales 1 y 3 y en el río, con picos de abundancia en el sitio aguas abajo. Sólo se encontraron efipios en el canal 3. 


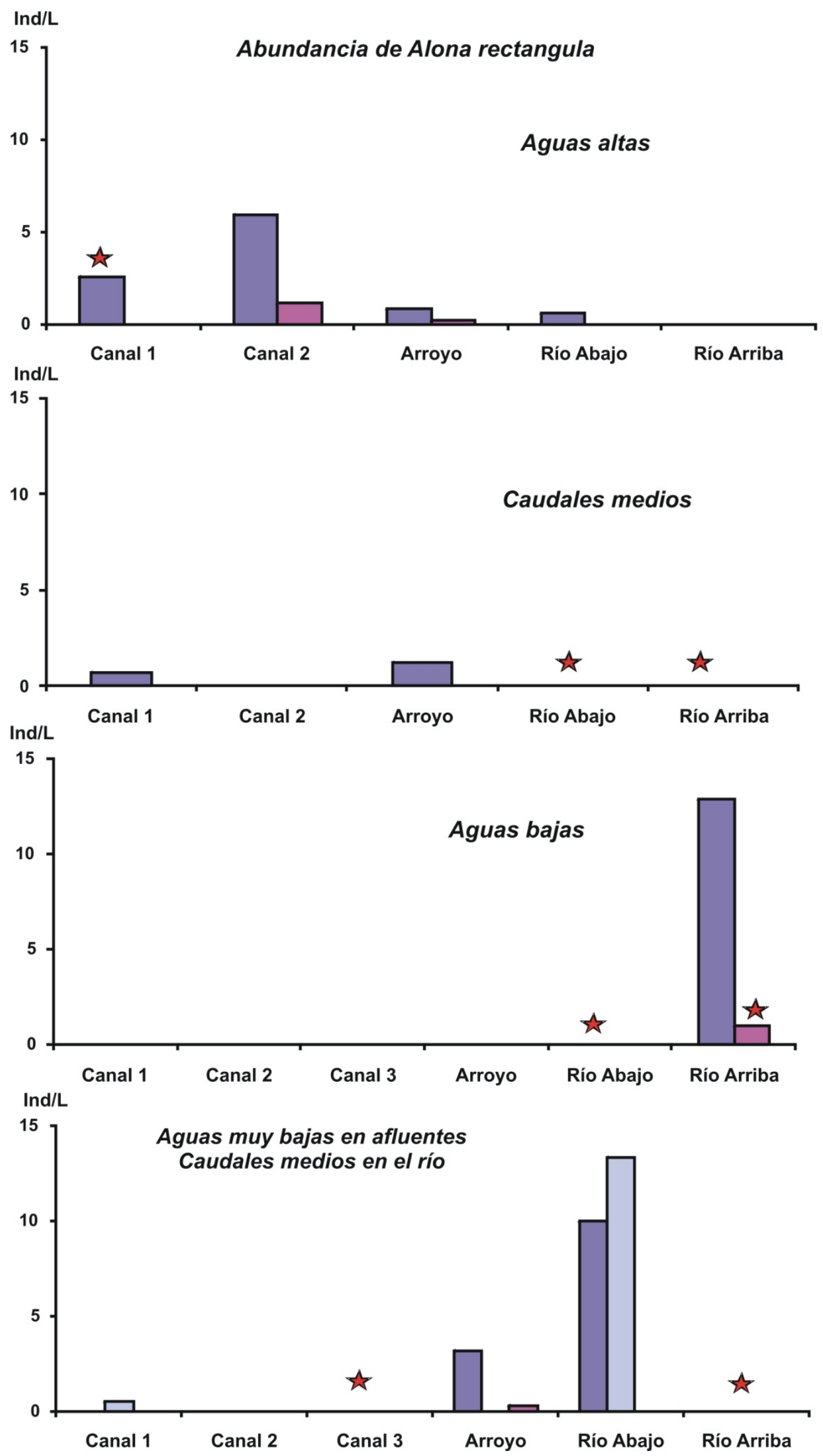

Figura 4.63: Valores promedio (días 1 y 2) de la abundancia total de adultos (violeta), de hembras ovígeras (rosado) y juveniles (lila) de Alona rectangula, por sitio de muestreo y condición hidrológica: aguas altas (mayo 2007), caudales medios (marzo 2008), aguas bajas (nov. 2008) y aguas muy bajas en afluentes con caudales medios en el río (sept. 2009). Las estrellas rojas indican la presencia de efipios del género. 


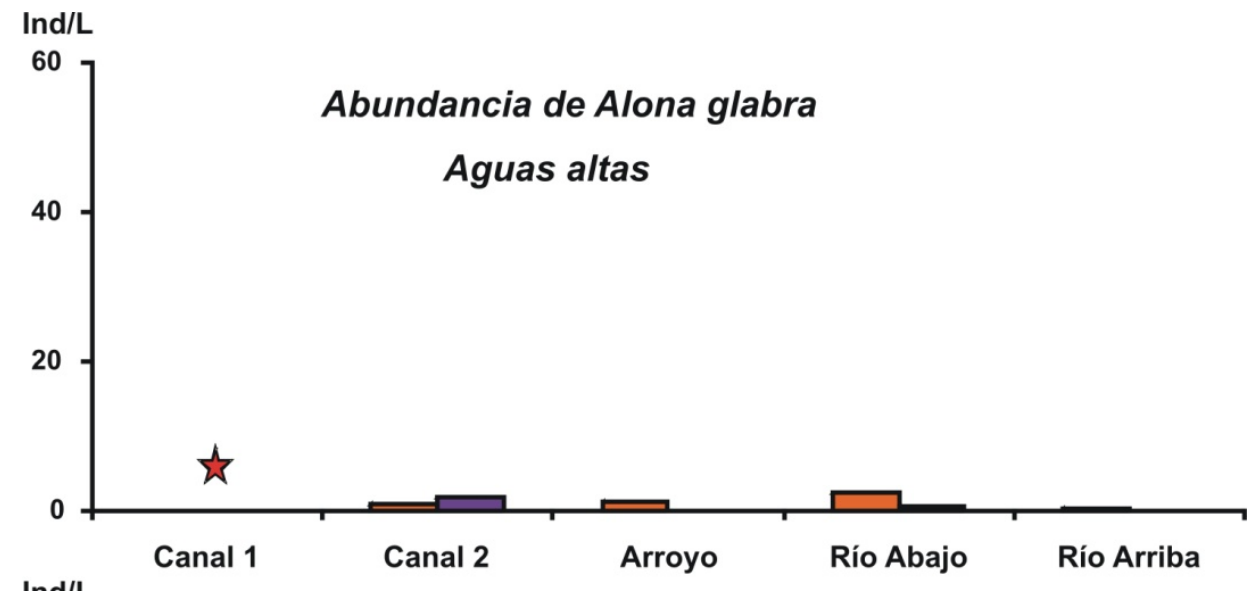

Ind/L
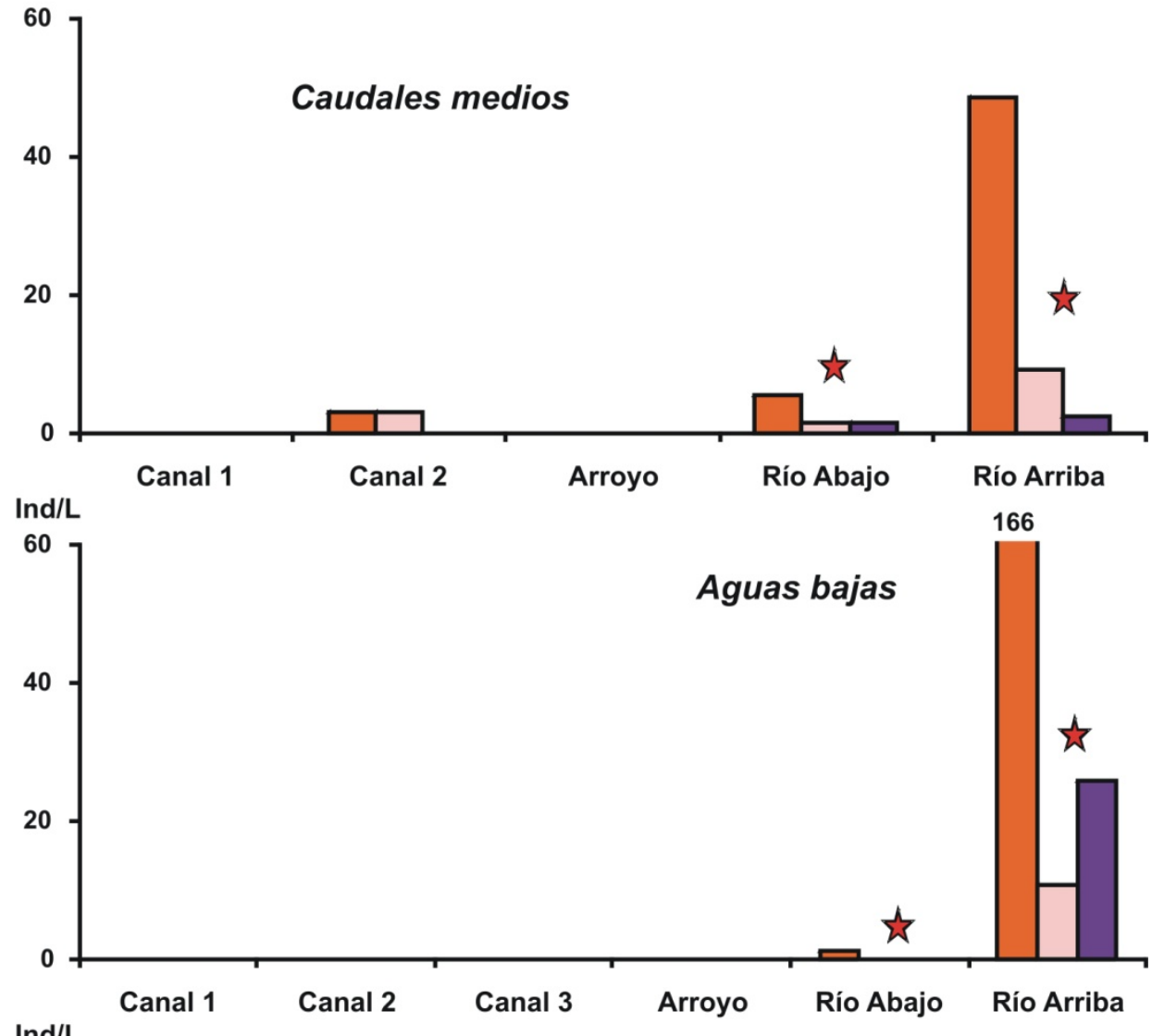

Ind/L

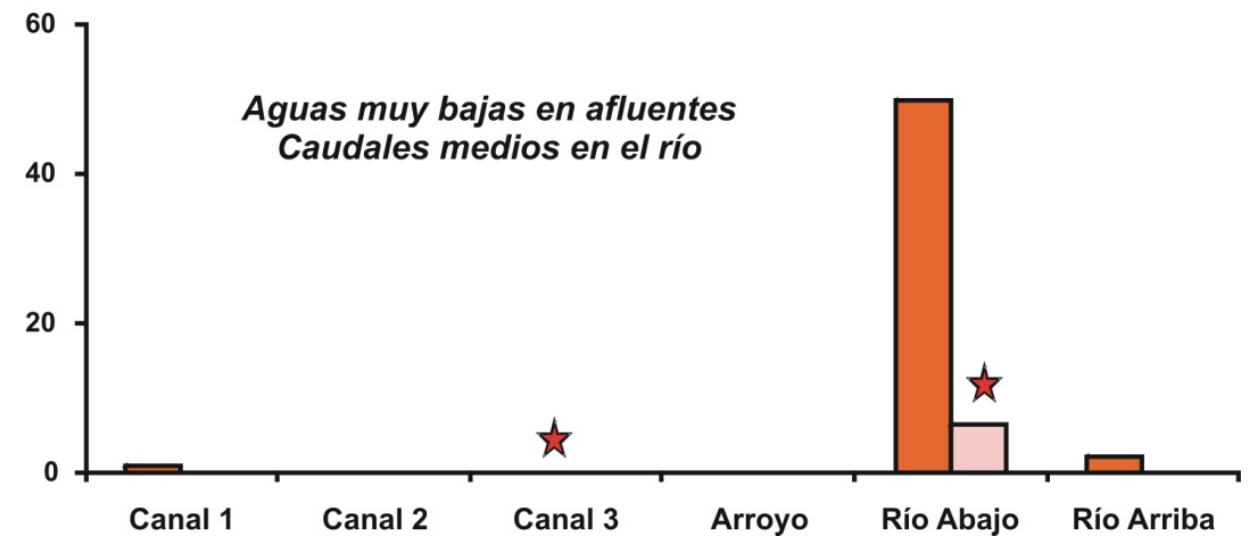

Figura 4.64: Valores promedio (días 1 y 2) de la abundancia total de adultos (anaranjado), de hembras ovígeras (rosado) y juveniles (violeta) de Alona glabra por sitio de muestreo y condición hidrológica: aguas altas (mayo 2007), caudales medios (marzo 2008), aguas bajas (nov. 2008) y aguas muy bajas en afluentes con caudales medios en el río (sept. 2009). Las estrellas rojas indican la presencia de efipios del género. 

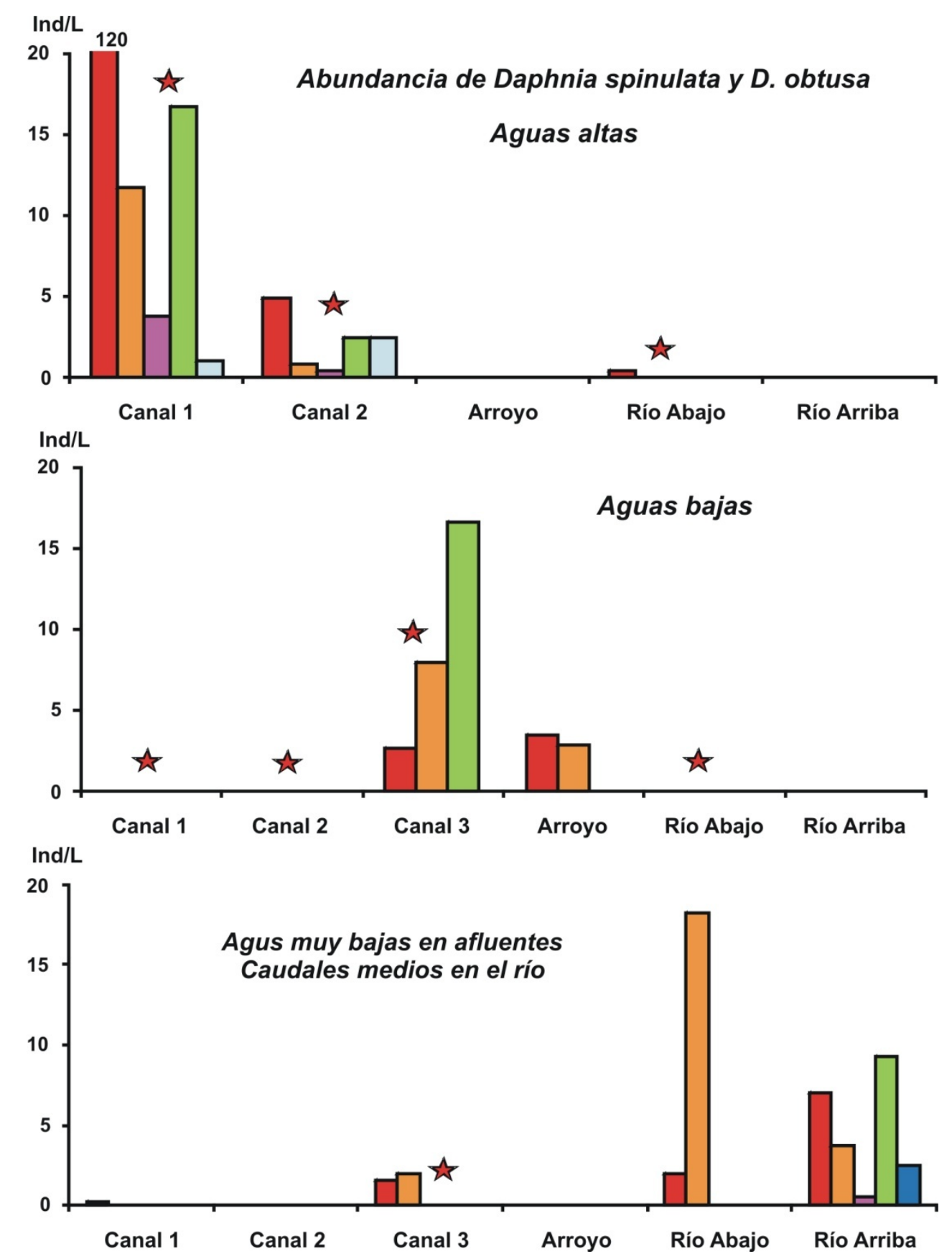

Figura 4.65: Valores promedio (días 1 y 2) de la abundancia total de las especies de Daphnia por sitio de muestreo y condición hidrológica: aguas altas (mayo 2007), aguas bajas (nov. 2008) y aguas muy bajas en afluentes con caudales medios en el río (sept. 2009). Referencias: adultos de Daphnia spinulata (rojo), 9 ovígeras (rosado) y juveniles (anaranjado); adultos de Daphnia obtusa (verde), juveniles (celeste) y $\widehat{\delta}$ (azul). Las estrellas rojas indican la presencia de efipios. 


\subsection{Relaciones tróficas}

\subsubsection{Fracciones del fitoplancton y relación con el zooplancton}

En todos los sitios de muestreo y condiciones hidrológicas la biomasa total del microplancton superó al nanoplancton, siendo también superior a la biomasa total de zooplancton. En aguas altas (mayo 2007) se observaron los valores mínimos de estas variables y lo opuesto en condiciones de caudales medios (marzo 2008). La biomasa total de zooplancton también fue menor a ambas fracciones del fitoplancton en la gran mayoría de los muestreos, a excepción del canal 2 en aguas bajas (nov. 2008) y en aguas muy bajas (sept. 2009) donde superó al nanoplancton (Fig. 4.66).

En aguas altas, el micro y nanoplancton y el zooplancton presentaron los valores máximos de biomasa total en el canal 1, disminuyeron su importancia a lo largo del sistema Bragado y registraron los valores mínimos en el río, con escasas variaciones entre sitios. El microplancton representó entre el 62 y 76\% de la biomasa total de fitoplancton en los sitios de muestreo.

En caudales medios, la biomasa del microplancton fue $>83 \%$ del total, con máximos porcentajes en el sistema Bragado. Ambas fracciones del fitoplancton se destacaron por su biomasa en los canales 1 y 2, y en el río aguas abajo. En el río aguas abajo se observó una disminución en la biomasa total de zooplancton, respecto al sitio aguas arriba, a la vez que un aumento en la biomasa de micro y nanoplancton. En aguas bajas, el microplancton constituyó el 70-76\% de la biomasa total de fitoplancton en el canal 2 y en el río, y de alrededor de 50-54\% en el canal 3 y el arroyo. La biomasa total del zooplancton siguió el mismo patrón que el microplancton, con valores máximos en el canal $2(4.840 \mu \mathrm{g} \mathrm{C} / \mathrm{L})$, superando al nanoplancton $(2.328 \mu \mathrm{g} \mathrm{C} / \mathrm{L})$.

En aguas muy bajas en el sistema Bragado pero con caudales medios en el río (sept. 2009), el microplancton representó entre un $67-82 \%$ de la biomasa total de fitoplancton, con porcentajes extremos para el río y el canal 1, respectivamente. Ambas fracciones del fitoplancton se destacaron por su biomasa total en el río, mientras que en el canal 1 se hallaron los valores mínimos. El zooplancton fue relevante por su biomasa en el canal 2, seguido por los sitios del río, y en el arroyo se observaron los valores mínimos $(36 \mu \mathrm{g}$ C/L). En este muestreo se observó escasa variación en la biomasa total del plancton entre los sitios del río.

Las cianobacterias, especialmente las filamentosas, dominaron la biomasa del microplancton en todas las condiciones hidrológicas, seguidas por las clorofitas, y en menor medida las diatomeas y las euglenofitas de gran tamaño, variando según los sitios y momentos de muestreo. Entre los 
representantes del nanoplancton predominaron las clorofitas clorococcales, seguidas por las criptofitas y algunas pocas especies de diatomeas centrales (Cyclotella glomerata, C. meneghiniana y Stephanodiscus sp.).

En aguas altas, el nanoplancton estuvo mejor representado en el canal 1, y entre las especies más conspicuas se hallaron las clorofitas Monoraphidium spp., Crucigenia spp., Kirchneriella spp., Chlorella spp. y Scotiellopsis reticulata, y las diatomeas centrales nanoplanctónicas Cyclotella glomerata y C. meneghiniana. Por otro lado, las criptofitas se destacaron en el arroyo y en el río aguas abajo (Cryptomonas obovoidea, C. phaseolus, C. pusilla y Chroomonas coerulea).

En caudales medios, las clorofitas clorococcales mantuvieron valores de biomasa muy similares entre los sitios de muestreo (900-1.100 $\mu \mathrm{g}$ C/L), a excepción del arroyo (360 $\mu \mathrm{g}$ C/L). Entre las especies más importantes se registró a Crucigeniella rectangularis, Crucigenia quadrata, Chlamydomonas grovei, Chlorella vulgaris, Oocystis spp. y Scotiellopsis reticulata. En orden de importancia siguieron las criptofitas (Cryptomonas obovoidea, C. phaseolus, Rhodomonas sp. y Chroomonas coerulea), que presentaron picos de biomasa en el canal 1 (1.900 $\mu \mathrm{g} \mathrm{C/L}$ ), seguidos por el canal 2 y el río aguas abajo.

En aguas bajas, la biomasa del nanoplancton estuvo mayormente integrada por las clorofitas clorococcales (Chlorella vulgaris, Crucigenia quadrata, Crucigeniella rectangularis, Oocystis lacustris y Hindakochloris nygaardii), las cuales se destacaron en el canal $3(3.000 \mu \mathrm{g} C / \mathrm{L})$, seguido por el arroyo y el río aguas abajo. Las diatomeas centrales de pequeño tamaño se destacaron por su biomasa en el canal 1, y las criptofitas nanoplanctónicas en el canal 2, entre ellas Cryptomonas obovoidea.

En aguas muy bajas en el sistema Bragado pero con caudales medios en el río (sept. 2009), el nanoplancton estuvo compuesto mayormente por las clorofitas clorococcales Oocystis lacustris, Monoraphidium spp., Kirchneriella spp., y células aisladas de Acutodesmus dimorphus y Actinastrum hantzschii en el río (caudales medios), mientras que en los canales 2 y 3 se observó a Chlamydomonas spp. (aguas muy bajas). Entre las diatomeas de pequeño tamaño se hallaron las centrales Stephanodiscus sp., Cyclotella glomerata y C. meneghiniana, siendo más relevantes en el río. Las criptofitas nanoplanctónicas se destacaron en el canal 2, en especial Plagioselmis nannoplanctica, Komma caudata, Cryptomonas phaseolus y C. obovoidea, en este orden de importancia. 

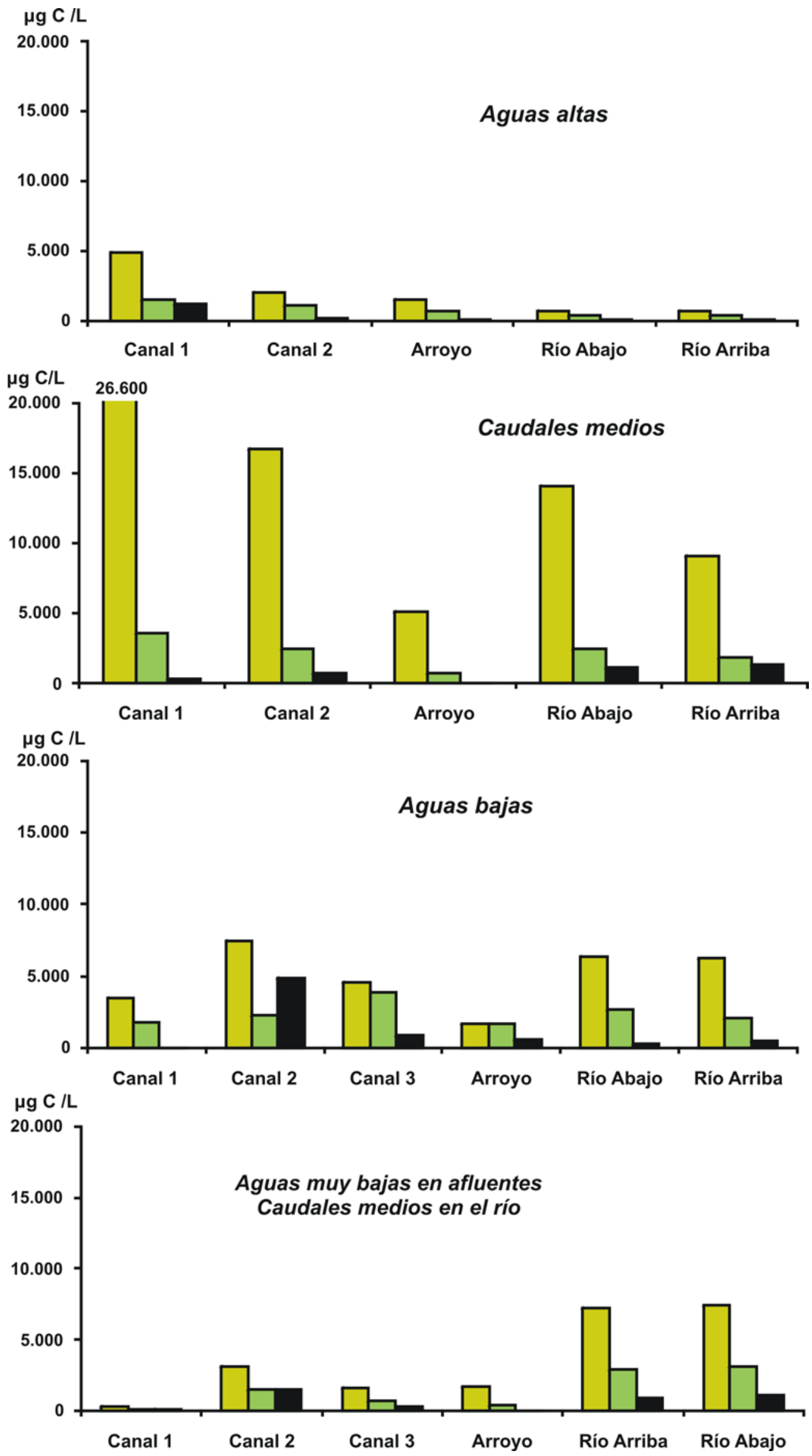

Figura 4.66: Biomasa total del microplancton (amarillo), del nanoplancton (verde) y del zooplancton total (negro). Se grafican los valores promedio (días 1 y 2) por sitio de muestreo y condición hidrológica: aguas altas (mayo 2007), caudales medios (marzo 2008), aguas bajas (nov. 2008) y aguas muy bajas en afluentes (sistema Bragado) con caudales medios en el río (sept. 2009). 


\subsubsection{Especies componentes del zooplancton herbívoro}

Entre los representantes del zooplancton herbívoro, los cladóceros dominaron la biomasa de zooplancton total (45-57\%) en condiciones de aguas altas, con máximos porcentajes en los canales, seguido por los copépodos, siendo más relevantes en el río aguas abajo (45\%). En el canal 1 se destacaron por su biomasa los cladóceros Daphnia spinulata y D. obtusa (43\%), y en menor medida se halló el rotífero Keratella tropica, aunque este último fue más relevante en el canal 2 y en el arroyo (14\%). El cladócero Ceriodaphnia cf. dubia se destacó por su biomasa en el arroyo (18\%) y en el río aguas arriba (25\%). En el río aguas abajo prevaleció el copépodo Notodiaptomus incompositus (25\%) junto con D. spinulata. En el canal 1, la biomasa de los cladóceros superó a las clorofitas nanoplanctónicas, preferidas por el zooplancton, así como también a la biomasa total de las especies nanoplanctónicas palatables. En los restantes sitios de muestreo no se observó un posible control del zooplancton sobre la biomasa del fitoplancton nanoplanctónico (Fig. 4.67).

En caudales medios, el canal 2 y el río fueron los sitios con mayor biomasa de zooplancton herbívoro, mientras que en el canal 1 y el arroyo su presencia fue escasa. Entre las especies presentes, Brachionus plicatilis dominó particularmente en el canal 2 donde representó un $60 \%$ de la biomasa total de zooplancton. En este canal también se destacaron los copépodos harpacticoideos (Cletocamptus deitersi). En el río, el zooplancton herbívoro estuvo mayormente compuesto por las larvas nauplii y los copepoditos, pero también por los cladóceros Moina micrura y Alona glabra $(<30 \%)$ en el sitio aguas arriba. En ningún caso se observó un posible control del zooplancton sobre la biomasa del fitoplancton nanoplanctónico palatable. La biomasa del zooplancton herbívoro fue máxima en el canal 2 en aguas bajas, superando la biomasa del nanofitoplancton palatable, con una fuerte presión de pastoreo dada por Brachionus plicatilis (34.800 ind/L y $4.400 \mu \mathrm{g} \mathrm{C} / \mathrm{L}$ ). En los restantes sitios de muestreo, la especie no superó al fitoplancton nanoplanctónico en ninguno de ellos. En el sistema Bragado también fueron relevantes por su biomasa el ciliado herbívoro Strombilidium caudatum (230 $\mu \mathrm{g} \mathrm{C/L}$ en el canal 2), y los cladóceros Daphnia obtusa (canal 3), D. spinulata y Moina micrura (arroyo). Las larvas nauplii y los copepoditos herbívoros fueron relevantes por su biomasa en el canal 3. En condiciones de aguas muy bajas, la biomasa del zooplancton herbívoro fue máxima en el canal 2. En este sitio dominaron las larvas nauplii ( $26 \%$ de la biomasa total de zooplancton), seguido por el copépodo Notodiaptomus incompositus (22 \%) y el rotífero Brachionus plicatilis (20\%), y en menor medida los copepoditos $(8,7 \%)$. Los cladóceros se destacaron en el río, donde fueron subdominantes con la presencia de Moina micrura (5\%), Daphnia obtusa, D. spinulata (10\%) y Alona glabra (12\%). En ninguno de los sitios se observó un control del zooplancton sobre la biomasa del nanofitoplancton palatable 
$\mu \mathrm{g} \mathrm{C/L}$

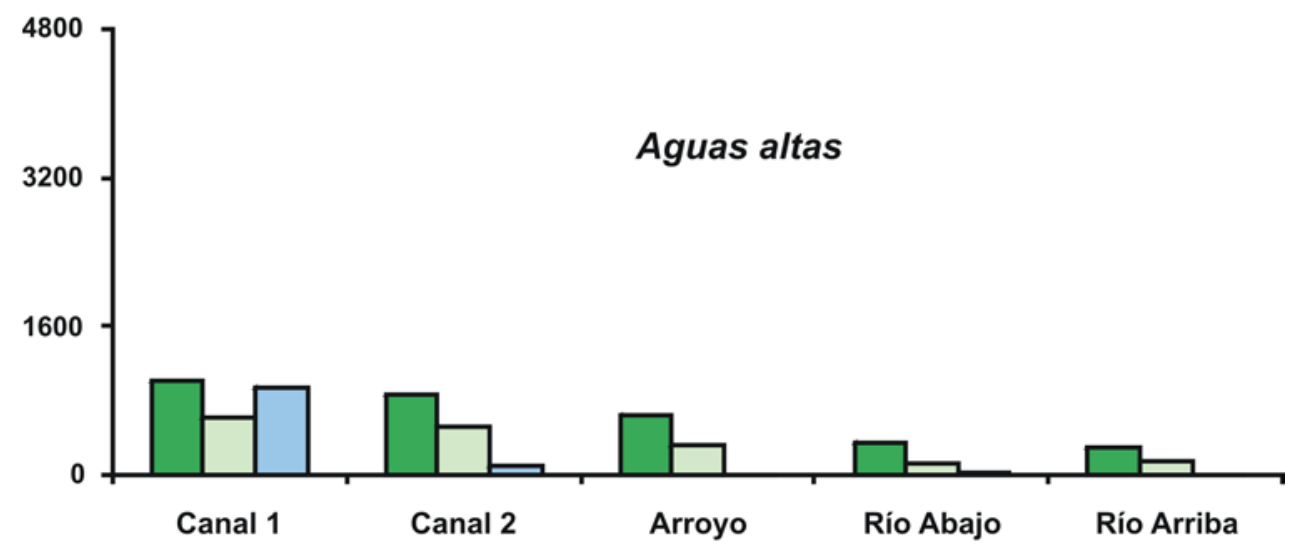

$\mu \mathrm{g} \mathrm{C/L}$

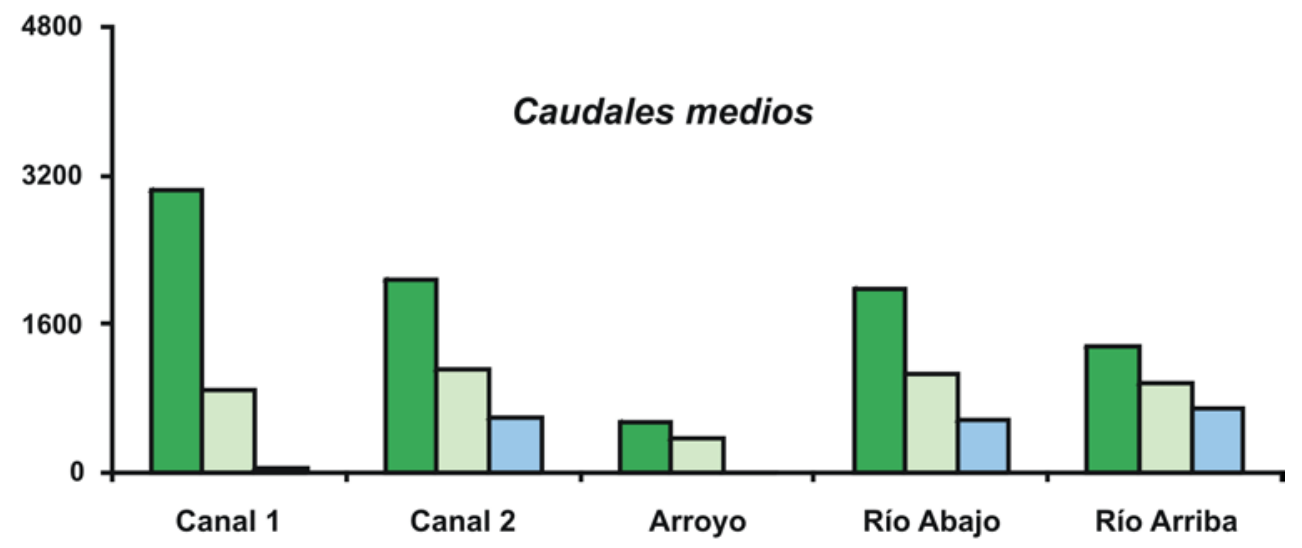

$\mu \mathrm{g} \mathrm{C/L}$

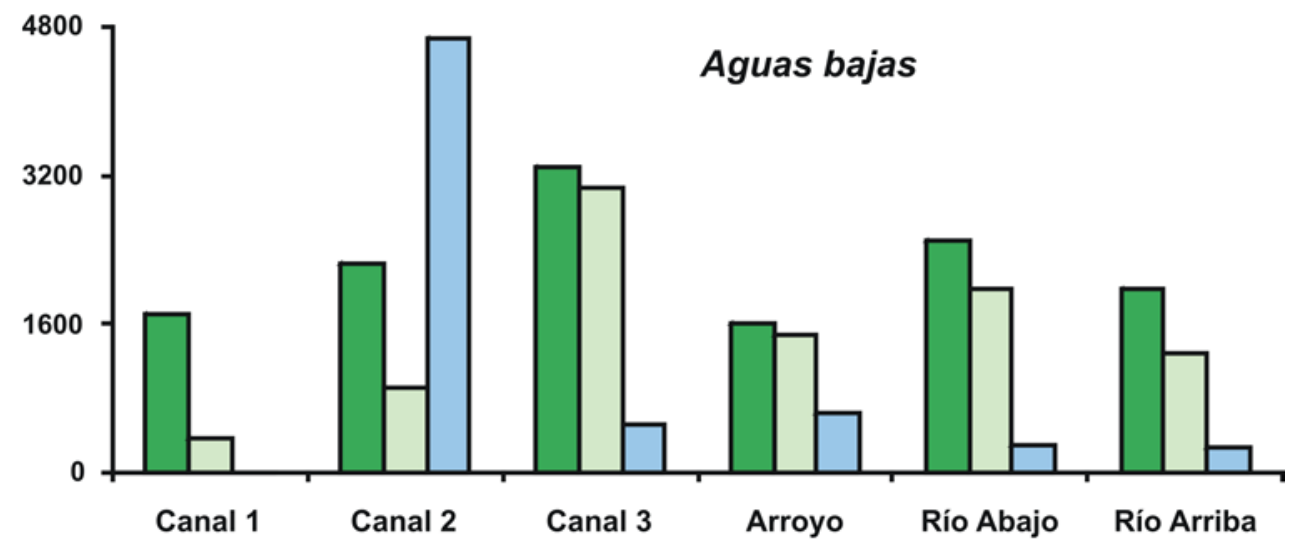

$\mu \mathrm{g} \mathrm{C/L}$

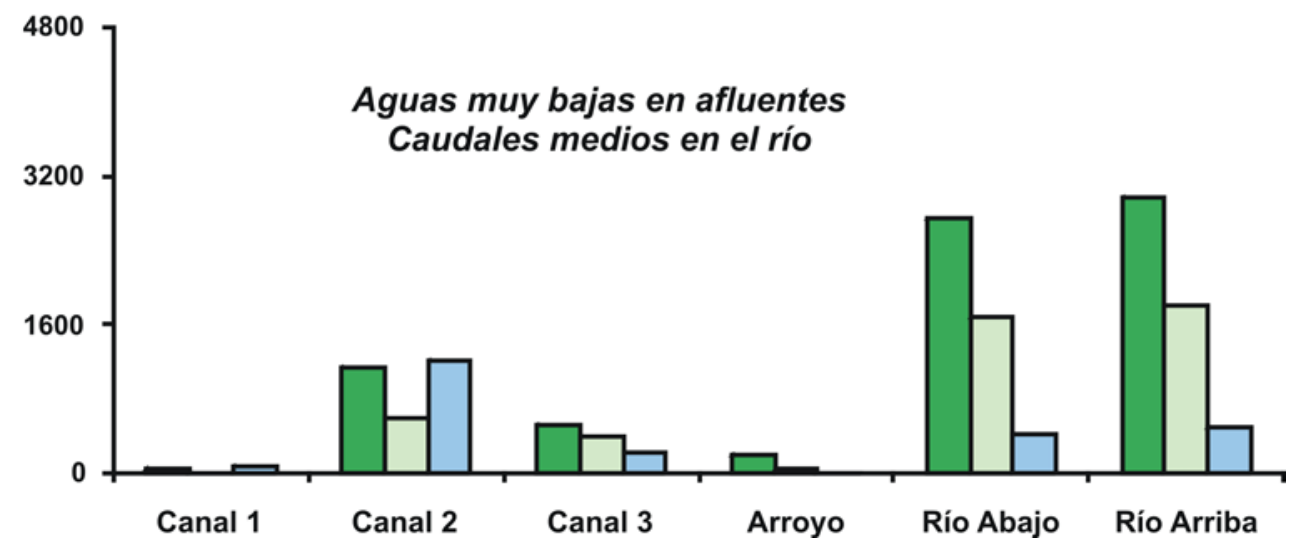

Figura 4.67: Biomasa total del nanoplancton (diatomeas, clorofitas y criptofitas) (verde oscuro), de las clorofitas nanoplanctónicas (verde claro) periferidas por el zooplancton herbívoro (celeste). Se grafican los valores promedio (días 1 y 2) por sitio y muestreo: aguas altas (mayo 2007), caudales medios (marzo 2008), aguas bajas (nov. 2008) y aguas muy bajas en afluentes y caudales medios en el río (sept. 2009). 


\subsection{Relación entre los nutrientes, la materia orgánica particulada y el plancton}

En aguas altas, se observaron en el canal 1 los valores máximos de carbono total calculado a partir de la biomasa del plancton, los cuales disminuyeron a lo largo del sistema Bragado (Fig. 4.68). En el río se registraron los valores mínimos, con un leve aumento de la biomasa de plancton total, con una reducción del nitrógeno inorgánico total $(62 \%)\left(\mathrm{N}+\mathrm{N}\right.$ y N-NH $\left.4^{+}\right)$. En este muestreo se observaron los valores mínimos de \% de contribución a la MOP (5-14\%), considerando todos momentos hidrológicos (Fig. 4.69), y en el arroyo y en el canal 2 se registraron los valores máximos. La biomasa total de fitoplancton contribuyó en gran medida a la MOP en todas las condiciones hidrológicas, no así el zooplancton, siendo $<1,3 \%$ del total en este muestreo (canal 1).

En caudales medios, la relación N:P estuvo entre 5,2 (arroyo) y 8,9 (canal 1), y se registraron valores similares en el canal $2(6,9)$ y el río $(6,4)$; los valores de biomasa total del plancton fueron máximos en el canal 1, y mínimos en el arroyo. El canal 2 y el río aguas abajo presentaron valores similares, aumentando respecto al sitio aguas arriba. La contribución a la MOP fue máxima en el canal 1 (41\%), siendo el valor más elevado registrado en este estudio.

En condiciones de aguas bajas, la relación N:P fue mínima en el río aguas arriba $(1,7)$, y en el sistema Bragado estuvo entre 4,9 (canal 3) y 6,3 (arroyo). El carbono total (biomasa total del plancton) presentó los valores extremos en el sistema Bragado, con mínimos en el arroyo y máximos en el canal 2, contribuyendo un 32\% de la MOP. En el río aguas abajo se observó un leve aumento de la biomasa total de plancton y de la relación N:P, pero la contribución a la MOP se duplicó, respecto al sitio aguas arriba. El aporte de la biomasa total de zooplancton a la MOP muy fue relevante en el canal $2(10,5 \%)$, siendo el \% máximo registrado en este estudio.

En sept. 2009, el río registró los valores máximos de biomasa total del plancton, con escasa variación entre sitios (caudales medios), y en los canales (aguas muy bajas) se observaron los valores mínimos (canal 1). La relación N:P fue similar en el arroyo y en el río (3,2-3,4), entre los canales 1 y $3(4,2-4,4)$, siendo máxima en el canal $2(7,5)$. Los \% de contribución de la biomasa total del plancton a la MOP fueron máximos en el canal 3, seguido por el canal 2 y el río, sin variaciones entre sitios. El aporte de la biomasa del zooplancton sólo se destacó en el canal 2. 

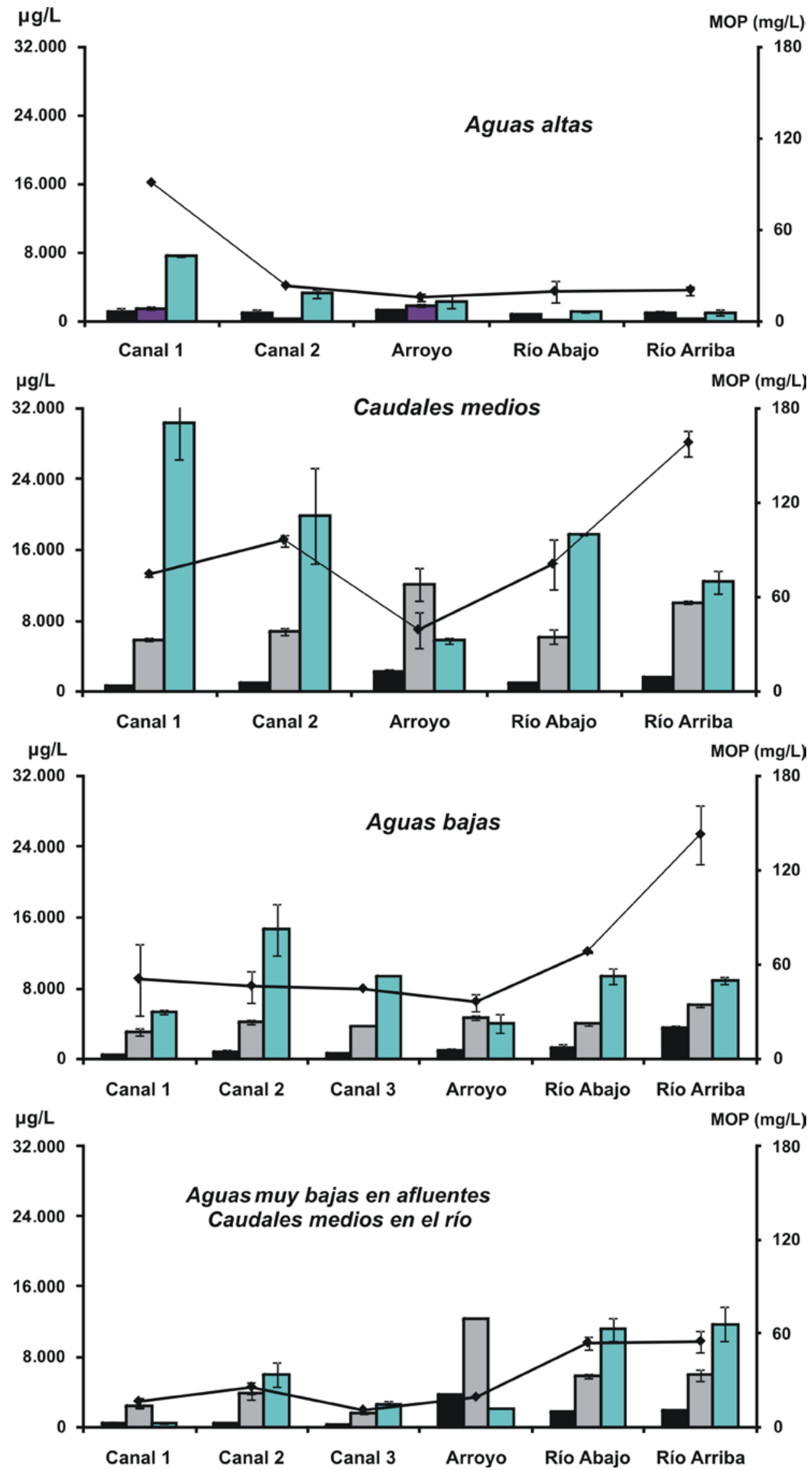

Figura 4.68: Valores de fósforo total (columna en negro), nitrógeno total (columna gris), biomasa total del plancton (columna verde) y materia orgánica particulada (MOP) (línea negra) y. Se grafican los valores promedio (días 1 y 2 ) y sus respectivos rangos de valores por sitio de muestreo y condición hidrológica: aguas altas (mayo 2007), caudales medios (marzo 2008), aguas bajas (nov. 2008) y aguas muy bajas en afluentes pero con caudales medios en el río Salado (sept. 2009). En aguas altas se utilizó el nitrógeno inorgánico (amonio+nitrato+nitrito) (columna violeta). 

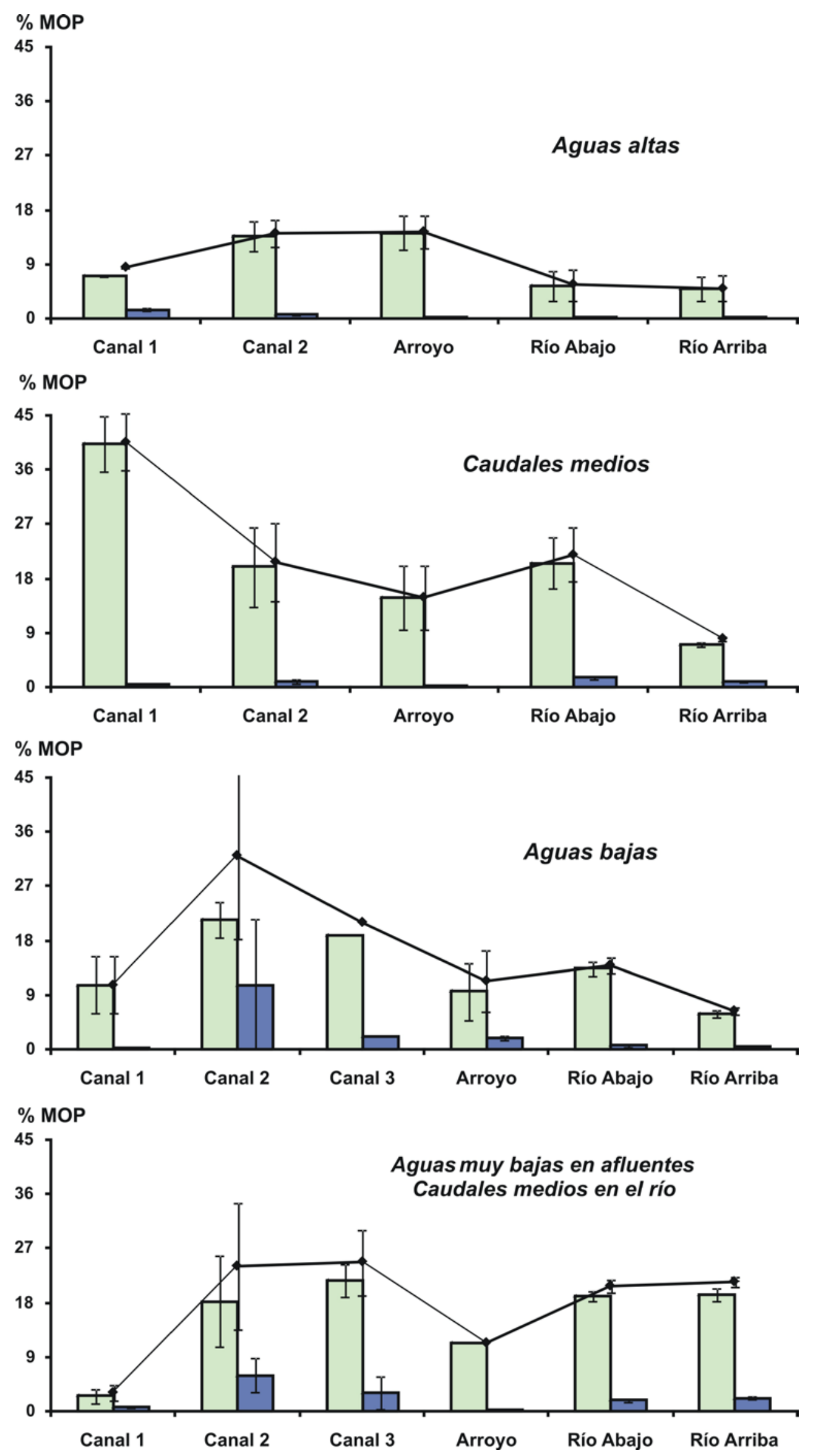

Figura 4.69: Contribución \% del carbono de la biomasa total del plancton a la materia orgánica particulada (MOP) (línea negra), \% de contribución de la biomasa total del fitoplancton (columna verde) y del zooplancton (columna azul). Se grafican los porcentajes promedio (días 1 y 2) y sus respectivos desvíos por sitio de muestreo y condición hidrológica: aguas altas (mayo 2007), caudales medios (marzo 2008), aguas bajas (nov. 2008) y aguas muy bajas en afluentes pero con caudales medios en el río Salado (sept. 2009). 


\section{7. Índice del valor indicador (INDVAL)}

Mediante este método se establecieron 101 especies características de fitoplancton (Tabla 1 Anexo III), las cuales se hallaron principalmente en el canal 3 (26 taxa), seguido por el río y el canal 2 (17-19 taxa) y en último término en el canal 1 y el arroyo (10-12 taxa). La mayoría de estas especies pertenecieron a las clorofitas (37) y diatomeas (32), que se destacaron en el canal 3 y el río, mientras que las cianobacterias (23 taxa) en los canales 1 y 2. Sólo se hallaron criptofitas y dinoflagelados característicos en los canales 2 y 3 (2-3 taxa), y euglenofitas características en el arroyo (3) y el canal 2 (1) (Fig. 4.70).

Asimismo, se determinaron 37 especies comunes (all habitat) siendo la mayoría de ellas ubicuas y cosmopolitas y pertenecientes a las clorofitas (18), seguidas por las cianobacterias (9), las diatomeas (5), las criptofitas (4) y una euglenofita (Tabla 2, Anexo III).

A través de la aplicación de este índice, también se detectaron otros patrones de distribución de las especies de fitoplancton como ser: (a) especies sólo presentes en el sistema Bragado; (b) presentes en el sistema Bragado e son incorporadas en el río Salado aguas abajo; (c) especies que sólo se hallaron en el río; y (d) especies propias de un sitio en particular, no presentes en los restantes (Tablas 3-6, Anexo III).

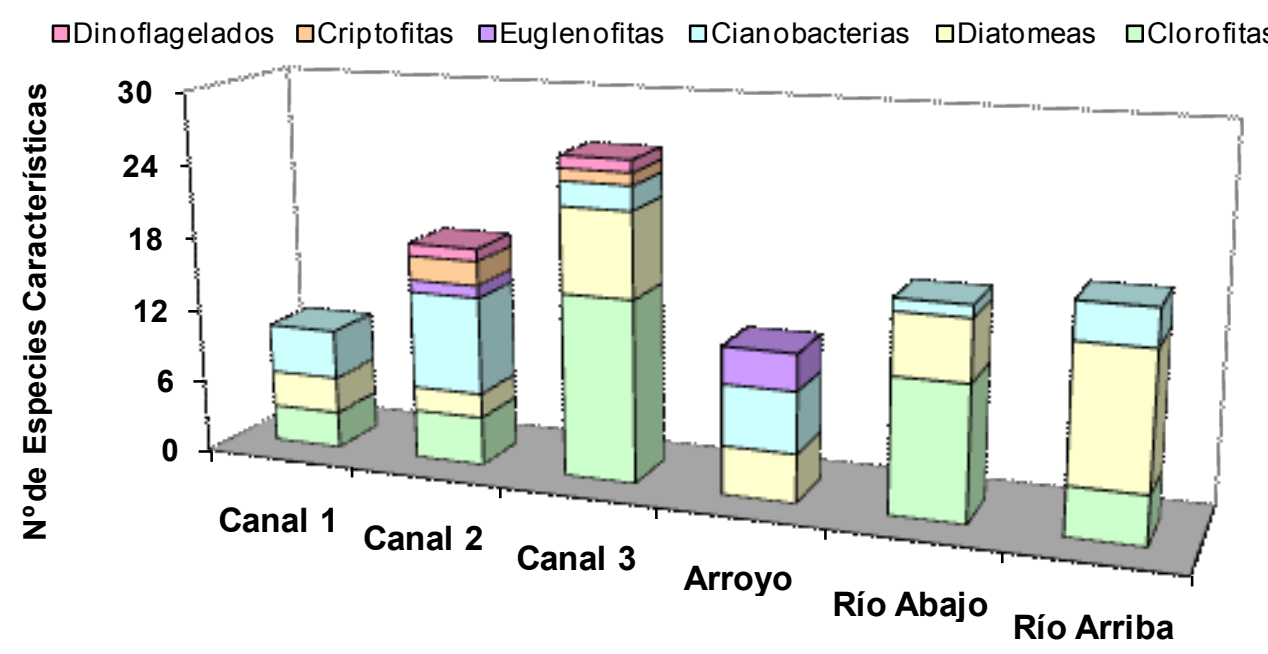

Figura 4.70: Especies características por grupo algal halladas en cada sitio de muestreo.

Se establecieron 53 especies características de zooplancton (Tabla 7, Anexo III), las cuales se hallaron principalmente en el canal 2 (16 taxa) y el canal 3 (13 taxa), seguido por el río (7-8 taxa), y en menor medida en el canal 1 y el arroyo (4-5 taxa). La mayoría de ellas fueron rotíferos (26 taxa) que se destacaron particularmente en el canal 2 (42\% del total), mientras que los ciliados 
característicos (14 taxa) sólo estuvieron presentes en el sistema Bragado. Sólo se hallaron cladóceros característicos en el río (3 especies), rizópodos característicos en el río aguas arriba y el canal 3, y 1 especie de ostrácodo en el río aguas abajo. Además, cada sitio de muestreo presentó 1 o 2 copépodos característicos, a excepción del arroyo (Fig. 4.71).

Asimismo, se hallaron 16 especies comunes de zooplancton (all habitat), mayormente integradas por ciliados y rotíferos ubicuos, abundantes y ampliamente distribuidos (Tabla 8, Anexo III). Algunas especies de zooplancton también registraron una distribución particular entre los sitios de muestreo, a saber: (a) sólo presentes en el sistema Bragado, (b) presentes a lo largo del sistema y que luego se incorporan al río, (c) especies que sólo se hallaron en el río Salado, y (d) especies características de un sitio en particular, no presentes en los restantes (Tablas 9-12, Anexo III).

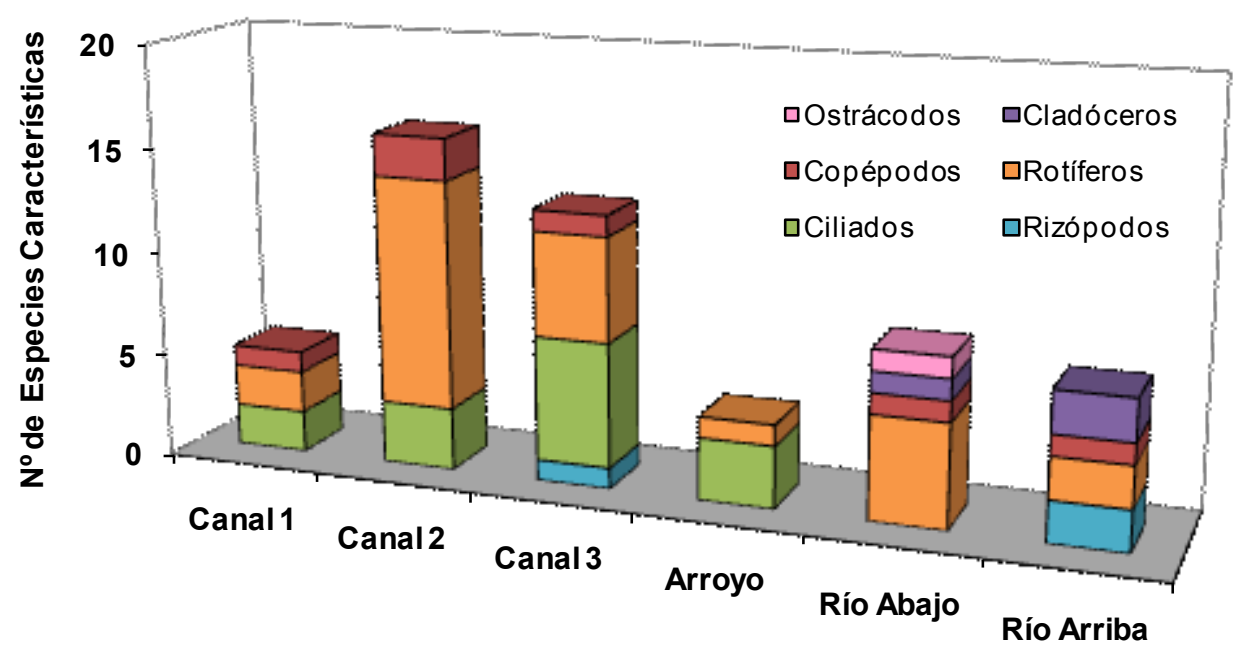

Figura 4.71: Especies características por grupo del zooplancton para cada sitio de muestreo. 


\subsection{Tasa de cambio de la comunidad del fitoplancton $\sigma_{s}$}

En aguas altas se observó la menor variación de la tasa entre los sitios de muestreo, favorecida por las condiciones ambientales homogéneas de inundación en la cuenca. Lo opuesto se observó en el último muestreo, donde hubo escasa variación en el índice entre los sitios del río dado el bajo aporte del sistema Bragado. Por otro lado, la presencia de aguas muy bajas en los canales determinó el máximo cambio en la comunidad del fitoplancton (0,92 - 1,12/día) en este muestreo. Asimismo, se observó una relación directa entre $\sigma_{s}$ y la distancia hidrométrica medida desde el pelo de agua hasta el guardarruedas del puente en cada sitio de muestreo, e inversa con la velocidad de corriente. Esto es, a mayor caudal, mayor velocidad de corriente, menor distancia hidrométrica (pelo de agua - guardarruedas) y menor valor de $\sigma_{s}$, y viceversa (Figs. 4.72-73).

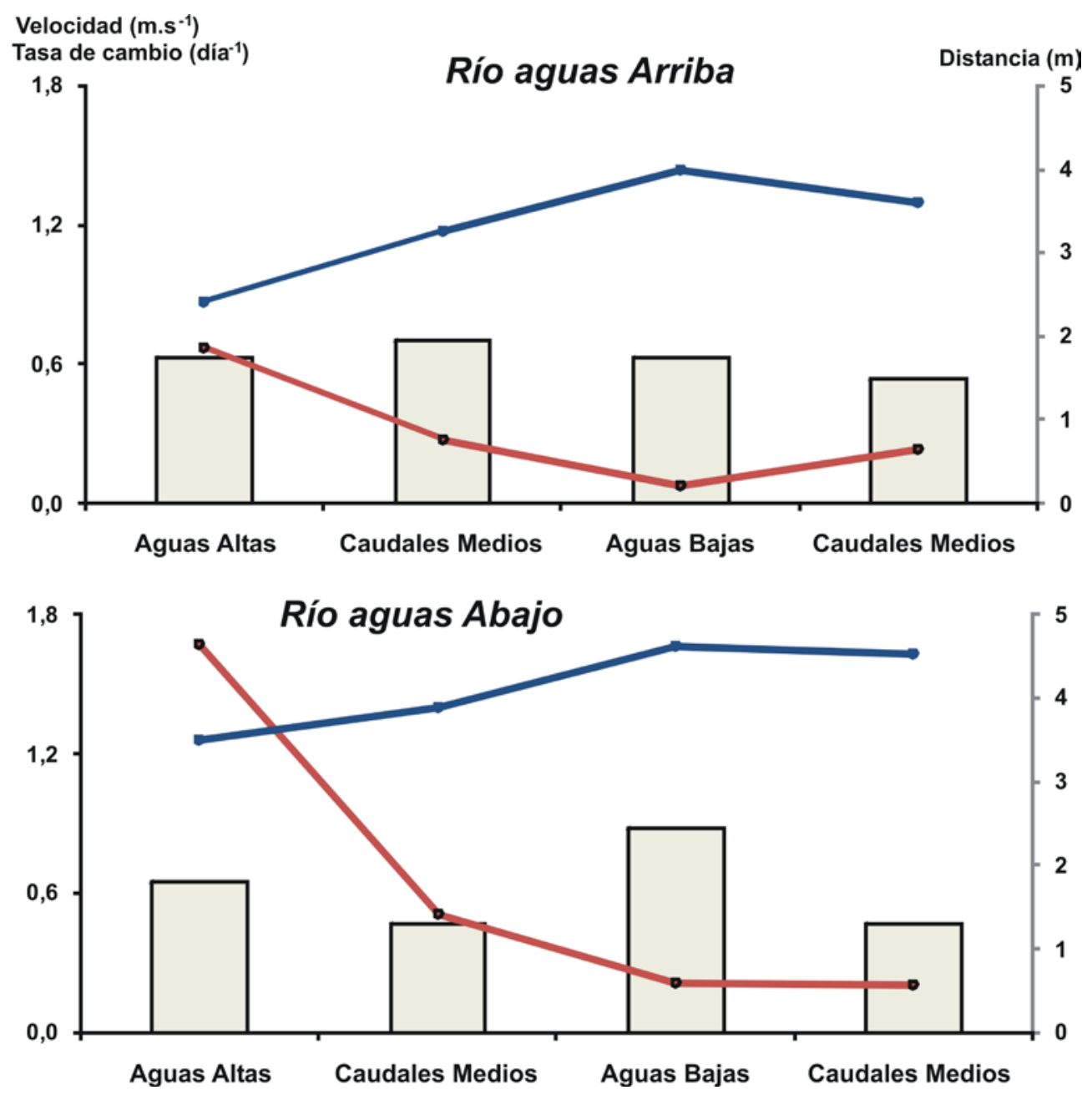

Figura 4.72: Valores de la tasa de cambio de la comunidad del fitoplancton (columnas), velocidad de corriente (línea roja) y distancia hidrométrica pelo de agua-guardarruedas del puente (línea azul) para los sitios del río Salado en los diferentes muestreos: aguas altas (mayo 2007), caudales medios (marzo 2008), aguas bajas (nov. 2008) y caudales medios (sept. 2009). 
En la Tabla 4 (Anexo IV) se resumen las principales especies halladas en diferentes los sitios de muestreo y condiciones hidrológicas, pertenecientes a los grupos morfofuncionales (Reynolds et al., 2002)

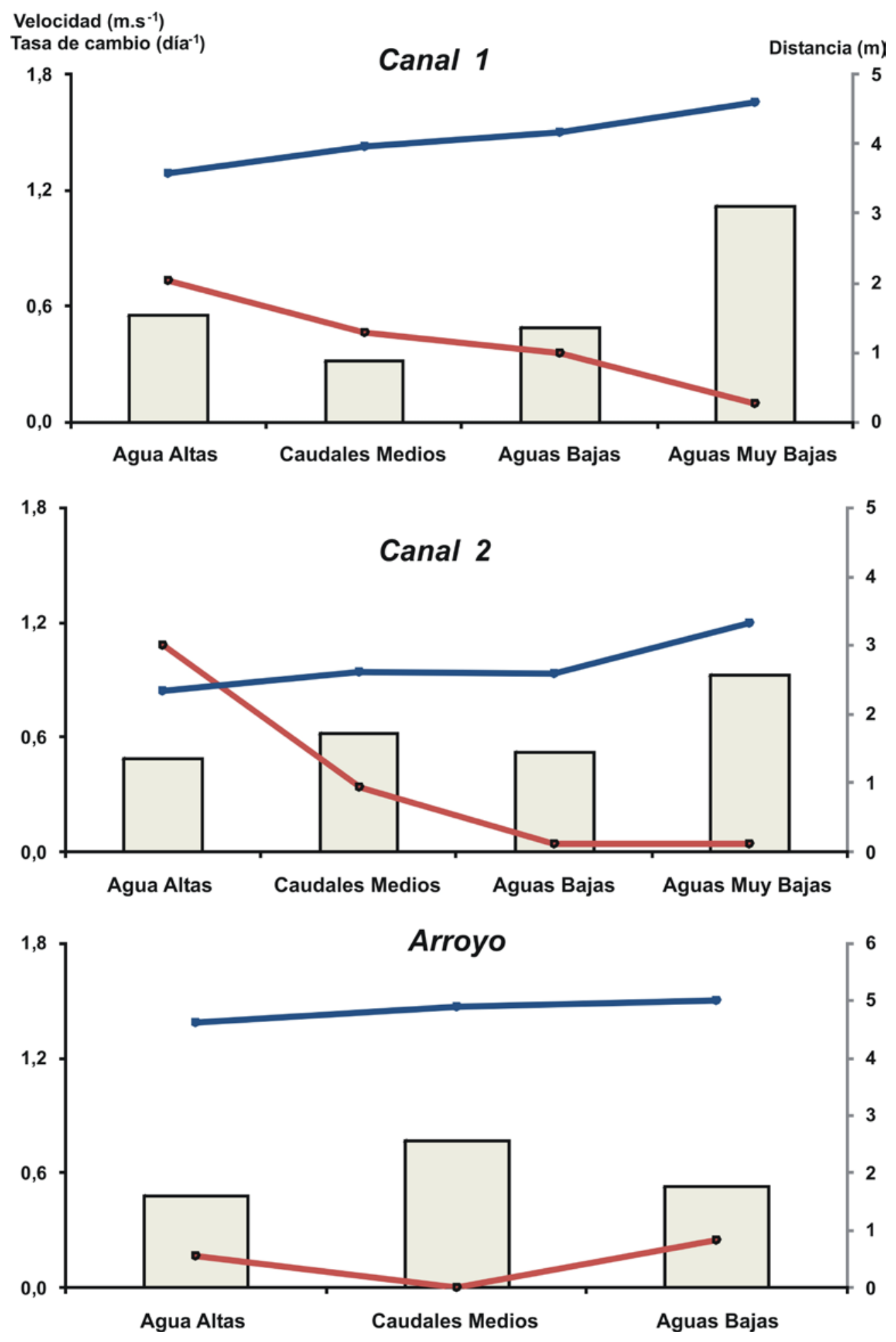

Figura 4.73: Valores de la tasa de cambio de la comunidad del fitoplancton (columnas), velocidad de corriente (línea roja) y la distancia hidrométrica medida desde el pelo de agua al guardarruedas del puente (línea azul) para los sitios del sistema Bragado en las diferentes condiciones hidrológicas: aguas altas (mayo 2007), caudales medios (marzo 2008), aguas bajas (nov. 2008) y aguas muy bajas (sept. 2009). (Datos faltantes: arroyo en aguas muy bajas). 


\subsection{Análisis multivariados}

\subsubsection{Ordenamiento MDS de la composición iónica del agua}

En el ordenamiento MDS (Fig. 4.74) se observa el agrupamiento de los canales 2 y 3, el río aguas abajo y el arroyo en aguas bajas, dado por las concentraciones de $\mathrm{Mg}^{++} \mathrm{y} \mathrm{SO}_{4}=$ (Fig. 4.75-6). El canal 1 se diferenció de los restantes sitios de muestreos por las concentraciones de $\mathrm{Na}^{+}+\mathrm{K}^{+}$y $\mathrm{Cl}^{-}$y $\mathrm{HCO}_{3}=$, en aguas bajas y en aguas muy bajas, respectivamente. En el sector derecho de la Figura 4.74, se encuentra un conglomerado de sitios superpuestos, formado por el río aguas arriba y abajo del trasvase, el canal 2 y el arroyo en aguas altas. Ambos sitios del río y el arroyo en caudales medios (marzo 2008) se relacionaron con el río aguas arriba en aguas bajas. Los sitios del último muestreo (sept. 2009) forman una diagonal en el sector superior derecho de la ordenación, relacionado a las concentraciones de $\mathrm{Ca}^{++}$, entre los cuales se distingue la asociación entre ambos sitios del río (caudales medios).

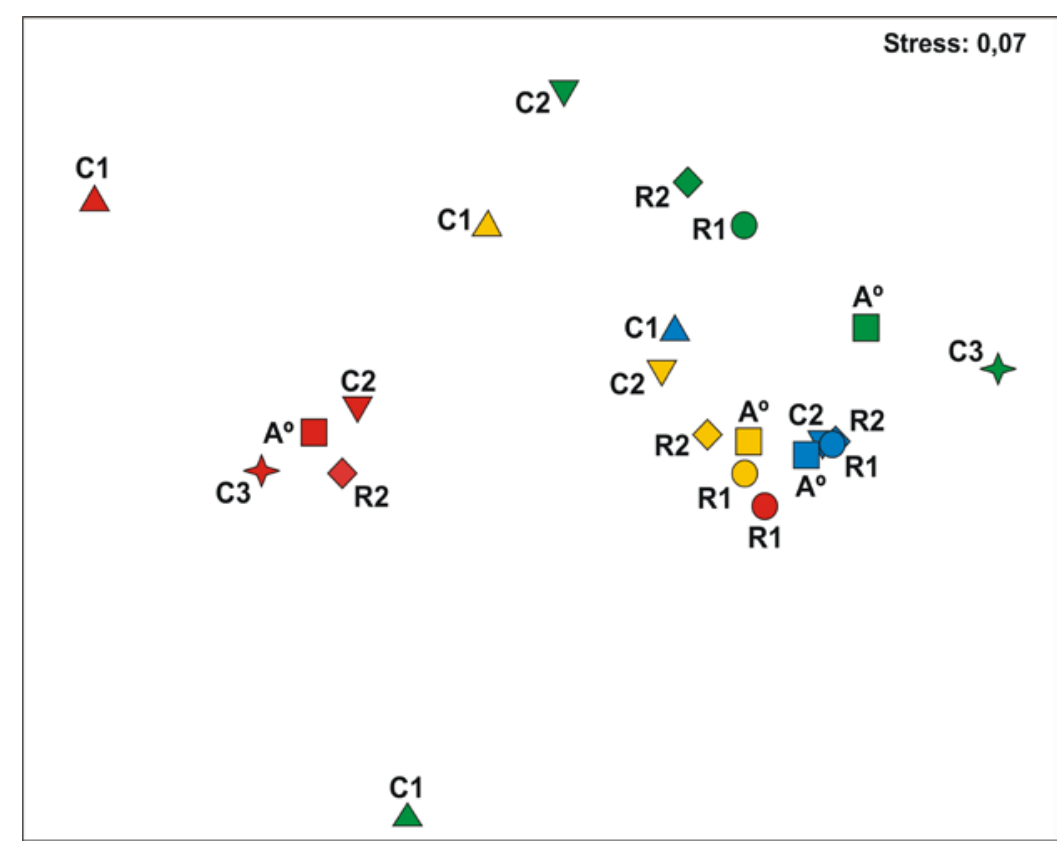

Figura 4.74: Ordenamiento MDS de los sitios de muestreo según la composición iónica del agua $\left(\mathrm{Ca}^{++}, \mathrm{Mg}^{++}\right.$, $\mathrm{Na}^{+}+\mathrm{K}^{+}, \mathrm{Cl}-, \mathrm{SO}_{4}{ }^{-}, \mathrm{HCO}_{3}-$ ) en las diferentes condiciones hidrológicas. Se utilizó una matriz de similitud (distancia Euclidiana, ligamiento completo) basada en los datos normalizados. Referencias: C1 (canal 1), C2 (canal 2), C3 (canal 3), Ao (arroyo), R1 (río aguas arriba), R2 (río aguas abajo), círculos en color azul (aguas altas - mayo 2007), amarillo (caudales medios - marzo 2008), rojo (aguas bajas - nov. 2008) y en verde (aguas muy bajas en el sistema Bragado con caudales medios en el río - sept. 2009). 

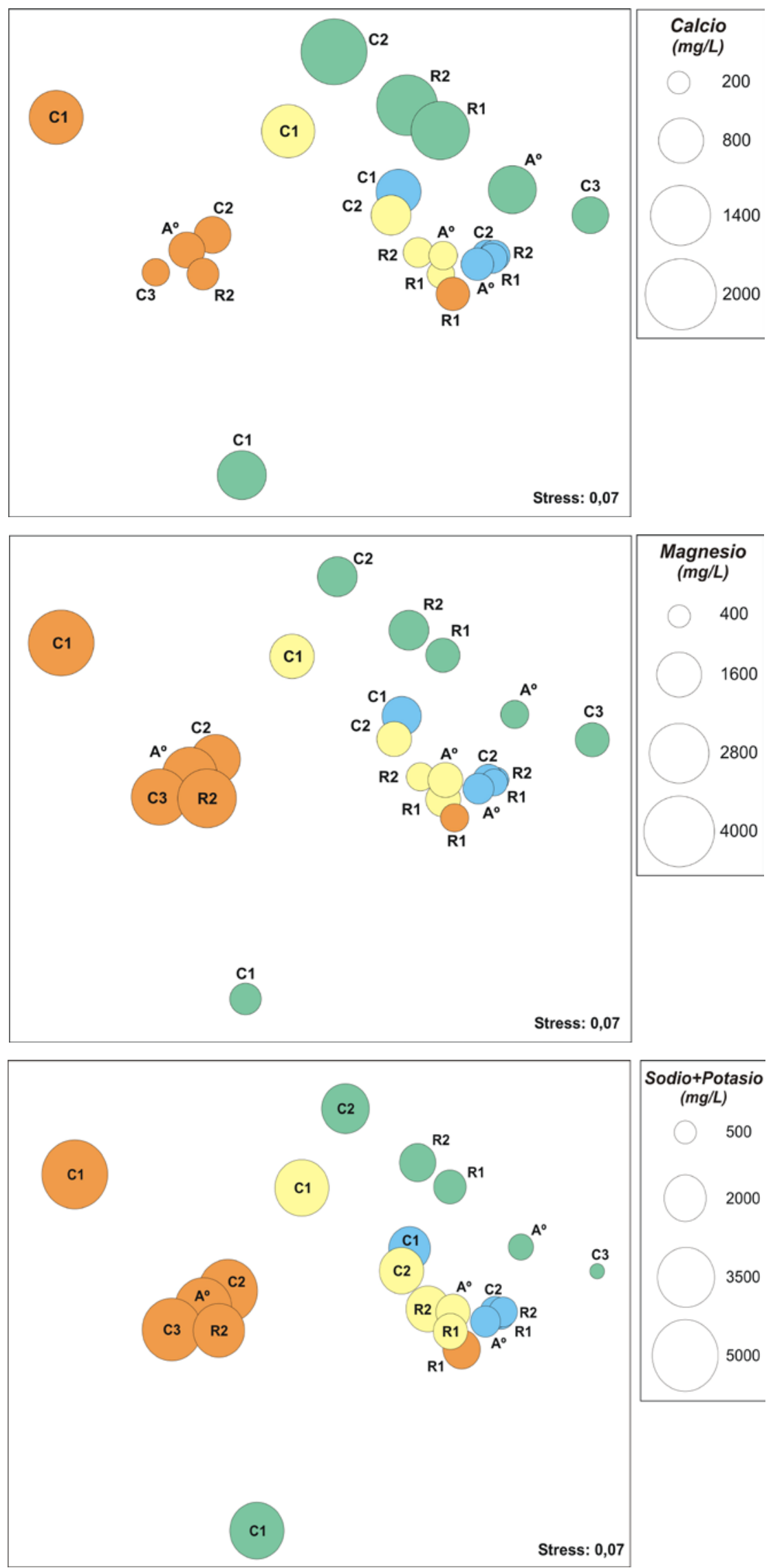

Figura 4.75: Ordenamiento MDS de la composición iónica del agua donde se detalla la concentración (mg/L) de $\mathrm{Ca}^{++}$(arriba), $\mathrm{Mg}^{++}$(centro) y Na+ $\mathrm{K}^{+}$(abajo) en los diferentes sitios y condiciones hidrológicas. Referencias: C1 (canal 1), C2 (canal 2), C3 (canal 3), Ao (arroyo), R1 (río aguas arriba), R2 (río aguas abajo), círculos en color azul (aguas altas - mayo 2007), amarillo (caudales medios - marzo 2008), anaranjado (aguas bajas nov. 2008) y en verde (aguas muy bajas en el sistema Bragado con caudales medios en el río - sept. 2009). 


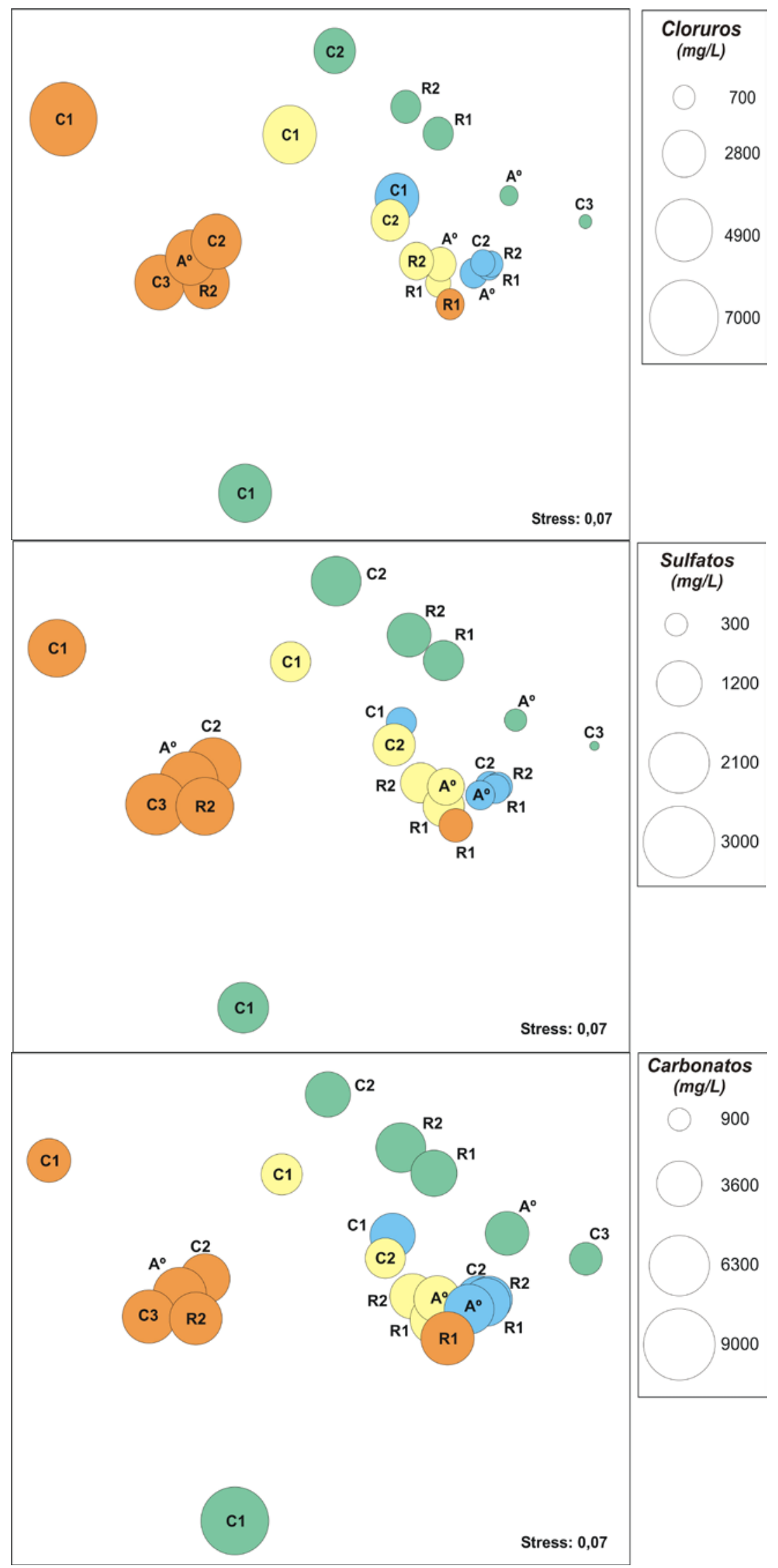

Figura 4.76: Ordenamiento MDS de la composición iónica del agua donde se detalla la concentración (mg/L) de $\mathrm{Cl}^{-}$(arriba), $\mathrm{SO}_{4}=$ (centro) y $\mathrm{HCO}_{3}^{-}$(abajo) en los diferentes sitios y condiciones hidrológicas. Referencias: $\mathrm{C} 1$ (canal 1), C2 (canal 2), C3 (canal 3), Ao (arroyo), R1 (río aguas arriba), R2 (río aguas abajo), círculos en color azul (aguas altas - mayo 2007), amarillo (caudales medios - marzo 2008), anaranjado (aguas bajas - nov. 2008) y en verde (aguas muy bajas en el sistema Bragado con caudales medios en el río - sept. 2009). 


\subsubsection{Análisis de agrupamientos cluster de la composición iónica del agua}

El análisis cluster basado en la matriz de similitud (distancia Euclidiana, ligamiento completo) arrojó diferencias significativas $(p<0,05)$ en 13 nodos del dendrograma, dividiendo a los sitios de muestreo en 6 grupos principales (Fig. 4.77). El Grupo I reunió al río, el canal 2 y el arroyo en aguas altas, siendo mínima la distancia entre ellos, seguido por el Grupo II, formado por el arroyo y el río aguas arriba en caudales medios (marzo 2008). El Grupo III estuvo formado por el río aguas abajo y el canal 2 en caudales medios y el canal 1 en aguas altas. En orden creciente de distancia entre nodos se halló el Grupo IV integrado por el arroyo, los canales 3 y 2 y el río aguas abajo en aguas bajas. El muestreo de aguas muy bajas en el sistema Bragado pero con caudales medios en el río (sept. 2009), fue dividido en dos partes: el grupo V, que reunió al río y al canal 2 con el canal 1 en caudales medios, y el Grupo VI, formado por el canal 3 y el arroyo en aguas muy bajas.

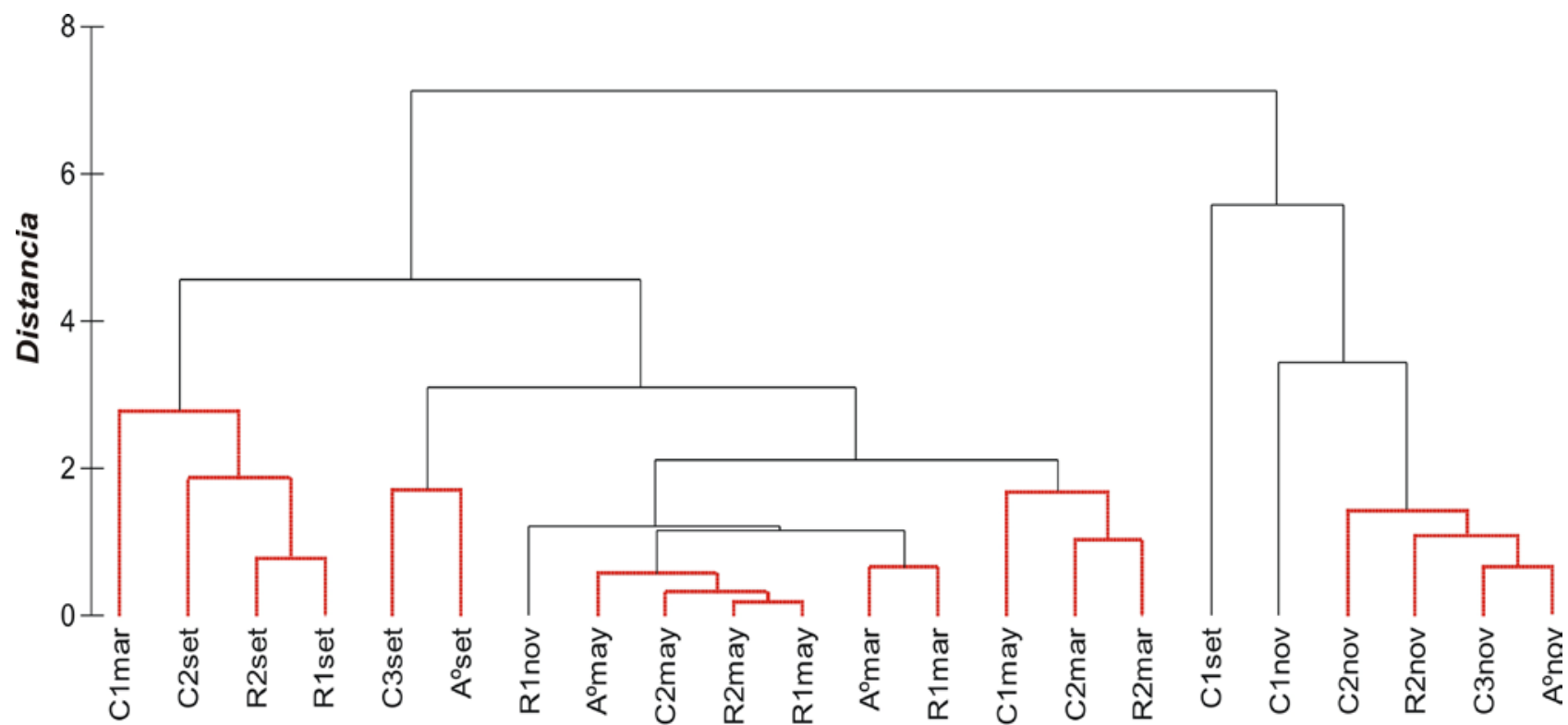

Figura 4.77: Análisis de agrupamientos (cluster) de los sitios de muestreo según la composición iónica del agua $\left(\mathrm{Ca}^{+}, \mathrm{Mg}^{+}, \mathrm{Na}^{+}+\mathrm{K}^{+}, \mathrm{Cl}-, \mathrm{SO}_{4}{ }^{-}, \mathrm{HCO}_{3}{ }^{-}\right)$. Se utilizó una matriz de similitud (distancia Euclidiana, ligamiento completo) basada en datos normalizados. En color rojo se distinguen los clados significativos ( $\mathrm{p}<0,05)$. Referencias: C1 (canal 1), C2 (canal 2), C3 (canal 3), Ao (arroyo), R1 (río aguas arriba), R2 (río aguas abajo), may (mayo 2007 - aguas altas), mar (caudales medios de marzo 2008), nov (nov. 2008 - aguas bajas) y set (Setiembre 2009 - aguas muy bajas en el sistema Bragado con caudales medios en el río).

\subsubsection{Análisis de componentes principales de las variables ambientales por muestreo}

A través del análisis PCA se obtuvo la ordenación de los sitos de muestreo, de acuerdo a los valores de las variables ambientales observadas en las diferentes condiciones hidrológicas. En aguas altas, los Factores 1 y 2 explicaron el 86\% de la varianza total acumulada (Tabla 4.9-A). El Factor 1 separó al canal 1 en el extremo inferior izquierdo, relacionado con mayores valores de conductividad, dureza, sólidos suspendidos (SS), turbidez, materia orgánica particulada (MOP), 
polifenoles totales disueltos (Polif.), nitratos + nitritos $(\mathrm{N}+\mathrm{N})$, fósforo total (PT) y fósforo total disuelto (PTD). En el lado opuesto se observó a los sitios del río, asociado a mayores valores de oxígenos disuelto (OD) y transparencia, aunque el río aguas abajo se ubicó en el mismo cuadrante que el canal 2 (Fig. 4.78). El Factor 2 separó al arroyo, quedando definido por la alcalinidad y el fósforo reactivo soluble (PRS), y negativamente por la velocidad de corriente (Veloc.).

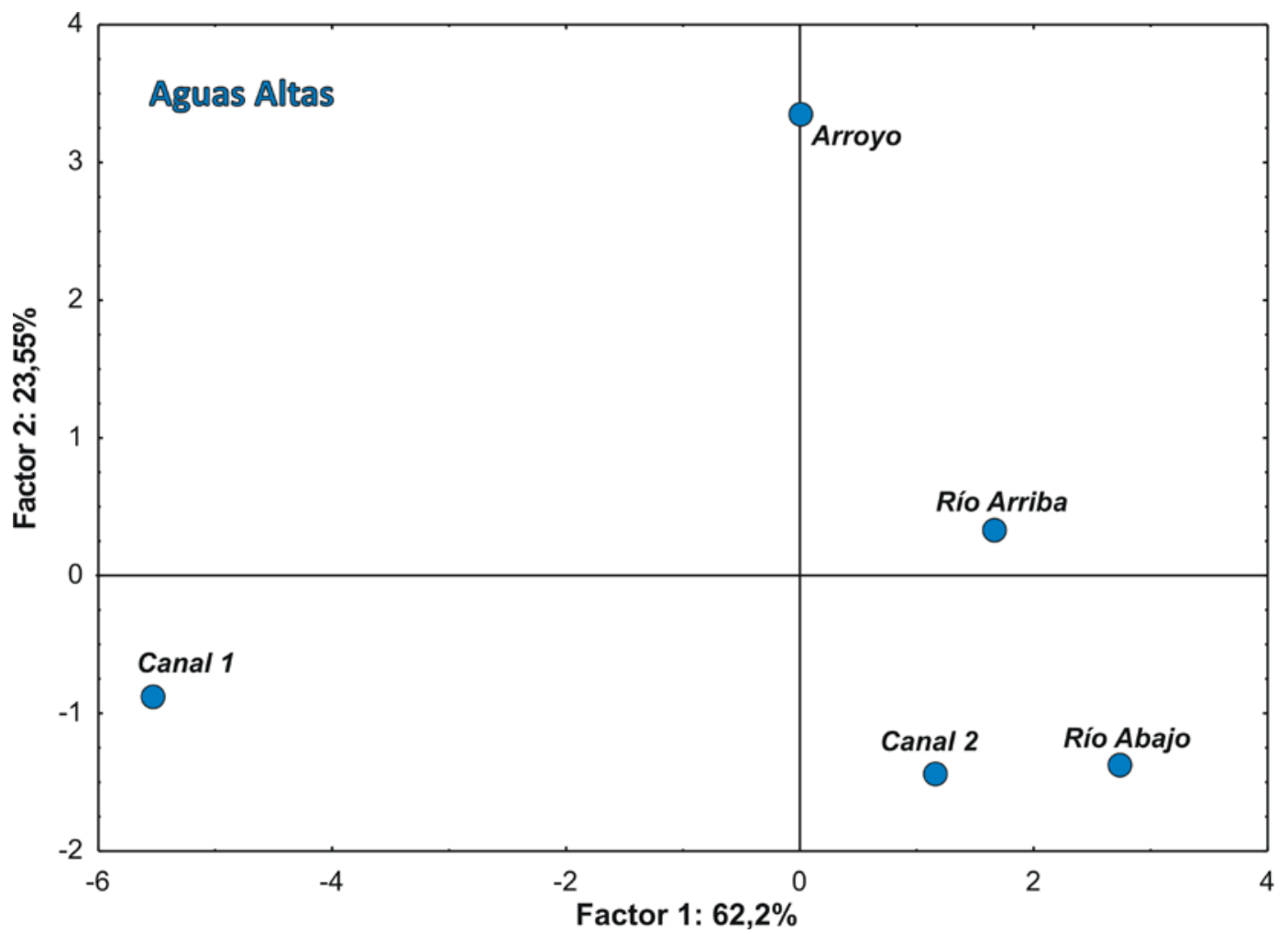

Figura 4.78: Análisis de Componentes Principales (PCA) del muestreo en condiciones de aguas altas (mayo 2007). Se representan los dos primeros ejes de ordenación que muestran la relación entre las variables ambientales y los sitios de muestreo.

En caudales medios, los Factores 1 y 2 explicaron el 83\% de la varianza total acumulada (Tabla 4.10-B). El Factor 1 separó al arroyo, asociado con mayores valores de amonio $\left(\mathrm{N}_{-} \mathrm{NH}_{4}^{+}\right)$, PTD, PRS, PT, N+N y materia orgánica disuelta (MOD), y menores valores de OD y Veloc. Lo opuesto se observó para el canal 2 y el río aguas abajo (Fig. 4.79). El Factor 2 separó al río aguas arriba del trasvase, relacionado con mayores valores de alcalinidad, turbidez, $\mathrm{pH}$, SS y MOP; y lo opuesto para el canal 1, definido por mayores valores de conductividad y transparencia. Nuevamente, el río aguas abajo del trasvase se ubicó en las cercanías del canal 2, y alejado del sitio aguas arriba.

En aguas bajas, los Factores 1 y 2 explicaron el 88\% de la varianza total acumulada (Tabla 4.11C). El Factor 1 separó al río aguas arriba asociado a mayores valores de turbidez, pH, PT, PTD, PRS, MOD, SS, MOP, alcalinidad y Polif. En el lado opuesto del eje se hallaron los canales, relacionados con mayores valores de conductividad, dureza y transparencia (Fig. 4.80). El río aguas abajo del trasvase se ubicó en el centro del plano de ordenación, cercano a los canales 2 y 3. El Factor 2 separó al arroyo, relacionado con valores positivos de $\mathrm{N}-\mathrm{NH}_{4}{ }^{+}$y N+N, y opuesto al OD. 
Tabla 4.10: Valores de las correlaciones de las variables ambientales asociadas a los Factores 1 y 2 para los muestreos de aguas altas y caudales medios. En rojo se resaltan las correlaciones positivas o negativas mayores a 0,7 .

\begin{tabular}{lcc} 
A-Aguas Altas & & \\
\hline Variable & Factor 1 & Factor 2 \\
\hline Dureza & $-0,99$ & $-0,07$ \\
Conductividad & $-0,98$ & $-0,15$ \\
SS & $-0,97$ & $-0,24$ \\
Turbidez & $-0,96$ & $-0,29$ \\
MOP & $-0,94$ & $-0,31$ \\
OD & 0,96 & $-0,17$ \\
PTD & $-0,85$ & $-0,11$ \\
PT & $-0,84$ & 0,38 \\
N+N & $-0,80$ & 0,56 \\
Polif. & $-0,74$ & $-0,35$ \\
Transparencia & 0,73 & 0,02 \\
Veloc. & 0,40 & $-0,83$ \\
Alcalinidad & 0,57 & 0,81 \\
PRS & 0,59 & 0,79 \\
\hline Varianza total & $62,2 \%$ & $23,55 \%$
\end{tabular}

\begin{tabular}{lcc} 
B- Caudales medios & & \\
\hline Variable & Factor 1 & Factor 2 \\
\hline${\mathrm{N}-\mathrm{NH}_{4}{ }^{+}}_{\mathrm{PTD}}$ & $-0,99$ & 0,03 \\
PRS & $-0,97$ & $-0,21$ \\
PT & $-0,94$ & $-0,32$ \\
Veloc. & $-0,92$ & $-0,38$ \\
OD & 0,87 & 0,31 \\
N+N & 0,87 & $-0,08$ \\
MOD & $-0,78$ & $-0,34$ \\
Alcalinidad & $-0,73$ & $-0,29$ \\
Turbidez & $-0,10$ & $-0,94$ \\
Conductividad & 0,49 & $-0,86$ \\
pH & 0,39 & 0,84 \\
Transparencia & 0,57 & $-0,81$ \\
MOP & $-0,57$ & 0,80 \\
SS & 0,65 & $-0,73$ \\
\hline Varianza total & 0,65 & $-0,73$ \\
\hline
\end{tabular}

Tabla 4.11: Valores de las correlaciones de las variables ambientales asociadas a los Factores 1 y 2 para los muestreos de aguas bajas (nov. 2008) y los Factores 1, 2 y 3 para el muestreo de aguas muy bajas en el sistema Bragado, pero con caudales medios en el río Salado (sept. 2009). En rojo se resaltan las correlaciones positivas o negativas $>0,7$.

\begin{tabular}{lcc} 
C-Aguas Bajas & & \\
\hline Variable & Factor 1 & Factor 2 \\
\hline Turbidez & $-0,98$ & $-0,17$ \\
pH & $-0,98$ & $-0,14$ \\
PT & $-0,98$ & $-0,11$ \\
PTD & $-0,97$ & $-0,08$ \\
PRS & $-0,96$ & $-0,06$ \\
Conductividad & 0,96 & $-0,19$ \\
MOD & $-0,95$ & $-0,30$ \\
Alcalinidad & $-0,94$ & 0,28 \\
SS & $-0,94$ & $-0,33$ \\
MOP & $-0,93$ & $-0,36$ \\
Transparencia & 0,91 & $-0,39$ \\
Dureza & 0,89 & $-0,32$ \\
Polif. & $-0,70$ & 0,57 \\
OD & $-0,33$ & $-0,88$ \\
N-NH ${ }_{4}{ }^{+}$ & 0,11 & 0,76 \\
N+N $^{\text {Varianza total }}$ & $-0,20$ & 0,75 \\
\hline
\end{tabular}

\begin{tabular}{lccc} 
D-Aguas Muy Bajas & & \\
\hline Variable & Factor 1 & Factor 2 & Factor 3 \\
\hline MOD & $-0,99$ & 0,01 & 0,04 \\
Veloc. & $-0,98$ & 0,12 & $-0,09$ \\
PRS & $-0,97$ & 0,18 & $-0,03$ \\
Polif. & $-0,94$ & 0,06 & 0,24 \\
PTD & $-0,93$ & 0,35 & 0,03 \\
PT & $-0,93$ & 0,36 & 0,01 \\
Transparencia & 0,92 & 0,27 & $-0,17$ \\
OD & $-0,38$ & $-0,90$ & $-0,21$ \\
SS & $-0,48$ & $-0,86$ & 0,11 \\
Dureza & $-0,09$ & $-0,84$ & 0,25 \\
MOP & $-0,57$ & $-0,80$ & $-0,03$ \\
pH & 0,43 & $-0,79$ & $-0,34$ \\
Turbidez & $-0,56$ & $-0,79$ & $-0,02$ \\
N-NH ${ }^{+}$ & $-0,64$ & 0,74 & 0,04 \\
Conductividad & 0,35 & $-0,30$ & 0,88 \\
Alcalinidad & 0,19 & $-0,12$ & 0,83 \\
N+N & 0,00 & $-0,20$ & $-0,83$ \\
\hline Varianza total & $47,9 \%$ & $30,6 \%$ & $14,6 \%$
\end{tabular}




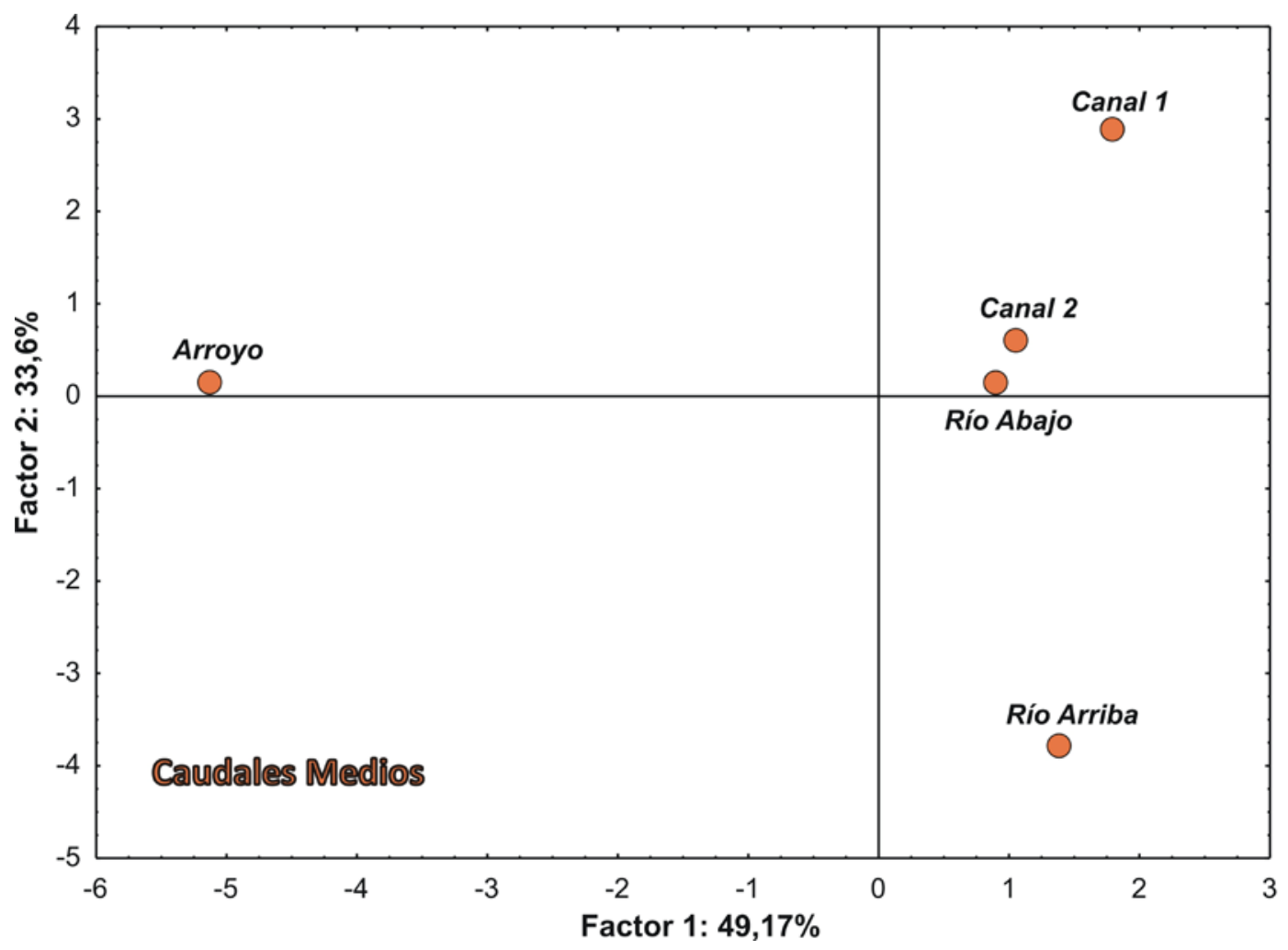

Figura 4.79: Análisis de Componentes Principales (PCA) del muestreo en condiciones de caudales medios (marzo 2008). Se representan los dos primeros ejes de ordenación que muestran la relación entre las variables ambientales y los sitios de muestreo.

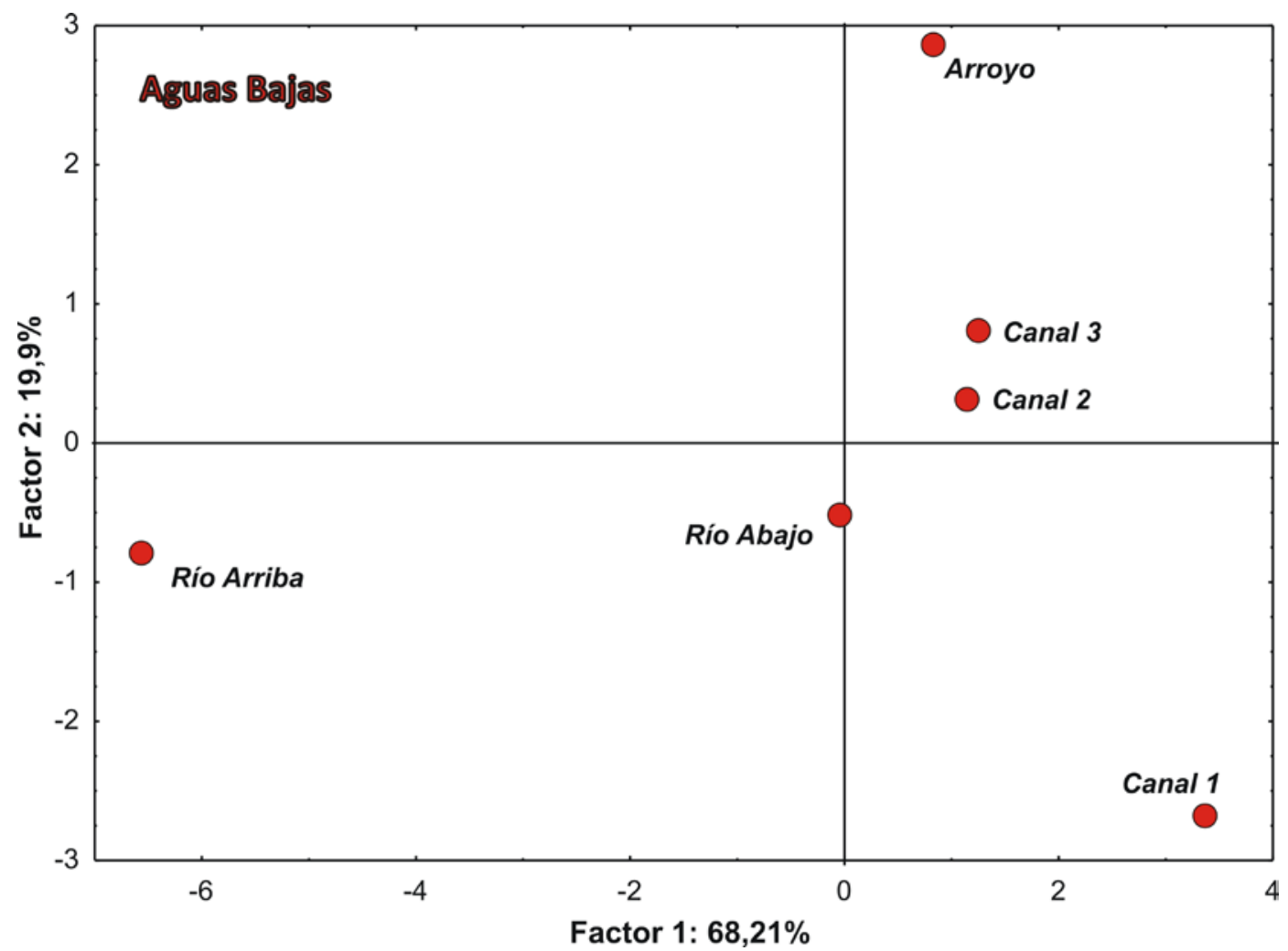

Figura 4.80: Análisis de Componentes Principales (PCA) del muestreo en condiciones de aguas bajas (nov. 2008). Se representan los dos primeros ejes de ordenación que muestran la relación entre las variables ambientales y los sitios de muestreo.

En aguas muy bajas en el sistema Bragado pero con caudales medios en el río Salado (sept. 2009) los Factores 1 y 2 explicaron el 78,5\% de la varianza total acumulada (Fig. 4.81). En este caso 
también se hallaron correlaciones $>0,8$ entre las variables ambientales para el Factor 3 (Tabla 4.11D). De este modo, se explicó el 93\% de la varianza total acumulada a través de los Factores 1, 2 y 3. A diferencia de los otros muestreos, los sitios del río quedaron agrupados en el mismo sector en el plano de ordenación de los Factores 1 y 2 y Factores 2 y 3, asociados a mayores valores de MOD, Veloc., Polif., PT, PTD, PRS, OD, SS, dureza, MOP, pH, N+N y turbidez. Por otro lado, los sitios del sistema Bragado variaron su ubicación según la representación de los ejes. El arroyo se separó del resto de los sitios por los valores de $\mathrm{N}_{-} \mathrm{NH}_{4}{ }^{+}$(Factores 1 y 2 ) y de alcalinidad (Factores 2 y 3 ). Los canales 1 y 3 se agruparon en el sector positivo de ambos ejes por la transparencia (Factores 1 y 2 ), y el canal 2 se ubicó en la cercanía de los sitios del río en la representación de los Factores 1 y 3.

\subsubsection{Análisis de agrupamientos $k$-means de las variables ambientales}

Mediante este análisis se reunió a los sitios de muestreo y a las variables ambientales en 4 grupos, definidos por la mínima distancia a los respectivos centroides (Tablas 4.12-13). El Grupo I asoció a todos los canales en condiciones de aguas muy bajas. El Grupo II correspondió al río aguas arriba del trasvase en condiciones de caudales medios y aguas bajas, junto con el río aguas abajo en caudales medios (sept. 2009). El Grupo III agrupó a todos los sitios de muestreo en aguas altas y el Grupo IV estuvo integrado por los sitios del sistema Bragado y el río aguas abajo del trasvase en caudales medios (marzo 2008) y en aguas bajas (nov. 2008). Las variables ambientales que integraron el Grupo I fueron los parámetros temperatura, conductividad y dureza, y el Grupo II los nutrientes N+N y N-NH $4^{+}$, PRS, PT y PTD. El Grupo III estuvo definido por la transparencia, Veloc., Polif. y distancia hidrométrica (pelo de agua-guardarruedas del puente), y el Grupo IV por el $\mathrm{pH}$, la turbidez, SS, MOP, MOD, alcalinidad y OD.

\subsubsection{Análisis de agrupamientos cluster de la composición del plancton}

\section{Fitoplancton}

Este análisis de agrupamientos (cluster) arrojó diferencias significativas $(p<0,05)$ en 10 nodos del dendrograma, agrupando a los sitios de muestreo en 5 grupos (Grupos I, II, III, IVa, IVb y V). El Grupo I estuvo integrado por ambos sitios del río en los caudales medios de sept. 2009, registrando el valor máximo de similitud entre sitios. Asociados a estos sitios también se hallaron los canales 2 y 3 (Grupo II) durante este mismo muestreo (aguas muy bajas en el sistema Bragado), aunque registraron un menor grado de similitud entre ellos (Fig. 4.82).

El Grupo III reunió a todos los sitios de muestreo en aguas altas, pero sólo fue significativa la relación entre el río y entre los canales 1 y 2. El Grupo IVa estuvo integrado por el río, el canal 3 y 
el arroyo en aguas bajas, y asociado a este grupo se hallaron ambos sitios del río y los canales 1 y 2 en caudales medios, formando el Grupo IVb. Y por fuera de los grupos mencionados se hallaron el arroyo y el canal 1 en aguas muy bajas (Grupo V), teniendo una relación significativa pero con valores mínimos de similitud.
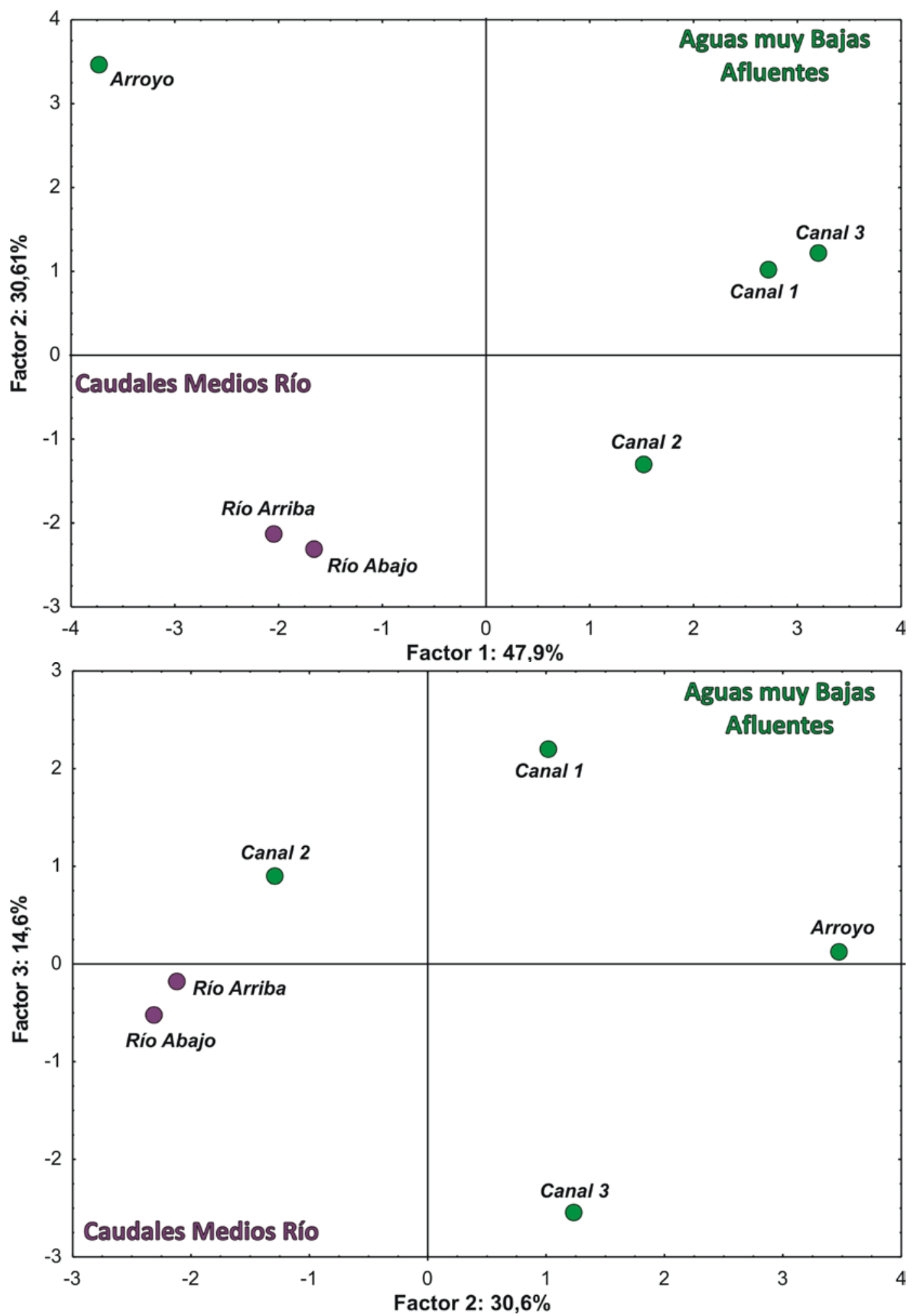

Figura 4.81: Análisis de Componentes Principales (PCA) del muestreo en condiciones de aguas muy bajas en afluentes (sistema Bragado) pero con caudales medios en el río Salado (sept. 2009). Se representan los ejes de ordenación 1 y 2 (arriba) y 2 y 3 (abajo) que muestran la relación entre las variables ambientales y los sitios. 
Tabla 4.12: Resultados del análisis de agrupamientos $k$-means para los sitios de muestreo (Grupos I, II, III y IV). Se especifican las distancias de cada variable al centro del cluster correspondiente. Referencias: letras en color azul (aguas altas - mayo 2007), anaranjado (caudales medios - marzo 2008), rojo (aguas bajas - nov. 2008) y en verde (aguas muy bajas en el sistema Bragado con caudales medios en el río - sept. 2009).

\begin{tabular}{|c|c|c|c|}
\hline \multicolumn{2}{|c|}{ Grupo II } & \multicolumn{2}{|c|}{ Grupo I } \\
\hline río abajo & 0,6571 & canal 1 & 0,7055 \\
\hline río arriba & 0,7897 & canal 2 & 0,4967 \\
\hline río arriba & 1,1457 & canal 3 & 0,6671 \\
\hline río arriba & 0,6130 & & \\
\hline
\end{tabular}

\begin{tabular}{lr} 
& Grupo III \\
\hline canal 1 & 0,8250 \\
arroyo & 0,5490 \\
arroyo & 1,0897 \\
arroyo & 1,1428 \\
río abajo & 0,8584 \\
canal 2 & 0,5626 \\
río arriba & 0,4402
\end{tabular}

\begin{tabular}{lr} 
& Grupo IV \\
\hline canal 1 & 0,3690 \\
canal 1 & 0,7754 \\
arroyo & 0,8774 \\
río abajo & 0,5960 \\
río abajo & 0,5340 \\
canal 2 & 0,6386 \\
canal 2 & 0,3491 \\
canal 3 & 0,3620
\end{tabular}

Tabla 4.13: Resultados del análisis de agrupamientos $k$-means para las variables ambientales (Grupos I, II, III y IV). Se especifican las distancias de cada variable al centro del cluster correspondiente.

\begin{tabular}{|c|c|c|c|}
\hline & Grupo II & & Grupo I \\
\hline Nitratos + Nitritos & 0,9383 & Temperatura & 0,6382 \\
\hline Amonio & 0,6541 & Conductividad & 0,3806 \\
\hline Fósforo reactivo soluble & 0,4968 & Dureza & 0,4910 \\
\hline Fósforo total & 0,4208 & & \\
\hline \multirow[t]{3}{*}{ Fósforo disuelto total } & 0,3955 & & Grupo IV \\
\hline & & $\mathrm{pH}$ & 0,7190 \\
\hline & Grupo III & Turbidez & 0,3851 \\
\hline Transparencia & 0,8522 & Sólidos suspendidos & 0,5482 \\
\hline Velocidad de corriente & 0,5271 & Materia orgánica particulada & 0,6255 \\
\hline Distancia hidrométrica & 0,5184 & Materia orgánica disuelta & 0,6786 \\
\hline \multirow[t]{2}{*}{ Polifenoles totales } & 0,6513 & Alcalinidad & 0,8519 \\
\hline & & Oxígeno disuelto & 0,9026 \\
\hline
\end{tabular}

\section{Zooplancton}

El análisis de agrupamientos (cluster, índice de Bray-Curtis, ligamiento completo) efectuado a la composición del zooplancton arrojó diferencias significativas en 14 nodos del dendrograma $(p<$ 0,05), reuniendo a los sitios de muestreo en 5 grupos principales (Grupos I, II, III, IV y V), con dos subgrupos en el Grupo III (a,b). El Grupo I registró la mínima similitud entre sitios y estuvo integrado por el arroyo en caudales medios y el canal 1 en aguas bajas y muy bajas (Fig. 4.83). El Grupo II asoció a los sitios del río, al canal 2 y el arroyo en aguas altas. El grupo más importante reunió a los muestreos de aguas bajas (Grupo IIIa) y de caudales medios (Grupo IIIb) en un gran clado central significativo. En orden ascendente de similitud, el arroyo, el canal 3, el río aguas abajo y el canal 2 integraron el Grupo IIIa, y lo mismo para el canal 2, el río aguas abajo y el canal 1 
en caudales medios y el canal 1 en aguas altas, que formaron el Grupo IIIb. Los canales 2 y 3 en aguas muy bajas integraron el Grupo IV, siendo significativa su relación con similitudes medias. El Grupo V estuvo integrado por ambos sitios del río en caudales medios (sept. 2009), con escaso aporte de los afluentes, y por el río aguas arriba en aguas bajas y caudales medios (marzo 2008).

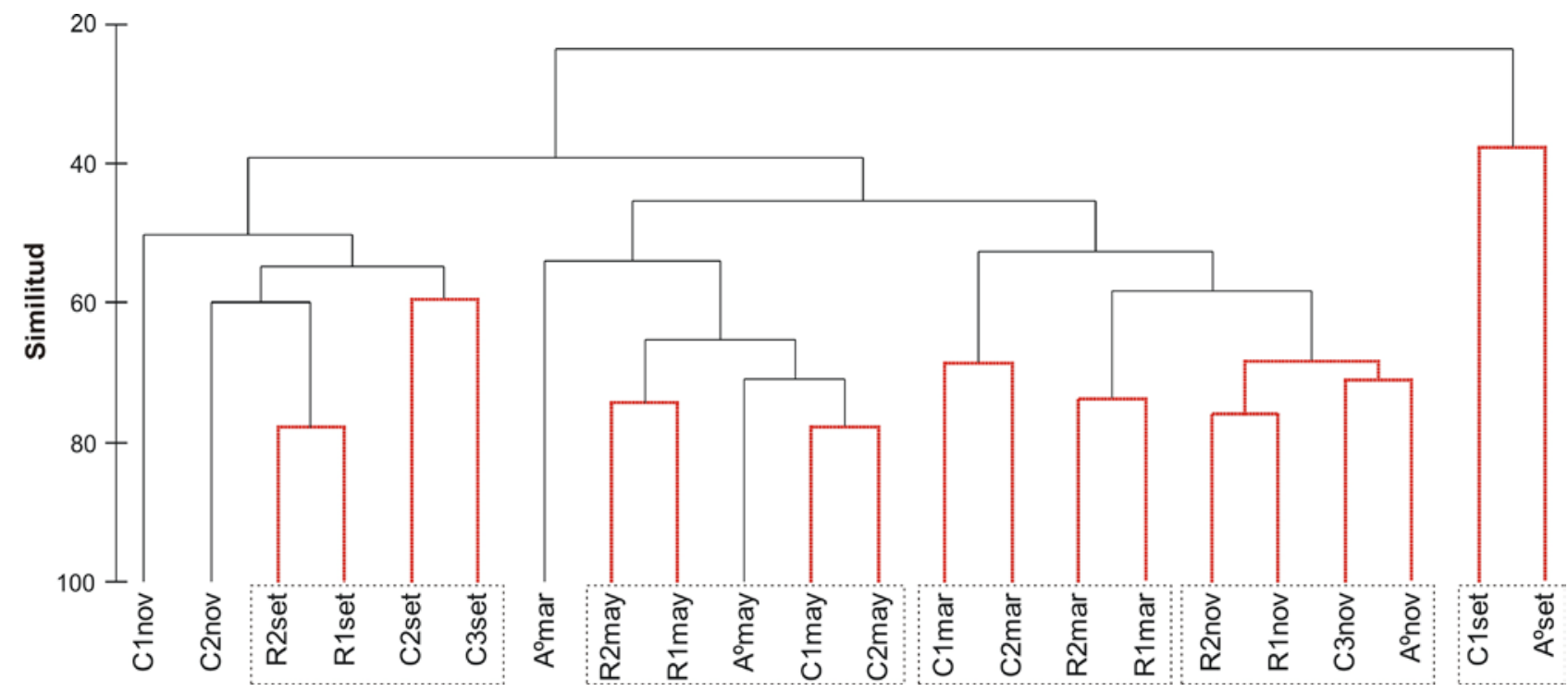

Figura 4.82: Análisis de agrupamientos de los sitios de muestreo según la composición de especies de fitoplancton (361 taxa). Los datos de la abundancia promedio (días 1 y 2) fueron transformados por log $(x+1)$ y se utilizó el índice de similitud de Bray Curtis. En color rojo se distinguen los clados significativos ( $<<0,05)$. Referencias: C1 (canal 1), C2 (canal 2), C3 (canal 3), Aº (arroyo), R1 (río aguas arriba), R2 (río aguas abajo), may (mayo 2007 - aguas altas), mar (marzo 2008 - caudales medios), nov (noviembre 2008 - aguas bajas) y set (setiembre 2009 - aguas muy bajas en el sistema Bragado con caudales medios en el río Salado).

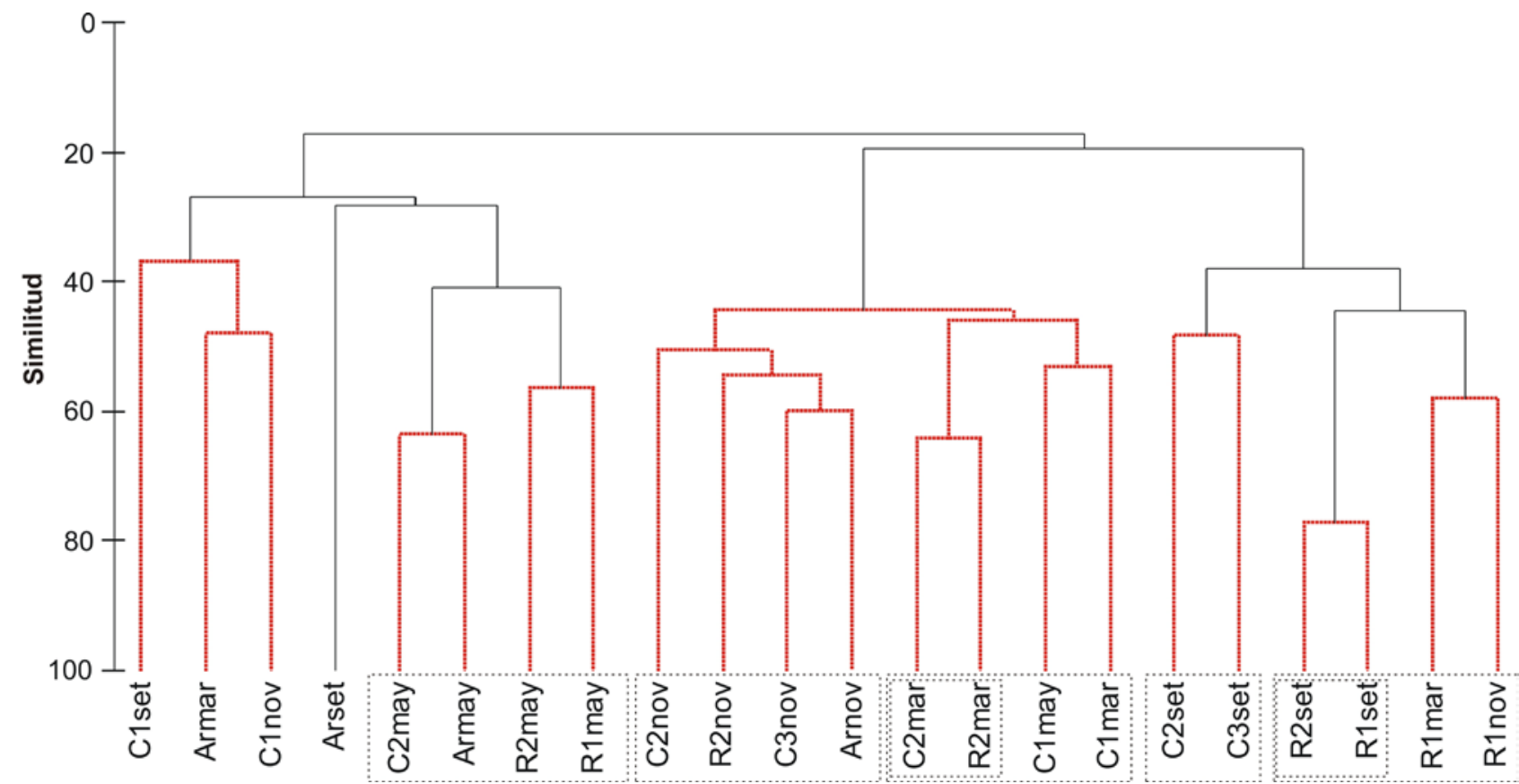

Figura 4.83: Análisis de agrupamientos de la composición de especies de zooplancton (132 taxa). Los datos de la abundancia promedio (días 1 y 2) fueron transformados por $\log (x+1)$ y se utilizó el índice de similitud de Bray Curtis. En color rojo se distinguen los clados significativos $(p<0,05)$. Referencias: C1 (canal 1), C2 (canal 2), C3 (canal 3), Ar (arroyo), R1 (río aguas arriba), R2 (río aguas abajo), may (mayo 2007 - aguas altas), mar (marzo 2008 -caudales medios), nov (noviembre 2008 - aguas bajas) y set (setiembre 2009 - aguas muy bajas en el sistema Bragado pero con caudales medios en el río Salado). 


\subsubsection{Análisis de redundancia (RDA)}

\section{Fitoplancton}

De acuerdo al análisis de redundancia de la abundancia de las especies de fitoplancton, la suma de los Ejes 1 y 2 explicó el 54\% de la varianza total acumulada, siendo significativos tanto el primer eje canónico como el conjunto de los ejes, según la prueba de Monte Carlo ( $p=0,02$ y $p=0,002$, respectivamente). Las variables ambientales que estuvieron mejor correlacionadas con el Eje 1 fueron el nivel de agua, la materia orgánica particulada (MOP) y en forma negativa los nitratos+nitritos $(\mathrm{N}+\mathrm{N})$; y con el Eje 2 la temperatura y la conductividad de manera negativa, y la velocidad de corriente de forma positiva. Los acrónimos de las especies de fitoplancton consideradas se detallan en la Tabla 4.14.

El análisis ordenó a los sitios de muestreo en 4 grupos según la condición hidrológica (Fig. 4.84). El Eje 2 diferenció a los muestreos de aguas bajas (nov. 2008), relacionado con mayores valores de conductividad y temperatura, y de aguas altas (mayo 2007), asociado a un mayor nivel de agua y velocidad de corriente. El Eje 1 distinguió a la condición de caudales medios (marzo 2008), relacionado con mayores valores de MOP y $\mathrm{N}+\mathrm{N}$, y a los sitios del último muestreo (caudales medios en el río Salado y aguas muy bajas en el sistema Bragado), asociado a mayores valores de fósforo reactivo soluble (PRS), oxígeno disuelto (OD) y alcalinidad (sept. 2009).

Las especies del fitoplancton relacionadas con mayores valores de $\mathrm{N}+\mathrm{N}$ y $\mathrm{MOP}$ fueron las cianobacterias Aphanocapsa incerta, A. delicatissima y Merismopedia tenuissima, las clorofitas Monoraphidium tortile, M. contortum, Kirchneriella obesa y Lagerheimia subsalsa, la criptofita Cryptomonas obovoidea y la euglenofita Euglena retronata (Eje 1, sector negativo) (Fig. 4.85).

Entre los taxa asociados a mayores valores de alcalinidad, OD y PRS se hallaron las cianobacterias Synechococcus subsalsus, Aphanocapsa elachista, Spirulina abbreviata y Geitlerinema amphibium, las clorofitas Acutodesmus dimorphus, Actinastrum hantzschii, Monoraphidium mirabile y Chlamydomonas spp., y las criptofitas Komma caudata, Plagioselmis nannoplanctica y Cryptomonas pyrenoidifera (Eje 1, sector positivo). Todas estas especies registrando picos de abundancia en aguas muy bajas en el sistema Bragado pero caudales medios en el río Salado (sept. 2009).

Otras especies se relacionaron con mayores valores de velocidad de corriente y el nivel de agua (Merismopedia warmingiana, Raphidiopsis mediterranea, Microcystis aeruginosa, Chlorella sp., Chroococcus prescottii, Nitzschia fonticola y Planothidium delicatulum), registrando picos de abundancia en aguas altas y caudales medios (Eje 2, sector positivo). Entre las especies relacionadas con mayores valores de conductividad se ubicaron Stephanodiscus sp., Monoraphidium 
pusillum, M. circinale, Chlamydomonas grovei y Spirulina major, y Achnanthidium minutissimum, M. pseudobraunii y Planktolyngbya limnetica también con la temperatura (Eje 2, sector negativo).

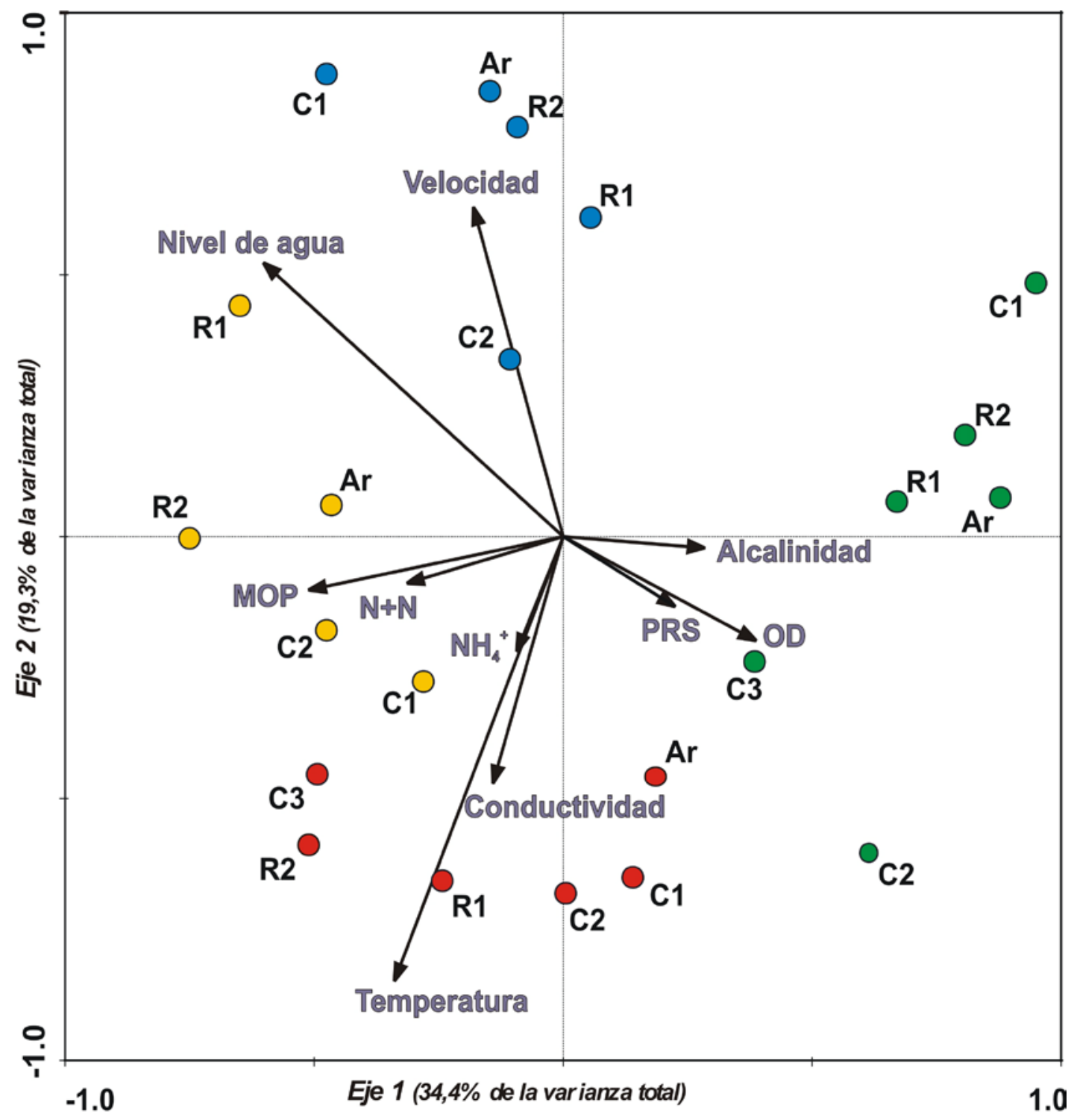

Figura 4.84: Representación bidimensional del análisis de redundancia (RDA) (ejes 1 y 2) aplicado al fitoplancton. Se muestran las variables ambientales (flechas) y los sitios de muestreo (círculos). Referencias. Variables: PRS (fósforo reactivo soluble), OD (oxígeno disuelto), MOP (materia orgánica particulada), N+N (nitrato más nitrito), $\mathrm{NH}_{4}{ }^{+}$(amonio), Velocidad (velocidad de corriente). Sitios: $\mathrm{C} 1$ (canal 1), C2 (canal 2), C3 (canal 3), Ar (arroyo), R1 (río aguas arriba) y R2 (río aguas abajo). Muestreos: mayo 2007 - aguas altas (azul), marzo 2008 - caudales medios (amarillo), noviembre 2008 - aguas bajas (rojo) y septiembre 2009 - aguas muy bajas en el sistema Bragado con caudales medios en el río Salado (verde).

Varias especies de clorofitas estuvieron relacionadas con los valores de temperatura, conductividad, N+N y MOP, siendo relevantes por su abundancia durante la época favorable de crecimiento (marzo y noviembre 2008), entre éstas: Monoraphidium spp., Oocystis spp., Kirchneriella spp., Didymocystis bicellularis, Crucigenia quadrata, Lagerheimia subsalsa, Crucigeniella rectangularis, Schizochlamydella sphaerica y Pseudoschroederia antillarum. 
Tabla 4.14: Acrónimos de las especies de fitoplancton seleccionadas para el análisis de redundancia (RDA).

\begin{tabular}{|c|c|c|c|}
\hline Acrónimo & Taxa & Acrónimo & Taxa \\
\hline & Cianobacterias & & Clorofitas (cont.) \\
\hline $\mathrm{AC}$ & Anabaenopsis circularis & $\mathrm{KO}$ & Kirchneriella obesa \\
\hline AN & Anabaenopsis nadsonii & $\mathrm{KP}$ & Kirchneriella pseudoaperta \\
\hline AT & Anabaenopsis tanganyikae & LS & Lagerheimia subsalsa \\
\hline $\mathrm{ADE}$ & Aphanocapsa delicatissima & MAR & Monoraphidium arcuatum \\
\hline $\mathrm{AE}$ & Aphanocapsa elachista & MC & Monoraphidium circinale \\
\hline AI & Aphanocapsa incerta & MCT & Monoraphidium contortum \\
\hline $\mathrm{A}$ & Aphanothece sp. & $\mathrm{MCV}$ & Monoraphidium convolutum \\
\hline AS & Arthrospira skujae & MF & Monoraphidium fontinale \\
\hline $\mathrm{CD}$ & Chroococcus dispersus & MGR & Monoraphidium griffithii \\
\hline $\mathrm{CM}$ & Chroococcus minimus & MK & Monoraphidium komarkovae \\
\hline CMT & Chroococcus minutus & $\mathrm{MM}$ & Monoraphidium minutum \\
\hline $\mathrm{CP}$ & Chroococcus prescottii & MMI & Monoraphidium mirabile \\
\hline CT & Chroococcus turgidus & MP & Monoraphidium pusillum \\
\hline GA & Geitlerinema amphibium & MPS & Monoraphidium pseudobraunii \\
\hline LL & Leptolyngbya lagerheimii & MTO & Monoraphidium tortile \\
\hline MA & Microcystis aeruginosa & OL & Oocystis lacustris \\
\hline MG & Merismopedia glauca & OP & Oocystis parva \\
\hline MT & Merismopedia tenuissima & OPU & Oocystis pusilla \\
\hline MW & Merismopedia warmingiana & PA & Pseudoschroederia antillarum \\
\hline PG & Phormidium granulatum & PC & Pseudokirchneriella contorta \\
\hline PLA & Phormidium laetevirens & $\mathrm{PF}$ & Pseudodidymocystis fina \\
\hline PLI & Planktolyngbya limnetica & SCS & Schizochlamydella sphaerica \\
\hline PM & Planktolyngbya minor & SI & Schroederia indica \\
\hline $\mathrm{R}$ & Romeria spp. & SR & Scotiellopsis reticulata \\
\hline $\mathrm{RM}$ & Raphidiopsis mediterranea & & Criptofitas \\
\hline SA & Sphaerospermopsis aphanizomenoides & $\mathrm{CC}$ & Chroomonas coerulea \\
\hline SAB & Spirulina abbreviata & CER & Cryptomonas erosa \\
\hline SL & Spirulina laxissima & $\mathrm{COB}$ & Cryptomonas obovoidea \\
\hline SM & Spirulina major & $\mathrm{CPH}$ & Cryptomonas phaseolus \\
\hline SE & Synechococcus elongatus & CPU & Cryptomonas pusilla \\
\hline \multirow[t]{2}{*}{ SS } & Synechococcus subsalsus & CPY & Cryptomonas pyrenoidifera \\
\hline & Clorofitas & $\mathrm{KC}$ & Komma caudata \\
\hline $\mathrm{AH}$ & Actinastrum hantzschii & PN & Plagioselmis nannoplanctica \\
\hline $\mathrm{AD}$ & Acutodesmus dimorphus & & Diatomeas \\
\hline CHL & Chlorella sp. & $\mathrm{AM}$ & Achnanthidium minutissimum \\
\hline CAG & Carteria globosa & CG & Cyclotella glomerata \\
\hline $\mathrm{CE}$ & Chlamydomonas epibiotica & CME & Cyclotella meneghiniana \\
\hline CGL & Chlamydomonas globosa & $\mathrm{FC}$ & Fragilaria crotonensis \\
\hline CGR & Chlamydomonas grovei & NF & Nitzschia fonticola \\
\hline $\mathrm{CF}$ & Coenochloris fottii & NP & Nitzschia palea \\
\hline CQ & Crucigenia quadrata & PD & Planothidium delicatulum \\
\hline $\mathrm{CR}$ & Crucigeniella rectangularis & PL & Planothidium lanceolata \\
\hline DB & Didymocystis bicellularis & RL & Rossithidium linearis \\
\hline ET & Eutetramorus tetrasporus & $S$ & Stephanodiscus sp. \\
\hline $\mathrm{HN}$ & Hindakochloris nygaardii & & Euglenofitas \\
\hline KI & Kirchneriella irregularis & ER & Euglena retronata \\
\hline KL & Kirchneriella lunaris & & \\
\hline
\end{tabular}




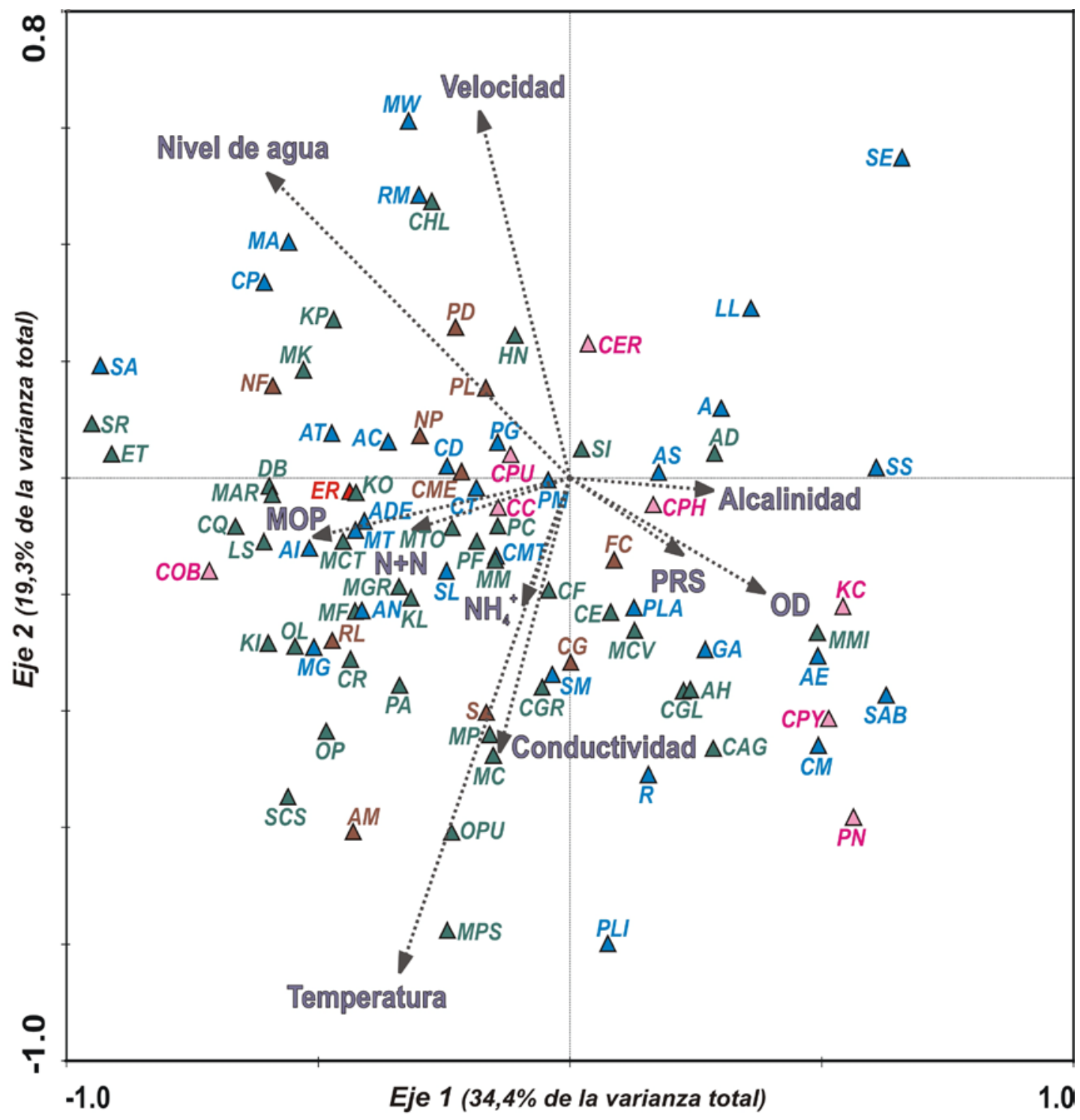

Figura 4.85: Representación bidimensional del análisis de redundancia (RDA) (ejes 1 y 2). Se muestran las variables ambientales (flechas punteadas) y la abundancia de las especies de fitoplancton (triángulos) cuyos acrónimos se encuentran en la Tabla 4.14. Referencias. Variables: PRS (fósforo reactivo soluble), OD (oxígeno disuelto), MOP (materia orgánica particulada), $\mathrm{N}+\mathrm{N}$ (nitrato+nitrito), $\mathrm{NH}_{4}{ }^{+}$(amonio), Velocidad (velocidad de corriente). Especies: de clorofitas (triángulos en color verde), cianobacterias (celeste), diatomeas (marrón), criptofitas (rosado) y euglenofita (rojo).

\section{Zooplancton}

De acuerdo al análisis de redundancia de la abundancia de las especies de zooplancton, la suma de los Ejes 1 y 2 explicó el 55\% de la varianza total acumulada, siendo significativos tanto el primer eje canónico como el conjunto de los ejes, según la prueba de Monte Carlo $(p=0,02$ y $p=0,006$, respectivamente). Las variables ambientales que estuvieron mejor correlacionadas con el Eje 1 fueron la temperatura y la conductividad en forma negativa, y el PRS en forma positiva. Se correlacionaron con el Eje 2 el pH y la clorofila $a$ en forma positiva, y negativa con la transparencia y el nivel de agua. Los acrónimos de las especies de zooplancton consideradas se detallan en la Tabla 4.15. 
Tabla 4.15: Acrónimos de las especies de zooplancton seleccionadas para el análisis de redundancia (RDA).

\begin{tabular}{|c|c|c|c|}
\hline Acrónimo & Taxa & Acrónimo & Taxa \\
\hline \multicolumn{3}{|c|}{ Ciliados } & Rotíferos \\
\hline $\mathrm{A}$ & Askenasia sp. & $\mathrm{AB}$ & Asplanchna brigthwellii \\
\hline BL & Blepharisma sp. & $\mathrm{A} 2$ & Asplanchna sp2 \\
\hline C & Carchesium sp. & BD1 & Bdelloideo sp1 \\
\hline COL & Colpoda sp. & BD2 & Bdelloideo sp2 \\
\hline E & Enchelys sp. & BD3 & Bdelloideo sp3 \\
\hline EP1 & Epistylis sp1 & BD4 & Bdelloideo sp4 \\
\hline EP2 & Epistylis sp2 & BD5 & Bdelloideo sp5 \\
\hline EU & Euplotes patela & BA & Brachionus angularis \\
\hline HG & Halteria grandinella & BB & Brachionus bidentata \\
\hline $\mathrm{H}$ & Holophrya sp. & BDI & Brachionus dimidiatus \\
\hline $\mathrm{OP}$ & Opercularia sp. & $\mathrm{BP}$ & Brachionus plicatilis \\
\hline PR1 & Prorodon sp1 & $\mathrm{BPT}$ & Brachionus pterodinoides \\
\hline PR2 & Prorodon $\mathrm{sp} 2$ & BQ & Brachionus quadridentatus \\
\hline SC & Strombilidium caudatum & BU & Brachionus urceolaris \\
\hline ST1 & Stentor sp 1 & EN1 & Encentrum sp1 \\
\hline ST2 & Stentor sp2 & EN3 & Encentrum sp3 \\
\hline S1 & Strombidium sp1 & EN4 & Encentrum sp4 \\
\hline V1 & Vorticella sp1 & $\mathrm{FL}$ & Filinia longiseta \\
\hline \multirow[t]{2}{*}{$\mathrm{V} 2$} & Vorticella sp2 & FT & Filinia terminalis \\
\hline & Copépodos & KT & Keratella tropica \\
\hline ACR & Acanthocyclops robustus & PD1 & Proalides sp1 \\
\hline CLE & Cletocamptus deitersi & PD2 & Proalides sp2 \\
\hline $\mathrm{COP}$ & Copepoditos & PL6 & Proales sp6 \\
\hline HAR & Harpacticoideo sp. & POM & Pompholyx sulcata \\
\hline MA & Microcyclops alius & $\mathrm{SP}$ & Synchaeta pectinata \\
\hline MME & Metacyclops mendocinus & TC & Trichocerca capuchina \\
\hline \multirow[t]{3}{*}{ NAU } & Nauplii & $\mathrm{TP}$ & Trichocerca pusilla \\
\hline & & & Cladóceros \\
\hline & Rizópodos & AG & Alona glabra \\
\hline $\mathrm{AH}$ & Arcella hemisphaerica & ARE & Alona rectangula \\
\hline \multirow[t]{3}{*}{$\mathrm{T}$} & Trinema sp. & $\mathrm{CD}$ & Ceriodaphnia cf. dubia \\
\hline & & DS & Daphnia spinulata \\
\hline & Ostrácodos & MM & Moina micrura \\
\hline $\mathrm{CV}$ & Cypridopsis vidua & $S$ & Simocephalus sp. \\
\hline
\end{tabular}

En la Figura 4.86 se observa la distribución de los sitios de muestreo de acuerdo a la condición hidrológica. En el sector negativo del Eje 1, asociado a un mayor nivel de agua y transparencia, se ubica el muestreo de aguas altas (mayo 2007). En el sector opuesto, relacionado con mayores valores de $\mathrm{pH}, \mathrm{OD}$ y PRS, se ubicó el muestreo de aguas muy bajas en el sistema Bragado y caudales medios en el río (sept. 2009). Los sitios con elevada abundancia de zooplancton durante el período favorable de crecimiento (marzo y nov. 2008) fueron relacionados con mayores valores de clorofila a y temperatura. Este aglomerado de sitios estuvo constituido por el los canales 2 y 3 , el 
río aguas abajo y el arroyo en aguas bajas y caudales medios (marzo 2008), quedando claramente separados de este grupo el canal 1 y el río aguas arriba del trasvase. Los sitios del canal 1 se agruparon entre sí, asociados con mayores valores de conductividad en caudales medios y aguas bajas, al nivel del agua y la transparencia en aguas altas y muy bajas.

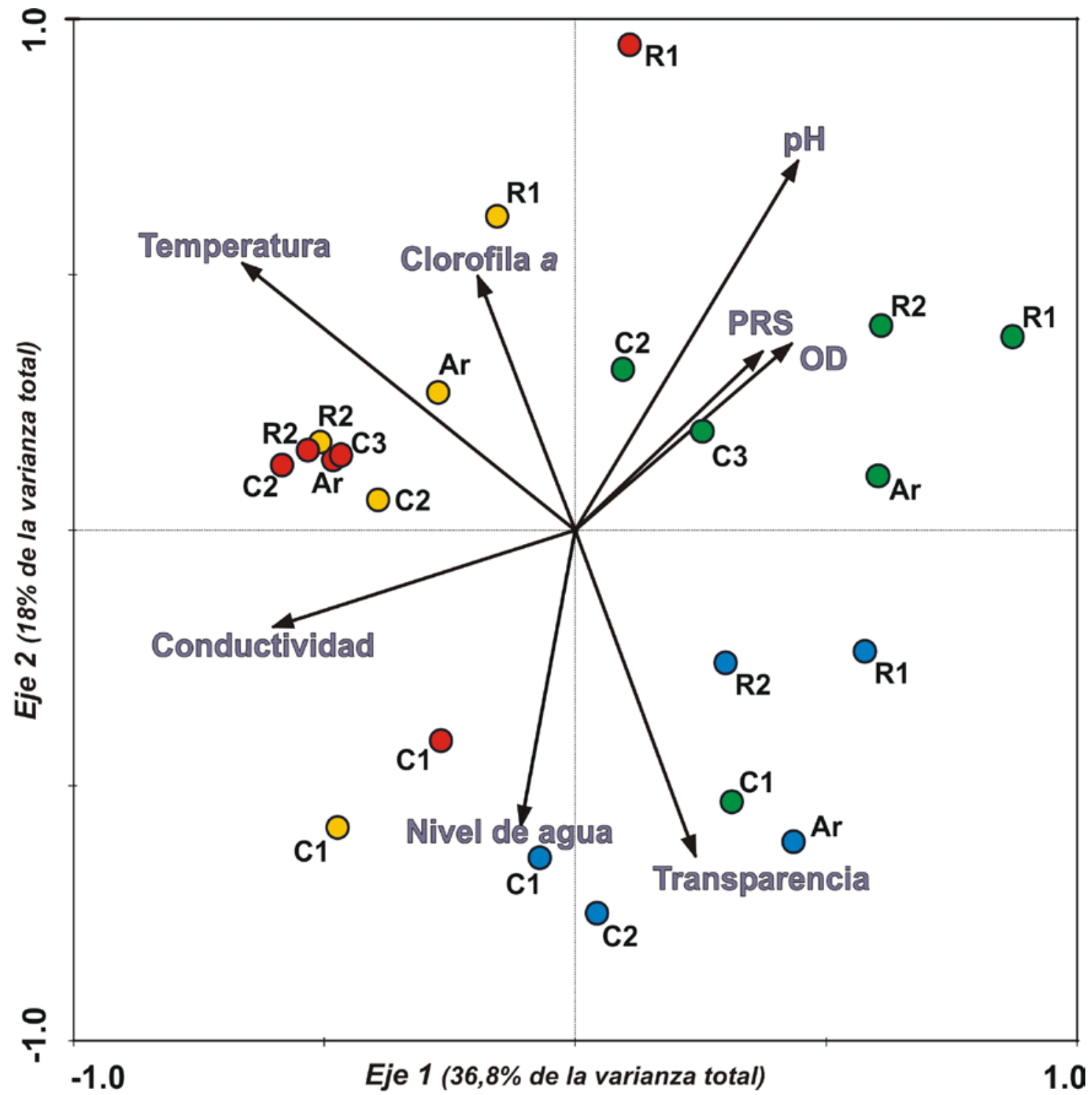

Figura 4.86: Representación bidimensional del análisis de redundancia (RDA) (ejes 1 y 2) aplicado al zooplancton. Se muestran las variables ambientales (flechas) y los sitios de muestreo (círculos). Referencias. Variables: PRS (fósforo reactivo soluble), OD (oxígeno disuelto). Sitios: C1 (canal 1), C2 (canal 2), C3 (canal 3), Ar (arroyo), R1 (río aguas arriba) y R2 (río aguas abajo). Muestreos: mayo 2007 - aguas altas (azul), marzo 2008 - caudales medios (amarillo), noviembre 2008 - aguas bajas (rojo) y septiembre 2009 - aguas muy bajas en el sistema Bragado con caudales medios en el río Salado (verde).

Las especies de zooplancton asociadas a mayores valores de conductividad fueron los ciliados Stentor spp., Blepharisma sp., Strombilidium caudatum y Vorticella sp2 y el bdelloideo sp2; y con la temperatura, los rotíferos Brachionus angularis, B. plicatilis y Pompholyx sulcata, destacándose por su abundancia en el sistema Bragado y en el río aguas abajo en caudales medios y aguas bajas (Eje 1, sector negativo) (Figura 4.87). 


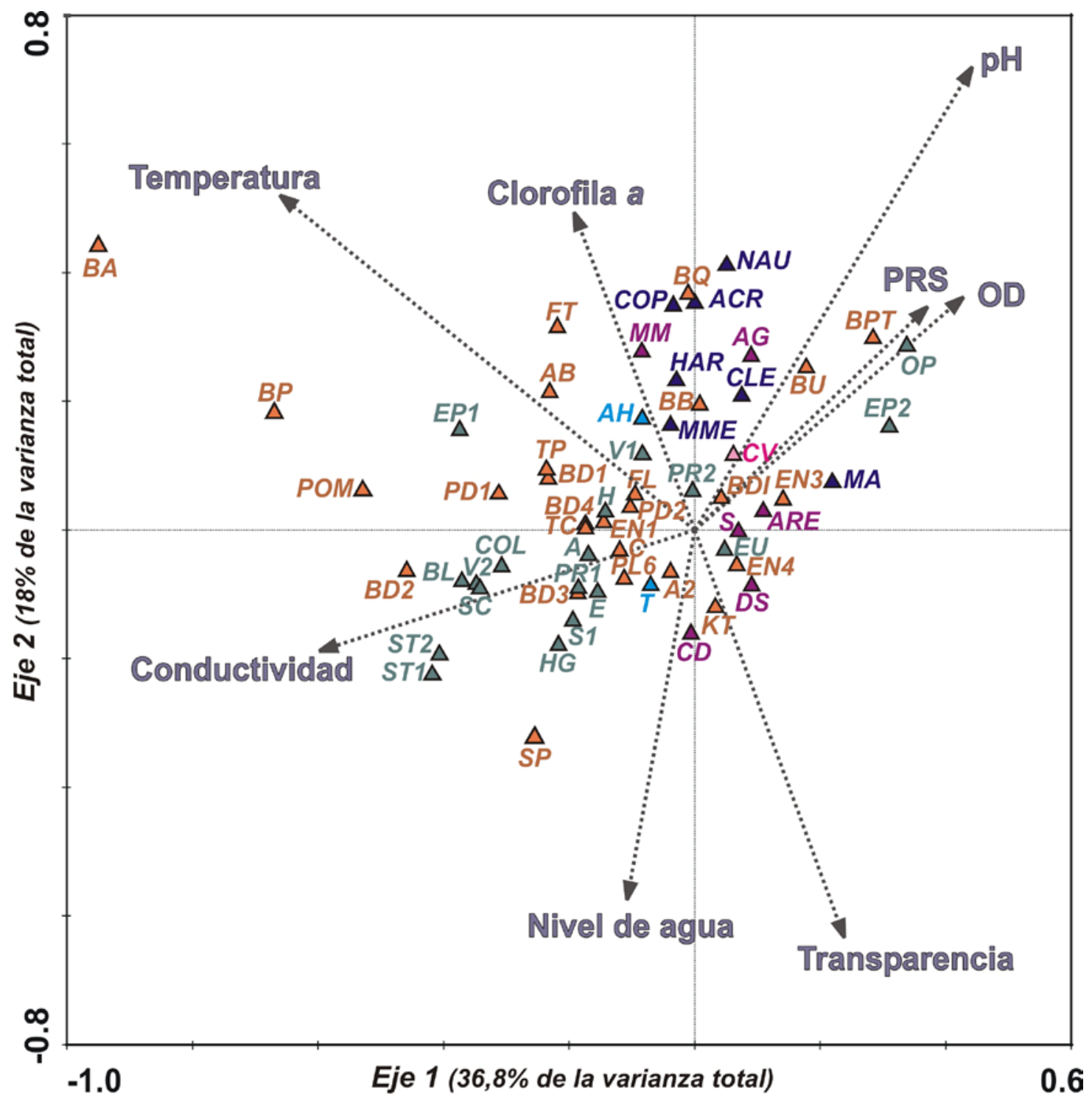

Figura 4.87: Representación bidimensional del análisis de redundancia (RDA) (ejes 1 y 2). Se muestran las variables ambientales (flechas punteadas) y la abundancia de las especies de zooplancton (triángulos) cuyos acrónimos se encuentran en la Tabla 4.15. Referencias: PRS (fósforo reactivo soluble), OD (oxígeno disuelto). Especies de ciliados (triángulos en color verde), rotíferos (anaranjado), rizópodos (celeste), copépodos (azul), ostrácodo (rosado) y cladóceros (violeta).

Otros rotíferos como Asplanchna brigthwellii y Filinia terminalis se asociaron con mayores valores de clorofila a y temperatura. En el sector opuesto, el rotífero Synchaeta pectinata se relacionó con valores positivos de conductividad y de nivel de agua (sector negativo Ejes 1 y 2). Los rotíferos Brachionus urceolaris y B. pterodinoides, los ciliados Opercularia sp. y Epistylis sp2, y el copépodo Microcylcops alius se asociaron a mayores valores de $\mathrm{pH}$, PRS y OD (sector positivo Ejes 1 y 2). Los cladóceros se distribuyeron en el sector positivo del Eje 1, y particularmente Ceriodaphnia dubia y Daphnia spinulata se relacionaron con el nivel de agua y la transparencia (aguas altas), al igual que el rotífero Keratella tropica. En el sector positivo del Eje 2, se ubicaron algunos copépodos (Acanthocylcops robustus, copepoditos, larvas nauplii, Cletocamptus deitersii, Metacyclops mendocinus) 
y cladóceros (Moina micrura, Alona glabra), relacionados con mayores valores de clorofila a y pH al igual que el rotífero Brachionus quadridentatus.

Varias especies de zooplancton debieron ser eliminadas de la Figura 4.87 debido a que quedaron muy superpuestas en el área central del diagrama, con una escasa representación en el modelo. Se trató de especies poco frecuentes en el zooplancton o con una distribución restringida entre los sitios de muestreo: Ptygura sp., Lecane piriformis, L. closterocerca, Aspidisca sp., Polyarthra sp1, Colurella obtusa, Nassula sp., Proales sp5, Colurella uncinata, Conochilus sp. y Notodiaptomus incompositus. 
Discusión 


\subsection{Parámetros físico-químicos}

\subsubsection{Conductividad y composición iónica del agua}

La cuenca del río Salado se caracteriza por la presencia de aguas alcalinas y muy mineralizadas (Solari et al., 2002), y sólo unos pocos ríos europeos y australianos presentan aguas cloruro-sódicas de características comparables (Gabellone et al., 2008). Por otro lado su alta alcalinidad se debe a la disolución del carbonato de calcio presente en la roca madre (O’Farrell, 1993), rasgo que también comparte con otros arroyos pampeanos (Bauer et al., 2002; Rodrigues Capítulo et al., 2010)

La conductividad y la concentración de los iones $\mathrm{Na}^{+}, \mathrm{Cl}^{-}, \mathrm{K}^{+}, \mathrm{SO}_{4}=\mathrm{Mg}^{++}$y Ca $\mathrm{Ca}^{++}$estuvieron asociadas al régimen hidrológico, presentando los valores mínimos en aguas altas, por el efecto dilutorio de las precipitaciones y la escorrentía superficial, y los valores máximos en aguas bajas, tal como lo observado en estudio previos en la cuenca (O'Farrell, 1993; Neschuk, 2001; Neschuk et al., 2002b; Feijoó \& Lombardo, 2007; Gabellone et al., 2008). Sin embargo, los valores de conductividad hallados en el canal 1 en aguas bajas $(25 \mathrm{mS} / \mathrm{cm})$, superan a los registrados previamente.

La elevada conductividad de las aguas y la dominancia de los iones $\mathrm{Na}^{+}$y $\mathrm{Cl}^{-}$deben su origen al aporte salino de las aguas subterráneas, a la dominancia de los procesos de evaporación, y a las canalizaciones presentes en la cuenca (Feijoó \& Lombardo, 2007; Gabellone et al., 2008). Los canales provenientes de la Pampa Arenosa (Halcrow \& Partners, 1999) drenan zonas arreicas de diferente composición química, y su trasvase al río Salado tuvo importantes consecuencias en la composición química del agua, así como en la calidad de los materiales presentes, el aporte de nutrientes y la incorporación de organismos del plancton.

En el río se observó un aumento de la conductividad aguas abajo del trasvase del sistema Bragado en todos los muestreos, con máxima diferencia en aguas bajas (de 5,6 a 13,9 mS/cm) y mínima en aguas altas (otoño tardío) coincidiendo este último con la época de mayores precipitaciones. El notable incremento en la conductividad del río en condiciones de aguas bajas se debió a que el arroyo y el canal 3 registraron conductividades $>16 \mathrm{mS} / \mathrm{cm}$, incrementando, consecuentemente, el contenido de sales en el río aguas abajo del trasvase. Estos valores de conductividad son muy superiores a los registrados por Neschuk (2001) en muestreos estacionales realizados en la cuenca entre los años 1998-1999. Asimismo, la influencia de tributarios como el arroyo Saladillo en el aumento de la conductividad del río Salado ha sido detectada en otros 
estudios en la cuenca (Gabellone et al., 2005). La presencia de eflorescencias superficiales en los cursos de agua analizados, particularmente en el canal 1, constituye una manifestación del proceso de salinización (Herzeg et al., 2001), al igual que el aumento de los iones mayoritarios $\left(\mathrm{Na}^{+}, \mathrm{Cl}^{-} \mathrm{y}\right.$ $\left.\mathrm{SO}_{4}=\right)$ (Meybeck, 2003) en las aguas de la cuenca.

De acuerdo a los diagramas de Piper, en aguas altas dominaron las aguas $\mathrm{Na}_{-} \mathrm{ClHCO}_{3}$ en todos los sitios de muestreo. La presencia de carbonatos se debe a que el ascenso de los niveles freáticos en los canales permite el ingreso del agua dulce subterránea presente en las lomadas y mantos eólicos (lentes), cuya composición iónica depende de la disolución de carbonatos cálcicos del intercambio de bases $\mathrm{Ca}^{++} / \mathrm{Na}^{+}$y la evaporación (Kruse et al., 2010). De esta forma, las canalizaciones sustraen agua de buena calidad durante los períodos húmedos (Rojo et al., 2006). En caudales medios (verano tardío) y en aguas bajas dominaron las aguas $\mathrm{Na}-\mathrm{ClSO}_{4}$ en todos los sitios de muestreo, al igual que lo observado en estudios previos en la cuenca (Gabellone et al., 2008). Esta composición es típica de los niveles freáticos de las planicies de inundación del río Salado, donde prevalecen los procesos de evaporación (Kruse et al., 2010). En aguas muy bajas en el sistema Bragado pero con caudales medios en el río, se observó una composición iónica diferencial según los sitios analizados, con predominancia de los procesos locales: en el río y el canal $2\left(\mathrm{Na}-\mathrm{ClSO}_{4}\right)$, en el canal 1 y el arroyo $\left(\mathrm{Na}-\mathrm{ClHCO}_{3}\right)$, y en el canal $3\left(\mathrm{Mg}-\mathrm{ClHCO}_{3}\right)$. Asimismo, el canal 3 y el arroyo presentaron aguas oligohalinas $(0,04-0,13 \%$ o $)$ que indicarían la afluencia de las aguas subterráneas dulces y de aportes por escorrentía superficial.

El ordenamiento MDS y el análisis de clusters de la composición iónica del agua agruparon a los sitios de muestreo según la condición hidrológica (aguas altas, aguas bajas y caudales medios), siendo además significativa la relación de similitud entre los sitios, a excepción del canal 1. La elevada concentración de los iones $\mathrm{Na}^{+}$y $\mathrm{Cl}^{-}$separó claramente al canal 1 del resto de los sitios, y sólo en el muestreo de aguas altas su composición iónica fue cercana a la hallada en el canal 2, el arroyo y el río en caudales medios (marzo 2008). El río aguas abajo del trasvase estuvo estrechamente relacionado con los sitios del sistema Bragado en caudales medios y aguas bajas, quedando por fuera de estos clados el río aguas arriba. Ambos análisis estadísticos agruparon en aguas muy bajas (sistema Bragado) a los sitios del río y el canal 2 por la predominancia de Na$\mathrm{ClSO}_{4}$, y el arroyo y el canal 3 por la presencia de aguas con baja concentración de sales.

Estas variaciones en la composición química del agua en las diferentes condiciones hidrológicas ponen en evidencia la importante interacción entre las aguas superficiales y subterráneas y el control que ejercen los rasgos geomorfológicos locales en este sistema fluvial complejo (Kruse \& Laurencena, 2005; Rojo et al., 2006; Carol et al., 2010; Kruse et al., 2010). Estas características, 
sumadas a la litología de la cuenca, el régimen hidrológico y las descargas de caudal representan los principales reguladores de su dinámica (Meybeck, 1996). De esta forma, la geología y la geomorfología de la cuenca, dada por el escaso escurrimiento superficial y la predominancia de los movimientos verticales del agua (evapotranspiración e infiltración) (Varni \& Usunoff, 1999; Tanco \& Kruse, 2001; Forte Lay et al., 2007; Gonzalez \& Fernandez, 2007; Iriondo \& Kröhling, 2007; Cesanelli \& Guarracino, 2011), constituyen aspectos relevantes en la distribución del plancton en los ambientes lóticos (Lair, 2006), al afectar los tiempos de residencia del agua y la concentración de sales disueltas.

\subsubsection{Oxígeno disuelto}

Las variaciones en la concentración de OD estuvieron relacionadas a la condición hidrológica y la temperatura, registrando valores mínimos en aguas altas y bajas temperaturas, al igual que lo observado en el río Paraná y en el río Luján (Izaguirre et al., 2001; O’Farrell et al., 2002; Devercelli, 2010). Esto podría deberse a que en los momentos de inundación, la degradación de los materiales alóctonos consume oxígeno, sumado al menor desarrollo del fitoplancton en esta época desfavorable. En el arroyo, el valor mínimo de OD se registró en aguas bajas y temperaturas estivales, asociado a una menor solubilidad del oxígeno y sus características de curso de agua con alta carga de materia orgánica, como en otros arroyos de la cuenca (Feijoó \& Lombardo, 2007).

\subsubsection{Sólidos suspendidos, materia orgánica particulada y polifenoles totales disueltos}

Durante las condiciones de aguas altas se observaron menores valores de conductividad, turbidez, SS, MOP, materia orgánica disuelta (MOD), dureza, alcalinidad y la concentración de los principales iones $\left(\mathrm{Na}^{+}, \mathrm{Cl}^{-}, \mathrm{SO}_{4}=\mathrm{K}^{+}\right)$por un efecto de dilución, tal como lo observado en estudios previos en la cuenca y en otros ríos de llanura (O'Farrell, 1993; Solari et al., 2002; Schagerl et al., 2009; Devercelli, 2010).

Los valores máximos de SS y MOP se observaron en caudales medios o en aguas bajas debido a la resuspensión de materiales por una mayor interacción con el lecho (O'Farrell, 1993; Solari et al., 2002; Gabellone et al., 2005), tal como ocurre en los ríos Uruguay y Paraná (O’Farrell \& Izaguirre, 1994; Devercelli, 2010), y en ríos europeos (Picard \& Lair, 2005). Lo opuesto se observó en el canal 1 donde los valores máximos de SS y MOP se observaron en aguas altas. La transparencia tuvo una relación inversa con los SS y la MOP, como en los ríos Uruguay y Paraná (O’Farrell \& Izaguirre, 1994; Izaguirre et al., 2001). También se halló una relación entre el P y los SS en estudios previos en la cuenca (O’Farrell, 1993), y entre el PT y la turbidez en el río Támesis (Jarvie et al., 2002). 
Los polifenoles totales solubles derivan del lavado de los suelos y de la vegetación terrestre circundante, teniendo un efecto negativo sobre el plancton (Hedges et al., 2000). Su concentración fue máxima en aguas altas y mínima en aguas bajas, en acuerdo con estudios previos en la cuenca (Neschuk, 2001). La correlación positiva $(p<0,05)$ hallada entre estos compuestos y la velocidad de corriente dan cuenta de su relación con la condición hidrológica.

\subsubsection{Nutrientes}

Los elevados niveles de nutrientes hallados en este estudio derivarían de los diferentes usos del suelo, en particular de las prácticas agrícolas en los meses de primavera (Neschuk et al., 2002b), de la meteorización y erosión del suelo (Gabellone et al., 2005), y de la incidencia de los asentamientos humanos (Neschuk et al., 2000; Neschuck, 2001), tal como se observa en ríos del litoral argentino (José de Paggi \& Devercelli, 2011). Sin embargo, de acuerdo a otros antecedentes en la región, la elevada concentración de fosfatos presente en los arroyos pampeanos no sólo se debería al uso agrícola (aplicación de fertilizantes), sino que también responde a una condición geológica dada por la depositación de materiales volcánicos ricos en P (loess) en el Cuaternario, registrando suelos Arguidoles (Giorgi et al., 2005; Mugni et al., 2005; Mugni, 2008; Feijoó et al., 2011).

Los nutrientes no registraron un claro patrón de distribución temporal o estacional, tal como en otros ríos de la región (O’Farrell \& Izaguirre, 1994), ni tampoco en los diferentes momentos hidrológicos, aunque prevalecieron las condiciones locales en el sistema Bragado, como lo observado en otros afluentes del río Salado (Feijoó \& Lombardo, 2007). Sin embargo, se evidenció una tendencia espacial en la distribución puntual del $\mathrm{N}^{-\mathrm{NH}_{4}+}, \mathrm{N}-\mathrm{NO}_{2}{ }^{-}$y PT en el arroyo y en el canal 1, posiblemente relacionado con el impacto antrópico que reciben desde las ciudades aledañas (Bragado y 9 de Julio, respectivamente). La incidencia de las poblaciones humanas en la concentración de estos nutrientes también se ha observado en la cuenca del río Emajõgi (Piirsoo et al., 2008) y en ríos de Santa Fe (José de Paggi \& Devercelli, 2011).

En el arroyo Saladillo se observaron valores muy elevados de $\mathrm{N}-\mathrm{NH}_{4}{ }^{+}(8.500 \mu \mathrm{g} / \mathrm{L}), \mathrm{NT}(12.700$ $\mu \mathrm{g} / \mathrm{L})$, PRS $(1.500 \mu \mathrm{g} / \mathrm{L})$ y PT $(3.760 \mu \mathrm{g} / \mathrm{L})$, y algunas características atípicas como la coloración oscura del agua, abundante espuma, olores nauseabundos, condiciones de anoxia y poliquetos tubícolas con hemoglobina. Esto podría asociarse con la descarga de efluentes con alta carga orgánica, ya que su vuelco sin tratamiento genera hipoxia y anoxia en los cuerpos de agua superficiales, y elevadas concentraciones de compuestos reducidos ( $\left.\mathrm{N}-\mathrm{NH}_{4}{ }^{+}\right)$(Meybeck, 2003).

En las cercanías del arroyo Saladillo se ubica una planta de tratamiento de efluentes líquidos domiciliarios de la ciudad de Bragado, y aún cuando no se encontró su punto de descarga directo, 
los resultados obtenidos dan cuenta de un curso de agua con alta carga de materia orgánica en descomposición. En especial, la concentración de PT observada se encuentra dentro del rango establecido para un efluente de una cámara séptica (Withers \& Jarvie, 2008). En este sentido, en el río Támesis los picos de concentración de $\mathrm{N}-\mathrm{NH}_{4}{ }^{+}$se asocian a la descarga de efluentes cloacales (Jarvie et al., 2002), y también el PT, PRS y PTD en varios ríos del Reino Unido (Neal et al., 2010). Estudios previos en la cuenca también destacan la elevada concentración de PT hallada en este afluente, siendo el punto máximo registrado a lo largo del río Salado (Neschuk, 2001; Gabellone et al., 2013b). Asimismo, se han reportado altos niveles de nutrientes en otros arroyos afluentes del río Salado, registrando aguas eutróficas o meso-eutróficas aún en sitios con baja o moderada agricultura o ganadería (Feijoó \& Lombardo, 2007).

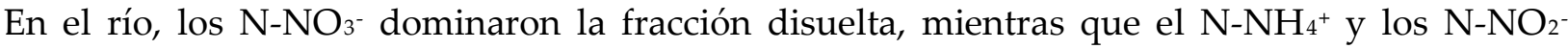
fueron poco importantes, al igual que en otros ríos de llanura (Descy \& Gosselain, 1994). Los

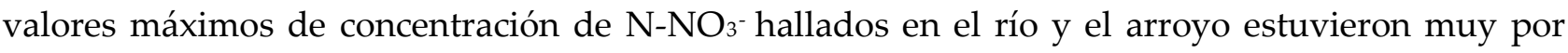
debajo (un orden de magnitud menos) que lo reportado recientemente por Feijoó et al. (2011) en el A o Las Flores, perteneciente a la cuenca del río Luján, y que lo observado por Vilches et al. (2011) en la toda cuenca superior del río Reconquista.

La concentración de NT en el río Salado $(4.000-10.000 \mu \mathrm{g} / \mathrm{L})$ fue superior a la hallada en otros estudios realizados en la cuenca (O'Farrell, 1993), y relativamente alta comparada a otros ríos del mundo como el río Po (Rossetti et al., 2009), o regulados como los ríos Tennessee, Ohio y Cumberland (Koch et al., 2004).

Se considera que los $\mathrm{N}^{-\mathrm{NO}_{3}}{ }^{-}$y el PRS hallados en los ríos de áreas intensamente cultivadas están asociados a las prácticas agrícolas (Jarvie et al., 2002), y particularmente en las cuencas de los ríos Támesis y Hampshire Avon, su máxima concentración está asociada a la contribución de las aguas subterráneas durante los bajos caudales de verano (Jarvie et al., 2008). En el río Siena, el mayor ingreso de nutrientes al cauce principal sucede por la escorrentía superficial, mientras que en caudales base se registra a través del flujo subsuperficial y las aguas subterráneas (Billen et al., 2007). Estos hallazgos también podría explicar los valores máximos de $\mathrm{N}^{-\mathrm{NO}_{3}}$ - en el río Salado en aguas bajas, donde los aportes subterráneos fueron notorios dada la composición iónica del agua.

Los valores máximos de PRS observados en este estudio, en el arroyo y en el río Salado aguas arriba, resultan superiores a los detectados en arroyos de Arrecifes con uso agrícola-ganadero $(<460 \mu \mathrm{g} / \mathrm{L})$ (Mugni, 2008) y a los reportados en estudios recientes en el A $\mathrm{A}^{\mathrm{o}}$ La Choza (Ferreiro et al., 2011) y en toda la cuenca superior del río Reconquista (Vilches et al., 2011). Sin embargo, los valores máximos de PRS reportados para el Aํㅡ Las Flores (Giorgi et al., 2005) y para otros afluentes 
del río Luján (Feijoó et al., 1999), resultan muy superiores a los hallados en este estudio. Asimismo, otros arroyos pampeanos ubicados en el Gran La Plata y al este de la Provincia también registran valores de $\mathrm{P}_{-} \mathrm{PO}_{4}{ }^{-}$que hasta cuadriplican los encontrados en el área de estudio (Bauer et al., 2002a; Bauer et al., 2002b; Licursi, 2005; Bauer, 2009; Licursi \& Gómez, 2009; Bauer et al., 2010).

En el río, el PT y PRS fueron mínimos en aguas altas por el efecto dilutorio del aumento de caudal, y máximo en aguas bajas, este último atribuible a los aportes de las áreas urbanas en la cuenca superior (Gabellone et al., 2005), al igual que en otros ríos del mundo (Jarvie et al., 2002; Weilhoefer et al., 2008; Neal et al., 2010). De acuerdo a Neschuk (2001), los aportes de fósforo de la cuenca del río Salado derivan mayormente de fuentes superficiales difusas (agricultura), aunque también de fuentes puntuales (efluentes cloacales), siendo más evidentes en los períodos de bajos caudales, con un concomitante aumento del riesgo de eutrofización, tal como en algunos ríos europeos (Kronvang et al., 2007; Jarvie et al., 2008). En este sentido, otros antecedentes en la cuenca del río Salado también destacan la elevada concentración de PRS en el tramo superior de la cuenca, relacionada al uso de la tierra (Feijoó \& Lombardo, 2007).

Se reconoce que las fuentes difusas de contaminación, como es la aplicación de fertilizantes con derivados de $\mathrm{P}$ y N, pueden magnificar problemáticas locales de eutrofización, tal como se observa en la cuenca del río Reconquista (Vilches et al., 2011), y en otros ríos del mundo como el río Támesis (Jarvie et al., 2002, 2008) y Marne (Garnier et al., 2005) o deteriorar las aguas subterráneas, como en otros ríos europeos (Kronvang et al., 2005b). Las fuentes difusas de P resultan relevantes dada la alta proporción de las formas particuladas derivadas de la erosión del suelo agrícola, las cuales se intercambian en la fase disuelta y quedan disponibles para el crecimiento algal (Garnier et al., 2005). De esta forma, el enriquecimiento con nutrientes degrada la calidad del agua y constituye una problemática creciente en muchos ríos de llanura (Jarvie et al., 2002, 2008). Según antecedentes en la región pampeana, el escaso desarrollo de los suelos y de la vegetación ribereña, por acción de los pesticidas, contribuyen al proceso de eutrofización por el incremento del escurrimiento superficial y el movimiento de partículas (Vilches et al., 2011). En este sentido se recomiendan mejores prácticas agrícolas (Mugni, 2008), tendientes a controlar los niveles de fosfatos en los suelos para evadir la eutrofización de los cuerpos superficiales, y los niveles de nitrógeno, para prevenir la contaminación de las aguas subterráneas (Vilches et al., 2011).

En los canales se observó un comportamiento opuesto, donde el PRS disminuyó notoriamente en aguas muy bajas, siendo consumido por el plancton y transformado en biomasa, al igual que en la planicie de inundación del río Danubio en su fase desconectada (Hein et al., 1999; 2005). Particularmente en el canal 2, se observaron valores máximos de todas las fracciones disueltas de $\mathrm{P}$ 
y $\mathrm{N}$ en aguas altas y mínimos en aguas muy bajas decreciendo escalonadamente con la reducción de los caudales. En otros efluentes de lagos y humedales se ha demostrado que los mayores tiempos de residencia y la vegetación ribereña permiten un consumo más eficiente de los nutrientes por parte de los organismos, disminuyendo su concentración (Jarvie et al., 2008). Por otro lado, Mugni (2008) halló una relación directa entre el nivel hidrométrico y el contenido de PRS en arroyos de $1^{\underline{0}}$ orden (Arrecifes, Buenos Aires), siendo máxima su concentración en los períodos de mayores precipitaciones.

En el río predominaron las fracciones particuladas (NTP y PTP) en caudales medios de verano tardío y en aguas bajas, y las disueltas (PTD, PRS y NTD) en aguas altas y caudales medios de primavera, similar a lo observado en el río Danubio (Schagerl et al., 2009) y en ríos del Reino Unido (Neal et al., 2010), pero opuesto al río Rin, donde las fracciones particuladas se mantienen bajas a lo largo del año (de Ruyter van Steveninck et al., 1992). La correlación inversa $(p<0,05)$ hallada entre el PTP y la transparencia podría deberse al conspicuo desarrollo del fitoplancton observado en caudales medios y en aguas bajas (primavera-verano), que al consumir el P disponible, promueve la presencia de las fracciones particuladas, y donde ambos contribuyen a la reducción de la transparencia del agua. Otros antecedentes en el río Salado destacan la predominancia de las formas particuladas de P en la cuenca superior, asociado a un intenso uso agrícola, sin embargo, todavía se desconoce la magnitud de este trasporte desde los suelos y los mecanismos por los cuales sucede (Gabellone et al., 2013b).

La disponibilidad de P también estaría relacionada a los procesos de sorción con partículas de arcilla $(<2 \mu \mathrm{m})$ presentes en los sedimentos y materiales suspendidos (House \& Denison, 1998; Garnier et al., 2005). Asimismo, existe una tendencia a la acumulación de P dentro de los sistemas fluviales, particularmente durante los bajos flujos del verano y la primavera, siendo los momentos de mayor riesgo por eutrofización (Withers \& Jarvie, 2008). El PRS contribuyó en gran medida al PTD en la mayoría de los sitios de muestreo en aguas altas, pero sólo en el arroyo y el río en las restantes condiciones hidrológicas. Otros antecedentes en la cuenca, también destacan la predominancia del PRS en las aguas del río Salado en su tramo superior, siendo esta característica de gran relevancia ecológica (Neschuk, 2001; Gabellone et al., 2013b).

En la mayoría de los sitios de muestreo y condiciones hidrológicas predominaron las fracciones particuladas del PO, a excepción del canal 1 en aguas altas y el arroyo en caudales medios, donde se destacó el POD. Los valores de POP hallados en ambos sitios del río Salado en aguas bajas y en el arroyo en aguas muy bajas fueron superiores a los registrados por Neschuk (2001) y Gabellone et al. (2013b) durante muestreos estacionales realizados en la cuenca entre los años 1997-1999. Dado 
que los compuestos de POD son utilizados enzimáticamente de manera más lenta que el PRS, estas formas orgánicas de P predominan en los sistemas acuáticos, siendo exportados aguas abajo (Newbold, 1992; Wetzel, 2001).

En el río, se observó cierta tendencia a la disminución de los nutrientes (NT, PT y fracciones) en el sitio aguas abajo del trasvase del sistema Bragado. Resulta evidente que, aún cuando el arroyo registró muy elevada concentración de nutrientes, la presencia de caudales mínimos y su paulatina desvinculación por la construcción de un vertedero en sus nacientes (laguna del Bragado) hizo que sus aportes no se vieran reflejados en el río aguas abajo. Asimismo, el otro efluente de la laguna del Bragado (canal 3) presentó baja concentración de NT y PT en comparación al río aguas arriba (hasta 5,9 veces menos), y su aporte fue considerablemente mayor que el arroyo, pudiendo diluir su concentración en el río aguas abajo. Neschuk (2001) también halló esta misma tendencia, con una reducción en la concentración del PT y de todas sus fracciones en este sector del río Salado. La dilución de la concentración de los nutrientes por aportes de los tributarios también ha sido mencionada para otros ríos de llanura (O'Farrell et al., 2002).

\subsubsection{Análisis de componentes principales de las variables ambientales por muestreo}

Este análisis practicado a las variables ambientales mostró que el río aguas abajo del trasvase estuvo más relacionado con el canal 2 en aguas altas, caudales medios y aguas bajas, que con el sitio del río aguas arriba. Ambos sitios del río sólo estuvieron asociados entre sí en los caudales medios de sept. 2009, donde hubo un escaso aporte de los afluentes, por las aguas muy bajas presentes en el sistema Bragado. Este comportamiento sugiere que los aportes de las canalizaciones de la Pampa Arenosa modifican al río Salado aguas abajo del trasvase, dependiendo del momento hidrológico.

El arroyo se diferenció de los restantes sitios de muestreo principalmente por los valores positivos de $\mathrm{N}-\mathrm{NH}_{4}{ }^{+}$, pero también de PRS, N+N, PT y PTD, y negativos de OD, en todas las condiciones hidrológicas, lo cual se condice con el vertido continuo de efluentes con alta carga de materia orgánica en descomposición.

El canal 1 también se ubicó en sectores extremos en todas las representaciones de los planos de ordenación, relacionado con mayores valores de conductividad, dureza y transparencia en caudales medios, aguas bajas y muy bajas. En aguas altas, además de la conductividad y la dureza, también se relacionó con mayores valores de SS, MOP, turbidez, polifenoles totales disueltos y nutrientes, resaltando los componentes de los aportes de las canalizaciones provenientes de la Pampa Arenosa en estas condiciones. 


\subsection{Relación entre los nutrientes, la materia orgánica particulada y el plancton}

La relación N:P fue menor al coeficiente de Redfield (1958) en todos los sitios de muestreo y condiciones hidrológicas (máximo 8,9), lo cual sugiere que no hubo limitaciones de $\mathrm{P}$ para el desarrollo del fitoplancton (Hecky \& Kilham, 1988). Por el contrario, las limitaciones de P son habituales en otros ríos de llanura, como en el río Uruguay (O’Farrell \& Izaguirre, 1994), en el río Támesis (Jarvie et al., 2002a), en el río Mississippi (Turner et al., 2003), y con un fuerte desbalance de N, como en otros ríos norteamericanos (Hunt et al., 2005). En este sentido, Neal et al. (2006) consideran que la concentración mínima necesaria para evitar las limitaciones nutricionales es de $100 \mu \mathrm{g}$ P/L, condición que fue superada durante este estudio. Los cocientes hallados en este estudio resultaron menores a los reportados por Schenone et al. (2008) en la cuenca inferior del río Salado y en sus canales aliviadores hacia la bahía Samborombón (N:P 10-30), posiblemente relacionado a la depositación del P particulado por la disminución de la velocidad de corriente en la desembocadura.

El fitoplancton ejerce un importante rol en el funcionamiento de los sistemas fluviales, y constituye la principal fuente de carbono orgánico, de oxígeno disuelto y de alimento para los consumidores en muchos ríos de llanura (Thorp \& Delong, 1994; Köhler, 1995; Reynolds \& Descy, 1996). Sin embargo, en el río Salado la biomasa del fitoplancton sólo representó entre un 5 a $20 \%$ de la MOP. Estos valores son bajos en comparación con lo hallado en el río Támesis (86\% máximo) y en otros ríos del Reino Unido (Ladle \& Westlake, 1995), donde los componentes alóctonos constituyen la fracción minoritaria. Sin embargo, el valor máximo de contribución de la biomasa del plancton a la MOP (41\%) se observó en el canal 1 en caudales medios (marzo 2008), dado mayormente por el fitoplancton. En orden de importancia se halló el canal 2 en aguas bajas (33\%), siendo en este caso máxima la contribución del zooplancton a la MOP (11\%).

En ambos sistemas la mayor parte de la MOP se debió a componentes alóctonos y refractarios derivados de los ambientes terrestres (Hedges et al., 2000), con máximas contribuciones en aguas altas. De esta forma, la importancia relativa de las fuentes alóctonas y autóctonas de la MOP estuvo relacionada a la conectividad hidrológica, tal como fuera observado en el río Danubio (Hein et al., 2003). Asimismo, los porcentajes máximos de contribución a la MOP registrados en los canales indican una mayor productividad, transformando los aportes alóctonos en biomasa de plancton, lábil y de mayor calidad energética (Hein et al., 2003). El rol del sistema Bragado resulta de vital importancia en el ciclado biogeoquímico de los nutrientes y en la retención de los compuestos orgánicos dentro de la estructura interna de la comunidad, pero también en su 
modificación y degradación durante el transporte (Hopkinson et al., 1998), afectando la dinámica del río aguas abajo del trasvase.

En el río Salado se observó un aumento de la contribución de la biomasa del plancton a la MOP en el sitio aguas abajo del trasvase del sistema Bragado a lo largo de los muestreos, siendo máximo en caudales medios (43\%). La incorporación de biomasa de plancton a través de los aportes de los tributarios también ha sido mencionada para el río Siena (Garnier \& Billen, 2007), siendo una fuente adicional de carbono para el río aguas abajo. 


\subsection{Fitoplancton}

\subsubsection{Clorofila a}

El río Salado presentó mayores valores de clorofila a que el sistema Bragado, a excepción del momento de aguas altas, donde se observaron los valores mínimos, posiblemente debido a que las mayores velocidades de corriente y las bajas temperaturas restringieron el desarrollo del fitoplancton. En este sentido, se ha detectado una relación inversa entre el contenido de clorofila $a$ y la descarga de caudal en el río Danubio (Schagerl et al., 2009) y para los ríos Támesis y Humber (Neal et al., 2006), colaborando a la dilución del plancton (Sellers \& Bukaveckas, 2003). De esta forma, el desarrollo del fitoplancton estaría regulado principalmente por la combinación de los cambios hidrológicos y la temperatura, registrando valores máximos en aguas bajas y cálidas, en la época favorable de crecimiento, al igual que lo observado en el río Paraná (Izaguirre et al., 2001), en el río Rideau (Basu \& Pick, 1994) y el río Loire Medio (Picard \& Lair, 2005).

La relación hallada entre la clorofila $a$ y los SS ha sido citada para otros ríos eutróficos europeos (Neal et al., 2006), pero sin embargo, no se halló ninguna relación entre los nutrientes y la clorofila a a diferencia de lo observado en otros ríos del mundo (Soballe \& Kimmel, 1987; Basu \& Pick, 1996; Van Nieuwenhuyse, 2007; Bukaveckas et al., 2011). Tampoco se halló una relación directa entre la abundancia y biomasa total de fitoplancton, ni de los principales grupos que la integran (clorofitas, cianobacterias, diatomeas, criptofitas, euglenofitas) con la concentración de nutrientes, en contraposición a lo observado en arroyos pampeanos (Bauer, 2009; Bauer et al., 2002a, 2010). Esto podría deberse a que se trata de un ambiente eutrófico muy afectado por los factores físicos, tal como ocurre en otros sistemas lóticos (Miltner \& Rankin, 1998; Wehr \& Descy, 1998).

\subsubsection{Riqueza de especies de fitoplancton}

Del total de 438 taxa registrados, las clorofitas y las diatomeas fueron los grupos mejor representados en número de especies (140 taxa c/u), seguidas por las cianobacterias (91 taxa), al igual que lo observado previamente en la cuenca del Salado (O'Farrell, 1993; Neschuk et al., 2002b; Solari et al., 2002b, Gabellone et al., 2005; Bazzuri et al., 2008, 2010a, 2010b; Solari \& Mac Donagh, 2014) y en otros ríos de llanura (Rojo et al., 1994; O’Farrell et al., 2002; Descy et al., 2012). También se observó gran número de especies de euglenofitas (45), y en menor medida de criptofitas (13) y dinoflagelados (8). La riqueza total de especies fue superior a la hallada en estudios previos en la cuenca, y esto posiblemente se deba a la inclusión de muestras de fitoplancton de red, y a que el estudio abarcó ambientes con características disímiles (canales, humedal canalizado, arroyo y río), en condiciones hidrológicas contrastantes. 
Los valores máximos de riqueza de especies de fitoplancton se hallaron durante el otoño tardío (mayo 2007), en acuerdo con otros antecedentes en la cuenca (Gabellone et al., 2013), y también se observó escasa variación en la riqueza específica entre los sitios de muestreo. Esto podría deberse a la homogeneidad del ambiente dada por la crecida (aguas altas) y a la alta conectividad entre el río y su planicie de inundación, y entre los canales, lagunas, humedales y ambientes lénticos asociados, de donde fueran reclutadas gran cantidad de especies esporádicas (O'Farrell, 1994; Reynolds \& Descy, 1996; Welker \& Walz, 1998; Neschuk et al., 2002b; Solari et al., 2002; Bazzuri et al., 2010a, b; Solari \& Mac Donagh, 2014). Las correlaciones halladas $(p<0,05)$ entre la riqueza de especies de fitoplancton y los polifenoles solubles totales, y con la velocidad de corriente podrían estar indicando su relación con la condición hidrológica de aguas altas y la conectividad entre ambientes de manera indirecta.

A pesar de las condiciones hidrológicas contrastantes, los sitios del río mantuvieron la misma riqueza de especies de fitoplancton a lo largo de los muestreos, siendo más rico el sitio aguas abajo del trasvase. Esto podría asociarse con la incorporación de especies desde la planicie de inundación y los ambientes lénticos presentes en el área de estudio, al igual que en otros ríos de llanura de la región (Izaguirre et al., 2001; Devercelli, 2010). En contraposición, el canal 1 y el arroyo registraron una gran amplitud en la riqueza de especies entre muestreos, siendo mínima en aguas muy bajas donde la falta de flujo acentuó las características particulares de los sitios (elevada salinidad y concentración de amonio, respectivamente) y máxima en aguas altas, asociado a la incorporación de especies desde los ambientes vinculados.

En el canal 2 se observaron elevadas riquezas específicas de fitoplancton a lo largo de todos los muestreos. Su condición de humedal canalizado lo dotaría de una diversidad de hábitats y heterogeneidad espacial suficiente como para albergar a gran número de especies, sumado a los aportes continuos que recibe de la laguna Municipal. Sin embargo, en aguas muy bajas se observó un descenso en la riqueza total, lo cual podría estar relacionado con las obras de mejora hídrica observadas en este sitio, intensificadas en los últimos muestreos. En este sentido, Bauer (2009) registró un aumento inmediato en la riqueza total de especies de fitoplancton posteriormente al dragado y la canalización del $\mathrm{A}^{\mathrm{o}}$ Rodríguez, disminuyendo luego hacia fines del estudio. Esta misma tendencia se observó en las diatomeas epibentónicas (Licursi, 2005; Licursi \& Gómez, 2009).

\subsubsection{Distribución de la abundancia y biomasa total del fitoplancton}

A excepción del canal 1, la abundancia y biomasa total de fitoplancton fue mínima en aguas altas y bajas temperaturas, en acuerdo con otros estudios en la cuenca (O'Farrell, 1993; Neschuk, 
2001; Neschuk et al., 2002b; Solari et al., 2002). Antecedentes en otros ríos de llanura coinciden con estos resultados, como el río Bure (Moss et al., 1989), el río San Joaquín (Leland et al., 2001), el río Paraná (García de Emiliani, 1997; Izaguirre et al., 2001; de Cabo et al., 2003), el río Salado (Santa Fe) y sus afluentes (Devercelli \& O’Farrell, 2013), entre otros (Reynolds 1988b; Pace et al., 1992; Basu \& Pick, 1996; Schagerl et al., 2009). El desarrollo del fitoplancton, en términos de biomasa, fue máximo en caudales medios (verano tardío) en todos los sitios de muestreo, tal como lo observado en el río Ohio (Sellers \& Bukaveckas, 2003), el río San Lorenzo (Vis et al., 2007), el río Siena (Garnier et al., 1995) y otros ríos europeos (Gosselain et al., 1994; Reynolds, 1994b; Reynolds \& Descy, 1996).

Se observaron picos de densidad de organismos del fitoplancton (células, colonias, filamentos) en caudales medios (río y canal 1) y en aguas bajas (canales 2 y 3 y el arroyo), hallándose una correlación directa con la temperatura y coincidiendo con la época favorable de crecimiento (primavera-verano) (Reynolds, 1995; Walz \& Welker, 1998; Reckendorfer et al., 1999; Schagerl et al., 2009). Los bajos flujos y la menor velocidad de corriente otorgaron tiempos de residencia lo suficientemente largos como para favorecer el desarrollo del fitoplancton, al igual que en el río Danubio (Hein et al., 2003) y en arroyos pampeanos, dada la baja pendiente de la región y el enriquecimiento con nutrientes (Bauer et al., 2010).

\subsubsection{Morfologías del fitoplancton}

El fitoplancton del río estuvo caracterizado por la abundancia de las algas nanoplanctónicas en otoño tardío y primavera, y por el microplancton en aguas con temperaturas cálidas junto con un mayor desarrollo del zooplancton, en acuerdo con Neschuk et al. (2002b). Sin embargo, a diferencia de estos autores las morfologías predominantes del fitoplancton (unicelulares, coloniales o filamentosas) fueron diferentes según los eventos hidrológicos y la estación climática.

En aguas altas se destacaron las algas unicelulares de clorofitas y criptofitas (Monoraphidium spp., Cryptomonas spp.) y las cianobacterias coloniales (Aphanocapsa incerta), en caudales medios y aguas bajas los filamentos de cianobacterias (Raphidiopsis mediterranea, Sphaerospermopsis aphanizomenoides y Planktolyngbya limnetica), y en caudales medios de primavera nuevamente las unicelulares de diatomeas y clorofitas (Cyclotella glomerata, Monoraphidium spp.) y las clorofitas coloniales (Actinastrum hantzschii). En este sentido, la dominancia de las formas cocales de clorofitas y cianobacterias, seguidas por las cianobacterias filamentosas y las diatomeas unicelulares constituye un rasgo común en el fitoplancton del río Salado (Gabellone et al., 2013a).

En términos de biomasa, el plancton de red predominó por sobre el nanoplancton en todos los sitios de muestreos y momentos hidrológicos, a excepción del arroyo en aguas bajas donde se 
destacaron las clorofitas clorococcales. A diferencia de lo hallado en este estudio, la dominancia del nanoplancton en la biomasa total es común en otros ríos del mundo (Gosselain et al., 1998; Chételat et al., 2006), sin contar con antecedentes de este tipo para la cuenca del río Salado.

\subsubsection{Composición de especies y principales grupos del fitoplancton}

La composición de especies de fitoplancton fue similar a la hallada en otros estudios de la cuenca (O'Farrell, 1993; Neschuk et al., 2002a; Gabellone et al., 2005; Bazzuri et al., 2008, 2010a; Solari et al., 2002, 2014), con predominancia de especies tolerantes a las variaciones en la salinidad (Gabellone et al., 2013a). Asimismo, estuvo determinada por la alcalinidad y el estado trófico del sistema, con la presencia de especies típicas de ambientes alcalinos, eutróficos o mesoeutróficos, e indicativas de condiciones mesosapróbicas (O'Farrell, 1993). Tal como en el río Meuse, el fitoplancton varió en función de la descarga de caudal, la temperatura y la disponibilidad de luz (Gosselain et al., 1998). En acuerdo con estos resultados, antecedentes en arroyos pampeanos determinan que la geomorfología y las características químicas del agua determinan la composición y dinámica del fitoplancton, donde también se observa una clara influencia de los usos de la tierra (Bauer et a., 2002a, b; Bauer, 2009).

Los cambios estacionales en la temperatura del agua y el fotoperíodo alteran la composición del plancton (Reynolds, 2003b), y entre estas modificaciones se observó un conspicuo desarrollo de especies estivales de fitoplancton (Bazzuri et al., 2010a) en aguas templado-cálidas $\left(>20^{\circ} \mathrm{C}\right)$, tales como: Dictyosphaerium ehrenbergianum; Scotiellopsis reticulata, Rossithidium linearis, Geminella interrupta, Tetraedron minumum, T. trigonum, Oscystis parva, Crucigenia quadrata, Aphanocapsa delicatissima, Chroomonas coerulea, Ooplanctella planoconvexa, Chroococcus minutus, Didymocystis bicellularis, Arthrospira platensis, Desmodesmus intermedius, Kirchneriella irregularis; Crucigeniella rectangularis, Merismopedia glauca, M. tenuissima, Monoraphidium convolutum y M. minutum.

\section{Cianobacterias}

Las cianobacterias fueron dominantes y subdominantes de la abundancia y biomasa de fitoplancton total, con mayor importancia en temperaturas cálidas. Su correlación directa con la temperatura, la turbidez, los SS, la MOP e inversa con la transparencia, dan cuenta de su preferencia por los momentos de bajos caudales en la época estival, y su tolerancia a los ambientes eutrofizados. Esta situación coincide con otros antecedentes de la cuenca (O’Farrell, 1993; Neschuk et al., 2002b), en el río Luján (O’Farrell et al., 2002), el río Paraná (Devercelli, 2006) y en arroyos pampeanos (Bauer, 2009). Su dominancia fue particularmente importante en los períodos de aguas 
bajas, tal como lo observado en el río Spree (Köhler, 1993), en el río Bure (Moss et al., 1989), en ríos australianos (Sherman et al., 1998; Maier et al., 2001) y el río Uruguay (O’Farrell \& Izaguirre, 1994). Dadas sus lentas tasas de crecimiento y su inhabilidad para crecer en sistemas turbulentos, los bajos flujos les permitieron un mejor desarrollo (Garnier et al., 1995; Picard \& Lair, 2005; Chételat et al., 2006). A la vez se vieron favorecidas por la mayor disponibilidad de nutrientes (Reynolds, 1988b), dado su alto grado de tolerancia a los ambientes eutrofizados (Paerl, 1988). Asimismo, su desarrollo óptimo se observa en ambientes alcalinos o salinos (Zalocar de Domitrovic \& Forastier, 2005), y resisten mejor la presión de pastoreo, coincidiendo su cenit con los picos de abundancia del zooplancton en la época favorable (Köhler, 1994) (aguas bajas y cálidas temperaturas).

De esta forma, en aguas templado-cálidas se observó máximo desarrollo de cianobacterias filamentosas de escaso diámetro circular como Raphidiopsis mediterranea, Planktolyngbya spp., Leptolyngbya spp., dominando el fitoplancton, como lo observado en el río St. Johns (Phlips et al., 2007). Entre éstas, R. mediterranea estuvo inversamente relacionada al nivel de agua, y se destacó como especie dominante del fitoplancton en caudales medios, mientras que Planktolyngbya limnetica predominó en aguas bajas y temperaturas prácticamente estivales, en los canales 2 y 3, el arroyo y el río aguas abajo. Se trata de especies habituales en el potamoplancton de otros ríos del mundo a lo largo del año (Maier et al., 2001; Piirsoo et al., 2008).

A diferencia de estos resultados, en el río Paraná se ha observado el predominio de las cianobacterias cocales (Merismopedia tennuissima y Chroococcus sp.) en aguas bajas y temperaturas estivales (Devercelli, 2006). En este estudio, las cianobacterias coloniales cocales dominaron el fitoplancton de los canales en aguas altas (Aphanocapsa incerta), particularmente en el canal 1, disminuyendo paulatinamente su importancia en el sistema Bragado; en el cauce principal del río Salado debido a que las mayores velocidades de corriente y la turbulencia del cauce (Maier et al., 2001) no permitieron su desarrollo. Las cianobacterias filamentosas Oscillatoria spp. y Phormidium spp. (P. versicolor, P. diguetii, y P. granulatum) se destacaron en el canal 2 en aguas bajas, siendo géneros de temperaturas estivales y típicamente bentónicos (Leland et al., 2001).

Nodularia spumigena también registró máximos de biomasa en el canal 2 pero en aguas muy bajas (9,6\% del total). Aunque no constituyó una especie importante en la cuenca, su condición de potencial productora de toxina hepatotóxica amerita cierta atención, dado que la producción de nodularina está regulada por la salinidad (Blackburn et al., 1996). Esta especie también ha sido citada como formadora de floraciones en ríos de Santa $\mathrm{Fe}$, en condiciones de elevada conductividad, al igual que Anabaenopsis arnoldii y A. circinalis (Zalocar de Domitrovic \& Forastier, 2005), todas ellas habituales en este estudio, particularmente en el sistema Bragado. 
En los ríos templados, el riesgo de floraciones algales nocivas es bajo, aunque algunos sistemas con largos tiempos de residencia o vinculados a ambientes lénticos eutróficos, como el canal 2, pueden desarrollar estos fenómenos (Soballe \& Kimmel, 1987; Wehr \& Descy, 1998). Sin embargo, existen evidencias sobre el aumento de la abundancia de las cianobacterias en los sistemas acuáticos como resultado del incremento de los aportes de nutrientes y las mayores temperaturas del agua, siendo un fenómeno de seriedad en virtud de los veranos más cálidos predichos por la tendencia de calentamiento global (Ghadouani et al., 2003). En particular en los ríos templados con escasa pendiente como es el río Salado, con tributarios que drenan áreas urbanas, suburbanas y tierras de uso agrícola-ganadero y proveen de nutrientes en exceso, sumado a las bajas velocidades de corriente y altas irradiancias en la época estival, generan condiciones que en su conjunto potencian el desarrollo de floraciones algales (Phlips et al., 2007). La correlación inversa hallada entre la abundancia total de las cianobacterias y la diversidad de fitoplancton estaría relacionada con la fuerte dominancia de varias especies del grupo, teniendo efectos sobre la equitabilidad de la comunidad y la distribución de las especies subdominantes.

\section{Clorofitas}

El predominio de las clorofitas, en especial de las clorococcales nanoplanctónicas, también ha sido mencionado en trabajos previos en la cuenca del río Salado (O'Farrell, 1993; Neschuk et al., 2002a; Gabellone et al., 2005, 2013a; Bazzuri et al., 2008, 2010a,b; Solari et al., 2002, 2014). De igual manera en el río Danubio (Stoyneva, 1994), el río Rin (Iestwaart et al., 1999), el río Loire (Lair et al., 1999; Picard \& Lair, 2005; Descy et al., 2012), el río Meuse (Descy \& Gosselain, 1994), el río Paraná Medio (Zalocar de Domitrovic et al., 2007) y el río Salado (Santa Fe) y afluentes (Devercelli \& O'Farrell, 2013). Esto difiere con lo hallado en otros ríos de llanura donde dominan las diatomeas (Garnier et al., 1995; Descy \& Métens, 1996; Train \& Rodrigues, 1998; Lair et al., 1999; Leland et al., 2001) y las clorofitas suelen ser subdominantes, como en el río Luján ( $\mathrm{O}^{\prime}$ Farrell et al., 2002) y en otros ríos europeos (Stankovic et al., 2012).

Las clorofitas registraron mayores abundancias y biomasas en los tributarios que en el cauce principal del río, tal como lo hallado en la cuenca del río Uruguay (O’Farrell \& Izaguirre, 1994). De esta forma, se observó el aumento de la abundancia relativa de las clorofitas en el río aguas abajo del trasvase del sistema Bragado durante las condiciones de aguas bajas y caudales medios, de igual manera que en el río Rin (Iestwaart et al., 1999) y el río Paraná (Devercelli, 2006); y lo opuesto en condiciones de aguas altas debido a la dilución por los tributarios, como lo observado en el río Luján (O’Farrell et al., 2002). 
Las clorofitas más relevantes (Scenedesmus, Crucigenia, Chlamydomonas, Monoraphidium, Eutetramorus, Chlorella, Pediastrum, Oocystis y Actinastrum) también son habituales en otros ríos de llanura, y se destacan por su abundancia típicamente en la primavera-verano (Köhler, 1993; Rojo et al., 1994; Lair \& Reyes-Marchant, 1997; Gosselain et al., 1998a; Lair et al., 1999; Izaguirre et al., 2001; Devercelli, 2006; Schagerl et al., 2009; Istvánovics et al., 2010; Descy et al., 2012). Asimismo, se observaron coincidencias florísticas con las especies de clorofitas halladas por Bauer et al., (2002a) y Bauer (2009) en el fitoplancton de arroyos pampeanos.

En términos de abundancia se destacó el género Monoraphidium, integrado por 13 especies, entre ellas algunas estuvieron relacionadas a la temperatura, dureza, SS, MOP y turbidez. M. minutum constituyó la especie más importante, al igual que en otros estudios de la cuenca (Gabellone et al., 2013a; Solari et al., 2014) y en arroyos pampeanos (Bauer, 2009), siendo de amplia distribución y tolerante a las variaciones de salinidad y nutrientes (Solari et al., 2002; Carrillo et al., 2009). En este sentido, las especies del género se encuentran adaptadas a las condiciones lóticas, por sus características morfológicas y estrategias de vida (Reynolds \& Descy, 1996), y representan un componente importante del fitoplancton en ríos europeos como el río Siena (Garnier et al., 1995), el río Danubio (Stoyneva, 1994), el río Meuse (Gosselain et al., 1994), el río Loire (Lair et al., 1999), y también en el río Paraná Medio (Zalocar de Domitrovic et al., 2007). Otros importantes representantes del género como $M$. komarkovae y $M$. tortile, son conocidos por su tolerancia a los cambios en la salinidad (Flöder et al., 2010).

Otro de los géneros destacables fue Oocystis, mayormente representado por Oocystis lacustris cuyo desarrollo fue máximo en condiciones de aguas bajas al igual que en el río Paraná (Izaguirre et al., 2001). Su dominancia en el río aguas abajo pudo estar relacionado a los aportes de los ambientes lénticos asociados, a través de los afluentes (canal 3 y arroyo) donde la especie fue subdominante de la biomasa. En el río, también se destacó por su abundancia y biomasa Actinastrum hantzschii en caudales medios (sept. 2009), siendo una de las especies dominantes del río Loire en la época favorable (Lair et al., 1999), y tolerante a las variaciones en la salinidad (Flöder et al., 2010). En acuerdo con O'Farrell (1993) el desarrollo de las clorofitas planctónicas en el río Salado estuvo relacionado con la temperatura en aguas bajas y caudales medios durante la época favorable (primavera-verano), aunque con aporte de los ambientes lénticos asociados.

\section{Diatomeas}

Las diatomeas constituyeron el tercer grupo en importancia en abundancia y biomasa, luego de las clorofitas y las cianobacterias, al igual que en otros ríos de llanura europeos (de Ruyter van 
Stevenink et al., 1992; Gosselain et al., 1994; Yang et al., 1997). La escasa profundidad del río Salado y su baja turbulencia serían los factores limitantes para su desarrollo (Solari \& Mac Donagh, 2014), condiciones que favorecerían a las clorofitas, sumado al enriquecimiento con nutrientes. Análisis de la composición química del agua en la cuenca del río Salado determinaron que las concentraciones de sílice son suficientes como para asegurar su crecimiento (Miretzky et al., 2001).

Los tributarios registraron mayor abundancia de diatomeas que en el cauce principal, al igual que lo observado en el río Rin (Scherwass et al., 2010), pero lo opuesto en términos de biomasa. Esto podría deberse a que los canales estuvieron caracterizados por diatomeas centrales de pequeño tamaño, mientras que en el río también se registraron grandes diatomeas pennales, que aún en bajas abundancias contribuyeron en gran medida a la biomasa total.

Las diatomeas centrales se destacaron por su abundancia en el canal 1 en aguas bajas y en el río en caudales medios (sept. 2009), superando a las pennales, en acuerdo con otros antecedentes en la cuenca (O'Farrell, 1993). En este sentido, la dominancia de las diatomeas centrales es un rasgo común a muchos ríos de llanura en la Argentina (O’Farrell \& Izaguirre, 1994; García de Emiliani, 1997; Izaguirre et al., 2001; O’Farrell et al., 2002; García de Emiliani \& Devercelli, 2003), y del mundo (Reynolds, 1988a; Köhler, 1993; Descy \& Métens, 1996; Ietswaart et al., 1999; Holst et al., 2002). Además, se reconoce que las diatomeas centrales presentan mayores tasas de división celular que las pennales ( 2 y $<1$ divisiones/día, respectivamente), favoreciendo su dominancia (Leland, 2003). De este modo, las diatomeas centrales son el grupo taxonómico mejor adaptado al ambiente fluvial altamente inestable (Rojo et al. 1994), ya que son capaces de sobrevivir a los flujos turbulentos, y en presencia de alta concentración de nutrientes (Reynolds, 1994b).

Entre las diatomeas centrales presentes se destacaron Cyclotella glomerata, C. meneghiniana y Stephanodiscus spp., siendo especies típicas de ambientes eutróficos e hiper-eutróficos (Van Dam et al., 1994) y conocidas por sus elevadas densidades en ríos templados (Gosselain et al., 1994; Rojo et al., 1994; Reynolds, 1995; Lair \& Reyes-Marchant, 1997; Yang et al., 1997; O'Farrell et al., 2002; Istvánovics et al., 2010; Salmaso \& Zignin, 2010), donde suelen dominar en biomasa (Chételat et al., 2006). Asimismo pertenecen al meroplancton, y su habilidad de pasar parte del ciclo de vida fuera del flujo turbulento les otorga una capacidad adicional de utilizar estos eventos como oportunidades de dispersión poblacional (Reynolds \& Descy, 1996). En este sentido, se hallaron auxosporas en el canal 1 y en el río aguas arriba en aguas bajas y en todos los canales en aguas muy bajas (Kowe et al., 1998).

Entre las especies presentes, Cyclotella meneghiniana se destacó en aguas altas (otoño tardío) particularmente en el canal 1, siendo una especie adaptada a las condiciones lóticas en ambientes 
ricos en nutrientes (Rojo et al., 1994), tal como lo observado en el río Paraná (Izaguirre et al., 2001). Por otro lado, Cyclotella glomerata y Stephanodiscus spp. presentaron máximas densidades en los canales 1 y 2 en aguas bajas, y también se destacaron en el río en caudales medios (sept. 2009) con temperaturas templado-cálidas de inicios de la primavera, tal como en otros ríos europeos (Rojo et al., 1994; Reynolds, 1995; Gosselain et al., 1998; Leland, 2003; Descy et al., 2012). En acuerdo con lo observado por Giorgi et al. (2005) en el fitobentos del Ao Las Flores, Cyclotella glomerata registró picos de abundancia a fines del invierno y principios de la primavera en el río.

Además, el género Cyclotella es conocido por desarrollarse en aguas ricas en materia orgánica, siendo un componente habitual del fitoplancton del río Matanza-Riachuelo, altamente poluído (Conforti et al., 1995), tal como lo evidencian las relaciones encontradas entre la abundancia de las especies con la MOP, los SS y turbidez. En el estuario de Bahía Blanca, se ha registrado un incremento en la densidad Cyclotella (6-15 $\mu \mathrm{m}$ de diámetro) en la última década, generando florecimientos típicos en los meses de otoño y verano (Popovich et al., 2008; Guinder et al., 2010).

En el río, las diatomeas pennales superaron en número a las centrales en aguas altas y caudales medios (verano tardío), posiblemente relacionado a la mayor velocidad de corriente, como lo observado en el río Loire (Descy et al., 2012) Antecedentes en la cuenca del río Salado indican la presencia habitual de diatomeas pennales (O’Farrell, 1993; Neschuk et al., 2002b; Solari et al., 2002), siendo algunas de ellas características del río (Craticula ambigua, Campylodiscus clypeus, Nitszchia linearis, N. tryblionella, Neidium iridis, Surirella striatula y Fragilaria virescens). En aguas bajas las menores velocidades de corriente y la escasa profundidad del cauce del río pueden haber promovido la sedimentación de las grandes diatomeas (Köhler, 1994), que requieren de cierta intensidad de turbulencia para mantenerse suspendidas (Reynolds \& Descy, 1996). Esta situación también es frecuentemente observada en el río Paraná (O’Farrell et al., 2001; Devercelli, 2010).

En aguas muy bajas se observó la prevalencia de las diatomeas pennales en el sistema Bragado, posiblemente asociada a la mayor transparencia del agua, menor turbidez, contenido de material particulado y nutrientes, condiciones que podrían haber favorecido la proliferación de las algas epibentónicas y epifíticas. En aguas altas también predominaron las pennales en la mayoría de los sitios de muestreo del sistema Bragado, lo cual podría explicarse por la presencia de altos flujos que aumentan la probabilidad de resuspensión de algas desde el bentos y las comunidades asociadas (Kowe et al., 1998), tal como lo observado en el río Adige (Italia) (Centis et al., 2010).

En el arroyo dominaron las diatomeas pennales de hábitos perifíticos y bentónicos en todas las condiciones hidrológicas, registrando los valores máximos en caudales medios, previo a la desvinculación del cauce. Su continua dominancia en este sitio posiblemente se relaciona a la 
escasa profundidad del arroyo, al desarrollo de cierta la vegetación ribereña y el elevado contenido de nutrientes, condiciones que podrían favorecer el crecimiento de las comunidades asociadas (bentos, epifiton, epipelon) (Bauer, 2009). En este sentido, el bentos puede servir como origen de las algas planctónicas con un aporte regular y periódico en arroyos (Swanson \& Bachmann, 1976) y en ríos de llanura (Margalef, 1983). Tal como se observa en el río San Joaquín (Leland et al., 2001; Leland, 2003), el drenaje de la cuenca y los aportes de los tributarios son fuente de inmigración de diatomeas pennales bentónicas, y entre éstas, se hallaron especies de ambientes eutróficos y alcalinos (Van Dam et al., 1994) (Anexo V).

El predominio de las diatomeas pennales ha sido previamente mencionado por O'Farrell \& Izaguirre (1994) para los tributarios del río Uruguay, con importante presencia de géneros ticoplanctónicos como Synedra, Nitzschia y Navicula, pertenecientes al bentos o epifiton, pero de frecuente presencia en el plancton (Patrick, 1977; Rojo et al., 1994). Asimismo, géneros como Gomphonema, Achnanthes, Cymbella, Fragilaria, Navicula, Pinnularia y Melosira presentes en este estudio constituyen representantes habituales del fitobentos del $\mathrm{A}^{\mathrm{o}}$ Las Flores (Giorgi et al., 2005).

En particular, Nitzschia palea y N. fonticola fueron abundantes en el arroyo y en el río, siendo especies tolerantes a la contaminación con materia orgánica y habituales en el fitoplancton y fitobentos de arroyos afluentes del Río de La Plata (Gómez \& Licursi, 2001; O’Farrell et al., 2002; Licursi, 2005; Bauer, 2009; Licursi \& Gómez, 2009; Sierra \& Gómez, 2010); al igual que Sellaphora pupula y Diadesmis confervacea, presentes en el arroyo Saladillo.

Otras especies también citadas como tolerantes a la contaminación orgánica en el río MatanzaRiachuelo fueron Bacillaria paradoxa, Navicula capitata, N. cryptocephala, Fallacia pygmea y Nitzschia acicularis (Conforti et al., 1995). Sin embargo, Cochero et al. (2015) hallaron a N. cryptocephala y Luticola mutica como especies sensibles al enriquecimiento con nutrientes en condiciones de laboratorio, a la vez que un incremento en la abundancia de Nitzschia, Navicula y Sellaphora, siendo diatomeas móviles y señaladas como mejores competidoras. Estudios realizados por Dos Santos (2015) en el fitobentos de los mismos sitios de muestreo durante la última campaña (sept. 2009), destacan la dominancia de las diatomeas en esta comunidad, particularmente de los géneros Cyclotella, Navicula, Nitzschia, Rhopalodia, Synedra, Fragilaria. Asimismo, destaca la presencia de Campilodiscus clypeus, Entomoneis spp., Amphora spp., Cyclotella meneghiniana, Planothidium delicatulum y Surirella striatula, especies también presentes en el plancton. Se observó a Synedra cyclopum en los canales 1 y 2 (aguas bajas) y en el río (caudales medios - sept. 2009), siendo una diatomea pennal epibióntica conocida por su infestación en dáfnidos y copépodos de lagos en primavera, con repercusiones negativas sobre sus tasas de mortalidad (Allen et al., 1993). 


\section{Criptofitas}

Las criptofitas constituyeron el cuarto grupo en importancia en la mayoría de los sitios de muestreo y condiciones hidrológicas, y sólo fueron co-dominantes del fitoplancton junto con las clorofitas en el canal 2 en aguas muy bajas. Este pico de abundancia estuvo dado por Plagioselmis nannoplanctica, siendo también una especie importante en condiciones similares en el río Paraná (Devercelli, 2006), y por Rhodomonas minuta, citada como componente habitual de ríos eutróficos (Istvánovics et al., 2010). Sin embargo, su máximo desarrollo se observó en caudales medios y estuvo relacionado a la presencia de especies de mayor tamaño como Cryptomonas spp., tal como en el río Paraná (Devercelli, 2006). Asimismo, se observaron algunas coincidencias florísticas con estudios en arroyos pampeanos (Bauer et al., 2002a; Bauer, 2009).

Las criptofitas se destacaron por su abundancia y biomasa en los canales 1 y 2 en caudales medios, aguas bajas y muy bajas, variando los picos de abundancia según las especies presentes. En el río, el máximo desarrollo del grupo se observó en caudales medios (verano tardío) y aguas cálidas, tal como en el río Rin (Köhler, 1993), siendo un componente importante del fitoplancton en la cuenca superior, por los aportes de los tributarios (Scherwass et al., 2010). A diferencia de otros ríos de llanura, no se observó una clara relación entre al abundancia del grupo y la disminución de los nitratos o la disponibilidad de fósforo (O'Farrell et al., 2002; Devercelli, 2006). Sin embargo, su abundancia y biomasa estuvo relacionada al nivel de agua y a la turbidez, tal como lo hallado en el río Paraná (García de Emiliani, 1997; Train \& Rodrigues, 1998; Zalocar de Domitrovic et al., 2007). En este sentido, las criptofitas son conocidas como oportunistas (Garnier et al., 1995), que se desarrollan bien en ambientes ricos en nutrientes (Klaveness, 1988), y cuya estrategia adaptativa se relaciona con la tolerancia a las condiciones de poca luz, manteniendo altas tasas reproductivas (Reynolds, 1997).

\section{Euglenofitas}

Las euglenofitas se destacaron en el arroyo y en el canal 1, registrando ambos sitios aguas ricas en nutrientes y con cierto grado de contaminación con materia orgánica posiblemente asociado a la cercanía de las ciudades de Bragado y 9 de Julio, respectivamente. En este sentido, de Cabo et al. (2003) hallaron una máxima presencia del grupo en relación a asentamientos humanos sobre el río Paraná de las Palmas y Zalocar de Domitrovic (2003) en la planicie de inundación del río Paraná Medio (puente “Gral. Belgrano", Resistencia-Corrientes).

Las euglenofitas son conocidas como indicadores de contaminación con materia orgánica, y en el río Luján y en la cuenca del río Matanza-Riachuelo se relaciona su presencia con la 
concentración de cloruros (O’Farrell et al., 2002), registrándose el máximo desarrollo en sitios con muy alto contenido de materia orgánica (Conforti et al., 1995), condiciones que también se observaron en el arroyo y en el canal 1. En este sentido, se hallaron algunas especies indicadoras de condiciones de saprobios, como Lepocinclis acus en el arroyo, siendo $\beta$-mesosaprobios, y Lepocinclis oxyuris en el canal 2, siendo $\alpha$-mesosaprobios (Barinova et al., 2011).

Los valores máximos de abundancia y biomasa del grupo se observaron en el arroyo, durante las aguas cálidas de verano tardío, situación también observada en el río Paraná (Izaguirre et al., 2001) y en el río Luján (O’Farrell et al., 2002). La riqueza de especies fue máxima en el muestreo de otoño tardío, tal como en otros antecedentes de la cuenca (otoño-invierno) (Neschuk et al., 2002b).

El canal 2 fue el sitio con mayor riqueza de especies de euglenofitas loricadas (Strombomonas spp., Trachelomonas spp.), siendo algunas de ellas características, aunque su abundancia fue muy baja. Estos resultados se contraponen a lo observado en las cabeceras del A o Rodríguez, donde las euglenofitas loricadas constituyen importantes componentes del fitoplancton (Bauer et al., 2002a; Bauer, 2009; Conforti et al., 2009). Sin embargo, los autores hallaron una estrecha relación entre el aumento de las euglenofitas loricadas y la ejecución de obras de dragado y canalización en este arroyo, tales como las observadas en el canal 2 a partir del segundo muestreo (marzo 2008, nov. 2008 y sept. 2009). Asimismo, se encontraron algunas coincidencias florísticas: Lepocinclis acus, Euglena viridis, E. proxima, Strombomonas cf verrucosa, S. cf fluviatilis, S. cf borystheniensis, Phacus granum, P. pleuronectes, P. curvicauda y P. textus (Bauer, 2009; Conforti et al., 2009).

\subsubsection{Diversidad del fitoplancton}

En general, el río presentó una mayor diversidad de fitoplancton que los sitios del sistema Bragado, con valores máximos en aguas altas y mínimos en aguas bajas, en acuerdo con lo observado en el río Danubio y en ríos de Croacia (Stankovic et al., 2012). Los bajos valores de diversidad hallados en el canal 1 podrían deberse a la elevada conductividad y concentración de sales presente en el sitio, que condiciona el desarrollo de unas pocas especies tolerantes. Tanto el arroyo como el canal 2 registraron los valores máximos de diversidad en caudales medios, donde las temperaturas de verano tardío posiblemente colaboraron al desarrollo del plancton en las lagunas que drenan, y a su transporte a través de estos afluentes. Estos valores fueron previos a las obras de mejora hídrica, que incluyeron movimientos de tierra, la ampliación del cauce y construcción de terraplenes en el canal 2, y un nuevo vertedero en las nacientes del arroyo en la laguna del Bragado. Estas tareas en su conjunto seguramente perjudicaron a la biota, por la 
pérdida de hábitats y la fragmentación del ambiente, observándose una disminución de la diversidad de fitoplancton en los muestreos subsiguientes.

En acuerdo con estos resultados, Conforti et al. (2009) hallaron una pérdida en la diversidad de euglenofitas en el $\mathrm{A}^{\mathrm{o}}$ Rodríguez, luego de obras de canalización y dragado, observando asimismo, cambios en la fisionomía del ensamble de especies presentes. Sin embargo, opuesto a estos resultados, otros autores hallaron un incremento inmediato en la diversidad de las diatomeas epipélicas y en el fitoplancton total del arroyo (Licursi, 2005; Licursi \& Gómez, 2009; Bauer, 2009). 


\subsection{Zooplancton}

\subsubsection{Riqueza de especies del zooplancton}

Se registró un total de 166 taxa de zooplancton, siendo los rotíferos el grupo más diverso (93), seguido por los ciliados (45), y en menor medida los cladóceros y copépodos (9 taxa c/u), rizópodos (6) y ostrácodos (2). La prevalencia de las especies de rotíferos y ciliados es común en la cuenca del río Salado (Neschuk et al., 2002a; Claps et al., 2009; Gabellone et al., 2014), al igual que en otros ríos de llanura de Argentina (José de Paggi, 1984; José de Paggi \& Paggi, 1998; Rojas Molina \& José de Paggi, 2008; José de Paggi \& Devercelli, 2011) y en los arroyos pampeanos (Rodrigues Capítulo et al., 2010).

La riqueza de especies de zooplancton en el río Salado fue superior a otros estudios en la cuenca (Claps et al., 2009; Gabellone et al., 2014), con valores máximos en caudales medios y con un notorio aumento en el río aguas abajo, posiblemente asociado a la descarga de los canales.

El arroyo registró valores mínimos de riqueza de especies de zooplancton en todas las condiciones hidrológicas, y esta característica podría relacionarse a la continua contaminación con materia orgánica registrada, y al efecto tóxico del amonio que resulta deletéreo para el zooplancton, tal como fuera observado en ríos de Santa Fe (José de Paggi \& Paggi, 1998). El canal 2 presentó máxima variación en la riqueza de especies del zooplancton, con valores máximos en caudales medios y mínimos en aguas muy bajas, respectivamente. Este canal es efluente de la laguna Municipal, y de un modo similar Rojas Molina \& José de Paggi (2008) también hallaron máxima riqueza de especies de zooplancton en el río Santa Fe, aguas abajo de la laguna Setúbal.

La riqueza total de especies de rotíferos fue superior a la registrada en estudios previos en la cuenca del río Salado (Neschuk et al., 2002; Claps et al., 2009; Gabellone et al., 2014), y de otros ríos de llanura de la región como el río Samborombón (Modenutti, 1998), y en el delta y estuario del Río de La Plata (Modenutti \& Claps, 1988). La máxima riqueza acumulada del grupo se observó en el canal 2 (66 taxa), siendo comparable a la descripta para oxbows (lagos relictuales, paleocauces) de ríos australianos (Shiel \& Koste, 1983) y del río Paraná Alto (Lansac-Tôha et al., 2009). El número total de especies de ciliados fue inferior a la registrada en otros ríos de llanura (Kiss et al., 2009; Pauleto et al., 2009), pero similar a estudios previos en la cuenca (Claps et al., 2009).La elevada riqueza de especies de ambos grupos estaría asociada al grado trófico de los canales, incrementando luego el número de especies de rotíferos y ciliados aguas abajo del trasvase.

En el río aguas arriba se observó la máxima riqueza acumulada de rizópodos, cladóceros y copépodos, en oposición a lo hallado en el río aguas abajo del trasvase. De esta forma se evidencia el efecto de los aportes de las canalizaciones sobre la composición y riqueza de especies de 
zooplancton del río Salado, incrementando la presencia de rotíferos y ciliados en detrimento de los rizópodos, cladóceros y copépodos. La variación en la riqueza de especies de zooplancton hallada podría deberse a la combinación de muestreos en diferentes condiciones hidrológicas y estación climática, y a la presencia de sitios con características geomorfológicas muy dispares.

Asimismo se observó un incremento en la riqueza de especies de zooplancton en el río aguas abajo del trasvase, particularmente en aguas altas, por la incorporación de organismos desde los tributarios y las lagunas que drenan. En este sentido, es conocida la importancia de estos ambientes vinculados como fuentes de inóculos para el plancton de ríos, en acuerdo con estudios previos en la cuenca (Neschuk et al., 2002a; Solari et al., 2002; Claps et al., 2009) y de otros ríos de llanura en el mundo (Saunders \& Lewis, 1989; Vásquez \& Rey, 1989; Pourriot et al., 1997; Akopian et al., 1999; Welker \& Walz, 1998; Wahl et al., 2008).

\subsubsection{Distribución de la abundancia y biomasa total de zooplancton}

El zooplancton registró los valores máximos de abundancia y biomasa en aguas bajas en la mayoría de los sitios de muestreo, destacándose el canal 2 (47.400 ind/L y $4.840 \mu \mathrm{g}$ C/L) con gran abundancia de rotíferos, la cual influenció a los sitios aguas abajo (canal 3, arroyo y río aguas abajo). Este pico de abundancia coincidió con temperaturas del agua entre 24 a $33^{\circ} \mathrm{C}$, y dado que los organismos del zooplancton son poiquilotermos, su crecimiento se encuentra relacionado a la temperatura (Kobayashi, 1997). La combinación de bajos caudales y cálidas temperaturas también propició la presencia de elevadas densidades de zooplancton en el río Po (Rossetti et al., 2009), en el río Orinoco (Vásquez \& Rey, 1989), en el río Rin (de Ruyter van Steveninck et al., 1992), en estudios previos en la cuenca del río Salado (Modenutti, 1998; Neschuk, 2001; Neschuk et al., 2002b) y en otros ríos de Argentina (José de Paggi \& Paggi, 1998; José de Paggi \& Devercelli, 2011).

La densidad del zooplancton estuvo relacionada al nivel trófico de los ambientes y a las bajas velocidades de corriente, donde los mayores tiempos de residencia del agua permitirían un mejor desarrollo de las poblaciones (Pace et al., 1992; Thorp et al., 1994; José de Paggi \& Paggi, 1998; Baranyi et al., 2002). Sin embargo, en el río aguas arriba, los valores máximos de biomasa de zooplancton total se observaron en caudales medios de verano tardío, debido a la presencia de cladóceros y copépodos (Moina micrura, Acanthocyclops robustus, Microcyclops alius, Metacyclops mendocinus) como importantes contribuyentes. En general se considera que los crustáceos son más frecuentes durante los bajos caudales de verano, momento en el cual pueden hacer frente a las corrientes de agua del río, y eventualmente en condiciones de aguas altas (picos de inundación) por su incorporación desde los ambientes adyacentes (Viroux, 2002). 
El régimen hidrológico del río tuvo una gran influencia en la dinámica del zooplancton, registrando los valores mínimos de abundancia y biomasa total en condiciones de aguas altas. Las bajas temperaturas y la dilución por la crecida habrían afectado negativamente al plancton, tal como lo observado en otros ríos del mundo (Kim et al., 2012) y en estudios previos en la cuenca (Claps et al., 2009). Sólo el canal 1 presentó un comportamiento distinto al resto de los sitios de muestreo, registrando los valores máximos de abundancia y biomasa total de zooplancton en aguas altas, situación que podría relacionarse al descenso de la conductividad eléctrica y a la mayor conectividad con los ambientes adyacentes, actuando como fuentes de inóculos.

Los valores de abundancia total de zooplancton hallados en el canal 2 en aguas bajas fueron muy superiores a los descriptos para la cuenca del río Salado, y para otros ambientes lóticos del mundo. Sin embargo, la dominancia de los rotíferos asociada a un carácter hidromorfológico es concordante con estudios en otros ríos del mundo (de Ruyter van Steveninck et al., 1992; Basu et al., 2000; Kim \& Joo, 2000; Holst et al., 2002; Zimmermann-Timm et al., 2007). Tal sería el caso del río Elbe, donde Holst et al. (2002) hallaron 10.000 ind/L de rotíferos en la época favorable, y del río Loire, con densidades de 4.000 ind/L durante un evento de sequía (Lair, 2006). El aumento de las áreas lénticas y la baja velocidad de corriente habrían favorecido la proliferación del plancton, tal como fuera observado en el canal 2. Por otro lado, Bass et al. (1997) detectaron densidades de hasta 18.000 ind/L de rotíferos en una sección canalizada y muy regulada del río Great Ouse (Inglaterra), durante la época favorable (primavera-verano).

Cada especie del plancton presenta niveles óptimos en sus requerimientos que en general sólo son alcanzados durante un corto período de tiempo, causando un rápido crecimiento de las poblaciones residentes (Lair, 2005, 2006). De esta forma, las condiciones halladas en el canal 2 durante ese muestreo (aguas bajas, elevadas temperaturas, salinidad, recursos) fueron sin lugar a dudas óptimas para la explosión demográfica de Brachionus plicatilis (34.800 ind/L). El máximo desarrollo de los rotíferos en el río Nakdong (Kim et al., 2012) y en el río Missouri (Dickerson et al., 2010) también estuvo asociado a la temperatura.

Los canales registraron mayor abundancias de zooplancton total y de los principales grupos (rotíferos, ciliados, copépodos) en comparación con el río Salado, constituyendo una importante fuente de inóculos, en acuerdo con otros antecedentes en la cuenca (Neschuk 2001; Neschuk et al., 2002a; Benítez \& Claps, 2009; Claps et al., 1997, 2009; Gabellone et al., 2014).

De un modo más general, los rotíferos dominaron en las aguas jóvenes (low age), como son los canales, y los ensambles de cladóceros y copépodos en las aguas de mayor edad (greater age) como es el río Salado (aguas arriba), tal como lo observado en los ríos australianos (Shiel, 2002). 
Asimismo, Baranyi et al. (2002) encontraron una relación positiva entre la edad del agua del río Danubio y el incremento de la biomasa total de zooplancton por la contribución de los crustáceos.

\subsubsection{Composición de especies y principales grupos del zooplancton}

La composición del zooplancton hallada en este estudio es comparable a la descripta para otros ríos de llanura (Saunders \& Lewis, 1989; Pace et al., 1992; Thorp et al., 1994; Lair et al., 1999; Picard \& Lair, 2005), donde predominan los organismos filtradores de pequeño tamaño, tales como los rotíferos, registrando algunas similitudes con los ensambles de especies presentes en los ríos australianos (Shiel et al., 1982, 2006; Kobayashi, 1997; Kobayashi et al., 1998; Burger et al., 2002; Nielsen et al., 2005). Asimismo, se condice con estudios previos en la cuenca, tanto del cauce principal del río como de sus tributarios y lagunas vinculadas (Neschuk et al., 2002a; Benítez \& Claps, 2009; Claps et al., 1997, 2009; Gabellone et al., 2014).

Además de los rotíferos y ciliados, también se hallaron algunas especies de cladóceros de pequeño tamaño y copépodos cyclopoideos, siendo estos grupos más relevantes en otros ríos del mundo (Margalef, 1983; Krylov, 2004). De esta forma, se considera que la disponibilidad de recursos (nutrientes, materia orgánica, biomasa algal) permitió la co-dominancia de los diferentes grupos en los ambientes eutróficos estudiados (Shiel, 2002).

La abundancia y biomasa total de los rotíferos estuvo relacionada a la turbidez, SS, MOP, a la abundancia y biomasa total de fitoplancton y a la clorofila $a$. En este sentido, la elevada concentración de SS puede haber beneficiado la dominancia de los rotíferos, por los efectos negativos de la turbidez sobre sus competidores (cladóceros), y depredadores (algunos copépodos y peces planctívoros), tal como fue propuesto para los ríos de praderas norteamericanos (Thorp \& Mantovani, 2005). Además, los rotíferos tendrían ventajas competitivas por su capacidad de consumir partículas en ambientes altamente advectivos, sumado a sus cortos tiempos generacionales y altas tasas de crecimiento (estrategas $r$ ) (Kirk \& Gilbert, 1990; Pace et al., 1992; Holst et al., 2002, José de Paggi \& Devercelli 2011), a diferencia de los crustáceos que requieren de mayores tiempos de residencia para crecer y reproducirse (Thorp et al., 1994; Basu \& Pick, 1996; Kobayashi, 1997; Wahl et al., 2008). Asimismo, la elevada biomasa de cianobacterias coloniales y filamentosas observada en la época favorable pueden hacer que los cursos de agua sean inhóspitos para el zooplancton de gran tamaño y al mismo tiempo, generar un ambiente ideal para el microzooplancton (Kim et al., 2000; 2001).

La dominancia de ciliados en el río Loire Medio estuvo asociada a la ejecución de obras de dragado que aumentaron los SS y MOP, promoviendo la actividad bacteriana y la presencia de 
flagelados bacteriófagos como fuentes de alimento para los ciliados (Lair et al., 1999). Este hecho constituye una evidencia de cómo los disturbios antrópicos pueden generar reacciones en cadena en el plancton, a pesar de tratarse de ríos eutróficos sin limitaciones nutricionales.

\section{$\underline{\text { Rizópodos }}$}

Los rizópodos se destacaron por su abundancia en el canal el canal 3 y el arroyo en aguas bajas y cálidas temperaturas, dado por Trinema sp., Amoeba sp. y Arcella hemisphaerica. Sin embargo, en el río Salado su presencia fue más estable a lo largo de los muestreos, presentando valores similares a las hallados en estudios previos en la cuenca (Claps et al., 2009). En el río, los picos de abundancia se observaron en caudales medios (verano tardío), y estuvieron dados por $A$. discoides $A$. hemisphaerica, siendo esta última una especie ubicua y cosmopolita. Las abundancias totales de las amebas testáceas halladas en este estudio resultan inferiores a las descriptas para otros ríos eutróficos como el río Danubio (Kiss et al., 2009).

\section{$\underline{\text { Ciliados }}$}

La composición de especies de ciliados estuvo integrada mayormente por formas bentónicas (peritrichios en deriva: Epistylis spp., Opercularia spp., Vorticella spp.) y por algunas pelágicas de oligotrichos (Halteria spp., Tintinnidium fluviatile) y algunos prostomátidos (Askenasia sp., Monodinium sp., Holophrya sp., Urotricha sp., Litonotus sp.), con algunas similitudes a la composición de ciliados del río Rin (Scherwass \& Arndt, 2005; Weitere et al., 2005; Scherwass et al., 2010), del río Danubio (Kiss et al., 2009) del río Loire (Lair et al., 1999)y el Alto Paraná (Pauleto et al., 2009). La presencia de gran número de especies de ciliados bentónicos sería una característica propia de los grandes ríos (Kiss et al., 2009).

Al igual que en otros ríos de llanura, como el río Rin (Scherwass et al., 2010), se observaron mayores abundancias de ciliados en los tributarios que en el cauce principal del río Salado. En este sentido, el grupo se destacó por su abundancia en el arroyo y en el canal 2, en condiciones de aguas bajas y cálidas temperaturas, en acuerdo con los antecedentes en la cuenca (Neschuk et al., 2002b; Gabellone et al., 2014). Estos picos estuvieron dados por Epistylis sp1 en el arroyo, indicadora de contaminación con materia orgánica; y por el heterotrichio nanófago Blepharisma sp. (Scherwass \& Arndt, 2005) en el canal 2. Estos valores máximos de densidad del grupo fueron inferiores a los citados en otros ríos eutróficos, como el río Danubio (Kiss et al., 2009). La menor abundancia del grupo en el río Salado se observó en aguas altas y bajas temperaturas, al igual que en otros antecedentes de la cuenca (Gabellone et al., 2014) y del río Po (Rosetti et al., 2009). 
En el canal 1 y el arroyo se registró elevada abundancia de Vorticella spp., Stentor spp. y Epistylis spp., en particular en el arroyo, entre los cuales se observaron especies tolerantes a elevadas salinidades (Foissner et al., 1999); mientras que en el río se destacó Opercularia sp., con máxima presencia en los caudales medios de sept. 2009. Muchos de estos organismos se alimentan de las bacterias presentes en las aguas eutrofizadas con elevado contenido de materia orgánica (Lampert \& Sommer, 1997).

Representantes de Urotricha y Halteria se destacaron en las aguas eutrofizadas del sistema Bragado, en particular Halteria grandinella en el arroyo en aguas bajas. Ambos géneros son conocidos bacteriófogos de ambientes de agua dulce (Sanders et al., 1989; Weisse, 2002), aunque algunas especies de Halteria también pueden alimentarse de picoplancton (Šimek et al., 2000). Hipotrichios como Euplotes patela y Aspidisca sp. presentaron elevadas densidades en el sistema Bragado, en especial en el canal 3 en primavera, como en el río Rin (Scherwass \& Arndt, 2005).

Los tintínnidos no constituyeron los ciliados más abundantes, ni tampoco se destacaron como pastoreadores importantes del nanoplancton, en oposición a lo hallado en estudios previos en el río Salado inferior (Claps et al., 2009; Gabellone et al., 2014). De igual manera, Tintinnidium fluviatile estuvo ampliamente distribuida entre los sitios de muestreo, siendo una especie común en estuarios y en aguas salinas (Sanders, 1987), y particularmente en las costas bonaerenses, como el estuario del Río de La Plata (Gómez et al., 2009). En este sentido, la densidad máxima de la especie se registró en el canal 2 en caudales medios con 0,55 \%o de salinidad. Algunos géneros de ciliados comunes en el estuario de Bahía Blanca, también estuvieron presentes entre los sitios de muestreo, particularmente en los canales, como Strombidium y Strobilidium (Popovich et al., 2008).

En el sistema Bragado también se registraron elevadas abundancias de ciliados depredadores como Prorodon spp. y suctorios, particularmente Prorodon sp2 fue la especie dominante de la biomasa del zooplancton en el arroyo en aguas muy bajas (61\%). De esta forma, podrían estar controlando la abundancia de otros protozoos en estos sitios, a diferencia de lo observado en la cuenca del río Danubio, donde su presencia es despreciable (Scherwass \& Arndt, 2005).

\section{$\underline{\text { Rotíferos }}$}

Los rotíferos dominaron la abundancia, biomasa y riqueza de especies del zooplancton en los sitios estudiados, al igual que en otros ríos del mundo (Thorp et al., 1994; Marneffe et al., 1996; Lair \& Reyes-Marchant, 1997; Pourriot et al., 1997; Kobayashi et al., 1998; Burger et al., 2002; Nielsen et al., 2005; Thorp \& Mantovani, 2005; Lair, 2006; Rossetti et al., 2009), y en otros antecedentes en la cuenca (Neschuk, 2001; Neschuk et al., 2002a; Claps et al., 2009). Los rotíferos constituyen el 
componente más importante del potamoplancton, y se destacan por su capacidad de desarrollar grandes poblaciones en ambientes eutróficos, dados sus cortos tiempos generacionales y su habilidad reproductiva en condiciones óptimas (Admiraal et al., 1994; Ghadouani et al., 1998; Gosselain et al., 1998; Modenutti, 1998; Reckendorfer et al., 1999; Welker \& Walz, 1998).

Entre las familias presentes, las más importantes fueron Brachionidae y Lecanidae con 12 y 13 taxa, respectivamente. Entre éstas, las especies del género Brachionus son típicas de ambientes lóticos (Shiel et al., 1982), siendo también dominantes en otros ríos eutróficos (Lair \& ReyesMarchant, 1997; Kim et al., 2001) y asociadas a aguas salinas en áreas rurales (José de Paggi \& Devercelli, 2011). Por otro lado, la mayoría de los lecánidos presentes son considerados como de hábitos litorales (Shiel et al., 1982), eurihalinos o tolerantes de condiciones salinas (Segers, 1995), y su presencia en el plancton fue ocasional, tal como fuera observado por Neschuk et al., (2002b). La mayor riqueza de especies de rotíferos, y de Lecane en particular, se observó en el canal 2, donde su condición de humedal canalizado entre dos lagunas permanentes posiblemente favoreció la diversidad del grupo, al igual que de otras especies.

Los rotíferos registraron importantes valores de abundancia y biomasa total tanto en los tributarios como en el cauce del río, particularmente en aguas bajas, al igual que en otros ríos del mundo (Vásquez \& Rey, 1989; Kim et al., 2001; Thorp \& Mantovani, 2005; Rosetti et al., 2009). La contribución de los rotíferos a la abundancia total de zooplancton (hasta 94\% en el río aguas abajo), fue similar a la de otros ríos de llanura como el río Salado (Santa Fe) (95\%) (José de Paggi \& Devercelli, 2011) y el río Murray (Australia) (Shiel et al., 1982). Asimismo, en el río Orinoco (Vásquez \& Rey, 1989) y en ríos de pradera estadounidenses (97-99\%) (Thorp \& Mantovani, 2005). Por el contrario, en el río Rin (de Ruyter van Steveninck et al., 1992) los rotíferos registran bajas abundancias, aún en la época favorable (Ietswaart et al., 1999). En este sentido, se considera que existe una relación directa entre el tiempo de residencia del agua y la abundancia de los rotíferos en los grandes ríos (Viroux, 1997; Basu et al., 2000), la cual se suma al efecto de la temperatura sobre las tasas de crecimiento y la disponibilidad de alimento (Bass et al., 1997; Holst et al., 2002; Zimmermann-Timm et al., 2007; Burdis \& Hoxmeier, 2011).

Las especies de rotíferos que dominaron el zooplancton (Keratella tropica, Brachionus plicatilis, B. angularis, Synchaeta pectinata) son conocidas por sus amplios rangos de tolerancia a la salinidad y su afinidad por los ambientes eutróficos, siendo mencionadas como componentes importante del zooplancton en estudios previos en la cuenca (Neschuk, 2001; Neschuk et al., 2002a; Claps et al., 2009; Gabellone et al., 2014) y en otros ríos de llanura de Argentina (José de Paggi, 1984; José de Paggi \& Paggi, 1998; José de Paggi \& Devercelli, 2011). Además, Keratella tropica, Filinia longiseta y 
Brachionus calyciflorus son consideradas como indicadoras de mesosaprobios, siendo esta última muy poco abundante en este estudio, y de acuerdo a José de Paggi \& Paggi (1998), B. plicatilis y B. caudatus serían sus equivalentes ecológicos en ambientes más salinos.

Los rotíferos loricados como los brachiónidos fueron dominantes en el río, mientras que las formas de cuerpo blando como Trichocerca spp., Polyarthra spp., Filinia spp., Hexarthra fennica, bdelloideos, Synchaeta pectinata, Proalides spp., Proales spp., Asplanchna spp., fueron más importantes en los afluentes de los ambientes lénticos vinculados (sistema Bragado), en acuerdo con lo hallado en otros ríos de llanura (Spaink et al., 1998; Walz \&Welker, 1998; Lair et al., 1999; Lair, 2005, 2006; Zimmermann-Timm et al., 2007). Asimismo, experiencias de mesocosmos en el río Ohio determinaron que rotíferos como Brachionus y Keratella son beneficiados por la turbulencia del cauce principal (Sluss et al., 2008).

En condiciones de aguas altas y bajas temperaturas el zooplancton estuvo dominado por Keratella tropica, siendo una especie típica de ambientes eutróficos (Ghadouani et al., 1998) y tolerante a las variaciones de salinidad (José de Paggi \& Paggi, 1998), considerada como perenne en aguas del río Paraná (José de Paggi, 1984). Tal como fuera observado por Claps et al. (2009), la especie registró máxima abundancia en la época invernal, acompañando el pasaje de ambientes más eutróficos (canales) a menos eutróficos (río Salado). Asimismo, José de Paggi \& Deverelli (2011) destacan su presencia en los arroyos Saladillos (Santa Fe) en aguas altas con menores valores de conductividad.

Synchaeta pectinata también se destacó en aguas altas como subdominante del zooplancton en el canal 2 y como dominante en el canal 1 en caudales medios. Las especies del género son conocidas como típicamente limnéticas y tolerantes de la salinidad, siendo abundantes en ríos eutróficos como el río Salado (Santa Fe) (José de Paggi \& Paggi, 1998), el río Colorado (USA) (Speas, 2000) y algunos ríos europeos (Marneffe et al., 1996; Everbecq et al., 2001). Sus cortos tiempos generacionales, aún en bajas temperaturas, podrían haber favorecido su desarrollo en los canales en estas condiciones, otorgándole cierta ventaja competitiva frente a otras especies de rotíferos planctónicos presentes (Baranyi et al., 2002).

Brachionus plicatilis registró picos de abundancia en aguas bajas y cálidas temperaturas del agua $\left(24-33^{\circ} \mathrm{C}\right)$, siendo una especie típica de los meses de verano en la cuenca del río Salado (Claps et al., 2009). Por otro lado, Echaniz \& Vignatti (2011) y Echaniz et al., 2005 también hallaron máximo desarrollo de B. plicatilis en meses estivales (Diciembre) en lagunas con elevado tenor salino (El Prato y El Carancho, La Pampa). Esta especie es conocida por su tolerancia a la salinidad (José de Paggi \& Paggi, 1998; Shiel et al., 2006), y su abundancia estuvo correlacionada con la temperatura, 
la conductividad y el contenido de $\mathrm{Na}^{+}, \mathrm{K}^{+}, \mathrm{Cl}^{-}$y SO${ }_{4}=$. En acuerdo con estos resultados, Neschuk et al. (2002b) halló picos de densidad de la especie durante momentos de elevada conductividad en las aguas del río Salado.

Brachionus plicatilis dominó la abundancia del zooplancton total en la mayoría de las condiciones hidrológicas, aunque se destacó particularmente en el canal 2 en aguas bajas, alcanzando 34.800 ind/L (73\% del zooplancton total), con $19 \mathrm{mS} / \mathrm{cm}$ de conductividad y altas temperaturas del agua $\left(29^{\circ} \mathrm{C}\right)$. Hasta el momento no se conocen precedentes de abundancias tan elevadas de la especie en ambientes lóticos. Sin embargo, en la desembocadura del río Elbe se observaron 12.000 ind/L de Brachionus plicatilis, donde se consideró que la alta concentración de sales pudo haber favorecido su desarrollo (Holst et al., 2002). Además de las altas temperaturas y conductividades registradas, el bajo flujo de las aguas también pudo haber contribuido al crecimiento excepcional de la especie.

Brachionus angularis también se destacó como dominante del zooplancton en aguas bajas en el canal 3, el arroyo y el río aguas abajo (18.500 ind/L), y su abundancia estuvo correlacionada con la temperatura. Al igual que para B. plicatilis, su crecimiento se vio favorecido por las cálidas temperaturas, la disponibilidad de alimento y su tolerancia a los valores de salinidad (0,7-1\%o). En acuerdo con estos resultados, se ha mencionado a $B$. angularis como uno de los rotíferos más abundantes en el río Meuse durante la época favorable (Marneffe et al., 1996).

Brachionus pterodinoides y B. urceolaris se destacaron en el río en caudales medios (sept. 2009) con escaso aporte de los canales. A diferencia de lo hallado por Neschuk et al. (2002b), las especies presentaron picos de abundancia en valores medios de conductividad (5,6-6,7 $\mathrm{mS} / \mathrm{cm})$, estando prácticamente ausentes en los tributarios. De hecho, B. pterodinoides resultó como especie característica del río aguas arriba, donde la conductividad fue $<5,9 \mathrm{mS} / \mathrm{cm}$. En este sentido, Echaniz et al. (2005) observaron el máximo desarrollo de la especie en la laguna Los Manantiales (La Pampa) con contenido intermedio de sales ( $\mathrm{STD}=8,4 \mathrm{~g} / \mathrm{L}$ ).

Hexarthra fennica es una especie cosmopolita y de ambientes salinos (Shiel et al., 2006), característica del canal 3 donde registró máximas abundancias en aguas bajas y elevadas conductividades $(16,9 \mathrm{mS} / \mathrm{cm})$. Este canal es afluente de la laguna del Bragado, y en este sentido, Echaniz et al. (2005) destacaron la presencia de la especie en una laguna salina de La Pampa.

Notholca acuminata sólo estuvo presente en los canales en períodos de baja temperatura del agua y en bajas densidades $(<8,1$ ind/L). Estudios previos en la cuenca mencionan a la especie como típica de los meses de invierno (Neschuk et al., 2002a), al igual que en ríos de Santa Fe (José de Paggi \& Devercelli, 2011). 
Trichocerca pusilla se destacó por su abundancia en el canal 2 en caudales medios, siendo una especie indicadora de condiciones eutróficas, que se desarrolla en áreas lénticas vinculadas a los ríos (Welker \& Walz, 1998; Holst et al., 2002), y con un crecimiento poblacional relacionado a la temperatura (Reckendorfer et al., 1999; Zimmermann-Timm et al., 2007).

En el canal 2 también fueron relevantes varias especies de Proalides, Cephalodella y Encentrum, siendo especies típicas de zonas lénticas y epibénticas de ríos australianos (Ning et al., 2010). Filinia terminalis y F. longiseta también se destacaron por su abundancia en el canal 2 y en el río en caudales medios (verano tardío), siendo especies cosmopolitas (Shiel et al., 1982), de hábitos limnéticos (Speas, 2000) y típicas de ambientes eutróficos (Ghadouani et al., 1998).

La presencia de los rotíferos depredadores como Asplanchna spp. (A. brightwellii, A. girodi, Asplanchna sp.) pareciera estar relacionada a los picos de abundancia de Keratella tropica en el canal 1 en aguas altas, y de Brachionus angularis en el canal 3 en aguas bajas. Este último sitio constituye un importante efluente de la laguna del Bragado, y en este sentido, los asplánchnidos son conocidos como rotíferos abundantes en ambientes lénticos (Picard \& Lair, 2005; Lair, 2006)

\section{Copépodos}

Los copépodos hallados en todos los sitios de muestreo pertenecen a especies ubicuas tanto de ambientes lóticos como lénticos (Claps et al., 1997). Los estadios larvales de nauplii comprendieron la mayor parte de la abundancia del grupo en los diferentes sitios de muestreo y condiciones hidrológicas, tal como lo observado en otros ríos (Vásquez \& Rey, 1989; Kim et al., 2001; Casper \& Thorp, 2007; Rossetti et al., 2009). Sus picos de densidad se observaron en la época favorable, particularmente en el canal 2, influenciando el río aguas abajo del trasvase. En el río, el máximo desarrollo del grupo coincidió con los períodos de caudales medios (verano tardío), en acuerdo con las observaciones de Gosselain et al. (1998) en el río Meuse. La abundancia y biomasa total de los copépodos estuvo correlacionada con el pH y la turbidez, al igual que la abundancia de los copepoditos y el cyclopoideo dominante Acanthocyclops robustus, pero sin embargo, se desconocen los motivos de esta relación aparente.

Entre los copépodos presentes predominaron los cyclopoideos, siendo Acanthocylops robustus la especie más conspicua, estando ampliamente distribuida, al igual que en el río Danubio (VadadiFülöp et al., 2009). En otros ríos de llanura, como el río Meuse, también se han reportado elevadas densidades de copépodos cyclopoideos (Marneffe et al., 1996). Metacyclops mendocinus es una especie ubicua y endémica de la región neotropical (José de Paggi \& Paggi, 2007; Silva, 2008), siendo un componente habitual del plancton en ríos eutróficos de Santa Fe (José de Paggi \& Paggi, 
1998). Paracyclops fimbriatus fue poco abundante y estuvo restringido al río, coincidiendo con su naturaleza de especie de hábitats litorales, asociada a la vegetación o los sedimentos (Speas, 2000).

Notodiaptomus incompositus constituyó el copépodos calanoideo más abundante, siendo una especie endémica de la región (José de Paggi \& Paggi, 2007; Silva, 2008). El otro copépodo calanoideo presente, Boeckella poopensis, sólo se halló en el canal 1, en muy bajas densidades y con salinidades de 0,8-1\%. Se trata de una especie típica de ambientes salinos, cuya distribución geográfica es bastante amplia y se extiende desde el norte de la Patagonia hasta el sur de Perú (Menu-Marque et al., 2000; Locascio de Mitrovich et al., 2005). Asimismo, Echaniz \& Vignatti (2011) destacan la presencia de B. poopensis durante el verano en lagunas mesosalinas hipereutróficas del norte de La Pampa.

El copépodo harpacticoideo Cletocamptus deitersi es una especie ticoplanctónica y típica de ambientes salinos, también considerada como cosmopolita, pero dada su alta variabilidad morfológica puede que su amplia distribución se deba a especies crípticas (Gómez et al., 2004; Echaniz et al., 2005). Su pico de abundancia en el canal 2 (caudales medios) puede relacionarse con las características de humedal canalizado de este ambiente y al aporte de la laguna Municipal. En el río Salado, la especie también se destacó en caudales medios de verano tardío, en acuerdo con otros antecedentes en la cuenca (Gabellone et al., 2014).

\section{Cladóceros}

Entre los cladóceros dominaron las especies de pequeña talla de distribución restringida a la región Neotropical (Paggi, 1979; Sinev, 2001). Aún cuando las aguas de los sitios analizados son turbias, siendo un factor limitante para su desarrollo, en los ríos australianos también se ha detectado la presencia del grupo aún en aguas con mayores valores de turbidez (Shiel et al., 1982). La abundancia y riqueza de las especies de cladóceros hallada fue inferior a la registrada en otros ríos, en particular en comparación a aquellos regulados, donde los embalses contribuyen en gran medida a la distribución del grupo aguas abajo (Dickerson et al., 2010).

En el río, particularmente aguas arriba, se observaron valores máximos de abundancia, biomasa y riqueza de especies de cladóceros en caudales medios (verano tardío), en acuerdo con otros estudios en la cuenca (Neschuk et al., 2002b) y de otros ríos del mundo (Gosselain et al., 1998a). Por el contrario, en el sistema Bragado los cladóceros se destacaron en condiciones de aguas altas, con la prevalencia de Daphnia spinulata y D. obtusa en el canal 1 y de Ceriodaphnia cf. dubia en el canal 2 y el arroyo. La mayor conectividad registrada en aguas altas seguramente propició la incorporación de estos organismos desde los ambientes lénticos vinculados, tal como lo observado 
en otros ríos del mundo (Pourriot et al., 1997; Akopian et al., 1999). Esto se opone a lo observado en el río regulado Nakdong donde los cladóceros de pequeño tamaño aparecen en el cauce principal en condiciones de flujo lento y mayores tiempos de residencia (Kim et al., 2012).

Ambas especies de Daphnia registraron valores máximos de abundancia y biomasa en el canal 1 en aguas altas con moderada conductividad $(10 \mathrm{mS} / \mathrm{cm})$, con el predominio de Daphnia spinulata, siendo un dáfnido típico de ambientes salinos en la Provincia (Claps et al., 2009). Daphnia obtusa estuvo ampliamente distribuida, aunque en bajas densidades. Se considera que 2 o 3 especies de Daphnia pueden aparecer en un mismo sitio, debido a una posible diferenciación del hábitat, del tipo de alimentación o de su respuesta frente a los depredadores. En este sentido, Daphnia obtusa podría alimentarse de partículas del fondo mediante movimientos en sus apéndices (Segers, 1995), a diferencia de $D$. spinulata, lo que podría permitir su coexistencia. En acuerdo con estos resultados, se considera que la presencia de especies de Daphnia en los grandes ríos depende de su introducción desde los ambientes lénticos vinculados durante los períodos de aguas altas, o desde efluentes de lagos, lagunas o embalses (Segers, 1995).

El río presentó como cladóceros característicos a especies de hábitos bentónicos y litorales como Alona spp. y los dáfnidos Moina micrura y Simocephalus sp., también comunes en otros ríos del mundo, y asociados a la vegetación ribereña (Burdis \& Hoxmeier, 2011). Entre las especies de quidóridos presentes, Alona rectangula es cosmopolita y Alona glabra se encuentra restringida a la región Neotropical (Paggi, 1979; Sinev, 2001). Simocephalus sp. estuvo restringida al río y en aguas altas, siendo un género típico de áreas de bajo flujo y de zonas litorales-bentónicas donde crecen y se reproducen (Dickenson et al., 2010), por lo que su presencia estuvo relacionada con la mayor conexión con estos ambientes adyacentes (Lair, 2006). En este sentido, Viroux (2002) concluyó que los cladóceros bentónicos son los más sensibles al aumento de las descargas de caudal, siendo incorporados al cauce durante estos eventos. Otros cladóceros que sólo estuvieron presentes en el río, y en muy bajas densidades, fueron Diaphanosoma birgei (aguas arriba) y Leydigya louisi (aguas abajo). Entre éstos, las especies de Diaphanosoma son habituales en otros ríos del mundo, y también en bajas abundancias (Kim et al., 2001; Burdis \& Hoxmeier, 2011).

Moina micrura registró máximo desarrollo en el río en aguas bajas, particularmente en el río aguas arriba, siendo también importante en el río Po en la época favorable (primavera-verano) (Rossetti et al., 2009) y en ríos de Santa Fe (José de Paggi \& Paggi, 1998; Rojas Molina \& José de Paggi, 2008). La presencia del género es habitual en otros ríos de llanura (Kim et al., 2001; VadadiFülöp et al., 2009) y es conocido por su tolerancia a la elevada turbidez y a la concentración de SS (Wahl et al., 2008), como los observados en el río Salado en estas condiciones. 


\section{Ostrácodos}

Entre los ostrácodos presentes se hallaron Cypridopsis vidua y Heterocypris incongruens, y a pesar de estar bien distribuidas entre los sitios de muestreo, se destacaron por su abundancia en el río, con máximos valores aguas abajo en condiciones de aguas bajas; posiblemente asociado a una mayor relación con el lecho del río y la comunidad del bentos. Entre estas especies, Cypridopsis vidua se encuentra ampliamente distribuida, siendo común en humedales del río Oglio (Italia) (Rossetti et al., 2004).

\subsubsection{Diversidad del zooplancton}

Los elevados valores de diversidad del zooplancton observados en el canal 1 (aguas muy bajas) y en el arroyo (aguas altas) estuvieron relacionados a un gran desarrollo de los ciliados. Este fenómeno posiblemente se deba a la influencia de las ciudades aledañas, como el vertido de efluentes con alta carga de materia orgánica, particularmente en el arroyo (planta de tratamiento de efluentes cloacales de Bragado). El considerable aumento de los SS, la MOP y los nutrientes, sumados al déficit de OD, promueven la proliferación bacteriana (Marneffe et al., 1996), siendo otra fuente de recursos para el zooplancton. Estos resultados se oponen a lo hallado por José de Paggi y Paggi (1998) en ríos de Santa Fe, donde hubo una relación inversa entre el nivel trófico y la riqueza de especies y diversidad de zooplancton, debido a la dominancia de unas pocas especies tolerantes a esas condiciones, y a la disminución de las más sensibles.

En general, se observó que el río aguas abajo del trasvase presentó mayores valores de diversidad de zooplancton que el sitio aguas arriba, posiblemente relacionado a la incorporación de especies desde el sistema Bragado. Sin embargo, el rango de valores entre muestreos fue máximo en el río aguas abajo, en comparación a los restantes sitios, y en particular si se lo compara con el sitio aguas arriba. De todos modos, ambos sitios del río coincidieron en que la diversidad fue mínima en aguas bajas y que los valores máximos se hallaron en caudales medios (sept. 2009) con escaso aporte de los canales. En este sentido, la variedad de hábitats presentes en el río influencian la diversidad de especies del zooplancton, en particular por la incursión de organismos de otras comunidades (Shiel et al., 1982). Por otro lado, el canal 2 constituyó el sitio con la menor variación en la diversidad entre muestreos, y los valores mínimos hallado estuvieron relacionados a la explosión demográfica de Brachionus plicatilis y B. angularis en aguas bajas. Su característica de humedal canalizado y al continuo aporte de la laguna Municipal, podría haber colaborado a una mayor estabilidad ambiental, heterogeneidad espacial y variedad de hábitats presentes, que en su conjunto promueven el desarrollo del zooplancton (Lair, 2006). 


\subsection{Reproducción del plancton}

\subsubsection{Reproducción del fitoplancton}

El canal 2 fue el sitio con mayor riqueza acumulada de especies de fitoplancton en reproducción (17 taxa), seguido por el río (13 taxa c/u). En el arroyo sólo se observaron 4 especies en reproducción a lo largo de los muestreos, y valores intermedios en los canales 1 y 3 . Las condiciones de humedal canalizado y su vinculación a lagunas permanentes pueden haber colaborado a la presencia de un mayor $\mathrm{n}^{\mathrm{o}}$ de especies en reproducción en el canal 2. En aguas altas, el $\mathrm{n}^{\circ}$ de especies en reproducción fue máximo en los canales 1 y 2 (12-13 taxa), posiblemente relacionado con una mayor conectividad hidrológica y la afluencia desde ambientes lénticos vinculados, de donde se incorporan los inóculos. En el arroyo no se observaron especies de fitoplancton en reproducción en aguas bajas ni muy bajas, coincidiendo con su desvinculación del sistema por la construcción del vertedero en sus nacientes (laguna del Bragado).

En aguas altas no se observaron estructuras de resistencia o de propagación en ninguno de los sitios de muestreo, probablemente asociado a la homogeneización del ambiente y a las bajas temperaturas. Los acinetos estuvieron restringidos al sistema Bragado en caudales medios, aguas bajas y muy bajas, siendo estructuras de resistencia que les permiten a las cianobacterias sobrevivir durante la época desfavorable (Zalocar de Domitrovic \& Forastier, 2005). Por otro lado, se observaron auxosporas en aguas bajasy muy bajas, donde la menor profundidad de la columna de agua pudo haber colaborado en la resuspensión de estas estructuras de resistencia desde el cauce de los canales y el río. En este sentido, la producción de propágulos regenerativos representa un aspecto adicional en la supervivencia del fitoplancton, promoviendo su restablecimiento al momento de instaurarse las condiciones favorables para el crecimiento (Raven \& Richardson, 1984; Reynolds, 1988a), observadas en las otras condiciones hidrológicas.

\subsubsection{Reproducción del zooplancton}

La reproducción del zooplancton tuvo lugar principalmente en el canal 2, donde se registraron los valores máximos de riqueza acumulada de especies en reproducción ( 25 taxa), de abundancia de $q$ ovígeras, de huevos totales portados por $q$ y $\mathrm{n}^{\mathrm{o}}$ total de huevos libres en la muestra. Este notable desarrollo del zooplancton reproductivo tuvo implicancias en el río aguas abajo del trasvase, donde se observó un gran incremento en el contenido de huevos y de $q$ ovígeras. De esta forma el sistema Bragado constituye una importante fuente de inóculos para el río, los cuales son importados desde los humedales y ambientes lénticos vinculados, tal como lo observado en otros ríos de llanura (Welker \& Walz, 1998; Burdis \& Hoxmeier, 2011). 
En aguas altas se observaron los valores mínimos de egg ratio (n⿳o promedio de huevos por hembra ovígera) de rotíferos, cladóceros y copépodos en todos los sitios de muestreo, mientras que los máximos se registraron en aguas bajas o en caudales medios. Algunos autores (Saunders \& Lewis, 1989; Reckendorfer et al., 1999), también hallaron una relación inversa entre el egg ratio de diferentes especies y la velocidad de corriente, y se reconoce que las altas descargas de caudal tienen efectos negativos sobre la reproducción del zooplancton (Baranyi et al., 2002). Además, se trata de organismos poiquilotermos, donde su tiempo de desarrollo depende en gran medida de la temperatura del agua (Lehman, 1988), y en este sentido, los valores máximos de egg ratio se observaron en temperaturas del agua entre 24 y $33^{\circ} \mathrm{C}$.

Los huevos de resistencia de los rotíferos y los efipios de los cladóceros les permiten subsistir en un ambiente hostil, hasta tanto se restablezcan las condiciones favorables, a la vez que constituyen importantes dispositivos de propagación (Schröeder, 2001). Estas estructuras de resistencia generalmente se producen por un disparador externo, como puede ser un cambio abrupto en las condiciones físicas, la falta de alimento o por causas demográficas (excesivo crecimiento poblacional) (Lehman, 1988; Schröeder, 2001). En este sentido, el máximo desarrollo de las estructuras de resistencia se observó en aguas bajas, con picos de abundancia de rotíferos con huevos de resistencia en formación (río aguas abajo) o libres en las muestras (canal 2). Lo mismo se observó con la distribución de los efipios de Daphnia, mientras que los efipios de Alona se registraron particularmente en el río aguas arriba. Por otro lado, en aguas altas se observaron algunos pocos efipios de Daphnia y Alona en los canales.

El rotífero dominante, Brachionus plicatilis, se reprodujo preferentemente en el canal 2 y en el río aguas abajo del trasvase del sistema Bragado. En aguas bajas (nov. 2008), se observaron en el canal 2 los valores máximos de abundancia total y de 9 ovígeras $(12.400 \mathrm{ind} / \mathrm{L}, 36 \%$ del total) de la especie, posiblemente asociado a las cálidas temperaturas del agua $\left(24-33{ }^{\circ} \mathrm{C}\right)$ registradas. En este muestreo, las $q$ ovígeras registraron de 1 a 7 huevos en el canal 2, con un egg ratio de 1,15. Sin embargo, el valor máximo de egg ratio de la especie (2 huevos promedio por hembra ovígera) se observó en el río aguas abajo en esta misma ocasión, con un considerable aumento respecto al sitio aguas arriba. Estos valores de egg ratio son superiores a los hallados para los rotíferos del río Krutynia (Polonia) y sus lagos asociados $(<0,4)$ (Hillbricht-Ilkowska, 1999). Por otro lado, la mínima reproducción de $B$. plicatilis se observó en aguas altas con temperaturas $<13^{\circ} \mathrm{C}$. Asimismo, fue la única especie que presentó huevos de resistencia en todos los sitios de muestreo, aunque en mayor medida en aguas bajas. Otras especies de rotíferos como Brachionus angularis, B. calyciflorus y Polyarthra spp. no registraron poblaciones estables a lo largo de los muestreos, siendo conocidas 
por utilizar los períodos favorables de disponibilidad de recursos y baja competencia para generar poblaciones de rápido crecimiento, presentando una estrategia de reproducción oportunista y con posterior dispersión (Schröeder, 2001).

La mayor parte de las especies de rotíferos en reproducción registraron los valores máximos de abundancia relativa de $q$ ovígeras (\% de la abundancia total) en los muestreos de caudales medios y aguas bajas, siendo la época favorable de crecimiento y con temperaturas más cálidas. Entre éstas especies $B$. angularis se destacó por su abundancia total, de $q$ ovígeras, de huevos de resistencia en formación y libres en las muestras en el río aguas abajo, en condiciones de aguas bajas y temperaturas cálidas, que en su conjunto favorecieron su crecimiento y desarrollo, al igual que en el río Rin (Reckendorfer et al., 1999). De esta forma, resulta evidente que bajo condiciones favorables, la reproducción de los rotíferos puede generar poblaciones muy numerosas, con abundancias totales comparables a las reportadas en ambientes lénticos (Holst et al., 2002).

Los cladóceros presentaron los valores máximos de abundancia de $q$ ovígeras en el río y en aguas bajas, tal como lo observado en el río Orinoco (Vásquez \& Rey, 1989). Entre las especies presentes, Moina micrura, Daphnia obtusa y Simocephalus sp. sólo registraron $q$ ovígeras en el río Salado y en caudales medios. Por otro lado, Daphnia spinulata sólo presentó $q$ ovígeras en los canales 1 y 2 en aguas altas, lo que podría estar relacionado a su procedencia desde las lagunas vinculadas. El ingreso de $q$ ovígeras de cladóceros desde lagos asociados ha sido documentado para el río Krutynia (Polonia) (Hillbricht-Ilkowska, 1999).

Entre los cladóceros, Moina representa el género mejor adaptado al ambiente fluvial por su habilidad de explotar hábitats transitorios de manera eficiente, a diferencia de Daphnia, que requiere de condiciones ambientales más estables para su crecimiento y reproducción (Reynolds, 2003). Los quidóridos Alona glabra y A. rectangula se reprodujeron en el sistema Bragado y en el río, aunque la abundancia de las $q$ ovígeras fue máxima en el río aguas arriba en aguas bajas. En el río St. Lawrence se ha observado mayor proporción de $q$ ovígeras de cladóceros en áreas de aguas estancadas con menor velocidad de corriente (Casper \& Thorp, 2007).

Los copépodos presentan una reproducción sexual obligada y por lo tanto necesitan de ambientes más estables que permitan el apareamiento a lo largo del año (Lair, 2006), como las lagunas permanentes de la zona (Municipal y del Bragado). Este requerimiento biológico podría explicar la elevada abundancia de las larvas nauplii en los canales 2 y 3, siendo canales efluentes de estas lagunas, y en el río aguas abajo del trasvase, particularmente en primavera. La mayoría de las especies de copépodos presentes registraron $q$ ovígeras tanto en el sistema Bragado como en el río. Sin embargo, los valores máximos de abundancia total de estas $q$ ovígeras se observaron en el 
río en caudales medios y aguas bajas, dados principalmente por Acanthocyclops robustus. En este sentido, Viroux (2002) propone la hipótesis de las poblaciones residentes para explicar los picos de abundancia de copépodos hallados en el río Meuse, tal como podría aplicarse en este caso. Asimismo, la gran heterogeneidad de hábitats físicos presentes pueden haber influenciado en la dinámica del zooplancton como sitios de reproducción para los copépodos, como lo observado en el río Loire (Picard \& Lair, 2005)

En aguas altas, la distribución de las $q$ ovígeras de cladóceros y de copépodos estuvo restringida a los canales, situación que pudo estar relacionada a la disponibilidad de nutrientes y de fitoplancton en estos sitios, sumado a la mayor conectividad con las lagunas que drenan. Por otro lado, las mayores velocidades de corriente del río posiblemente actuaron como factores limitantes para el zooplancton (Baranyi et al., 2002), a la vez que la mayor descarga de caudal diluyó el fitoplancton presente, siendo la falta de alimento otro de los factores que afectan negativamente el éxito reproductivo del zooplancton (Wahl et al., 2008).

El río Salado, además de recibir inóculos desde el sistema Bragado, también presentó condiciones apropiadas para el desarrollo y la reproducción del zooplancton, como sucede habitualmente en ríos de otras regiones (Lair \& Reyes-Marchant, 1997; Reckendorfer et al., 1999; Lair, 2006; Wahl et al., 2008). La configuración más natural de las márgenes, particularmente en el sitio aguas arriba, la presencia de zonas de almacenamiento, áreas con baja velocidad de corriente dentro del cauce, y los ambientes asociados de la planicie de inundación, podrían haber actuado como potenciales refugios para el crecimiento y la reproducción del zooplancton, en acuerdo con otros autores (Hynes, 1970; Reckendorfer et al., 1999; Picard \& Lair, 2005; Vadadi-Fülöp et al., 2009).

En este sentido, estas conexiones laterales, importantes en el río y en el canal 2, resultan críticas para los organismos acuáticos que utilizan los hábitats presentes en el cauce principal, en la planicie de inundación y la vegetación ribereña durante los diferentes estadios de su ciclo de vida (Bunn \& Arthington, 2002). De esta forma, la conectividad con los ambientes adyacentes provee de una ruta eficiente de dispersión, incrementando la probabilidad de incorporación de nuevas especies al río aguas abajo (Tablas 15 y 21, Anexo III), tal como pudo observarse en el río Paraná (Bini et al., 2003). Además, de la emergencia de organismos desde los bancos de huevos (Gyllstrom \& Hansson, 2004) y el transporte fluvial o aéreo (Wetzel, 2001), para algunos autores la reproducción del zooplancton también tiene lugar dentro del propio cauce de los ríos (Thorp et al., 1994; Viroux, 2002; Casper \& Thorp, 2007). Tal sería la condición del río Salado, sumado a los aportes de inóculos que recibe de los tributarios y de los ambientes lénticos vinculados (sistema Bragado). 


\subsection{Relaciones tróficas entre el fito y zooplancton}

En todos los sitios de muestreo y condiciones hidrológicas, la biomasa y abundancia del fitoplancton estuvo dominada por el plancton de red (microplancton), al igual que lo observado en el río Paraná (García de Emiliani, 1997). En el río Salado, los picos de biomasa del microplancton se observaron en caudales medios (marzo 2008) coincidiendo con el máximo desarrollo de la biomasa del zooplancton, en acuerdo con Gosselain et al (1998a).

La biomasa total del zooplancton fue siempre inferior a la biomasa total del fitoplancton y de las fracciones algales del micro y nanoplancton en todos los sitios de muestreo y condiciones hidrológicas, a excepción del canal 2 en aguas bajas y muy bajas. En tales situaciones, la biomasa total del zooplancton pastoreador superó a la biomasa de las algas nanoplanctónicas y a la fracción palatable que la integran (diatomeas centrales, criptofitas y clorofitas), debido a una importante presión de pastoreo por parte de Brachionus plicatilis y de las larvas nauplii, respectivamente.

En los ríos templados, sólo se detecta un control top-down sobre el fitoplancton cuando las condiciones ambientales son favorables para el crecimiento del zooplancton. Esta interacción está regulada por los herbívoros de pequeño tamaño (Gosselain et al., 1998b), tal como se observó en el canal 2 durante una explosión demográfica de Brachionus plicatilis en aguas bajas, y de larvas nauplii en aguas muy bajas. Las cálidas temperaturas del agua, los bajos flujos y el aumento del tiempo de residencia permitieron el desarrollo del zooplancton, junto a una mayor disponibilidad de recursos y de algas palatables capaces de sostener la elevada biomasa observada en este sitio.

En este sentido, se reconoce que el zooplancton pastoreador puede ejercer cierto control sobre la biomasa del fitoplancton en condiciones de bajos caudales y temperaturas estivales, donde los rotíferos, los cladóceros de pequeño tamaño y los estadios tempranos de copépodos (larvas nauplii) son abundantes (de Ruyter van Steveninck et al., 1992; Admiraal et al., 1993; Garnier et al., 1995, Köhler 1995; Rossetti et al., 2009) sugieren. Asimismo, en el río St. Lawrence la presencia de larvas nauplii generó una importante presión de pastoreo sobre el fitoplancton en áreas de aguas estancadas y zonas de almacenamiento (Casper \& Thorp, 2007). De modo que las interacciones bióticas sólo se destacaron en el canal 2 cuando las limitaciones físicas fueron aliviadas, en acuerdo con lo observado en el río Meuse (Gosselain et al., 1994, 1998a), en el río Rin (Ietswaart et al., 1999), en ríos del Reino Unido (Reynolds, 2000), y en el río Danubio (Schagerl et al., 2009).

En el río Salado no se detectó un efecto top-down, y el pastoreo del zooplancton no fue efectivo en el control de la biomasa algal en ninguna de las condiciones hidrológicas analizadas, dado que la estructura y dinámica de la comunidad del zooplancton estuvo básicamente regulada por las condiciones hidrológicas y por las características biológicas propias de los grupos presentes; y sólo 
secundariamente estuvieron involucradas las interacciones (Kim et al., 2001). Esto podría deberse a las restricciones ejercidas por los parámetros físicos sobre el zooplancton, y a la frecuente dominancia de los rotíferos, que aunque son herbívoros eficientes, su tasa de consumo es muy inferior a la registrada para cualquier microcrustáceo. En este sentido, el rol de los pastoreadores como factor regulador de la biomasa del fitoplancton fue poco importante, tal como lo observado en otros ríos eutróficos (Garnier et al., 1995; Basu \& Pick, 1997; José de Paggi \& Paggi, 2007) y en estudios previos en la cuenca (Gabellone et al., 2014).

Las interacciones bióticas de autoregulación (competencia y depredación) aparecieron junto con la presencia de elevadas densidades de zooplancton, particularmente de rotíferos (Hynes, 1970) y asociado a los períodos de bajos caudales (Reynolds, 1992; Gosselain et al., 1994) donde los parámetros físicos como la velocidad de corriente, las pérdidas por advección, turbulencia o turbidez se ven disminuidos (Baranyi et al., 2002; Zimmermann-Timm et al., 2007). Sin embargo, se reconoce que la presión de pastoreo no es una fuerza constante, sino que varía en el tiempo en función de la estación climática y del ensamble de especies de pastoreadores presentes (Lehman, 1988). En este sentido, el control top-down del zooplancton sólo ha sido observado en los ambientes lóticos por cortos intervalos de tiempo (Lair et al., 1999; Lair, 2005; Picard \& Lair, 2005; Rossetti et al., 2009; Bertani et al., 2012). Por otro lado, estudios recientes en sistemas lóticos pampeanos reconocen el incremento en las relaciones top-down como respuesta al enriquecimiento con nutrientes, y destacan la complejidad y compartimentalización de las relaciones tróficas en estos ambientes, siendo capaces de amortiguar los efectos de la eutrofización (Artigas et al., 2013).

Entre los ciliados herbívoros se destacaron Strombidium spp. y Strombilidium caudatum en el canal 2 en aguas bajas, siendo esta última especie característica de este sitio, con $230 \mu \mathrm{g}$ C/L de biomasa. Se considera que los protozoos pueden generar una presión de pastoreo importante aún en biomasa $<100 \mu \mathrm{g} \mathrm{C/L}$ (Garnier et al., 1995), y particularmente en sectores de escasa profundidad de la columna de agua (Kobayashi et al., 1996). En el río, los protozoos herbívoros no constituyeron los consumidores más importantes del fitoplancton en esta ocasión, en oposición a estudios en la cuenca inferior del río Salado (Gabellone et al., 2014), y de otros ríos del mundo (Kiss et al., 2009).

Los rotíferos, como principales componentes del zooplancton, también regulan la abundancia de microalgas en los períodos de aguas bajas del río Danubio (Keckeis et al., 2003) y contribuyen a la pérdida de especies de clorofitas clorococcales y de diatomeas centrales planctónicas (Stephanodiscus hantszchii, Cyclotella glomerata, C. meneghiniana) en otros ríos europeos (Gosselain et al., 1994; Reynolds \& Descy, 1996), tal como lo observado en este estudio. 
Los cladóceros como Daphnia spinulata y D. obtusa, se observaron en el canal 1 en aguas altas y hacia la época invernal, en acuerdo con la tendencia general hallada por Gabellone et al. (2014) en la cuenca inferior del río Salado. Sin embargo, su relevancia fue menor y tampoco se observó un control del zooplancton pastoreador sobre la biomasa del nanoplancton palatable. En este sentido, se considera que los cladóceros no ejercen una influencia significativa sobre la estructura y biomasa del fitoplancton en los ríos, dada su menor abundancia y su persistencia limitada por los cortos tiempos de residencia (de Ruyter van Steveninck et al., 1992; Pace et al., 1992; Thorp et al., 1994; Marneffe et al., 1996; Pourriot et al., 1997; Gosselain et al., 1998a).

Se cree que en los ríos el zooplancton herbívoro es altamente específico al tamaño de partícula, y que el efecto de su pastoreo se concentra en algas unicelulares de clorofitas, diatomeas, criptofitas, y algunos otros flagelados de pequeño tamaño (Lehman, 1988). Por lo tanto, su dinámica depende de la abundancia y composición de las especies palatables y de las interacciones entre ambas comunidades (Gosselain et al., 1998b). De esta forma, la selectividad de los pastoreadores afecta el balance competitivo entre las diferentes especies de algas presentes, y si el pastoreo es selectivo, las poblaciones de cianobacterias no son consumidas, incrementado consecuentemente su abundancia (Scheffer \& Rinaldi, 2000). Este fenómeno pudo comprobarse claramente en los diferentes sitios de muestreo en la época favorable de aguas bajas y caudales medios con la dominancia de cianobacterias filamentosas o coloniales (e.j. Aphanocapsa incerta, Geitlerinema amphibium, Raphidiopsis mediterranea, Sphaerospermopsis aphanizomenoides, Planktolyngbya minor, P. limnetica). Los incrementos en el microplancton por la presión de pastoreo del zooplancton, y los florecimientos algales de cianobacterias filamentosas también son habituales en el río Meuse durante los bajos caudales de verano (Gosselain et al., 1998a). Tal como se reconoce en los ríos australianos, puede que los rotíferos consuman la fracción más pequeña del fitoplancton en estas condiciones (Kobayashi et al., 1996).

Además, los rotíferos parecen no estar afectados por la presencia de algas filamentosas, obteniendo una ventaja competitiva frente a los dáfnidos, de mayor tamaño y capacidad filtradora, que sí resultan susceptibles a la presencia de estas cianobacterias (Scheffer \& Rinaldi, 2000; Burger et al., 2002). En este sentido, Kirk (1991) sugirió que la mayor selectividad de los rotíferos en sus hábitos alimenticios les otorga ciertas ventajas competitivas en las aguas turbias, dado que su alimentación no se ve interferida por las partículas no digeribles, como sucede con los cladóceros. Por otro lado, Ghadouani et al. (2003) demostraron por experiencias in situ que un incremento en la abundancia de las cianobacterias (filamentosas y coloniales) afecta considerablemente la estructura de la comunidad del zooplancton, provocando la pérdida de los cladóceros en el corto plazo 
(pocas semanas). De acuerdo a otros autores, algunos rotíferos también pueden pastorear algas de mayor tamaño (Walz, 1995) e incluso algunas filamentosas (Kobayashi et al., 1996); pero según Bogdan \& Gilbert (1984) no existe una relación directa entre el largo del cuerpo del organismo y el tamaño máximo de partículas de alimento que pueda digerir.

Las especies de Brachionus son consideradas como generalistas filtradores de pequeñas partículas, pero selectivas del tamaño. Se reconoce que B. angularis ingiere esferas de $6 \mu \mathrm{m}$ de manera casi exclusiva, mientras que B. calyciflorus prefiere aquellas de $12 \mu \mathrm{m}$ y el diámetro óptimo de B. plicatilis es de 8,3 $\mu$ m (DeMott, 1986; Rothhaupt, 1990; Kobayashi et al., 1996; Hansen et al., 1997), mientras que para Keratella sería <10 $\mu$ m (Sládeček, 1983). En estos tamaños celulares se encuentran las clorofitas clorococcales y algunas diatomeas centrales de pequeño tamaño, además de los flagelados heterótrofos y otros componentes de la cadena trófica microbiana (Lair et al., 1999). De esta forma, la co-dominancia de varias especies de rotíferos sería posible debido a su capacidad de alimentarse de partículas de diferente tamaño, evadiendo la competencia por los recursos (Shiel, 2002). Tal sería el caso de los rotíferos dominantes hallados en el canal 2 en las diferentes condiciones hidrológicas: K. tropica y Synchaeta pectinata en aguas altas, B. plicatilis y B. angularis en caudales medios y aguas bajas, B. plicatilis y K. tropica en aguas muy bajas. En este sentido, José de Paggi \& Paggi (1998) también hallaron la asociación entre B. plicatilis y K. tropica en el río Salado (Santa Fe) en el mes de Septiembre, al igual que en este estudio. Por otro lado, Stelzer (1998) pudo determinar que Synchaeta pectinata es mejor competidor en aguas con temperaturas $<16^{\circ} \mathrm{C}$, como se observó en el muestreo de aguas altas.

También se ha demostrado que especies emparentadas de rotíferos pueden co-existir dividiendo la fuente del alimento según sus tamaños corporales y de partículas (Bogdan \& Gilbert, 1984), como sería el caso de B. plicatilis y B. angularis. Además, B. plicatilis presentó morfotipos S y L, particularmente en la época favorable, con una importante variación en el tamaño de cada ejemplar promedio (0,15-0,17 y 0,36-0,43 $\mu \mathrm{g}$ C/L de biomasa, respectivamente). En este sentido, la distribución de los morfotipos S y L también podría entenderse como una estrategia poblacional en la partición de los recursos. Además, las características particulares del canal 2 permitirían una mayor productividad del ambiente y variedad en las fuentes de alimento para el zooplancton. Los humedales se caracterizan por una alta heterogeneidad espacial, la cual genera un efecto de aislación parcial de los hábitats en parches, permitiendo la co-existencia de especies y la presencia de múltiples osciladores depredadores-presa (pastoreadores-algas) (Scheffer \& Rinaldi, 2000).

El microzooplancton, y el zooplancton en general, pueden tener variados recursos alimenticios, como el fitoplancton, los flagelados heterótrofos, los protozoos, detritos y la biomasa bacteriana 
(Sládeček, 1983; Gilbert \& Jack, 1993; José de Paggi \& Paggi, 1998; Everbecq et al., 2001). Los protistas fagótrofos son conocidos consumidores de bacterias, pero también pueden competir por las diferentes clases de tamaño del fitoplancton con el meso y macrozooplancton herbívoro (Sherr \& Sherr, 2002). Se tiene conocimiento de que muchos ciliados y rotíferos son consumidores eficientes de los componentes microbianos y de partículas <2 $\mu$ m (Fenchel, 1980; Sherr \& Sherr, 1994; Kobayashi et al., 1996), y que algunos dáfnidos, copépodos y otros rotíferos también se alimentan de protozoos (Sanders \& Wickham, 1993; Mohr \& Adrian, 2002; Zöllner et al., 2003; Joaquim-Justo et al., 2006; Sommer \& Sommer, 2006).

De esta forma, los protozoos pueden servir como un eslabón trófico en la transferencia de la biomasa bacteriana a los organismos del metazooplancton, teniendo el bucle microbiano cierto rol dentro de la dinámica trófica de los sistemas acuáticos (Azam et al., 1983). Aún cuando se trata de un ciclo abierto y su importancia en los niveles superiores es poco relevante, constituye una parte integral de las redes tróficas en los ambientes dulceacuícolas (Sanders \& Wickham, 1993). Estos compartimentos tróficos seguramente se han destacado en las aguas del arroyo, donde la elevada concentración de nutrientes y la alta carga de materia orgánica han promovido el desarrollo de bacterias, eventualmente consumidas por los ciliados.

Por otro lado, se reconoce que los microcrustáceos pueden alterar en gran medida la composición de especies del fitoplancton, aún cuando la biomasa total de las algas se vea poco alterada, debido a que los copépodos consumen preferentemente las algas del microplancton, mientras que los cladóceros pastorean principalmente sobre la fracción del nanoplancton (Sommer et al., 2003). Asimismo, los copépodos presentan cambios en su dieta según su estado de desarrollo, y es así como los copépodos adultos y los últimos copepoditos son carnívoros, mientras que las larvas nauplii y los primeros copepoditos son predominantemente herbívoros (Guelda et al., 2005). Por otro lado, los calanoideos planctónicos tienen una alimentación más selectiva, ya que están equipados para localizar, discriminar y elegir los organismos presa (Hart, 1996), gracias a la utilización de sus quimioreceptores (Lehman, 1988).

Tal como fuera detectado en el río Meuse (Viroux, 2002), también podrían registrarse influencias bottom-down a través del zooplancton depredador presente en los sitios de estudio. Entre éstos se hallaron rotíferos del género Asplanchna, conocidos depredadores de otros rotíferos y de ciliados (Sládeček, 1983; Bertani et al., 2012), y Synchaeta, también conocido por su depredación sobre ciliados, al igual que el ciliado Prorodon y varios suctorios (Sanders \& Wickham, 1993). Especies de estos géneros se destacaron por su abundancia y biomasa en el sistema Bragado, 
particularmente en el arroyo (Prorodon sp2) y en el canal 1 (Acineta sp., Synchaeta pectinata), coincidiendo con los picos de abundancia de los individuos presa. De esta forma podría inferirse una depredación heterotrófica sobre los componentes del bucle microbiano, pudiendo ser una fuente importante de alimento para el metazooplancton presente (Sherr \& Sherr, 2002), particularmente en el arroyo. En este sentido, se reconoce que los rotíferos desempeñan un rol clave en los ambientes acuáticos, ya que utilizan variadas fuentes de alimento y se destacan como productores secundarios, teniendo importantes funciones en el ciclado de los nutrientes y en la transferencia de carbono a los niveles tróficos superiores (José de Paggi, 2004; Rodrigues Capítulo et al., 2010). Entre los copépodos depredadores predominó Acanthocylops robustus, en términos de abundancia, biomasa y por su amplia distribución, y en menor medida se hallaron Metacyclops mendocinus y Microcyclops alius. Asimismo, el plancton y otros materiales suspendidos provenientes del sistema Bragado, en particular los efluentes de los cuerpos de agua lénticos (arroyo, canales 2 y 3) constituyen un alimento de alta calidad para los organismos presentes en los ríos (Walks \& Cyr, 2004). 


\section{7. Índice del valor indicador (INDVAL)}

En el río se destacaron como especies características las diatomeas de gran tamaño (e.g. Nitzschia tryblionella, N. linearis, Campylodiscus clypeus, Craticula ambigua, Melosira numuloides, M. lineata, Surirella striatula, Neidium iridis), donde las mayores velocidades de corriente permiten su transporte y resuspensión. Además, se reconoce que las diatomeas se encuentran adaptadas al ambiente fluvial, dada su tolerancia a las variaciones en la intensidad de la luz y al flujo turbulento (Rojo et al. 1994; Reynolds, 1994b).

Entre las diatomeas características del canal 1, Pleurosira laevis es conocida por su afinidad a las aguas salobres, en acuerdo con los observado por Dos Santos (2015) en el fitobentos de este mismo sitio y por Vinocur et al. (1994) en la cuenca media del río Salado. Asimismo, P. laevis también ha sido citada como tolerante a la conductividad y la turbidez en el estuario del Río de La Plata (Gómez et al., 2009). Chaetoceros sp. también fue característica del canal 1 y sólo estuvo presente en este sitio, asociada con elevados valores de conductividad y concentración de sales. En este sentido, varias especies de Chaetoceros resultan dominantes del fitoplancton en el estuario de Bahía Blanca (Popovich et al., 2008; Guinder et al., 2009).

Planothidium delicatulum fue característica del río aguas arriba, registrándose en conductividades mayores al óptimo establecido por Licursi et al. (2010) en el Río de La Plata, pero en acuerdo con otros antecedentes en el río Salado (Dos Santos, 2015). Nitzschia linearis, Navicula cryptocephala y Gomphonema parvulum también constituyeron especies características del río aguas arriba, y junto con Craticula cuspidata, que sólo estuvo presente en este sitio, serían especies indicadoras de aguas eutrofizadas y fuertemente contaminadas con materia orgánica, con un importante grado de disturbio por ganadería y agricultura intensiva, con moderada-alta actividad industrial y asentamientos humanos, de acuerdo a su valor del índice IDP (índice de diatomeas pampeanas) elaborado por Gómez \& Licursi (2001). Lo mismo para Tryblionella hungarica y Fallacia pygmea halladas como especies características del arroyo, y Tryblionella angustata sólo presente en este sitio, aunque el nivel de disturbio señalado sería moderado. Sin embargo, Neidium iridis, característica del río aguas arriba, Surirella tenera (río), Nitzschia fonticola característica del arroyo, Calloneis bacillum (arroyo), Planothidium delicatulum y Pleurosira laevis presentan un valor de IDP entre 1 y 2, y se corresponderían con aguas de buena calidad a aceptable, poco a moderadamente eutrofizadas y contaminadas con materia orgánica (Gómez \& Licursi, 2001). Además, Neidium iridis también es conocida por su estrecho rango de tolerancia a la turbidez y a la conductividad, y Gomphonema parvulum, Planothidium delicatulum, Stauroneis construens y Nitzschia paleacea estuvieron asociadas a una elevada concentración de nutrientes y materia orgánica en el estuario del Río de La Plata 
(Licursi et al., 2010). Asimismo, Navicula recens fue especie característica del río aguas arriba, posiblemente asociada a mayores valores de OD, en acuerdo con Licursi et al. (2010).

En el arroyo se observó escaso número de especies características, y entre ellas prevalecieron las de euglenofitas (Lepocinclis acus, Euglenaria caudata y Euglena retronata), siendo conocidas por su tolerancia a ambientes con alta carga de materia orgánica en descomposición, dado el evidente vertido de efluentes cloacales que presenta este sitio.

Entre las clorofitas características predominaron las formas nanoplanctónicas como Monoraphidium spp., conocidas por sus cortos tiempos generacionales y su adaptación al ambiente fluvial con disponibilidad de nutrientes, siendo especies típicas de la cuenca del río Salado (Solari et al., 2002; Bazzuri et al., 2008, 2010a, b; Carrillo et al., 2009).

Entre las cianobacterias características se destacaron las formas filamentosas, particularmente en el canal 2 (Arthrospira platensis, Anabaenopsis spp. y Phormidium spp.), posiblemente relacionado con la concentración de sales halladas y la importante presión de pastoreo observada en este sitio, por parte de rotíferos y larvas nauplii, siendo algas no palatables y tolerantes a las variaciones de salinidad (Zalocar de Domitrovic \& Forastier, 2005). La cianobacteria filamentosa Phormidium okenii fue característica del arroyo, siendo además un importante representante del fitobentos del área de estudio, estando asociada a mayores concentraciones de nutrientes (Dos Santos, 2015).

En el canal 2, también se halló el no máximo de especies características del zooplancton, mayormente representadas por los rotíferos (Anuraeopsis fissa, Asplanchna girodi, Proales sp5, Encentrum sp1, Trichocerca pusilla, Brachionus plicatilis, B. caudatus y bdelloideos). Sólo se hallaron ciliados característicos en el sistema Bragado (Epistylis sp1, Vorticella sp2, Codonella sp., Stentor sp1, Strombidium sp.; Strobilidium caudatum, Prorodon sp2, Urotrichia sp., Dileptus sp., Litonotus sp., Uroleptus sp. y Vaginicola sp.), posiblemente asociado al mayor contenido de nutrientes y materiales suspendidos en estos sitios (Lampert \& Sommer, 1997), y entre las cuales se observan especies tolerantes a elevadas salinidades (Foissner et al., 1999). Por otro lado, los cladóceros característicos estuvieron restringidos al río (Alona glabra, Simocephalus sp. y Moina micrura), al igual que los rizópodos (Arcella discoides y Euglypha sp.), y un ostrácodo (Cypridopsis vidua), posiblemente relacionado a la presencia de aguas más oxigenadas. Las especies características de copépodos fueron propias de cada sitio de muestreo, a excepción del arroyo, donde sólo se destacaron unos pocos ciliados. Entre ellas, el copépodo calanoideo Boeckella poopensis sólo estuvo presente en el canal 1, siendo una especie típica de aguas mesosalinas (Echaniz \& Vignatti, 2011).

Muchas de las especies que resultaron comunes estuvieron ampliamente distribuidas en los sitios de muestreo, siendo mayormente cosmopolitas, ubicuas, algunas de ambientes salobres, 
dominantes o subdominantes del fito y zooplancton y habituales en la cuenca del río Salado (Claps et al., 2009). Entre éstas se hallaron las clorofitas clorococcales de los géneros Monoraphidium, Kirchneriella y Oocystis, las cianobacterias Aphanocapsa incerta, Sphaerospermopsis aphanizomenoides, Planktolyngbya minor y Geitlerinema amphibium, y la diatomea Cyclotella meneghiniana, entre otras. Las especies all habitat más destacables del zooplancton fueron el ciliado Tintinnidium fluviatile, que es una especie común en estuarios y aguas salinas (Sanders, 1987), los rotíferos Brachionus angularis, Keratella tropica y Lecane closterocerca, el copépodo Acanthocyclops robustus, los cladóceros Alona rectangula y Daphnia obtusa, y el rizópodo Arcella hemisphaerica. La mayor parte de estas especies son conocidas por sus amplios rangos de tolerancia a la salinidad y su afinidad por los ambientes eutróficos, siendo importantes componentes del zooplancton en la cuenca (Neschuk, 2001; Neschuk et al., 2002a; Claps et al., 2009) y en otros ríos de llanura de Argentina (José de Paggi, 1984; José de Paggi \& Paggi, 1998; José de Paggi \& Devercelli, 2011). 


\subsection{Tasa de cambio de la comunidad del fitoplancton}

El canal 1 presentó la mayor amplitud de la tasa de cambio de la comunidad del fitoplancton $\sigma_{s}$ entre muestreos (0,32-1,12/día), con valores mínimos en caudales medios y la dominancia de Raphidiopsis mediterranea, estratega $K$ perteneciente al codón $\mathbf{S 2}$, tolerante a las deficiencias de luz (Reynolds et al., 2002). El máximo cambio en la comunidad se observó en condiciones de aguas muy bajas, con la predominancia de Synechococcus spp., siendo estrategas $r$ del codón $\mathbf{Z}$, tolerantes a la baja disponibilidad de nutrientes (Reynolds et al., 2002). En acuerdo con Reynolds (1997) la dominancia del picoplancton se observó en condiciones de extrema limitación de nutrientes.

El canal 2 también registró máximo valor de $\sigma_{\mathrm{s}}$ (0,92/día) en aguas muy bajas, con la prevalencia de estrategas $r$ como Komma caudata y Plagioselmis nannoplanctica (codón X2). El grupo X2 está integrado por especies meso-eutróficas colonizadoras (estrategas $C$ ), de rápidas tasas reproductivas, pero sensibles a las condiciones de mezcla y la falta de luz (Reynolds, 1997). Resultados similares se observaron en la fase potamon del río Paraná, donde las aguas bajas del cauce principal permitieron el inusual desarrollo de fitoflagelados nanoplanctónicos (García de Emiliani \& Devercelli, 2003; Devercelli, 2006; 2010), al igual que en el río Salado (Santa Fe) (Devercelli \& O'Farrell, 2013).

El mínimo valor de $\sigma_{\mathrm{s}}$ en el canal 2 (0,49/día) se observó en aguas altas en presencia de condiciones ambientales homogéneas y la dominancia de Aphanocapsa incerta y Cryptomonas obovoidea. La cianobacteria colonial $A$. incerta es una especie común en aguas enriquecidas con nutrientes (codón $\mathbf{K})$, y C. obovoidea pertenece al codón $\mathbf{Y}$, siendo tolerante a las condiciones de baja luz (Reynolds et al., 2002). En el río Paraná también se destacó la presencia de Cryptomonas spp. en los períodos de inundación, donde la selección favoreció a las pequeñas especies con rápido crecimiento intrínseco y con una mayor tolerancia a la alta frecuencia del disturbio hidráulico, siendo capaces de compensar la dilución (García de Emiliani, 1997). Distinto de lo hallado en el río Salado (Santa Fe), donde se atribuyó su escasa presencia a una contribución desde los ambientes lénticos adyacentes (Devercelli \& O’Farrell, 2013). Aphanocapsa sp. constituyó una de las especies dominantes del fitoplancton del río Pomba (Brasil), y la dominancia del grupo morfofuncional al que pertenece (codón $\mathbf{K}$ ) estuvo relacionada a la descarga de efluentes cloacales en las cabeceras (Soares et al., 2007).

En el arroyo, el máximo valor de $\sigma_{\mathrm{s}}(0,77 /$ día) se registró en caudales medios junto con al desarrollo de Monoraphidium spp., siendo especies estrategas $r$ del codón X1. El valor mínimo de la tasa de cambio se observó en aguas altas (0,48/día), coincidiendo con lo observado en el canal 2. 
El río aguas arriba registró la menor variación del índice en los sucesivos muestreos (0,540,7/día), con máximos valores en caudales medios de verano tardío y la prevalencia de Sphaerospermopsis aphanizomenoides del codón H1, fijadora de nitrógeno y tolerante al estrés (Reynolds, 1988b), siendo una especie habitual del río Salado, al igual que Dolichospermum spiroides y Anabaenopsis circularis (Gabellone et al., 2013a), también presentes en esta ocasión. Otra especie importante fue Planktolyngbya minor (codón S1) en condiciones de aguas bajas, siendo una especie común en ambientes mezclados y turbios, con tolerancia a la falta de luz, pero sensible al lavado (Reynolds et al., 2002). En el río aguas abajo se registró el valor máximo de la tasa (0,88/día) en aguas bajas, con la dominancia de Monoraphidium spp. (codón X1) y Planktolyngbya limnetica (codón S1). Los grupos morfofuncionales X1 y X2 co-dominaron el fitoplancton del río Salado durante el período 1995-2005, tanto en eventos de caudales normales como en condiciones extremas (ENSO - El Niño y La Niña); representados mayormente por los géneros Monoraphidium y Chlamydomonas, respectivamente (Solari et al., 2014).

El mínimo cambio en la comunidad del fitoplancton para el río Salado se registró en caudales medios de primavera (0,54 y 0,47/día para el río aguas arriba y abajo, respectivamente), con escaso aporte del sistema Bragado, y la dominancia de Actinastrum hantzschii en ambos sitios (estratega K). Esta especie colonial pertenece al codón $\mathbf{J}$ de las grandes algas, integrado por especies comunes en ríos y lagunas enriquecidos con nutrientes, siendo sensible a la falta de luz (Reynolds et al., 2002). Este codón J también se destacó en otros estudios en el río Salado (Gabellone et al., 2013a), e incluye clorofitas cenobiales algunas palatables para el fitoplancton filtrador.

También se destacaron las diatomeas centrales Cyclotella spp. (codón C) y Stephanodiscus sp. (codón D) comunes en ambientes bien mezclados y tolerantes a las deficiencias de luz y la velocidad de corriente (Reynolds et al., 2002). Se trata de especies unicelulares de pequeño tamaño (estrategas $r$ ), propensas a la depredación, con una baja tasa de sedimentación, halladas habitualmente en el río Salado (Gabellone et al., 2013a), en el río Salado (Santa Fe) y el Ao El Vado (Devercelli \& O’Farrell, 2013), en el río Paraná (Devercelli, 2010) y el rio Danubio (Schagerl et al., 2009) en el cauce principal durante una fase de desvinculación con la planicie de inundación, tal como en esta ocasión. Si bien Cyclotella no posee altas tasas de duplicación, su capacidad para sobrevivir como organismo meroplanctónico especializado constituye una ventaja adaptativa del género (García de Emiliani \& Devercelli, 2003). Asimismo, las diatomeas son consideradas como especies ruderales $\boldsymbol{R}$ típicas, por su adaptación a crecer en aguas turbias, bien mezcladas, con alta concentración de nutrientes y tolerando condiciones de luz fluctuante, propia del ambiente lótico (García de Emiliani, 1997; Reynolds, 1997). En acuerdo con Reynolds (1988b), el grupo se destacó 
en aguas templado-cálidas $\left(>15^{\circ} \mathrm{C}\right)$ con buena mezcla vertical y disponibilidad de nutrientes. En el río Loire también se observó la dominancia de estos mismos grupos morfofuncionales, aunque en un gradiente longitudinal donde los codones $\mathbf{H 1}$ e $\mathbf{Y}$ se destacaron en la cuenca superior, asociado a la presencia de ambientes eutróficos con aguas estancadas, y los codones $\mathbf{X 1}, \mathbf{X} \mathbf{2}$ y $\mathbf{J}$ aguas abajo, relacionado a un incremento del tiempo de residencia y reducción de la profundidad del cauce, intercalando con los codones C y D de las diatomeas centrales (Abonyi et al., 2012). Estudios en arroyos pampeanos (Bauer, 2009), también señalan la predominancia, en términos de abundancia, de los grupos funcionales $\mathbf{F}, \mathbf{X} \mathbf{1}$, J y $\mathbf{D}$, asociados a elevados valores de fosfato el codón $\mathbf{F}$ y de nitratos, los restantes.

Altos valores en la tasa de cambio $\sigma_{s}$ estuvieron relacionados a condiciones hidrológicas de aguas bajas en el río y aguas muy bajas en los canales, asociado a la dominancia de especies estrategas $r$ del fitoplancton. En la planicie de inundación del río Paraná también se observó un gran desarrollo de los flagelados nanoplanctónicos unicelulares pertenecientes al codón X2 (Plagioselmis nannoplanctonica) en el período de aguas bajas (Devercelli, 2006), dadas sus características de especies colonizadoras, con rápido crecimiento y altas tasas de reproducción, con cierta movilidad y menor susceptibilidad a la sedimentación (Reynolds, 1997). Por otra parte, los mínimos valores del índice se asociaron a momentos de inundación en los canales y a caudales medios en el río, con la predominancia de estrategas $K$ y condiciones ambientales más estables, que permitieron un mejor desarrollo de la comunidad. En acuerdo con estos resultados, Zalocar de Domitrovic (2003) observó bajos valores de $\sigma_{s}(<0,1 /$ día) en la comunidad del fitoplancton del río Paraná durante la etapa de limnofase, asociada a una mayor estabilidad en la columna de agua; y los valores máximos en el período de potamofase (0,33/día), sugiriendo que las elevadas tasas de los procesos biogeoquímicos aportaron variabilidad ambiental al sistema. Bajos valores de $\sigma_{\mathrm{s}}$ indican escasa variación en la composición de la comunidad en el tiempo, asociada a condiciones ambientales más estables (Reynolds, 1992; Zalocar de Domitrovic, 2003).

Condiciones extremas en el régimen hidrológico del río Salado provocaron importantes cambios en la estructura del fitoplancton, tanto en momentos de inundación como de sequía, favoreciendo los grupos funcionales Y (aguas altas) y X2 (aguas bajas), al igual que en el río Paraná (Devercelli, 2010). Estos grupos presentan como ventajas adaptativas los altos cocientes $A S / V$, su elevada actividad metabólica, y mayor capacidad de captación de la luz y toma de nutrientes (Tablas 1 y 2, Anexo IV). También presentan altas tasas de crecimiento intrínseco y reproducción que aseguran su dispersión y compensan las pérdidas por dilución (Reynolds, 1997). El codón X2 está formado por especies colonizadoras y el codón $\mathbf{Y}$ por especies capaces de mantenerse en 
suspensión y de crecer aún en flujos de luz heterogéneos, presentando rasgos intermedios entre las estrategias primarias $\boldsymbol{R}$ y $\boldsymbol{C}$ (ruderales y competitivas) (Reynolds, 1997; García de Emiliani \& Devercelli, 2003). Asimismo, García de Emiliani (1993) halló que las poblaciones de fitoflagelados constituyen la fracción dominante del fitoplancton durante los pulsos de inundación en el río Paraná, donde las especies estrategas $K$ son reemplazadas por los estrategas $r$.

En acuerdo con Reynolds (1997), en los momentos de bajo intercambio hidráulico del río con la planicie de inundación, pero con renovación de nutrientes, dominaron las grandes algas verdes (codón $\mathbf{J}$ ), y también las diatomeas (codones $\mathbf{C}$ y D), siendo estrategas $\boldsymbol{R}$ ruderales con cualidades fotoadaptativas, altos cocientes $A S / V$ y moderadas tasas de crecimiento poblacional. La dominancia de los codones S1 y S2, dado por las cianobacterias filamentosas Planktolyngbya limnetica y Raphidiopsis mediterranea, ha sido mencionada en otros ríos del mundo (Piirsoo et al., 2008). P. limnetica es una especie común en lagos eutróficos e hiper-eutróficos, pero también en grandes ríos (Reynolds \& Descy, 1996), y es conocida por sus mecanismos de regulación de la flotación, el cual también le otorga una ventaja adaptativa en el ambiente fluvial (Piirsoo et al., 2008), particularmente en aguas bajas.

El enfoque de los grupos morfo-funcionales describe mejor los sistemas analizados, demostrando las principales características adaptativas de las especies dominantes, en condiciones de aguas turbias, turbulentas y enriquecidas con nutrientes (Soares et al., 2007). Las diferencias en la abundancia y distribución de las especies de los grupos morfofuncionales ponen de manifiesto las diferentes estrategias frente a la adaptación (Modesto-Iregui et al., 2002). Tal como lo observado en el río Danubio (Schagerl et al., 2009), la dominancia de especies de fitoplancton de rápido crecimiento (estrategas $r$ ) estuvo asociada a momentos de alta conectividad con la planicie de inundación (aguas altas), mientras que en los momentos de conectividad moderada y altos tiempos de residencia (caudales medios y aguas bajas) otros grupos algales cobraron importancia (estrategas K), promoviendo la biodiversidad.

Estas fases hidrológicas extremas constituyen un disturbio para las poblaciones del fitoplancton (Sparks et al. 1990; Lake, 2003) y son habituales las condiciones desencadenantes de una fase inicial en la sucesión (Reynolds, 1997). Debido a estos disturbios frecuentes los ensambles de fitoplancton de muchos ríos muestran rasgos de comunidades pioneras, con una organización primitiva, débiles conexiones tróficas y baja competencia interespecífica; generalmente conformadas por especies oportunistas, colonizadoras y de crecimiento rápido (Reynolds \& Descy, 1996) adaptados a estas condiciones (estrategas r) (García de Emiliani, 1993). En este sentido, los sistemas eutróficos están definidos por especies con amplios rangos de tolerancia; pero si los disturbios son muy 
intensos es posible que las condiciones favorezcan la recolonización de estos sitios por especies con altas tasas reproductivas y cortos ciclos de vida (Conforti et al., 1995).

Como las tasas de crecimiento y reproducción están inversamente relacionadas al tamaño celular (Chételat et al., 2006), las algas de pequeño tamaño tienden a dominar en sistemas con cortos tiempos de residencia, independientemente de su afiliación taxonómica. En este sentido, las formas unicelulares de pequeñas clorofitas, diatomeas y criptofitas son características del potamoplancton, debido a sus mayores eficiencias fotosintéticas, rápidas tasas de replicación celular y baja sedimentación (Reynolds, 1994b; Chételat et al., 2006). De esta forma el ambiente fluvial selecciona a las especies mejor capacitadas para sobrellevar estos cambios (Reynolds et al., 1994b), y la respuesta biótica a las condiciones ambientales prevalecientes dependerá de la propia capacidad de los organismos para explotarlas (Sparks \& Spink, 1998). Sin embargo, debe distinguirse entre las estrategias que responden a renovaciones ambientales abruptas y los ensambles de especies debidos a cambios más graduales, como las estaciones. De esta forma, puede interpretarse a la composición del fitoplancton como el resultado de la interacción entre los procesos de verdadero desarrollo sucesional y los disturbios de frecuencia intermedia (Reynolds, 1997; Zalocar de Domitrovic, 2002), como las inundaciones periódicas y los eventos de sequía.

El régimen hidrológico fue el factor controlador más importante que actuó sobre el fitoplancton, influenciando su abundancia, estructura y composición específica, así como también la dinámica de los grupos funcionales y especies dominantes, modificando en consecuencia, la tasa de cambio $\sigma_{s}$; en acuerdo con García de Emiliani ( 1997), según lo observado en el río Paraná.

Los canales, como ambientes artificiales, presentan menor resiliencia a estos disturbios, generando una mayor variación en las comunidades en el tiempo, reflejada a través de la mayor amplitud en los valores del índice $\sigma_{s}$, particularmente en el canal 1. En el río, la heterogeneidad espacio-temporal y la robustez de los procesos ecológicos otorgan al sistema una mayor resiliencia, permitiendo una mejor absorción y amortiguamiento de los cambios. En este sentido, el río aguas arriba del trasvase presentó la mínima variación del índice entre muestreos, a pesar de los drásticos cambios hidrológicos y de la composición del fitoplancton observada. 


\subsection{Plancton y variables forzantes en la cuenca superior del río Salado}

\subsubsection{Características del plancton en la cuenca superior del río Salado}

El río Salado presentó verdaderas poblaciones de potamoplancton, capaces de persistir e incrementar su biomasa en el flujo fluvial aguas abajo, independientemente de la procedencia del inóculo, al igual que otros grandes ríos de llanura (Reynolds, 1988b, 1995; Reynolds \& Descy, 1996; Rojo et al., 1994; Ietswaart et al., 1999; Rossetti et al., 2009). La alta proporción de especies ticoplanctónicas registradas en el plancton, con presencia temporaria de organismos provenientes de ambientes lénticos, bentos o perifiton, coincide con lo observado en otros sistemas fluviales (Hynes, 1970; Margalef, 1983; Gosselain et al., 1994; Rojo et al., 1994), como la cuenca del río Siena (Billen et al., 1994), el río Rideau (Yang et al., 1997), el río San Joaquín (Leland, 2003), el río Adige (Centis et al., 2010) y varios ríos canadienses (Chételat et al., 2006).

La presencia de especies esporádicas fue particularmente importante en aguas altas, siendo atribuible al intercambio con la planicie de inundación, tal como lo hallado en el río Paraná (García de Emiliani, 1997; Devercelli, 2006) y en la cuenca del río Salado (Izaguirre \& Vinocur, 1994). De manera opuesta, la menor interacción entre ambientes observada en aguas bajas redujo el reclutamiento de los organismos desde las zonas de almacenamiento (Reynolds \& Glaister, 1993).

Los canales presentaron mayor abundancia y biomasa total de plancton que el río Salado en aguas altas y en caudales medios (canal 1), y en aguas bajas (canales 2 y 3), constituyendo una importante fuente de inóculos, en acuerdo con otros antecedentes en la cuenca (Neschuk, 2001; Neschuk et al., 2002a,b; Solari et al., 2002; Benítez \& Claps, 2009; Claps et al., 1997, 2009; Bazzuri et al., 2008, 2010a,b; Gabellone et al., 2014).

\subsubsection{Variables forzantes del plancton}

Los Análisis de Redundancia realizados a la composición de especies de fito y zooplancton explicaron el 54 y 55\% de la varianza total, respectivamente, sumando la variación de los Ejes 1 y 2 $(p<0,02)$. Estos porcentajes resultan similares a los mencionados en un análisis de correspondencia canónica de la composición de especies de fitoplancton (Bauer, 2009) y de diatomeas epipélicas en arroyos pampeanos (Licursi, 2005).

Las variables ambientales más importantes en ambos modelos fueron la conductividad, la temperatura y el nivel de agua (\% de la distancia desde el pelo de agua al guardarruedas del puente). También condicionan la distribución espacio-temporal de las especies de fitoplancton los nutrientes $\mathrm{N}+\mathrm{N}$ y $\mathrm{N}-\mathrm{NH}_{4}{ }^{+}$, la MOP, la velocidad de corriente y la alcalinidad, y del zooplancton la clorofila $a$, el $\mathrm{pH}$ y la transparencia. De esta forma, las variaciones estacionales (temperatura), la 
conductividad y la descarga de caudal (nivel de agua, velocidad de corriente) constituyeron las variables forzantes que actuaron sobre el plancton, aceptándose la Hipótesis I.

\subsubsection{Plancton y condiciones estacionales e hidrológicas}

A lo largo de este estudio se observó un patrón estacional en el desarrollo del fito y zooplancton con marcados cambios en función de la temperatura, con una fase favorable de crecimiento (primavera-verano) y otra desfavorable (otoño tardío). En aguas altas (mayo 2007), se registraron los valores mínimos de abundancia y biomasa total de plancton, debido a las condiciones de bajas temperaturas y la reducción del fotoperíodo (Garnier et al., 1995), sumado al efecto dilutorio de las mayores descargas de caudal (Neschuk et al., 2002b; Bazzuri et al., 2010a,b).

Esta relación inversa hallada entre la abundancia y biomasa de plancton y la condición de aguas altas (elevados caudales) también es un rasgo común de otros ríos de llanura (de Ruyter van Steveninck et al., 1992; Pace et al., 1992; Thorp et al., 1994; Basú \& Pick, 1996; Reckendorfer et al., 1999; Lair, 2006). En este sentido, el clima y la temperatura actúan como importantes reguladores del flujo en los ríos de regiones templadas (Williams, 1996; de Cabo et al., 2003) por la concentración de las precipitaciones y las consecuentes variaciones en los caudales, ejerciendo un control sobre la abundancia, composición de especies y diversidad de las comunidades fluviales (Reynolds et al., 1994; Bunn \& Arthington, 2002; Lair, 2006).

A pesar de la complejidad de los procesos fluviales observados, la dinámica del fitoplancton del río Salado y del sistema Bragado estuvo influenciada por los procesos físicos, y su abundancia y composición estuvo condicionada por la condición climática estacional (temperatura) y las variables físico-químicas (velocidad de corriente, transparencia, $\mathrm{pH}$, conductividad) asociadas al régimen hidrológico. En acuerdo con otros autores (Leland et al., 2001; Leland, 2003; Flöder et al., 2010; Salmaso \& Zignin, 2010; Wang et al., 2014), la salinidad, medida a partir de la conductividad, también tuvo una importante influencia en la composición de especies de fitoplancton hallada, y en la dinámica de estos ensambles a lo largo de los muestreos.

Por otro lado, estudios en arroyo pampeanos (Giorgi et al., 2005) y en la cuenca del río Salado (Dos Santos, 2015), han demostrado que la velocidad de corriente es un importante condicionante de la estructura del fitobentos, y que la concentración de los nutrientes y la herbivoría actuaron como factores asociados en estos ambientes. Asimismo, el nivel de agua condicionó el intercambio de organismos del fitoplancton con la planicie de inundación y los ambientes lénticos asociados, tal como lo observado en el río Paraná (Izaguirre et al., 2001; de Cabo et al., 2003; Devercelli, 2006, 2010), en el río Salado (Santa Fe) (Devercelli \& O’Farrell, 2013), en el río Pomba (Brasil) (Soares et 
al., 2007) y el río Loire (Descy et al., 2012) y en el propio río Salado (O’Farrell, 1993; Neschuk, 2001; Solari et al., 2002; Bazzuri et al., 2008; 2010a,b; Solari \& Mac Donagh, 2014).

La abundancia y composición de especies del zooplancton en el área de estudio estuvo determinada por la conductividad, la temperatura y el ciclo hidrológico del río, en acuerdo con estudios previos en la cuenca (Neschuk et al., 2002a; Claps et al., 2009; Gabellone et al., 2014) y de otros ríos de Argentina (Jose de Paggi, 1984; José de Paggi \& Paggi, 1998; Modenutti, 1998; José de Paggi \& Devercelli, 2011). La temperatura y la salinidad, medida a partir de la conductividad, también han sido mencionados como factores estructurantes del zooplancton en los ríos australianos (Shiel et al., 1982, 2006) y en ríos europeos, junto con el nivel trófico de las aguas (Lair, 2006; Rossetti et al., 2009). Asimismo, el incremento del tiempo de residencia en las condiciones de aguas bajas favoreció su desarrollo (Reckendorfer et al., 1999; Vadadi-Fülöp et al., 2009), estando su crecimiento íntimamente relacionado al nivel de agua y la velocidad de corriente (Kim et al., 2001; 2012; Sluss et al., 2008).

Además, variaciones temporales en la descarga de caudal conllevan a rápidas fluctuaciones en el zooplancton (Viroux, 1997, 2002; Kim \& Joo, 2000), debido a la acción de los factores limitantes asociados, como son la turbidez (inversa a la transparencia), la velocidad de corriente, y la reducción del reclutamiento de inóculos desde las zonas de almacenamiento (Reynolds, 1994a; 2000; Sellers \& Bukaveckas, 2003), asimismo relacionados al nivel de agua. Modificaciones frecuentes en estas variables físicas generan ambientes heterogéneos e inestables, donde prosperan especies oportunistas con habilidades fisiológicas intrínsecas que les permite hacer frente al cambio continuo (Lair, 2006). Tal sería el caso de los rotíferos dominantes en el área de estudio, conocidos por sus cortos ciclos de vida y altas tasas de crecimiento (estrategas $r$ ) (Holst et al., 2002; José de Paggi \& Devercelli, 2011).

\subsubsection{Plancton y nutrientes}

La comunidad planctónica hallada en el área de estudio es típica de un sistema eutróficomesotrófico (Ghadouani et al., 1998; Neschuk et al., 2002b), y de acuerdo a los análisis RDA, los nutrientes derivados de $\mathrm{P}$ y $\mathrm{N}$ (PRS, $\mathrm{N}+\mathrm{N}$ y $\mathrm{N}-\mathrm{NH}_{4}{ }^{+}$) afectaron su abundancia, composición y distribución espacio-temporal. En este sentido, la incorporación de nutrientes y el proceso de eutrofización promueven el desarrollo del plancton (de Ruyter van Steveninck et al., 1992; Basu \& Pick, 1994, 1997; Ibelings et al., 1998), y la estrecha relación existente entre el aumento de la biomasa del plancton y el enriquecimiento con nutrientes se encuentra bien documentada en varios ríos de llanura (Gosselain et al., 1994; Izaguirre \& Vinocur, 1994; García de Emiliani, 1997; 
Pourriot et al., 1997; Reckendorfer et al., 1999). Los ríos son considerados como ambientes particularmente vulnerables a los cambios en el uso de la tierra y la eutrofización, debido a su cercanía con los centros urbanos (Withers \& Jarvie, 2008), en particular en la cuenca superior del río Salado (Neschuk et al., 2002b). Asimismo, se reconoce que los ríos y arroyos cercanos a las principales ciudades de la Provincia se encuentran impactados por los efluentes domiciliarios y los vertidos industriales (Rodrigues Capítulo et al., 2010).

En el canal 1 y en el arroyo se vio claramente la influencia de las ciudades aledañas (9 de Julio y Bragado, respectivamente) sobre estos cursos de agua, los cuales presentaron baja concentración de OD y elevados valores de $\mathrm{N}^{-\mathrm{NH}_{4}+}$, NT y PT, particularmente en el arroyo, por un evidente vertido de efluentes (planta de tratamiento de efluentes cloacales de la ciudad de Bragado). En ambos sitios se observó la dominancia de ciliados indicadores de contaminación con materia orgánica y partículas en suspensión (Epistylis spp., Stentor spp., Vorticella spp., suctorios), siendo algunas de estas especies características del sistema Bragado (Anexo III). Asimismo, en el arroyo se observó la presencia de euglenofitas características (Anexo III), conocidas por su tolerancia a ambientes con alta carga de materia orgánica en descomposición, y de otras especies típicas de saprobios y de ambientes enriquecidos con nutrientes en la región pampeana (Licursi, 2005; Bauer, 2009) (Anexo V). 


\subsection{Influencia de los aportes del Sistema Bragado en el río Salado}

\subsubsection{Análisis de la influencia del sistema Bragado}

Se observaron algunas similitudes en los resultados obtenidos a partir de la aplicación de los diferentes análisis multivariados, como la agrupación de los sitios de muestreo principalmente por la condición hidrológica. De esta forma, el análisis $k$-means efectuado a las variables ambientales, reunió a los sitios de muestreo en 4 grupos, de manera análoga a lo observado en la composición iónica del agua (ordenamiento MDS y cluster - distancia euclidiana), y en los planos de ordenación del análisis RDA, tanto del fito como del zooplancton. Asimismo, los análisis de cluster aplicados a la composición específica del fitoplancton y zooplancton (índice Bray-Curtis) reunieron a los sitios de muestreo de manera significativa $(p<0,05)$ principalmente por la condición hidrológica.

El análisis $k$-means agrupó a todos los sitios de muestreo en aguas altas, al igual que en los análisis de cluster practicados a la composición específica del fitoplancton y zooplancton, pudiéndose relacionar con la estacionalidad, las grandes descargas de caudal, la homogeneidad del ambiente y el efecto de dilución de las aguas por la crecida.

De acuerdo al análisis $k$-means el río Salado aguas arriba del trasvase se relacionó consigo mismo en caudales medios y aguas bajas, y con el río aguas abajo sólo en caudales medios de sept. 2009, donde no se observó una influencia del sistema Bragado por el escaso aporte de los canales (aguas muy bajas). Por otro lado, las variables ambientales subdivididas en 4 grupos, reunieron principalmente a los nutrientes derivados del $\mathrm{N}$ y $\mathrm{P}$, a aquellas variables que registraron los valores máximos en aguas altas (velocidad de corriente, distancia hidrométrica, polifenoles totales disueltos) y en aguas bajas (temperatura, conductividad, dureza), y un último grupo de variables relacionadas con el desarrollo del plancton (MOP, SS, pH, turbidez, OD).

En el análisis de clusters, la asociación del canal 1 y el arroyo en la composición de especies de fitoplancton (aguas muy bajas) y zooplancton (aguas bajas y muy bajas) posiblemente se deba al escaso desarrollo de ambas comunidades, y a la dominancia de las cianobacterias Synechoccocus spp. y los ciliados Vorticella spp. y Epistylis spp. El impacto que reciben de las ciudades aledañas (9 de Julio y Bragado, respectivamente), probablemente condicionó el desarrollo del plancton, en particular en el arroyo, por el evidente vertido de efluentes con alta carga de nutrientes, y materia orgánica en descomposición. Por otro lado, en el análisis RDA del zooplancton, los sitios del canal 1 de los diferentes muestreos se ubicaron en el mismo cuadrante (sector negativo de los Ejes 1 y 2), indicando cierta similitud en la composición específica en las diferentes condiciones hidrológicas.

De acuerdo al análisis de cluster de la composición del fitoplancton, los sitios del río Salado estuvieron relacionados entre sí en todas las condiciones hidrológicas, siendo máxima su similitud 
en momentos de escaso aporte de los canales (aguas muy bajas en el sistema Bragado). En el zooplancton, se observó esta misma tendencia en aguas altas y aguas muy bajas en el sistema Bragado; pero en caudales medios y aguas bajas (primavera-verano) el río aguas abajo del trasvase estuvo estrechamente relacionado con el canal 2. Por otro lado, el río aguas arriba se relacionó consigo en estos muestreos. Este mismo patrón también fue observado en el análisis $k$-means de las variables ambientales y en el análisis RDA del zooplancton.

En este sentido, en el análisis RDA efectuado al zooplancton, los sitios de muestreos en aguas altas y aguas muy bajas estuvieron claramente definidos en el plano de ordenación. Sin embargo, en caudales medios y aguas bajas se observó una estrecha relación entre los sitios del sistema Bragado (canales 2 y 3 y arroyo) y el río aguas abajo del trasvase. Este mismo aglomerado de sitios también estuvo presente en el análisis $k$-means de las variables ambientales, donde esta asociación se debió a los mayores valores de temperatura y de conductividad.

Asimismo, en los análisis de cluster de la composición del fito y zooplancton se observó la agrupación de los sitios de muestreo en caudales medios y aguas bajas, coincidiendo con la época favorable de crecimiento. En caudales medios, prevalecieron las especies Raphidiopsis mediterranea, Aphanocapsa incerta, Monoraphidium spp. y Cryptomonas obovoidea en los sitios de muestreo estrechamente relacionados. En aguas bajas, se destacaron en el fitoplancton las especies Planktolyngbya limnetica, A. incerta y Monoraphidium spp., y en el zooplancton los rotíferos Brachionus plicatilis y B. angularis, particularmente en el canal 2 y en el río aguas abajo del trasvase, siendo conocidos por su afinidad a las aguas salinas en la región pampeana (Claps et al., 2009).

Tanto en el análisis RDA de la composición del zooplancton como en el análisis $k$-means practicado a las variables ambientales, los sitios del río Salado aguas arriba del trasvase se relacionaron entre sí en aguas bajas y caudales medios (marzo 2008 y sept. 2009), y con el río aguas abajo del trasvase en caudales medios (sept. 2009), dado el escaso aporte del sistema Bragado por su condición de aguas muy bajas. Estos resultados sugieren que el sistema Bragado afecta a las aguas río Salado aguas abajo del trasvase en términos de las variables ambientales y de la composición del plancton, dependiendo de la descarga de los canales y condición hidrológica, en concordancia con la Hipótesis II.

\subsubsection{Aportes del sistema Bragado al plancton del río Salado}

A lo largo de los muestreos se observó un incremento en la densidad y biomasa de plancton y en la riqueza de especies en el río Salado aguas abajo del trasvase del sistema Bragado, dado por la incorporación de organismos provenientes de los canales tributarios, que drenan humedales y 
lagunas asociadas, y las zonas de almacenamiento del propio cauce, que en su conjunto actuaron como generadores de inóculos para el río. Estos resultados avalan los conceptos del River Continum Concept (Vannote et al., 1980), que predice una progresión en la abundancia de los organismos, con un aumento directo del plancton en los sitios aguas abajo, en acuerdo con lo observados en otros ríos del mundo, tanto para el fito como para el zooplancton (Saunders \& Lewis, 1989; de Ruyter van Steveninck et al., 1992; Köhler, 1993; Gosselain et al., 1994; Rojo et al., 1994; Stoyneva, 1994; Reynolds, 1995; Pourriot et al., 1997; Lair \& Reyes-Marchant, 1997; Viroux, 1997, 2002; Yang et al., 1997; Reckendorfer et al., 1999; Kim \& Joo, 2000; Neal et al., 2006; Withers \& Jarvie, 2008).

Los mayores tiempos de residencia de estos ambientes permiten su accionar como zonas de reproducción y desarrollo de las especies fluviales, enriqueciendo el plancton lótico aguas abajo por la incorporación de inóculos al cauce principal del río (Reynolds \& Descy, 1996; Welker \& Walz, 1998; Baranyi et al., 2002; Hein et al., 2005; Lair, 2006). Este fenómeno también ha sido observado en ríos de Argentina, como el río Paraná (García de Emiliani \& Devercelli, 2003; Devercelli, 2006, 2010), en tributarios del Río de La Plata (O’Farrell, 1994) y en el propio río Salado (Izaguirre \& Vinocur, 1994; Neschuk et al., 2002b; Solari et al., 2002; Gabellone et al., 2005; Bazzuri et al., 2010a, b; Solari \& Mac Donagh, 2014).

\subsubsection{Variación de los aportes de los tributarios según la condición hidrológica}

Según el análisis de agrupamientos de la composición del fito y zooplancton (cluster, índice de Bray-Curtis, ligamiento completo), la influencia de los tributarios sobre el plancton del río Salado fue significativa $(p<0,05)$ en caudales medios y aguas bajas. En aguas altas este efecto fue menor debido a la dilución y la homogenización del ambiente por la crecida, y en aguas muy bajas, por el escaso caudal de los afluentes del sistema Bragado. El escaso aporte de inóculos al río aguas abajo observado en condiciones de aguas muy bajas podría deberse a que una menor conectividad con la planicie de inundación reduce el intercambio y la incorporación de organismos desde los ambientes lénticos vinculados (Ferrari et al., 2006). Además, los zooplanctontes son menos propensos al arrastre y al transporte aguas abajo durante eventos de bajos caudales (Hynes, 1970; Speas, 2000).

En acuerdo con Zimmermann-Timm et al. (2007) la influencia cuali-cuantitativa de los tributarios sobre la comunidad del potamoplancton es muy variable, y depende de las características de los aportes y de su contribución a la descarga total del río. La incidencia de los tributarios sobre el plancton del cauce principal aguas abajo también ha sido mencionada para 
otros ríos del mundo (Thorp et al., 1994; Hudon, 2000; Kim \& Joo, 2000; Lair, 2005; Vis et al., 2007; Scherwass et al., 2010).

En oposición a estos resultados, en otros ríos de llanura se ha observado la disminución de la densidad total de fitoplancton debido a los aportes de los tributarios, como en el río Luján (O'Farrell et al., 2002), en el tramo inferior del río Salado (Santa Fe) (Devercelli \& O'Farrell, 2013), en el río San Joaquín (Stringfellow et al., 2009) y en el plancton del río Danubio (Istvánovics et al., 2010). Asimismo, otros autores han encontrado escasa influencia de las zonas de almacenamiento en la composición de especies del plancton aguas abajo, como en el río Po (Rossetti et al., 2003, 2009), y en otros ríos largamente canalizados (Spaink et al., 1998).

Antecedentes en arroyos pampeanos, también hallaron un aumento en la abundancia total de fitoplancton aguas abajo de una pequeña laguna artificial en el ํㅡำ Rodríguez (Bauer et al., 2002a), y en la abundancia de macroinvertebrados (efemerópteros) en las cabeceras del A $\mathrm{o}$ Buriñigo, debido a la migración de organismos desde humedales adyacentes (Ocón \& Rodrigues Capítulo, 2004).

\subsubsection{Rol de los ambientes lénticos vinculados en la atenuación de los aportes de la Pampa Arenosa}

La importancia del mantenimiento del sistema Bragado como subcuenca del río Salado queda demostrada en su carácter amortiguador de las características intrínsecas de los aportes alóctonos de la Pampa Arenosa, a través del complejo sistema de lagunas, bañados y humedales interconectados. Su efecto atenuante en la conductividad pudo comprobarse en todos los muestreos, pasando desde valores máximos en el canal 1, menores en el canal 2, luego en el arroyo y en el canal 3, hasta su desembocadura en el río Salado. Particularmente en aguas altas se observó un claro gradiente de concentración en varios parámetros físico-químicos y biológicos, además de la salinidad y la concentración de los iones mayoritarios $\left(\mathrm{Na}^{+}, \mathrm{K}^{+}, \mathrm{Cl}-\right)$, como ser: la turbidez, los SS, MOP, Polif., PT, POT, clorofila $a$, abundancia y biomasa total de plancton, abundancia y biomasa total de fito y zooplancton (Fig. 5.1).

Siguieron una tendencia decreciente a lo largo del sistema Bragado en aguas altas (mayo 2007), la abundancia y biomasa total de las cianobacterias, clorofitas, diatomeas, euglenofitas y dinoflagelados, y las especies dominantes: Aphanocapsa incerta, Planktolyngbya minor, Raphidiopsis mediterranea y Euglena oblonga. En el zooplancton, se observó la disminución paulatina de la abundancia y biomasa total de los rotíferos, de los cladóceros, ciliados, copépodos y rizópodos, y de algunas especies dominantes, como Daphnia spinulata, Keratella tropica, Acanthocyclops robustus, Stentor spp. y Notodiaptomus incompositus. Asimismo, la riqueza de especies del zooplancton, la abundancia de $q$ ovígeras totales y de rotíferos, copépodos y cladóceros, larvas nauplii, 
copepoditos, juveniles y efipios, y $q$ ovígeras de K. tropica y A. robustus. Un caso similar se observó en la cuenca del río San Joaquín, donde el drenaje de los aportes agrícolas de los tributarios y el flujo subsuperficial contribuyeron a un complejo gradiente de salinidad y nutrientes (Leland et al., 2001). En este sentido, se reconoce que los arroyos, ríos y humedales contribuyen al cambio en la calidad y cantidad de los materiales transportados, y en su régimen de transporte temporario, a través de su almacenamiento, pérdida y transformación, donde su eficiencia en la retención de nutrientes se encuentra estrechamente relacionada a la variación hidrológica (Fisher et al., 1998).

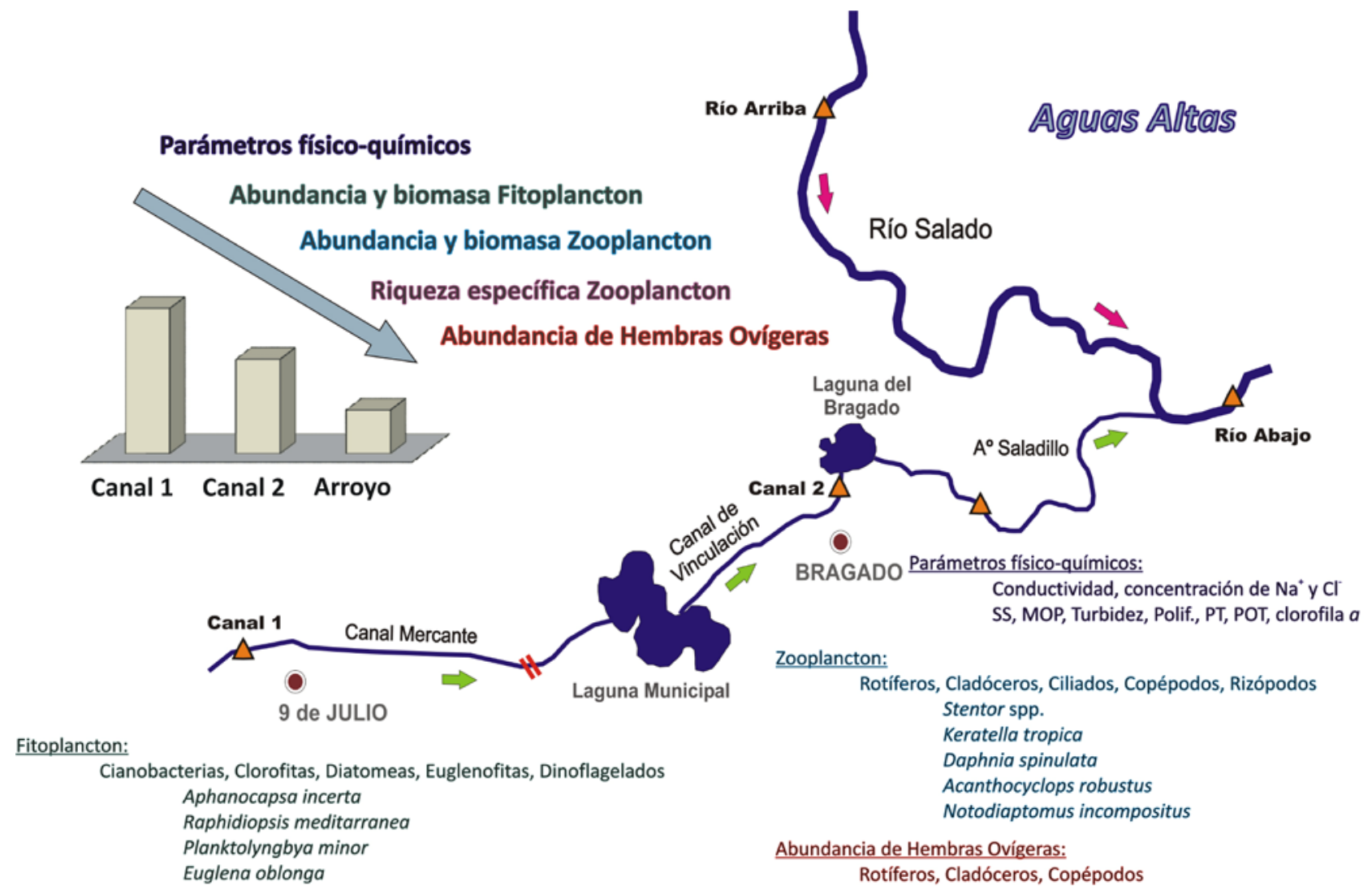

Figura 5.1: Gradiente observado a lo largo del sistema Bragado (canal 1, canal 2 y arroyo) en algunos de los parámetros físico-químicos y biológicos medidos, en condiciones de aguas altas (mayo 2007).

En caudales medios (marzo 2008) también pudo comprobarse un gradiente desde el canal 1, al canal 2 y luego en el arroyo, en la conductividad y en la concentración de los iones mayoritarios, en la abundancia y biomasa total de fitoplancton, así como de los principales grupos algales (clorofitas, cianobacterias, criptofitas y diatomeas), de las especies dominantes (Raphidiopsis mediterranea, Aphanocapsa incerta, Cryptomonas obovoidea, Sphaerospermopsis aphanizomenoides), y en la diversidad de especies del zooplancton. Las condiciones hidrológicas de aguas bajas (nov. 2008) y aguas muy bajas (sept. 2009), resaltaron las diferencias locales en los parámetros ambientales, promoviendo el desarrollo de comunidades planctónicas particulares en cada sitio del sistema 
Bragado, variando en su estructura y composición de especies, tal como lo observado en el río Danubio (Schagerl et al., 2009).

En los últimos años Mugni (2008) ha demostrado la importancia de los humedales, de la vegetación ribereña y de las zonas de atenuación en la retención de nutrientes y pesticidas en arroyos pampeanos. El valor los humedales reside en las importantes funciones que desempeñan, como el aumento de la calidad del agua, la denitrificación, la retención y la degradación de los materiales particulados (Hein et al., 2005; Coops et al., 2006). También intervienen en la transformación de los nutrientes, la incorporación a través de los organismos y su almacenamiento en la biomasa, regulando los ciclos biogeoquímicos en los sistemas fluviales (Garnier et al., 2005; Kronvang et al., 2005a; Billen et al., 2007). Pero estas transformaciones biogeoquímicas están fuertemente gobernadas por la hidrología (Reddy \& DeLaune, 2008).

La vegetación ribereña también otorga una mayor heterogeneidad en la conformación de los ríos y arroyos, actúan como filtros y sumideros de contaminantes, nutrientes y materiales suspendidos dentro del corredor fluvial, a la vez que regulan la productividad y diversidad de estos ambientes (Sparks, 1995; Zalewski et al., 1998). De esta forma, los compuestos quedan atrapados en los sedimentos o forman parte de la biomasa vegetal, reduciendo de manera significativa el efecto de los aportes difusos por el uso de la tierra (Kronvang et al., 2007). Además, reducen la erosión de la cuenca, la turbidez y el contenido de materiales en el río, aumentando en consecuencia su capacidad de auto-purificación (Pinay et al., 1990).

De este modo, resulta clave la protección, restauración e implementación de zonas de atenuación (zonas buffer), como son los humedales y ecotonos ribereños, para el mantenimiento de la integridad biológica de los ecosistemas acuáticos, dado que la calidad del hábitat se encuentra estrechamente ligada a las fuentes de nutrientes, su procesamiento interno y exportación (Miltner \& Rankin, 1998). Asimismo, la aplicación de mejoras en las prácticas agrícolas reducirían en gran medida los aportes de fósforo en la cuenca, como fue demostrado en otros ríos del mundo (Honti et al., 2010) y en áreas agrícolas al norte de la Provincia de Bs. As. (Mugni, 2008). 


\section{11. Funcionamiento del sistema}

\subsubsection{Plancton y rasgos geomorfológicos}

Los canales, como modificaciones antrópicas en la red de drenaje del río Salado, presentan una área transversal trapezoidal (canales 1 y 3) que dificulta el desarrollo de sus márgenes y las comunidades asociadas (plantas vasculares y macrófitas, epifiton, bentos, epipelon), capaces de actuar como zonas de amortiguamiento ante los aportes del ecosistema terrestre. Estas características incrementan la descarga de caudal y la velocidad de corriente, facilitan la deriva de los organismos residentes y perjudican la reproducción (Reynolds, 1994; Reynolds \& Descy, 1996), en particular del zooplancton (Reynolds 2000; Rosetti et al., 2009; Kim et al., 2012). El arroyo también presenta tramos con márgenes rectificadas, y sus nacientes fueron modificadas durante la construcción del nuevo vertedero en la laguna del Bragado.

Estos aspectos geomorfológicos afectaron las características de estos ambientes, registrando los canales la máxima amplitud en el rango de valores de los parámetros físico-químicos y descriptores biológicos analizados a lo largo de los muestreos. A diferencia de los cursos de agua naturales, los canales carecen de rasgos morfológicos que promuevan la heterogeneidad espacial, la distribución diferencial de las velocidades de corriente, y la generación de zonas de almacenamiento (remansos, áreas de aguas estancadas), que les permitan la permanencia temporaria del plancton en las aguas fluyentes (Walks, 2007; Withers \& Jarvie, 2008).

De acuerdo al Telescoping Ecosystem Model (Fisher et al., 1998) la configuración de los cauces afecta su respuesta ante los disturbios, dado que la resiliencia depende de la interacción entre los subsistemas que conforman el sistema arroyo, y de su grado de sensibilidad. Asimismo, considera que la sinuosidad del cauce aumenta la retención de los nutrientes y acorta la longitud de procesamiento, por el aumento de la conectividad lateral (Fisher et al., 1998). Lo inverso debería esperarse para los canales, donde los cursos de agua prosiguen una línea recta y registran un escaso desarrollo de sus márgenes (lecho en forma de U), provocando una menor interacción lateral entre los subsistemas, con predominancia de un flujo unidireccional. Estas características hacen que los canales sean menos resilientes al disturbio, tal como fue hallado para la comunidad del fitoplancton, a través de la tasa de cambio $\sigma_{s}$.

Asimismo, los resultados observados se condicen con algunos de los supuestos del River Continuum Concept (RCC) (Vannote et al., 1980), que considera a la geología de la cuenca, a la composición de sus rocas y a la geomorfología de los cauces como aspectos conformadores del sistema (Ladle \& Westlake, 1995). Otros aspectos son contemplados por la Espiral de los nutrientes revisada (Ensign \& Doyle, 2006), donde se reconoce que la geomorfología de los cauces condiciona 
el tiempo de residencia del agua, afectando de manera indirecta el procesamiento de los nutrientes, dada su relación con el tamaño del cauce y la presencia de zonas de almacenamiento temporario.

Las características geomorfológicas de la región (baja pendiente, altas irradiancias por márgenes no forestados, lechos de materiales finos sin grava) promueven el desarrollo de macrófitas, epifiton, epiliton, así como del plancton, como productores primarios autóctonos de los sistemas lóticos pampeanos, los cuales determinan la heterogeneidad del hábitat y la estructura de estas comunidades (Giorgi et al., 2005; Vilches \& Giorgi, 2010).

Las características hidromorfológicas condicionaron el desarrollo del plancton en el área de estudio, en acuerdo con otros antecedentes de la cuenca del río Salado (O'Farrell, 1993; Neschuk et al., 2002a, b; Solari et al., 2002; Gabellone et al., 2005, 2014; Claps et al., 2009; Bazzuri et al., 2008; 2010a, b; Solari \& Mac Donagh, 2014). En este sentido, la presencia de sectores con diferente morfometría, profundidad del cauce, contenido de materiales suspendidos y flujo, ocasiona cambios en la dinámica del plancton (Descy \& Gosselain, 1994; Hein et al., 1999, Tockner et al., 1999). Asimismo, su dinámica estuvo controlada por los procesos que ocurren a escala de cuenca (Billen et al., 1994; Everbecq et al., 2001), como son los cambios en la red de drenaje presentes en el área de estudio (canalizaciones de la Pampa Arenosa - sistema Bragado). De esta forma, los aspectos geomorfológicos presentes en el área de estudio desempeñan un rol fundamental en la configuración de este sistema hidrológico complejo.

Esta influencia de la geomorfología en la dinámica del plancton también ha sido observada en otros ríos del mundo, siendo un rasgo predominante en los sistemas lóticos, y en particular en el potamon (Saunders \& Lewis, 1989; Junk et al., 1989; de Ruyter van Steveninck et al., 1992; Reynolds \& Glaister, 1993; Basu \& Pick, 1997; Lair \& Reyes-Marchant, 1997; Gosselain et al., 1998; Reckendorfer et al., 1999). Los procesos geomorfológicos e hidrológicos de gran escala también controlan la estructura y el funcionamiento del ecosistema fluvial a escala local (Buijse et al., 2005), y su inclusión es necesaria en el marco de un estudio integrado de los sistemas lóticos (van Nieuwenhuyse \& Jones, 1996).

\subsubsection{Aportes de las zonas de almacenamiento}

Los ambientes de la planicie de inundación y las zonas de almacenamiento, además de explicar los incrementos observados en el fitoplancton (Reynolds \& Glaister 1993; Reynolds, 1994) también juegan un rol esencial como lugares de exportación de organismos planctónicos (Schröder, 2001). Sin embargo, su significado es más importante para el zooplancton que para el fitoplancton, 
debido a sus tiempos generacionales más largos (Basú \& Pick, 1996) y a su mayor susceptibilidad a la velocidad de corriente y a los materiales suspendidos (Reckendorfer et al., 1999).

La teoría de las áreas de retención o Inshore Retention Concept (Schiemer et al., 2001) establece que la heterogeneidad de flujos crea áreas de refugio dentro del propio cauce de los ríos, o cercanas a la costa, siendo importantes hábitats para el desarrollo del plancton, particularmente para los copépodos y los cladóceros (Walks, 2007). De esta manera, la observación de los valores máximos de abundancia total de copépodos y cladóceros, de sus hembras ovígeras y de $n^{o}$ de especies de estos grupos en reproducción en el río aguas arriba podría ser explicada por la disponibilidad temporal de estas zonas de almacenamiento.

La extensión de estas zonas de almacenamiento depende del nivel de agua y de la morfología de las orillas del río (Baranyi et al., 2002), siendo estos aspectos más relevantes en el río aguas arriba del trasvase, dada la conformación más natural de sus márgenes. En este sentido, VadadiFülöp et al. (2009) postulan que en los ríos regulados o canalizados la producción del zooplancton no es demasiado importante, sino que la disponibilidad de las zonas de almacenamiento es la que determina sus densidades en el cauce principal.

Este concepto de las áreas de retención o zonas de almacenamiento (Schiemer et al., 2001), también reconoce que las interacciones bióticas son mayores durante los momentos de bajos caudales, tal como lo observado en el canal 2 durante este estudio. Asimismo, la mayor abundancia y presencia de organismos del plancton en reproducción hallada en el canal 2 y en el río también podría ser explicada por este concepto, ya que establece que los ecotonos ribereños y los humedales de la planicie de inundación son importantes refugios para los animales acuáticos, a la vez que actúan como corredores fluviales, propiciando su dispersión (Kronvang et al., 2007). Además, en el canal 2 también se observó la máxima riqueza acumulada de especies zooplancton, destacándose los rotíferos, con representantes típicamente lóticos (Brachionus, Keratella) y litorales (Lecane, Trichocerca, Synchaeta, Proales, Proalides, Filinia, Polyarthra, Asplanchna, y bdelloideos), dada su relación con los ambientes lénticos vinculados del sistema Bragado. En este sentido, se reconoce que la presencia de macrófitas y de vegetación ribereña favorece la heterogeneidad del hábitat en los ambientes fluviales (Stoyneva, 1994; Giorgi et al., 2005).

De esta manera, la abundancia y riqueza de especies de zooplancton en la cuenca superior del río Salado estuvo condicionada por la conectividad con los hábitats de la planicie de inundación, la disponibilidad de zonas de almacenamiento, la heterogeneidad espacial de los tributarios y los mayores tiempos de residencia de los ambientes lénticos vinculados, tal como lo observado en otros grandes ríos de llanura (Saunders \& Lewis, 1989; Basu \& Pick, 1996; Hein et al., 1999; Kim et 
al., 2001, 2012; Scheimer et al., 2001; Baranyi et al., 2002; Holst et al., 2002; Picard \& Lair, 2005; Lair, 2006; Zimmermann-Timm et al., 2007; Sluss et al., 2008; Lansac-Tôha et al., 2009; Ning et al., 2010).

\subsubsection{Plancton, resiliencia y disturbios}

La resiliencia es la habilidad de un ecosistema para reorganizar su estructura y recuperar sus funciones a un estado ambiental previo a la disrupción por fuerzas externas (Harrison, 1979), y puede medirse a través de la intensidad de la perturbación que el sistema puede resistir (Garnier \& Billen, 2007). Estudios en el río Po determinaron que el zooplancton, dominado por los rotíferos, presenta una fuerte tendencia hacia la recuperación luego de eventos de disturbio (descarga de caudal, depredación en exceso), destacando la importancia de los mecanismos de auto-regulación (Rossetti et al., 2009). Asimismo, se reconoce que el plancton es una comunidad resiliente dadas sus características claves como son los cortos ciclos de vida de los organismos y las estructuras de resistencia que a menudo producen (Rossetti et al., 2009). En este sentido, el plancton de la cuenca superior del río Salado estuvo dominado por los rotíferos y las clorofitas clorococcales, siendo organismos de rápido crecimiento, capaces de recuperarse ante los disturbios. Estos grupos del plancton estarían adaptados al régimen hidrológico y a las variaciones en la conductividad en la cuenca (Gabellone et al., 2013a).

La elevada riqueza de especies hallada en el área de estudio, 438 taxa de fitoplancton y 166 taxa de zooplancton, dan cuenta de que el plancton de la cuenca superior del río Salado constituye un sistema resiliente, aunque también redundante, con posibilidad de reemplazo de especies ante la superación de los niveles de tolerancia. Además, el grado de conectividad con la planicie de inundación y los ambientes lénticos asociados facilitarían el proceso de incorporación de especies a lo largo de su recorrido hacia el mar (Gabellone et al., 2013a). En este sentido, se considera que la riqueza de especies aumenta la función del ecosistema en la transferencia del carbono, ya que una red trófica compleja permite una mayor resiliencia, al haber más conexiones alternativas por donde pueda fluir la energía (Reynolds, 1998). Esta idea de "red trófica" se opone a la postura de "redundancia", y establece que las especies raras no son importantes para el funcionamiento de la comunidad, ya que la organización de la comunidad se basa en la diversidad de especies y sus interacciones (Reynolds, 1997). Sin embargo, otros autores ven a la redundancia como un seguro natural contra la pérdida de especies (Walker, 1992), como por ejemplo, ante un disturbio, donde el crecimiento compensatorio de las especies raras o poco abundantes aseguraría el mantenimiento de la comunidad. 
Estos resultados también se condicen con la Paradoja del Plancton (Hutchinson, 1961) que revela la contradicción aparente entre el número de especies y los recursos limitados por los cuales compiten, bajo las premisas del Principio de Exclusión Competitiva (Hardin, 1960). Explicaciones posibles sugieren que las comunidades planctónicas no se encuentran en un estado de equilibrio continuo (Wilson, 1990) y que el cambio frecuente en las variables ambientales evitaría la exclusión competitiva de las especies raras subdominantes (Levin, 2000). De este modo, los factores externos observados como el ciclo estacional, el régimen hidrológico, los disturbios y la heterogeneidad espacial, en su conjunto permitirían la coexistencia de las especies, promoviendo la diversidad (Padisák, 1994).

Los eventos de inundación y de sequía observados en este estudio pueden ser interpretados como pulsos (Junk, 1999), constituyendo disturbios hidrológicos que afectan la abundancia y composición del plancton (Train \& Rodriguez, 1998; Nabout et al., 2007), dados los cambios que se producen en las variables ambientales (Schagerl et al., 2009; Thomaz et al., 2007). Además, los disturbios generan condiciones que permiten la superposición de nichos (Ward et al., 2002), provocando cambios en la composición específica y en la relación depredador-presa entre los organismos del plancton (Sommer et al., 1993). De esta forma, la heterogeneidad espacio-temporal de los sistemas río-planicie de inundación permite que sean ambientes diversos y ricos en especies debido a esta dinámica fluvial dominada por los pulsos de inundación y los eventos de sequía (Junk et al., 1989; Neiff, 1996; Ward et al., 1999), donde la comunidad del plancton es modulada por fuerzas internas y externas periódicas, asociadas al régimen hidrológico (Weilhoefer et al., 2008).

Los disturbios también promueven la distribución de los hábitats en parches (Pringle et al., 1988), y es el régimen de flujo el que determina su naturaleza dinámica en los ríos (Hill et al., 1991). El nivel hidrométrico resulta un factor clave en la regulación de la conexión entre los parches de paisaje, y de esta forma, la conectividad hidrológica contribuye a la heterogeneidad espacial de la planicie de inundación de los ríos (Amoros \& Bornette, 2002). En este sentido, la teoría del Telescoping Ecosystem Model (Fisher et al., 1998) considera a los arroyos como ecosistemas heterogéneos, constituidos por la interacción entre parches de paisaje denominados como subsistemas (área central, hiporreica, parafluvial y ribereña). Asimismo, también establece que en los arroyos, la recuperación pos-disturbio (inundación) va a ser mayor en el área central del cauce que en los restantes subsistemas concéntricos, constituyendo las algas microscópicas (plancton, epifiton, epibentos) uno de los componentes más resilientes, dados sus cortos ciclos de vida. Sin embargo, Vilches \& Giorgi (2010) hallaron que el Aº Las Flores registró un bajo nivel de resiliencia 
luego de una inundación importante, debido a que el epifiton se encuentra relacionado a la disponibilidad de macrófitas como sustratos, siendo también son afectadas por la crecida.

Se reconoce que las comunidades que se desarrollan en un ambiente altamente estresante resultan más resistentes al disturbio, que aquellas que crecen en condiciones de bajo estrés (Sierra \& Gómez, 2010). Algunos organismos pueden tolerar la variabilidad en las condiciones ambientales dependiendo de sus estrategias adaptativas, pero su costo biológico se traduce en una reducción en las tasas de reproducción (Köhler, 1994). Esta situación pudo haberse registrado en el arroyo, donde el plancton estuvo integrado por especies del fito y zooplancton tolerantes a las condiciones de alta carga de nutrientes y contaminación con materia orgánica, a la vez que se registró mínima presencia de organismos en reproducción a lo largo de los muestreos. En acuerdo con estos resultados, Dos Santos (2015) halló un escaso desarrollo del fitobenton en el arroyo durante este estudio, compuesto principalmente por especies de diatomeas pennales tolerantes.

Estudios sobre enriquecimiento artificial con nutrientes en arroyos pampeanos han demostrado un aumento en la capacidad de incorporación de nutrientes por parte de las algas perifíticas (Giorgi, 1995) y de las diatomeas epipélicas (Cochero et al., 2015) en condiciones de laboratorio. Una respuesta similar sería esperable en el fitoplancton del arroyo Saladillo, pero sin embargo, en este sitio se observaron los valores mínimos de abundancia, biomasa y clorofila $a$, posiblemente relacionado al efecto tóxico e inhibitorio de la fotosíntesis que presenta el amonio (Azov \& Goldman, 1982; Källqvist \& Svenson, 2003).

En el canal 1, la elevada concentración de sales pudo haber actuado como un factor de estrés, simplificando la estructura de la comunidad y de sus interacciones a lo largo de los muestreos. En acuerdo con estos resultados, Dos Santos (2015) halló en este mismo sitio de muestreo una comunidad del fitobentos compuesta por especies adaptadas a las elevadas concentraciones de sales, así como también un gradiente en su distribución en los restantes sitios del sistema Bragado y el río Salado (Dos Santos, 2015). En este sentido, se reconoce que los ambientes artificiales, como son los canales, carecen de una organización de la comunidad compleja que otorgue cierta resiliencia ante los disturbios (Withers \& Jarvie, 2008). Asimismo, se tiene conocimiento de que la salinidad actúa como factor de estrés sobre el crecimiento y la distribución del fitoplancton en los ecosistemas salobres (Flöder et al., 2010), y que también afecta la diversidad, la productividad primaria y las interacciones tróficas (Barinova et al., 2011). 


\subsubsection{Plancton y conectividad hidrológica}

La conectividad hidrológica observada entre ambientes en condiciones de aguas altas promovió la presencia de comunidades planctónicas similares, con la dominancia de las mismas especies del fito y zooplancton, tanto en el río Salado como en el sistema Bragado, posiblemente asociado al proceso de homogenización del hábitat y a la reducción de la variabilidad espacial durante las inundaciones (Thomaz et al., 2007). Por otro lado, la baja recurrencia del plancton en condiciones de aguas altas, además del factor estacional y la dilución por la crecida, también podría ser explicada por la migración de los organismos desde el cauce principal a la planicie de inundación, donde encuentran nuevos hábitats y recursos disponibles (Johnson et al., 1995). Asimismo, esta elevada conectividad también favoreció la incorporación de inóculos desde los ambientes asociados (Reynolds, 2000) hacia los canales y el río Salado aguas abajo.

De un modo inverso, las sequías también son disturbios y durante estos eventos la conectividad hidrológica se ve reducida, y prevalecen las condiciones locales (Lake, 2003). De esta forma, en condiciones de aguas bajas y muy bajas se observó la diferenciación de las comunidades del plancton entre los sitios de muestreo, tal como lo hallado en otros ríos de llanura fuertemente condicionados por el régimen hidrológico, como son el río Paraná (de Cabo et al., 2003; Thomaz et al., 2007) y el río Salado (Santa Fe) (Devercelli \& O’Farrell, 2013).

De acuerdo al Telescoping Ecosystem Model (Fisher et al., 1998), las sequías pueden ser disturbios muy severos en los arroyos, ya que el área central donde se halla el plancton se ve reducida y hasta puede volverse intermitente, acentuando la influencia de los componentes laterales por la falta de dilución. De esta forma, la falta de flujo genera la pérdida de muchos hábitats para los organismos acuáticos, y se produce un deterioro de la calidad del agua y de las fuentes de alimento, provocando cambios en las comunidades, en las relaciones interespecíficas y en los procesos del ecosistema (Lake, 2003).

Esta situación se observó en el canal 1 en aguas muy bajas, donde la comunidad del plancton registró un escaso desarrollo y estuvo dominada por cianobacterias tolerantes a la baja disponibilidad de nutrientes (Reynolds et al., 2002), y por ciliados y rotíferos de ambientes salobres, como representantes del zooplancton. Asimismo, los bajos flujos observados en el canal 2 realzaron la importancia de las interacciones bióticas (pastoreo, depredación) como controladores de la estructura y composición del plancton, dada por los rotíferos y las larvas nauplii en aguas bajas y muy bajas, en acuerdo con estudios en otros sistemas lóticos (Gosselain et al., 1998a; Lair et al., 1999; Thorp \& Casper, 2003; Lair, 2005; Rosetti et al., 2009). 


\subsubsection{Funcionamiento del sistema en diferentes condiciones hidrológicas}

A través de los muestreos se observaron patrones distintivos en el funcionamiento del río Salado entre eventos de inundación (aguas altas) y de sequía (aguas bajas), tal como lo observado en otros ríos de llanura (Ward et al., 1999; Tockner et al., 2000; Ward \& Tockner, 2001; Devercelli, 2006, 2010; Thomaz et al., 2007; Schagerl et al., 2009; de Morais Costa et al., 2011; Devercelli \& O'Farrell, 2013), aunque con algunas particularidades.

En aguas altas se observó una gran conectividad entre el río y la planicie de inundación y los ambientes adyacentes, altas velocidades de corriente y contenido de polifenoles totales disueltos, y valores mínimos de conductividad eléctrica. Este evento coincidió con bajas temperaturas del agua (otoño tardío), las cuales limitaron el desarrollo del fito y zooplancton, registrándose los valores mínimos de abundancia y biomasa total, y de clorofila $a$. Estas características propiciaron las fuentes alóctonas de carbono orgánico, presentando mínima proporción entre la biomasa del plancton y la MOP.

Por el contrario, en aguas bajas se observaron los valores máximos de conductividad, de concentración de iones mayoritarios, turbidez, SS y MOP, estos últimos dados por la menor profundidad del cauce, la cual propició la resuspensión de materiales desde el lecho del río. Aún cuando el flujo fue escaso, la menor velocidad de corriente y las altas temperaturas registradas promovieron el desarrollo y la reproducción del plancton, particularmente de especies de rotíferos tolerantes a la elevada salinidad (Brachionus plicatilis y B. angularis). Sin embargo, en caudales medios se observó el máximo desarrollo del plancton, tanto de la abundancia como la biomasa total de fito y zooplancton, de la diversidad de especies, y la proporción de carbono autóctono constituyente de la MOP (Fig. 5.2). De un modo similar, en el río Danubio se halló máxima productividad primaria, biodiversidad y prevalencia de los procesos autogénicos en la toma de los nutrientes en conectividades intermedias entre el río y la planicie de inundación (caudales medios) (Tockner et al., 2000; Schagerl et al., 2009). Mientras que en aguas altas prevaleció el transporte aguas abajo como característica principal del sistema fluvial, en aguas bajas se destacaron las interacciones tróficas (Tabla 3, Anexo IV).

La Hipótesis del Disturbio Intermedio (Connell, 1978) establece que la diversidad de la comunidad será máxima cuando los disturbios sucedan en escalas intermedias de frecuencia e intensidad, mediante la reducción de la abundancia de las especies dominantes competitivas (Reynolds, 1998b). En el plancton, los disturbios modifican las tasas de pérdida y crecimiento de los organismos, y su frecuencia resulta esencial en el mantenimiento de la diversidad y la riqueza de 
especies (Sommer et al., 1993; Reynolds, 2002), al mantener a la comunidad por debajo del estado de exclusión competitiva (Padisák, 1994). En este sentido, Ward et al. (1999) aplicaron estos conceptos al funcionamiento de los grandes ríos, y propusieron que el máximo de diversidad se observarían en los niveles de conectividad intermedia, dado que una baja conectividad (sequía) obstaculiza el intercambio entre los parches de paisaje y disminuye la diversidad por la fragmentación del hábitat. De un modo opuesto, una excesiva conectividad (inundación) afecta negativamente la diversidad por la reducción de la heterogeneidad del hábitat, a la vez que aumenta la movilidad de los organismos a través del paisaje fluvial (Ward et al., 1999).

Sin embargo, en este estudio no se observó en aguas altas una reducción tan importante de la diversidad del fito y zooplancton, como la hallada en aguas bajas, posiblemente debido a que el pico de crecida muestreado no fue lo suficientemente importante como para afectarla. Por el contrario, la conectividad hidrológica favoreció la incorporación de especies desde la planicie de inundación y los ambientes lénticos vinculados, siendo máxima la riqueza específica del fito y zooplancton en estas condiciones (aguas altas). En este sentido, Thomaz et al. (2007) enfatizan que aún cuando la máxima diversidad de especies se observe en niveles intermedios de disturbio, las inundaciones intensas son importantes para el intercambio de nutrientes, propágulos y organismos entre hábitats, ya que durante estos eventos las especies raras incrementan su posibilidad de dispersión y colonización, promoviendo la diversidad.

De esta forma, la riqueza de especies en los sistemas río-planicie de inundación se maximiza debido a la superposición de tres conceptos relacionados: la Hipótesis del Disturbio Intermedio (Connell, 1978; Ward \& Stanford, 1983), la conectividad hidrológica y los ecotonos ribereños (Ward \& Tockner, 2001), pudiendo explicar estos conceptos la diversidad y riqueza de especies hallada en los sitios de muestreo. En acuerdo con el modelo Serial Discontinuity Concept ampliado (Ward \& Stanford, 1995b), el río Salado debe ser entendido como un sistema integrado río-planicie de inundación, donde los niveles intermedios de disturbio natural (ciclos secos y húmedos) resultan como precursores de la heterogeneidad del hábitat y de variedad de recursos presentes, promoviendo la riqueza de especies y la diversidad observada en los diferentes tramos del río.

Las teorías previamente expuestas sobre el River Continumm Concept (Vannote et al., 1980), los conceptos de Junk et al. (1989) sobre el Pulso de inundación y de las áreas de retención (Schiemer et al., 2001) y la heterogeneidad espacial dada por la distribución del hábitat en parches (Hill et al., 1991), también colaboran en el entendimiento de la distribución del plancton en la cuenca superior del río Salado en los diferentes momentos hidrológicos. Sin embargo, en estos esquemas conceptuales, los componentes fundamentales del flujo de la energía dentro del sistema río-planicie de inundación 
son el consumo de la materia orgánica alóctona y la producción primaria de las macrófitas y las plantas vasculares, teniendo las microalgas una menor contribución (Sedell et al., 1989).

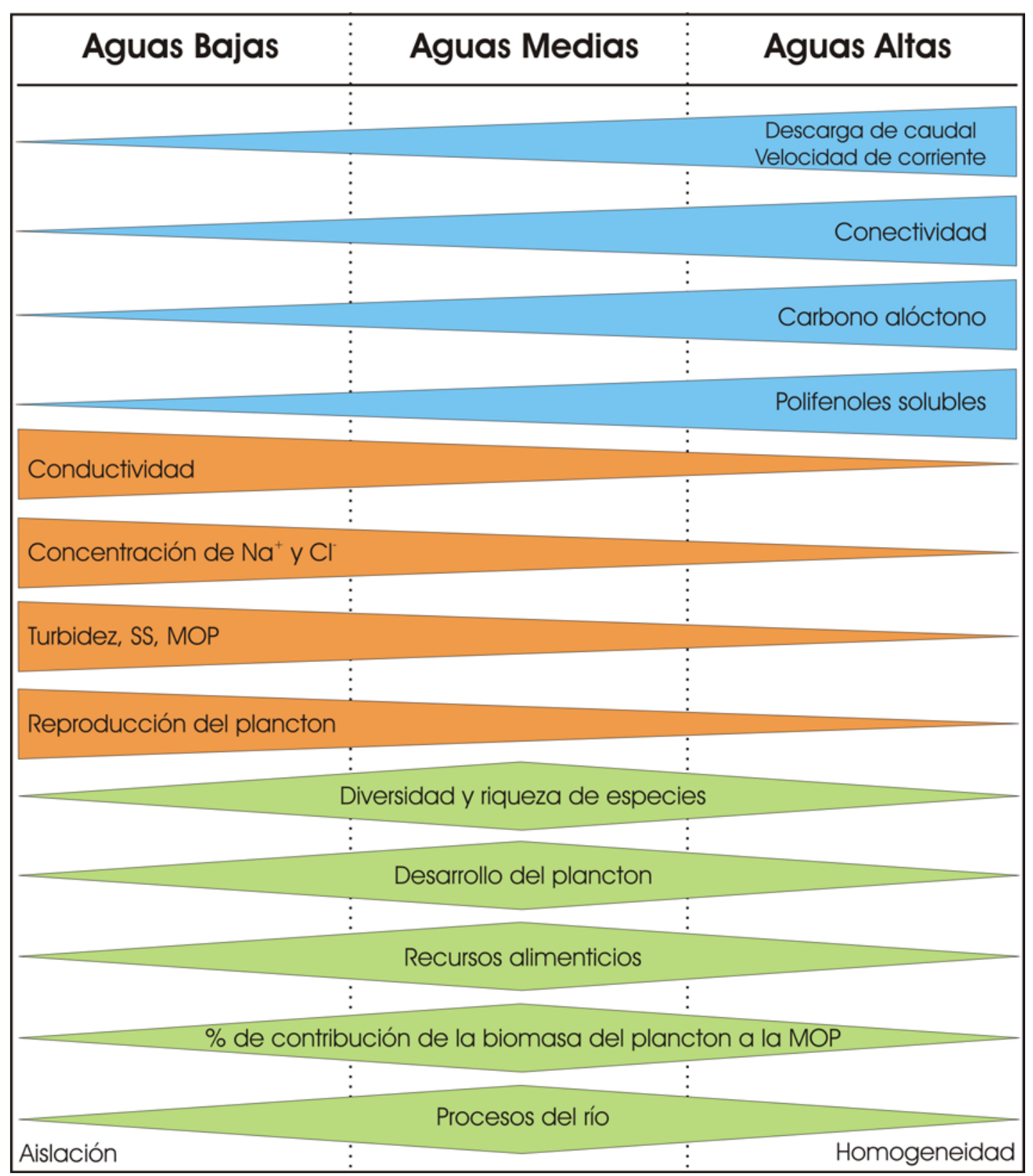

Figura 5.2.: Esquema de las condiciones hidrológicas de aguas altas, caudales medios y aguas bajas en el río Salado, y los principales procesos del ecosistema.

En contraposición, el modelo de Productividad Fluvial (Thorp \& Delong, 1994) considera que la producción es básicamente autóctona, y que se desarrolla en el propio cauce del río, en la planicie de inundación o en áreas adyacentes permanentemente inundadas, que se conectan durante las crecidas. En este esquema la productividad primaria estaría dada por las microalgas, siendo a su vez la fuente principal de materia orgánica que se moviliza a través de las redes tróficas (Delong \& Thorp, 2006). De todos modos, ambos modelos conceptuales, del Pulso de inundación (Junk et al., 1989) y de la Productividad Fluvial (Thorp \& Delong, 1994), destacan la importancia de las 
conexiones laterales en los ciclos biogeoquímicos, en la estructura de las comunidades biológicas y la integridad del sistema río-planicie de inundación (Thoms, 2003). Asimismo, los conceptos de la Ecología de Paisajes, que integran los sistemas terrestres y acuáticos en una unidad funcional (Wiens, 2002) basada en las interacciones (Thompson \& Lake, 2010), y la comprensión de los regímenes de disturbios (Tockner et al., 2000; Ward et al., 2002), constituyen importantes desafíos para futuras investigaciones, debiendo ser considerados para un mejor entendimiento ecológico de los sistemas lóticos en la cuenca superior del río Salado.

La Hipótesis del Disturbio Intermedio, ha sido demostrada en experiencias in situ de mesocosmos en lagos (Flöder \& Sommer, 1999), a campo en embalses (Grover \& Chrzanowski, 2004), y mediante la utilización de modelos matemáticos de fitoplancton (Elliott et al., 2001). En acuerdo con las variables forzantes halladas en este estudio (temperatura, conductividad, velocidad de corriente, nivel de agua), tales investigaciones destacan la importancia de los disturbios hidrológicos como agentes rectores de la diversidad del plancton, más que la limitación por los recursos (luz, nutrientes) (Hutchinson, 1961; Tilman et al., 1982). En este sentido, resulta necesario profundizar estos conceptos a futuro, mediante ensayos en condiciones de laboratorio, siendo una herramienta imprescindible para contrastar tales afirmaciones. 


\subsection{Implicancias de las actividades humanas}

\subsubsection{Efecto de la ejecución de obras de mejora hídrica}

Durante este estudio se observó la ejecución de obras de mejora hídrica en el canal 2 y en las nacientes del arroyo Saladillo, a partir del segundo muestreo. Estas obras estuvieron relacionadas con la construcción de un nuevo vertedero en la laguna del Bragado, que interrumpieron el flujo de agua en las nacientes del arroyo, desvinculándolo del sistema. De esta forma, se evidenció el empobrecimiento del plancton y la degradación de las aguas del arroyo en los últimos muestreos, por ser un cuerpo receptor de vertidos con alta carga de nutrientes y materia orgánica (planta de tratamiento de efluentes cloacales de la ciudad de Bragado). En este sentido, se reconoce que los disturbios interfieren en el proceso interno de auto-organización y en el equilibrio ecológico de los sistemas (Reynolds et al., 1993), pudiéndose interpretar como "gatillos" que disparan la sucesión (Scheffer et al., 2003), donde la frecuencia de estas fuerzas físicas resulta crítica para el desarrollo del plancton (Padisák, 1994). La falta de flujo de agua por las obras en sus nacientes redujo la capacidad de dilución de los vertidos que recibe, y el aumento del tiempo de residencia de los compuestos orgánicos condujo a la anoxia y a las vías reductoras. Esta situación, afectaría el procesamiento interno de los nutrientes en la espiral (Ensing \& Doyle, 2006).

La presencia de asentamientos humanos, particularmente en la cuenca superior del río Salado (Neschuk, 2001; Neschuk et al., 2000; Solari \& Mac Donagh, 2014) perjudican el estado trófico de las aguas, siendo la eutrofización una de las principales problemáticas mundiales que afecta la calidad ecológica y la diversidad de los sistemas acuáticos (Kronvang et al., 1999). En las últimas décadas, se ha observado un aumento en la biomasa algal en ríos de Europa y Norteamérica, asociado al incremento de los aportes de nutrientes, junto con las modificaciones hidrológicas y las obras de regulación (Wehr \& Descy, 1998). En este sentido, se reconoce que las canalizaciones aceleran el transporte de nutrientes y materiales suspendidos, afectando la capacidad de retención y transformación de los mismos (Kronvang et al., 1999) y en el ciclado del carbono (Walks, 2007).

Estudios en arroyos pampeanos han demostrado que estas obras hidráulicas tienen importantes consecuencias en la abundancia y composición de especies, y en la riqueza y diversidad del fitoplancton y fitobentos (Licursi, 2005; Bauer, 2009; Conforti et al., 2009). Estos cambios se deben a que el dragado afecta el lecho de los cauces por la remoción de material y modifica las condiciones físico-químicas de la columna de agua, incrementando los sólidos suspendidos, la materia orgánica y los nutrientes, deteriorando la calidad del agua (Licursi \& Gómez, 2009).

En el canal 2 se observó una situación diferente, donde a pesar de las obras realizadas durante el período de estudio (modificación de las márgenes, construcción de terraplenes en los márgenes 
y un muro de contención que interrumpía el flujo), el plancton desarrolló una estructura compleja y diversa. El continuo aporte de la laguna Municipal, sumado a su naturaleza de humedal canalizado de vastas dimensiones, posiblemente le confirió una mayor resiliencia y capacidad de recuperación ante estos disturbios, dada su heterogeneidad espacial, diversidad de hábitats y riqueza de especies. En acuerdo con Licursi \& Gómez (2009) y Bauer (2009), el aporte de algas provenientes desde sitios aguas arriba seguramente contribuyó a la recolonización de especies, tal como fuera observado en el fitobentos y fitoplancton del $\mathrm{A}^{\mathrm{o}}$ Rodríguez, durante obras de canalización y dragado.

Sin embargo, en el último muestreo (aguas muy bajas - sept. 2009) se observó una leve merma en la riqueza de especies de ambas fracciones del plancton en el canal 2, si se lo compara consigo mismo y con los valores hallados en el canal 3 (no afectado por obras). Esto podría deberse a que las obras hidráulicas llevadas a cabo, además de constituir un disturbio, también alteran la conectividad lateral con los ambientes adyacentes por la fragmentación de los ecosistemas (Thoms, 2003). Asimismo, Dos Santos (2015) concluye que el fitobentos del canal 2 sufrió modificaciones en su estructura por la ejecución de estas obras hidráulicas, afectando su abundancia y biomasa total y la composición de especies. De igual manera, Licursi \& Gómez (2009) hallaron un aumento en la abundancia de diatomeas bentónicas tolerantes y muy tolerantes a las condiciones observadas durante obras de dragado en un arroyo pampeano (aumento de SS, materia orgánica y nutrientes).

En este sentido, se reconoce que las obras de manejo hídrico tienden a aislar el cauce principal de su planicie de inundación y de las zonas transicionales de vegetación ribereña (Johnson et al., 1995), teniendo efectos sobre las interacciones que estructuran los ecotonos (Zalewski et al., 1998), y en consecuencia, sobre la diversidad de estos ambientes (Ward et al., 1999). La pérdida de los ambientes adyacentes y sus interacciones tiene efectos deletéreos sobre la diversidad y la riqueza de especies (Thomaz et al., 2007), los cuales también afectan los procesos del río, como el mantenimiento de las comunidades del plancton en el cauce principal del río (Reynolds, 2000), el uso de los recursos y la producción de biomasa (Balvanera et al., 2006; Flöder et al., 2010).

Está demostrado que la intervención humana en los ecosistemas fluviales, como es la remoción de meandros, la construcción de defensas contra las inundaciones, el drenaje de los humedales y bañados (Van Dijk et al., 1996), afecta directamente los ríos y sus cuencas de drenaje (Johnson et al., 1995). Asimismo, los terraplenes construidos en el humedal que atraviesa el canal 2 constituyen una barrera física que también interfiere en la acción modeladora de los caudales extraordinarios (Ward \& Stanford, 1995a; Dickenson et al., 2010), limita la transferencia de materiales y organismos en estos períodos (Tockner et al., 1999; Hein et al., 2004) y reduce la capacidad de retención de los 
ambientes adyacentes (Withers \& Jarvie, 2008). En este sentido, el mantenimiento de los patrones naturales de conectividad lateral resulta esencial para la viabilidad de muchas especies acuáticas que utilizan los diferentes hábitats presentes en el cauce principal, la planicie de inundación y la vegetación ribereña, a lo largo de su ciclo de vida (Bunn \& Arthington, 2002). Además, las obras observadas en las lagunas Municipal y del Bragado seguramente también modificaron su dinámica hidrológica, pudiendo afectar la descarga de caudal, el tiempo de residencia y la capacidad de dilución de los aportes que reciben, así como su función como áreas de refugio, reproducción y reclutamiento de organismos al cauce principal del río (Humphries et al., 2006).

\subsubsection{Efecto de las canalizaciones de la Pampa Arenosa en la cuenca superior del río Salado}

A menudo los ríos son regulados por obras de ingeniería sin considerar los procesos biológicos (Zalewski et al., 1998), y muchas propuestas de manejo fallan en el reconocimiento de un principio científico básico, como es que la integridad de los sistemas lóticos depende en gran medida del carácter natural de su dinámica interna (Poff et al., 1997). Además, perjudican el proceso fundamental que los mantiene, como son las inundaciones regulares y la interacción dinámica entre los ambientes acuático y terrestre (Bayley, 1995). En este sentido, el manejo de los grandes ríos requiere de un balance entre las necesidades humanas y la integridad ecológica (Wehr \& Descy, 1998), y para su ejecución es necesario un conocimiento pormenorizado de los patrones funcionales y estructurales del sistema (Baigún et al., 2007).

Se reconoce que décadas de control hídrico en la Provincia de Buenos Aires han producido impactos negativos en la cuenca del río Salado, como la aceleración de la descarga, el aumento de la amplitud de las inundaciones, la erosión del cauce y modificaciones en los niveles de las aguas subterráneas (Neschuk, 2001). Asimismo, la construcción de canales ha acentuado los problemas de anegamientos en la región, dado que éstos se producen por causas naturales relacionadas a las características hidrológicas propias del sistema, siendo de difícil control por medio de la regulación antrópica (Kruse \& Laurencena, 2005).

Además, la ejecución de obras hidráulicas puede tener efectos muy variables sobre la dinámica hidrológica de los canales afluentes del río Salado, dependiendo del rasgo geomorfológico que afecten (planicie de inundación, lomadas eólicas o mantos eólicos), lo cual exige un manejo muy cuidadoso (Rojo et al., 2006). En este sentido, las modificaciones antrópicas observadas en la cuenca de drenaje del río Salado (canalizaciones de la Pampa Arenosa - sistema Bragado) tienen importantes consecuencias sobre las características del agua, el comportamiento hidrológico y las 
comunidades biológicas, en acuerdo con estudios en otros ríos del mundo impactados por obras hidráulicas (Weilhoefer et al., 2008; Withers \& Jarvie, 2008).

Dado que las conexiones hidrológicas estructuran los ecosistemas a nivel de paisaje (Pringle, 2003), reconocer estas relaciones dentro de un marco holístico que considere los procesos internos y las variables forzantes que operan en las diferentes escalas espacio-temporales (Amoros \& Bornette, 2002), así como las alteraciones que se producen por las obras de regulación (Ward \& Stanford, 1995a), permitiría el desarrollo de controles y un mejor manejo de las fuentes de recursos (Likens, 2001), dentro de la Provincia de Buenos Aires, particularmente en la cuenca del río Salado.

\subsubsection{Perspectivas}

Se pronostica que el Cambio Climático causará profundos efectos en la hidrología de los ríos, como la persistencia de bajas descargas de caudal, rápidos eventos de inundación transitoria y la acentuación de la eutrofización (Rossetti et al., 2009). Además, el aumento de la temperatura causará importantes cambios en la dinámica del plancton, ya que influencia el metabolismo de los organismos, su crecimiento y respiración, y las interacciones, como la depredación (Kowe et al., 1998). Dados estos escenarios climáticos y las proyecciones sobre el crecimiento de la población mundial, se prevé un incremento en las demandas de agua y la regulación de los ríos en la próxima centuria (Meybeck, 2003).

En la región pampeana, estudios climatológicos predicen el aumento de las precipitaciones y la temperatura media anual, y aún en el mejor de los escenarios posibles, se esperan importantes efectos en los sistemas lóticos y sus comunidades (Rodrigues Capítulo et al., 2010). Entre éstos se señalan: el aumento del caudal de los ríos y arroyos, la frecuencia de las inundaciones, la erosión de los suelos, la disminución de la calidad del agua por el aumento de los materiales suspendidos y los nutrientes, y el crecimiento de especies tolerantes a la turbidez y la eutrofización. Asimismo, la expansión de la frontera agrícola, acentuando las demandas en las fuentes de agua y los usos de la tierra en la región (Rodrigues Capítulo et al., 2010).

El entendimiento del régimen natural de las inundaciones provee de herramientas que aseguran la integridad ecológica de los sistemas fluviales en el largo plazo (Benke et al., 2000), siendo fundamentales para la proyección de su comportamiento hidrológico en el marco de estas tendencias climáticas y en el mantenimiento de las reservas de agua (Petts, 2009). En este contexto, resulta clave el estudio del potamoplancton, dada su complejidad estructural y estabilidad, y la inclusión de las relaciones tróficas entre el fito y zooplancton (Sommer \& Lewandouska, 2010). A futuro, la realización de ensayos a escala de laboratorio servirá para evaluar la respuesta de los 
organismos del plancton a las variables asociadas con el cambio climático, y el incremento en la concentración de sales, dados los aportes que recibe el río Salado en su cuenca superior. 


\section{Conclusiones}




\section{Conclusiones}

Este trabajo de tesis representa el primer antecedente de un estudio limnológico de las canalizaciones provenientes de la Pampa Arenosa en la región noroeste de la provincia de Bs. As., en el cual se analiza la modificación de estos aportes a lo largo de una serie de lagunas y humedales interconectados por canales (sistema Bragado) que desembocan en el río Salado, así como también los cambios que se producen aguas abajo de este trasvase; incluyendo el funcionamiento integrado del sistema en momentos hidrológicos contrastantes. A continuación se presentan las principales conclusiones obtenidas:

\section{Características generales de la cuenca superior del río Salado}

- Las aguas fueron predominantemente clorurado-sódicas y dentro del rango alcalino, con variaciones en la contribución de los iones mayoritarios (aguas $\mathrm{Na}-\mathrm{ClHCO}_{3}, \mathrm{Na}-\mathrm{ClSO}_{4}, \mathrm{Mg}$ $\mathrm{ClHCO}_{3}$ ) según los sitios de muestreo y la condición hidrológica.

- El plancton estuvo dominado por especies típicas de ambientes eutróficos-mesotróficos, pertenecientes a las clorofitas clorococcales, diatomeas centrales, cianobacterias coloniales y filamentosas entre los representantes del fitoplancton, y a los rotíferos y ciliados entre los componentes del zooplancton, siendo estos últimos organismos filtradores de pequeño tamaño, de rápido crecimiento y adaptados al ambiente fluvial.

- La composición específica del plancton varío de acuerdo a la estacionalidad climática, al momento hidrológico y a las características locales de los sitios de muestreo.

- Se observaron especies propias de aguas salobres, mesosalinas o con un amplio rango de tolerancia a la salinidad. Varias de ellas estuvieron ampliamente distribuidas en el área de estudio, o resultaron características de un sitio en particular (índice Indval).

En relación con la Hipótesis I: “Dado que el plancton de los sistemas lóticos responde a las variables ambientales, la comunidad planctónica de la cuenca superior del río Salado presentará cambios en su estructura y composición en relación con la condición hidrológica (conductividad, velocidad de corriente, distancia hidrométrica) y la estacionalidad (temperatura)" se concluye que:

- La conductividad, la temperatura y el nivel de agua constituyeron las variables forzantes que actuaron sobre el plancton en la cuenca superior del río Salado, y en menor medida el PRS y el OD, de acuerdo a los análisis de redundancia efectuados. También regularon la distribución espacio- 
temporal de las especies de fitoplancton los nutrientes $\mathrm{N}+\mathrm{N}$ y $\mathrm{N}-\mathrm{NH}_{4}{ }^{+}$, la $\mathrm{MOP}$, la velocidad de corriente y la alcalinidad, y en el zooplancton la clorofila $a$, el $\mathrm{pH}$ y la transparencia.

- El desarrollo del plancton siguió un patrón estacional, con marcados cambios en función de la temperatura, presentando una fase favorable de crecimiento y reproducción (primavera-verano) y otra desfavorable (otoño-inverno). También se comprobó una relación con la condición hidrológica, registrándose los valores máximos de densidad y biomasa total del fitoplancton en caudales medios (verano tardío) y del zooplancton en aguas bajas (primavera).

- La presencia de especies ticoplanctónicas estuvo relacionada con la velocidad de corriente y el nivel de agua (aguas altas) siendo una medida indirecta del grado de conectividad hidrológica con la planicie de inundación, los ambientes lénticos vinculados y las zonas de almacenamiento presentes en el área de estudio.

En acuerdo con la Hipótesis II: "Dado que las canalizaciones de la Pampa Arenosa drenan una zona arreica con aguas subterráneas salinas, presentan aguas con características físico-químicas particulares y un plancton adaptado a estas condiciones. Sus aportes de origen alóctono, luego de pasar por las lagunas y humedales interconectados del sistema Bragado, descargan en el río Salado, afectando las aguas del río aguas abajo de su trasvase (conductividad, composición iónica, estructura del plancton), según la condición hidrológica", se concluye que:

- Se observó una estrecha relación entre la composición iónica del agua y la condición hidrológica, agrupándose a los sitios según el momento de muestreo en aguas altas, aguas bajas y caudales medios en los análisis MDS y cluster, a excepción del canal 1.

- Los aportes de las canalizaciones de la Pampa Arenosa se caracterizaron por elevados valores de conductividad, concentración de $\mathrm{Na}^{+}$y $\mathrm{Cl}^{-}$y dureza, separando claramente al canal 1 del resto de los sitios de muestreo en todas las condiciones hidrológicas, y por el contenido de SS, MOP, la turbidez, los Polif. y los nutrientes, particularmente en aguas altas, según los diferentes análisis multivariados practicados.

- En el río Salado, la conductividad aumentó aguas abajo del trasvase en todas las condiciones hidrológicas, siendo máxima esta diferencia en aguas bajas. De acuerdo a los análisis MDS, cluster, PCA y $k$-means, la conductividad, la composición iónica del agua $\left(\mathrm{Na}^{+}, \mathrm{K}^{+}, \mathrm{Cl}^{-}, \mathrm{SO}_{4}{ }^{-}\right)$, la dureza y otras variables ambientales, condicionaron la estrecha relación entre el canal 2 y el río aguas abajo del trasvase en aguas altas, caudales medios y aguas bajas. Por otro lado, ambos sitios del río sólo estuvieron relacionados entre sí en los caudales medios del último muestreo, con escasos aportes del sistema Bragado dada su condición de aguas muy bajas. Este comportamiento 
diferencial sugiere que los aportes de las canalizaciones de la Pampa Arenosa modifican las características físico-químicas del río aguas abajo del trasvase del sistema Bragado, dependiendo del momento hidrológico.

- La descarga del sistema Bragado influenció al plancton del río Salado en el sitio aguas abajo del trasvase incrementando en las diferentes condiciones hidrológicas: (a) la abundancia y biomasa total del plancton; (b) del fito y zooplancton; (c) de los principales grupos que los integran (cianobacterias, euglenofitas, criptofitas y clorofitas clorococcales; ciliados y rotíferos), en detrimento de otros grupos mejor representados aguas arriba (diatomeas, rizópodos, cladóceros y copépodos); (d) la abundancia y biomasa total de las principales especies dominantes del plancton; (e) la riqueza de especies de fito y zooplancton; (f) la densidad total de $q$ ovígeras de zooplancton; (g) la abundancia de estadios de desarrollo (larvas nauplii, copepoditos, cladoceritos, juveniles); (h) el egg ratio de los principales zooplanctontes en reproducción; (i) el no total de huevos portados por $q$ y libres en las muestras.

- La condición hidrológica moduló el efecto de los aportes del sistema Bragado sobre la composición del plancton del río Salado aguas abajo del trasvase, de acuerdo a los análisis de agrupamiento (cluster, índice de Bray-Curtis) efectuados para el fito y zooplancton. Esta influencia fue más importante en caudales medios y en aguas bajas, asociado con la época favorable de crecimiento y un máximo desarrollo del plancton en los canales 2 y 3. En aguas altas, se observaron escasas variaciones en la abundancia, biomasa y composición del plancton entre los sitios del río, relacionado con la estación climática (otoño tardío), las descargas de caudal y la homogenización del ambiente por la crecida. La máxima similitud entre los sitios del río, aguas arriba y abajo, del trasvase se observó durante aguas muy bajas en el sistema Bragado, debido al escaso aporte de los tributarios y a su dilución en el río, en presencia de caudales medios.

- A lo largo del sistema Bragado, se registró un gradiente en las características físicoquímicas del agua y en la abundancia y biomasa total del fito y zooplancton, de los principales grupos componentes y especies dominantes, y en la distribución de los organismos en reproducción particularmente en aguas altas, con los valores máximos en el canal 1, disminuyendo luego en el canal 2 y el arroyo, hasta su desembocadura en el río Salado. En caudales medios este gradiente fue moderado en el plancton, pero aún en aguas bajas y muy bajas se observó en el sistema Bragado la reducción en forma escalonada de la conductividad y de otras características de las aguas de las canalizaciones de la Pampa Arenosa. El pasaje a través de esta serie de canales interconectados por lagunas y humedales presentes en el área de estudio permite amortiguar el efecto de los aportes alóctonos en el río, en todas las condiciones hidrológicas. 
Considerando además los Objetivos específicos propuestos y a partir de los resultados obtenidos, también se enumeran las siguientes Conclusiones:

Características particulares de sitios desconocidos desde el punto de vista limnológico (sistema Bragado)

- Los canales 1 y 3, como ambientes artificiales, registran un menor desarrollo de sus márgenes y de las comunidades asociadas, reduciendo su heterogeneidad espacial y capacidad de amortiguamiento de los aportes externos. Asimismo, la predominancia de un flujo unidireccional restringe la interacción lateral con otros subsistemas. Estos aspectos geomorfológicos condicionaron la composición del plancton, y su menor resiliencia ante los disturbios (tasa de cambio $\left.\sigma_{s}\right)$. Además, las elevadas conductividades y concentración de sales observadas en el canal 1 actuaron como un factor de estrés, simplificando la estructura de la comunidad planctónica y sus interacciones (aguas bajas y muy bajas).

- La naturaleza de humedal canalizado y afluente de una laguna permanente, que registra el canal 2 promovió la riqueza de especies típicas de ambientes lénticos, de hábitos litorales o bentónicos a lo largo de los muestreos. Asimismo, presenta condiciones que promueven el desarrollo del zooplancton y su reproducción. Particularmente en aguas bajas, el rotífero Brachionus plicatilis alcanzó densidades sin precedentes a nivel regional y mundial (34.800 ind/L).

- De acuerdo a los resultados del PCA, el A $\mathrm{N}^{\mathrm{o}}$ Saladillo (arroyo) estuvo definido por la concentración de $\mathrm{N}-\mathrm{NH}_{4}{ }^{+}, \mathrm{PRS}, \mathrm{N}+\mathrm{N}, \mathrm{PT}$ y PTD, y en forma negativa por el OD, evidenciando el continuo vertido de efluentes con alta carga de nutrientes y materia orgánica en descomposición (planta de tratamiento de efluentes cloacales de Bragado).

- El sistema Bragado, como típicos tributarios, registró un mayor desarrollo del plancton que el río Salado en aguas altas y caudales medios (canal 1) y en aguas bajas (canales 2 y 3), y lo inverso se observó en aguas muy bajas, dados los bajos caudales registrados. En el río Salado, el plancton registró su máximo desarrollo y diversidad en caudales medios asociado a la época favorable de crecimiento y a las conectividades intermedias con la planicie de inundación y las áreas de retención.

\section{Relaciones tróficas entre el fito y zooplancton}

- Se observó un gran desarrollo de las fracciones micro y nanoplanctónicas de fitoplancton, favorecidas por los aportes de nutrientes y una baja presión de pastoreo, salvo en dos ocasiones puntuales observadas en el canal 2 (aguas bajas y muy bajas). En tales situaciones, el zooplancton pastoreador, integrado por Brachionus plicatilis y las larvas nauplii respectivamente, ejerció un 
control top-down sobre las algas nanoplanctónicas palatables, particularmente sobre las clorofitas, propiciados por las cálidas temperaturas y bajas velocidades de corriente.

\section{Reproducción del plancton}

- La reproducción del plancton estuvo asociada a la época favorable de crecimiento (primavera-verano), coincidiendo con las cálidas temperaturas del agua y los momentos de aguas bajas y caudales medios, variando según la especie y el sitio de muestreo. En aguas altas se registraron los valores mínimos y baja presencia de estados de resistencia, asociado a la estación climática (otoño tardío), las bajas temperaturas del agua y la importante descarga de caudal.

- En el canal 2, el aporte continuo de la laguna y los bañados que drena, y la elevada heterogeneidad espacial y la diversidad de hábitats presentes, promovieron la reproducción del plancton, actuando como fuente de inóculos para el río Salado. En este sitio se registraron los valores máximos de riqueza acumulada de especies de fito y zooplancton en reproducción, de densidad de $q$ ovígeras, de $\hat{\partial}$ y sus estadios de desarrollo (nauplii, copepoditos, cladoceritos, juveniles), egg ratio, nomáximo de huevos en + y libres en las muestras.

- El río Salado aguas arriba del trasvase también presentó condiciones apropiadas para el desarrollo y la reproducción del zooplancton, particularmente de los cladóceros, relacionado con la conectividad con los ambientes adyacentes y las áreas de retención (zonas de almacenamiento temporario).

\section{Efectos por la ejecución temporaria de obras de mejora hídrica}

- La construcción de un nuevo vertedero en las nacientes del arroyo Saladillo en la laguna del Bragado provocó la degradación de la calidad del agua y el empobrecimiento del plancton en los dos últimos muestreos. La interrupción del flujo de agua en el arroyo, por las obras en las cabeceras, redujo su capacidad de procesamiento de los vertidos con alta carga de nutrientes y materia orgánica que recibe. El aumento del tiempo de residencia de los compuestos orgánicos condujo a la anoxia y a las vías reductoras, observándose bajos valores de OD y muy elevadas concentraciones $\mathrm{N}-\mathrm{NH}_{4}{ }^{+}$, teniendo efectos deletéreos sobre los organismos. De esta forma, la comunidad planctónica estuvo conformada por unas pocas especies tolerantes a estas condiciones, con representantes de cianobacterias, euglenofitas, diatomeas pennales y ciliados conocidos como indicadores de saprobios y de aguas enriquecidas con nutrientes, materia orgánica y partículas en suspensión. 
- En el canal 2, las obras de mejora hídrica observadas a partir del segundo muestreo (modificación de las márgenes del cauce, construcción de terraplenes y un muro de contención interrumpiendo parcialmente el flujo), tuvieron poca influencia en la comunidad planctónica, ya que la misma desarrolló una estructura compleja y diversa, particularmente del zooplancton y sus interacciones. Su resiliencia y capacidad de recuperación ante estos disturbios puede deberse al aporte que recibe de la laguna Municipal, que propicia su recolonización, y a su naturaleza de humedal canalizado con gran heterogeneidad espacial y diversidad de hábitats.

\section{Futuras implicancias}

- Este trabajo de tesis permitió conocer el funcionamiento ecológico y la dinámica de los canales en diferentes condiciones hidrológicas, su relación con las aguas subterráneas y su influencia sobre el río Salado, pudiendo ser tomado como información de base para futuras comparaciones con otras canalizaciones previstas. Entre éstas se encuentra la ampliación del Canal Mones-Cazón, entre las ciudades de Bragado y 9 de Julio, y su derivación directa al río Salado, sin el pasaje previo por los humedales y lagunas interconectadas del sistema Bragado, que amortigüen los aportes alóctonos y salinos de las aguas provenientes de la Pampa Arenosa.

- El sistema Bragado constituye un sistema hidrológico complejo, controlado por los aspectos geomorfológicos y las características propias de funcionamiento de los canales, como es una fuerte interacción con las aguas subterráneas, de alto tenor salino en el área de estudio. En este contexto, resulta necesario un manejo cuidadoso de estas canalizaciones, ya que extraen agua de buena calidad en aguas altas y promueven la incorporación de sales en caudales medios y aguas bajas, en virtud de la problemática de salinización secundaria instaurada en la región noroeste de la Provincia. 
Referencias 
ABONYI A., LEITÃO M., LANÇON A. M. \& PADISÁK J. 2012. Phytoplankton functional groups as indicators of human impacts along the River Loire (France). Hydrobiologia, 698: 233-249.

ADMIRAAL W., BREEBAART L., TUBBING G. M. J., VAN ZANTEN B., DE RUYTER VAN STEVENINCK E. D. \& BIJKERK R. 1994. Seasonal variation in composition and production of planktonic communities in the lower river Rhine. Freshwater Biology, 32: 519-531.

AKOPIAN M., GARNIER J. \& POURRIOT R. 1999. A large reservoir as a source of zooplankton for the river: structure of the populations and influence of fish predation. Journal of Plankton Research, 21 (2): 285-297.

ALLEN Y. C., DE STASIO B. T. \& RAMCHARAN C. W. 1993. Individual and population level consequences of an algal epibiont on Daphnia. Limnology \& Oceanography, 38: 592-601.

AMERICAN PUBLIC HEALTH ASSOCIATION. 1995. Standard Methods for the Examination of Water and Wastewater. 19th Ed. APHA, Washington, D.C.

AMOROS C. \& BORNETTE G. 2002. Connectivity and biocomplexity in waterbodies of riverine floodplains. Freshwater Biology, 47: 761-776.

ANDERSEN T. \& HESSEN D. O. 1991. Carbon, nitrogen, and phosphorus content of freshwater zooplankton. Limnology \& Oceanography, 36: 807-814.

AQUACHEM. 2006. Programm. Waterloo Hydrogeologic Inc. Schlumberger Water Services.

ARMENGOL J. 1992. Cicles versión 3.0/C. Departament D' Ecologia, Facultat de Biología, Universitat de Barcelona.

ARTIGAS J., GARCÍA-BERTHOU E., BAUER D. E., CASTRO M. I., COCHERO J., COLAUTTI D. C., CORTElEZZI A., DONATO J. C., ELOSEGI A., FEIJOÓ C., GIORGI A., GÓMEZ N., LEGGIERI L., MUÑOZ I., RODRIGUES CAPÍTULO A., ROMANÍ A \& SABATER S. 2013. Global pressures, specific responses: effects of nutrient enrichment in streams from different biomes. Environmental Research Letters, 8: 1-13.

AZAM F., FENCHEL T., FIELD J. G., GRAY J. S., MEYER-REIL L. A. \& THINGSTAD F. 1983. The ecological role of water-column microbes in the sea. Marine ecology progress series, 10: 257-263.

AZOV Y. \& GOLDMAN J. C. 1982. Free ammonia inhibition of algal photosynthesis in intensive cultures. Applied and environmental microbiology, 43: 735-739.

BADANO N. D. 2010. Modelación integrada de grandes cuencas de llanura con énfasis en la evaluación de inundaciones". Tesina de Grado para Ing. Civil. Fac. de Ingeniería de la Universidad de Bs. As. (FIUBA).

BAIGÚN C. R. M., NESTLER J. M., OLDANI N. O. \& VIONNET C. 2007. Applying the reference river concept for large rivers restoration: using an interhemispheric approach. In: Scarpati O. \& Jones A. (Eds). Environmental change and rational water use, Pág. 139-145. Orientación Gráfica Editora, Buenos Aires.

BALVANERA P., PFISTERER A. B., BUCHMANN N., HE J. S., NAKASHIZUKA T., RAFFAELLI D. \& SCHMID B. 2006. Quantifying the evidence for biodiversity effects on ecosystem functioning and services. Ecology letters, 9: 1146-1156.

BARANYI C., HEIN T., HOLAREK C., KECKEIS S. \& SCHEIMER F. 2002. Zooplankton biomass and community structure in a Danube River floodplain system: effects of hydrology. Freshwater Biology, 47: 473-482.

BARINOVA S. S., NEVO E. \& BRAGINA T. M. 2011. Ecological assessment of wetland ecosystems of northernKazakhstan on the basis of hydrochemistry and algal biodiversity. Acta Botanica Croatica, 70: 215-244. 
BASS J. A. B., PINDER L. C. V. \& LEACH D. V. 1997. Temporal and spatial variation in zooplankton populations in the River Great Ouse: an ephemeral food resource for larval and juvenile fish. Regulated Rivers: Research \& Management, 13: 245-258.

BASU B. K. \& PICK F. R. 1994. Longitudinal and seasonal development of planktonic chlorophyll a in the Rideau River, Ontario. Canadian Journal of Fisheries $\mathcal{E}$ Aquatic Sciences, 52: 804-815.

BASU B. K. \& PICK F. R. 1996. Factors regulating phytoplankton and zooplankton biomass in temperate rivers. Limnology \& Oceanography, 41: 1572-1577.

BASU B. K. \& PICK F. R. 1997. Phytoplankton and zooplankton development in a lowland, temperate river. Journal of Plankton Research, 19: 237-253.

BASU B. K., KALFF J. \& PINEL-ALLOUL B. 2000. Midsummer plankton development along a large temperate river: the St. Lawrence River. Canadian Journal of Fisheries $\mathcal{E}$ Aquatic Sciences, 57: 7-15.

BAUER D. 2009. Ecología del fitoplancton de arroyos pampeanos y su valor como indicador de la calidad del agua. Tesis Doctoral. Universidad Nacional de La Plata.

BAUER D. E., CONDE M. E., \& GOMEZ N. 2002a. Phytoplankton of a small lowland stream related to water quality and hydraulic discontinuities. Archiv für Hydrobiologie, 153: 421-442.

BAUER D. E., DONADELLI J., GÓMEZ N., LICURSI M., OCÓN C., PAGGI A. C., RODRIGUES CAPÍTULO A. \& TANGORRA M. 2002b. Ecological status of the Pampean plain streams and rivers (Argentina). Verh. Internat. Verein. Limnol., 28: 259-262.

BAUER D., GÓMEZ N. \& DONADELLI J.L. 2010. Descriptores estructurales del fitoplancton de arroyos de llanura como herramienta de monitoreo para la evaluación de la contaminación orgánica y la eutrofización. I Congreso Internacional de Hidrología de Llanuras. Actas de Congreso, Tomo II: 369-709.

BAYLEY P. B. 1995. Understanding large river: floodplain ecosystems. BioScience, 45: 153-158.

BAZZURI M. E., GABELLONE N. \& SOLARI L. 2008. Variación estacional de fitoplancton en la cuenca inferior del Río Salado (Prov. Buenos Aires). Biología Acuática, 24: 137-148.

BAZZURI M. E., GABELLONE N. \& SOLARI L. 2010a. Influencia ecológica de los canales de drenaje de la pampa arenosa en la cuenca superior del río Salado (Buenos Aires, Argentina). En: Actas I Congreso Internacional de Hidrología de Llanuras, Hacia la gestión integral de los recursos hídricos en zonas de llanura: 609-616.

BAZZURI M. E., GABELLONE N. \& SOLARI L. 2010b. Seasonal variation in the phytoplankton during an intensive sampling period in a saline lowland river (Buenos Aires, Argentina). River Research \& Applications, 26: 766-778.

BENÍTEZ H. \& CLAPS M. 2010. Distribución horizontal y vertical del zooplancton en un ciclo diario en el litoral de una laguna pampásica. Biología Acuática, 26: 19-31.

BENKE A. C., CHAUBEY I., WARD G. M. \& DUNN E. L. 2000. Flood pulse dynamics of an unregulated river floodplain in the southeastern US coastal plain. Ecology, 81 (10): 2730-2741.

BERTANI I., FERRARI I. \& ROSSETTI G. 2012. Role of intra-community biotic interactions in structuring riverine zooplankton under low-flow, summer conditions. Journal of Plankton Research, 34 (4): 308-320.

BILLEN G., GARNIER J. \& HANSET P. 1994. Modelling phytoplankton development in whole drainage networks: the RIVERSTRAHLER model applied to the Seine river system. En Phytoplankton in Turbid Environments: Rivers and Shallow Lakes, pág. 119-137. Springer Netherlands.

BILLEN G., GARNIER J., NEMERY J., SEBILO M., SFERRATORE A., BARLES S., BENOIT P. \& BENOÎT M. 2007. A long-term view of nutrient transfers through the Seine river continuum. Science of the total Environment, 375: 80-97.

BINI L. M., VELHO L. F. M. \& LANSAC-TÔHA F. A. 2003. The effect of connectivity on the relationship between local and regional species richness of testate amoebae (Protozoa, Rhizopoda) in floodplain lagoons of the Upper Paraná River, Brazil. Acta Oecologica, 24: 145-151. 
BLACKBURN S. I., MC CAUSLAND M. A., BOLCH C. J. S., NEWMAN S. J. \& JONES G. J. 1996. Effect of salinity on growth and toxin production in cultures of the bloom-forming cyanobacterium Nodularia spumigena from Australian waters. Phycologia, 35: 511-522.

BOGDAN K. G. \& GILBERT J. J. 1984. Body size and food size in freshwater zooplankton. Proceedings of the National Academy of Sciences, 81: 6427-6431.

BOTTRELL H. H., DUNCAN A., GLIWICZ Z. M., GRYGIEREK E., HERZIG A., HILLBRICHTILKOWSKA A., KURASAWA H., LARSSON P. \& WEGLENSKA T. 1976. A review of some problems in zooplankton production studies. Norwegian Journal of Zoology, 24: 419-456.

BOURRELLY P. 1968. Les algues d'eau doulce. Tomo II: les algues jeunes et brunes, Boubée \& Cie, Paris.

BOURRELLY P. 1970. Les algues d'eau doulce. Tomo III: les algues bleues et rouges. Les Eugleniens, Peridiniens et Cryptomonadines. Boubée \& Cie, Paris

BOURRELLY P. 1972. Les algues d'eau doulce. Tomo I: les algues vertes. Boubée \& Cie, Paris.

BUIJSE A. D., KLIJN F., LEUVEN R. S. E. W., MIDDELKOOP H., SCHIEMER F., THORP J. H. \& WOLFERT H. P. 2005. Rehabilitation of large rivers: references, achievements and integration into river management. Archiv fur Hydrobiologie Supplement, 155: 1-4.

BUKAVECKAS P. A. \& CRAIN A. S. 2002. Inter-annual, seasonal and spatial variability in nutrient limitation of phytoplankton production in a river impoundment. Hydrobiologia, 481: 19-31.

BUKAVECKAS P. A., MACDONALD A., AUFDENKAMPE A., CHICK J. H., HAVEL J. E., SCHULTZ R., ANGRADI T. R., BOLGRIEN D. W., JICHA T. M. \& TAYLOR D. 2011. Phytoplankton abundance and contributions to suspended particulate matter in the Ohio, Upper Mississippi and Missouri Rivers. Aquatic Sciences, 73: 419-436.

BUNN S. E. \& ARTHINGTON A. H. 2002. Basic principles and ecological consequences of altered flow regimes for aquatic biodiversity. Environmental Management, 30 (4): 492-507.

BURDIS R. M. \& HOXMEIER R. J. H. 2011. Seasonal zooplankton dynamics in main channel and backwater habitats of the Upper Mississippi River. Hydrobiologia, 667: 69-87.

BURGER D. F., HOGG I. D. \& GREEN, J. D. 2002. Distribution and abundance of zooplankton in the Waikato River, New Zealand. Hydrobiologia, 479: 31-38.

CAROL E. S., KRUSE E. E. \& POUSA J. L. 2010. Eco-hydrological role of deep aquifers in the Salado sedimentary basin in the Province of Buenos Aires, Argentina. Environmental Earth Sciences, 60: 749-756.

CARRILlO U., GABELLONE N. A. \& SOLARI L. C. 2009. Algas fitoplanctónicas de ambientes lénticos y lóticos de la cuenca del río Salado: tolerancia a factores físicos. Biol. Acuát, 26: 33-45.

CASPER A. F. \& THORP J. H. 2007. Diel and lateral patterns of zooplankton distribution in the St. Lawrence River. River Research \& Applications, 23: 73-85.

CENTIS B., TOLOTTI M. \& SALMASO N. 2010. Structure of the diatom community of the River Adige (North-Eastern Italy) along a hydrological gradient. Hydrobiologia, 639: 37-42.

CESANELLI A. 2012. Modelado y análisis de la evapotranspiración en ambientes de llanura. Tesis Doctoral. Universidad Nacional de La Plata.

CESANELLI A. \& GUARRACINO L. 2011. Estimation of regional evapotranspiration in the extended Salado Basin (Argentina) from satellite gravity measurements. Hydrogeology Journal, 19: 629-639.

CHÉTELAT J., PICK F. R. \& HAMILTON P. B. 2006. Potamoplankton size structure and taxonomic composition: Influence of river size and nutrient concentrations. Limnology \& Oceanography, 51: 681-689.

CLAPS M. C., GABELLONE N. A. \& NESCHUK N. C. 2009. Influence of regional factors on zooplankton structure in a saline lowland river: the Salado River (Buenos Aires, Argentina). River Research \& Applications, 24: 1-19. 
CLAPS M. C., SOLARI L. C. \& GABELLONE N. A. 1997. Pond-river interactions in a pampean basin (Salado River, Buenos Aires, Argentina): an approach. Proc. 7th International Conference on the Conservation and Management of Lakes: 41-44.

COCHERO J., LICURSI M., \& GÓMEZ N. 2015. Changes in the epipelic diatom assemblage in nutrient rich streams due to the variations of simultaneous stressors. Limnologica-Ecology $\mathcal{E}$ Management of Inland Waters, 51: 15-23.

CONFORTI V., ALBERGHINA J. \& GONZALEZ URDA E. 1995. Structural changes and dynamics of the phytoplankton along a highly polluted lowland river of Argentina. Journal of Aquatic Ecosystem Health, 4: 59-75.

CONFORTI V., OHIRKO E., \& GÓMEZ N. 2009. Euglenophyta from a stream of Pampean plain subjected to anthropic effects: $\mathrm{A}^{\mathrm{o}}$ Rodriguez, Buenos Aires, Argentina. Algological Studies, 131: 63-86.

CONNELL J. H. 1978. Diversity in tropical rain forests and coral reefs. Science, 199: 1302-1310.

CONZONNO V. H., MIRETZSKY P. S. \& FERNÁNDEZ CIRELLI A. 2002. Estudio y planteo de solución para una región carente de agua en la Cuenca Baja del Río Salado (Buenos Aires). Natura Neotropicalis, 33: 71-79.

COOPS H., TOCKNER K., AMOROS C., HEIN T. \& QUINN G. 2006. Restoring lateral connections between rivers and floodplains: lessons from rehabilitation projects. En: Wetlands and natural resource management, pág. 15-32. Springer Berlin Heidelberg.

DE CABO L., PUIG A., ARREGHINI S., OLGUÍN H. F., SEOANE R. \& OBERTELLO I. 2003. Physicochemical variables and plankton from the Lower Delta of the Paraná River (Argentina) in relation to flow. Hydrological processes, 17: 1279-1290.

DE MORAIS COSTA D., ALVES G. M., VELHO L. F. M. \& LANSAC-TÔHA F. A. 2011. Species richness of testate amoebae in different environments from the upper Paraná river floodplain (PR/MS). Acta Scientiarum. Biological Sciences, 33: 263-270.

DE RUYTER VAN STEVENINCK E. D., ADMIRAAL W., BREBAART L., TUBBING G. M. J. \& VAN ZANTEN B. 1992. Plankton in the River Rhine: structural and functional changes observed during downstream transport. Journal of Plankton Research, 14: 1351-1368.

DE SMET W. 1996. Rotifera: the Proalidae (Monogononta). En: Dumont (ed.). Guides to the Identification of the Microinvertebrates of the Continental Waters of the World, Vol. 4. SPB Academic Publishing, The Hague.

DELONG M. D. \& THORP J. H. 2006. Significance of instream autotrophs in trophic dynamics of the Upper Mississippi River. Oecologia, 147: 76-85.

DEMOTT W. R. 1986. The role of taste in food selection by freshwater zooplankton. Oecologia, 69: 334-340.

DESCY J-P \& GOSSELAIN V. 1994. Development and ecological importance of phytoplankton in a large lowland river (River Meuse, Belgium). Hydrobiologia, 289: 139-155.

DESCY J-P. \& METENS A. 1996. Biomass-pigment relationships in potamoplankton. Journal of Plankton Research, 18: 1557-1566.

DESCY J-P., LEITAO M., EVERBECQ E., SMITZ J. S. \& DELIÈGE J. F. 2012. Phytoplankton of the River Loire, France: a biodiversity and modelling study. Journal of Plankton Research, 34 (2): 120135.

DEVERCELLI M. \& O'FARRELL I. 2013. Factors affecting the structure and maintenance of phytoplankton functional groups in a nutrient rich lowland river. Limnologica, 43: 67-78.

DEVERCELLI M. 2006. Phytoplankton of the Middle Paraná River during an anomalous hydrological period: a morphological and functional approach. Hydrobiologia, 563: 465-478.

DEVERCELLI M. 2010. Changes in phytoplankton morpho-functional groups induced by extreme hydroclimatic events in the Middle Paraná River. Hydrobiologia, 639: 5-19. 
DÍAZ-ZORITA M., DUARTE G. A. \& GROVE J. H. 2002. A review of no-till systems and soil management for sustainable crop-production in the subhumid and semiarid Pampas of Argentina. Soil \& Tillage Research, 65: 1-18.

DICKERSON K. D., MEDLEY K. A. \& HAVEL J. E. 2010. Spatial variation in zooplankton community structure is related to hydrologic flow units in the Missouri River, USA. River Research E Applications, 26: 605-618.

DOS SANTOS A. 2015. Estudio del fitobenton del río Salado (Buenos Aires) en vinculación a obras hidráulicas realizadas en la cuenca. Tesis doctoral. Facultad de Ciencias Naturales y Museo. Universidad Nacional de La Plata.

DUFRÊNE M. \& LEGENDRE P. 1997. Species assemblages and indicator species: the need for a flexible asymmetrical approach. Ecological Monographs, 67: 345-366.

DUMONT H. J., VAN DE VELDE I. \& DUMONT S. 1975. The dry weight estimate of biomass in a selection of cladócera, copépoda and rotífera from the plankton, periphyton and bentos of continental waters. Oecologia, 19: 75-97.

DUSSART B. \& DEFAYE D. 2002. World Directory of Crustacea Copepoda of Inland Waters, I: Calaniformes (Vol. 1). Backhuys

DUSSART B. \& DEFAYE D. 2006. World Directory of Crustacea Copepoda of Inland Waters, II: Cyclopiformes (Vol. 2). Backhuys.

ECHANIZ S. A. \& VIGNATTI A. M. 2011. Seasonal variation and influence of turbidity and salinity on the zooplankton of a saline lake in central Argentina. Latin American Journal of Aquatic Research, 39: 306-315.

ECHANIZ S., VIGNATTI A. M., JOSÉ DE PAGGI S. \& PAGGI J. C. 2005. Riqueza y composición del zooplancton de lagunas saladas de la región pampeana argentina. Revista FABICIB 9: 25-39.

ELLIOTT J. A., IRISH A. E. \& REYNOLDS C. S. 2001. The effects of vertical mixing on a phytoplankton community: a modelling approach to the intermediate disturbance hypothesis. Freshwater Biology, 46 (10): 1291-1297.

ENSIGN S. H. \& DOYLE M. W. 2006. Nutrient spiraling in streams and river networks. Journal of Geophysical Research: Biogeosciences, 111 (G4).

EVERBECQ E., GOSSELAIN V., VIROUX L. \& DESCY J-P. 2001. POTAMON: a dynamic model for predicting phytoplankton composition and biomass in lowland rivers. Water Research, 35: 901912.

FEIJOÓ C. S. \& LOMBARDO R. J. 2007. Baseline water quality and macrophyte assemblages in Pampean streams: A regional approach. Water Research, 41: 1399-1410.

FEIJOÓ C. S., GIORGI A., GARCÍA M. E. \& MOMO F. 1999. Temporal and spatial variability in streams of a pampean basin. Hydrobiologia, 394: 41-52.

FEIJOÓ C., GIORGI A. \& FERREIRO N. 2011. Phosphate uptake in a macrophyte-rich Pampean stream. Limnologica-Ecology \& Management of Inland Waters, 41: 285-289.

FENCHEL T. 1980. Suspension feeding in Ciliated Protozoa: Structure and Function of Feeding Organelles. Archiv für Protistenkunde, 123: 239-260.

FERRARI I., VIGLIOLI S., VIAROLI P. \& ROSSETTI G. 2006. The impact of the summer 2003 drought event on the zooplankton of the Po River (Italy). Verhandlungen der Internationalen Vereinigung für Theoretische und Angewandte Limnologie, 29: 2143.

FERREIRO N. A., GIORGI A., LEGGIERI L., FEIJOÓ C. \& VILCHES C. 2011. Phosphorus enrichment affects immobilization but not litter decomposition or exoenzymatic activities in a Pampean stream. International Review of Hydrobiology, 96: 209-220.

FISHER S. G., GRIMM N. B., MARTÍ E., HOLMES R. M. \& JONES J. B. 1998. Material spiraling in stream corridors: a telescoping ecosystem model. Ecosystems, 1: 19-34.

FLIPO N., EVEN S., POULIN M., TUSSEAU-VUILLEMIN M. H., AMEZIANE T. \& DAUTA A. 2004. iogeochemical modelling at the river scale: plankton and periphyton dynamics: Grand Morin case study, rance. Ecological Modelling, 176: 333-347. 
FLÖDER S. \& SOMMER U. 1999. Diversity in planktonic communities: an experimental test of the intertmediate disturbance hypothesis. Limnology \& Oceanography, 44: 1114-1119.

FLÖDER S., JASCHINSKI S., WELLS G. \& BURNS C. W. 2010. Dominance and compensatory growth in phytoplankton communities under salinity stress. Journal of Experimental Marine Biology \& Ecology, 395: 223-231.

FOISSNER W., BERGER H. \& SCHAUMBEURG J. 1999. Identification and ecology of limnetic plankton ciliates. Bavarian State Office for Water Management, Munich.

FORTE LAY J. A., KRUSE E. \& AIELLO J. L. 2007. Hydrologic scenarios applied to the agricultural management of the northwest of the Buenos Aires Province, Argentina. GeoJournal, 70: 263-271.

GABELLONE N. A., CLAPS M. C., ARDOHAIN D. M., DIPPOLITTO A., BAZZURI M. E. \& SOLARI L. C. 2014. Relationship between the zoo- and phytoplankton biomasses in a saline lowland river (Argentina): a short-time-scale analysis. Fundamental \& Applied Limnology, 184: 307-327.

GABELLONE N. A., CLAPS M. C., SOLARI L. C. \& NESCHUK N. C. 2005. Nutrients, conductivity and plankton in a landscape approach to a Pampean saline lowland river (Salado River, Argentina). Biogeochemistry, 75: 455-477.

GABELLONE N. A., CLAPS M. C., SOLARI L. C., NESCHUK N. C. \& ARDOHAIN, D. M. 2013 b. Spatial and temporal distribution pattern of phosphorus fractions in a saline lowland river with agricultural land use (Salado River, Buenos Aires, Argentina). Fundamental \& Applied Limnology, 183 (4): 271-286.

GABELLONE N. A., SARANDÓN R. \& CLAPS M. C. 2003. Caracterización y zonificación ecológica de la cuenca del río Salado. En: Gabellone N., Hernández M. \& Maiola O. (Eds). Inundaciones en la Región Pampeana, Editorial Universidad Nacional de La Plata.

GABELLONE N. A., SOLARI L. C. \& CLAPS M. C. 2001. Planktonic and physico-chemical dynamics of a markedly fluctuating backwater pond associated with a lowland river (Salado River, Buenos Aires, Argentina). Lakes \& Reservoirs, Research \& Management, 6: 133-142.

GABELlONE N. A., SOLARI L. C., CASCO M. A. \& CLAPS M. C. 2013a. Conservación del plancton y protección de las cuencas hídricas. AUGMDOMUS, 5: 100-119.

GABELLONE N. A., SOLARI L., CLAPS M. \& NESCHUCK N. 2008. Chemical classification of the water in a lowland river basin (Salado River, Buenos Aires, Argentina) affected by hydraulic modifications. Environmental Geology, 53: 1353-1363.

GARCÍA DE EMILIANI M. O. \& DEVERCELLI M. 2003. Influencia del fenómeno “El Niño” sobre el transporte y la estructura del fitoplancton en el cauce principal del río Paraná Medio, Argentina. Boletín Sociedad Argentina de Botánica, 38: 29-38.

GARCÍA DE EMILIANI M. O. 1993. Seasonal succession of phytoplankton in a lake of the Paraná River floodplain, Argentina. Hydrobiologia, 264: 101-114.

GARCÍA DE EMILIANI M. O. 1997. Effects of water level fluctuations on phytoplankton in riverfloodplain lake system (Paraná River, Argentina). Hydrobiologia, 257: 1-15.

GARNIER J. \& BILLEN G. 2007. Production vs. Respiration in river systems: An indicator of an "ecological status". Science of the Total Environment, 375 (1): 110-124.

GARNIER J., BILLEN G. \& COSTE M. 1995. Seasonal succession of diatoms and Chlorophyceae in the drainage network of the Seine River: Observations and modelling. Limnology $\mathcal{E}$ Oceanography, 40: 750-765.

GARNIER J., NÉMERY J., BILLEN G. \& THÉRY S. 2005. Nutrient dynamics and control of eutrophication in the Marne River system: modelling the role of exchangeable phosphorus. Journal of Hydrology, 304: 397-412.

GERMAIN H. 1981. Flore des diatomées. Diatomophycées. Societé Nouvelle des editions. Boubée 11, Saint-Michael, Paris. 
GHADOUANI A., ALLOUL B. P., ZHANG Y. \& PREPAS E. E. 1998. Relationships between zooplankton community structure and phytoplankton in two lime-treated eutrophic hardwater lakes. Freshwater Biology, 37: 775-790.

GHADOUANI A., PINEL-ALLOUL B. \& PREPAS E. E. 2003. Effects of experimentally induced cyanobacterial blooms on crustacean zooplankton communities. Freshwater Biology, 48: 363-381.

GHERSA C. M., DE LA FUENTE E., SUAREZ S. \& LEON R. J. C. 2002. Woody species invasion in the Rolling Pampa grasslands, Argentina. Agriculture, Ecosystems \& Environment, 88: 271-278.

GILBERT J. J. \& JACK J. D. 1993. Rotifers as predators on small ciliates. In: Rotifer Symposium VI. Springer, Netherlands. pág. 247-253.

GIORGI A. 1995. Response of periphyton biomass to high phosphorus concentrations in laboratory experiments. Bulletin of environmental contamination and toxicology, 55: 825-832.

GIORGI A., FEIJOÓ C. \& TELL G. 2005. Primary producers in a Pampean stream: temporal variation and structuring role. Biodiversity $\mathcal{E}$ Conservation, 14(7): 1699-1718.

GÓMEZ N. \& LICURSI M. 2001. The Pampean Diatom Index (IDP) for assessment of rivers and streams in Argentina. Aquatic Ecology, 35: 173-181.

GÓMEZ N., LICURSI M. \& COCHERO J. 2009. Seasonal and spatial distribution of the microbenthic communities of the Rio de la Plata estuary (Argentina) and possible environmental controls. Marine pollution bulletin, 58: 878-887.

GÓMEZ S., FLEEGER J. W., ROCHA-OLIVARES A. \& FOLTZ D. 2004. Four new species of Cletocamptus Schmankewitsch, 1875, closely related to Cletocamptus deitersi (Richard, 1897) (Copepoda: Harpacticoida). Journal of Natural History, 38 (21): 2669-2732.

GONZALEZ M. H. \& FERNANDEZ A. E. 2007. Floods increasing in Buenos Aires Salado River basin, Argentina. En: Scarpati O. \& Jones A. (Eds). Environmental change and rational water use. Pág. 96-113. Orientación Gráfica Editora, Buenos Aires.

GOSSELAIN V., DESCY J-P. \& EVERBECQ E. 1994. The phytoplankton community of the River Meuse, Belgium: Seasonal dynamics (year 1992) and the possible incidence of zooplankton grazing. Hydrobiologia, 289: 179-191.

GOSSELAIN V., DESCY J-P., VIROUX L., JOAQUIM-JUSTO C., HAMMER A., MÉTENS A. \& SCHWEITZER S. 1998a. Grazing by large river zooplankton: a key to summer potamoplankton decline? The case of the Meuse and Moselle rivers in 1994 and 1995. Hydrobiologia, 369/370: 199216.

GOSSELAIN V., VIROUX L \& DESCY J-P. 1998b. Can a community of small-bodied grazers control phytoplankton in rivers? Freshwater Biology, 39: 9-24.

GRIME J.P. 1979. Plant Strategies and Vegetation Processes. Wiley, Chichester.

GROVER J. P. \& CHRZANOWSKI T. H. 2004. Limiting resources, disturbance, and diversity in phytoplankton communities. Ecological monographs, 74: 533-551.

GUARRERA S. A., CABRERA S. M., LOPEZ F. \& TELL G. 1968. Fitoplancton de las aguas superficiales de la provincia de Buenos Aires. Revista del Museo de La Plata, Botánica 10: 223-331.

GUARRERA S. A., MALACALZA L. \& LOPEZ F. 1972. Fitoplancton de las aguas superficiales de la provincia de Buenos Aires II. Complejo lagunar Salada Grande - Encadenadas del Oeste y Encadenadas del Sur. Revista del Museo de La Plata, Botánica 12: 161-219.

GUELDA D. L., KOCH R. W., JACK J. D. \& BUKAVECKAS P. A. 2005. Experimental evidence for density-dependent effects and the importance of algal production in determining population growth rates of riverine zooplankton. River Research \& Applications, 21: 595-608.

GUINDER V. A., POPOVICH C. A. \& PERILLO G. M. 2009. Particulate suspended matter concentrations in the Bahía Blanca Estuary, Argentina: implication for the development of phytoplankton blooms. Estuarine, Coastal and Shelf Science, 85: 157-165.

GUINDER V. A., POPOVICH C. A., MOLINERO J. C. \& PERILLO G. M. 2010. Long-term changes in phytoplankton phenology and community structure in the Bahía Blanca Estuary, Argentina. Marine Biology, 157: 2703-2716. 
GYLLSTRÖM M. \& HANSSON L. A. 2004. Dormancy in freshwater zooplankton: induction, termination and the importance of benthic-pelagic coupling. Aquatic Sciences, 66: 274-295.

HALCROW \& PARTNERS. 1999. Plan Maestro Integral de la cuenca del Río Salado. Informe de Situación Base. Anexo Hidrología. Ministerio de Obras Públicas de la Prov. de Buenos Aires.

HANEY J. F. \& HALL D. J. 1972. Sugar-coated Daphnia: a preservation technique for Cladocera. Limnology \& Oceanography, 23: 331-333

HANSEN B., WERNBERG-MOLLER T. \& WITTRUP L. 1997. Particle grazing efficiency and specific growth efficiency of the rotifer Brachionus plicatilis (Muller). Journal of Experimental Marine Biology \& Ecology, 215: 217-233.

HARDIN G. 1960. The competitive exclusion principle. Science, 131: 1292-1297.

HARRIS G. P. 1994. Pattern, process and prediction in aquatic ecology. A limnological view of some general ecological problems. Freshwater Biology, 32: 143-160.

HARRISON G. W. 1979. Stability under environmental stress: resistance, resilience, persistence, and variability. American Naturalist, 113: 659-669.

HART R. C. 1996. Naupliar and copepodite growth and survival of two freshwater calanoids at various food levels: demographic contrasts, similarities, and food needs. Limnology $\mathcal{E}$ Oceanography, 41: 648-658.

HAWKES H. A. 1975. River zonation and classification. River Ecology: 312-374.

HECKY R. E. \& KILHAM P. 1988. Nutrient limitation of phytoplankton in freshwater and marine environments: a review of recent evidence on the effects of enrichment. Limnology $\mathcal{E}$ Oceanography, 33: 796-822.

HEDGES J. I., EGLINTON G., HATCHER P. G., KIRCHMAN D. L., ARNOSTI C., DERENNE S., EVERSHEDG R. P., KÖGEL-KNABNERH I., DE LEEUWI J. W., LITTKEJ R., MICHAELISK W. \& RULLKÖTTER J. 2000. The molecularly-uncharacterized component of nonliving organic matter in natural environments. Organic Geochemistry, 31: 945-958.

HEILER G., HEIN T., SCHIEMER F., \& BORNETTE G. 1995. Hydrological connectivity and flood pulses as the central aspects for the integrity of a river-floodplain system. Regulated Rivers: Research \& Management, 11 (3-4): 351-361.

HEIN T., BARANYI C., HERNDL G. J., WANEK W. \& SCHIEMER F. 2003. Allochthonous and autocththonous particulate organic matter in floodplains of the River Danube: the importance of hydrological connectivity. Freshwater Biology, 48: 220-232.

HEIN T., BARANYI C., RECKENDORFER W. \& SCHIEMER F. 2004. The impact of surface water exchange on the nutrient and particle dynamics in side-arms along the River Danube, Austria. Science of the Total Environment, 328: 207-218.

HEIN T., HEILER G., PENNETZDORFER D., RIEDLER P., SCHAGERL M. \& SCHIEMER F. 1999. The Danube restoration project: functional aspects and planktonic productivity in the floodplain system. Regulated Rivers: Research \& Management, 15: 259-270.

HEIN T., RECKENDORFER W., THORP J. H. \& SCHIEMER F. 2005. The role of slackwater areas for biogeochemical processes in rehabilitated river corridors: examples from the Danube. Arch. Hydrobiol. Suppl., 155: 425-442.

HERZEG A. L., DOGRAMACI S. \& LEANEY F. 2001. Origin of dissolved salt in a large, semi-arid groundwater system: Murray basin, Australia. Marine E Freshwater Research, 52: 41-53.

HERZER H. 2003. Flooding in the Pampean Region of Argentina: The Salado Basin. En: Kreimer A., Arnold M. \& Carlin A. (Eds.). Building safer cities: the future of disaster risk. The World Bank, Washington DC.

HILDREW A. G. 1996. Whole river ecology: spatial scale and heterogeneity in the ecology of running waters. Large Rivers, 25-43.

HILL M. T., PLATTS W. S. \& BESCHTA R. L. 1991. Ecological and geomorphological concepts for instream and out-of-channel flow requirements. Rivers, 2: 198-210. 
HILLBRICHT-ILKOWSKA A. 1999. Shallow lakes in lowland river systems: Role in transport and transformations of nutrients and in biological diversity. Hydrobiologia ,408: 349-358.

HILLEBRAND H., DÜRSELEN C-D., KIRSCHTEL D., POLLINGHER U. \& ZOHARY T. 1999. Biovolume calculation for pelagic and benthic microalgae. Journal of Phycology, 35: 403-424.

HOLST H., ZIMMERMANN-TIMM H. \& KAUSCH H. 2002. Longitudinal and transverse distrivbution of plankton rotifers in the potamal of the river Elbe (Germany) during late summer. International Review of Hydrobiology, 87: 267-280.

HONTI M., ISTVÁNOVICS V. \& KOVÁCS Á. S. 2010. Balancing between retention and flushing in river networks-optimizing nutrient management to improve trophic state. Science of the total environment, 408 (20): 4712-4721.

HOPKINSON C. S., BUFFAM I., HOBBIE J., VALLINO J., PERDUE M., EVERSMEYER B., PRAHL F., COVERT J., HODSON R., MORAN M. A., SMITH E., BAROSS J., CRUMP B., FINDLAY T. \& FOREMAN K. 1998. Terrestrial inputs of organic matter to coastal ecosystems: An intercomparison of chemical characteristics and bioavailability. Biogeochemistry, 43: 211-234.

HOUSE W. A. \& DENISON F. H. 1998. Phosphorus dynamics in a lowland river. Water Research, 32: $1819-1830$.

HUDON C. 2000. Phytoplankton assemblages in the St. Lawrence River, downstream of its confluence with the Ottawa River, Quebec, Canada. Canadian Journal of Fisheries \& Aquatic Sciences, 57: 16-30.

HUMPHRIES P., COOK R. A., RICHARDSON A. J. \& SERAFINI L. G. 2006. Creating a disturbance: manipulating slackwaters in a lowland river. River Research \& Applications, 22: 525542.

HUNT C. W., LODER III T. \& VÖRÖSMARTY C. 2005. Spatial and temporal patterns of inorganic nutrient concentrations in the Androscoggin and Kennebec Rivers, Maine. Water, air, and soil pollution, 163 (1-4): 303-323.

HUTCHINSON G. E. 1961. The paradox of the plankton. American Naturalist, 137-145.

HYNES H. B. N. 1970. The ecology of running waters. University of Toronto Press.

IBELINGS B., ADMIRAAL W., BIJKERK R., IETSWAART T. \& PRINS H. 1998. Monitoring of algae in Dutch rivers: does it meet its goals? Journal of Applied Phycology, 10: 171-181.

IETSWAART T., BREEBAART L., VAN ZANTEN B. \& BIJKERK R. 1999. Plankton dynamics in the river Rhine during downstream transport as influenced by biotic interactions and hydrological conditions. Hydrobiologia, 410: 1-10.

IMBELLONE P. A. \& GIMÉNEZ J. E. 1998. Parent materials, buried soils and fragipans in Northwestern Buenos Aires province, Argentina. Quaternary International 51-52: 115-126.

IRIONDO M. \& KRÖHLING D. 2007. Geomorfología y sedimentología de la cuenca superior del río Salado (Sur de Santa Fe y Noroeste de Buenos Aires, Argentina). Latin American Journal of Sedimentology \& Basin Analysis, 14: 1-23.

IRIONDO M. 1999. Climatic changes in the South American plains: records of a continent-scale oscillation. Quaternary International, 57: 93-112.

ISTVÁNOVICS V., HONTI M., VÖRÖS L. \& KOZMA Z. 2010. Phytoplankton dynamics in relation to connectivity, flow dynamics and resource availability - the case of a large, lowland river, the Hungarian Tisza. Hydrobiologia, 637: 121-141.

IZAGUIRRE I. \& VINOCUR A. 1994. Typology of shallow lakes of the Salado River basin (Argentina), based on phytoplankton communities. Hydrobiologia, 277: 49-62.

IZAGUIRRE I., O'FARRELL I. \& TELL G. 2001. Variation in phytoplankton composition and limnological features in a water-water ecotone of Lower Paraná Basin (Argentina). Freshwater Biology, 46: 63-74.

IZAGUIRRE I., O'FARRELL I., UNREIN F., SINISTRO R., DOS SANTOS AFONSO M. \& TELL G. 2004. Algal assemblages across a wetland, from a shallow lake to relictual oxbow lakes (Lower Paraná River, South America). Hydrobiologia, 511: 25-36. 
JARVIE H. P., LYCETT E., NEAL C. \& LOVE A. 2002.Patterns in nutrient concentrations and biological quality indices across the upper Thames river basin, UK. Science of the total environment, 282: 263-294.

JARVIE H. P., WITHERS P. J., HODGKINSON R., BATES A., NEAL M., WICKHAM H. D., ARMAN S. A. \& ARMSTRONG L. 2008. Influence of rural land use on streamwater nutrients and their ecological significance. Journal of Hydrology, 350: 166-186.

JOAQUIM-JUSTO C., PIRLOT S., VIROUX L., SERVAIS P., THOMÉ J. P. \& DESCY J-P. 2006. Trophic links in the lowland River Meuse (Belgium): assessing the role of bacteria and protozoans in planktonic food webs. Journal of plankton research, 28 (9): 857-870.

JOHNSON B. L., RICHARDSON W. B. \& NAIMO T. J. 1995. Past, present, and future concepts in large river ecology. BioScience, 45: 134-141.

JOSÉ DE PAGGI S. \& PAGGI J. C. 1998. Zooplancton de ambientes acuáticos con diferente estado trófico y salinidad. Neotrópica, 44: 95-106.

JOSÉ DE PAGGI S. \& PAGGI J. C. 2007. Zooplankton. En: Iriondo, M. H., Paggi J. C. \& Parma M. J. (Eds.). The Middle Parana' River: Limnology of a Subtropical Wetland, Pág. 229-249. Springer, Berlin.

JOSÉ DE PAGGI S. 1984. Estudios limnológicos en una sección transversal del tramo medio del río Paraná: distribución estacional del zooplancton. Revista de la Asociación de Ciencias Naturales del Litoral, 15: 135-155.

JOSÉ DE PAGGI S. 2002. Family Asplanchnidae. En: Guides to the Identification of the Microinvertebrates of the Continental Waters of the World. Rotifera, Vol. 6: 1-27.

JOSÉ DE PAGGI S. B. J. \& DEVERCELLI M. 2011. Land use and basin characteristics determine the composition and abundance of the microzooplankton. Water, Air \& Soil Pollution 218: 93-108.

JUNK W. J. 1999. The flood pulse concept of large rivers: learning from the tropics. Archiv für Hydrobiologie. Supplementband. Large rivers, 11 (3): 261-280.

JUNK W. J., BAYLEY P. B. \& SPARKS R. E. 1989. The flood pulse concept in river-floodplain systems. En: Proceedings of the international large river symposium. D. P. Dodge (Ed.). Canadian Special Publication of Fisheries \& Aquatic Sciences, 106: 110-127.

KÄLLQVIST T. \& SVENSON A. 2003. Assessment of ammonia toxicity in tests with the microalga, Nephroselmis pyriformis, Chlorophyta. Water research, 37: 477-484.

KECKEIS S., BARANYI C., HEIN T., HOLAREK C., RIEDLER P. \& SCHIEMER F. 2003. The significance of zooplankton grazing in a floodplain system of the River Danube. Journal of Plankton Research, 25: 243-253.

KIM D. K., JEONG K. S., CHANG K. H., LA G. H., JOO G. J. \& KIM H. W. 2012. Patterning zooplankton communities in accordance with annual climatic conditions in a regulated river system (Nakdong River, South Korea). International Review of Hydrobiology, 97: 55-72.

KIM H. W. \& JOO G. J. 2000. The longitudinal distribution and community dynamics of zooplankton in a regulated large river: a case study of the Nakdong River (Korea). Hydrobiologia, 438: 171-184.

KIM H. W., HWANG S. J. \& JOO G. J. 2000. Zooplankton grazing on bacteria and phytoplankton in a regulated large river (Nakdong River, Korea). Journal of Plankton Research, 22: 1559-1577.

KIM H. W., JOO G. J. \& WALZ N. 2001. Zooplankton dynamics in the hiper-eutrophic Nakdong River System (Korea) regulated by an estuary dam and side channels. International Review of Hydrobiology, 86: 127-143.

KIRK K. L. \& GILBERT J. J. 1990. Suspended clay and the population dynamics of planktonic rotifers and cladocerans. Ecology, 1741-1755.

KIRK K. L. 1991. Inorganic particles alter competition in grazing plankton: the role of selective feeding. Ecology, 72: 915-923.

KIRK T. O. 1983. Light and photosynthesis in aquatic ecosystems. Cambridge University Press. 401 pág. 
KISS Á. K., ÁCS É., KISS K. T. \& TÖRÖK J. K. 2009. Structure and seasonal dynamics of the protozoan community (heterotrophic flagellates, ciliates, amoeboid protozoa) in the plankton of a large river (River Danube, Hungary). European Journal of Protistology, 45: 121-138.

KLAVENESS D. 1988. Ecology of the Cryptomonadida: a first review. In: Sandgren C. D. (ed.). Growth and reproductive strategies of freshwater phytoplankton. Cambridge University Press.

KOBAYASHI T. 1997. Associations between environmental variables and zooplankton body masses in a regulated Australian river. Marine E Freshwater Research, 48: 523-529.

KOBAYASHI T., GIBBS P., DIXON P. I. \& SHIEL R. J. 1996. Grazing by a river zooplankton community: importance of microzooplankton. Marine \& Freshwater Research, 47: 1025-1036.

KOBAYASHI T., SHIEL R. J. \& GIBBS P. 1998. Size structure of river zooplankton: seasonal variation, overall pattern and functional aspect. Marine E Freshwater Research, 49: 547-552.

KOCH R. W., GUELDA D. L. \& BUKAVECKAS P. A. 2004. Phytoplankton growth in the Ohio, Cumberland and Tennessee Rivers, USA: inter-site differences in light and nutrient limitation. Aquatic Ecology, 38: 17-26.

KÖHLER J. 1993. Growth, production and losses of phytoplankton in the lowland River Spree. I. Population dynamics. Journal of Plankton Research, 15: 335-349.

KÖHLER J. 1994. Origin and succession of phytoplankton in a river-lake system (Spree, Germany). Hydrobiologia, 289: 73-83.

KÖHLER J. 1995. Growth, production and losses of phytoplankton in the lowland River Spree: Carbon balance. Freshwater Biol. (34): 501-512

KOMÁREK J. \& ANAGNOSTIDIS K. 1998. Cyanoprokariota, 1. Teil: Chroococcales. In: Ettl H., Gärtner G., Heynigh H. \& Mollenhauer D. (Eds.). Süßwasserflora von Mitteleuropa 19/1. Spektrum Akademischer Verlag GmbH, Berlin.

KOMÁREK J. \& ANAGNOSTIDIS K. 2005. Cyanoprokariota, 2. Teil: Oscillatoriales. In: Budel B., Krienitz L., Gartner G. \& Schagerl M. (Eds.). Süßwasserflora von Mitteleuropa 19/2. Elsevier, Munchen.

KOMÁREK J. \& FOTT B. 1983. Das Phytoplankton des Süßwasser Systematik und Biologie. Chlorophyceae (Grünalgen) Ordnung: Chlorococcales. Von Huber-Pestalozzi. E. schweizerbart'sche Verlagsbunchhandlung (Nägele u Obermiller). Sttutgart, Germany.

KOSTE W. 1978. Rotatoria. Die Rädertiere Mitteleuropas. Ein Bestimmungswerk, begründet von Max Voigt. Überrordung Monogononta. Gebr.

KOWE R., SKIDMORE R. E., WHITTON B. A. \& PINDER A. C. 1998. Modelling phytoplankton dynamics in the River Swale, an upland river in NE England. The Science of the Total Environment, 210/211: 535-546.

KRONVANG B., BECHMANN M., LUNDEKVAM H., BEHRENDT H., RUBÆK G. H., SCHOUMANS O. F., SYVERSEN N., ANDERSEN H. E. \& HOFFMANN C. C. 2005 a. Phosphorus losses from agricultural areas in river basins: effects and uncertainties of targeted mitigation measures. Journal of Environmental Quality, 34: 2129-2144.

KRONVANG B., HOFFMANN C. C., SVENDSEN L. M., WINDOLF J., JENSEN J. P. \& DØRGE J. 1999. Retention of nutrients in river basins. Aquatic Ecology, 33 (1): 29-40.

KRONVANG B., JEPPESEN E., CONLEY D. J., SØNDERGAARD M., LARSEN S. E., OVESEN N. B. \& CARSTENSEN J. 2005b. Nutrient pressures and ecological responses to nutrient loading reductions in Danish streams, lakes and coastal waters. Journal of Hydrology, 304: 274-288.

KRONVANG B., VAGSTAD N., BEHRENDT H., BØGESTRAND J. \& LARSEN S. E. 2007. Phosphorus losses at the catchment scale within Europe: an overview. Soil Use \& Management, 23: 104-116.

KRUSE E. \& LAURENCENA P. 2005. Aguas superficiales, relación con el régimen subterráneo y fenómenos de anegamiento En: de Barrio R., Etcheverry R., Caballé M., Llambias E. (Eds), Geologia y Recursos Minerales de la Provincia de Buenos Aires, pág. 313-326. Relatorio del XVI Congreso Geológico Argentino, La Plata. 
KRUSE E. \& ZIMMERMANN E. D. 2002. Hidrogeología de grandes llanuras: particularidades en la llanura pampeana (Argentina). Workshop publication on Groundwater and Human development, 2025-2038.

KRUSE E., CAROL E., DELUCHI M., LAURENCENA P. \& ROJO A. 2010. Hidroquímica subterránea en un sector de la zona deprimida del Salado, Provincia de Buenos Aires. I Congreso Internacional de Hidrología de Llanuras. Azul, Argentina.

KRYLOV A. V. 2004. Distribution of zooplankton along the longitudinal profile of two disturbed small rivers of the upper Volga Basin. Russian Journal of Ecology, 35: 316-323.

LADLE M. \& WESTLAKE D. F. 1995. River and stream ecosystems of Great Britain. En: Cushing C. E., Cummins K. W. \& Minshall G. W. (Eds.). River and streams ecosystems. Serie: Ecosystems of the World, Vol. 22. Elsevier, Amsterdam - New York.

LAIR N. \& REYES-MARCHANT P. 1997. The potamoplankton of the Middle Loire and the role of the "moving littoral" in downstream transfer of algae and rotifers. Hydrobiologia, 356: 33-52.

LAIR N. 2005. Abiotic vs. biotic factors: lessons drawn from rotifers in the Middle Loire, a meandering river monitored from 1995 to 2002, during low flow periods. En: Rotifera X (pp. 457-472). Springer, Netherlands.

LAIR N. 2006. A review of regulation mechanisms of metazoan plankton in riverine ecosystemas: aquatic habitat versus biota. River Research \& Applications, 22: 567-593.

LAIR N., JACQUET V. \& REYES-MARCHANT P. 1999. Factors related to autotrophic potamoplankton, heterotrophic protists and micrometazoan abundance, at two sites in a lowland temperate river during low water flow. Hydrobiologia, 394: 13-28.

LAKE P. S. 2003. Ecological effects of perturbation by drought in flowing waters. Freshwater biology, 48: 1161-1172.

LAMPERT, W. \& U. SOMMER. 1997. Limnoecology: The ecology of lakes and streams. Oxford University Press Inc., New York.

LANSAC-TÔHA F. A., BONECKER C. C., VELHO L. F. M., SIMÕES N. R., DIAS J. D., ALVES G. M. \& TAKAHASHI E. M. 2009. Biodiversity of zooplankton communities in the Upper Paraná River floodplain: interannual variation from long-term studies. Brazilian Journal of Biology, 69: 539-549.

LAWRENCE S. G., MALLEY D. F., FINDLAY W. J., MACLVER M. A. \& DELBAERE I. L. 1987. Method for estimating dry weight of freshwater planktonic crustaceans from measures of legth and shape. Canadian Journal of Fisheries E Aquatic Sciences, 44: 264-274.

LEHMAN J. T. 1988. Selective herbibory and its role in the evolution of phytoplankton growth strategies. En: Sandgren C. D. (Ed.). Growth and reproductive strategies of freshwater phytoplankton. Cambridge University Press.

LELAND H. V. 2003. The influence of water depth and flow regime on phytoplankton biomass and community structure in a shallow, lowland river. Hydrobiologia, 506: 247-255.

LELAND H. V., BROWN L. R. \& MUELLER D. K. 2001. Distribution of algae in the San Joaquin River, California, in relation to nutrient supply, salinity and other environmental factors. Freshwater Biology, 46: 1139-1167.

LEVIN S. A. 2000. Multiple scales and the maintenance of biodiversity. Ecosystems, 3: 498-506.

LEWIS JR. W. M., \& SAUNDERS III J. F. 1989. Concentration and transport of dissolved and suspended substances in the Orinoco River. Biogeochemistry, 7 (3): 203-240.

LEWIS W. M. 1978. Analysis of succession in a tropical phytoplankton community and a new measure of succession rate. The American Naturalist, 112: 401-414.

LICURSI M. \& GÓMEZ N. 2009. Effects of dredging on benthic diatom assemblages in a lowland stream. Journal of environmental management, 90: 973-982.

LICURSI M. 2005. Efectos de las perturbaciones antropogénicas sobre la taxocenosis de diatomeas bentónicas en sistemas lóticos pampeanos. Tesis Doctoral. Facultad de Ciencias Naturales y Museo. Universidad Nacional de La Plata. 
LICURSI M., GÓMEZ N. \& DONADELLI J. 2010. Ecological optima and tolerances of coastal benthic diatoms in the freshwater-mixohaline zone of the Río de la Plata estuary. Marine Ecology Progress Series, 418: 105-117.

LIKENS G. E. 2001. Biogeochemistry, the watershed approach: some uses and limitations. Marine $\mathcal{E}$ Freshwater Research, 52 (1): 5-12.

LOCASCIO DE MITROVICH C., VILLAGRA DE GAMUNDI A., JUÁREZ J. \& CERAOLO M. 2005. Características limnológicas y zooplancton de cinco lagunas de la Puna-Argentina. Ecología en Bolivia, 40: 10-24.

LUDUEÑA S. G. 2006. Farm-scale pounding susceptibility for potential land reclamation assessment in large flatlands. A case study in the Salado River Basin, Province of Buenos Aires, Argentina. Tesis para el grado de: Master of Science in Geo-information Science and Earth Observation. Integrated Catchment and Water Resourses Management. ITC, International Institute for Geo-information Science and Earth Observation, Eschede, The Netherlands.

MAGURRAN A. E. 2004. Measuring biological diversity. Blackwell Publishing Company, UK.

MAIER H. R., BURCH M. D. \& BORMANS M. 2001. Flow management strategies to control blooms of the cyanobacterium, Anabaena circinalis, in the River Murray at Morgan, South Australia. Regulated Rivers: Research \& Management, 17: 637-650.

MARGALEF R. 1968. Fluctuaciones de varios años de período medio en la producción de fitoplancton en el Mediterráneo occidental. Collectanea Botanica, 7 (41): 727-747.

MARGALEF R. 1978. Life-forms of phytoplankton as survival alternatives in an unstable environment. Acta Oceanologica, 1: 493-509.

MARGALEF R. 1983. Limnología. Ediciones Omega. 1010 pág.

MARNEFFE Y., DESCY J. P. \& THOMÉ J. P. 1996. The zooplankton of the lower river Meuse, Belgium: seasonal changes and impact of industrial and municipal discharges. Hydrobiologia, 319: 1-13.

MATOSSIAN B., BARRÍA G. M., GONIADZKI D. \& DÍAZ R. 2007. Application of satellite monitoring and geographic information system for a water-excess warning system for the rural area in the north-west of Buenos Aires province, Argentina. En: Scarpati O. \& Jones A. (Eds). Environmental change and rational water use. Pág. 24-30. Orientación Gráfica Editora, Bs. As.

MENDEN-DEUER, S. \& LESSARD E. J. 2000. Carbon to volume relationships for dinoflagellates, diatoms, and other protist plankton. Limnology \& Oceanography, 45: 569-579.

MENU-MARQUE S., MORRONE J. J. \& LOCASCIO DE MITROVICH C. 2000. Distributional patterns of the South American species of Boeckella (Copepoda: Centropagidae): a track analysis. Journal of Crustacean Biology, 20: 262-272.

METZELTIN D. \& GARCIA-RODRIGUEZ F. 2003. Las diatomeas uruguayas. Montevideo D.I.R.A.C., Uruguay.

MEYBECK M. 1996 River water quality, global ranges time and space variabilities. Vehr. Int. Verein. Limnol., 26: 81-96.

MEYBECK M. 2003. Global analysis of river systems: from Earth system controls to Anthropocene syndromes. Philosophical Transactions of the Royal Society B., Biological Sciences, 358 (1440): 19351955.

MILTNER R. J. \& RANKIN E. T. 1998. Primary nutrients and the biotic integrity of rivers and streams. Freshwater Biology, 40: 145-158.

MIRETZKY P., CONZONNO V. \& FERNÁNDEZ CIRELLI A. 2001. Geochemical processes controlling silica concentrations in groundwaters of the Salado River drainage basin, Argentina. Journal of Geochemical Exploration, 73: 155-166.

MODENUTTI B. E. \& CLAPS M. C. 1988. Monogononta rotifers from plankton and periphyton of pampasic lotic environments (Argentina). Limnologica. 19 (2): 167-175.

MODENUTTI B. E. 1998. Planktonic rotifers of Samborombón River Basin (Argentina). Hidrobiologia, 387/388: 259-265. 
MODESTO-IREGUI M., GUILLOT G., DONATO J. C. \& ORTEGÓN M. T. 2002. Dimensión fractal y relación área superficial/volumen de algas del fitoplancton de lagos colombianos. Caldasia, 24: 121-134.

MOHR S. \& ADRIAN R. 2002. Effects of Brachionus calyciflorus and Brachionus rubens on a manipulated freshwater microbial community. Journal of Plankton Research, 24: 25-31.

MOSCUZZA C., VOLPEDO A. V., OJEDA C. \& FERNÁNDEZ CIRELLI A. 2007. Water quality index as an tool for river assessment in agricultural areas in the pampean plains of Argentina. Journal of Urban and Environmental Engineering, 1: 18-25.

MOSS B. \& BALLS H. 1989. Phytoplankton distribution in a floodplain lake and river system. II Seasonal changes in the phytoplankton communities and their control by hydrology and nutrient availability. Journal of Plankton Research, 11 (4): 839-867.

MOSS, B., BOOKER I., BALLS H. \& MANSON K. 1989. Phytoplankton distribution in a temperate floodplain lake and river system. 1. Hydrology, nutrient sources and phytoplankton biomass. Journal of Plankton Research, 11: 813-838.

MUGNI H. 2008. Concentración de nutrientes y toxicidad de pesticidas en aguas superficiales de cuencas rurales. Tesis Doctoral. Universidad Nacional de La Plata.

MUGNI H., JERGENTZ S., SCHULZ R., MAINE A. \& BONETTO C. 2005. Phosphate and nitrogen compounds in streams of Pampean Plain areas under intensive cultivation (Buenos Aires, Argentina). Phosphates in Sediments. Backhuys Publishers, The Netherlands: 163-170.

NABOUT J. C., de NOGUEIRA I. S., de OLIVEIRA L. G. \& MORAIS R. R. 2007. Phytoplankton diversity (alpha, beta and gamma) from Araguaia River tropical floodplain lakes (central Brazil). Hydrobiologia, 557: 455-461.

NEAL C., HILTON J., WADE A. J., NEAL M. \& WICKHAM H. 2006. Chlorophyll-a in the rivers of eastern England. Science of the Total Environment, 365: 84-104.

NEAL C., JARVIE H. P., WITHERS P. J., WHITTON B. A. \& NEAL M. 2010. The strategic significance of wastewater sources to pollutant phosphorus levels in English rivers and to environmental management for rural, agricultural and urban catchments. Science of the Total Environment, 408: 1485-1500.

NEIFF J. J. 1990. Ideas para la interpretación ecológica del Paraná. Interciencia, 15 (6): 424-441.

NEIFF J. J. 1996. Large rivers of South America: toward the new approach. Verh. Int. Verein. Limnol. 26: $167-181$.

NEIFF J. J., IRIONDO M. H. \& CARIGNAN R. 1994. Large tropical South American wetlands: an overview. En: Proc. of the Internat. Workshop on the Ecology \& Management of Aquatic-Terrestrial Ecotones: 156-165.

NESCHUK N. C. 2001. Limnología del Río Salado (Buenos Aires) y el uso de la tierra en su cuenca. Tesis de doctorado, FCNyM, UNLP.

NESCHUK N., CLAPS M. \& GABELLONE N. 2002a. Planktonic rotifers of a saline lowland river (Salado River, Argentina). Annales de Limnologie - International Journal of Limnology, 38: 191-198.

NESCHUK N., GABELLONE N. A. \& CLAPS M. C. 2000. Caracterización espacial del río Salado (Buenos Aires) mediante concentraciones de fósforo total. Diversidad y Ambiente, 1: 13-19.

NESCHUK N., GABELLONE N. A. \& SOLARI L. 2002b. Plankton characterization of a lowland river (Salado River, Argentina). Verhandlungen des Internationalen Verein Limnologie, 28: 13361339.

NEWBOLD J. D. 1992. Cycles and Spirals of Nutrients. In: Calow, P., and Petts, G. (Eds.) Rivers Handbook, Vol. 1, pág. 379-408.

NIELSEN D., WATSON G. \& PETRIE R. 2005. Microfaunal communities in three lowland rivers under differing flow regimes. Hydrobiologia, 543: 101-111.

NING N. S., NIELSEN D. L., PAUL W. L., HILLMAN T. J. \& SUTER P. J. 2010. Microinvertebrate dynamics in riverine slackwater and mid-channel habitats in relation to physico-chemical parameters and food availability. River Research \& Applications, 26: 279-296. 
O'FARRELL I. \& IZAGUIRRE I. 1994. Phytoplankton ecology and limnology of the River Uruguay Lower Basin (Argentina). Archiv für Hydrobiologie, 99: 155-179.

O'FARRELL I. 1993. Phytoplankton ecology and limnology of the Salado River (Buenos Aires, Argentina). Hydrobiologia, 271: 169-178.

O'FARRELL I., LOMBARDO R. J., de TEZANOS PINTO P. \& LOEZ C. 2002. The assessment of water quality in the Lower Luján River (Buenos Aires, Argentina): phytoplankton and algal bioassays. Environmental Pollution, 120: 207-218.

OCÓN C. S. \& RODRIGUES CAPÍTULO A. 2004. Presence and abundance of Ephemeroptera and other sensitive macroinvertebrates in relation with habitat conditions in pampean streams (Buenos Aires, Argentina). Archiv für Hydrobiologie, 159: 473-487.

ODUM E. P. 1969. The strategy of ecosystem development. Sustainability, 164: 58.

O'FARRELL I., TELL G. \& PODLEJSKI A. 2001. Morphological variability of Aulacoseira granulata (Ehr.) Simonsen (Bacillariophyceae) in the Lower Paraná River (Argentina). Limnology, 2: 65-71.

PACE M. L., FINDLAY S. E. \& LINTS D. 1992. Zooplankton in advective environments: the Hudson River community and a comparative analysis. Canadian Journal of Fisheries $\mathcal{E}$ Aquatic Sciences, 49 (5): 1060-1069.

PADISÁK J. \& G.-TÓTH L. 1991. Some aspects of the ecology of subdominant green algae in a large, nutrient limited shallow lake (Balaton, Hungary). Archiv für Protistenkunde, 139(1): 225242.

PADISÁK J. \& ADRIAN R. 1999. Biomasse und Bioaktivität. En: Tümpling W. \& G. Friedrich (Eds.). Methoden der Biologischen Wasseruntersuchung 2. Biologische Gewässeruntersuchung. Pág. 334-367. Gustav Fischer Verlag, Jena.

PADISÁK J. 1994. Identification of relevant time-scales in non-equilibrium community dynamics: conclusions from phytoplankton surveys. New Zealand Journal of Ecology, 18: 169-176.

PAERL H. W. 1988. Growth and reproductive strategies of freshwater blue-green algae (Cyanobacteria). En: Sandgren C. D. (Ed.). Growth and reproductive strategies of freshwater phytoplankton. Pág. 261-315. Cambridge University Press.

PAGGI J. C. 1979. Revisión de las especies argentinas del género Bosmina Baird agrupadas en el subgénero Neobosmina Lieder (Crustacea, Cladocera). Acta Zool. lilloana, 35: 137-162.

PAGGI J. C. 1995a. Biodiversidad del zooplancton en los ecosistemas acuáticos continentales de la región neotropical: revisión de las especies del género Notodiaptomus Kiefer (Copepoda, Calanoidea). Tesis de Magister de la Universidad Nacional del Litoral, 127 pp.

PAGGI J. C. 1995b. Crustacea Cladocera. En: Ecosistemas de Aguas Continentales, Metodologías para su estudio. Lopretto E. C. \& Tell G. (Dirs.). Edicione Sur La Plata, Argentina.

PAGGI J. C. 1998. Cladocera (Anomopoda y Ctenopoda). En: Biodiversidad de Artrópodos Argentinos: Una perspectiva biotaxonómica. Morrone J. J. \& Coscarón S. (Dirs.). Ediciones Sur, La Plata.

PALMER J., SUTER S. N. \& ARADAS R. D. 2002. The Río Salado Basin in Argentina: an integrated Master Plan. WaterE Environment Journal, 16: 141-146.

PATRICK R. \& REIMER C. 1966. The diatoms of United States. Vol. 1. Monogr. Ac. Nat. Sciences, Philadelphia.

PATRICK R. \& REIMER C. 1975. The diatoms of United States. Vol. 2. Part I. Monogr. Ac. Nat. Sciences. Philadelphia.

PATRICK R. 1977. Ecology of freshwater diatoms and diatom communities. The biology of diatoms, 13: 284-332.

PAULETO G. M., VELHO L. F. M., BUOSI P. R. B., BRÃO A. F. S., LANSAC-TÔHA F. A., \& BONECKER C. C. 2009. Spatial and temporal patterns of ciliate species composition (Protozoa: Ciliophora) in the plankton of the Upper Paraná River floodplain. Brazilian Journal of Biology, 69 (2): 517-527.

PETERS R. H. 1987. Metabolism in Daphnia. Memorie dell' Istituto Italiano di Idrobiologia 45: 193-243. 
PETTS G. E. 2009. Instream flow science for sustainable river management. Journal of the American water resources Association, 45: 1071-1086.

PHLIPS E. J., HENDRICKSON J., QUINLAN E. L. \& CICHRA M. 2007. Meteorological influences on algal bloom potential in a nutrient-rich blackwater river. Freshwater Biology, 52: 2141-2155.

PIANKA E. R. 1970. On r-and K-selection. American naturalist: 592-597.

PICARD V. \& LAIR N. 2005. Spatio-temporal investigations on the planktonic organisms of the Middle Loire (France), during the low water period: biodiversity and community dynamics. Hydrobiologia, 551: 69-86.

PIIRSOO K., PALL P., TUVIKENE A. \& VIIK M. 2008. Temporal and spatial patterns of phytoplankton in a temperate lowland river (Emajõgi, Estonia). Journal of Plankton Research, 30: 1285-1295.

PINAY G., DECAMPS H., CHAUVET E. \& FUSTEC E. 1990. Functions of ecotones in fluvial systems. En: Naiman R.J. \& Décamp H. (Eds). The ecology and management of aquaticterrestrial ecotones, Pág. 141-169. Unesco, Paris.

POFF N. L. \& ZIMMERMAN J. K. 2010. Ecological responses to altered flow regimes: a literature review to inform the science and management of environmental flows. Freshwater Biology, 55(1): 194-205.

POFF N. L., ALLAN J. D., BAIN M. B., KARR J. R., PRESTEGAARD K. L., RICHTER B. D., SPARKS R. E. \& STROMBERG J. C. 1997. The natural flow regime. BioScience: 769-784.

POPOVICH C. A., GUINDER V. A. \& PETTIGROSSO R. E. 2008. Composition and dynamics of phytoplankton and aloricate ciliate communities in the Bahía Blanca Estuary. Integrated coastal zone management in Latin America. Lisboa: IST Press, Scientific Publishers, pág. 255-270.

POURRIOT R., ROUGIER C. \& MIQUELIS A. 1997. Origin and development of river zooplankton: example of the Marne. Hydrobiologia, 345: 143-148.

PRINGLE C. 2003. What is hydrologic connectivity and why is it ecologically important? Hydrological Processes, 17: 2685-2689.

PRINGLE C. M., NAIMAN R. J., BRETSCHKO G., KARR J. R., OSWOOD M. W., WEBSTER J. R., WELCOMME R. L. \& WINTERBOURN M. J. 1988. Patch dynamics in lotic systems: the stream as a mosaic. Journal of the North American Benthological Society, 7: 503-524.

PUTT M. \& STOECKNER D. K. 1989. An experimentally determined carbon: volume ratio for marine "oligotrichous" ciliates from estuarine and coastal waters. Limnology E Oceanography, 34: 1097-1103.

QUIROGA A. R., BUSCHIAZZO D. E. \& PEINEMANN A. N. 1999. Soil compaction is related to management practices in the semi-arid Argentine pampas. Soil \& Tillage Research, 52: 21-28.

QUIRÓS R., RENELLA A. M., BOVERI M. B., ROSSO J. J. \& SOSNOVSKY A. 2002. Factores que afectan la estructura y funcionamiento de las lagunas pampeanas. Ecología Austral, 12: 175-185.

RAHKOLA M., KARJALAINEN J. \& AVINSKY V. A. 1998. Individual weight estimates of zooplankton based onf legth-weight regressions in lake Ladoga and Saimaa lake system. Nordic Journal of Freshwater Research, 74: 110-120.

RAVEN J. A. \& RICHARDSON K. 1984. Dinophyte flagella: a cost-benefit analysis. New Phytologist, 98 (2): 259-276.

RECKENDORFER W., KECKEIS H., WINKLER G. \& SCHIEMER F. 1999. Zooplankton abundance in the river Danube, Austria: the significance of inshore retention. Freshwater Biology, 41: 583591.

REDDY R. \& DELAUNE R. D. 2008. Biogeochemistry of Wetlands: Science and Applications. CRC Press, Taylor \& Francis Group. Boca Raton, FL.

REDFIELD A. C. 1958. The biological control of chemical factors in the environment. American scientist: 205-221. 
REYNOLDS C. S \& GLAISTER M. S. 1993. Spatial and temporal changes in phytoplankton abundance in the upper and middle reach of the River Sevem. Archiv für Hydrobiologie, Suppl. Large Rivers 9: 1-22.

REYNOLDS C. S. \& DESCY J-P. 1996. The production, biomass and structure of phytoplankton in large rivers. Archiv für Hydrobiologie, Suppl. Large Rivers, 10: 161-187.

REYNOLDS C. S. 1984. The ecology of freshwater phytoplankton. Cambridge University Press.

REYNOLDS C. S. 1988a. Potamoplankton: paradigms, paradoxes and prognoses. En: Round, F. E. (Ed.). Algae and aquatic environments. Biopress Ltd., Bristol, U.K.

REYNOLDS C. S. 1988b. Functional morphology and the adaptive strategies of freshwater phytoplankton. En: Sandgren C. D. (ed.) Growth and reproductive strategies of freshwater phytoplankton. Cambridge University Press.

REYNOLDS C. S. 1992. Dynamics, selection and composition of phytoplankton in relation to vertical structure in lakes. Archiv für Hydrobiologie, 35: 13-31.

REYNOLDS C. S. 1994a. The role of fluid motion in the dynamics of phytoplankton in lakes and rivers. En: Guiller P. S., Hildrew A. \& Raffaelli D. G. (Eds). Aquatic ecology: scale, pattern and process. The 34th Symposium of the British Ecological Society with the American Society of Limnology and Oceanography, University College, Cork.

REYNOLDS C. S. 1994b. The long, the short and the stalled: on the attributes of phytoplankton selected by physical mixing in lakes and rivers. Hydrobiologia, 289: 9-21.

REYNOLDS C. S. 1995. River Plankton: The Paradigm Regained. En: Harper D. M. \& Ferguson A. J. D.. The Ecological Basis for River Management. Pág. 161-173. John Wiley \& Sons Ltd.

REYNOLDS C. S. 1997. Vegetation process in the pelagic: a model for ecosystem theory. En: Serie Excellence in Ecology (9), Assembly of pelagic plant communities. Ecology Institute, Oldendorf.

REYNOLDS C. S. 1998. The state of freshwater ecology. Freshwater Biology, 39: 741-753.

REYNOLDS C. S. 2000. Hydroecology of river plankton: the role of variability in channel flow. Hydrological Processes, 14: 3119-3132.

REYNOLDS C. S. 2002. Ecological pattern and ecosystem theory. Ecological Modelling, 158: 181-200.

REYNOLDS C. S. 2003. Planktonic community assembly in flowing water and the ecosystem health of rivers. Ecological Modelling, 160: 191-203.

REYNOLDS C. S., 1989. Physical determinants of phytoplankton succession. En: Sommer, U. (Ed.), Plankton Ecology. Brock, Spring, Madison. Pág: 9-56.

REYNOLDS C. S., DESCY J-P. \& PADISÁK J. 1994. Are phytoplankton dynamics in rivers so different from those in shallow lakes? Hydrobiologia, 289: 1-7.

REYNOLDS C. S., HUSZAR V., KRUK C., NASELLI-FLORES L. \& MELO S. 2002. Towards a functional classification of the freshwater phytoplankton. Journal of Plankton Research, 24: 417428.

REYNOLDS C. S., PADISÁK J. \& SOMMER U. 1993. Intermediate disturbance in the ecology of phytoplankton and the maintenance of species diversity: a synthesis. Hydrobiologia, 249 (1-3): 183-188.

RICHEY J. E. E., HEDGES J. I., DEVOL A. H., QUAY P. D., VICTORIA R., MARTINELLI L. \& FORSBERG B. R. 1990. Biogeochemistry of carbon in the Amazon River. Limnology $\mathcal{E}$ Oceanography, 35: 352-371.

RODRIGUES CAPÍTULO A., GÓMEZ N., GIORGI A. \& FEIJOÓ C. 2010. Global changes in pampean lowland streams (Argentina): implications for biodiversity and functioning. Hydrobiologia, 657: 53-70.

ROJAS MOLINA F. \& JOSE DE PAGGI S. 2008. Zooplankton in the Paraná River floodplain (South America) before and after the invasion of Limnoperna fortunei (Bivalvia). Wetlands, 28: 695-702.

ROJO A., KRUSE E., LAURENCENA P., DELUCHI M. \& CAROL E. 2006. Relación de la capa freática y las obras de regulación en la región Vallimanca - Las Flores. VIII Congreso Latinoamericano de Hidrología Subterránea, Septiembre 2006 - Asunción, Paraguay. 
ROJO C., ALVAREZ COBELAS M. \& ARAUZO M. 1994. An elementary, structural analysis of river phytoplankton. Hydrobiologia, 289: 43-55.

ROSSETTI G., BARTOLI M. \& MARTENS K. 2004. Limnological characteristics and recent ostracods (Crustacea, Ostracoda) of freshwater wetlands in the Parco Oglio Sud (Northern Italy). Annales de Limnologie-International Journal of Limnology, 40: 329-341.

ROSSETTI G., TIRENI F., VIGLIOLI S. \& FERRARI I. 2003. Ricerche ecologiche in un ambiente acquatico della golena del Po nei pressi di Casalmaggiore. Studi Trentini di Scienze Naturali, Acta Biológica, 80: 193-200.

ROSSETTI G., VIAROLI P. \& FERRARI I. 2009. Role of abiotic and biotic factors in structuring the metazoan plankton community in a lowland river. River Research $\mathcal{E}$ Applications, 25: 814-835.

ROTHHAUPT K. O. 1990. Population growth rates of two closely related rotifer species: effects of food quantity, particle size, and nutritional quality. Freshwater Biology, 23: 561-570.

RUTTNER-KOLISKO A. 1974. Plankton rotifers: biology and taxonomy. Volumen 26. Schweizerbart.

SADS. 2007. Vulnerabilidad de la Pampa Bonaerense. Reporte Final de los Estudios de Vulnerabilidad y Mitigación frente al Cambio Climático. Dirección de Cambio Climático, Secretaría de Ambiente y Desarrollo Sustentable de la Nación, 113 pág. http://aplicaciones.medioambiente.gov.ar.

SALMASO N. \& ZIGNIN A. 2010. At the extreme of physical gradients: phytoplankton in highly flushed, large rivers. Hydrobiologia, 639: 21-36.

SANDERS R. W. \& WICKHAM S. A. 1993. Planktonic protozoa and metazoa: predation, food quality and population control. Marine Microbial Food Webs, 7: 197-223.

SANDERS R. W. 1987. Tintinnids and other microzooplankton-seasonal distributions and relationships to resources and hydrography in a Maine estuary. Journal of Plankton Research, 9: 65-77.

SANDERS R. W., PORTER K. G., BENNETT S. J. \& DEBIASE A. E. 1989. Seasonal patterns of bacterivory by flagellates, ciliates, rotifers, and cladocerans in a freshwater planktonic community. Limnology and oceanography, 34 (4): 673-687.

SANTA CRUZ J. N. \& SILVA BUSSO A. 1999. Escenario hidrogeológico general de los principales acuíferos de la llanura pampeana y Mesopotamia meridional Argentina. Escenario Hidrogeológico General de los Principales Acuíferos de la Llanura Pampeana y Mesopotamia Meridional Argentina. II Congreso Argentino de Hidrogeología y IV Seminario Hispano Argentino sobre temas actuales en hidrología subterránea. Actas Tomo I: 461-473.

SAUNDERS III J. F. \& LEWIS JR W. M. 1989. Zooplankton abundance in the lower Orinoco River, Venezuela. Limnology \& Oceanography, 34: 397-409.

SCARPATI O. E., SPECHA L. \& CAPRIOLO A. 2002. Occurrence of severe floods in the Salado river basin, Buenos Aires Province, Argentina. Mitigation and Adaptation Strategies for Global Change, 7: 285-301.

SCHAGERL M., DROZDOWSKI I., ANGELER D. G., HEIN T. \& PREINER S. 2009. Water age-a major factor controlling phytoplankton community structure in a reconnected dynamic floodplain (Danube, Regelsbrunn, Austria). Journal of Limnology, 68 (2): 274-287.

SCHEFFER M. \& RINALDI S. 2000. Minimal models of top-down control of phytoplankton. Freshwater Biology, 45: 265-283.

SCHEFFER M., RINALDI S., HUISMAN J. \& WEISSING F. J. 2003. Why plankton communities have no equilibrium: solutions to the paradox. Hydrobiologia, 491 (1-3): 9-18.

SCHENONE N., VOLPEDO A. \& FERNÁNDEZ CIRELLI A. 2008. Estado trofico y variación estacional de nutrientes en los ríos y canales del humedal mixo-halino de bahía samborombon (Argentina). Limnética, 27: 143-150.

SCHERWASS A. \& ARNDT H. 2005. Structure, dynamics and control of the ciliate fauna in the potamoplancton of the River Rhine. Archiv für Hydrobiologie, 164: 287-307. 
SCHERWASS A., BERGFELD T., SCHÖL A., WEITERE M. \& ARNDT H. 2010. Changes in the plankton community along the length of the River Rhine: Lagrangian sampling during a spring situation. Journal of plankton research, 32: 491-502.

SCHIEMER F., KECKEIS H., RECKENDORFER W. \& WINKLER G. 2001. The "inshore retention concept" and its significance for large rivers. Archiv für Hydrobiologie, 135: 509-516.

SCHRÖDER T. 2001. Colonising strategies and diapause of planktonic rotifers (Monogononta, Rotifera) during aquatic and terrestrial phases in a floodplain (Lower Oder Valley, Germany). International Review of Hydrobiology, 86: 635-660.

SEDELL J. R., RICHEY J. E. \& SWANSON F. J. 1989. The river continuum concept: a basis for the expected ecosystem behavior of very large rivers. En Proceedings of the International Large Rivers Symposium (LARS). Canadian Special Publication Fisheries \& Aquatic Science, 106: 49-55.

SEGERS H. 1995. Rotifera: the Lecanidae (Monogonota). En: Dumont (Ed.). Guides to the identification of the Microinvertebrates of the Continental Waters of the World. SPB Academic Publishing, The Hague.

SELLERS T. \& BUKAVECKAS P. A. 2003. Phytoplankton production in a large, regulated river: A modeling and mass balance assessment. Limnology \& Oceanography, 48: 1476-1487.

SHERMAN B. S., WEBSTER I. T., JONES G. J. \& OLIVER R. L. 1998. Transitions between Aulcoseira and Anabaena dominance in a turbid river weir pool. Limnology \& Oceanography, 43: 1902-1915.

SHERR E. B. \& SHERR B. F. 1994. Bacterivory and herbivory: key roles of phagotrophic protists in pelagic food webs. Microbial Ecology, 28: 223-235.

SHERR E. B. \& SHERR B. F. 2002. Significance of predation by protists in aquatic microbial food webs. Antonie van Leeuwenhoek, 81: 293-308.

SHIEL R. J. \& KOSTE W. 1983. Rotifer communities of billabongs in northern and south-eastern Australia. Hydrobiologia, 104: 41-47.

SHIEL R. J. \& KOSTE W. 1992. Rotifer from Australian inland waters VIII. Trichocercidae (Monogononta).

SHIEL R. J. 2002. Murray river microfauna. The Victorian naturalist, 119: 205-211.

SHIEL R. J., COSTELLOE J. F., REID J. R., HUDSON P. \& POWLING J. 2006. Zooplankton diversity and assemblages in arid zone rivers of the Lake Eyre Basin, Australia. Marine $\mathcal{E}$ Freshwater Research, 57: 49-60.

SHIEL R. J., WALKER K. F. \& WILLIAMS W. D. 1982. Plankton of the lower River Murray, South Australia. Australian Journal of Marine E Freshwater Research, 33: 301-327.

SIERRA M. V. \& GÓMEZ N. 2010. Assessing the disturbance caused by an industrial discharge using field transfer epipelic biofilm. Science of the total environment, 408: 2696-2705.

SILVA W. M. 2008. Diversity and distribution of the free-living freshwater Cyclopoida (Copepoda: Crustacea) in the Neotropics. Brazilian Journal of Biology, 68: 1099-1106.

ŠIMEK K., JÜRGENS K., NEDOMA J., COMERMA M. \& ARMENGOL J. 2000. Ecological role and bacterial grazing of Halteria spp.: small freshwater oligotrichs as dominant pelagic ciliate bacterivores. Aquatic Microbial Ecology, 22: 43-56.

SINEV A. Y. 2001. Redescription of Alona glabra Sars, 1901, a South American species of the pulchella-group (Branchiopoda: Anomopoda: Chydoridae). Arthropoda Selecta 10: 273-280.

SLÁDEČEK V. 1983. Rotifers as indicators of water quality. Hydrobiologia, 100 (1), 169-201.

SLUSS T. D., COBBS G. A. \& THORP J. H. 2008. Impact of turbulence on riverine zooplankton: a mesocosm experiment. Freshwater Biology, 53: 1999-2010.

SMITH V. H., TILMAN G. D. \& NEKOLA J. C. 1999. Eutrophication: impacts of excess nutrient inputs on freshwater, marine, and terrestrial ecosystems. Environmental Pollution, 100: 179-196.

SOARES M. C. S., HUSZAR V. L. \& ROLAND F. 2007. Phytoplankton dynamics in two tropical rivers with different degrees of human impact (Southeast Brazil). River Research $\mathcal{E}$ Applications, 23: 698-714. 
SOBALLE D. M. \& KIMMEL B. L. 1987. A large-scale comparison of factors influencing phytoplankton abundance in rivers, lakes, and impoundments. Ecology, 68: 1943-1954.

SOLARI L. \& MAC DONAGH M. E. 2014. Lotic and lentic environments of the Pampean Plain. Advances in Limnology, 65: 143-165.

SOLARI L. C., GABELLONE N. A., CLAPS M. C., CASCO M. A., QUAÍNI K. P. \& NESCHUK N. C. 2014. Phytoplankton chlorophyte structure as related to ENSO events in a saline lowland river (Salado River, Buenos Aires, Argentina). Ecology \& Evolution, 4: 918-932.

SOLARI L., CLAPS M. \& GABELLONE N. 2002. River-pond (backwater) interactions in the lower basin of the Salado River (Buenos Aires, Argentina). Archiv für Hydrobiologie, Suppl. Large Rivers, 13: 99-119.

SOLBRIG O. T. 1997. Towards a sustainable Pampa agriculture: past performance and prospective analysis. David Rockefeller Center for Latin American Studies, Harvard University.

SOMMER U. \& SOMMER F. 2006. Cladocerans versus copepods: the cause of contrasting topdown controls on freshwater and marine phytoplankton. Oecologia, 147: 183-194.

SOMMER U., PADISÁK J., REYNOLDS C. S. \& JUHÁSZ-NAGY P. 1993. Hutchinson's heritage: the diversity-disturbance relationship in phytoplankton. Hydrobiologia, 249: 1-7.

SOMMER U., SOMMER F., SANTER B., ZÖLLNER E., JÜRGENS K., JAMIESON C., BOERSMA M. \& GOCKE K. 2003. Daphnia versus copepod impact on summer phytoplankton: functional compensation at both trophic levels. Oecologia, 135: 639-647.

SOMMER U. \& LEWANDOWSKA A. 2011. Climate change and the phytoplankton spring bloom: warming and overwintering zooplankton have similar effects on phytoplankton. Global Change Biology, 17(1): 154-162.

SPAINK P. A., IETSWAART T. \& ROIJACKERS R. 1998. Plankton dynamics in a dead arm of the River Waal: a comparison with the main channel. Journal of Plankton Research, 20: 1997-2007.

SPARKS R. E. \& SPINK A. 1998. Disturbance, succession and ecosystem processes in rivers and estuaries: effects of extreme hydrologic events. Regulated Rivers: Research \& Management, 14: 155159.

SPARKS R. E. 1995. Need for ecosystem management of large rivers and their floodplains. BioScience: $168-182$.

SPARKS R. E., BAYLEY P. B., KÖHLER S. L. \& OSBORNE L. L. 1990. Disturbance and recovery of large floodplain rivers. Environmental Management, 14 (5): 699-709.

SPEAS D. W. 2000. Zooplankton density and community composition following an experimental flood in the Colorado River, Grand Canyon, Arizona. Regulated Rivers: Research \& Management, 16: 73-81.

STANKOVIĆ I., VLAHOVIĆ T., UDOVIČ M. G., VÁRBÍRÓ G. \& BORICS G. 2012. Phytoplankton functional and morpho-functional approach in large floodplain rivers. Hydrobiologia, 698 (1): 217-231.

STELZER C. P. 1998. Population growth in planktonic rotifers. Does temperature shift the competitive advantage for different species?. Hydrobiologia, 387/388: 349-353.

STOYNEVA M. P. 1994. Shallows of the Lower Danube as additional sources of potamoplankton. Hydrobiologia, 289: 171-178.

STRINGFELLOW W., HERR J., LITTON G., BRUNELL M., BORGLIN S., HANLON J., CHEN C., GRAHAM J., BURKS R., DAHLGREN R., KENDALL C., BROWN R. \& QUINN N. 2009. Investigation of river eutrophication as part of a low dissolved oxygen total maximum daily load implementation. Water Science \& Technology, 59(1): 9.

SUN J. \& LIU D. 2003. Geometric models for calculating cell biovolume and surface area for phytoplankton. Journal of Plankton Research, 25: 1331-1346.

SWANSON C. D. \& BACHMANN R. W. 1976. A model of algal exports in some Iowa streams. Ecology, 57: 1076-1080. 
TABOADA M., DAMIANO F. \& LAVADO R. S. 2009. Inundaciones en la región pampeana. Consecuencias sobre los suelos. Sitio Argentino de Producción Animal. 36 pág. http://www.produccion-animal.com.ar/inundacion/82-Inundaciones_en_la_region_pampeana

TALLING J. F. \& RZOSKA J. 1967. The development of plankton in relation to hydrological regime in the Blue Nile. The Journal of Ecology: 637-662.

TANCO R. \& KRUSE E. 2001. Prediction of seasonal water-table fluctuations in La Pampa and Buenos Aires, Argentina. Hydrogeology Journal, 39: 339-347.

TARTARI G. A. \& MOSELLO R. 1997. Metodologia analitiche e conrolli di qualitá nel laboratorio chimico dell' instituto di idrobiologia. Consiglio Nazionale delle Ricerche, Istituto Italiano di Idrobiolgia.

TELL G. \& CONFORTI V. 1986. Euglenofitas pigmentadas de Argentina. J. Cramer Berlín, Stuttgart.

TER BRAAK C. J. \& VERDONSCHOT P. F. 1995. Canonical correspondence analysis and related multivariate methods in aquatic ecology. Aquatic sciences, 57(3): 255-289.

TER BRAAK C.J.F. \& SMILAUER P. 1998. CANOCO Reference Manual and Canoco Draw for Windows User's Guide: Software for Canonical Community Ordination (Version 4.5). Microcomputer Power (Ithaca, NY, USA).

THOMAZ S. M., BINI L. M. \& BOZELLI R. L. 2007. Floods increase similarity among aquatic habitats in river-floodplain systems. Hydrobiologia, 579(1): 1-13.

THOMPSON R. M. \& LAKE P. S. 2010. Reconciling theory and practise: the role of stream ecology. River Research \& Applications, 26: 5-14.

THOMS M. C. 2003. Floodplain-river ecosystems: lateral connections and the implications of human interference. Geomorphology, 56: 335-349.

THORNTHWAITE C. W. 1948. An approach toward a rational classification of climate. Geographical review, 55-94.

THORP J. H. \& CASPER A. F. 2003. Importance of biotic interactions in large rivers: an experiment with planktivorous fish, dreissenid mussels and zooplankton in the St. Lawrence River. River Research \& Applications, 19: 265-279.

THORP J. H. \& DELONG M. D. 1994. The riverine productivity model: an heuristic view of carbon sources and organic processing in large river ecosystems. Oikos, 70: 305-308.

THORP J. H. \& MANTOVANI S. 2005. Zooplankton of turbid and hydrologically dynamic prairie rivers. Freshwater Biology, 50: 1474-1491.

THORP J. H., BLACK A. R. \& HAAG K. H. 1994. Zooplancton assemblages in the Ohio River. Seasonal, tributary, and navigation dam effects. Canadian Journal of Fisheries $\mathcal{E}$ Aquatic Sciences, 51: 1634-1643.

TILMAN D., KILHAM S. S. \& KILHAM P. 1982. Phytoplankton community ecology: the role of limiting nutrients. Annual Review of Ecology \& Systematics, 13: 349-372.

TOCKNER K., MALARD F. \& WARD J. V. 2000. An extension of the flood pulse concept. Hydrological processes, 14: 2861-2883.

TOCKNER K., PENNETZDORFER D., REINER N., SCHIEMER F. \& WARD J. V. 1999. Hydrological connectivity, and the exchange of organic matter and nutrients in a dynamic river-floodplain system (Danube, Austria). Freshwater Biology, 41(3): 521-535.

TOWNSEND C. R. 1996. Concepts in river ecology: pattern and process in the catchment hierarchy. Large Rivers, 3-21.

TRAIN S. \& RODRIGUES L. C. 1998. Temporal fluctuations of the phytoplankton community of the Baía River, in the upper Paraná River floodplain, Mato Grosso do Sul, Brazil. Hydrobiologia, 361: 125-134.

TURNER R. E., RABALAIS N. N., JUSTIC D. \& DORTCH Q. 2003. Global patterns of dissolved N, $\mathrm{P}$ and Si in large rivers. Biogeochemistry, 64: 297-317. 
VADADI-FÜLÖP C., HUFNAGEL L., JABLONSZKY G. \& ZSUGA K. 2009. Crustacean plankton abundance in the Danube River and in its side arms in Hungary. Biologia, 64: 1184-1195.

VADADI-FÜLÖP C., SIPKAY C., MÉSZÁROS G. \& HUFNAGEL L. 2012. Climate change and freshwater zooplankton: what does it boil down to? Aquatic Ecology, 46: 501-519.

VAN DAM H., MERTENS A. \& SINKELDAM J. 1994. A coded checklist and ecological indicator values of freshwater diatoms from the Netherlands. Netherland Journal of Aquatic Ecology, 28: 117-133.

VAN DIJK G. M., STALNACKE P., GRIMVALL A., TONDERSKI A., SUNDBLAD K. \& SCHÄFER A. 1996. Long-term trends in nitrogen and phosphorus concentrations in the Lower River Rhine. Large Rivers: 99-109.

VAN NIEUWENHUYSE E. E. \& JONES J. R. 1996. Phosphorus chlorophyll relationship in temperate streams and its variation with stream catchment area. Canadian Journal of Fisheries $\mathcal{E}$ Aquatic Sciences, 53 (1): 99-105.

VAN NIEUWENHUYSE E. E. 2007. Response of summer chlorophyll concentration to reduced total phosphorus concentration in the Rhine River (Netherlands) and the Sacramento-San Joaquin Delta (California, USA). Canadian Journal of Fisheries \& Aquatic Sciences, 64(11): 15291542.

VANNOTE R. L., MINSHALL G. W., CUMMINS K. W., SEDELL J. R. \& CUSHING C. E. 1980. The River Continuum Concept. Canadian Journal of Fisheries \& Aquatic Sciences, 37 (1): 130-137.

VARNI M. R. \& USUNOFF E. J. 1999. Simulation of regional-scale groundwater flow in the Azul River basin, Buenos Aires Province, Argentina. Hydrogeology Journal, 7: 180-187.

VÁSQUEZ E. \& REY J. 1989. A longitudinal study of zooplankton along the Lower Orinoco River and its Delta (Venezuela). Annales de Limnologie, 25: 107-120.

VIGLIZZO E. F. \& FRANK F. C. 2006. Ecological interactions, feedbacks, thresholds and collapses in the Argentine Pampas in response to climate and farming during the last century. Quaternary International, 158: 122-126.

VIGLIZZO E. F., LÉRTORA F., PORDOMINGO A. J., BERNARDOS J. N., ROBERTO Z. E. \& DEL VALLE H. 2001. Ecological lessons and applications from one century of low external-input farming in the pampas of Argentina. Agriculture, Ecosystems \& Environment, 83: 65-81.

VIGLIZZO E. F., ROBERTO Z. E., LÉRTORA F., LOPEZ GAY E. \& BERNARDOS J. 1997. Climate and land-use change in field-crop ecosystems of Argentina. Agriculture, Ecosystems $\mathcal{E}$ Environment, 66: 61-70.

VILCHES C. \& GIORGI A. 2010. Metabolism in a macrophyte-rich stream exposed to flooding. Hydrobiologia, 654: 57-65.

VILCHES C., GIORGI A., MASTRÁNGELO M. \& FERRARI L. 2011. Non-point contamination homogenizes the water quality of Pampean streams. Bulletin of environmental contamination $\mathcal{E}$ toxicology, 87: 147-151.

VINOCUR A., O'FARRELL I. \& IZAGUIRRE I. 1994. Contribution to the knowledge of the diatom flora of the Salado River Basin (Buenos Aires Province, Argentina). Nova Hedwigia, 58: 153-175.

VIROUX L. 1997. Zooplankton development in two large lowland rivers, the Moselle (France) and the Meuse (Belgium), in 1993. Journal of Plankton Research, 19: 1743-1762.

VIROUX L. 2002. Seasonal and longitudinal aspects of microcrustacean (Cladocera, Copepoda) dynamics in a lowland river. Journal of Plankton Research, 24: 281-292.

VIS C., HUDON C., CARIGNAN R. \& GAGNON P. 2007. Spatial analysis of production by macrophytes, phytoplankton and epiphyton in a large river system under different wáter-level conditions. Ecosystems, 10: 293-310.

WAHL D. H., GOODRICH J., NANNINI M. A., DETTMERS J. M. \& SOLUK D. A. 2008. Exploring riverine zooplankton in three habitats of the Illinois River ecosystem: Where do they come from? Limnology \& Oceanography, 53: 2583-2593.

WALKER B. H. 1992. Biodiversity and ecological redundancy. Conservation Biology, 6: 18-23. 
WALKS D. J. \& CYR H. 2004. Movement of plankton through lake-stream systems. Freshwater Biology, 49: 745-759.

WALKS D. J. 2007. Persistence of plankton in flowing water. Canadian Journal of Fisheries $\mathcal{E}$ Aquatic Sciences, 64: 1693-1702.

WALZ N. \& WELKER M. 1998. Plankton development in a rapidly flushed lake in the River Spree system (Neuendorfer See, Northeast Germany). Journal of Plankton Research, 20: 2071-2087.

WALZ N. 1995. Rotifer populations in plankton communities: Energetics and life history strategies. Experientia, 51: 437-453.

WANG C., LI X., LAI Z., LI Y., DAUTA A. \& LEK S. 2014. Patterning and predicting phytoplankton assemblages in a large subtropical river. Fundam. Appl. Limnol., 185 (3-4): 263279.

WARD J. V. \& STANFORD J. A. 1983. Intermediate-disturbance hypothesis: an explanation for biotic diversity patterns in lotic ecosystems. In: Fontaine T. D. \& Bartell S. M. (Eds). Dynamics of Lotic Systems, Pág. 347-356. Ann Arbor Science, Michigan.

WARD J. V. \& STANFORD J. A. 1995a. Ecological connectivity in alluvial river ecosystems and its disruption by flow regulation. Regulated Rivers: Research \& Management, 11: 105-119.

WARD J. V. \& STANFORD J. A. 1995b. The serial discontinuity concept: extending the model to floodplain rivers. Regulated Rivers: Research \& Management, 10: 159-168.

WARD J. V. \& TOCKNER K. 2001. Biodiversity: towards a unifying theme for river ecology. Freshwater Biology, 46 (6): 807-820.

WARD J. V. 1989. The four-dimensional nature of lotic ecosystems. Journal of the North American Benthological Society: 2-8.

WARD J. V. 1998. Riverine landscapes: biodiversity patterns, disturbance regimes, and aquatic conservation. Biological conservation, 83 (3): 269-278.

WARD J. V., TOCKNER K. \& SCHIEMER F. 1999. Biodiversity of floodplain river ecosystems: ecotones and connectivity. Regulated Rivers: Research \& Management 15: 125-139.

WARD J. V., TOCKNER K., ARSCOTT D. B. \& CLARET C. 2002. Riverine landscape diversity. Freshwater Biology, 47 (4): 517-539.

WEBB C. O., ACKERLY D. D., MCPEEK M. A. \& DONOGHUE M. J. 2002. Phylogenies and community ecology. Annual Review of Ecology \& Systematics, 33: 475-505.

WEBER C. I. 1971. A guide to the common diatoms at Water Pollution Surveillance System Stations. USEPA, Ohio.

WEHR J. \& DESCY J-P. 1998. Use of phytoplankton in large river management. Journal of Phycology, 34: 741-749.

WEILHOEFER C. L., PAN Y. \& EPPARD S. 2008. The effects of river floodwaters on floodplain wetland water quality and diatom assemblages. Wetlands, 28: 473-486.

WEISSE T. 2002. The significance of inter-and intraspecific variation in bacterivorous and herbivorous protists. Antonie van Leeuwenhoek, 81: 327-341.

WEITERE M., SCHERWASS A., SIEBEN K. T. \& ARNDT H. 2005. Planktonic food web structure and potential carbon flow in the lower river Rhine with a focus on the role of protozoans. River Research \& Applications, 21: 535-549.

WELKER M. \& WALZ N. 1999. Plankton dynamics in a river-lake system-on continuity and discontinuity. Hydrobiologia, 408/409: 233-239

WETZEL R. G. \& LIKENS G. E. 1991. Limnological Analyses. 2da. Edición. Springer-Verlag, NY. 291 pág.

WETZEL R. G. 2001. Limnology: Lake \& River Ecosystems. Academic Press. San Diego, California. 1006 pág.

WHITTON B. A. 1975. River Ecology. Studies in Ecology, Vol. 2. Blackwell Scientific Publications. Oxford London Edinburgh Melbourne. 
WIENS J. A. 2002. Riverine landscapes: taking landscape ecology into the water. Freshwater Biology, 47 (4): 501-515.

WILEY M. J., OSBORNE L. L. \& LARIMORE R. W. 1990. Longitudinal structure of an agricultural prairie river system and its relationship to current stream ecosystem theory. Canadian Journal of Fisheries and Aquatic Sciences, 47 (2): 373-384.

WILLIAMS W. D. 1996. The largest, highest and lowest lakes of the world: saline lakes. Verhandlungen des Internationalen Verein Limnologie, 26: 61-79.

WILLIAMS W. D. 1999. Salinisation: a major threat to water resources in the arid and semi-arid regions of the world. Lakes \& Reservoirs, 4: 85-91.

WILSON J. B. 1990. Mechanisms of species coexistence: twelve explanations for Hutchinson's' paradox of the plankton': evidence from New Zealand plant communities. New Zealand Journal of Ecology, 13: 17-42.

WISSMAR R. C. \& SWANSON F. J. 1990. Landscape disturbance and lotic ecotones. En: Naiman R.J. \& Décamp H. (Eds).The ecology and management of aquatic terrestrial ecotones, man and the biosphere series, Pág. 65-102. Unesco, Paris.

WITHERS P. J. A. \& JARVIE H. P. 2008. Delivery and cycling of phosphorus in rivers: A review. Science of the Total Environment, 400: 379-395.

YANG J. R., BASU B. K., HAMILTON P. B. \& PICK F. R. 1997. The development of a true riverine phytoplankton assemblage along a lake-fed lowland river. Archiv für Hydrobiologie, 140 (2): 243260.

ZALEWSKI M., BIS B., KAPINSKA M., FRANKIEWICZ P. \& PUCHALSKI W. 1998. The importance of the riparian ecotone and river hydraulics for sustainable basin-scale restoration scenarios. Aquatic Conservation: Marine \& Freshwater Ecosystems, 8: 287-307.

ZALOCAR DE DOMITROVIC Y. \& FORASTIER M. 2005. Biodiversidad de Cyanophyceae (Cyanobacteria) y especies toxigénicas del litoral fluvial argentino. INSUGEO, Miscelánea, 14: $213-228$.

ZALOCAR DE DOMITROVIC Y. 2002. Structure and variation of the Paraguay River phytoplankton in two periods of its hydrological cycle. Hydrobiologia, 472: 177-196.

ZALOCAR DE DOMITROVIC Y. 2003. Effect of fluctuations in water level on phytoplankton development in three lakes of the Paraná river floodplain (Argentina). Hydrobiologia, 510: 175193.

ZALOCAR DE DOMITROVIC Y., POI DE NEIFF A. S. G. \& CASCO S. L. 2007. Abundance and diversity of phytoplankton in the Paraná River (Argentina) $220 \mathrm{~km}$ downstream of the Yacyretá reservoir. Brazilian Journal of Biology, 67: 53-63.

ZÁRATE M. A. 2003. Loess of Southern South America. Quaternary Science Reviews, 22: 1987-2006.

ZIMMERMANN-TIMM H., HOLST H. \& KAUSCH H. 2007. Spatial dynamics of rotifers in a large lowland river, the Elbe, Germany: How important are retentive shoreline habitats for the plankton community? Hydrobiologia, 593: 49-58.

ZÖLLNER E., SANTER B., BOERSMA M., HOPPE H. G. \& JÜRGENS K. 2003. Cascading predation effects of Daphnia and copepods on microbial food web components. Freshwater Biology, 48: 2174-2193. 
Anexos 


\section{ANEXO I}

Tablas de los parámetros físico-químicos medidos en cada sitio por campaña de muestreo. Referencias: C1 (canal 1 - Canal Mercante), C2 (canal 2 - Canal de Vinculación), C3 (canal 3 - Canal Este), Arroyo (Aํㅗaladillo), R2 (río Salado aguas abajo) y R1 (río aguas arriba)

\begin{tabular}{|c|c|c|c|c|c|}
\hline A - Aguas altas (22 mayo 2007) & C1 & $\mathrm{C} 2$ & Arroyo & R2 & R1 \\
\hline Temperatura del agua $\left({ }^{\circ} \mathrm{C}\right)$ & 11,90 & 13,90 & 15 & 13,60 & 12,80 \\
\hline Conductividad $\left(\mathrm{mS} \mathrm{cm}^{-1}\right)$ & 10,3 & 4,11 & 4,69 & 3,79 & 3,73 \\
\hline Salinidad (\%o) & 0,56 & 0,20 & 0,24 & 0,19 & 0,18 \\
\hline $\mathrm{pH}$ & 8,30 & 8,48 & 8,14 & 8,69 & 8,63 \\
\hline Turbidez (UNT) & 234 & 70 & 54 & 44 & 56 \\
\hline Oxígeno disuelto (mg/L) & 5,8 & 10,8 & 8,8 & 12 & 10,6 \\
\hline \% de saturación de oxígeno & 56 & 109 & 87,8 & 126,8 & 101,7 \\
\hline Transparencia disco de Secchi $(\mathrm{cm})$ & 27 & 32 & 40 & 40 & 37 \\
\hline Velocidad de corriente $(\mathrm{m} / \mathrm{s})$ & 0,73 & 1,09 & 0,17 & 1,67 & 0,52 \\
\hline Altura del guardarrueda (m) & 3,58 & 2,34 & 4,63 & 3,50 & 2,4 \\
\hline Sólidos suspendidos (mg/L) & 207 & 42,67 & 35,5 & 30,5 & 32,4 \\
\hline Materia orgánica particulada (mg/L) & $\mathrm{s} / \mathrm{d}$ & 22,67 & 17,5 & 24,5 & 18 \\
\hline Materia orgánica disuelta (Abs.440nm) & 0,04 & 0,07 & 0,04 & 0,05 & 0,06 \\
\hline Polifenoles solubles (mg/L) & 3,68 & 3,25 & 2,51 & 1,94 & 1,98 \\
\hline Alcalinidad total $(\mathrm{mg} / \mathrm{L})$ & 410,4 & 428,4 & 477 & 446,4 & 444,6 \\
\hline Dureza total $(\mathrm{mg} / \mathrm{L})$ & 2000 & 1060 & 1200 & 840 & 920 \\
\hline $\mathrm{Na}^{+}(\mathrm{meq} / \mathrm{L})$ & 77,4 & 37,8 & 40,1 & 37,0 & 37,8 \\
\hline $\mathrm{K}^{+}(\mathrm{meg} / \mathrm{L})$ & 1,58 & 1,25 & 1,50 & 1,36 & 1,41 \\
\hline $\mathrm{Ca}^{++}(\mathrm{meq} / \mathrm{L})$ & 7,84 & 3,43 & 3,92 & 2,94 & 3,43 \\
\hline $\mathrm{Mg}^{++}(\mathrm{meq} / \mathrm{L})$ & 13,90 & 8,23 & 9,27 & 6,26 & 6,60 \\
\hline $\mathrm{Cl}^{-}(\mathrm{meq} / \mathrm{L})$ & 80,13 & 30,64 & 32,99 & 23,57 & 25,92 \\
\hline $\mathrm{SO}_{4}=(\mathrm{meq} / \mathrm{L})$ & 5,19 & 5,02 & 5,03 & 5,25 & 5,21 \\
\hline $\mathrm{N}-\mathrm{NO}_{2}{ }^{-}(\mu \mathrm{g} / \mathrm{L})$ & 227,6 & 39,3 & 114,4 & 16,9 & 31,1 \\
\hline $\mathrm{N}-\mathrm{NO}_{3}=(\mu \mathrm{g} / \mathrm{L})$ & 89,4 & 81,96 & 193,3 & 43,3 & 133,3 \\
\hline $\mathrm{N}-\mathrm{NH}_{4}{ }^{+}(\mu \mathrm{g} / \mathrm{L})$ & 1334,3 & 40,11 & 1590,3 & 25,3 & 33,9 \\
\hline Fósforo reactivo total $(\mu \mathrm{g} / \mathrm{L})$ & 278,3 & 444,1 & 804,5 & 522,4 & 668 \\
\hline Fósforo reactivo soluble $(\mu \mathrm{g} / \mathrm{L})$ & 72,4 & 353 & 770 & 464 & 597 \\
\hline Fósforo total ( $\mu \mathrm{g} / \mathrm{L})$ & 911,7 & 593 & 1230,4 & 708 & 1106,4 \\
\hline Fósforo total disuelto $(\mu \mathrm{g} / \mathrm{L})$ & 364 & 433,7 & 1028,6 & 610,8 & 690,4 \\
\hline Fósforo orgánico total ( $\mu \mathrm{g} / \mathrm{L})$ & 633,4 & 148,96 & 425,9 & 185,7 & 438,4 \\
\hline Fósforo orgánico disuelto $(\mu \mathrm{g} / \mathrm{L})$ & 291,5 & 80,7 & 258,5 & 146,6 & 93,37 \\
\hline Fósforo orgánico particulado $(\mu \mathrm{g} / \mathrm{L})$ & 341,9 & 68,3 & 167,4 & 39,1 & 345 \\
\hline Clorofila $a\left(\mathrm{mg} / \mathrm{m}^{3}\right)$ & 40,37 & 37 & 12,9 & 2,33 & 3,4 \\
\hline
\end{tabular}




\begin{tabular}{|c|c|c|c|c|c|}
\hline A - Aguas altas (23 mayo 2007) & $\mathrm{C} 1$ & $\mathrm{C} 2$ & Arroyo & R2 & R1 \\
\hline Temperatura del agua $\left({ }^{\circ} \mathrm{C}\right)$ & 11,4 & 9 & 11,6 & 9,8 & 9,9 \\
\hline Conductividad $\left(\mathrm{mS} . \mathrm{cm}^{-1}\right)$ & 10,20 & 4,18 & 4,61 & 3,75 & 3,69 \\
\hline Salinidad (\%o) & 0,56 & 0,22 & 0,23 & 0,18 & 0,18 \\
\hline $\mathrm{pH}$ & 8,38 & 8,46 & 8,17 & 8,38 & 8,59 \\
\hline Turbidez (UNT) & 208 & 87 & 52 & 47 & 42 \\
\hline Oxígeno disuelto (mg/L) & 5,30 & 8,37 & 6,77 & 7,05 & 8,47 \\
\hline \% de saturación de oxígeno & 50 & 76 & 64,9 & 65,2 & 76 \\
\hline Transparencia disco de Secchi $(\mathrm{cm})$ & 30 & 35 & 40 & 65 & 37 \\
\hline Velocidad de corriente $(\mathrm{m} / \mathrm{s})$ & $\mathrm{s} / \mathrm{d}$ & 1,07 & $\mathrm{~s} / \mathrm{d}$ & $\mathrm{s} / \mathrm{d}$ & 0,82 \\
\hline Sólidos suspendidos (mg/L) & 146 & 43,33 & 34 & 23 & 34 \\
\hline Materia orgánica particulada (mg/L) & 91 & 22,70 & 14 & 14,30 & 22 \\
\hline Materia orgánica disuelta (Abs.440nm) & 0,05 & 0,07 & 0,04 & 0,05 & 0,07 \\
\hline Polifenoles solubles (mg/L) & 3,38 & 3,20 & 2,40 & 2,51 & 1,80 \\
\hline Alcalinidad total (mg/L) & 390,6 & 419,4 & 469,8 & 421,2 & 469,8 \\
\hline Dureza total (mg/L) & 2020 & 1100 & 1160 & 900 & 900 \\
\hline $\mathrm{Na}^{+}(\mathrm{meq} / \mathrm{L})$ & 75,4 & 38,8 & 41,2 & 36,7 & 36,2 \\
\hline $\mathrm{K}^{+}(\mathrm{meq} / \mathrm{L})$ & 1,96 & 1,28 & 1,50 & 1,18 & 1,33 \\
\hline $\mathrm{Ca}^{++}(\mathrm{meq} / \mathrm{L})$ & 7,84 & 3,43 & 3,92 & 4,31 & 3,43 \\
\hline $\mathrm{Mg}^{++}(\mathrm{meq} / \mathrm{L})$ & 14,14 & 8,69 & 8,81 & 5,33 & 6,37 \\
\hline $\mathrm{Cl}$ - (meq/L) & 84,84 & 29,46 & 32,99 & 23,57 & 25,92 \\
\hline $\mathrm{SO}_{4}=(\mathrm{meq} / \mathrm{L})$ & 5,34 & 5,13 & 4,90 & 4,94 & 5,13 \\
\hline $\mathrm{N}-\mathrm{NO}_{2}-(\mu \mathrm{g} / \mathrm{L})$ & 213,4 & 33,6 & 99,9 & 163 & 29 \\
\hline $\mathrm{N}-\mathrm{NO}_{3}=(\mu \mathrm{g} / \mathrm{L})$ & 161,3 & 100,9 & 212,95 & 55,6 & 235,43 \\
\hline $\mathrm{N}-\mathrm{NH}_{4}{ }^{+}(\mu \mathrm{g} / \mathrm{L})$ & 967 & 47,5 & 1381,7 & 37,6 & 46,3 \\
\hline Fósforo reactivo total $(\mu \mathrm{g} / \mathrm{L})$ & 282 & 415 & 831,15 & 303,9 & 706,3 \\
\hline Fósforo reactivo soluble $(\mu \mathrm{g} / \mathrm{L})$ & 91,5 & 376,7 & 762,5 & 287,5 & 633,5 \\
\hline Fósforo total ( $\mu \mathrm{g} / \mathrm{L})$ & 1363 & 1141,9 & 1168,4 & 637,3 & 902,9 \\
\hline Fósforo total disuelto $(\mu \mathrm{g} / \mathrm{L})$ & 773,7 & 619,6 & 846,5 & 362,9 & 717 \\
\hline Fósforo orgánico total $(\mu \mathrm{g} / \mathrm{L})$ & 1081 & 727 & 337,3 & 333,4 & 196,5 \\
\hline Fósforo orgánico disuelto $(\mu \mathrm{g} / \mathrm{L})$ & 682,2 & 242,9 & 84 & 75,43 & 83,5 \\
\hline Fósforo orgánico particulado $(\mu \mathrm{g} / \mathrm{L})$ & 398,8 & 484 & 253,3 & 258 & 113 \\
\hline Clorofila $a\left(\mathrm{mg} / \mathrm{m}^{3}\right)$ & 67,28 & 20,75 & 14,15 & 2,78 & 4,36 \\
\hline
\end{tabular}




\begin{tabular}{|c|c|c|c|c|c|}
\hline B-Caudales medios (11 marzo 2008) & C1 & $\mathrm{C} 2$ & Arroyo & R2 & R1 \\
\hline Temperatura del agua $\left({ }^{\circ} \mathrm{C}\right)$ & 21,9 & 21,3 & 29 & 24,3 & 23,1 \\
\hline Temperatura del aire $\left({ }^{\circ} \mathrm{C}\right)$ & 22,9 & 27,8 & 29 & 23,6 & 29 \\
\hline Conductividad $\left(\mathrm{mS} . \mathrm{cm}^{-1}\right)$ & 17,8 & 9,2 & 6,74 & 9,2 & 5,86 \\
\hline Salinidad (\%o) & 1,05 & 0,51 & 0,36 & 0,51 & 0,31 \\
\hline $\mathrm{pH}$ & 8,50 & 8,78 & 8,51 & 8,89 & 9,18 \\
\hline Turbidez (UNT) & 148 & 273 & 66 & 213 & 591 \\
\hline Oxígeno disuelto (mg/L) & 8,19 & 6,52 & 17 & 14,28 & 12,57 \\
\hline$\%$ de saturación de oxígeno & 100 & 76,5 & 200 & 173,3 & 149,7 \\
\hline Transparencia disco de Secchi $(\mathrm{cm})$ & 28 & 18 & fondo & 24 & 7 \\
\hline Velocidad de corriente (m/s) & 0,45 & 0,31 & $\mathrm{n} / \mathrm{d}^{*}$ & 0,53 & 0,28 \\
\hline Altura del guardarrueda (m) & 3,96 & 2,62 & 4,9 & 3,9 & 3,25 \\
\hline Sólidos suspendidos (mg/L) & 160 & 176,3 & 34 & 135 & 384 \\
\hline Materia orgánica particulada $(\mathrm{mg} / \mathrm{L})$ & 76 & 93,8 & 31 & 70 & 164 \\
\hline Materia orgánica disuelta (Abs.440nm) & 0,027 & 0,048 & 0,043 & 0,037 & 0,039 \\
\hline Polifenoles solubles $(\mathrm{mg} / \mathrm{L})$ & 1,24 & 2,08 & 1,49 & 1,59 & 1,36 \\
\hline Alcalinidad total (mg/L) & 320 & 344 & 436 & 419 & 563 \\
\hline Dureza total (mg/L) & 2600 & 1600 & 1100 & 1000 & 1300 \\
\hline $\mathrm{Na}^{+}(\mathrm{meq} / \mathrm{L})$ & 130,7 & 87,3 & 53,7 & 90,8 & 52,3 \\
\hline $\mathrm{K}^{+}(\mathrm{meq} / \mathrm{L})$ & 2,58 & 1,9 & 1,63 & 1,97 & 1,77 \\
\hline $\mathrm{Ca}^{++}(\mathrm{meq} / \mathrm{L})$ & 9,79 & 5,88 & 2,94 & 3,92 & 2,94 \\
\hline $\mathrm{Mg}^{++}(\mathrm{meq} / \mathrm{L})$ & 18,54 & 11,59 & 9,27 & 6,95 & 11,59 \\
\hline $\mathrm{Cl}-(\mathrm{meq} / \mathrm{L})$ & 119,9 & 57,1 & 37,72 & 49,33 & 28 \\
\hline $\mathrm{SO}_{4}=(\mathrm{meq} / \mathrm{L})$ & 9,73 & 10,89 & 7,69 & 10,24 & 9,7 \\
\hline $\mathrm{N}-\mathrm{NO}_{2}-(\mu \mathrm{g} / \mathrm{L})$ & 6,28 & 5,7 & 13,17 & 5,1 & 24,8 \\
\hline $\mathrm{N}-\mathrm{NO}_{3}=(\mu \mathrm{g} / \mathrm{L})$ & 122,1 & 57 & 294,4 & 42,7 & 181,1 \\
\hline $\mathrm{N}-\mathrm{NH}_{4}{ }^{+}(\mu \mathrm{g} / \mathrm{L})$ & 164,3 & 65 & 8086,4 & 34,7 & 155,2 \\
\hline Nitrógeno total $(\mu \mathrm{g} / \mathrm{L})$ & 5800 & 7130 & 10800 & 5620 & 10000 \\
\hline Nitrógeno total disuelto $(\mu \mathrm{g} / \mathrm{L})$ & 3080 & 3250 & 8760 & 2630 & 3900 \\
\hline Fósforo reactivo total $(\mu \mathrm{g} / \mathrm{L})$ & 124,5 & 217,4 & 987,7 & 284,8 & 554,3 \\
\hline Fósforo reactivo soluble $(\mu \mathrm{g} / \mathrm{L})$ & 29,8 & 73,5 & 827,4 & 190 & 332 \\
\hline Fósforo total $(\mu \mathrm{g} / \mathrm{L})$ & 719 & 1046,8 & 2166,8 & 873,8 & 1702,4 \\
\hline Fósforo total disuelto $(\mu \mathrm{g} / \mathrm{L})$ & 136,3 & 436,8 & 1875,4 & 291,1 & 664,4 \\
\hline Fósforo orgánico total $(\mu \mathrm{g} / \mathrm{L})$ & 594,6 & 829,5 & 1179,1 & 589,1 & 1148,1 \\
\hline Fósforo orgánico disuelto $(\mu \mathrm{g} / \mathrm{L})$ & 106,5 & 363,3 & 1048 & 101 & 332,3 \\
\hline Fósforo orgánico particulado $(\mu \mathrm{g} / \mathrm{L})$ & 488 & 466 & 131 & 488 & 815,8 \\
\hline Clorofila $a\left(\mathrm{mg} / \mathrm{m}^{3}\right)$ & 153,8 & 104 & 96,8 & 74,76 & 115,5 \\
\hline
\end{tabular}

*n/d: no detectable 


\begin{tabular}{|c|c|c|c|c|c|}
\hline B-Caudales medios (12 marzo 2008) & $\mathrm{C} 1$ & $\mathrm{C} 2$ & Arroyo & R2 & R1 \\
\hline Temperatura del agua $\left({ }^{\circ} \mathrm{C}\right)$ & 23,3 & 21,6 & 24,5 & 20,7 & 19,6 \\
\hline Temperatura del aire $\left({ }^{\circ} \mathrm{C}\right)$ & 30,7 & 18 & 25 & 22 & 19,1 \\
\hline Conductividad $\left(\mathrm{mS} . \mathrm{cm}^{-1}\right)$ & 17,7 & 10,3 & 7,76 & 8,45 & 5,93 \\
\hline Salinidad (\%o) & 1,05 & 0,58 & 0,42 & 0,46 & 0,31 \\
\hline $\mathrm{pH}$ & 8,54 & 8,50 & 8,32 & 8,62 & 8,92 \\
\hline Turbidez (UNT) & 170 & 204 & 131 & 267 & 550 \\
\hline Oxígeno disuelto (mg/L) & 9,08 & 5,60 & 13,86 & 7,05 & 5,98 \\
\hline \% de saturación de oxígeno & 113,2 & 65,8 & 170 & 80,7 & 66,4 \\
\hline Transparencia disco de Secchi (cm) & 25 & 20 & fondo & 20 & 9 \\
\hline Velocidad de corriente (m/s) & 0,475 & 0,368 & $\mathrm{n} / \mathrm{d}$ & 0,50 & 0,261 \\
\hline Sólidos suspendidos (mg/L) & 158 & 197,5 & 56,5 & 203 & 402 \\
\hline Materia orgánica particulada (mg/L) & 74 & 98,7 & 47 & 92 & 152 \\
\hline Materia orgánica disuelta (Abs.440nm) & 0,029 & 0,043 & 0,056 & 0,036 & 0,037 \\
\hline Polifenoles solubles $(\mathrm{mg} / \mathrm{L})$ & 1,19 & 2,10 & 1,87 & 1,62 & 1,47 \\
\hline Alcalinidad total $(\mathrm{mg} / \mathrm{L})$ & 342 & 333 & 429 & 430 & 565 \\
\hline Dureza total $(\mathrm{mg} / \mathrm{L})$ & 2700 & 1600 & 1400 & 900 & 1200 \\
\hline $\mathrm{Na}^{+}(\mathrm{meq} / \mathrm{L})$ & 126,9 & 93,6 & 59,5 & 88,9 & 52,5 \\
\hline $\mathrm{K}^{+}(\mathrm{meq} / \mathrm{L})$ & 3,33 & 2,04 & 1,77 & 1,9 & 1,77 \\
\hline $\mathrm{Ca}^{++}(\mathrm{meq} / \mathrm{L})$ & 11,75 & 6,86 & 3,43 & 2,94 & 2,94 \\
\hline $\mathrm{Mg}^{++}(\mathrm{meq} / \mathrm{L})$ & 17,38 & 10,43 & 12,17 & 6,95 & 10,43 \\
\hline $\mathrm{Cl}^{-}(\mathrm{meq} / \mathrm{L})$ & 122,8 & 62,87 & 43,53 & 50,3 & 27,08 \\
\hline $\mathrm{SO}_{4}=(\mathrm{meq} / \mathrm{L})$ & 10,11 & 10,24 & 9 & 9,65 & 11,16 \\
\hline $\mathrm{N}-\mathrm{NO}_{2}-(\mu \mathrm{g} / \mathrm{L})$ & 4,49 & 5,09 & 9,28 & 19,15 & 13,5 \\
\hline $\mathrm{N}-\mathrm{NO}_{3}=(\mu \mathrm{g} / \mathrm{L})$ & 100 & 51,64 & 169,27 & 127,15 & 126,9 \\
\hline $\mathrm{N}-\mathrm{NH}_{4}{ }^{+}(\mu \mathrm{g} / \mathrm{L})$ & 47,2 & 113,96 & 8883 & 130 & 185 \\
\hline Nitrógeno total $(\mu \mathrm{g} / \mathrm{L})$ & 5980 & 6490 & 13500 & 6800 & 10150 \\
\hline Nitrógeno total disuelto $(\mu \mathrm{g} / \mathrm{L})$ & 2800 & 4100 & 9500 & 2670 & 4000 \\
\hline Fósforo reactivo total $(\mu \mathrm{g} / \mathrm{L})$ & 120,9 & 168 & 971,3 & 350,3 & 559,7 \\
\hline Fósforo reactivo soluble $(\mu \mathrm{g} / \mathrm{L})$ & 27,99 & 77,16 & 829 & 170 & 337,6 \\
\hline Fósforo total $(\mu \mathrm{g} / \mathrm{L})$ & 600,7 & 919,4 & 2503,6 & 1056 & 1666 \\
\hline Fósforo total disuelto $(\mu \mathrm{g} / \mathrm{L})$ & 136,3 & 409,5 & 1693,3 & 300 & 546 \\
\hline Fósforo orgánico total $(\mu \mathrm{g} / \mathrm{L})$ & 479,8 & 751 & 1532,4 & 705,6 & 1106,3 \\
\hline Fósforo orgánico disuelto $(\mu \mathrm{g} / \mathrm{L})$ & 108,4 & 332,3 & 864 & 130 & 208,5 \\
\hline Fósforo orgánico particulado $(\mu \mathrm{g} / \mathrm{L})$ & 371,5 & 418,8 & 668,3 & 575,4 & 897,8 \\
\hline Clorofila $a\left(\mathrm{mg} / \mathrm{m}^{3}\right)$ & 108 & 84,4 & 85,44 & 76,1 & 129 \\
\hline
\end{tabular}




\begin{tabular}{|c|c|c|c|c|c|}
\hline C - Aguas bajas (12 noviembre 2008) & $\mathrm{C} 1$ & $\mathrm{C} 2$ & Arroyo & R2 & R1 \\
\hline Temperatura del agua $\left({ }^{\circ} \mathrm{C}\right)$ & 25,8 & 31,5 & 24 & 27 & 33,2 \\
\hline Temperatura del aire $\left({ }^{\circ} \mathrm{C}\right)$ & 34,1 & 35 & 20,5 & 29 & 34,1 \\
\hline Conductividad $\left(\mathrm{mS} . \mathrm{cm}^{-1}\right)$ & 25,1 & 19,3 & 16,4 & 13,4 & 5,68 \\
\hline Salinidad (\%o) & 1,54 & 1,10 & 0,96 & 0,81 & 0,30 \\
\hline $\mathrm{pH}$ & 8,41 & 8,65 & 8,54 & 8,96 & 9,29 \\
\hline Turbidez (UNT) & 85 & 165,33 & 191,5 & 269 & 694 \\
\hline Oxígeno disuelto (mg/L) & 12,35 & 13,7 & 2,62 & 12,2 & 12,94 \\
\hline$\%$ de saturación de oxígeno & 168,5 & +200 & 35 & 123 & 154,5 \\
\hline Transparencia disco de Secchi $(\mathrm{cm})$ & 42 & 25 & fondo & 32 & 13 \\
\hline Velocidad de corriente $(\mathrm{m} / \mathrm{s})$ & 0,352 & 0,048 & $\mathrm{n} / \mathrm{d}$ & 0,291 & 0,078 \\
\hline Altura del guardarrueda (m) & 4,16 & 2,6 & 5 & 4,63 & 4 \\
\hline Sólidos suspendidos (mg/L) & 94,5 & 100,7 & 101,5 & 152 & 340 \\
\hline Materia orgánica particulada $(\mathrm{mg} / \mathrm{L})$ & 34,5 & 53,3 & 32 & 68,7 & 130 \\
\hline Materia orgánica disuelta (Abs.440nm) & 0,119 & 0,184 & 0,130 & 0,269 & 0,705 \\
\hline Polifenoles solubles $(\mathrm{mg} / \mathrm{L})$ & 0,588 & 1,00 & 0,92 & 0,92 & 1,07 \\
\hline Alcalinidad total $(\mathrm{mg} / \mathrm{L})$ & 387 & 522 & 576 & 613,8 & 784,8 \\
\hline Dureza total $(\mathrm{mg} / \mathrm{L})$ & 4600 & 2400 & 2950 & 2900 & 1200 \\
\hline $\mathrm{Na}^{+}(\mathrm{meq} / \mathrm{L})$ & 195,3 & 155,2 & 143,6 & 116 & 63,9 \\
\hline $\mathrm{K}^{+}(\mathrm{meq} / \mathrm{L})$ & 3,39 & 2,75 & 3 & 2,62 & 1,98 \\
\hline $\mathrm{Ca}^{++}(\mathrm{meq} / \mathrm{L})$ & 11,75 & 5,39 & 4,9 & 3,92 & 4,9 \\
\hline $\mathrm{Mg}^{++}(\mathrm{meq} / \mathrm{L})$ & 39,4 & 21,4 & 28,39 & 28,97 & 8,11 \\
\hline $\mathrm{Cl}-(\mathrm{meq} / \mathrm{L})$ & 183,6 & 103,6 & 105,9 & 90,6 & 34,12 \\
\hline $\mathrm{SO}_{4}=(\mathrm{meq} / \mathrm{L})$ & 19,36 & 17,2 & 20,5 & 18,7 & 7,3 \\
\hline $\mathrm{N}-\mathrm{NO}_{2}{ }^{-}(\mu \mathrm{g} / \mathrm{L})$ & 12,2 & 21,35 & 33,5 & 21,35 & 45,75 \\
\hline $\mathrm{N}-\mathrm{NO}_{3}=(\mu \mathrm{g} / \mathrm{L})$ & 85,9 & 106,2 & 152,8 & 66,93 & 150,4 \\
\hline $\mathrm{N}-\mathrm{NH}_{4}{ }^{+}(\mu \mathrm{g} / \mathrm{L})$ & 4,95 & 13,6 & 3472 & 10,52 & 61,88 \\
\hline Nitrógeno total $(\mu \mathrm{g} / \mathrm{L})$ & 2730 & 4060 & 4830 & 3890 & 5980 \\
\hline Nitrógeno total disuelto $(\mu \mathrm{g} / \mathrm{L})$ & 1900 & 1090 & 3000 & 1660 & 1800 \\
\hline Fósforo reactivo total $(\mu \mathrm{g} / \mathrm{L})$ & 70,2 & 51,97 & 390,7 & 174 & 1339 \\
\hline Fósforo reactivo soluble $(\mu \mathrm{g} / \mathrm{L})$ & 39,22 & 42,86 & 350,6 & 130,3 & 1274 \\
\hline Fósforo total $(\mu \mathrm{g} / \mathrm{L})$ & 620 & 784,5 & 1141,4 & 930 & 3251 \\
\hline Fósforo total disuelto $(\mu \mathrm{g} / \mathrm{L})$ & 145,6 & 197,3 & 488,5 & 446,2 & 2086 \\
\hline Fósforo orgánico total $(\mu \mathrm{g} / \mathrm{L})$ & 549,9 & 732,5 & 750,8 & 756 & 1911 \\
\hline Fósforo orgánico disuelto $(\mu \mathrm{g} / \mathrm{L})$ & 106,4 & 154,4 & 137,9 & 315,97 & 811,7 \\
\hline Fósforo orgánico particulado $(\mu \mathrm{g} / \mathrm{L})$ & 443,5 & 578 & 612,9 & 440 & 1099 \\
\hline Clorofila $a\left(\mathrm{mg} / \mathrm{m}^{3}\right)$ & 29,37 & 10,7 & 14,02 & 46,99 & 53,4 \\
\hline
\end{tabular}




\begin{tabular}{|c|c|c|c|c|c|c|}
\hline C - Aguas bajas (13 noviembre 2008) & $\mathrm{C} 1$ & $\mathrm{C} 2$ & $\mathrm{C} 3$ & Arroyo & $\mathbf{R} 2$ & R1 \\
\hline Temperatura del agua $\left({ }^{\circ} \mathrm{C}\right)$ & 29,7 & 26,9 & 25,8 & 26 & 24,5 & 30,4 \\
\hline Temperatura del aire $\left({ }^{\circ} \mathrm{C}\right)$ & 30 & 30,6 & 27 & 29,8 & 28,7 & 31 \\
\hline Conductividad $\left(\mathrm{mS} \mathrm{cm}^{-1}\right)$ & 24,8 & 19 & 16,9 & 16,8 & 14,4 & 5,5 \\
\hline Salinidad (\%o) & 1,52 & 1,14 & 1 & 0,99 & 0,54 & 0,3 \\
\hline $\mathrm{pH}$ & 8,65 & 8,57 & 8,65 & 8,72 & 8,78 & 9,32 \\
\hline Turbidez (UNT) & 223 & 259 & 223 & 200 & 361 & 677 \\
\hline Oxígeno disuelto (mg/L) & 18 & 7,39 & 6,29 & 8,53 & 8,53 & 17,1 \\
\hline \% de saturación de oxígeno & +200 & 98,2 & 81,1 & 118,7 & 107 & +200 \\
\hline Transparencia disco de Secchi $(\mathrm{cm})$ & 24 & 25 & 26 & fondo & 16 & 12 \\
\hline Velocidad de corriente $(\mathrm{m} / \mathrm{s})$ & 0,365 & $\mathrm{n} / \mathrm{d}$ & 0,006 & 0,254 & 0,139 & 0,083 \\
\hline Sólidos suspendidos (mg/L) & 144,7 & 95,33 & 103,28 & 84,7 & 182 & 380 \\
\hline Materia orgánica particulada $(\mathrm{mg} / \mathrm{L})$ & 66,7 & 38,7 & 44,9 & 40 & 67,7 & 156 \\
\hline Materia orgánica disuelta (Abs.440nm) & 0,228 & 0,169 & 0,166 & 0,141 & 0,326 & 0,744 \\
\hline Polifenoles solubles (mg/L) & 0,59 & 0,95 & 0,92 & 1 & 1,04 & 1,06 \\
\hline Alcalinidad total (mg/L) & 397,8 & 523,8 & 574,2 & 581,4 & 585 & 750,6 \\
\hline Dureza total $(\mathrm{mg} / \mathrm{L})$ & 4500 & 2500 & 2800 & 2800 & 3300 & 900 \\
\hline $\mathrm{Na}^{+}(\mathrm{meq} / \mathrm{L})$ & 194,9 & 175,2 & 164 & 146,1 & 120,5 & 60,1 \\
\hline $\mathrm{K}^{+}(\mathrm{meq} / \mathrm{L})$ & 3,52 & 3,39 & 3,01 & 3,45 & 2,75 & 1,85 \\
\hline $\mathrm{Ca}^{++}(\mathrm{meq} / \mathrm{L})$ & 10,77 & 4,9 & 2,94 & 4,9 & 3,92 & 3,92 \\
\hline $\mathrm{Mg}^{++}(\mathrm{meq} / \mathrm{L})$ & 39,4 & 23,17 & 28,97 & 26,65 & 33,6 & 5,79 \\
\hline $\mathrm{Cl}^{-}(\mathrm{meq} / \mathrm{L})$ & 181,2 & 109,4 & 109,4 & 107,1 & 91,8 & 35,3 \\
\hline $\mathrm{SO}_{4}=(\mathrm{meq} / \mathrm{L})$ & 20,37 & 20,91 & 22,52 & 21,3 & 21,51 & 6,05 \\
\hline $\mathrm{N}-\mathrm{NO}_{2}{ }^{-}(\mu \mathrm{g} / \mathrm{L})$ & 18,3 & 30,5 & 57,94 & 152,5 & 24,4 & 51,84 \\
\hline $\mathrm{N}-\mathrm{NO}_{3}=(\mu \mathrm{g} / \mathrm{L})$ & 79,8 & 97 & 79,38 & 730,3 & 112,9 & 262 \\
\hline $\mathrm{N}-\mathrm{NH}_{4}{ }^{+}(\mu \mathrm{g} / \mathrm{L})$ & 6,81 & 17,33 & 12,38 & 3280 & 10,5 & 62,5 \\
\hline Nitrógeno total $(\mu \mathrm{g} / \mathrm{L})$ & 3290 & 4450 & 3780 & 4550 & 4150 & 6240 \\
\hline Nitrógeno total disuelto $(\mu \mathrm{g} / \mathrm{L})$ & 2050 & 2300 & 2170 & 2870 & 1780 & 1830 \\
\hline Fósforo reactivo total $(\mu \mathrm{g} / \mathrm{L})$ & 68,35 & 66,53 & 124,8 & 285 & 237,7 & 1418 \\
\hline Fósforo reactivo soluble $(\mu \mathrm{g} / \mathrm{L})$ & 30,1 & 39,2 & 92 & 250,5 & 148,5 & 1389 \\
\hline Fósforo total ( $\mu \mathrm{g} / \mathrm{L})$ & 507,3 & 953,6 & 596,6 & 916 & 1564 & 3767 \\
\hline Fósforo total disuelto ( $\mu \mathrm{g} / \mathrm{L}$ ) & 145,6 & 450,9 & 183,2 & 507,3 & 418 & 2019,8 \\
\hline Fósforo orgánico total $(\mu \mathrm{g} / \mathrm{L})$ & 439 & 887 & 471,8 & 630,9 & 1326,5 & 2349,5 \\
\hline Fósforo orgánico disuelto ( $\mu \mathrm{g} / \mathrm{L})$ & 115,5 & 411,7 & 91,16 & 256,9 & 269,6 & 631,3 \\
\hline Fósforo orgánico particulado $(\mu \mathrm{g} / \mathrm{L})$ & 323,5 & 475,3 & 380,6 & 374 & 1056,9 & 1718,3 \\
\hline Clorofila $a\left(\mathrm{mg} / \mathrm{m}^{3}\right)$ & 28,04 & 8,9 & 8,01 & 8,01 & 41,12 & 60,8 \\
\hline
\end{tabular}




\begin{tabular}{|c|c|c|c|c|c|c|}
\hline D - Aguas muy bajas (19 sept. 2009) & $\mathrm{C} 1$ & $\mathrm{C} 2$ & C3 & Arroyo & $\mathbf{R} 2$ & R1 \\
\hline Temperatura del agua $\left({ }^{\circ} \mathrm{C}\right)$ & 13,9 & 14,2 & 15,7 & 18 & 17 & 17 \\
\hline Temperatura del aire $\left({ }^{\circ} \mathrm{C}\right)$ & 18 & 20,5 & 21,7 & 18,4 & 20 & 18,2 \\
\hline Conductividad (mS/cm) & 13,8 & 10,9 & 1,03 & 2,73 & 6,48 & 6,04 \\
\hline Salinidad (\%o) & 0,78 & 0,61 & 0,04 & 0,13 & 0,34 & 0,31 \\
\hline $\mathrm{pH}$ & 8,90 & 9,18 & 9,26 & 8,62 & 9,01 & 9,08 \\
\hline Turbidez (UNT) & 91,7 & 264,2 & 47,9 & 147 & 259 & 220 \\
\hline Oxígeno disuelto $(\mathrm{mg} / \mathrm{L})$ & 5 & 12,02 & 8,05 & 8,83 & 15,99 & 16,2 \\
\hline$\%$ de saturación de oxígeno & 49,3 & 118,3 & 92,4 & 87,2 & 165,65 & 166,3 \\
\hline Transparencia disco de Secchi $(\mathrm{cm})$ & 52 & 26 & fondo & 13,5 & 16 & 60 \\
\hline Velocidad de corriente $(\mathrm{m} / \mathrm{s})$ & $\mathrm{n} / \mathrm{d}$ & 0,006 & 0,04 & 0,031 & 0,233 & 0,229 \\
\hline Altura del guardarrueda (m) & 4,59 & 3,32 & 4,74 & 5,11 & 4,53 & 3,60 \\
\hline Sólidos suspendidos (mg/L) & 43,33 & 77,33 & 16 & 36,55 & 125 & 101,43 \\
\hline Materia orgánica particulada (mg/L) & 18 & 28 & 11,5 & 19,3 & 51,25 & 50 \\
\hline Materia orgánica disuelta (440nm) & 0,012 & 0,018 & 0,009 & 0,053 & 0,044 & 0,038 \\
\hline Polifenoles solubles (mg/L) & 0,740 & 1 & 0,32 & 2,03 & 1,46 & 1,35 \\
\hline Alcalinidad total (mg/L) & 1019 & 505,8 & 230 & 388,8 & 574,2 & 523,8 \\
\hline Dureza total $(\mathrm{mg} / \mathrm{L})$ & 1800 & 2900 & 1500 & 1500 & 2700 & 2200 \\
\hline $\mathrm{Na}^{+}(\mathrm{meq} / \mathrm{L})$ & 134 & 105,9 & 8,27 & 27,88 & 59,97 & 49,9 \\
\hline $\mathrm{K}^{+}(\mathrm{meq} / \mathrm{L})$ & 2,13 & 1,92 & 0,48 & 1,01 & 1,92 & 1,49 \\
\hline $\mathrm{Ca}^{++}(\mathrm{meq} / \mathrm{L})$ & 8,81 & 16,65 & 5,39 & 8,81 & 14,69 & 12,73 \\
\hline $\mathrm{Mg}^{++}(\mathrm{meq} / \mathrm{L})$ & 10,43 & 13,9 & 11 & 6,95 & 13,90 & 10,43 \\
\hline $\mathrm{Cl}^{-}(\mathrm{meq} / \mathrm{L})$ & 120,9 & 76,4 & 7,25 & 15,48 & 36,76 & 37,72 \\
\hline $\mathrm{SO}_{4}=(\mathrm{meq} / \mathrm{L})$ & 15,22 & 15,07 & 0,45 & 3,02 & 11,41 & 10,69 \\
\hline $\mathrm{N}-\mathrm{NO}_{2}-(\mu \mathrm{g} / \mathrm{L})$ & 1,83 & 1,83 & 8,55 & 8,25 & 45,5 & 14,66 \\
\hline $\mathrm{N}-\mathrm{NO}_{3}=(\mu \mathrm{g} / \mathrm{L})$ & 7,36 & 5,20 & 153,1 & 34,46 & 272,9 & 86,43 \\
\hline $\mathrm{N}-\mathrm{NH}_{4}{ }^{+}(\mu \mathrm{g} / \mathrm{L})$ & 2,03 & 16,91 & 3,38 & 4584,6 & 52,74 & 6,76 \\
\hline Nitrógeno total $(\mu \mathrm{g} / \mathrm{L})$ & 2300 & 4380 & 1580 & 12320 & 6020 & 5540 \\
\hline Nitrógeno total disuelto $(\mu \mathrm{g} / \mathrm{L})$ & 1850 & 2570 & 930 & 11460 & 3350 & 2590 \\
\hline Fósforo reactivo total $(\mu \mathrm{g} / \mathrm{L})$ & 150 & 122,7 & 38,9 & 1493 & 1009,5 & 1082 \\
\hline Fósforo reactivo soluble $(\mu \mathrm{g} / \mathrm{L})$ & 137,3 & 33,45 & 11,6 & 1465 & 909,4 & 971,3 \\
\hline Fósforo total $(\mu \mathrm{g} / \mathrm{L})$ & 542 & 585,3 & 333,5 & 3763 & 1722 & 1862,5 \\
\hline Fósforo total disuelto $(\mu \mathrm{g} / \mathrm{L})$ & 333,5 & 254,6 & 160,7 & 2419 & 1111 & 1313 \\
\hline Fósforo orgánico total $(\mu \mathrm{g} / \mathrm{L})$ & 392 & 462,6 & 295 & 2270 & 712 & 780 \\
\hline Fósforo orgánico disuelto $(\mu \mathrm{g} / \mathrm{L})$ & 196,3 & 221,1 & 149 & 954,4 & 201,6 & 341,6 \\
\hline Fósforo orgánico particulado $(\mu \mathrm{g} / \mathrm{L})$ & 195,8 & 241,5 & 145,6 & 1315 & 510,5 & 438,5 \\
\hline Clorofila $a\left(\mathrm{mg} / \mathrm{m}^{3}\right)$ & 7,01 & 14,69 & 2,40 & 7,34 & 29,37 & 28,04 \\
\hline
\end{tabular}




\begin{tabular}{|c|c|c|c|c|c|}
\hline D-Aguas muy bajas (20 sept. 2009) & C1 & $\mathrm{C} 2$ & C3 & $\mathbf{R} 2$ & R1 \\
\hline Temperatura del agua $\left({ }^{\circ} \mathrm{C}\right)$ & 15,6 & 16,8 & 19,3 & 18,7 & 18,1 \\
\hline Temperatura del aire $\left({ }^{\circ} \mathrm{C}\right)$ & 19 & 21,6 & 24 & 21,3 & 18 \\
\hline Conductividad $(\mathrm{mS} / \mathrm{cm})$ & 13,6 & 10,5 & 1,03 & 6,88 & 5,19 \\
\hline Salinidad $(\%$ ) & 0,78 & 0,59 & 0,04 & 0,37 & 0,26 \\
\hline $\mathrm{pH}$ & 8,93 & 9,28 & 9,16 & 9,23 & 9,4 \\
\hline Turbidez (UNT) & 129,8 & 137,8 & 157,9 & 281 & 464,7 \\
\hline Oxígeno disuelto $(\mathrm{mg} / \mathrm{L})$ & 11 & 14,35 & 12 & 18,35 & 16,6 \\
\hline$\%$ de saturación de oxígeno & 109,8 & 148,3 & 137,8 & 194 & 179 \\
\hline Transparencia disco de Secchi $(\mathrm{cm})$ & 46 & 29 & 56 & 19 & 16 \\
\hline Velocidad de corriente (m/s) & 0,095 & 0,078 & 0,055 & 0,183 & 0,231 \\
\hline Sólidos suspendidos (mg/L) & 48,4 & 65,3 & 15 & 135 & 145,7 \\
\hline Materia orgánica particulada $(\mathrm{mg} / \mathrm{L})$ & 14,19 & 22,67 & 10 & 56,67 & 60 \\
\hline Materia orgánica disuelta (440nm) & 0,014 & 0,015 & 0,003 & 0,04 & 0,042 \\
\hline Polifenoles solubles (mg/L) & 0,69 & 1,35 & 0,31 & 1,32 & 1,48 \\
\hline Alcalinidad total (mg/L) & 973,8 & 419,4 & 239,4 & 565,2 & 518,4 \\
\hline Dureza total (mg/L) & 1700 & 2950 & 1400 & 2650 & 2300 \\
\hline $\mathrm{Na}^{+}(\mathrm{meq} / \mathrm{L})$ & 130,7 & 104,1 & 10,44 & 56,46 & 44,5 \\
\hline $\mathrm{K}^{+}(\mathrm{meq} / \mathrm{L})$ & 2,34 & 2,24 & 0,53 & 1,49 & 1,44 \\
\hline $\mathrm{Ca}^{++}$ & 9,79 & 16,65 & 4,90 & 13,71 & 13,22 \\
\hline $\mathrm{Mg}^{++}(\mathrm{meq} / \mathrm{L})$ & 8,11 & 14,48 & 10,43 & 14,5 & 11 \\
\hline $\mathrm{Cl}^{-}(\mathrm{meq} / \mathrm{L})$ & 111,24 & 72,55 & 6,77 & 38,69 & 38,69 \\
\hline $\mathrm{SO}_{4}=(\mathrm{meq} / \mathrm{L})$ & 15,98 & 15,09 & 0,52 & 12,44 & 8,94 \\
\hline $\mathrm{N}-\mathrm{NO}_{2}{ }^{-}(\mu \mathrm{g} / \mathrm{L})$ & 3,67 & 1,22 & 12,52 & 3,97 & 3,67 \\
\hline $\mathrm{N}-\mathrm{NO}_{3}=(\mu \mathrm{g} / \mathrm{L})$ & 12 & 3,64 & 148 & 10,63 & 15,26 \\
\hline $\mathrm{N}-\mathrm{NH}_{4}{ }^{+}(\mu \mathrm{g} / \mathrm{L})$ & 0,68 & 6,09 & 0,68 & 50,72 & 5,4 \\
\hline Nitrógeno total $(\mu \mathrm{g} / \mathrm{L})$ & 2550 & 3430 & 1750 & 5750 & 6440 \\
\hline Nitrógeno total disuelto $(\mu \mathrm{g} / \mathrm{L})$ & 2150 & 1960 & 1070 & 2740 & 2630 \\
\hline Fósforo reactivo total $(\mu \mathrm{g} / \mathrm{L})$ & 130 & 82,6 & 35,3 & 807,4 & 1142 \\
\hline Fósforo reactivo soluble $(\mu \mathrm{g} / \mathrm{L})$ & 93,5 & 24,4 & 15,2 & 703,6 & 988 \\
\hline Fósforo total $(\mu \mathrm{g} / \mathrm{L})$ & 561 & 463,2 & 453,8 & 1740 & 1928 \\
\hline Fósforo total disuelto ( $\mu \mathrm{g} / \mathrm{L})$ & $\mathrm{s} / \mathrm{d}$ & 218,9 & 74,2 & 899,5 & 1256,5 \\
\hline Fósforo orgánico total $(\mu \mathrm{g} / \mathrm{L})$ & $\mathrm{s} / \mathrm{d}$ & 380,5 & 418,5 & 933 & 785,8 \\
\hline Fósforo orgánico disuelto $(\mu \mathrm{g} / \mathrm{L})$ & $\mathrm{s} / \mathrm{d}$ & 194,5 & 58,98 & 195,95 & 268,9 \\
\hline Fósforo orgánico particulado $(\mu \mathrm{g} / \mathrm{L})$ & $\mathrm{s} / \mathrm{d}$ & 186 & 359,5 & 737 & 516,9 \\
\hline Clorofila $a\left(\mathrm{mg} / \mathrm{m}^{3}\right)$ & 5,61 & 7,21 & 3,03 & 25,23 & 27,90 \\
\hline
\end{tabular}

${ }_{\mathrm{S}} \mathrm{d} / \mathrm{d}=\sin$ determinar (missing data) 


\section{ANEXO II}

Tablas de las correlaciones significativas $(p<0,05$ y r $>0,6)$ de Spearman entre los parámetros físicoquímicos y biológicos (fito y zooplancton).

Referencias: Transp. (transparencia medida por disco de Secchi), SS (sólidos suspendidos), MOP (materia orgánica particulada), PRP (fósforo reactivo particulado), PRS (fósforo reactivo soluble), PTP (fósforo total particulado), Veloc. (velocidad de corriente), PTD (fósforo total disuelto), Turb. (turbidez) (NTU), Clor.a (clorofila $a$ ), Ab.Fitopl (abundancia total de fitoplancton), B.Fitopl (biomasa total de fitoplancton), Ab.Cripto (abundancia total de las criptofitas), Ab.Eugl. (abundancia total de las euglenofitas), Dist. (distancia pelo de agua-guardarruedas) (a mayor nivel de agua, menor distancia al puente), Cond. (conductividad), Ab.Diato (abundancia total de las diatomeas), Ab.Dino (abundancia total de los dinoflagelados), B.Diato (biomasa total de diatomeas), Ab.Cloro (abundancia total de clorofitas), \%OD (\% de saturación de oxígeno disuelto), temperatura $\left(\mathrm{T}^{\circ}\right)$, Polif. (polifenoles solubles totales), Ab.Rotíf (abundancia total de los rotíferos), Ab.Zoopl (abundancia total de zooplancton) y B.Zoopl. (biomasa total de zooplancton), № total de huevos en organismos (H.enOrg) y libres en la muestra (H.lib.), Rotíf.Ov (abundancia total de hembras ovígeras de rotíferos), Ab.Clad (abundancia total de cladóceros) (Ind/L), Ab.Rizop (abundancia total de rizópodos) (Ind/L), B.Cop. (biomasa total de copépodos).

\begin{tabular}{|l|c|c|c|c|c|c|c|c|c|}
\cline { 2 - 11 } \multicolumn{1}{c|}{} & Dureza & $\mathrm{Na}^{+}$ & $\mathrm{K}^{+}$ & $\mathrm{Mg}^{++}$ & $\mathrm{Cl}^{-}$ & $\mathrm{SO}_{4}=$ & Turbidez & Transp. & SS \\
\hline $\mathrm{Na}^{+}(\mathrm{mg} / \mathrm{L})$ & 0,7 & & & & & & & & \\
\hline $\mathrm{Ca}^{++}(\mathrm{mg} / \mathrm{L})$ & 0,55 & & & & & & & & \\
\hline $\mathrm{K}^{+}(\mathrm{mg} / \mathrm{L})$ & 0,68 & 0,94 & & & & & & & \\
\hline $\mathrm{Mg}^{++}(\mathrm{mg} / \mathrm{L})$ & 0,92 & 0,76 & 0,76 & & & & & & \\
\hline $\mathrm{Cl}^{-}(\mathrm{mg} / \mathrm{L})$ & 0,71 & 0,95 & 0,91 & 0,74 & & & & & \\
\hline $\mathrm{SO}_{4}=(\mathrm{mg} / \mathrm{L})$ & 0,73 & 0,89 & 0,89 & 0,77 & 0,8 & & & & \\
\hline Temperatura & & 0,6 & 0,63 & & & & & & \\
\hline $\mathrm{SS}(\mathrm{mg} / \mathrm{L})$ & & & & & & & 0,88 & $-0,71$ & \\
\hline MOP $(\mathrm{mg} / \mathrm{L})$ & & & & & & & 0,82 & $-0,69$ & 0,96 \\
\hline Conductividad $(\mathrm{mS} / \mathrm{cm})$ & 0,75 & 0,97 & 0,96 & 0,82 & 0,97 & 0,86 & & & \\
\hline
\end{tabular}

\begin{tabular}{|l|c|c|c|c|}
\cline { 2 - 5 } \multicolumn{1}{c|}{} & Transp. & PRP & PTP & Veloc. \\
\hline PRS $(\mu \mathrm{g} / \mathrm{L})$ & & 0,93 & 0,81 & \\
\hline PTP $(\mu \mathrm{g} / \mathrm{L})$ & $-0,64$ & 0,81 & & \\
\hline PTD $(\mu \mathrm{g} / \mathrm{L})$ & & 0,86 & 0,9 & \\
\hline Polifenoles totales $(\mathrm{mg} / \mathrm{L})$ & & & & 0,6 \\
\hline
\end{tabular}

\begin{tabular}{|l|c|c|c|c|c|c|c|c|}
\cline { 2 - 10 } \multicolumn{1}{c|}{} & Turb. & $\mathrm{T}^{\circ}$ & Transp. & SS & MOP & Clor. $a$ & Ab.Fitopl. & B.Fitopl \\
\hline Clorofila $a\left(\mathrm{mg} / \mathrm{m}^{3}\right)$ & 0,86 & & $-0,76$ & 0,9 & 0,92 & & & \\
\hline Abundancia Fitoplancton $(\mathrm{Ind} / \mathrm{ml})$ & 0,71 & 0,59 & & 0,67 & 0,67 & 0,79 & & \\
\hline Abundancia Clorofitas $(\mathrm{Ind} / \mathrm{mL})$ & 0,7 & & & & 0,6 & 0,76 & 0,88 & 0,77 \\
\hline Abundancia Cianobacterias $(\mathrm{Ind} / \mathrm{mL})$ & 0,72 & 0,66 & $-0,6$ & 0,76 & 0,75 & 0,73 & 0,94 & \\
\hline Abundancia Diatomeas $(\mathrm{Ind} / \mathrm{mL})$ & 0,65 & 0,66 & & 0,64 & 0,69 & 0,81 & 0,81 & 0,72 \\
\hline Abundancia Criptofitas $(\mathrm{Ind} / \mathrm{mL})$ & & & & & & 0,61 & 0,63 & 0,75 \\
\hline Biomasa Fitoplancton total $(\mu \mathrm{g} \mathrm{C} / \mathrm{L})$ & 0,77 & & $-0,65$ & 0,8 & 0,83 & 0,89 & 0,86 & \\
\hline Biomasa Cianobacterias $(\mu \mathrm{g} \mathrm{C} / \mathrm{L})$ & 0,78 & & $-0,68$ & 0,82 & 0,83 & 0,86 & & 0,98 \\
\hline Biomasa Criptofitas $(\mu \mathrm{g} \mathrm{C} / \mathrm{L})$ & 0,76 & & & & & & & 0,6 \\
\hline Biomasa Clorofitas $(\mu \mathrm{g} \mathrm{C} / \mathrm{L})$ & & & & 0,65 & 0,62 & 0,71 & & 0,75 \\
\hline Biomasa Diatomeas $(\mu \mathrm{g} \mathrm{C} / \mathrm{L})$ & 0,69 & 0,6 & & & 0,6 & 0,74 & & 0,6 \\
\hline
\end{tabular}




\begin{tabular}{|l|c|c|c|c|c|c|}
\cline { 2 - 7 } \multicolumn{1}{c|}{} & Ab.Cripto & Ab.Eugl & Dist. & Polif. & Dureza & $\mathrm{Mg}^{++}$ \\
\hline Biomasa Criptofitas $(\mu \mathrm{g}$ C/L) & 0,94 & & $-0,62$ & & & \\
\hline Biomasa Euglenofitas $(\mu \mathrm{g}$ C/L) & & 0,83 & & & & \\
\hline Abundancia Criptofitas (Ind/mL) & & & $-0,6$ & & & \\
\hline Raphidiopsis mediterranea & & & $-0,6$ & & & \\
\hline Riqueza de especies de fitoplancton & & & & 0,6 & & \\
\hline Abundancia Clorofitas (Ind/mL) & & & & & 0,62 & 0,66 \\
\hline Monoraphidium circinale & & & & & & 0,71 \\
\hline Abundancia Fitoplancton total $(\mathrm{Ind} / \mathrm{mL})$ & & & & & & 0,63 \\
\hline
\end{tabular}

\begin{tabular}{|l|c|c|c|c|c|c|c|c|}
\cline { 2 - 8 } \multicolumn{1}{c|}{} & $\% \mathrm{OD}$ & PRS & B.Cloro & B.Diato & Ab.Dino & Ab.Cloro & Ab.Ciano & B.Ciano \\
\hline Abundancia de Diatomeas (Ind/mL) & 0,64 & & & 0,89 & & & & \\
\hline Biomasa Dinoflagelados $(\mu \mathrm{g}$ C/L) & & $-0,65$ & & & 0,96 & & & \\
\hline Biomasa Clorofitas $(\mu \mathrm{g} \mathrm{C} / \mathrm{L})$ & & & & & & 0,92 & & \\
\hline Abundancia Dinoflagelados $(\mathrm{Ind} / \mathrm{mL})$ & & $-0,67$ & & & & & & \\
\hline Biomasa Cianobacterias $\mu \mathrm{g} \mathrm{C} / \mathrm{L})$ & & & & & & & 0,88 & \\
\hline Diversidad Simpson Fitoplancton & & & & & & & $-0,6$ & \\
\hline Aphanocapsa incerta & & & & & & & 0,77 & 0,66 \\
\hline Monoraphidium circinale & & & 0,76 & & & 0,84 & & \\
\hline
\end{tabular}

\begin{tabular}{|l|c|c|c|c|c|c|c|c|c|c|c|}
\cline { 2 - 12 } \multicolumn{1}{c|}{} & $\mathrm{T}^{\mathrm{o}}$ & Clor. $a$ & Turb. & Cl- & Ab.Fito & Dureza & SS & MOP & Cond. & $\mathrm{Na}^{+}$ & $\mathrm{K}^{+}$ \\
\hline Aphanocapsa incerta & & 0,71 & & & 0,75 & & 0,72 & 0,75 & & & \\
\hline Monoraphidium circinale & 0,65 & & 0,61 & & 0,75 & 0,67 & & & & & \\
\hline Monoraphidium minutum & & 0,66 & 0,65 & & 0,71 & 0,6 & 0,62 & 0,6 & & & \\
\hline Monoraphidium pseudobraunii & & 0,6 & & & 0,64 & & & & & & \\
\hline Planktolyngbya limnetica & 0,6 & & & & 0,74 & 0,61 & & & & 0,62 & 0,63 \\
\hline Cyclotella glomerata & & 0,74 & 0,66 & 0,6 & 0,82 & 0,6 & 0,67 & 0,64 & 0,61 & 0,61 & 0,6 \\
\hline Monoraphidium griffithii & & 0,61 & 0,66 & & 0,6 & & & & & & \\
\hline Monoraphidium tortile & & 0,6 & & & 0,76 & & & & & & \\
\hline Cyclotella meneghiniana & & 0,71 & & & & & & 0,65 & & & \\
\hline
\end{tabular}

\begin{tabular}{|l|c|c|c|c|c|c|c|c|}
\cline { 2 - 9 } \multicolumn{1}{c|}{} & $\mathrm{pH}$ & Turbidez & SS & Ab.Fito & MOP & Ab.Zopl & B.Zoopl & Ab.Rotíf \\
\hline Abundancia Rotíferos (Ind/L) & & 0,7 & 0,67 & 0,65 & 0,61 & & & \\
\hline Abundancia Fitoplancton $(\mathrm{Ind} / \mathrm{ml})$ & & & & & & 0,71 & & 0,65 \\
\hline Biomasa de Fitoplancton total $(\mu \mathrm{g}$ C/L) & & & & & & 0,68 & & \\
\hline Clorofila $a\left(\mathrm{mg} / \mathrm{m}^{3}\right)$ & & & & & & 0,6 & & \\
\hline Abundancia Zooplancton total (Ind/L) & & 0,71 & 0,61 & & & & 0,79 & 0,95 \\
\hline Abundancia de Ciliados & & & & 0,6 & & 0,74 & & \\
\hline Biomasa de Rotíferos $(\mu \mathrm{g} \mathrm{C} / \mathrm{L})$ & & 0,65 & & & & & 0,8 & 0,93 \\
\hline Biomasa de Copépodos $(\mu \mathrm{g} \mathrm{C} / \mathrm{L})$ & 0,66 & 0,67 & & & & & 0,81 & \\
\hline
\end{tabular}

\begin{tabular}{|l|c|c|c|c|c|c|}
\cline { 2 - 7 } \multicolumn{1}{c|}{} & Ab.Ciliad & B.Rotíf & Rotíf.Ov & H.enOrg & H.lib. & B.Cop. \\
\hline Biomasa Zooplancton total $(\mu \mathrm{gC} / \mathrm{L})$ & & 0,8 & & & & 0,81 \\
\hline Biomasa de Ciliados $(\mu \mathrm{g} \mathrm{C} / \mathrm{L})$ & 0,84 & & & & & \\
\hline Abundancia de Rotíferos $(\mathrm{Ind} / \mathrm{L})$ & & 0,93 & 0,98 & 0,98 & 0,86 & \\
\hline Epistylis sp1 & 0,82 & & & & & \\
\hline Vorticella sp1 & 0,75 & & & & & \\
\hline
\end{tabular}




\begin{tabular}{|l|c|c|}
\cline { 2 - 3 } \multicolumn{1}{c|}{} & Ab.Cop & Ab.Clad. \\
\hline Abundancia Copépodos Ovígeras (Ind/L) & 0,82 & \\
\hline Biomasa Copépodos $(\mu \mathrm{g}$ C/L) & 0,94 & \\
\hline Abundancia Cladóceros hembras ovígeras & & 0,69 \\
\hline
\end{tabular}

\begin{tabular}{|l|c|c|c|c|c|c|c|c|c|c|}
\cline { 2 - 12 } \multicolumn{1}{c|}{} & $\mathrm{T}^{\mathrm{o}}$ & $\mathrm{SS}$ & Turb. & Cond. & $\mathrm{Na}^{+}$ & $\mathrm{K}^{+}$ & $\mathrm{SO}_{4}=$ & $\mathrm{Cl}_{-}$ & Dureza & Ab.Rotíf \\
\hline Abundancia Rotíferos (Ind/L) & & & 0,7 & 0,6 & 0,63 & 0,64 & 0,66 & & & \\
\hline Biomasa de Rotíferos $(\mu \mathrm{g}$ C/L) & & 0,64 & & 0,64 & 0,67 & 0,7 & 0,69 & & & \\
\hline Brachionus angularis & 0,67 & & & & & & & & & 0,71 \\
\hline Brachionus plicatilis & 0,7 & 0,61 & & 0,6 & 0,74 & 0,77 & 0,71 & 0,6 & & 0,8 \\
\hline Pompholyx sulcata & 0,64 & & & 0,64 & 0,65 & 0,71 & 0,62 & & & 0,63 \\
\hline Stentor sp2 & & & & 0,65 & 0,6 & & & 0,64 & & \\
\hline Blepharisma sp. & 0,6 & & & 0,76 & 0,73 & 0,75 & 0,64 & 0,69 & 0,63 & \\
\hline
\end{tabular}

\begin{tabular}{|l|c|c|c|c|c|c|c|c|}
\cline { 2 - 9 } \multicolumn{1}{c|}{} & $\mathrm{pH}$ & Turbidez & MOP & Clor. $a$ & SS & Ab.Rotíf & Ab.Cop & Ab.Rizop. \\
\hline Acanthocyclops robustus & & 0,7 & & & & & 0,91 & \\
\hline Copepoditos & 0,77 & & & & & & & \\
\hline Larvas nauplii & 0,74 & 0,6 & & & & & 0,99 & \\
\hline Synchaeta pectinata & $-0,6$ & & & & & & & \\
\hline Proalides sp1 & & & 0,6 & 0,62 & & 0,67 & & \\
\hline Brachionus pterodinoides & 0,71 & & & & & & & \\
\hline Brachionus urceolaris & & 0,65 & 0,7 & 0,73 & 0,73 & & & \\
\hline Opercularia sp. & 0,62 & & & & & & & \\
\hline Stentor sp1 & $-0,6$ & & & & & & & \\
\hline Arcella hemisphaerica & & & & & & & & 0,92 \\
\hline
\end{tabular}


ANEXO III

Tablas del índice del valor indicador (INDVAL) aplicado al fito y zooplancton.

Tabla 1: Especies características de fitoplancton con su correspondiente valor del índice Indval.

\section{Canal 1}

Pleurosira laevis

Pseudoschroederia robusta

Pseudoschroederia antillarum

Spirulina laxissima

Cyclotella glomerata

Dolichospermum spiroides

Chaetoceros sp.

Raphidiopsis mediterranea

Merismopedia warmingiana

Spirogyra sp2

Canal 3

Closteriopsis acicularis

Hindakochloris nygardii

Amphora ovalis

Diploneis minuta

Kirchneriella lunaris

Coelastrum sphaericum

Denticula elegans

Raphidocelis subcapitata

Peridineal sp3

Rhopalodia gibba

Tetraedron tumidulum

Fragilaria crotonensis

Raphidocelis sigmoidea

Cryptomonas pyrenoidifera

Symploca sp2

Merismopedia tennuissima

Nitzschia fasciculata

Monoraphidium fontinale

Eutetramorus tetrasporus

Navicula cincta

Crucigeniella rectangularis

Pseudokirchneriella contorta

Monoraphidium mirabile

Monoraphidium nanum

Monoraphidium convolutum

Monoraphidium contortum

\section{Río Abajo}

Melosira lineata

Fragilaria virescens

Coenochloris fottii

Komvophoron sp.

Scenedesmus obliquus

Fallacia pygmaea

\section{Canal 2}

(64) Phormidium versicolor

(50) Desmodesmus intermedius

\section{Arroyo}

Euglena retronata

Phormidium okenii

$$
\text { Nitzschia fonticola }
$$

Closterium costatum

Craticula ambigua 
Desmodesmus opoliensis

Actinastrum hantzschii

Schroederia indica

Cosmarium abbreviatum

Scenedesmus ecornis

Oocystis borgei

Oocystis submarina

Planothidium delicatulum

Cosmarium sp.

Frustulia sp1

Acutodesmus acuminatus
(52) Chroococcus limneticus

(51) Spirulina subsalsa

(51) Microcystis firma

(48) Cosmioneis pusilla

(48) Navicula cryptocephala

(47) Chlamydomonas globosa

(45) Melosira nummuloides

(40) Nitzschia tryblionella

(40) Surirella striatula

(40) Navicula recens

(40)
(47)

Tabla 2: Especies comunes de fitoplancton (all habitat).

Rossithidium linearis

Sphaerospermopsis aphanizomenoides

Aphanocapsa delicatissima

Aphanocapsa incerta

Chlamydomonas grovei

Chroococcus dispersus

Chroococcus minutus

Chroomonas coerulea

Closterium acutum var. linea

Ooplanctella planconvexa

Crucigenia quadrata

Cryptomonas erosa

Cryptomonas phaseolus

Cryptomonas pusilla

Cyclotella meneghiniana

Diadesmis laevissima

Didymocystis bicellularis

Pseudodidymocystis fina
Kirchneriella aperta

Kirchneriella obesa

Lagerheimia subsalsa

Monoraphidium circinale

Monoraphidium griffithii

Monoraphidium minutum

Monoraphidium pusillum

Monoraphidium tortile

Oocystis parva

Monomorphina pyrum

Planktolyngbya minor

Quadricoccus ellipticus

Geitlerinema amphibium

Spirulina major

Surirella ovalis

Synecococcus subsalsus

Tetraedron minimum

Nitzschia paleacea

Tabla 3: Especies de fitoplancton sólo presentes a lo largo del sistema Bragado.

\begin{tabular}{ll}
\hline Chondrocystis dermochroa & Phacus sp. \\
Euglena clavata & Phacus pusillus \\
Lepocinclis oxyuris & Rhodomonas sp. \\
Euglena rostrata & Schroederia nitzschiodes \\
Hindakochloris nygardii & Spirogyra sp1 \\
Pseudoquadrigula obtusa & Spirulina subtilissima \\
Navicula salinarum & Tetraedron longispinum \\
Oocystis panduriformis & Ulothrix sp1 \\
Phacus acuminatus &
\end{tabular}

Tabla 4: Especies de fitoplancton presentes a lo largo del sistema 
Bragado que luego se incorporan al río Salado aguas abajo del trasvase.

Arthrospira skujae

Biddulphia sp1

Binuclearia eriensis

Chaetoceros sp.

Fusola viridis

Euglena brevicaudata

Euglenaria caudata

Euglena oblonga

Euglenaria anabaena

Gymnodinium sp2

Gyrosigma attenuatum

Keratococcus raphidioides
Kirchneriella microscopica

Luticola mutica

Pandorina morum

Pediastrum angulosum

Peridineal sp2

Phormidium aerugino-caeruleum

Pleurosira laevis

Scenedesmus longispina

Schroederia sp.

Spirulina nordstedtii

Strombomonas cf. borystheniensis

Tabla 5: Especies de fitoplancton sólo presentes en el río Salado.

\begin{tabular}{ll}
\hline Closterium costatum & Pinnularia sp. \\
Craticula ambigua & Surirella tenera \\
Diadesmis sp. & Trachelomonas sp.4 \\
Geitlerinema acutissimum & Ulothrix sp2 \\
Lagerheimia circumfilata &
\end{tabular}

Tabla 6: Especies de fitoplancton sólo presentes en un sitio de muestreo.

\section{Canal 1}

Biddulphia sp2

Closterium sp.

Enteromorpha sp.

Jaaginema subtilissimum

Peridineal sp5

Pleurosigma angulatum

Trachelomonas sp5

\section{Canal 2}

Achnanthidium affine

Cryptomonas marsonii

Cymbella leptoceros

Hegewaldia parvula

Gymnodiunium sp3

Lagerheimia trigona

Phacus helikoides

Phacus textus

Pseudanabaena sp.

Pseudocapsa sp.

Strombomonas of fluviatilis

Strombomonas cf verrucosa

\section{Canal 3}

Coelastrum sphaericum

Denticula elegans

Raphidocelis subcapitata

Peridineal sp3

Rhopalodia gibba

Tetraedron tumidulum

\section{Arroyo}

Denticula tenuis

Caloneis bacillum

Calothrix sp.

Cymbella cistula

Lepocinclis acus

Euglena pisciformis

Gleocapsa sp.

Jaaginema unigranulatum

Lagerheimia chodatii

Navicula maculata

Tryblionella angustata

Phacus pleuronectes

Trachelomonas sp3 
Trachelomonas cf planctonica

Trachelomonas sp.2

\section{Río aguas Arriba}

Cladophora sp.

Craticula cuspidata

Cyclotella sp.

Cymbella tumida

Eucapsis sp.

Staurosira construens

Fragilaria vaucherie

Franceia amphitricha

Golenkinia paucispina

Navicula trivialis

Oedogonium sp.

Planktothrix sp.

Tetraedron muticum

Trachelomonas sp6
Río aguas Abajo

Campylodiscus sp.

Crucigeniella crucifera

Cryptomonas ovata

Pseudodictyococcus fusisporus

Entomoneis sp.

Euglena fundoversata

Frustulia cf vulgaris

Menoidium sp.

Meridion sp.

Phormidium sp.

Pinnularia abaujensis

Rhopalodia gibberula

Spirulina princeps

Stigonema sp2

Strombomonas sp1

Synedra pulchella

Ulothrix sp3

Tabla 7: Especies características del zooplancton por sitio de muestreo con su correspondiente valor del índice Indval entre paréntesis.

\begin{tabular}{|c|c|c|c|}
\hline Canal 2 & & Canal 3 & \\
\hline Proales sp5 & $(72)$ & Hexarthra fennica & $(100)$ \\
\hline Brachionus plicatilis & $(69)$ & Euplotes sp. & $(94)$ \\
\hline Anuraeopsis fissa & $(66)$ & Trinema sp. & $(65)$ \\
\hline Asplanchna girodi & $(65)$ & Vaginicola sp. & $(55)$ \\
\hline Strobilidium caudatum & $(57)$ & Ciliado sp2 & $(50)$ \\
\hline Notodiaptomus incompositus & $(51)$ & Dileptus sp. & $(50)$ \\
\hline Bdelloideo sp2 & $(49)$ & Litonotus sp. & $(50)$ \\
\hline Encentrum sp1 & $(48)$ & Uroleptus sp. & $(50)$ \\
\hline Trichocerca pusilla & $(47)$ & Encentrum sp2 & $(50)$ \\
\hline Brachionus caudatus & $(46)$ & Polyarthra sp2 & $(50)$ \\
\hline Cletocamptus deitersi & $(46)$ & Collotheca sp1 & $(45)$ \\
\hline Urotrichia sp. & $(42)$ & Metacyclops mendocinus & $(41)$ \\
\hline Bdeloideo sp1 & $(40)$ & Canal 1 & \\
\hline Prorodon sp2 & $(40)$ & Strombidium sp1 & $(51)$ \\
\hline Arroyo & & Collotheca sp2 & $(50)$ \\
\hline Vorticella sp2 & $(62)$ & Boeckella poopensis & $(50)$ \\
\hline Codonella sp. & $(49)$ & Stentor sp1 & $(48)$ \\
\hline Bdelloideo sp4 & $(47)$ & Synchaeta pectinata & $(41)$ \\
\hline Epistylis sp1 & $(45)$ & Río Abajo & \\
\hline Río Arriba & & Proales sp6 & $(56)$ \\
\hline Alona glabra & $(74)$ & Paracyclops fimbriatus & (54) \\
\hline Arcella discoides & $(71)$ & Cypridopsis vidua & $(51)$ \\
\hline Euglypha sp. & $(50)$ & Notommata sp. & $(50)$ \\
\hline Moina micrura & $(49)$ & Brachionus urceolaris & $(48)$ \\
\hline
\end{tabular}


Harpacticoideo sp.

Brachionus quadridentatus

Lecane piriformis
Proalides sp1

Simocephalus sp.

Brachionus pterodinoides

Tabla 8: Especies comunes del zooplancton (all habitat).

\begin{tabular}{ll}
\hline Acanthocyclops robustus & Daphnia obtusa \\
Alona rectangula & Enchelys sp. \\
Arcella hemisphaerica & Keratella tropica \\
Ascomorpha ovata & Lecane closterocerca \\
Askenasia sp. & Testudinella patina \\
Bdeloideo sp3 & Tintinnidium fluviatile \\
Brachionus angularis & Tokophrya sp. \\
Colpoda sp. & Vorticella sp1 \\
& \\
\hline
\end{tabular}

Tabla 9: Especies de zooplancton sólo presentes en el sistema Bragado.

\begin{tabular}{ll}
\hline Ameba sp. & Halteria sp. \\
Codonella sp. & Lecane curvicornis \\
Collotheca sp1 & Lecane hemimonostila \\
Colurella colurus & Monodinium sp. \\
Colurella sp. & Notholca acuminata \\
Conochilus sp. & Polyarthra sp1 \\
Dicranophorus sp. & Strobilidium caudatum \\
Encentrum sp1 & Strombidium sp1 \\
Euchlanis dilatata & Strombidium sp2 \\
Fabria salina & Strobilidium sulcatum
\end{tabular}

Tabla 10: Especies de zooplancton presentes en el sistema Bragado, que luego se incorporan al río Salado aguas abajo del trasvase

\begin{tabular}{ll}
\hline Blepharisma sp. & Nassula sp. \\
Bdeloideo sp5 & Notodiaptomus incompositus \\
Brachionus ibericus & Proales sp6 \\
Cephalodella sp1 & Thuricola sp. \\
Ciliado sp1 & Trichocerca capuchina \\
Filinia longiseta & Urotrichia sp.
\end{tabular}

Tabla 11: Especies de zooplancton sólo presentes en el río Salado.
Arcella discoides
Cephalodella macrodactyla
Euplotes eurystomus
Paramecio caudatum
Simocephalus sp. 
Tabla 12: Especies de zooplancton sólo presentes en un sitio de muestreo.

\section{Canal 1}

Boeckella poopensis

Carchesium sp.

Ciliado sp3

Collotheca sp2

Collotheca sp3

Encentrum sp5

Halteria grandinella

Lecane quadridentatus

Mytilina mucronata

Spirostomun sp.

Suctorio sp.

Testudinella sp.

Canal 2

Cephalodella sp.2

Lecane clara

Lecane grandis

Lecane hamata

Pompholyx sp.

Proalides sp4

Radiolario sp.

Trichocerca cilindrica

Trichocerca sp.

\section{Canal 3}

Ciliado sp2

Dileptus sp.

Encentrum sp2

Hexarthra fennica

Litonotus sp.

Polyarthra sp2

Proalides sp.2

Proalides sp. 3

Uroleptus sp.

\section{Río aguas Abajo}

Holophrya sp.

Lecane luna

Lecane nana

Leydigia louisi

Monomata sp.

Notommata sp.

Proales sp1

Río aguas Arriba

Brachionus havanaensis

Diaphanosoma birgei

Euglypha sp. 


\section{ANEXO IV}

Tabla 1: Características de las estrategias primarias de las comunidades terrestres (Grime, 1979) aplicadas al fitoplancton, sensu Reynolds (1988b).

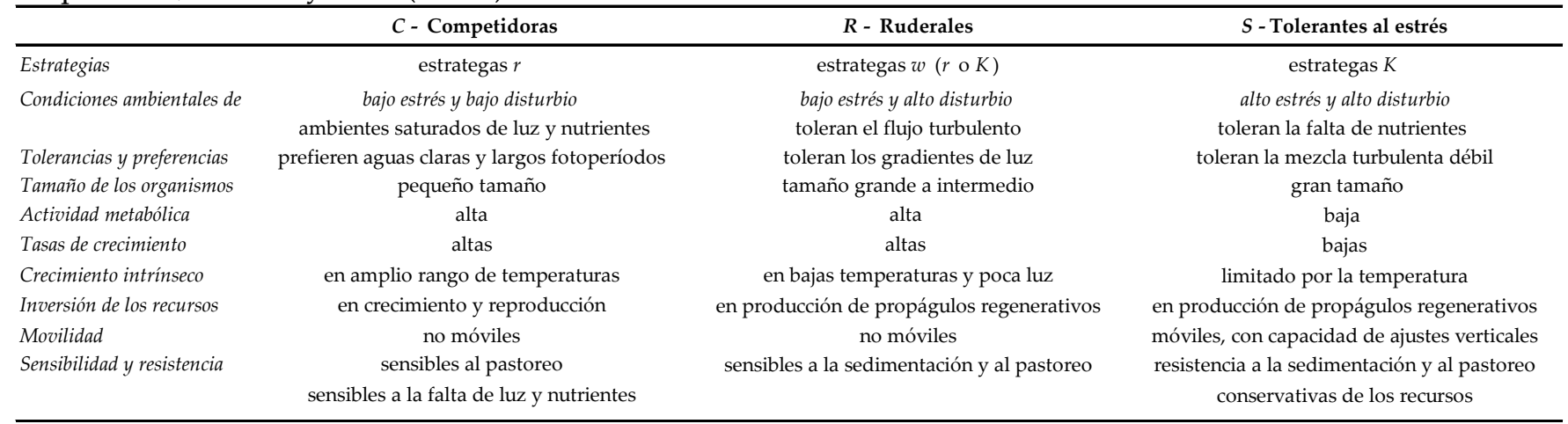

Tabla 2: Estrategias primarias y sus principales características aplicadas al fitoplancton, tomado de Margalef (1968), Odum (1969), Reynolds (1988, 1994a,b, 1997).

\begin{tabular}{lcc} 
& Estrategias $r$ & Estrategias $K$ \\
\hline Tamaño celular & pequeño & grande \\
Morfotipo típico & unicelular esférica u ovodie & cenobios, colonias, filamentos \\
Coeficientes $A S / V$ & Alto & Bajo \\
Actividad metabólica & Alta & Baja \\
Limitación del crecimiento & fotosíntesis neta & transporte intracelular \\
Cociente Producción / Biomasa & Alto & Bajo \\
Requerimientos energéticos & Altos & Bajos \\
Captación de la luz y los nutrientes & Mayor & Menor \\
Tasas de crecimiento intrínseco & Altas & Bajas \\
Inversión en reproducción y dispersión & Mayor & Menor \\
Características ecológicas & oportunistas, colonizadoras & buenas competidoras \\
\hline
\end{tabular}

Tabla 3: Principales procesos del río y su planicie de inundación en diferentes condiciones hidrológicas, tomado de Tockner et al. (2000).

Aguas Bajas Conectividad Intermedia Aguas Altas

\begin{tabular}{lccc}
\hline Tiempo de residencia & Muy alto & Alto & Bajo \\
Dinámica de nutrientes & Ciclo Cerrado & Ciclo Abierto & Espiral Abierto \\
Toma de nutrientes & Autogénica & Autogénica & Alogénica \\
Productividad Primaria & Media & Alta & Baja \\
Cociente $P / R$ & $\approx 1$ & $>1$ & $<1$ \\
Característica principal & Sumidero (autóctono) & Fuente de clorofila $a$ & Sumidero \\
\hline
\end{tabular}


Tabla 4: Resumen de las especies dominantes pertenecientes a los grupos morfofuncionales según Reynolds et al. (2002) presentes en las diferentes condiciones hidrológicas, y sus principales características.

\begin{tabular}{|c|c|c|c|c|}
\hline Sitio & Muestreo & Especie & Codón & Características ecológicas \\
\hline \multirow[t]{2}{*}{ canal 1} & aguas altas & Raphidiopsis mediterranea & S2 & tolerante a las deficiencias de luz \\
\hline & aguas bajas & Synechococcus spp. & $\mathbf{Z}$ & tolerantes a la baja disponibilidad de nutrientes \\
\hline \multirow{3}{*}{$\begin{array}{c}\text { canal } 2 \\
\text { y arroyo }\end{array}$} & aguas altas & Aphanocapsa incerta & K & cianobacteria colonial, común en aguas enriquecidas con nutrientes \\
\hline & & Cryptomonas obovoidea & $\mathbf{Y}$ & tolerante a las deficiencias de luz y sensible al pastoreo \\
\hline & & Monoraphidium spp. & $\mathbf{X 1}$ & especies eutróficas e hipereutróficas, \\
\hline \multirow[t]{2}{*}{ canal 2} & aguas bajas & Komma caudata & $\mathrm{X} 2$ & especies colonizadoras, meso-eutróficas, \\
\hline & & Plagioselmis nannoplanctonica & & limitadas por la mezcla y las deficiencias de luz \\
\hline arroyo & caudales medios & Monoraphidium spp. & $\mathbf{X 1}$ & \\
\hline $\begin{array}{c}\text { río arriba } \\
\text { y abajo }\end{array}$ & caudales medios & Actinastrum hantzschii & $\mathbf{J}$ & grupo común en ríos y lagunas enriquecidos con nutrientes \\
\hline \multirow[t]{2}{*}{ río arriba } & aguas bajas & Sphaerospermopsis aphanizomenoides & H1 & fijadora de nitrógeno y sensible a la falta de fósforo \\
\hline & & Planktolyngbya minor & S1 & grupo común en ambientes mezclados y turbios \\
\hline \multirow[t]{2}{*}{ río abajo } & aguas bajas & Planktolyngbya limnetica & & tolerantes a la falta de luz, pero sensibles al lavado \\
\hline & & Monoraphidium spp. & $\mathbf{X 1}$ & sensibles al déficit de nutrientes y al pastoreo \\
\hline
\end{tabular}




\section{ANEXO V}

Tabla 10.1: Caracterización de las especies del fitoplancton presentes según su afinidad a ambientes alcalinos (A), eutróficos (E), meso-eutróficos $(\mathrm{M})$ o hiper-eutróficos $(\mathrm{H})$; tolerantes a elevada turbidez y conductividad (TB); de hábitat bentónico o perifítico (BP), y grado de saprobios: alfa-mesosaprobios $(\alpha)$, beta-mesosaprobio ( $\beta$ ) y polisaprobios (Po); tomado de Van Dam et al. (1994), Izaguirre \& Vinocur (1994), Gómez \& Licursi (2001), Licursi et al. (2010) y Barinova et al. (2011).

\section{Cianobacterias}

Anabaena spiroides

Arthrospira platensis

Chroococcus turgidus

Merismopedia tenuissima

Microcystis aeruginosa

$\begin{array}{ll}\mathrm{E} & \beta \\ & \beta\end{array}$

Oscillatoria princeps

Oscillatoria tenuis

Euglenofitas

Euglena viridis

Lepocinclis oxyuris

Lepocinclis acus

Clorofitas

\begin{tabular}{|c|c|c|c|c|}
\hline & \multicolumn{3}{|c|}{$\mathrm{E}$} & $\beta$ \\
\hline Acutodesmus acuminatus & \multicolumn{3}{|c|}{ E } & $\beta$ \\
\hline Coelastrum microporum & \multicolumn{3}{|c|}{ E } & $\beta$ \\
\hline Crucigenia tetrapedia & \multicolumn{3}{|c|}{$\mathrm{E}$} & $\beta$ \\
\hline Crucigenia quadrata & \multicolumn{3}{|c|}{$\mathrm{E}$} & \\
\hline Didymocystis bicellularis & \multicolumn{3}{|c|}{ E } & \\
\hline Dyctiosphaerium pulchellum & \multicolumn{3}{|c|}{ E } & $\beta$ \\
\hline Monoraphidium circinale & \multicolumn{3}{|c|}{ E } & \\
\hline Monoraphidium contortum & \multicolumn{3}{|c|}{$\mathrm{E}$} & \\
\hline Monoraphidium komarkovae & \multicolumn{3}{|c|}{$\mathrm{E}$} & \\
\hline Monoraphidium tortile & \multicolumn{3}{|c|}{$\mathrm{M}$} & \\
\hline Oocystis lacustris & \multicolumn{3}{|c|}{ E } & $\beta$ \\
\hline Scenedesmus quadricauda & \multicolumn{3}{|c|}{ E } & $\beta$ \\
\hline Pediastrum duplex & \multicolumn{3}{|c|}{ E } & $\beta$ \\
\hline Pediastrum tetras & \multicolumn{3}{|c|}{$\mathrm{E}$} & $\beta$ \\
\hline Pseudopediastrum boryanum & \multicolumn{3}{|c|}{ E } & $\beta$ \\
\hline Scenedesmus acutus & \multicolumn{3}{|c|}{$\mathrm{E}$} & $\beta$ \\
\hline Scenedesmus ecornis & \multicolumn{3}{|c|}{ E } & \\
\hline Tetraedron caudatus & \multicolumn{3}{|c|}{ E } & $\beta$ \\
\hline Tetraedron minimum & \multicolumn{3}{|c|}{ E } & $\beta$ \\
\hline Tetraedron triangulare & \multicolumn{3}{|c|}{ E } & \\
\hline Tetrastrum triangulare & \multicolumn{3}{|c|}{ E } & \\
\hline \multicolumn{5}{|l|}{ Diatomeas } \\
\hline Achnanthidium minutissimum & & $\mathrm{H}$ & $\mathrm{BP}$ & \\
\hline Amphora ovalis & A & $\mathrm{E}$ & & \\
\hline Amphora pediculus & A & $\mathrm{E}$ & & Po \\
\hline Amphora veneta & & & & $\mathrm{Po}$ \\
\hline Anomoneis sphaerophora & A & $\mathrm{E}$ & $\mathrm{BP}$ & \\
\hline Aulacoseirca granulata var. angustissima & A & $\mathrm{E}$ & & \\
\hline Bacillaria paxillifera & A & $\mathrm{E}$ & $\mathrm{BP}$ & \\
\hline Caloneis amphisbaena & A & $\mathrm{E}$ & & \\
\hline
\end{tabular}


Campylodiscus clypeus

Chaetoceros sp.

Cyclotella glomerata

Cyclotella meneghiniana

Cymbella affinis

Diadesmis confervacea

Diatoma vulgaris

Fallacia pygmea

Staurosira construens

Fragilaria crotonensis

Fragilaria vaucherie

Gomphonema parvalum

Gyrosigma attenuatum

Halamphora coffeaeformis

Melosira lineata

Melosira numuloides

Melosira varians

Navicula cincta

Navicula cryptocephala

Placoneis gastrum

Navicula gregaria

Navicula recens

Navicula tripunctata

Navicula viridula

Neidium iridis

Nitzschia acicularis

Nitzschia fonticola

Nitzschia fruticosa

Nitzschia linearis

Nitzschia palea

Nitzschia paleacea

Nitzschia sigma

Nitzschia tryblionella

Nitzschia umbonata

Pinnularia viridis

Planothidium delicatulum

Planothidium lanceolatum

Pleurosira laevis

Pseudostaurosira brevistriata

Rhopalodia gibba

Rossithidium linearis

Sellaphora pupula

Stephanodiscus sp.

Surirella ovalis

Surirella striatula

Surirella tenera

Ulnaria ulna

Tryblionella hungarica

Tryblionella levidensis

Tryblionella apiculata
A

A $\mathrm{E}$

E

E

$\alpha$

A $E$

A $\quad$ E $\quad$ BP $\quad$ TC

A $\mathrm{E} \quad \mathrm{BP}$

A $\quad$ BP

M BP

A $\mathrm{M}$

A E

E-H BP

A $\mathrm{E} \quad \mathrm{BP}$

A $\mathrm{E} \quad \mathrm{BP}$

E

E

A E

E

$\alpha$

A E

E

A $\mathrm{M} \quad \mathrm{BP} \quad \alpha \beta$

A E

A E

E BP

A $\mathrm{E}$

$\beta$

BP

A E

E $\quad \beta$

H BP $\alpha$

A E-H BP

A $\mathrm{E}$ BP TC

E

$\mathrm{H} \quad \mathrm{BP}$

$\mathrm{H} \quad \beta$

A $\mathrm{M}$ BP

A E BP

$\beta$

A E BP

$\mathrm{H}$ BP

A E

A E BP

E-H BP

$\alpha$

E $\alpha$

A $E$

E BP

A $\mathrm{E} \quad \mathrm{BP} \quad \beta$

$\mathrm{H} \quad \mathrm{BP}$

E BP

A $\mathrm{E} \quad \mathrm{BP}$

BP TC 


\section{ANEXO VI}

Tablas de aumento y disminución de los diferentes componentes del fito y zooplancton en el río Salado aguas abajo del trasvase del sistema Bragado, respecto al sitio del río aguas arriba, en cada condición hidrológica: A- Aguas altas (mayo 2007), B-Caudales medios (marzo 2008), C- Aguas bajas

(nov. 2008) y D-Aguas muy bajas en el sistema Bragado y con caudales medios en el río (sept. 2009).

\begin{tabular}{|c|c|c|c|}
\hline \multicolumn{4}{|c|}{ A- Aguas altas (mayo 2007) } \\
\hline \multicolumn{3}{|c|}{ Aumento } & \multirow[t]{2}{*}{ Disminución } \\
\hline $17 \%$ & abundancia total de criptofitas & & \\
\hline $32,5 \%$ & abundancia absoluta y relativa de las cianobacterias & $28 \%$ & abundancia de las clorofitas \\
\hline 2 veces & biomasa relativa de diatomeas y dinoflagelados & $11 \%$ & biomasa de las clorofitas \\
\hline 2,5 veces & biomasa de los dinoflagelados & $11 \%$ & biomasa de las criptofitas \\
\hline $80 \%$ & biomasa de las diatomeas & $30 \%$ & abundancia de Monoraphidium spp. \\
\hline 2,8 veces & abundancia y biomasa de Cryptomonas obovoidea & $60 \%$ & biomasa de Monoraphidium spp. \\
\hline 2 veces & abundancia y biomasa de Aphanocapsa incerta & $50 \%$ & biomasa de Cryptomonas erosa \\
\hline 3 veces & abundancia y biomasa Cyclotella meneghiniana & 3 veces & biomasa de Raphidiopsis mediterranea \\
\hline $33 \%$ & abundancia de ciliados & & Diversidad de Simpson fitoplancton \\
\hline 2 veces & abundancia de cladóceros & $74 \%$ & abundancia de rizópodos \\
\hline 5,6 veces & abundancia de copépodos & $13 \%$ & abundancia de ostrácodos \\
\hline 48 veces & abundancia de copépodos harpacticoideos & $60 \%$ & biomasa de los ciliados \\
\hline 2 veces & biomasa total de zooplancton & 3,7 veces & abundancia Arcella hemisphaerica \\
\hline $33 \%$ & biomasa total de cladóceros y rotíferos & $35 \%$ & número de huevos libres en la muestra \\
\hline 4 veces & biomasa total de copépodos & $7 \%$ & abundancia de copepoditos \\
\hline 6 veces & abundancia de Brachionus plicatilis & & Relación de la biomasa entre fito y zooplancton \\
\hline 8 veces & abundancia de Synchaeta pectinata & & \\
\hline $24 \%$ & abundancia de hembras ovígeras zooplancton & & Incorporación de organismos aguas abajo \\
\hline 3,5 veces & abundancia hembras ovígeras de copépodos & & Didymocystis bicellularis y Oocystis lacustris en reproducción \\
\hline $24 \%$ & abundancia de hembras ovígeras de rotíferos & & Daphnia spinulata y Daphnia obtusa \\
\hline 6 veces & abundancia de larvas nauplii & & Notodiaptomus incompositus \\
\hline 1,7 veces & abundancia de cladóceros adultos & & Acanthocyclops robustus \\
\hline \multirow[t]{2}{*}{7,3 veces } & abundancia de cladóceros juveniles & & \\
\hline & Diversidad Simpson del zooplancton & & Escasa variación entre sitios \\
\hline $8 \%$ & carbono total biomasa del plancton & & $\begin{array}{l}\text { biomasa total del microplancton } \\
\text { abundancia y biomasa total de fitoplancton }\end{array}$ \\
\hline
\end{tabular}




\begin{tabular}{|c|c|c|c|}
\hline \multicolumn{3}{|c|}{ Aumento } & \multirow[t]{2}{*}{ Disminución } \\
\hline $57 \%$ & abundancia total de fitoplancton & $39 \%$ & \\
\hline $23 \%$ & abundancia de clorofitas & $29-32 \%$ & abundancia y biomasa de las diatomeas \\
\hline $76 \%$ & abundancia de cianobacterias & $30 \%$ & abundancia y biomasa de Sphaerospormopsis aphanizomenoides \\
\hline $108 \%$ & abundancia de las criptofitas & $50 \%$ & diversidad Simpson del fitoplancton \\
\hline $300 \%$ & abundancia de las euglenofitas & & abundancia relativa de cladóceros, copépodos y rizópodos \\
\hline $100 \%$ & abundancia de Aphanocapsa incerta & 4 veces & abundancia de ostrácodos \\
\hline 5 veces & abundancia y biomasa de Raphidiopsis mediterranea & 5 veces & abundancia de cladóceros \\
\hline 5 veces & abundancia y biomasa de Cryptomonas obovoidea & $35 \%$ & abundancia de Harpacticoideo sp. \\
\hline $45 \%$ & abundancia de Monoraphidium spp. & $60 \%$ & abundancia de Acanthocyclops robustus \\
\hline $300 \%$ & abundancia de Cyclotella glomerata & $50 \%$ & abundancia de Keratella tropica \\
\hline $50 \%$ & biomasa total de fitoplancton & $15 \%$ & biomasa de zooplancton total \\
\hline 7 veces & biomasa de las euglenofitas & 8 veces & biomasa de cladóceros \\
\hline 2 veces & biomasa de los dinoflagelados & 7,8 veces & biomasa de Moina micrura \\
\hline $40 \%$ & biomasa de cianobacterias & 2,5 veces & biomasa de Metacyclops mendocinus \\
\hline 2 veces & biomasa de las clorofitas & 10 veces & biomasa de Alona graba \\
\hline $165 \%$ & biomasa de las criptofitas & $91 \%$ & abundancia de hembras ovígeras de cladóceros \\
\hline 2 veces & biomasa de Oocystis spp. & 10 veces & abundancia de huevos de cladóceros \\
\hline $10 \%$ & riqueza de especies de fitoplancton & $84 \%$ & abundancia de cladóceros juveniles y cladoceritos \\
\hline 3 veces & riqueza de especies de las euglenofitas & 1,4 veces & abundancia de machos de Acanthocyclops robustus \\
\hline \multirow[t]{2}{*}{2,6 veces } & abundancia de zooplancton total & & \\
\hline & abundancia y biomasa relativa de ciliados y rotíferos & & Incorporación de organismos aguas abajo \\
\hline 18 veces & abundancia de ciliados & & Synchaeta pectinata \\
\hline $18 \%$ & abundancia de copépodos & & Paracyclops fimbriatus \\
\hline 3,7 veces & abundancia de los rotíferos & & Stentor sp.1 \\
\hline $1000 \%$ & abundancia de Proalides sp.1 & & Euplotes sp. \\
\hline 3 veces & abundancia de Brachionus angularis & & Enchelys sp. \\
\hline 3,4 veces & abundancia de Brachionus plicatilis & & Brachionus calyciflorus \\
\hline 17 veces & abundancia de Epistylis sp.1 & & Vaginicola sp. \\
\hline 11 veces & biomasa de ciliados & & Strobilidium caudatum \\
\hline $88 \%$ & biomasa total de rotíferos & & Trichotria tetractis \\
\hline 3 veces & biomasa de Brachionus plicatilis & & Filinia longiseta \\
\hline $77 \%$ & biomasa de Microcyclops alius & & Proales sp. \\
\hline $62 \%$ & riqueza de especies del zooplancton & & Brachionus dimidiatus inermis \\
\hline 3 veces & riqueza de especies de ciliados & & Brachionus caudatus \\
\hline 15 taxa & riqueza de especies de rotíferos & & Brachionus bidentata \\
\hline \multicolumn{4}{|c|}{2,6 veces abundancia del zooplancton en reproducción } \\
\hline 1,3 veces & $\mathrm{n}^{\circ}$ de huevos portados por hembras & & Escasa variación entre sitios \\
\hline 5,5 veces & $\mathrm{n}^{\circ}$ de huevos libres en las muestras & & biomasa total de copépodos \\
\hline 2,3 veces & abundancia de hembras ovígeras & & Diversidad Simpson del zooplancton \\
\hline \multirow[t]{2}{*}{2,4 veces } & $\mathrm{n}^{\mathrm{o}}$ de huevos de rotíferos & & no de huevos de copépodos y cladóceros \\
\hline & abundancia de formas $\mathrm{S}$ de Brachionus plicatilis y egg ratio & & abundancia de larvas nauplii de cyclopoideos \\
\hline 3 veces & abundancia de hembras ovígeras de Brachionus plicatilis & & abundancia de hembras ovígeras de Acanthocyclops robustus \\
\hline $60 \%$ & abundancia de larvas nauplii & & \\
\hline $346 \%$ & abundancia larvas nauplii de harpacticoideos & & \\
\hline $30 \%$ & biomasa total del nanoplancton & & \\
\hline $55 \%$ & biomasa total del microplancton & & \\
\hline $43 \%$ & carbono total biomasa del plancton & & \\
\hline
\end{tabular}




\begin{tabular}{|c|c|c|c|}
\hline \multicolumn{3}{|c|}{ Aumento } & \multirow[t]{2}{*}{ Disminución } \\
\hline $9 \%$ & abundancia y biomasa de fitoplancton total & $36 \%$ & \\
\hline 2 veces & abundancia y biomasa de las clorofitas & & abundancia relativa de cianobacterias y diatomeas \\
\hline $55 \%$ & abundancia de euglenofitas & $20 \%$ & abundancia y biomasa de cianobacterias \\
\hline $17 \%$ & abundancia Planktolyngbya limnetica & $50 \%$ & abundancia de las diatomeas \\
\hline 2 veces & abundancia de Monoraphidium spp. & 3 veces & biomasa de las diatomeas \\
\hline $13 \%$ & biomasa de euglenofitas & $58 \%$ & biomasa de Cyclotella glomerata \\
\hline 5 veces & biomasa de Oocystis spp. & $35 \%$ & biomasa de Aphanocapsa incerta \\
\hline 2 veces & biomasa de Cryptomonas obovoidea & 1,7 veces & biomasa de Stephanodiscus sp. \\
\hline $370 \%$ & biomasa de Geitlerinema amphibium & 7 veces & biomasa de Melosira numuloides \\
\hline $6,3 \%$ & biomasa Planktolyngbya limnetica & $69 \%$ & abundancia de Stephanodiscus sp. \\
\hline \multirow[t]{2}{*}{33 taxa } & riqueza de especies del fitoplancton & & biomasa de diatomeas del micro y nanoplancton \\
\hline & diversidad Simpson del fitoplancton & & abundancia y biomasa relativa de copépodos y cladóceros \\
\hline \multirow[t]{2}{*}{5,5 veces } & abundancia total del zooplancton & & abundancia relativa de rizópodos y ostrácodos \\
\hline & abundancia y biomasa relativa de rotíferos y ciliados & 110 veces & abundancia de cladóceros \\
\hline 5 veces & abundancia de ciliados & $71 \%$ & abundancia de copépodos \\
\hline 4,2 veces & abundancia de ostrácodos & $93 \%$ & abundancia y biomasa de Alona glabra \\
\hline 5,5 veces & abundancia de rotíferos & & abundancia de Alona rectangula \\
\hline \multirow[t]{2}{*}{10 veces } & abundancia de Epistylis sp.1 & 20 veces & abundancia de Acanthocyclops robustus \\
\hline & abundancia y biomasa de Moina micrura & 7 veces & abundancia de Cletocamptus deitersi \\
\hline \multirow[t]{2}{*}{4,4 veces } & abundancia de Brachionus plicatilis & $50 \%$ & abundancia Harpacticoideo sp. \\
\hline & abundancia de formas $\mathrm{S}$ de Brachionus plicatilis & $20 \%$ & biomasa total de zooplancton \\
\hline 10 veces & abundancia y biomasa de Brachionus angularis & 5,3 veces & biomasa de copépodos \\
\hline 50 veces & abundancia de Keratella tropica & 33 veces & biomasa de cladóceros \\
\hline 4 veces & biomasa de ciliados & $93 \%$ & biomasa de Acanthocyclops robustus \\
\hline 2,6 veces & biomasa de rotíferos & & $\mathrm{n}^{\circ}$ de especies de zooplancton en reproducción por huevos \\
\hline 2,8 veces & biomasa de Brachionus plicatilis & $83 \%$ & abundancia de larvas nauplii \\
\hline 5,6 veces & abundancia de zooplancton en reproducción por huevos & & abundancia de larvas nauplii de harpacticoideos \\
\hline 8,7 veces & abundancia de hembras ovígeras & & abundancia hembras ovígeras de harpacticoideos \\
\hline 7,5 veces & $\mathrm{n}^{\mathrm{o}}$ de huevos portados por hembras & $61 \%$ & abundancia de copepoditos \\
\hline \multirow[t]{8}{*}{3,7 veces } & $\mathrm{n}^{\mathrm{o}}$ de huevos libres en las muestras & & diversidad Simpson del zooplancton \\
\hline & abundancia de hembras ovígeras de rotíferos & & \\
\hline & abundancia de hembras ovígeras de Brachionus plicatilis & & Incorporación de organismos aguas abajo \\
\hline & abundancia de hembras ovígeras de Brachionus angularis & & dinoflagelados \\
\hline & egg ratio de Brachionus plicatilis & & Pseudoschroederia sp. (subdominante en el canal 1) \\
\hline & egg ratio de Brachionus angularis & & copépodos calanoideos \\
\hline & riqueza de especies de zooplancton total & & hembras ovígeras de Keratella tropica \\
\hline & riqueza de especies de rotíferos y ciliados & & efipios de dáfnidos \\
\hline 2 veces & biomasa de clorofitas y criptofitas del micro y nanoplancton & & machos de Cletocamptus deitersi \\
\hline $6 \%$ & carbono total biomasa del plancton & & \\
\hline \multirow[t]{2}{*}{$6 \%$} & contribución del carbono biomasa del fitoplancton a la MOP & & Pérdida de organismos aguas abajo \\
\hline & $\%$ carbono total biomasa del plancton a la MOP & & copépodos y cladóceros en reproducción \\
\hline
\end{tabular}




\begin{tabular}{|c|c|c|c|}
\hline & Aumento & & Disminución \\
\hline leve & Clorofila $a$ & $13 \%$ & abundancia de criptofitas \\
\hline $9 \%$ & abundancia de las cianobacterias & $19 \%$ & abundancia de euglenofitas \\
\hline $10 \%$ & abundancia de las clorofitas & leve & abundancia de Planktolyngbya minor \\
\hline $13 \%$ & abundancia de Aphanocapsa incerta & $23 \%$ & abundancia de Chroococcus spp. \\
\hline $6 \%$ & $\begin{array}{l}\text { abundancia de Actinastrum hantzschii } \\
\text { biomasa relativa de las clorofitas, diatomeas y euglenofitas }\end{array}$ & $8-9 \%$ & $\begin{array}{l}\text { abundancia Cyclotella glomerata y Stephanodiscus sp. } \\
\text { biomasa relativa de cianobacterias y criptofitas }\end{array}$ \\
\hline 4 veces & biomasa de las euglenofitas & $20 \%$ & biomasa de cianobacterias \\
\hline $4 \%$ & biomasa de las clorofitas & $19 \%$ & biomasa Geitlerinema amphibium \\
\hline $16 \%$ & biomasa de las diatomeas & $27-29 \%$ & abundancia y biomasa de Raphidiopsis mediterranea \\
\hline 2 veces & biomasa de Fragilaria spp. & leve & biomasa cianobacterias del microplancton \\
\hline $10 \%$ & biomasa de Actinastrum hantzschii & & riqueza de especies de criptofitas \\
\hline 35 veces & biomasa de Euglenaria caudata & & $\mathrm{n}^{\mathrm{Q}}$ de especies de clorofitas en reproducción \\
\hline \multirow[t]{4}{*}{$27 \%$} & biomasa de Melosira numuloides & $38 \%$ & abundancia de zooplancton total \\
\hline & Riqueza de especies de diatomeas y euglenofitas & $50 \%$ & abundancia de ciliados \\
\hline & abundancia relativa de ciliados, cladóceros y rizópodos & & abundancia de ostrácodos \\
\hline & abundancia de rizópodos & $13 \%$ & abundancia de rotíferos \\
\hline 2 veces & abundancia de cladóceros & 4,2 veces & abundancia de Cletocamptus deitersi \\
\hline 7 veces & abundancia de Keratella tropica & 3,5 veces & abundancia de Daphnia spinulata \\
\hline $21 \%$ & abundancia de Brachionus pterodinoides & $21 \%$ & abundancia de Vorticella sp.1 \\
\hline $14 \%$ & abundancia de Brachionus urceolaris & $66 \%$ & abundancia de Epistylis sp.1 \\
\hline \multirow[t]{2}{*}{$14 \%$} & biomasa de los rotíferos & $25 \%$ & abundancia y biomasa de Opercularia sp. 1 \\
\hline & biomasa relativa de rotíferos y copépodos & $20 \%$ & biomasa de zooplancton total \\
\hline 56 veces & biomasa de Alona glabra & 2,3 veces & biomasa de ciliados \\
\hline $42 \%$ & biomasa de Microcyclops alius & $15 \%$ & biomasa de copépodos \\
\hline \multirow[t]{24}{*}{5,8 veces } & biomasa de Brachionus plicatilis & & biomasa de cladóceros \\
\hline & egg ratio de hembras ovígeras de cladóceros & 2,4 veces & biomasa de Daphnia spinulata \\
\hline & abundancia de cladóceros juveniles y hembras ovígeras & $37 \%$ & biomasa de Acanthocyclops robustus \\
\hline & abundancia de juveniles de Daphnia spinulata & $38 \%$ & abundancia de zooplancton en reproducción \\
\hline & Diversidad Simpson del zooplancton & $15 \%$ & $\mathrm{n}^{\mathrm{o}}$ de huevos en hembras \\
\hline & biomasa del microplancton euglenofitas y criptofitas & $14 \%$ & abundancia de hembras ovígeras totales \\
\hline & Relación entre la biomas del fito y zooplancton & $17 \%$ & abundancia de hembras ovígeras de rotíferos \\
\hline & & $67 \%$ & abundancia total de huevos libres en las muestras \\
\hline & Escasa variación entre sitios & $36 \%$ & abundancia de copépodos adultos y nauplii \\
\hline & abundancia y biomasa fitoplancton total & $8 \%$ & abundancia de hembras ovígeras \\
\hline & abundancia relativa de clorofitas, diatomeas y cianobacterias & & abundancia de larvas nauplii y copepoditos de harpacticoideos \\
\hline & abundancia total de diatomeas & $22 \%$ & $\mathrm{n}^{\mathrm{o}}$ de huevos de rotíferos \\
\hline & riqueza de especies y composición del zooplancton & $14 \%$ & $\mathrm{n}^{\circ}$ de huevos de copépodos \\
\hline & abundancia de Prorodon sp. 2 & $50 \%$ & abundancia de larvas nauplii y copepoditos \\
\hline & $\mathrm{n}^{\circ}$ de especies de zooplancton en reproducción & & abundancia de cladoceritos \\
\hline & carbono total de la biomasa del plancton & & abundancia de hembras ovígeras de harpacticoideos \\
\hline & \% contribución a la MOP del carbono biomasa del plancton & & abundancia de hembras ovígeras de Brachionus urceolaris \\
\hline & composición y biomasa del nanoplancton & & $\%$ hembras ovígeras y egg ratio de Brachionus urceolaris \\
\hline & & & $\%$ hembras ovígeras y $\mathrm{n}^{\circ}$ huevos de Keratella tropica \\
\hline & Incorporación de organismos aguas abajo & & $\mathrm{n}^{\circ}$ de huevos en hembras de Brachionus pterodinoides \\
\hline & dinoflagelados & & \\
\hline & Simocephalus sp. & & Pérdida de organismos aguas abajo \\
\hline & hembras ovígeras de Brachionus plicatilis & & Daphnia obtusa \\
\hline & Alona rectangula & & Arcella discoides \\
\hline
\end{tabular}

